HIERSEMANNS HANDBÜCHER BAND VIII

\title{
Handbuch
}

der

Glasmalerei

Von losef Ludwig Fischer 
Cooper-Hewitt Museum Library:

Smithsonian Institution

In Memoriam

STEPHEN BRIDGES $1909-1977$

President SGAA 1968-1970

Given by THE STAINED GLASS ASSOCIATION OF AMERICA 1979 


\section{HIERSEMANNS HANDBÜCHER}

BAND VIII 


\title{
HIERSEMANNS HANDBÜCHER
}

\author{
BAND VIII
}

\section{JOSEF LUDWIG FISCHER}

\section{HANDBUCH DER GLASMALEREI}

FÜR FORSCHER, SAMMLER UND KUNSTFREUNDE WIE FÜR KÜNSTLER, ARCHITEKTEN

\author{
UND GLASMALER
}

MIT 48 TEXTABBILDUNGEN UND

151 ABBILDUNGEN AUF 135 TAFELN

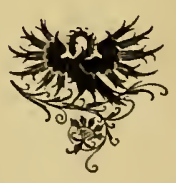

LEIPZIG

VERLAG VON KARL W. HIERSEMANN

1914 


\title{
HANDBUCH DER GLASMALEREI
}

FÜR FORSCHER, SAMMLER UND KUNSTFREUNDE WIE FÜR KÜNSTLER, ARCHITEKTEN UND GLASMALER VON

\section{JOSEF LUDWIG FISCHER}

\author{
MIT 48 TEXTABBILDUNGEN UND \\ 151 ABBILDUNGEN AUF 135 TAFELN
}

LEIPZIG

VERLAG VON KARL W. HIERSEMANN 1914 



\section{Geleitwort.}

Die Eigenart vorliegenden Buches ist zunächst durch dessen Einfügung in die Serie der Hiersemannschen Handbücher bestimmt. Es soll zeigen, einerseits, wie sich die Glasmalerei aus den Anfängen buntgläsernen Fensterschmucks zu einem selbständigen Glied des Kunstgewerbes entfaltet hat, und andererseits, welche Stellung dieser Zweig des Kunstgewerbes in der allgemeinen Entwicklung der Kunst einnimmt. Diese an sich selbstverständliche Forderung wird jedoch in der Glasmalerei von der, in der Regel allerdings übersehenen Tatsache modifiziert, daß die Glasmalerei in ihrer bescheidensten, wie glanzvollsten Erscheinung durch den Charakter eines integrierenden Bestandteils des Bauprogramms, der Vollendung des Raumes, ihre eigentümliche Gestaltung erhalten hat. Von dieser architektonischen Bedeutung der Glasmalerei ist nicht nur die Anlage dieses Buches beeinflußt worden, es hat sich vielmehr als notwendig erwiesen, einen Hauptabschnitt zu schaffen, der den Schönheitsgedanken der Glasmalerei in zusammenhängender Darstellung behandeln soll. Dieser Abschnitt enthält somit in knappster Zusammendrängung ein Bild davon, wie die Glasmalerei im Lauf der Zeiten ihrer monumentalen, architektonischen und raumgestaltenden Aufgabe gerecht geworden ist. Darum war es auch notwendig, den Faden der Entwicklung der Glasmalerei in die Gegenwart hereinzuführen. Auf einen erläuternden Text zu der Wiedergabe moderner Arbeiten konnte verzichtet werden, da die äußeren Bedingungen dieser Schöpfungen klar am Tag liegen, und da der Leser des Buches oder wenigstens des genannten Abschnitts selbst zu beurteilen vermag, inwieweit sich die moderne Glasmalerei über den mehr zufälligen Charakter eines wohl originellen, aber lediglich um seiner selbst willen komponierten Farbenspiels hinaus, auf die Stufe 
einer mit bewußter, innerer Notwendigkeit schaffenden Raumkunst erhebt.

Wenn nun die architektonische Bedeutung des buntfarbigen Fensterschmuckes für die Bearbeitung des Textes eine besondere Rolle spielte, so war es bei dem Format vorliegenden Buches natürlich nicht möglich, geschlossene Raumbilder zur Wiedergabe $\mathrm{zu}$ bringen. Dies ist jedoch schon deswegen kein Mangel, weil jeder Leser beim Besuch eines solchen Raumes, wie er noch in zahlreichen Domen usw. erhalten ist, die mystische Stimmung eines derartigen Raumbildes von selbst in sich lebendig machen und verstehen kann, was in vorliegendem Buche mit Worten darzustellen versucht worden ist.

Was die Abbildungen alter Glasgemälde betrifft, so wurde in erster Linie bisher unbekanntes oder schwer zugängliches Material wiedergegeben, während bereits öfter und gut publizierte Glasgemälde nur dann erneut abgebildet wurden, wenn es zur Erläuterung des Entwicklungsganges der Glasmalerei absolut unerläßlich war. Daß dabei in einigen Fällen schwächere Handschriften berücksichtigt werden mußten, wird wohl ebensowenig befremden, wie die Tatsache, daß für eine Reihe von Abbildungen mehr oder weniger restaurierte Fenster als Vorlage dienen mußten. Bei der Zusammenstellung des Abbildungsmaterials hatte sich der Verfasser der weitgehenden Hilfe zahlreicher Persönlichkeiten zu erfreuen, deren, außer im Texte, am Schlusse dieses Buches eigens gedacht ist. Mit dem herzlichsten Dank an alle, die zum Gelingen beigetragen haben, übergibt der Verfasser vorliegendes Buch der Öffentlichkeit. 


\section{Inhaltsverzeichnis.}

Geleitwort

I. Der Schönheitsgedanke in der Glasmalerei . . . . I

II. Die Entwicklung des Stils . . . . . . . . . . ${ }_{3} 8$

I. Die Monumentalglasmalerei . . . . . . . . . $3^{8}$

A) Die nur literarisch bezeugte Vorzeit . . . . . . 38

B) Das Zeitalter des reinen Flächenstils . . . . . . 45

I. Die frühromanisch-deutsche Schule . . . . . . 45

2. Die frühromanisch-französischen Schulen . . . 58

a) Die Schule von Chartres . . . . . . . 58

b) Die Schule von S. Denis . . . . . . . . . 62

3. Die deutschen Glasgemälde der späteren romanischen Schule . . . . . . . . . . . . . . 64

4. Das Auftreten von Architekturgliedern in der Glasmalerei 69

5. Die Glasmalerei während des Zeitalters der Frühgotik 76

6. Das System des gotischen Medaillonfensters . . . 8o

C) Die allmähliche Auflösung des Flächenstils in Bildwirkung unter dem Einfluß des italienischen Trecentos . . . . 84

7. Der Kunstkreis zu Königsfelden . . . . . . 84

8. Die oberrheinischen und ostdeutschen Schulen des I5. Jahrhunderts . . . . . . . . . . I00

9. Die französische Glasmalerei im Zeitalter der Gotik . I 2 I

D) Die Vorherrschaft des Malerischen infolge Trennung zwischen Visierer und Techniker . . . . . . . . . . 128

Iо. Die kölnische und niederländischen Schulen . . . I 28

I I. Die süddeutschen Meisterschulen . . . . . . I32

2. Die Kabinettsglasmalerei . . . . . . . . . . . 156

I2. Die deutsche Kabinettsscheibe . . . . . . 156

13. Die Schweizer Scheibe . . . . . . . . . 172

3. Die Kunstverglasung . . . . . . . . . . . . 182

4. Die Hinterglasmalerei . . . . . . . . . . . . 185

III. Die Wiederbelebung der monumentalen Glasmalerei im I9. Jahrhundert . . . . . . . . . . . . . . 190 
IV. Die Technik . . . . . . . . . . . . . . . . . 20 I

A) Das Material . . . . . . . . . . . . . . . 201

B) Die Malfarben . . . . . . . . . . . . . 2I 2

C) Die Bearbeitung des Materials . . . . . . . . . . 214

V. Die auf Glasgemälden dargestellten Gegenstände . . 23 I

VI. Die gesellschaftliche und materielle Lage des Glasmalers 263

VU. Das Glasgemälde als Sammelobjekt. - Echt und falsch ${ }_{28}$

VIII. Die Erhaltung und Wiederinstandsetzung alter Glasgemälde . . . . . . . . . . . . . . . . . 290

IX. Die Glasmalerei als Gegenstand der kunstwissenschaftlichen Forschung . . . . . . . . . . . . . 297

Literatur-Verzeichnis . . . . . . . . . . . . 3 Or

Register . . . . . . . . . . . . . . . . . 312 


\section{Verzeichnis der Textabbildungen.}

Abb. I. Rekonstruktion eines Fensters aus dem Chor der Sankt Ulrichskirche zu Augsburg. I I. Jahrh. . . . . . . . . . . . . . . 50

2. Blatt aus dem Evangeliar der Äbtissin Uta aus Regensburg. Um Ioo2 51

3. Mittelpunkt der großen Rose in der Kathedrale zu Lyon. r 3. Jahrh. 59

4. Detail aus einem Fenster der Kathedrale zu Lyon. 13. Jahrh. . . 6I

5. Detail aus einem Fenster des Westchors zu Naumburg. Mitte des I3. Jahrh. . . . . . . . . . . . . . . . . . . . 68

6. Detail aus einem spätromanischen Fenster der Elisabethkirche zu Marburg. Zweite Hälfte des I3. Jahrh. . . . . . . . . . . 70

7. Detail aus einem Flügel in dem Archiv der Elisabethkirche zu Marburg

8. Detail aus einem Zyklus des Klosters Seligenthal bei Landshut, jetzt im Bayrischen Nationalmuseum zu München. Um 1330. Landshuter Schule . . . . . . . . . . . . . . . . .

9. Die ägyptischen Plagen. Miniaturblatt aus dem Psalter Ludwigs des Heiligen. Ms. lat. der Bibliothèque Nationale Paris. Um 1260 I0. Standfigurenfenster in der Elisabethkirche zu Marburg. Anfang des I4. Jahrh. . . . . . . . . . . . . . . . . . . .

II. Teil eines Medaillonfensters im Chor des Ulmer Münsters. Anfang des I5. Jahrh. . . . . . . . . . . . . . . . . . $9 \pi$

12. Scheibe aus den Fenstern der Bessererkapelle im Münster zu UIm. Um 1420 IOI

13. Maßwerk aus einem Fenster der Bessererkapelle im Münster zu Ulm.

$\mathrm{Um} \mathrm{I} 420$. . . . . . . . . . . . . . . . . . . 102

14. Maßwerk aus einem Fenster der Bessererkapelle im Münster zu Ulm.

$\mathrm{Um} 1420$. . . . . . . . . . . . . . . . . . . 103

i 5. Glasgemälde im Rathaus zu Lüneburg. Erste Hälfte des 15. Jahrh. I 06

I6. Evangelist. Wohl aus Ulm stammend. Gegen Mitte des I5. Jahrh. Io9

I7. Detail aus einem Glasgemälde der Stadtkirche zu Friedberg . . . III

18. Detail aus dem Stammbaumfenster des Münsters zu Ulm . . . . I I8

19. Chorfenster in der Kirche zu Evreux. Zweites Viertel des 14. Jahrh. I 22

20. Detail aus einem Glasfenster der St. Chapelle zu Riom. Um I350 I 24

21. Geburt Christi. Glasgemälde in der Frauenkirche zu München. I480-I 490 I 44

22. Geburt Christi. Glasgemälde im Münster zu Ulm. Um I420 . . I44

23. Gemälde vom Münchener Petrialtar. Jan Pollack. Bayrisches Nationalmuseum, München . . . . . . . . . . . . I 45 
Abb. 24. Gemälde vom Münchener Petrialtar. Jan Pollack. Bayrisches Nationalmuseum, München . . . . . . . . . . . . . . I46

25. Gemälde von einem Jan Pollack nahestehenden Meister. Bayrisches Nationalmuseum, München . . . . . . . . . . . . . I 47

26. Scheibe mit der Meisterunterschrift des Münchener Glasmalers Jakob Kistenfeger. I496-I532. Schloß Erdödy. . . . . . . 148

27. Oberteil eines Glasgemäldes in der Salvatorkirche zu München. Um I 500 I 49

28. Detail aus den Chorfenstern der Pfarrkirche zu Landsberg a. L. Anfang des I6. Jahrh. .

29. Fragment eines Glasgemäldes im Bayrischen Nationalmuseum zu München. Ende des 15. Jahrh. . . . . . . . . . . . . . . 152

30. Detail aus einer Scheibe mit Johannes Ev. Hans Holbein d. Ä. Augsburg. Nach einer Photographie von Höfle-Augsburg . . . 153

31. Ungarisches Glasgemälde. Anfang des 15. Jahrh.. . . . . . I54

32. Kartondetail zu den Glasgemälden in Gouda. Lukas von Leyden? . I 55

33. Karton zu den Glasgemälden in Gouda. Lukas von Leyden( $(8)$ - . I 58

34. Karton zu einem Glasgemälde von W. Crabeth. (1543-1595) . . I60

35. Scheibe mit dem Wappen von Matzenheim. Dem Hausbuchmeister nahestehende oberrheinische Werkstatt. Um I480 . . . . . I6I

36. Rundscheibe aus einer oberrheinischen Werkstalt um 1490. . . I63

37. Rundscheibe mit der hl. Radegundis. Salzburg, datiert 1524 . . . I65

38. Rundscheibe mit den Wappen Welser und Schlüsselfelder. SchloßHohenschwangau. Um I 525. Nürnberger Arbeit (Hans Springinklee) 169

39. Wappenscheibe Wildenberg. Arbeit des Daniel Lindtmeyer von Schaffhausen . . . . . . . . . . . . . . . . 173

40. Wappenscheibe Sinner. I719. Historisches Museum zu Bern. . I 76

41. Wappenscheibe Messerlin. $I_{7} 8_{3}$. Historisches Museum in Bern . I 78

42. Teppichmuster. Dom zu Regensburg. I4. Jahrh. . . . . . . I84

43. Glasgemälde in Maursmünster. J. D. Danegger aus Straßburg I 767 I9I

44. Glasgemälde in der Mariahilfkirche zu München. Karton von Josef Anton Fischer. 1838 . . . . . . . . . . . 193

45. Glasgemälde in der Kirche zu Lennewitz. Entworfen und ausgeführt von R. Linnemann, Frankfurt . . . . . . . . . . . 195

46. Glasgemälde, entworfen und ausgeführt von der Glasmalerei Binsfeld, Trier 197

" 47. Monolithscheibe in Schwarzlot und Silbergelb, entworfen und ausgefïhrt von Glasmaler K. Gläsche, Stuttgart . . . . . . . . 199

48. Entwurf zu einer Kunstverglasung von Prof. Julius Diez, München . 202 


\section{Verzeichnis der Tafeln.}

Tafel I/2. Prophetengestalten. Dom zu Augsburg. Mitte des I I. Jahrh.

" 3. Teil eincr Prophetengestalt. Dom zu Augsburg. Mitte des II. Jahrh.

" 4. Teil der Gestalt des Königs David. Dom zu Augsburg. Mitte des I I. Jahrh.

" 5. Madonna. Glasgemälde im Schweizerischen Landesmuse um zu Zürich. Aus Flums. Anfang des 12. Jahrh. Hof- und Staatsbibliothek. Um I I 50.

7. Detail aus einem Glasgemälde der Kathedrale zu Poitiers. Zweite Hälfte des I2. Jahrh.

8. Fenster in der Kirche zu Le Champ (Isère). Zweite Hälfte des I2. Jahrh. Nach einer Photographie von L. Bégule.

9. Glasgemälde in der Kirche zu Chateauroux. Anfang des I3. Jahrh.

Io. Detail aus der großen Rose (mit Monatsbildern) in der Kathedrale zu Lyon. I3. Jahrh.

I I. Glasgemälde in Varennes. I3. Jahrh.

I2. Glasscheibe im Historischen Museum zu Frankfurt. Drittes Viertel des I3. Jahrh.

I3. Flügel aus einem Glasgemälde in Schloß Heiligenberg. Gegen I330. Nach einer Photographie von Frl. Dr. Hertha Wienecke.

I4. Flügel in der Altertümersarrmlung zu Karlsruhe. Gegen I330. Photographiert von W. Kratt, Karlsruhe.

I 5. Detail aus einem Fenster der Stephanskirche zu Mülhausen i. E. Um I 340.

I6. Detail aus einem Glasgemälde der Stephanskirche zu Mülhausen i.E Um I340.

17. Detail aus dem Fenster der Tugenden und Laster in der Stephanskirche zu Mülhausen i. E. Um I340.

I8. Teil aus dem Passionsfenster in der Klosterkirche zu Königsfelden. Erstes Viertel des I 4. Jahrh.

i9. Teil aus dem Franziskusfenster in der Klosterkirche zu Königsfelden. Erstes Viertel des I4. Jahrh.

20. Teil aus dem Täuferfenster in der Klosterkirche zu Königsfelden. Erste Hälfte des I4. Jahrh.

21. Christus am Kreuz. Burg Karlstein (Prag). Zweite Hälfte des I4. Jahrh. 22. Glasgemälde einst in der Pfarrkirche zu Culm, jetzt in der Marienburg. Ende des I4. Jahrh. 
Tafel 23. Teil einer Verkündigung. Nationalmuseum zu Krakau. Ende des I4. Jahrh. $\mathrm{Zu}$ Tafel 24 gehörig.

24. Teil einer Verkündigung. Nationalmuscum zu Krakau. Ende des 14. Jahrh. $\mathrm{Zu}$ Tafel 23 gehörig.

5. Detail aus einem Glasgemälde der Minoritenkirche zu Regeńsburg, jetzt im Bayrischen Nationalmuseum zu München. Um 1360.

26. Einzelblatt aus einer Regensburger Handschrift. Hof- und Staatsbibliothek zu München. Um I350.

27. Teil eines Fensters der Minoritenkirche in Regensburg, jetzt im Bayrischen Nationalmuseum zu München. L'm I 360 .

28. Teil des Katharinenfensters im Dom zu Regensburg. Letztes Viertel des I 4. Jahrh.

29. Teil eines Medaillonfensters im Bayrischen Nationalmuscum zu München. Anfang des 15. Jahrh.

30. Zusammengestellte Szenen aus einem mariologischen Fenster. Frauenkirche zu München.

31. Zwei Scheiben aus den Glasfenstern in der Bessererkapelle des Münsters zu Ulm. Um I 420 .

2. Glasgemälde vom Meister der Bessererfenster in Clm. Münster in Freiburg. Um 1420.

3. Teil eines Glasgemäldes in der Kirche zu Markterlbach. Letztes Viertel des I 4. Jahrh.

44. Teil aus einem Glasgemälde in der Blasiuskirche zu Mühlhausen in Thüringen. Zweite Hälfte des 14. Jahrh.

5. Teil aus dem Helenafenster im Dom zu Erfurt. L'm I 400.

6. Apostelkopf in einem Fenster des Domes zu Erfurt. Nach $\mathrm{I}_{4} 00$.

7. Mannahlese, Detail aus einem Fenster der S. Jakobskirche zu Rothenburg o. d. T. Erste Hälfte des 15. Jahrh.

38. Detail aus einem Glasgemälde der S. Jakobskirche zu Rothenburg o. d. T. Erste Hälfte des 15. Jahrh.

39. 'leil eines Fensters im Dom zu Stendal. Stiftung Friedrichs II. von Brandenburg (?) (I 440-7I). Nach einer Photographic von Dr. J. Engel.

o. Evangelist Johannes. Detail eines Glasgemäldes in Dome zu Halberstadt. Anfang des I 5. Jahrh.

I. Detail aus einem Glasgemälde in der Tillykapelle zu Altötting. Datiert 1426.

2. Detail aus dem Stammbaumfenster im Münster zu Ulm. Signiert Hans

Wild. I 48 .

Detail aus einem Glasgemälde von Hans Wild im Ulmer Münster. Um I 4 So.

4. Teil eines Glasgemäldes in der Stadtkirche zu Friedberg. Ende des

I5. Jahrh.

Rundscheibe in farbigem IIüttenglas:" Schloß zu Erbach. Ende des I5. Jahrh.

Rundscheibe in farbigem Ilüttenglas. Schloß zu Erbach. Ende des 15. Jahrl.

47. Chorfenster in der Kirche zu Evreux. Zweites Viertel des 14. Jahrh. 
Tafel 48. Teil eines Fensters in der Kirche zu Ambierlé. Stil der französischen Spätgotik.

„ 49. Detail eines Glasgemäldes in der Kirche zu Montmorency, im Stil der französischen Frührenaissance.

" 50. Fenster im Dom zu Troyes. Anfang des 16. Jahrh. Nach einer Photographie von G. Lancelot.

" 51. Detail aus einem französischen Renaissancefenster.

" 52. Glasgemälde aus einer englischen Kirche. I 5. Jahrh. Mittelbild restauriẹt.

" 53. Teil eines Glasgemäldes im Dom zu., Metz, von Valentin Busch.

" 54. Teil eines Glasgemäldes im Dom zu :Metz, von Valentin Busch.

" 55. Detail aus einem Glasgemälde in der Kathedrale zu Chalons. Ende des I 5. Jahrh.

" 56. Detail aus einem niederrheinischen Fenster, jetzt im Kunstgewerbemuseum zu Köln. Ende des I5. Jahrl.

" 57. Teil eines Fensters im Dome zu Köln. Anfang des 16. Jahrh.

" 58. Teil eines Glasgemäldes in der Kirche zu Xanten. Anfang des I6. Jahrh.

" 59. Teil eines Fensters in der Wallfahrtskirche zu Wilsnack, im Stil der niederrheinischen Spätgotik. Nach einer Aufnahme von Dr. J. Engel.

" 60. Rundfenster im Dom zu Florenz. Nach einer Zeichnung von L. Ghiberti.

"6I. Glasgemälde im Kloster S. Croce zu Florenz. Erste Hälfte des I 5. Jahrh.

" 62/63. Glasgemälde auf der Veste Koburg. Hirsvogel werkstatt. Anfang des I6. Jahrh.

" 64. Detail aus einem Glasgemälde in der Schwanenritterkapelle zu Ansbach.

Dürer-Hirsvogelwerkstatt. I 520 .

"65/66. Detail aus einem Fenster in der Marienkirche zu Hanau. Art des Matthias Grünewald. Um 1510 . Nach einer Aufnahme von der Glasmalerei Linnemann.

" 67. Glasgemälde aus der ehemaligen Kartause bei Freiburg. Stil Hans Bạldung Griens. Zwischen I5 IO und I520.

" 68. Glasgemälde in der Kgl. Residenz zu München. Stil Hans Baldung Griens. Nach einer Photographie von Oskar Zettler, München.

"69/70. Heinrich von Handschuhsheim als Stifter. Glasgemälde in der Kgl. Residenz zu München. Stil Hans Baldung Griens. Nach einer Photographie von Oskar Zettler, München.

Margarethe von Staufenberg als Stifterin. Glasgemälde in der Kgl. Residenz zu München. Stil Hans Baldung Griens. Nach einer Photographie von Oskar Zettler, München.

" 71. Detail aus einem Glasgemälde in dem Münster zu Freiburg i. B. Stil Hans Baldung Griens. Um I5I5. Nach einer Aufnahme von Professor Fritz Geiges.

" 72. Detail aus einem Glasgemälde der Frauenkirche zu München. Um die Mitte des 15 . Jahrh.

"73. Vier Flügel aus einem typologischen Cyklus in der Frauenkirche zu München. I $480-1490$.

"74. Vier Flügel aus einem typologischen Cyklus in der Frauenkirche zu München. I $480-$ I 490 . 
Tafel 75. Bethlehemitischer Kindermord. Detail aus einem Glasgemälde in der Frauenkirche zu München.

"76. Detail aus cinem Glasgemälde in der Fravenkirche zu München, um I 495.

" 77. Allegorisches Fenster in der Salvatorkirche zu München. Um 1500.

"78. Oberteil eines Fensters in der Salvatorkirche zu München. Um I500.

" 79. Detail aus den Chorfenstern der Pfarrkirche zu Landsberg a. L. Anfang des I6. Jahrh.

8o. Scheibe aus einem Passionscyklus in der Kirche zu Blutenburg bei München. Gegen 1500.

81. Detail aus einer Anbetung der Könige. Hans Holbein d. Ä. Augsburg. Nach einer Photographie von Höfle-Augsburg.

82. Detail aus einem Fenster in der Kirche zu Tölz. Beispiel für den Übergang der Gotik in die Renaissance. 1510-1515.

" 83. Fenster in der Kirche S. Gudule in Brüssel. I537.

" 84. Detail aus der Abbildung Tafel 83.

" 85. Detail aus der Abbildung Tafel 83.

" 86. Vierpaßscheibe des Deutschmeisters Dicter von Cleen. Um I525. Nürnberger Arbeit.

87. Scheibenriß eines fränkischen Meisters um $\mathrm{I}_{4} 80$.

88. Rundscheibe nach einem $\mathrm{RiB}$ von Jörg Breu, vielleicht ausgeführt von dem Glasmaler Hans Braun in Augsburg. München, Bayrisches Nationalmuseum.

89. Rundscheibe nach einem $\mathrm{Riß}$ von Jörg Breu, vielleicht ausgeführt von dem Glasmaler Hans Braun in Augsburg. Salzburg, Nuseum.

90. Wappenscheibe aus dem Jahre 1598. Nürnberger Arbeit.

9I. Wappenscheibe mit Wappen der Stadt Ulm. I663, von Johann Schaper in Nürnberg.

92. Wappenscheibe des Kantons Schwyz. Gegen I5 ro.

93. Wappenscheibe Basel. Historisches Museum zu Basel. Anfang des I6. Jahrh.

94. Oberteil einer Wappenscheibe des Glasmalers Jeronimus Lang aus Schaffhausen. 1542. Im Oberlicht Legende der hl. Ida.

95. Scheibe aus dem Cyklus: Der verlorene Sohn, von Chr. Murer.

96. Wappenscheibe Mülinen. Historisches Nuseum in Bcrn. Monogramm I. B.

97. Züricher Standesscheibe. Nüschelerwerkstatt, Zürich. 1628 .

9S. Wappenscheibe mit Fortuna. Nüschelerwerkstatt, Zürich. I 63 I.

99. Wappenscheibe Buccher. 1719. Historisches Museum zu Bern.

ıо. Glasgemälde in der Certosa von Florenz. I560. Giovanni da Udine.

Ior. Ornament der Asharmoschee in Kairo. Um 1000.

Ornamentscheibe in Heiligenkreuz. Um $\mathbf{2} 200$.

, 102. Ornamentscheiben in der Abtei Heiligenkreuz im Wienerwald. Um 1200.

"ro3. Ornamentscheiben in der Abtei Heiligenkreuz im Wienerwald. Um I 200. Rundscheiben später eingesetzt.

"I04. Berner Standesscheibe aus dem Jahre 1576, erneuert im Jahre I62 I von dem Glasmaler Ilans Rudolf Lando. Historisches Muscum in Bern.

" 105. Detail eines Teppichfensters für den Dom zu Altenberg. Entworfen und ausgeführt von l'rof. Alex. Linnemann, Fraukfurt, I $S_{92}$ 
Tafel ı06. Glasgemälde, als Stiftung des Deutschen Kaisers, entworfen und ausgeführt von Prof. C. de Bouché, München.

" I07. Glasgemälde von J. Drake, Exeter.

" I08. Detail aus einem Glasgemälde von C. E. Kempe, London.

" I09. Glasgemälde in der Westminsterabtei von J. N. Comper, London.

I 10. Glasgemälde, entworfen und ausgeführt von der Glasmalerei H. Oidtmann, Linnich.

II I. Glasgemälde, entworfen von Becker-Tempelburg, ausgeführt von der Glasmalerei G. Heinersdorff, Berlin.

I I 2. Glasgemälde, entworfen und ausgeführt von der Hofglasmalerei F. X. Zettler, München.

II3. Kunstverglasung in Schwarzlot und Silbergelb, entworfen und ausgeführt von der Hofglasmalerei Ostermann und Hartwein, München.

I 14. Detail aus der Abbildung Tafel II2.

I 5. Glasgemälde von Professor Josef Huber-Feldkirch, Düsseldorf.

I I6. Detail aus einem Glasgemälde von Professor Josef Huber-Feldkirch, Düsseldorf.

I I 7. Detail aus einem Glasgemälde von Professor Josef Huber-Feldkirch, Düsseldorf.

I 8. Glasgemälde, entworfen und ausgeführt von Wilh. Pütz, Köln.

I19. Glasgemälde, entworfen und ausgeführt von Wilh. Pütz, Köln.

I 20. Glasgemälde nach einem Entwurf von Thorn-Prikker, ausgeführt von der Glasmalerei G. Heinersdorff, Berlin.

I 2 I. Details aus einem Glasgemälde, .entworfen von Thorn-Prikker, ausgeführt von der Glasmalerei G. Heinersdorff, Berlin.

I22. Glasgemälde von Professor Josef Goller, Dresden.

Karton zu einem Glasgemälde von Stanislaus Wyspianski, Krakau.

123. Kunstverglasung: Dic 6 Sommermonate; für die Berliner Kunstausstellung I9I3. Entworfen von Professor Rich. Böhland, ausgeführt von der Glasmalerei J. Schmidt, Berlin.

I24. Glasgemälde von Professor Josef Goller, Dresden.

Kunstverglasung für das Krematorium zu Breslau. Entwurf von Wenzel Oswald, Wien, ausgeführt von J. Schmidt, Berlin.

125. Freya. Glasgemälde, entworfen von Horst-Schulze, ausgeführt von der Glasmalerei Richter \& Römer, Leipzig.

I26. Glasgemälde, entworfen von Professor Josef Goller, Dresden, ausgeführt von der Glasmalerei J. Schmidt, Berlin.

Buntverglasung in geschliffenen, geätzten Überfanggläsern mit facett. weißen Glasstücken, entworfen von C. O. Czeschka, Hamburg, ausgeführt von der Glasmalerei Eckhardt, Charlottenburg.

" 127. Glasgemälde für den Zirkus Sarasani; entworfen von Ludwig Kainer, Berlin, ausgeführt von der Glasmalerei Eckhardt, Charlottenburg.

128. Glasgemälde nach einem Entwurf von J. Méhoffer, Krakau, ausgeführt von der Glasmalerei Zelenski, Krakau.

I 29 Glasgemälde, entworfen von J. Würstl, München, ausgeführt in der Glasmalerei Jos. Kreuzer, München. 


\section{XVI}

Tafel I 30. Glasgemälde für das Kulturbaus in Marosvasarhely. Entworfen von Sandor Nagy, ausgeführt von der Glasmalerei $M$. Roth, Budapest.

" I3I. Detail aus den Trausaalfenstern des Spandauer Rathauses. Entworfen und ausgeführt von R. Linnemann, Frankfurt.

" I32. Glasgemälde, unter Verwendung antiker Motive entworfen und ausgefuihrt von der Hofglasmalerei F. X. Zettler, München.

" I33. Glasgemälde, unter Verwendung antiker Motive entworfen und ausgeführt von der Hofglasmalerei F. X. Zettler, München.

" I34. Glasgemälde, entworfen von Karl Kernstock, ausgeführt von Gedeon Walther in Budapest.

"I35. Ornamentfenster. Entworfen und ausgeführt von der Glasmalerei Zentner, Wiesbaden.

Ornamentscheibe. Entworfen und ausgeführt von II. Mühlenbein, Hannover. 


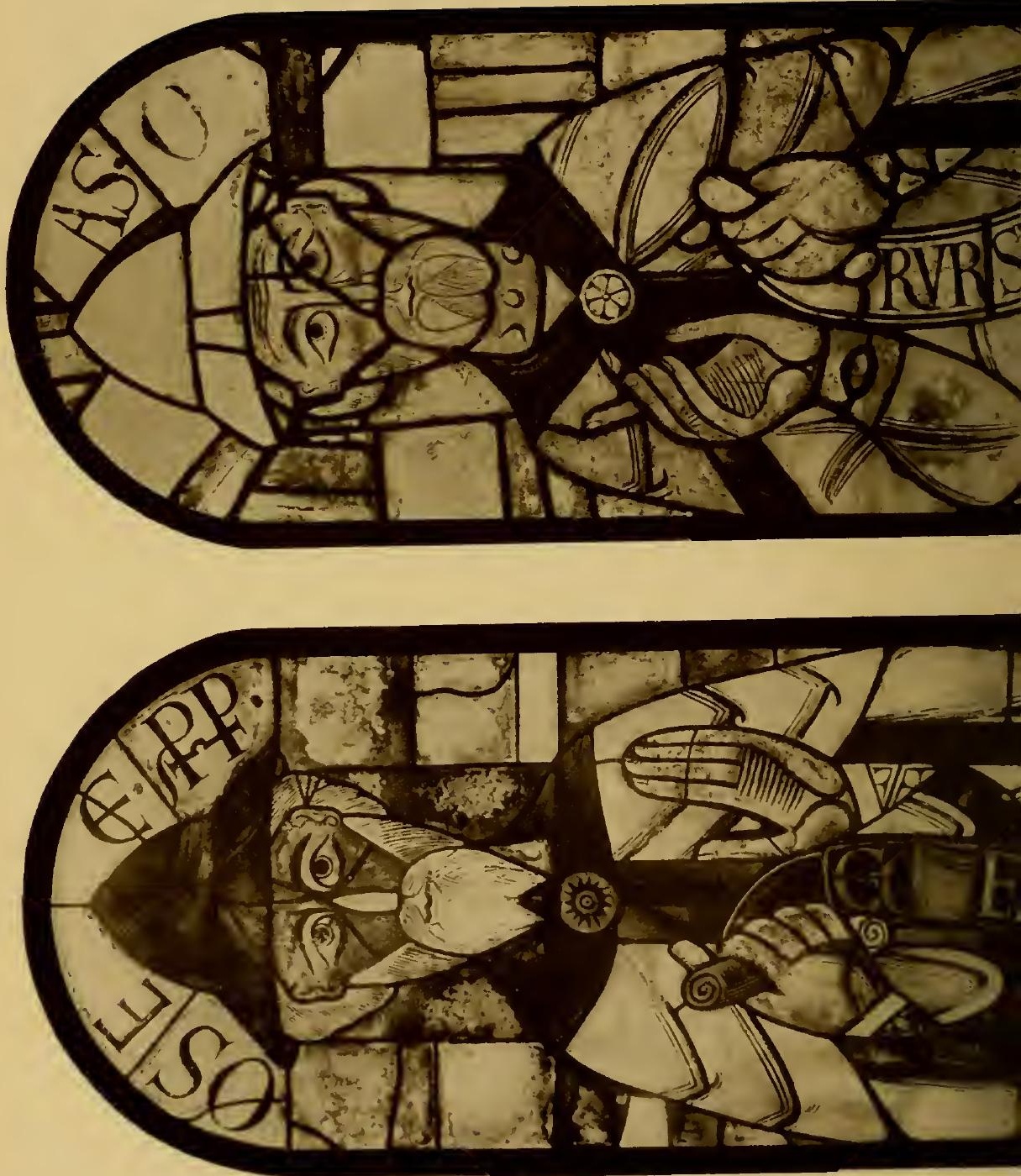


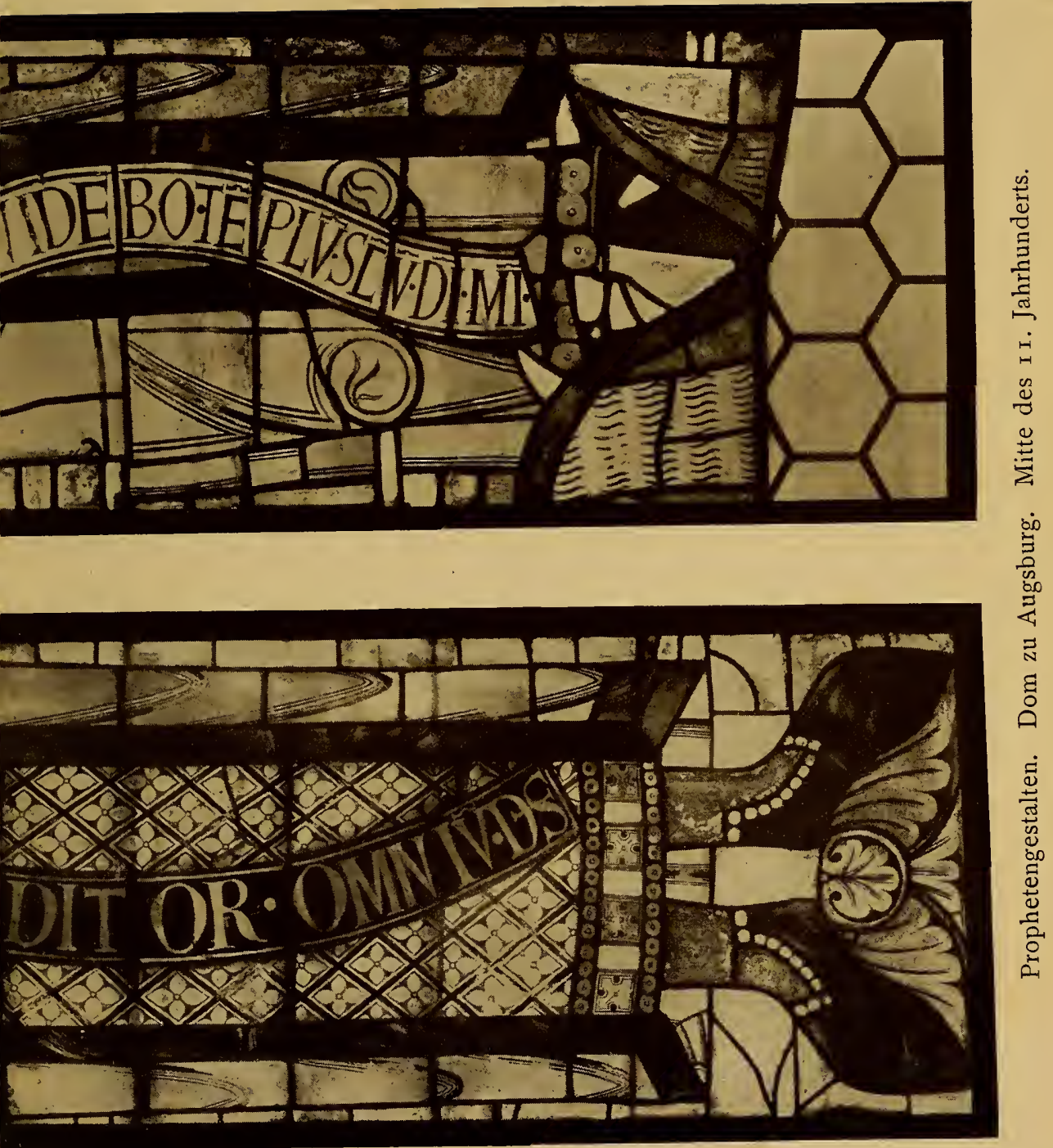



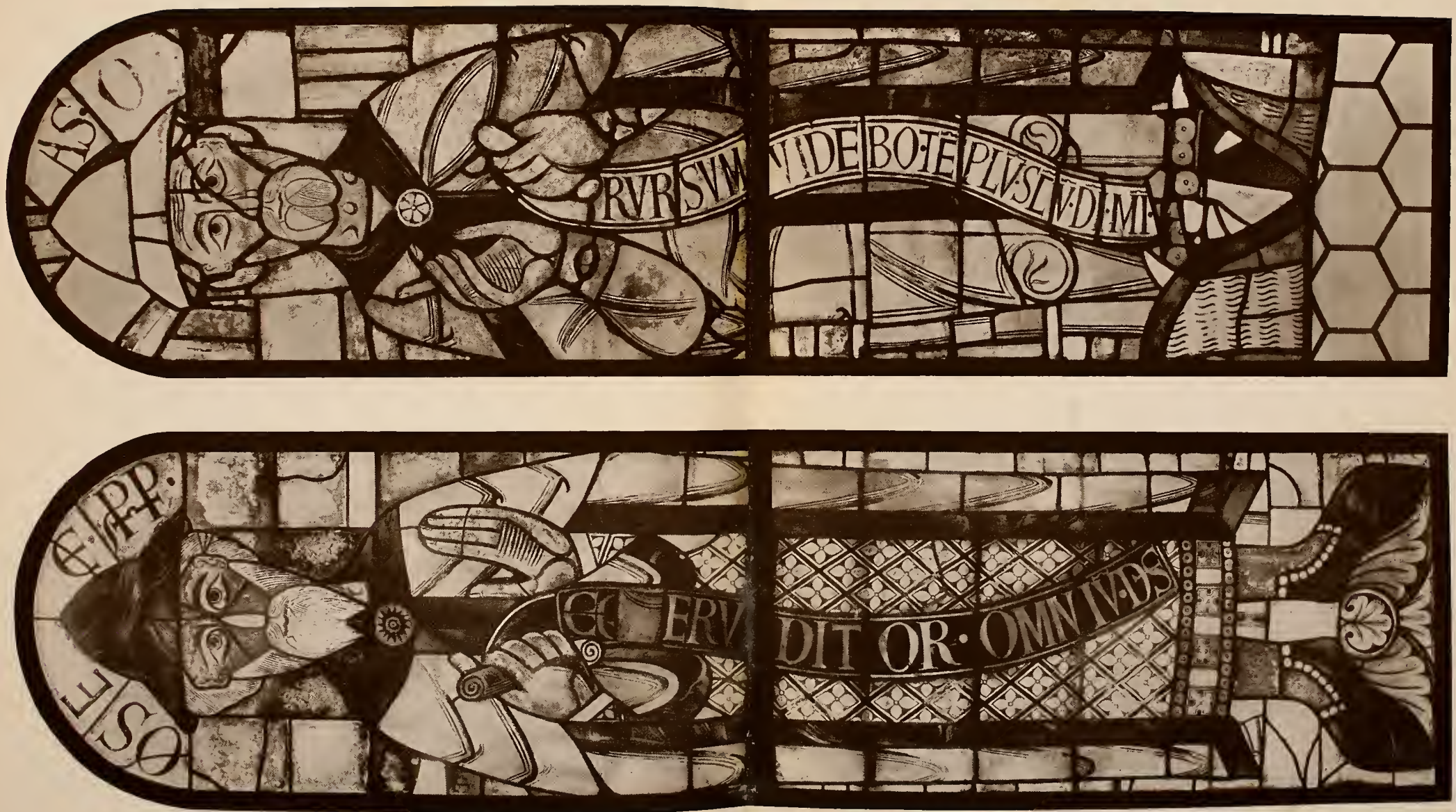



\title{
I.
}

\section{DerSchönheitsgedanke in der Glasmalerei.}

\author{
Weh! steck' ich in dem Kerker noch? \\ Verfluchtes, dumpfes Mauerloch! \\ Wo selbst das liebe Himmelslicht \\ Trüb' durch gemalte Scheiben bricht.
}

So jammert Dr. Faust in Goethes Drama, und Heine vergleicht die gemalten Scheiben gar mit Blut und Eiter. Wenn so unsere größten deutschen Dichter den bunten Fensterschmuck nur als Beispiel für Abschreckendes zu nennen wissen, so kann man fragen: "Liegt denn in gemalten Fensterscheiben irgend etwas, was das menschliche Gemüt erheitern und erheben kann?" Wir wollen nicht mit schulmeisterlicher Interpretationskunst zu erklären versuchen, aus welchem Zeitgeschmack heraus derlei Urteile zu begreifen und entschuldigen sind, wir wollen aber auch nicht vergessen, daß derselbe Goethe sich auf seiner SchweizerReise im Jahre 1797 einen mehrstündigen Aufenthalt im Gasthause zu Bülach mit der Bewunderung und dem Studium von ein paar Glasgemälden verkürzte. Er wußte also die Farbenpracht und den Schönheitsgehalt buntfarbigen Fensterschmuckes wohl zu schätzen. Es ließen sich sogar noch mehr Zeugnisse zusammenstellen, aus denen mit hinreichender Klarheit hervorgeht, daß Goethes dichterische Freiheit allem Schönen gegenüber das dem buntfarbigen Fensterschmuck innewohnende, verwandte Schöne wohl gefühlt und geschätzt hat. Wir könnten also über Fausts Unmut sorglos hinweggehen, wenn darin nicht der letzte Grund verborgen läge, warum die Glasmalerei verschiedene Male mißachtendem Vorurteil begegnet ist. Zur Zeit, als Goethe und Heine jene Sätze niederschrieben, war das Zeitalter der Aufklärung über die westlichen Völker Europas hereingezogen. Die

Fischer, Handbuch der Glasmalerei. 
meisten Menschen verstanden zwar nicht, was die führenden Geister wollten, bekundeten aber u. a. ihren Eifer dadurch, daß sie die Losung: „Mehr Licht!“ nur allzu buchstäblich auffaßten und aus Kirchen und Privathäusern die herrlichen Glasmalereien alter Zeiten hinausschlugen. Eine seltsame Ironie wollte, daß sich die Freigeister mit den Jesuiten dabei im Einklang fanden, die für ihre Bauten nach dem Vorbild von St. Peter in Rom jedweden buntfarbigen Fensterschmuck mit rücksichtsloser Strenge ausschlossen. Abermals wurde der Bestand jener kostbaren, alten Kunstwerke bedeutend gelichtet, dem die Reformation schon arg geschadet hatte. Ganze Fenster fielen dem Lichtbedürfnis zum Opfer. Nur vor den Stifterwappen machte man Halt, da man sich hütete, das Wappen eines mächtigen Geschlechts zu zerschlagen und sich so die Ungnade desselben zuzuziehen. Jede andere Rücksicht lag zu Boden, der Gedanke an den edlen Sinn früherer Geschlechter war erloschen, vorab jedoch das V.erständnis für das Wesen der Kunst erstorben. Vereinzelt ist freilich das Gefühl für die hohe Ästhetik eines Glasgemäldes erhalten geblieben, so z. B. bei dem Fürsten Leopold Friedrich von AnhaltDessau, und diesem erlauchten Manne ist es zuzuschreiben, daß das Gotische Haus in Wörlitz eine der schönsten Sammlungen von Glasgemälden darstellt, oder was uns hier mehr interessiert, daß eine Reihe der wichtigsten Zeugen machtvollen Kunstschaffens erhalten ist. Seit der Periode der Aufklärung hat sich das krank gewordene Verhältnis zur Glasmalerei bis zur Stunde nie mehr so recht ganz erholt, wenn auch, wie wir im Lauf dieses Buches sehen werden, wiederholt ernste Anläufe zu gerechter und vernünftiger Würdigung der Glasmalerei gemacht worden sind.

Steigen wir an dem breiten Strom christlichen Kunstschaffens hinauf zu dessen frischen Quellen, so bietet sich ein ganz anderes Bild, als jene düstere Stimmung, die wir eben verlassen haben. „In den runden Bogen der Fenster der Basilika erstrahlte vielfarbiges Glas, gleich der Pracht einer Frühlingswiese." Es ist der christliche Dichter Prudentius (348-413), der diese lapidare Inschrift an den Beginn der Entwicklung des buntfarbigen Fensterschmucks gesetzt hat. Kaum war also das Christentum aus den Katakomben, in denen es allerdings keiner Glasfenster bedurfte, an das Tageslicht einer Staatsreligion emporgestiegen, kaum war 
dadurch eine rege Bautätigkeit entstanden, da tritt auch der buntfarbige Fensterschmuck in den Kreis der übrigen Künste. Zweierlei sagt uns der kurze Spruch des Prudentius, nämlich daß und warum bunte Glasfenster in den ersten christlichen Basiliken Aufnahme gefunden haben. „Vielfarbiges Glas erstrahlte gleich der Pracht einer Frühlingswiese." Das herrliche Farbenspiel ist es also, das einst das unbefangene Gemüt der ersten christlichen Baumeister und Dichter gefangen hielt, wie auch das unverdorbene kindliche Gemüt von dem schillernden Schmuck einer Frühlingswiese am mächtigsten ergriffen wird. Jener unbefangene Sinn hat gleich zu Beginn des christlichen Altertums ein Bauprogramm geschaffen, von dem man niemals abwich, wofern nur die finanziellen und technischen Hilfsmittel zur Ausführung vorhanden waren. Um nicht mißverstanden zu werden, wollen wir gleich zu Beginn anmerken, daß wir mit der Charakterisierung der Glasmalerei als einer christlichen Kunst nicht den engen Begriff eines kirchlich-religiösen Ausdrucksmittels angewendet wissen wollen. Als das Christentum das Abendland eroberte, fand es andere Kultur- und Kunstbedingungen, andere Menschen als jene Künstler, die einst den Tempel der Athene Parthenos, das Heiligtum des Juppiter Capitolinus schufen. $\mathrm{Ob}$ in jene monumentale Bauten aus Marmor Glasgemälde gepaßt hätten, können wir nicht entscheiden, davon abgesehen, daß den Künstlern weder Fensteröffnungen noch Glas zur Verfügung gestanden sind. Das Christentum brachte mit der Eigenart seines Gottesdienstes ganz andere Anforderungen an den Grund- und Aufriß seiner Gotteshäuser, verlangte ein anderes Raumbild, hatte anderes Baumaterial und verfügte über das Glas. Durch die Jahrhunderte zieht sich seit Prudentius die ständige Erwähnung buntfarbigen Fensterschmuckes, aber nicht in nüchtener Prosa, sondern in den begeisterten Worten der Poesie: So warm ist es den Schriftstellern ums Herz, wenn sie von dem munteren Spiel berichten, das die Sonnenstahlen auf den farbigen Fenstern treiben. Zwar dürfte während der ganzen merowingischen Zeit der gläserne Schmuck wohl kaum über Buntverglasung hinausgegangen sein, allein das Wichtigste bildet die Tatsache, daß die christlichen Kulturvölker sich einen Raumgedanken ohne buntfarbigen Fensterschmuck gar nicht zu Ende denken konnten. 
Die Technik der Bemalung des Glases mit einbrennbaren Farben, an sich ein großer Fortschritt des 9. Jahrhunderts, bildet für die ästhetische Grundlage des farbigen Fensterschmuckes eine unbedeutende Nuance in der Gesamtentwicklung. Als sich im Jahre II34 das Generalkapitel der Zisterzienser gegen die figürliche Glasmalerei wandte, da ließ es den Ordensbrüdern die Möglichkeit offen, sich an Kunstverglasung, Grisaillen und Teppichfenstern schadlos zu halten; der beste Berreis, wie stark das ästhetische Behagen an buntfarbigen Fenstern gewurzelt war. Auch die arabische Kunst hat sich diesem nicht entzogen. Man war der Anschauung, daß die Sonnenstrahlen einen viel energischeren Glanz bekommen, wenn sie durch gemaltes Glas fielen. Den Alten war ja das Geheimnis des Prismas nicht bekannt; aber trotzdem versuchten sie das Naturspiel, das sie nur im Regenbogen oder an klaren Wassern bestaunten, auf den Fenstern $\mathrm{zu}$ wiederholen. So hoch war farbiges Glas geschätzt, daß man sich vor Begeisterung in wahre Phantome hineinlebte. So glaubte man schon im 6. Jahrhundert, besonders schönes Glas sei nicht auf dem sonst üblichen Wege hergestellt, sondern ein Erzeugnis geschmolzener Edelsteine. Als Wolfram von Eschenbach die Pracht der Gralsburg zu beschreiben hatte, und an die gemalten Fenster kam, sagte er:

$$
\begin{aligned}
& \text { adamas und ametiste } \\
& \text { diu aventiure uns wizzen lat } \\
& \text { thopazie und granat } \\
& \text { crisolte und rubine } \\
& \text { smaragde und sardine } \\
& \text { sus warn diu venster rühe. }
\end{aligned}
$$

Er teilt also mit dem Pfaffen Lambrecht die Meinung, daß die Gläser durch Edelsteine prachtvollere Farben bekämen. Nebenbei bemerkt, war es wirkliche Glasmalerei:

Der tjoste venster was gesniten

mit der glavine wit

alsus malet der strit:

wer gultes den schiltären

ob ir varwe alsus wären?

I)iu glasevenster waehe von vremden listen riche ich waen ie man gresaehe und ouch ie grehörte dem geliche 
sie waren nit mit aschenglas verspannen,

ez waren licht cristallen; swachiukost was gar nicht verjaget dannen. Berillen und cristallen ward da vür glas gesetzet

da durch begunde vallen des tages sovil, daz liht da waer geletzet ein ouge, ob ez die lenge vrevellichen

daz werk da wolt schowen, daz wart erwant mit listen meisterliche. Verwierens niht entwalen wold man, uf die berillen

entwerfen unde malen da mit man möht den brehnden glast gestillen und och der richen kost zu einer zierde

got und dem gral zu eren wan er den tempel richlich konduwierde. Swaz die meister garwe da uf diu glas entwürfen

swelherleie varwe si mit dem pensel wolten dar bedürfen

daz war verwieret mit edelem gesteine

der ie dieselben varwe het nach der art, lieht luter unde reine.

Es war also nicht bloß die Farbe allein, sondern noch mehr der magische Glanz, der sich durch buntes Glas auf den Raum goß. Eben die Vervollkommnung des Raumbildes durch bunten Fensterschmuck hat die naive Freude an der Farbe schon in frühester Zeit $z u$ einem überlegten, auf ästhetischer Grundlage beruhenden Kunstprinzip erweitert. Die alten Schriftsteller deuten dies schon dadurch an, daß sie den Fensterschmuck immer in Verbindung mit dem übrigen Bau- und Ausstattungsprogramm der Kirche bringen. Es war also nicht Zufall und Laune, sondern überlegter Plan von Bauherrn und Baumeistern. So heißt es, um nur ein Beispiel anzuführen, von der karolingischen Prinzessin Bertha, die den Bau des Kleinmünsters in Zürich vollendete: "Sie ließ das Gotteshaus in einem schönen Aufbau herstellen, mit hohen erhabenen und geplätteten Säulen ausstatten und darum ließ sie auch Fenster, Wand und Decke kunstvoll bemalen, so daß davon alles übertroffen wurde, wie wenn sie selbst durch bunte Blüten gefallende Blumen die Natur besiegt hätte." Die Glasmalerei war also ein unumgänglicher Bestandteil des Bauprogramms, eben wegen ihrer dekorativen und raumgestaltenden Eigenschaften. Man darf nicht glauben, die Alten hätten die Glasmalerei nur kirchlichen Gebäuden reserviert, während die Profangebäude niemals glasmalerischen Schmuck aufgewiesen hätten. Man verkennt dabei, daß die Wohnung im Mittelalter überhaupt keinen künstlerischen Schmuck zu be- 
kommen pflegte; ein paar Zinnkannen auf dem Geschrenz, ein paar Pergamentblätter an der Wand, höchstens noch ein bescheidenes Hausaltärchen, das war neben dem notwendigen Gebrauchsmobilar die Gesamtausrüstung des Innenbildes. Als aber seit dem Eindringen der Renaissance die Kunst auch weltliche Zwecke verfolgte, da hielt unter den ersten die Glasmalerei ihren Einzug in das Bürgerhaus und verschwand nicht mehr daraus, bis der Zusammenbruch des künstlerischen Geschmacks alle Zweige der Kunst ihres frischen Blütenschmucks beraubte.

Zur Ausstattung einer Basilika gehörte in alten Zeiten Mosaikschmuck in der Tribuna und im Hochschiff, Marmormosaik am Fußboden und bunte Fenster in den Wänden. In Deutschland trat an die Stelle des Wandmosaiks das Freskogemälde. Ob dieses oder jenes, jedenfalls bildete das bunte Fenster die organische und harmonische Fortsetzung des Wandschmucks. Es ist hier der Ort, an dem mit einem Wort die törichte Erklärung abgetan werden muß, als hätten die „bunten Sonnenstrahlen“, deren Schein auf dem FuBboden das angenehme Farbenspiel erzeugte, ihre „Buntheit" nicht durch ein farbiges Fenster bekommen, vielmehr habe der bestrahlte Mosaikboden in verschiedenen Farben geschimmert, oder das Licht sei auf die gegenüberliegenden Wandmosaiken gefallen. W'er so interpretiert, hat noch nie eine vom Sonnenschein beleuchtete Kirche mit und ohne Glasgemälde bzw. Mosaiken gesehen; und wer sich von dem herrlichen „Farbenspiel“ überzeugen will, das ein durch farbloses Fensterglas einfallendes Sonnenlicht auf einem frühchristlichen Mosaikboden erzeugt, der mag zunächst dieses Schauspiel in S. Clemente zu Rom bewundern; jedenfalls wird er hernach jener merkwürdigen Interpretation niemals mehr zustimmen. Manchesmal hört man auch den Einwand, bunte Fenster hätten bei der geringen Ausdehnung des Fensterbaues den an sich schon dunklen Raum niemals des Tageslichts froh werden lassen. Was hätten zudem Fresken und Mosaikschmuck genützt, wenn kein oder höchstens ein ungenügendes Licht sie erhellten? Dagregen ist zu bedenken, daß die ersten Christen, solange Glasfenster noch nicht $A$ llgemeinbrauch waren, ihre Fensteröffnungen mit Teppichen, bunt geschnittenem Alabaster oder sonstigen Transparenten verschlossen, also unter allen Umständen zweierlei erreichten: 
Abdunkelung des Raumes und Buntfarbigkeit. Diese zwei Punkte löst ein buntes Fenster geradezu in idealer Weise, und darum ist es kein Wunder, daß sich der Gebrauch dieses ebenso praktischen wie schönen Abschlußmittels so unverhä1tnismäßig schnell und nachhaltig eingebürgert hat.

Wie nun die ältesten bunten Fenster ausgesehen haben, dafür läßt sich kein Beleg mehr finden. Wenn wir jedoch den Sinn der alten Schriftsteller und den Geist der alten Bauten recht verstehen, so tritt wenigstens einiges mit ziemlicher Klarheit aus aus dem Dunkel der Zeiten hervor. Es hat Jahrhunderte gedauert, bis man dazu gekommen ist, Figuren auf Glasgemälden darzustellen, obwohl das Christentum der Wiedergabe der menschlichen Figur und heiliger Personen stets großes Interesse entgegenbrachte. Freilich war die Voraussetzung der figürlichen Glasmalerei die Kenntnis des Bleis und des Schwarzlots; unumgänglich kann das Schwarzlot indes nicht genannt werden, da man mit geschickter Führung der Bleikontur sehr wirkungsvolle Darstellungen von Figuren zu erreichen imstande ist. Mag sein, daß man sehr spät auf die Entdeckung des Bleis und des Schwarzlots gekommen ist, allein das Bedürfnis darnach erschien gar nicht so vordringlich, da der durch bunten Fensterschmuck erstrebte ästhetische und architektonische Zweck auch ohne diese beiden Hilfsmittel $\mathrm{zu}$ erreichen war. Die mit Fresken und Mosaiken geschmückte Basilika verlangte gar keine Figuren in den Fenstern. Im Gegenteil bei völliger Durchführung des alten Austellungsprogramms wären stark betonte Figurenfenster des Guten zu viel gewesen. Nachdem Wände und Säulen mit figürlichem Schmuck reich beladen waren, hätte ein Figurenfenster, dem das durchflutende Licht eine größere Wirkung sichert, die Ausdruckskraft der Wandmalereien behemmen müssen. Andererseits hätte der vollendete Schönheitssinn der alten Baumeister bei Verzicht auf farbiges Glas die Fensteröffnung als eine störende Unterbrechung des auf der Wand gesponnenen Dekorationsgedankens empfunden, und da bot sich die Kunstverglasung von selbst als das geeignetste System, indem die "Glaser" wohl sehr schnell eine außerordentliche Fertigkeit errungen haben. Die Entstehung des buntfarbigen Fensterschmucks fiel in eine fruchtbare Zeit. Die Künstler des Sassanidenreichs hatten die pracht- 
vollsten Ornamente entwickelt, wie auf ihren Messinggefäßen, die sich noch ziemlich zahlreich erhalten haben, zu bemerken ist; sowohl das christliche Morgenland, wie die arabische Kunst übernahmen die sassanidischen Anregungen und bildeten sie in charakteristischer Weise aus. Ursprünglich faßte man die farbigen Gläser in Holz- und Steinrahmen, die nach einem ornamentalen Muster gefügt waren. Diese Tradition hat sich bei den Arabern jahrhundertelang erhalten und wer auf der Ausstellung von Meisterwerken der mohammedanischen Kunst in München I9Io die reizenden Moscheebuntfensterung gesehen, der konnte sich ein Bild von der buntschillernden Farbstimmung machen, die in den alten Kulträumen des Morgen- und Abendlandes von den Fenstern herableuchtete. Gegen die Stein- und Holzgerippe bilden Bleilamellen einen technisch großen, ästhetisch aber unbedeutenden Schritt. Wie wir bei dem Kapitel Kunstverglasung sehen werden, hat sich von der Hakim- und Asharmoschee in Kairo (um I000) noch eine Reihe unvergleichlich schöner Fensterornamente erhalten, die als unmittelbare Vorlage aller Kunstverglasungen zu Heiligenkreuz im Wiener Wald angesprochen werden könnten. Die Geschichte schließt daraus, daß sich die mit Blei arbeitende Kunstverglasung und Glasmalerei, soweit sie nach den ältesten Denkmalen erfaßt werden kann, in der Tat aus dem Stein- und Holznetz entwickelt hat, die Ästhetik aber, $\mathrm{da}$ B die alten Baumeister die Buntverglasung zu ausschließlich ornamentalen Zwecken, zur harmonischen Fortsetzung des Wandschmucks herangezogen haben. Das Aussehen der alten Buntverglasungen war also von dem Gedanken geleitet, die Fensteröffnungen dem Ausstattungsprogramm dienstbar zu machen und $z u$ verhindern, daß der Wandschmuck durch klaffende Fensterlücken zerrissen wird. Fortsetzung der WVand ist das älteste, aber auch entscheidende Prinzip der Glasmalerei. Die Technik konnte keinerlei Schwierigkeiten bieten, da die "vitrearii“ bei den Goldschmieden reiche Erfahrungen vorfanden. Das System der Kastenfassung ist bereits in der spätrömischen Periode zu meisterhafter Vollendung gediehen. Die Stege, in die der Edelsteinfasser dic einzelnen Steine legte, boten ein ungezwungenes Vorbild für die Kunstverglasung. Es ist nicht recht verständlich, wie man immer die Technik des Mosaiks in den Zusammen- 
hang mit der alten Buntverglasung als Vorbild der letzteren bringt. Das Mosaik kennt keine farbtrennenden Stege, setzt vielmehr in kleinen oder größeren Würfelchen Farbe an Farbe und erreicht bzw. erstrebt Bildwirkung. Das Mosaik verbindet, die Kunstverglasung trennt die Farbwerte. Wohl aber kann man die umgekehrte Feststellung machen, daß das Mosaik durch die Buntverglasung beeinflußt wurde. In der Martorana zu Palermo befinden sich prächtige Mosaiken, Zeugen der großen Hofkunst König Rogers II. von Sizilien: Auf ihnen trennen breite Stege aus dunklen Würfelchen die einzelnen Farbwerte, genau wie das Bleinetz die farbigen Gläser, die Gold- und Kupferstege auf Fassungen der edlen Steine. Wohl zeigen die Mosaikgemälde des Mausoleums der Galla Placidia bereits Ähnliches, $\mathrm{zu}$ einer Zeit, in der buntfarbiger Fensterschmuck sich im ersten Stadium seiner Entwicklung befand. Daß aber der Anstoß dazu von byzantinischen Emailleuren und Edelsteinfassern gekommen ist, beweist ein Blick auf die Mosaiken in der Kirche S. Constanza zu Rom, die im Stil der pompejanischen Wangemälde ausgeführt, sich niemals zu den zeichnerischen Arbeiten in dem Mausoleum der Galla Placidia, oder in der Martorana zu Palermo entwickelt hätten. Wenn nicht von der Kunstverglasung, so war dieses System des Mosaiks, das als das seltenere dasteht und wegen seines aparten Charakters in der Gegenwart wieder gern nachgeahmt wird, von den Edelsteinfassern beeinflußt, die auch den alten vitrearii manch praktischen Wink gegeben haben. Noch im Io. Jahrhundert ist die Erinnerung an die Zusammengehörigkeit von Glasmalern und Emailleuren frisch in Theorie und Praxis. Wie Sackur ${ }^{1}$ ) berichtet, bestand in Cluny während des Io. und II. Jahrhunderts eine gemeinsame Werkstätte für Goldschmiede, Edelsteinfasser und Glasmacher.

An der allgemeinen Entwicklung des Stils, besonders des Ornaments läßt sich also mit ziemlicher Genauigkeit ablesen, welche Durchgangsreihen die Buntverglasung erlebt hat, bis wir auf die ersten erhaltenen Denkmale stoßen. Es sind geometrische und Pflanzenornamente in jener stilisierten Zubereitung, die auf Mosaiken, in Handschriften und späterhin auf Teppichen und

1) Sackur, die Cluniacenser bis zur Mitte des II. Jahrhunderts, II, S. 4 OI. 
Paramenten noch heute zu uns reden. Die Farben müssen äußerst kräftig und bunt gewesen sein, denn nur unter dieser Voraussetzung gibt das Bild des Prudentius von den Blumen der Frühlingswiese den Eindruck solcher Buntverglasung richtig wieder. Je leichter das Material des die Zeichnung führenden Gerippes wurde, desto näher lag der Gedanke, die Zeichnung ins Detail auszuarbeiten. Das Schwarzlot hatte also zunächst eine durchaus dienende Stellung, indem es zur bescheidenen Andeutung von Einzelheiten verwendet wurde. Erst als sich im 9. und Io. Jahrhundert das Dekorationssystem in den diesseits der Alpen gelegenen Kirchen änderte und man die Anbringung von figürlicher Glasmalerei in den Fensteröffnungen dem rein ornamentalen Sujet vorzog, da wurde das Schwarzlot ein willkommenes und unentbehrliches Hilfsmittel zu Konturierung und, allerdings in bescheidenem Maße, zur Modellierung wie zur Angabe von Licht und Schatten. Die ältesten uns erhaltenen Denkmale der Glasmalerei in Deutschland und Frankreich verleugnen ihre Herkunft aus der Kunstverglasung nicht. Wenn auch die auszufüllende Fensteröffnung sehr klein ist, so nimmt doch die aus Blättern und Blumenelementen gebildete Umrahmung einen breiten Raum ein, davon abgesehen, daß auch der figürliche Teil ganz in der Handschrift des Kunstverglasers erscheint. Am wichtigsten ist die Beobachtung, daß jene ältesten erhaltenen Glasmalereien nur zwei Ausdehnungen im Raum kennen, nämlich Höhe und Breite, alles Körperliche aber, Perspektivische, kurzum, das was man unter der dritten Dimension begreift, sorgfältig ausschließen. Man kann für diesen flächigen Charakter keineswegs die Entwicklung der Miniatur allein verantwortlich machen, obwohl diese jahrhundertelang für den Glasmaler die vollbesetzte Tafel der Stilistik bildet. Der Zweck des Fensters, mit seiner Buntverglasung Fortführung der Wand zu sein, der bis ins I5. Jahrhundert die Ästhetik der Glasmalerei beherrschte, lag den Künstlern so tief im Gebein, daß sie gar nichts andres wußten und versuchten. Mochten sie daher auch noch so arm an Erfindung, noch so unbeholfen in der Zeichnung, noch so fern von Naturwahrheit und Charakteristik sein, jenes sichere Gefühl für die flächige Art der Glasmalerei behütete sie stets vor Entgleisungen.

Breit und massig steht auf den ältesten Glasgemälden das 
Schwarzlot, als wolle es nichts anderes sein wie ein zu äußerster Handlichkeit verflüchtetes Blei. Wozu bedurfte es der Modellierung für einen Künstler, der nicht Menschen von unserm Fleisch und Bein, sondern lediglich prägnante Symbole geben wollte, der sich für die hellsehende Mystik des Mittelalters mit Andeutungen begnügen und verständlich machen konnte? In keiner anderen Kunst vermochten die Ästhetik und der religiöse Zweck sich so in die Hände zu arbeiten, wie gerade in der Glasmalerei. Darum konnte der Künstler nicht $\mathrm{bloß}$ in der Zeichnung von der Naturwahrheit absehen, sondern auch in den Farben. Was verschlug es, wenn die Schuhe grün, die Heiligenscheine blau, ja sogar die Bäume rot und blau dargestellt wurden. Es waren ja nicht wirkliche Bäume. Wer gläubigen und verständigen Herzens zum Fenster aufschaute, der verstand, was der Künstler sagen wollte, genau so wie die ersten Christen in dem Wort Fisch, gleich einem stenographischen Sigel, die ganze Wissenschaft des Christentums erfaßten. Und wenn wir heute mit dem strengen Auge des Ästheten auf ein solches Farbenzeugma blicken, so haben wir erst recht keinen Grund, unzufrieden zu sein. Denn aus der jahrhundertelangen Tradition geschmackvoller Farbenakkorde hatte sich ein so sicheres Empfinden für Kolorismus entwickelt, daß alle Zusammenstellungen schön und dem Zweck der Glasmalerei dienstbar sind. Freilich können wir uns keine Vorstellung mehr machen, wie die Glasgemälde ausgesehen haben, als sie die Werkstatt verließen, denn auf alle hat die Zeit ihren Schatten gehaucht, so daß die Patina, mag sie noch so ehrwürdig und stimmungsvoll sein, die Deutung der absoluten Farbwerte wesentlich erschwert. So viel aber steht fest, daß sich die Alten nicht scheuten, die schärfsten Kontrastfarben in ihrer völligen Nacktheit gegeneinander zu stellen und sich nicht einfallen ließen, wie es heute leider zu häufig geschieht, durch allzu kräftigen Überzug den absoluten Wert einer Farke abzuschwächen. Die einzige im Wesen der Buntverglasung liegende Abdunklung reguliert sich durch die größere oder geringere Weitläufigkeit des Bleinetzes, namentlich wenn die Bleie recht breit und der heutigen Praxis entsprechend durch Schwarzlot verstärkt sind. Je älter die erhaltenen Denkmale sind, desto weniger wird das durch die Zeichnung vorgeschriebene Bleinetz zugunsten kleinerer Glas- 
flächen überschritten. Große Figuren haben auch große Glasflächen, so z. B. auf den Fenstern im Dome zu Augsburg. Dazu kommt, daß der zu Ausgang des klassischen Altertums sich aus dem Malerischen loslösende zeichnerische Stil, der besonders in germanischen Gebieten Aufnahme fand, keinerlei Parzellierung kleiner Farbflecke zuläßt. jIm I I. und I2. Jahrhundert macht sich zum erstenmal eine wahrnehmbare Scheidung zwischen deutscher und französischer Glasmalerei geltend. Die Unterschiede beziehen sich jedoch weniger auf die Technik als auf die Zeichnung. Dies hängt mit der allgemeinen Verschiedenheit der Kunstrichtung beider Länder zusammen. Während sich das lebhafte Temperament des Keltoromanen an der malerisch dramatischen Gestaltung erfreut, folgt der bedächtige Sinn des Germanen jenem monumental-zeichnerischen Charakter, der sich am Ende der Antike als Ableger der romanischen Buchillustration entwickelt hat. Darum zieht auch die deutsche Glasmalerei die Einzelfigur der durchkomponierten Scene vor, wenngleich die französische Glasmalerei die Einzelfigur ebenfalls in ihr Programm, aber nicht aus ästhetischen, sondern theologischen Gründen, aufnehmen muß. Trotz der oft bizarren Körperhaltungen und Gliedverrenkungen, die mangels einer Charakterisierungsmöglichkeit seelische Erregungen schildern sollen, fällt auch die französische Glasmalerei nicht aus der Rolle, hält vielmehr durchweg an dem flächigen System der Glasmalerei fest.

Den stärksten Beweis für den Zweck der Buntverglasung, die künstlerisch ausgestattete Wand fortzusetzen, bildet der Kolorismus der Augsburger Fenster. Trotz der ihnen anhaftenden Patina leuchtet ihr heller Grundcharakter sieghaft durch. Das Licht sollte nicht behindert, sondern für die übrige Ausstattung reguliert, auf das Raumbild gestimmt sein. Farbenakkorde wie grün-rot, namentlich in großen Flächen, sind um ihrer selbstwillen gar nicht denkbar. Dagegen begreifen sie sich, wenn man an ihren Zweck denkt, aus bedeutender Höhe herab selbst das Natürlichste was es gibt, das Tageslicht, künstlerisch zu erheben und so bis zum äußersten den Kunstcharakter des Baus zu vollenden. $\mathrm{Zu}$ viel Bleie und $\mathrm{zu}$ viel Modellierung hätten in Anbetracht der kleinen Fensterflächen Verdunklung statt Stimmung hervorgerufen. Darum beschränkten sich die alten Meister so- 
wohl im Blei wie im Schwarzlot. Um so kräftiger und um so beredter mußte es aber sein, was durch diese beiden Ausdrucksmittel gesagt werden sollte. Vor allem hatte jede Hauptkontur, sei es Blei- oder Schwarzlotkontur, einen wichtigen Gedanken $\mathrm{zu}$ versinnbildlichen. Mit logischer Strenge hat der Meister der Augsburger Fenster die breiten massigen Schwarzlotstriche gezeichnet, sie aber mit drei bis vier immer dünner werdenden Parallelstreifen verbunden. Man hat dies der sich von der Buchillustration herleitenden Strichmanier zugeschrieben. In Wirklichkeit wollte der Glasmaler damit in großzügiger und echt monumentaler Weise die Schattierung angeben, was ihm ausgezeichnet gelungen ist, nachdem er für Fernwirkung (Hochschifffenster) entwerfen mußte. Auch die eigenartige Schraffierung der Haare und des Bartes, die Striche in den inneren Handflächen, die Alterslinien auf der Stirne, dienen dieser Berechnung auf Fernwirkung. Was für das in der Nähe betrachtende Auge als scharfe Trennung zwischen schwarzem Strich und hellem Zwischenraum erscheint, das zieht sich für die Fernbetrachtung zu einer harmonisch abschattierten Kontur zusammen. Die organische Verbindung von Kontur und Schattierung ist von den Künstlern der Augsburger Domfenster bereits in vollendeter Form gehandhabt worden. Verwandte dieser Augsburger Fenster auf französischem Boden finden sich in den etwa 50-I00 Jahre jüngeren Fenstern der Kathedralen zu Châlons-sur-Marne und Le Mans. Die Schraffierung der Haare, die Parallelisierung der Schwarzlotkonturen stimmen beidesmal genau überein. Ja die interessante Art, bei zusammenstoßenden Schwarzlotkonturen den einen Schenkel über den Scheitel zu verlängern, die wir auf den Augsburger Fenstern beobachten können, kehren mit genauer Gleichmäßigkeit auf den genannten Arbeiten wieder. Diese Eigenart zeigen besonders häufig Salzburger Miniaturen, wohl als Ausdruck gebrochener Falten.

Wenn wir von dem auf einem französischen Friedhof vor einigen Jahren gefundenen Reliquienschrein, der die älteste Verbindung des Bleis mit Glas darstellt, absehen, so bildet die eben besprochene Gruppe von Glasgemälden die älteste, geschichtlich greifbare Stufe des buntfarbigen Fensterschmucks. Der Künstler will unter allen Umständen rein ornamental wirken. Darum hat 
er die Farben ohne Rücksicht auf die Wirklichkeit gewählt. Durch kräftige Töne, kontrastreiche Zusammenstellungen wendet er sich an die naive Farbenfrohheit der Beschauer. Alles ist mit zeichnerischer Klarheit verteilt, scharf scheiden die Konturen, sei es durch Schwarzlot oder Blei die einzelnen Farbinseln von einander und unter sich. Breit und kraftvoll ist die Angabe der einzelnen Körperteile, man vergleiche z. B. die Darstellung des Auges. Trotz dieser monumentalen Starrheit verzichtet der Künstler nicht auf das Lieblingsgericht der Zeit, das Ornament. Dem Ornament dient die Anbringung und insbesondere Ausführung der Schriften, breiter Bordüren, prächtiger Palmetten. Auf zwei Scheiben ist sogar das ganze Untergewand mit Vierpässen gemustert. In der Technik dieser Ornamente wie besonders der Schriftbänder hält sich der Künstler teils an die Vorschrift des Rugerus (Theophilus), indem er die Zeichnung bzw. die Buchstaben aus dem aufgetragenen Überzug ausradiert, teils trägt er sie mit dem Malpinsel auf das Glas auf. In der Sicherheit der Ornamentbehandlung liegt eben noch ein Stück Tradition aus dem Zeitalter der Kunstverglasung. Auch die Einbleiung von farbigen Glasstückchen auf Gewandsäumen, Kronen, die selbstverständlich gefaßte Edelsteine nachahmen sollen, ist eine Erinnerung an jene Periode des buntfarbigen Fensterșchmucks in der Edelsteinfasser und Glaser in einer Werkstätte zusammen arbeiteten. Während die deutschen Glasgemälde mehr am zeichnerischen Stil haften blieben und auch in ihren Farben die scharfe Logik walten ließen, hat sich Frankreich so schnell wie möglich dem flüssigen Stil seiner Buchillustrationen ergeben. In der Verwendung des rot-blauen Grundakkords, in der Gruppierung anderer Töne um diesen Zweiklang, sind die Franzosen von Anfang an während der ganzen romanischen Periode, unerreichte Meister geblieben. Unter dem Einfluß der immer frisch anbrandenden byzantinischen Wogen entwickelte sich rasch ein üppiges Faltensystem für Gewänder, wie auch architektonische Bauglieder verhältnismäßig früh in die französische Glasmalerei eindringen. Dazu kommt die begeisterte Hingabe an die Scholastik, die bereits im I2. Jahrhundert ein geschlossenes System schuf, nicht mehr streng für den Theologen wie für den Künstler. Dadurch bildete sich das sogenannte Medaillonfenster aus. Und 
wiederum begegnen wir dabei einer Rückerinnerung an die Kunstverglasung. Das Fenster wird streng ornamental komponiert. Die Hauptfelder sind wohl bestimmt, die einzelnen Darstellungen aus der Heilsgeschichte aufzunehmen. Allein die Nebenfelder bieten ein ebenso wichtiges Glied, indem sie Ornamente aus Blumen und Blättern tragen. Die Figuren werden kleiner und nachdem sich auf die Außenseiten die Patina gesetzt hat, verlieren sie an Übersichtlichkeit und sind manchmal mit dem bloßen Auge überhaupt kaum erkenn- oder deutbar. Allein der Hauptreiz liegt, wie auf jedem Glasgemälde und hier besonders, in der Wahl und Zusammenstellung der Farben. Nachdem seit dem I2. Jahrhundert auch der Hintergrund ein ornamentales (meistens ausradiertes) Muster bekommen hat, ist die Anpassung des figürlichen Glasgemäldes an seinen dekorativen Zweck fertig. Daß bei steigender Größe des Fensters, die nur auf Kosten der Wandflächen und der darauf wiedergegebenen Wandmalereien entstehen konnte, das Glasgemälde auch vom Prediger mehr in Anspruch genommen und dem oben skizzierten System der Theologen untertan wurde, spielt für die ästhetische Betrachtung nur eine nebensächliche Rolle, da es in diesem Zusammenhang gar nicht auf das Was, sondern nur das Wie der Darstellung ankommt. Bis tief ins I3. Jahrhundert bleibt dem Kartonzeichner wenig zu tun. Die Figuren sind noch immer Symbole für die Wirklichkeit, ähnlich wie die Noten für die Wirklichkeit des Tons. Das religiös geschulte Publikum versteht zu sehen, begreift den Sinn der Abbreviaturen. Mit ein paar kräftigen Konturen oder breiten Radierungen sind Ornamente, Tiere und Menschen hingeworfen. Nicht sorgsam geglättetes Detail will geboten werden, um womöglich von dem Hauptthema abzulenken. Der Zeichnung haucht erst die Farbe den Odem des Lebens ein. Auch die Sprache der Farbe wurde von dem Beschauer verstanden. Denn in der christlichen Religion gab es auch eine Symbolik und Mystik der Farben. Genau wie das Rot des priesterlichen Gewandes noch heute dem christlichen Volke über die Bedeutung des Tages etwas anderes kündet; als wenn es den Priester in Violett einherschreiten sieht, so hatte auch das christliche Altertum und Mittelalter seine eigene Farbenmystik, die nur nachgefühlt, nicht aber kritisch analysiert werden kann. 
Was uns die geringen geschichtlichen Überlieferungen über das Ausstattungsprogramm einer Basilika sagen (vgl. nochmals den Bericht über den Bau des Kleinmünsters in Zürich), das bestätigt der Befund an den noch erhaltenen Denkmalen alter Glasmalereien. Die Farbe beherrschte von Anfang an das Raumbild. Selbst kleine Kapellen, auf die man nicht viel verwenden konnte, zeigen diese Tendenz (Flums!) und beweisen, daß man die Mystik der Farbe der Mystik des christlichen Gottesdienstes anpassen wollte. Wände und Decken boten Flächen genug, um den Raum warm und symbolisch zu stimmen. Wo man des Mosaiks oder des Freskos entbehrte, da konnte man sich mit farbigen Teppichen und Stoffen behelfen. Wie ungeheuer hätte ein unverkleidetes Fensterloch, und wenn es noch so klein war, den fortlaufenden Wandschmuck zerrissen, die feierliche Stimmung des Raumes, durch die man das Gotteshaus aus dem nackten Licht des Alltags emporheben wollte, vernichtet! Darum war buntfarbiger Fensterschmuck unerläßlich und die ärmlichen, aber doch so charakteristischen Vorläufer wie Teppiche, farbige Transparente zeigen, daß man nach bunten Fenstern unbewußt so unendlich heiß dürstete. Darum der sich überstürzende Wortschwall, mit dem der Abt von Tegernsee seinem gräflichen Gönner den Dank eines ästhetisch befriedigten Herzens stammelt, dafür daß die "goldhaarige Sonne nunmehr durch bunte Fenster in das Gotteshaus ihre Strahlen sende". In der Farbe mußte das Fenster die Wände fortsetzen und den Ton des Interieurs bestimmen; für die Zeichnung aber lag die Übereinstimmung mit dem Bau in der primitiven Ausdruckskraft, durch die alles nur angedeutet und dem Beschauer überlassen wurde, sich in die Mystik des Dargestellten einzuleben. Das Primitive war aber den Künstlern nicht Selbstzweck und dadurch unterscheiden sie sich von manchen Modernen, die ihnen in Primitivheit den Rang ablaufen möchten. Ihre Primitivheit stimmte mit dem naiven Gottes- und Christusglauben zusammen, der ihr ganzes künstlerisches Empfinden regelte. Darum ist ihre Handschrift echt und wahr; man glaubt ihr. Die größte weltgeschichtliche Bewegung, wie z. B. die Kreuzzüge, sind ebenso Ausdruck jener naivgläubigen Weltanschauung, wie das kleinste Scheibchen in einer Landkapelle. Gegenüber dieser Glaubenskraft des christ- 
lichen Abendlandes verschwinden die kleinen stilistischen Unterschiede, die eine französische oder deutsche Schule bestimmen. Die Idee $z u$ dienen, $z u$ erbauen, schafft hier wie dort ein vollkommenes und zusammengestimmtes, von dem allzeit gegenwärtigen Gott in Besitz zu nehmendes Raumbild. Das war die Mystik des frühen Mittelalters, die dem Glasgemälde eine so glühende Ausdruckskraft verlieh. Es geht ihre höchste Blütezeit durchs Land, ihre unsterbliche Kraft erfährt keine Steigerung mehr. Noch ist sie imstande, alle Anforderungen, die von der Architektonik an sie gestellt.werden, aus Eigenem zu befriedigen. Wo sie schafft, ist sie erfinderisch, im Ornament, wie in der Figur. Sie braucht dem Baumeister nichts abzugucken; nicht das bescheidenste Bauglied erscheint auf dem Glasgemälde als Hilfsornament und doch ist ihr Gesamtcharakter, ihre Komposition in schönster Beziehung zum Bau.

Langsam ändert sich dieses Aussehen des Glasfensters seit den ersten Jahrzehnten des I 3. Jahrhunderts. Zwar bleibt der flächige, zweidimensionale Ton noch über ein Jahrhundert lang gewahrt, aber je länger desto mehr dringt die Architektur in das Fenster ein. Die Glasgemälde der frühromanischen Periode umsäumt ein Kranz von stilisierten Blattornamenten, die girlandenartig angebracht sind und eine deutliche Rückerinnerung an die Zeit der Kunstverglasung darstellen. An deren Statt tritt nun, gleichwie in der Miniatur, die Beiziehung von säulengetragenen Bögen und sonstigen architektonischen Formen. Man hat dafür die immer stärker hervorgetretene byzantinische Beeinflussung verantwortlich gemacht, die sich über Sizilien her, zum Teil als Folge der Kreuzzüge in die Kunstzentren Frankreichs ergoß. Die Miniatur des karolingischen und ottonischen Zeitalters verfügt über einen reichen Schatz architektonischer Formen, die mit der byzantinischen Stilistik aufs engste verwandt sind. Durch die Kreuzzüge wurde dieser Gedankenkreis wieder aufgefrischt und mit ritterlicher Eleganz versehen. Die Klosterkunst wurde zur Hofkunst, ähnlich wie die schwesterliche Muse der Poesie in den Dienst des höfischen Epos getreten war. Frankreich huldigte dieser Mode und beeinflußte auch das westliche Nachbargebiet. Die neue Bewegung geht von Chartres aus und hat in dem Salomofenster des Straßburger Münsters seinen südwestlichsten 
Ausläufer. Bei der Glasmalerei fällt diese Mode besonders auf, da sie fast unvermittelt sich an jene Stufe gliedert, die nur Pflanzen- und geometrische Ornamente kennt. Die Architekturformen sind leere Schemen, die fast gar keine Beziehung zu der Wirklichkeit hatten, wie sie ein Studium am Bau ergeben hätte. Sie dienen daher lediglich als Dekorationselement, von den Fällen abgesehen, in denen die Szene irgendwelche Andeutung von einem Haus oder einer Stadt notwendig machte. Außerdem vervielfältigen sich die Medaillonrahmen, die sich aus dem Kreis in allerlei paßförmige Gebilde auflösen. Auch jetzt ist der $\mathrm{Zu}$ sammenhang der Glasmalerei mit dem übrigen Ausstattungsprogramm noch keineswegs gelockert. Je mehr sich die Wände verkleinern und dafür die Fensterflächen vergrößern, desto mehr Aufgaben treten an das Glasgemälde heran. Ihm fällt mit dem Fortschreiten des Jahrhunderts immer mehr die führende Rolle zu. Ganze Legenden, ja das gesamte Leben und Lehren Jesu muß auf den Fenstern wiedergegeben werden. Dadurch entstehen für die Figuren sehr bedeutendeDimensionsbeschränkungen und es erfordert vom Glasmaler ein großes Geschick, die dadurch bedingten weit kleineren Glasstücke harmonisch zu verteilen. Immer stärker tritt der Charakter eines bunten Teppichs, einer farbigen Wiese hervor. Da sich der Glasmaler für die darzustellenden "Gegenstände in der theologischen Literatur, wie sie besonders in den miniaturreichen Handschriften ihren Niederschlag gefunden hat, Rats erholen mußte, war eine größere Abhängigkeit des Glasgemäldes von der Miniatur die unvermeidliche Folge. Seitdem Mâle in seinem unvergleichlichen Buche L'art religieux du XIII. siècle en France, klargelegt hat, wie das ganze Bau- und Ausstattungsprogramm im i3. Jahrhundert aufs genaueste mit dem Lehrsystem der kirchlichen Wissenschaft übereinstimmt, ist nicht bloß der Inhalt, sondern auch der Stil so manchen Glasgemäldes ohne weiteres verständlich. In deutschen Landen hat man sich im wesentlichen auf die Biblia Pauperum (Armen-Bibel) und das Speculum humanae salvationis beschränkt. Nur in einem Falle ist es möglich, Miniaturenvorlage und ausgeführte Glasmalerei miteinander $z u$ vergleichen, nämlich bei den Fenstern der Stefanskirche zu Mühlhausen. Dieser Vergleich aber lehrt, daß sich der Glasmaler bei aller Abhängigkeit 
in Komposition und Stil, für die Farben und die Ausführung vollste Freiheit gewahrt hat. Auch auf deutschem Boden sind die Farben nunmehr satter und dunkler geworden. Der deutsche Glasmaler versucht ebenfalls mit dem Zweiklang rot-blau als Grundakkord zu arbeiten. Auch taucht, zunächst ganz bescheiden, das Silbergelb auf, eine Lasurfarbe, mit der man Gewandsäume, Heiligenscheine, Buchdeckel und sonstiges Detail tönen konnte. Das Silbergelb ist gegen Ausgang des I3. Jahrhunderts in Gebrauch gekommen. Trotz gewisser farbenästhetischer Grundregeln, die, wie wir später ausführlich sehen werden, in eigenen Werkstattbüchern, z. B. von Antonio da Pisa, kanonartig niedergelegt waren, ist der allgemeine Charakter der Farbenzusammenstellung in hervorragendem Maße das selbständige Betätigungsfeld des einzelnen Glasmalers. Darum kommt es nicht selten vor, daß bei Glasgemälden, die man auf eine gemeinsame zeichnerische Vorlage zurückführen kann, große Unterschiede in der Stellung der einzelnen Figuren findet, was nur aus dem verschiedenen Farbgefühl des einzelnen erklärt werden kann. In jener glücklichen Zeit, in der Entwurf und Ausführung in einer Werkstätte vereint waren, dachte und empfand man schon bei dem ersten Gedanken an den Entwurf glasmalerisch. Die Zeichnung war von der Farbe beeinflußt. Da es keinerlei Schutz der geistigen Arbeit gab, da man die Meister verschiedenemale direkt anhielt, anerkannte Vorbilder zu studieren und zu kopieren, was auch Antonio als das sicherste Hilfsmittel im Notfall vorschreibt, da man nicht auf künstlerische Originalität, sondern auf das dargestellte Lehrobjekt und die Gesamtwirkung für den Kirchenraum sah, waren Seitensprünge, wie aber auch starke zeichnerische Konzeptionen ausgeschlossen.

Um I 260 entsteht in Frankreich das sogenannte Psalmbuch Ludwigs des Heiligen (1e psautier de S. Louis). Es ist ein Gebetbuch dieses französischen Königs, ein Vorläufer der 150 Jahre später so reichlich ausgestatteten Stundenbücher der burgundischen Herzöge, die ebenfalls auf die Entwicklung der Glasmalerei von großem Einfluß sein sollten. In jenem Psalter sind die einzelnen Szenen unter gotische Wimperge gestellt (siehe Abbildung 9). Die Anlage und die dünnen Säulen erinnern noch an die Doppelrundbögen der Fenster von Chartres. Dagegen 
ist der Übergang zur Kirchengotik bereits vollzogen. Rasch dringt dieses System auf die Fenster von Kathedralen und einfacheren Kirchen, als Zeuge engsten Zusammenarbeitens des Architekten mit dem Glasmaler. Wir wissen aus der Geschichte der gotischen Baukunst, daß man sich während der Periode der Frühgotik sehr häufig französische Baumeister nach deutschen Bauhütten kommen ließ oder wenigstens die einheimischen Steinmetzen nach Nordfrankreich sandte, damit sie daselbst das Wesen des neuen Stils studieren sollten. Diese Tatsache übte auf die deutsche Glasmalerei eine eigenartige Wirkung aus. Man konnte sich in deren Werkstätten der neuen Mode, die von der Bürgerschaft mit Begeisterung aufgenommen wurde, nicht entziehen, darum gab man sich dem Lehrvortrag des fremden Baumeisters hin, der das gotische Umrahmungssystem zunächst vielleicht persönlich zu Pergament brachte. Für die darin eingefügten Personen aber verblieb der Glasmaler bei seinem spätromanischen Stil. Denn in diesem Punkt konnte ihm der Architekt nicht an die Hand gehen. Darum finden wir in verschiedenen deutschen Kathedralen, wie z. B. in Straßburg, Glasgemälde, die romanische Figuren unter gotischen Baldachinen wiedergeben. Das neue Architektursystem verließ die Glasmalerwerkstätte nicht mehr. Was der Psalter Ludwigs des Heiligen vorgebildet hat: Wimperg vor Lichtgaden, das wurde während der ersten Hälfte des I4. Jahrhunderts in den alamannischen Glasmalereiwerkstätten, bis zur stereotypen Formel erstarrt, getreulich nachgeahmt und festgehalten.

Es ist begreiflich, daß man dieses sich von selbst ergebende Hilfsmittel um so weniger sich entgehen ließ, als mit der stetigen Erweiterung der Fensterflächen an das Kompositionstalent des Glasmalers immer stärkere Ansprüche gestellt wurden. Je höher die Fenster emporstiegen, desto weniger war es möglich mit kleinen Szenen zu arbeiten, da man sie mit bloßem Auge ja doch nicht gesehen hätte. Man zog daher vor, Einzelfiguren darzustellen und die hauptsächlichsten Lehren der Religion, besonders die Kreuzigung, die hinter dem Hochaltar ihre Stelle hatte, auf die ganze Fensterbreite hin zu komponieren. Dadurch kam dem Hintergrunde wieder eine erhöhte Bedeutung zu. Er wechselte harmonisch zwischen rot und blau, und war mit Rauten, 
Kreisen, Vierpässen, später unter südlicher Einwirkung mit Damasten gemustert. Mit dieser Anlage erfüllte man das Hauptgebot des gotischen Baumeisters, himmelstürmende Höhenwirkungen $\mathrm{zu}$ erstreben. Wenn man daher das unermeßliche Fialen-Wimperg-Baldachinsystem auf Glasgemälden mit Recht als stilisierte Wiedergabe der gotischen Kirchenplastik, ähnlich wie bei dem Chorgestühl, erklärt, so darf man als den letzten Beweggrund des Glasmalers seinen Sinn für das Architektonische, das ihn stets mit dem Baumeister verbunden hielt, hinnehmer. Die deutsche Bauweise empfand die Mystik des Horizontalen in der Gotik viel stärker als die sich gern nach vertikaler Gliederung zersplitternde französische Hochgotik. Darum setzten die deutschen Baumeister an Stelle der breiten Fensterrosen, da wo sie ganz aus Eigenem schufen, gerne ein in die Höhe strebendes Fenster. Mit dieser Eigenart der deutschen und französischen Bauart in der Gotik stimmt auch die Entwicklung in der Glasmalerei überein. Die großen, nur dem Drang in die Höhe folgenden Glasgemälde, wie wir sie beispielsweise im Dom zu Köln, im Münster zu Freiburg bewundern, gehören in Frankreich zu den Seltenheiten. Vergleiche z. B. die Fenster zu Evreux und Riom. Sehr bald weicht die zeichnerische Schlankheit der Architekturformen einer massigeren, plastischen Fülle. Der sehnsüchtige Drang nach oben, der auf den deutschen Fenstern, wie ungelöscht weiter strebt, ist auf den französischen im behaglich Breiten gesättigt. Schon versuchen die Glasmaler Frankreichs mit keckem Schritt die Schranken des Flächigen, Zweidimensionalen zu durchbrechen und in gemessenen Abständen folgt die Kölner Schule. Der Übergang zur reinen Perspektive vollzieht sich jedoch auf schweizerischem Boden.

Die zweite Stufe der Entwicklung buntfarbigen Fensterschmucks bringt also im äußeren Aufbau die völlige Angliederung an die Architektur und bejaht so aufs entschiedenste den Gedanken der Zusammengehörigkeit mit dem Bau. Der Glasmaler holt seine Kompositionsglieder aus der Hütte des Steinmetzen und vervollständigt was der Architekt anstrebt. Die vergoldeten Fialen, die vom Hochaltar emporstreben, finden ihre Fortsetzung auf dem Glasgemälde, das mit seinem Maßwerk zu den bemalten Rippen und Kappen des Gewölbes überleitet. Derselbe Ge- 
danke pflanzt sich über das Chorgestühl in das von hohen Säulen getragene Schiff, um daselbst ein Raumbild von höchster Steigerung zu schaffen. Aber in die gigantische Größe dieses Raumbildes bringt die Farbe des Glasgemäldes die Stimmung, die Mystik, die sofort beim Eintritt den ganzen Menschen gefangen nimmt. Mitten in die Blütezeit der Glasmalerei fällt der bekannte Beschluß des Zisterzienserkapitels, in den Gotteshäusern des Ordens keinerlei Buntverglasung zuzulassen. Dieser puritanische Gedanke war von der Besorgnis eingegeben, die bunte Farbenpracht der Glasgemälde und die auf ihnen wiedergegebenen Szenen könnten von dem Blick auf den Altar, von der Betrachtung des Überirdischen ablenken. Bei der Straffheit der Disziplin und bei der Bedeutung des Gelübdes des unbedingten Gehorsams unter die geistlichen Oberen wird dieses Verbot, so muß man annehmen, jede Hinneigung zu glasmalerischem Schmuck erstickt haben. Was geschah aber in Wirklichkeit? Das Verbot wurde teils als überhaupt nicht bestehend angesehen, teils zögerte man seine Befolgung so lange hinaus, bis ein neues Gewohnheitsrecht ihm die Kraft nahm. Wo es aber Beachtung fand, z. B. in Heiligenkreuz im Wiener Wald, da schuf es die sogenannte Grisaille, die nur mit Schwarzlot und farblosem Glas arbeitende Kunstverglasung. Hier waren die Künstler noch einmal in ihrem Element. Eine Fülle von prachtvollen Ornamenten entstand und sehr schnell schlich sich farbiges Glas wieder ein, um das sogenannte Ornamentfenster zu höchster Vervollkommnung zu führen ${ }^{\mathbf{1}}$ ).

1) Vergl. Saur, Josef, Der Cisterzienserorden und die deutsche Kunst des Mittclalters in „Studien und Mitteilungen zur Geschichte des Benediktinerordens und seiner Zweige", I9I3, IV. Quartalheft, S. 668 ff.: „Die Gläser seien weiß, ohne Kreuze und Malereien." Verordnung des Jahres II34. Im Jahre II 82 mußte ein neues scharfes Gebot gegen die Glasgemälde erlassen werden: Glasgemälde müssen innerhalb zweier Jahre ausgenommen werden, widrigenfalls der Abt, der Prior und Kellermeister jeden Freitag bei Wasser und Brot zu fasten haben, bis die Glasgemälde herausgenommen sind. I 240 wird die Vorschrift abermals wiederholt. Wenn bei der Strenge des geistlichen Gehorsams so einschneidende Gebote immer wieder übertreten bezw. (durch Grisaillen) umgangen werden, so ist dies der stärkste Beweis, wie tief der ästhetische Genuß buntfarbigen Fensterschmucks in den Herzen der Mönche gewurzelt war. „Die Verbote waren ein Verstoß gegen eine Naturanlage der menschlichen Seele selbst, und eine solche läßt sich auf die Dauer nicht unterdrücken. Sie bricht sich mit Gewalt Bahn." a. a. O., S. 690. 
Wer einmal einen mit solchen Ornamentfenstern geschmückten Raum betreten hat, wird zugestehen, dah hier der buntfarbige Fensterschmuck sich am vollkommensten ausgelebt hat. So unbefleckt rein, so vollkommen frei von allen lehrhaften Rücksichten ist der Schönheitsgehalt des buntfarbigen Fensterschmuckes nie mehr in Erscheinung getreten wie eben in solchen Ornamentfenstern; denn sein Zweck zu dienen, war völlig erreicht. Darum hat auch die figürliche Glasmalerei sich dem Reiz des Ornamentfensters nicht entziehen können, sondern mit der Szenendarstellung verbunden, indem es selbe in Teppiche hineinkomponierte oder aber das Ornament als Fortsetzung des Figürlichen verwendete. Die deutschen Glasmaler gehen mit dem Ruhm durch die Geschichte, die stimmungsvollsten und wärmsten Muster geschaffen zu haben, während die sonst so häufig tonangebenden Franzosen nur zu sehr am Oberflächlichen, mehr vom Zirkel Hervorgebrachten haften blieben. Je weiter wir vom Westen weg südlich und östlich in die alamannischen Gebiete vordringen, desto zahlreicher werden die Ornamentfenster, desto schöner wird das Muster. Man vergleiche z. B. die Glasgemälde in Blumenstein, Köniz, in der Konstanzer Gegend, die aus Bayern stammenden Scheiben Nr. I4 bis 88 des Bayrischen Nationalmuseums in München. Die frische Naturbeobachtung und der prachtvoll stilisierte Reichtum der Pflanzenblätter erinnert an die durch und durch deutsche Arbeit an den Kapitellen und Friesen des Domes zu Naumburg. Da die französische Glasmalerei damit nicht konkurrieren konnte, hat sie sich sehr schnell auf die Anwendung von Rautenmustern aus farblosem Glas zurückgezogen, was ihr die Kölner Schule bald nachgemacht hat.

$\mathrm{Da}$ tritt verhältnismäßig unvermittelt eine Wendung in dem Grundcharakter der Glasmalerei ein. Sie geht von jenen Künstlern aus, die im ersten Drittel des I4. Jahrhunderts den Glasgemäldeschmuck des Klosters Königsfelden geschaffen haben. Zum Verständnis bedarf es der geringen geschichtlichen Auffrischung, daß dieses Kloster zur Sühne der Ermordung König Albrechts im Jahre I 308 an dem Ort der Tat, unweit des Stammsitzes der Habsburger, erbaut und von den Mitgliedern dieses Geschlechtes mit reichlichem Schmuck ausgestattet wurde. Während weniger Jahrzehnte wurden die elf großen Chorfenster 
aus Stiftungsmitteln der Habsburger Familie vollendet. Trotz ihrer zeitlichen Nähe gehen die Fenster im Stil weit auseinander. Neben dem bereits skizzierten System der flächigen Kirchengotik steht das dreidimensionale, perspektivische System vollkommen fertig da. Das Ideal Giottos ergreift das Körperliche, seine dem Profanbau entlehnten Architekturen treten an die Stelle der Kirchengotik. Mit unglaublicher Schnelligkeit verbreitet sich die neue Mode, einen Hauptstrahl nach dem Elsaß und nach Regensburg aussendend, der zum Anstoß weiter Entwicklung wird. Nebenher dringt eine andere italienische Welle nach Norden durch die Berufung des Thomas von Modena an den Hof Kaiser Karls IV. nach Prag, und um das Maß der Beziehungen zum Süden voll zu machen, gehen deutsche Kleriker und Studenten nach Oberitalien und bringen selbstverständlich von dort nicht bloß ihre gelehrte Bildung, sondern auch einen italienisierenden Kunstgeschmack mit. Darum finden die Arbeiten der im italienisierenden Stil von Prag schaffenden Glasmaler in Brandenburg und in den Deutschordensburgen so begeisterte Aufnahme. An den Fürstenhöfen Nordfrankreichs aber und Burgunds sproßt eine Hofkunst, die zunächst in der Miniatur ihre schönsten Blüten treibt. Es entstehen jene obengenannten Gebetbücher (Livres d'heures), Stundenbücher, •von denen jedes ein Kunstwerk für sich ist, und die eine große Anzahl deutscher Künstler nach Westen ziehen. Es mag dahingestellt bleiben, wie sich diese französisch-burgundische Hofkunst zu den oberitalienischen Schulen des Trecento verhält; Tatsache ist, daß in beiden Kunstrichtungen dasselbe verfolgt wird, nämlich völlige Auswertung der perspektivischen Errungenschaften und möglichst genaue Anpassung der Kunst an die Wirklichkeit in Zeichnung und Gewandung der Figuren. Da nach dem Charakter dieser Kunst als einer Hofkunst vor allem die fürstlichen Personen zur Darstellung kamen, entwickelte sich das Portrait, wie die Sitte die neuesten Kleidermoden mit größter Treue wiederzugeben. Diese beiden großen Kunstgebiete wirkten mit aller Macht auf die Glasmalerei ein; die deutschen Meister konnten sich den neuen Reizen am wenigsten entziehen. Merkwürdigerweise hat sich die Glasmalerei in Italien und Frankreich von der genannten Kunstrichtung fast gar nicht beeinflussen lassen. 
Im Elsaß aber, am Bodensee, an der Donau ergeben sich die deutschen Künstler in all ihren Arbeiten dem neuen Formenschatz. Jeder will den andern in der Kühnheit der Perspektiven, in der Kraft des Realismus und in der Lebhaftigkeit der Bewegung übertreffen. So entstehen die Fenster zu Ravensburg, Eriskirch, Schlettstadt, Lenzburg, Bern. Nebenher geht der Versuch, die Profanarchitektur mit der Kirchengotik zu versöhnen. Es kommt so zu Fenstern, die neben den breiten, in Kreuzblumen endigenden Eselsrücken und Kreuzgewölben giotteske Profanbaldachine und Konsolen aufweisen, keineswegs ein Bild schöner Harmonie, vielmehr oft genug uneinheitlich und zerrissen. Dazu kommt, daß die Künstler das lebhafte Interesse, das man den geistlichen Spielen entgegenbrachte, auch auf Glasgemälde übertrugen. Die reiche Beiziehung von Engeln als $\mathrm{Zu}-$ schauern stammt ursprünglich auch aus Italien. Deren lebhafte, schauspielerische Aktionen aber können nicht anders, denn als Umdeutung einer Regievorschrift aufgefaßt werden. Regensburg erscheint am frühesten im Vollbesitz jener perspektivischen Weisheit. Die Regensburger Schule war einem doppelten Andrängen italienischer Ideen ausgesetzt. Einerseits hat Königsfelden seine Ausläufer, wie an den erhaltenen Denkmälern nachweisbar ist, hierher entsandt, sodann aber hat die Prager Kunst verständnisvolle Aufnahme in den Werkstätten der Regensburger Glasmaler gefunden. Von hier aus wanderten die Ideen weiter; bald direkt, bald indirekt vermittelt treffen wir sie in Straubing, Nürnberg, U1m, Erfurt, Stendal. Wir dürfen vermuten, daß Nördlingen eine besondere Rolle in dieser Verbreitung der Mode gespielt hat.

Die Verwendung zahlreicher Bauglieder, die der zweiten Periode der Glasmalerei einen so charakteristischen Ausdruck gibt, ermöglicht an sich die strenge Zentralisation der Komposition und deren Unterordnung unter die Gesamtkomposition des Raumes. In der deutschen Vorliebe für die Einzelfigur und die Beschränkung auf die unbedingt nötige $Z$ ahl von Teilnehmern, wenn es sich um Szenendarstellungen handelte, lag eine große Erleichterung der kompositionellen Anlage. Die französischen Glasmaler jedoch waren von Anfang darauf gewiesen, die dramatische Lebhaftigkeit des heimischen Geschmacks in die richtige Ordnung zu bringen. Bereits die ältesten Arbeiten sind nach 
einem festen Kompositionssystem ausgeführt, das den strengen Regeln der Symmetrie folgt. Man vergleiche zu diesem Zweck 'die Tafeln 8, 9. Bei dem Reichtum an Figuren war die französische Glasmalerei genötigt, mehr in die Breite zu komponieren, als die deutsche. Dabei liebte sie aber einen ausgesprochenen Parallelismus, der sich nach der Mittelaxe orientiert. Rechts und links wird womöglich die gleiche Anzahl von Personen gruppiert, die in Haltung und Anordnung einander vollständig entsprechen. Ihr oberer AbschluB folgt einer geometrischen Linie, die, mit ihrer meistens nach oben sich zuneigenden Scheitelausbiegung die Tendenz der Mittelaxe und überhaupt des gesamten Fensters, in die Höhe zu streben, wesentlich unterstützt. Die Kreisform ist an sich kein geeignetes Mittel für die Komposition eines Fensters. Darum hat man die einzelnen Kreise in Ellipsen verdehnt, oder miteinander durch sich kreuzende Ranken verbunden, oder die $Z$ wickel mit vertikalstrebenden Ornamenten ausgestattet, stets aber in der Szene selbst auf die aufstrebende Pflicht des Glasfensters Rücksicht genommen. Das Fenster zu Champ (Isère) bildet das vollkommenste Beispiel der eben dargelegten Praxis: Symmetrie um eine Mittelaxe, die nach dem Scheitel des ganzen Fensters strebt; im oberen Medaillon womöglich vertikales Übergewicht über die horizontale Gliederung, was durch die Figur des in den Himmel auffahrenden Christus vortrefflich zum Ausdruck gebracht ist. Dem Parallelismus entsprach, nebenbei bemerkt, auch eine Symmetrie der Farbeinteilung. Die Rundscheibe mit Christus als Weltenrichter, die auf Tafel 9 abgebildet ist, zeigt, wie das Gesetz der Symmetrie bis ins Kleinste befolgt, nahezu mathematisch zur Formel entwickelt ist. Wo sich die einzelnen Szenen über größere Flächen erstreckten, war dieser Parallelismus auch ein nicht $\mathrm{zu}$ unterschätzendes Hilfsmittel für die Einordnung der Windeisen, der Mauerwerksrippen und Ränder. Die französischen Glasmaler sind dem Gêsetz der Symmetrie auch während der gotischen und Renaissanceperiode treu geblieben.

In Deutschland dagegen verhielt man sich diesem Prinzip gegenüber wesentlich freier und selbständiger. Man empfand die große Überlegenheit der unter vertikal angelegtes Architekturwerk gestellten Einzelfigur über alle Gruppensysteme. Darum 
teilte man im Zeitalter der Gotik, das dem Glasmaler erhöhte didaktische Pflichten auferlegte, die einzelnen Szenen unter Baldachine und zwischen Säulen, hielt sich jedoch bei der Gruppierung nicht sehr streng an die Herrschaft von harmonisch angebrachten Linien der Symmetrie. Nur in dem ornamental gehaltenen architektonischen Beiwerk gönnte man der Symmetrie ihr altes Recht und da dasselbe manchmal bis mehr als zwei Drittel des verfügbaren Raumes einnahm, so war für eine Ineinandergliederung und Symmetrie mehr wie hinreichend gesorgt. Beispiele symmetrischer Linien und Akzente im Figürlichen sind selten, so auf einem Fenster zu Münnerstadt, Erfurt, Regensburg. Umgekehrt findet man desto häufiger Fenster, auf denen Gruppensymmetrie ganz außer acht bleibt, ja direkt umgangen wird z. B. auf dem Fenster mit Mariae Tod zu Regensburg, wo die in den Himmel fahrende Maria, die als oberstes Glied der Komposition aus dem Scheitel der Architektur nach der Seite hin verrückt wird. Ein herrliches Beispiel horizontaler Gliederung bietet die Szene der Fußwaschung im Dome zu Erfurt und aus späterer Zeit die Darstellung von Mariae Heimgang zu Landsberg a. L. Die Anlehnung an die höfische Kunst hatte für die Glasgemälde noch eine andere Folge. An die Stelle der idealen Gewänder trat mehr und mehr das Zeitkostüm; ja gewisse geckenhafte Auswüchse der Mode, unnatürliche Körperhaltungen fanden getreue Kopie. Für dies alles entschädigt aber die auch in dieser Periode vortreffliche Farbenzusammenstimmung, sorgfältige und den alten Traditionen treue Ausführung der Glasbemalung. Die Schwarzlotkonturen werden zwar dünner, die Anwendung von Modellierung reichlicher, allein die Formen sind nicht minder kräftig und ernst, wahrhaftig und eindrucksvoll. An jene ungeheure Monumentalität, mit der uns die romanischen Glasgemälde entgegengetreten sind, reicht die gotische Glasmalerei nicht heran. Das Denken und Fühlen ist ein anderes geworden. Aus dem naiven, poetisch gläubigen und kindlichen Gemüt reifte in der christlichen Kultur und Kunst allmählich ein ernstes Denken, ein Erfassen des Göttlichen mit der Vernunft. Soviel Darstellungen auf den Glasgemälden, soviel Glaubenssätze. Auch jetzt noch sind die dargestellten Figuren Symbole, die dem Kundigen das Mysterium mitteilen. Trotz der strengen Abhängig- 
keit der Künstler von den Theologen war ihnen vom Inhalt des Darzustellenden abgesehen, eine große Freiheit eingeräumt: „Les artistes très surveillés quand ils devaient exprimer la pensée religieuse de leur temps, furent laissés libres d'orner la cathédrale à leur guise, d'innocentes fleurs. Heureuse liberté, combien leur naif amour de la nature nous touche plus que le symbolisme des clercs noble sans doute, mais stérile." So sagt Mâle, der beste Kenner der mittelalterlichen Typologie. In diesem eigenartigen Verhältnis der Künstler zu den Theologen, der Ausführung zu der Vorlage liegt der Grund für das merkwürdige Bild der mittelalterlichen Kunst, insbesondere der Glasmalerei. Die Künstler wiederholten den gleichen Stoff, der zudem in Evangelien- und sonstigen liturgischen Büchern oder in der biblia pauperum und dem speculum humanae salvationis darstellerisch bereits fixiert war. Darum die allgemeine Gleichheit im Gesamteindruck; den tieferen mystischen Sinn einer traditionellen Darstellung neu oder gar persönlich zu durchleben und daher mit subjektivem Gehalt zu erfüllen, war gar nicht Sache der Künstler. Diese hatten überhaupt nur zu sagen, was die Theologen ihnen vorsagten. In der Handschrift aber, in dem Verhalten gegenüber der Natur waren sie völlig frei und darum herrscht unter dem überkommenen Denkmalschatz, selbst unter nahverwandten Gruppen, doch eine erfrischende Mannigfaltigkeit und Abwechslung. Dazu kam, daß die Glasmaler, um den Meistertitel zu erlangen, nicht bloß technische Fertigkeiten aufzuweisen hatten, sondern imstande sein mußten, nach einer kleinen Skizze sich die Werkzeichnung selbst zu fertigen. Es ergab sich so von selbst eine leichte Variante und eine gewisse persönliche Note in dem ewigen Einerlei der Themata und ihrer Behandlung.

Die Übernahme der Perspektive, des Dreidimensionalen, hatte in die Glasmalerei etwas ihrem eigentlichen Wesen Fremdes hineingetragen. Zur Abhängigkeit von der Tafelmalerei führte nurmehr ein kleiner Schritt. Am frühesten tat die Kölner Schule diesen Schritt. Seitdem sich die Kölner Glasmaler von der Nachahmung der französischen Gotiker losgemacht hatten, war den Einflüssen der Niederländer Tafelmaler jede Werkstatttür offen und es macht keinen Unterschied, ob dieser Einfluß direkt vom Niederländischen kam oder durch heimische Künstler 
von ihrer Wanderschaft nach Köln gebracht wurde. Fast allen bedeutenden Kölner Tafelmalern wird eine nahe Beziehung zu irgendeinem noch erhaltenen Glasgemälde zuerkannt. Die strenge Zugehörigkeit $\mathrm{zu}$ dem Stil der Tafelmalerei macht die Kölner Glasmalerei etwas langweilig, weil ihr die originale Frische fehlt; die Gefahr wird um so größer, als sich mit der zweiten Hälfte des I5. Jahrhunderts in Köln, wie übrigens auch in anderen Kunstzentralen, Werkstätten mit Großbetrieb entwickeln. Nürnberg bekommt seine Hirsvogelwerkstatt, und Straßburg, Freiburg die Ropsteinwerkstatt usw. Dieser Großbetrieb erleichtert zwar die kunstgeschichtliche Forschung, für die Entwicklung der Glasmalerei konnte er sehr bedenklich werden. Obwohl die ganz großen Meister wie Dürer, Holbein, Baldung, Jerg Ziegler, Grünewald auf die Gestaltung der Visierung einen entscheidenden Einfluß nehmen, werden die Werkstattarbeiten doch recht unterschiedlich in der Qualität und Durchbildung. Die Großwerkstatt hatte die Lokalschulen wirtschaftlich zentralisiert. Als ältester Großbetrieb erscheint die Hans Wild-Werkstatt. Dieser Name bedeutet die gewaltigste Repräsentation des vom oberrheinischen Holzschnitt beeinflußten und in der manierierten Mode des letzten Drittels des I 5. Jahrhunderts auffrisierten Glasmalerstils. Wilds Kompositionen leiden unter dem Prunkmäßigen, das er seinen Glasgemälden auflegt. Die großen architektonischen Glieder mit ihren riesigen Baldachinen zerstören das gerade Streben nach oben, fallen auch in der Farbe aus der bisherigen Praxis der Unterordnung unter den Raumgedanken heraus. Der Einfluß Dürers, Baldungs hat das Gleichgewicht wieder hergestellt, obwohl die Helldunkeltechnik, die im Gefolge dieser Männer für die Farbgebung der Glasgemälde von Bedeutung wurde, auch den alten Traditionen nicht mehr entsprach. Die Anlehnung an die Tafelmalerei hätte mit der Zeit der süddeutschen Glasmalerei zum Verhängnis werden müssen; ähnlich wie die niederländische Glasmalerei, die sich am längsten weitergeführt hat, schließlich in völlige Entartung versank und mit der echten Glasmalerei nichts mehr gemein hatte, als den Namen und die Zufälligkeit farblosen Glases, die an Stelle der weißen Leinwand stand.

In der Technik hat die Monumentalmalerei an den alten Traditionen festgehalten. Was bedeuten die geringen Neuerungen, 
die das Rotlot brachte gegen den festen Bestand der Gläser und ihrer Behandlung. Auch die verschiedenen Praktiken zur Erzeugung der Lichter und Schatten sind Zufälligkeiten, die in nichts sich mit den Neuerungen messen können, die die Visierung um die Wende des Mittelalters erlebte. Die Figuren hören auf Symbole zu sein. Das Symbol ist Fleisch geworden. Nicht bloß jene Figuren, die Fleisch von unserem sündigen Fleisch darstellen, auch die Heiligen, ja das Göttliche selbst, steigt in die irdische Hülle, bekommt Hände, mit denen es greifen, Füße, mit denen es gehen, ein Gesicht, mit dem es die tiefsten seelischen Erlebnisse wiederspiegeln kann. Porträt und Charakterkopf, das Konkrete tritt an Stelle des Symbols und des Abstrakten. Auch die Architekturglieder kehren von ihrem Wesen in Stein zurück zu dem, wovon sie ausgegangen sind, zu der Natur. Trotz dieser veränderten Stilistik bleibt auch diese Art von Glasmalerei monumental. Es ist ein Zeichen von dem großen ästhetischen Gehalt der Glasmalerei, daß auch die weiteste Entfernung von ihrem ursprünglichen Wesen ihr nichts geschadet hat, solange sich große Künstler mit ihr beschäftigten. In der herrlichen Pietà zu Hanau, deren Karton vom Schreiber dieser Zeilen erstmals dem Aschaffenburger Meister Matthias Grünewald zugeschrieben werden konnte, erhebt sich die ausklingende monumentale Glasmalerei zu einer unerhört hohen Ausdruckskraft seelischer Affekte, gibt mit beinahe unfaßlicher Virtuosität die ergreifendsten Momente wieder (siehe Taf. 65, 66). Die Glasmalerei hat nie mehr ein Werk von solcher Größe hervorgebracht. Die Kunst des Meisters von Messkirch, Jerg Zieglers, bildet zwar noch eine beträchtliche Summe von ausgezeichneten glasmalerischen Qualitäten, aber mit ihm erlischt die monumentale Glasmalerei Süddeutschlands. Das späteste, was mir in diesem Charakter bekannt geworden ist, bilden die wenigen aber sehr wertvollen Reste von Glasgemälden, die im Jahre I 556 für Reichenau-Mittelzell geschaffen wurden und dem eben genannten Jerg Ziegler nahestehen. Der Baumeister des Chors ist Jakob Ross aus Straßburg, wie aus der Umschrift eines Schlußsteins im Gewölbe hervorgeht. Es wäre also möglich, daß die Glasgemälde ebenfalls aus Straßburger Ateliers stammen würden. Jedenfalls bilden die Reichenauer Fensterreste ein ästhetisches 
Gegengewicht gegen die in völliger Verflachung des Glasmalerischen versunkenen, nur noch vom Standpunkt des Tafelmalers interessanten kölnischen und niederländischen monumentalen Arbeiten aus der Mitte des I6. Jahrhunderts. Die acht Mittelzeller Glasgemälde, deren Photographie leider unmöglich war, sind eine glanzvolle Beendigung der süddeutschen Glasmalerei. Sie bestätigen aufs neue, daß der plötzliche Untergang der Glasmalerei hauptsächlich den Wirren der Reformation zuzuschreiben ist. Wo diese auch nicht vorübergehend Fuß fassen konnte, hat sich die große Tradition erhalten. Die Stadt Straßburg hat auch allein unter allen Städten Deutschlands die Technik der Monumentalglasmalerei bewahrt und zu einer Zeit Glasgemälde hervorgebracht, die im seichtesten Nachrokoko, sonst nichts für so ernste Künste übrig hatte.

Das Zeitalter der monumentalen Glasmalerei ist vorüber. In die Geschichte ist sie gleich als ganz große, fertige Kunst eingetreten und hat sich im Laufe der vier Jahrhunderte, die ihr zur Auslebung ihres ästhetischen Gehalts vergönnt waren, sehr reich entwickelt. Im Stil ist sie in enger Fühlung mit der Gesamtentwicklung von Kunst und Kultur geblieben, bald gebend, bald nehmend, meistens das letztere. Miniatur und Emailkunst standen zu Gevatter, als sich buntgläserner Fensterschmuck aus allerhand Vorläufern zu einem integrierenden Bestandteil des Bauprogramms und Raumbildes herausschälte und im Laufe der Zeit zur figürlichen Glasmalerei weiterbildete. Mit einer starken Anleihe aus der Tafelmalerei hat sie im I6. Jahrhundert ihre Wirksamkeit beendet. Die Fortschritte im Material und in den Ausdrucksmitteln (Silbergelb, Rotlot) sind für die Gesamtentwicklung der Glasmalerei ganz unbedeutend und auch die Gläser zeigen in ihren geringen Tonwandlungen die uns für das ganze Mittelalter geläufige Stabilität der Werkstattradition. Die Verschiebungen, die im äußeren so sinnenfällig sind, daß sie bei einseitiger Betrachtung zu den bedenklichsten Schlüssen verführen können und auch verführt haben, hängen lediglich mit der Entwicklung der Baugeschichte zusammen, die ihrerseits wieder Ausdruck des immer mehr reifenden Volksempfindens ist. Vom Westen und vom Süden haben fremde Formen an dem Paradies der Glasmalerei geklopft und auch Einlaß gefunden. 
Allein sie konnten in den zufälligen Eigenschaften wohl beeinflussen, das Wesentliche aber niemals alterieren. Stets war der Sinn auf die Seele, das heißt auf die Auswirkung der Ornamentalkraft der Glasmalerei gerichtet. Symbol und Kraft machen das Wesen dieser Kunst aus. Darum die Beschränkung auf wenige aber massige Farben, der Verzicht auf verwässerte, süßliche Mitteltöne, und strenge Unterordnung des Details. Wenn also die Männer um König Ludwig I. glaubten, die Neurenaissance im I9. Jahrhundert an ihre Glasgemälde der Mariahilfkirche zu München, in dem Dome zu Regensburg und Köln knüpfen zu können, so war dies in jedem Punkt ein Irrtum. Sie hatten weder das Glas der Alten, das mit seiner rauhen, gebläselten Oberfläche die Prosa und nüchterne Zweckmäßigkeit zur Poesie, zur Kunst erhebt und auch von keiner modernen Glassorte irgendwie erreicht oder gar übertroffen wird, noch das Verständnis für die ornamentale und symbolische Bedeutung der Glasmalerei. Gleich den Kölnern und Niederländern des I6. Jahrhunderts war die Übertragung von Tafelmalereien in und auf Glas nicht eine logische und ästhetische Umdeutung in die ornamentale Sprache der Glasmalerei, vielmehr eine sklavische Kopie, die dadurch nicht interessanter wird, daß sie für die Ausführenden Gelegenheit zu allerlei technischen Kunststückchen gab. Diese Richtung sollte gleichzeitig eine Reaktion gegen die Kabinettsglasmalerei sein, und doch verdanken wir dieser Manier die Erhaltung glasmalerischer Gedanken und technischer Traditionen.

Die Kabinettsglasmalerei wird in der Regel als eigner Zweig des buntfarbigen Fensterschmucks betrachtet. Sie ist indessen nichts anderes, wenigstens für die erste Zeit ihres Bestehens, als eine Anpassung des glasmalerischen Grundgedankens an einen kleinen und modifizierten Raum. Ihre Technik leitet sich so von der Monumentalglasmalerei her. Die Kabinettsscheibe tritt niemals. allein auf, ist vielmehr der farbige Pol in der weiten Fläche farblosen Glases. Was sie jedoch von der Einglasung einer farbigen Scheibe in gemustertes farbloses Glas unterscheidet, ist ihre kompositionelle Geschlossenheit, durch die sie zu einem Fenster im Kleinen wird. Man hat gerne die Schweizerscheibe als Urbild der Kabinettsmanier angesehen. Jene bildet allerdings einen wesentlichen Bestandteil und gehört auch der Zeit ihrer Entstehung- 
nach zu den wichtigsten Erscheinungsformen der Kabinettsscheibe. Lehmann hat die Anfänge der Schweizerscheibe bis in die erste Hälfte des I 5. Jahrhunderts hinauf verfolgt. Seitdem im Anschluß an die italienische und französisch-niederländische Renaissance die Sitte aufkommt, die Wohnung des Privatmanns behaglich und künstlerisch auszustatten, war das Bedürfnis nach buntfarbigem Fensterschmuck gegeben, und die Kabinettsglasmalerei hatte also nichts anderes zu tun als den Raum zu stimmen und dem Raumbild die Vollendung zu geben. Es war derselbe Zweck, den die monumentale Glasmalerei für große Räume verfolgte, und darum ist es sehr verkehrt, wenn man die Glasmalerei als eine einseitig religiöse Kunst darstellen will. Für den Architekten einer Kirche bildete nicht der Inhalt das Feld seines Interesses, diesen überließ er willig dem Theologen, für ihn kam nur der Farbakkord als ornamentale Kraftquelle in Betracht, was ebenso für den kirchlichen wie für den profanen Raum von Bedeutung war. In letzterem Falle stellte er Stoff und Technik dem Glasmaler anheim und verlangte nur Rücksicht des Gesamttons auf den Raum. Die Schweizerscheibe aber hatte außer ihrer ästhetischen Bedeutung noch einen anderen $Z$ weck. Sie war die sinnfällige Bestätigung, daß sich ihr Inhaber der Unterstützung zum Bau und der besonderen Gunst eines mächtigen Mannes oder einer Körperschaft zu erfreuen gehabt habe. Dieser außerhalb des Künstlerischen liegende Charakter hatte der Schweizerscheibe ibre besondere Kompositionsart verliehen. Das Wappen des Wohltäters mußte möglichst augenfällig den Hauptraum der Scheibe einnehmen, und damit man über den Namen des Wappeninhabers nicht im Zweifel sei, nannte ihn ein Inschriftensockel. Das gab für die Komposition ein sehr willkommenes Mittel. Als Gegenstück zur Basis entstand das Oberlicht, das mit Szenen aus der eidgenössischen Geschichte oder mit Beziehungen auf den Stifter geschmückt war. Die selbständige Geschlossenheit der Kabinettsscheibe kam in der Einfügung des Ganzen in einen architektonischen Rahmen zum Ausdruck. Diese Grundanlage wurde niemals verlassen, mochte die Ausführung im Laufe der Zeit auch noch so großen Wandlungen unterworfen sein. Die deutsche Kabinettsscheibe ging jedoch von rein ästhetischen Grundsätzen aus und ließ sich von der Schweizerscheibe nur in sehr beschränktem 
Maße beeinflussen. Bei ihr war die Darstellung des Themas die Hauptsache, sie lehnte sich daher in der Komposition an das monumentale System an. Ihre Stoffe entlehnte sie teils der Legende, teils der Sage und der klassischen Geschichte. Seltener sind Szenen aus dem täglichen Leben. Wo die Kabinettsscheibe zur reinen Wappenscheibe wurde, da nimmt man gerne zu wappenhaltenden Figuren Zuflucht. Das Wappen wird niemals Hauptsache. Darum war der deutschen Kabinettsscheibe eine viel reichere Kompositionsmöglichkeit eröffnet als der Schweizerscheibe. Ähnliche Ziele der Darstellung verfolgte die am Oberrhein zu üppiger Blüte emporgeschossene Stech- und Schnittkunst. Darum entlehnte die Kabinettsscheibe Stoff und Darstellungsart von den großen Meistern der graphischen Künste. Besonders beliebt waren der Meister E. S., der Meister des Hausbuchs, Martin Schongauer, Tobias Stimmer, Jörg Breu, Jost Amman. Auch der Stil des Stichs wirkte auf die Kabinettsglasmalerei ein, indem er die Entwicklung der feinen Lineartechnik begünstigte. Anfänglich hatte auch die Kabinettsglasmalerei die Farbwerte nur durch farbiges Hüttenglas auszudrücken vermocht. Mit der Zeit aber gesellten sich sogenannte Emailfarben dazu. Dies sind Glasflüsse, die auf farbloses Glas, wie der Ausdruck heißt, aufgeschwemmt und gleich dem Schwarzlot im Brande mit der Oberfläche des Glases verbunden werden. Am frühesten kam Kobaltblau auf, dann Bischofsrot, im I7. Jahrhundert ein prachtvolles aber sehr seltenes Grün. Am längsten hat sich rotes Hüttenglas erhalten. Gegen Ende des I7. Jahrhunderts stellte man ein Zinnoberrot als Schmelzfarbe her, das jedoch nicht in allgemeine Übung kam. Das System der eingebrannten Farben bot der Glasmalerei Gelegenheit, in das Gebiet der Kleinkünste einzudringen. Es gab auch in der Handhabung dieser Farbflüsse große Meister. Trotzdem wurde der Charakter, dem Raum eine bestimmte Tönung zu geben, immer mehr geschädigt, bis im i8. Jahrhundert auch die Kabinettsmanier völlig verflachte und sich in Äußerlichkeiten auflöste. Bezeichnenderweise hat erst die Prunkkunst des Rokoko auf buntfarbigen Fensterschmuck prinzipiell verzichtet, obwohl Scheiben aus Schwarzlot und Silbergelb dem Raumbild keinerlei Schaden zufügen konnten. Die ängstliche Sorge, alles vom Fenster fernzuhalten, was dem Glanz des üppigen Weiß und Gold Eintrag 
tun konnte, wurde der Glasmalerei gefährlich, und mit dem öden Grau des Fensterglases trat das an Poesie und Kunst ärmste Jahrhundert seinen Anfang an. Man hatte das Verständnis für ein geschlossenes, harmonisches Raumbild verloren. Als vor etwa 20 Jahren für die Baukunst eine etwas bessere Zeit anbrach, da regte sich allerdings in sehr bescheidenem Maße das Gefühl für die unerschöpfliche Schönheitsquelle des buntfarbigen Fensterschmucks. Dieses Gefühl setzte sich durch, obwohl manche als Baukünstler, die während eines Teils oder der ganzen Dauer ihres Lebens groß gefeiert wurden, ihrer nur aus der völligen Verständnislosigkeit für die ästhetische Bedeutung der Glasmalerei im Raumbild erklärbaren Abneigung gegen buntfarbigen Fensterschmuck unverhohlen Ausdruck gaben. Die um Anerkennung der Glasmalerei als gleichberechtigter Ausstattungskunst ringenden Glasmaler waren daher auf sich selbst angewiesen zu einer Zeit, in der sich der Geschmack läutern und aus der Umklammerung greulichster Mißgestalten befreien sollte. Mit aufdringlicher Beredsamkeit und süßer Innigkeit traten jene älteren Arbeiten auf, die vom Raum, für den sie bestimmt waren, nur die Fenstermaße und den Baustil zu wissen brauchten. In neuerer Zeit geht aber Frühlingswehen durch das Land. Symbol und Kraft bestimmt wieder Zeichnung und Technik, und auf die sieben mageren Kühe folgt wieder die goldene Fruchtbarkeit, freilich nicht ohne Kampf. Schon hat es in diesem ästhetischen Ringen zahlreiche Tote gegegeben: Konventionelle Formeln, blutleere Schemen, geistlose Kopien. „Kunstwerk ist etwas nur, insofern es, aus dem Geist entsprungen, die Taufe des Geistigen erhalten und dasjenige darstellt, was nach dem Anklange des Geistes ist", sagt Hegel in seinen "Vorlesungen über Ästhetik“. Jede Szene aus der Geschichte oder Gegenwart kann, ihres zufälligen Charakters und Sinnes entkleidet, als Geistiges aufgefaßt und wiedergegeben werden. Dieser ästhetische Grundsatz ist lange verborgen gelegen, am längsten in der Glasmalerei. Jahrzehntelang wurden im vergangenen Säculum Versinnlichungen weitergegeben, die als alte Formeln in den Ateliers der Glasmaler ein verstaubtes Kittelchen bekamen. Wohl wurden auch sie als Symbole aufgefaßt, aber als träge kraftlose Symbole, die keinen Inhalt hatten. Das Geistige an der Kunst, das Hegel verlangt, bezieht sich in 
der Glasmalerei auf die geheimnisvolle mystische Glut der Farben und auf die einfache, wuchtige Kraft der Formen. Breit und massig muß das Schwarzlot die leicht faßbare Kontur zeichnen. Denn es ist nichts Kompliziertes, das die Glasmalerei zu sagen hat. Ein verschieden gekörnter Überzug regelt die Lichter und gibt dem Glas das Ungleichmäßige des Lichtdurchtritts, was den spezifischen Charakter echter Glasmalerei, den gedämpften und doch so kräftig leuchtenden Ton, schafft. Klein ist die Zahl der farbigen Gläser, aber nur die kräftigsten Farben sind gerade gut genug. Mit Zwischentönen und süßen Farben mag sich abgeben wer will, echte Kunst gehen sie nichts an.

In bunter Mannigfaltigkeit werden nun die Gestalten vergangenen und gegenwärtigen Kunstschaffens an unserem Auge vorüberziehen, Werke hoher Kunst wie Arbeiten von handwerklicher Mittelmäßigkeit. Alle werden in irgend einer Form den Schönheitswert der Glasmalerei beleuchten. Es ist bekannt, daß man gegen die Glasmalerei des I9. Jahrhunderts die schwersten Anklagen geführt und sie nur als Gegenbeispiel echter Glasmalerei gelten lassen will. Allenthalben erhebe sich, so hört man, eine scharfe Reaktion gegen jenen "Stil“, den sogar die kirchliche Behörde als "Süßlichkeit" verurteilt habe. Gemeint ist damit der Hirtenbrief des Regensburger Bischofs von Henle, der gegen Ende vorigen Jahres erschienen ist und sich scharf gegen das "Süßliche“ in der Kunst wendet ${ }^{\mathbf{1}}$ ). Jeder pflichtet dem Bischofswort bei; wie soll aber die Reform betätigt werden? Einige gehen soweit, daß sie die kirchliche Glasmalerei für völlig unfähig halten, sich von sich selbst aus zu erneuern, vielmehr einen Umweg über die profane Glasmalerei für unerläßlich erklären, gleichzeitig aber doch die Periode der Gotik als das Ferment bezeichnen, das die Glasmalerei neu beleben soll. Ob Gotik oder romanische Periode, bleibt sich völlig gleich. Denn in beiden Zeitaltern hat die Glasmalerei ihre hohe Würde und Bestimmung restlos zum Ausdruck gebracht. Sie war Vollendung und Abstimmung des Raumbildes, vergab sich nichts an ihrer Monumentalität. Wer heute im gotischen oder romanischen Stil

1) Vgl. darüber Fischer, Das "Süßliche" in der Glasmalerei, Zeitschrift für alteund neue Glasmalerei, I9I3, S. I33. 
arbeitet, verhält sich zu dem Geist der Alten wie derjenige, der sich an Fasching ein romanisches Kettenhemd umhängt oder eine gotische Gugel aufsetzt. Nur die Mittel der Alten, ihr Begriff von der Wirkung des Glasmalerischen, ihre Koloristik dürfen der Gegenwart vorbildlich sein, da diese Elemente, dem Wesen der Glasmalerei immanent und unzeitlich, für alle Geschlechter gelten. Nur wer die ewig herrschenden absoluten Ideen in neue Formen zu gießen weiß, wer aus dem Innern seines Herzens bildet, wird ein Kunstwerk schaffen können. So einfach dieser Grundsatz ist, so muß er doch eine völlige Revolution in den gegenwärtigen Verhältnissen der Glasmalerei erzeugen; denn so wenig befriedigen diese den Begriff des ästhetisch Schönen in der Glasmalerei. Nur wo die unerhörtesten inneren Erlebnisse eines Mystikers in die flüssige Glut kräftigster Farben gegossen werden und in den monumentalsten Formen erstehen, kann man von echter Glasmalerei, von einem Kunstwerk reden. Denn „Kunstwerk ist nur das, was aus dem Geistigen entsprungen und die Taufe des Geistigen erhalten hat". 
II.

\section{Die Entwicklung des Stils.}

\section{Die Monumentalglasmalerei.}

\section{A) Die nur literarisch bezeugte Vorzeit.}

Das Kindesalter der Glasmalerei ist, wie das so vieler anderer Künste, in das undringliche Dunkel der Poesie eingebettet. Als die Bibel der Glasmalerei, die schedula des Theophilus (Rugkerus) vollendet war, da hatte sich der Übergang vom Mythologischen zum Tatsächlichen bereits vollzogen. In zahlreichen Basiliken mußte der Schimmer buntfarbigen Fensterschmucks in Form figürlicher Glasmalerei erglänzt haben; und doch sind im besten Falle eine Hand voll von Arbeiten erhalten, die in die Zeit des Theophilus hinaufragen. Was war, bevor im Dome zu Augsburg die Propheten aus den Hochschiffenstern zum Volke predigten? Kaum daß das Christentum aus den Katakomben an das helle Sonnenlicht einer Staatsreligion emporgestiegen war, da öffnen sich schon die Lippen der christlichen Schriftsteller, um das Lob der Glasfenster zu besingen. „Verius et manifestius est mentem esse, quae per oculos ea quae sunt opposita transspiciat, quasi per fenestras lucente vitro aut speculari lapide obductas" sagt Lactantius, der Erzieher von Konstantins Sohn Crispus. Prudentius rühmt von Kaiser Konstantin: „camuros hyalo insigni varie cucurrit arcus, sic prata vernis floribus renident." ${ }^{1}$ ) Die rundbogigen Maueröffnungen durchzog er mit herrlichem Glas mannigfaltig; so erstrahlen die Wiesen im Glanz der Frühlingsblumen. Die abendländischen Christen hatten sich im Schmuck ihrer

1) Opera: carmina liber peristephanon hymn. I 2. 
Basiliken naturgemäß an das römische Altertum angeschlossen; jedoch war dieses Altertum seit dem 3. Jahrhundert infolge der Herrschaft syrischer Cäsaren, durch den steten Austausch orientalischer und abendländischer Religiosen zum ausgesprochenen Eklektizismus geworden. Wir können uns daher keine Vorstellungen machen, wie die Glasfenster des christlichen Altertums ausgesehen haben. Für unsere Betrachtung genügt auch zu wissen, daß der Gebrauch des buntfarbigen Glases als Fensterverschluß in das christliche Altertum hinaufreicht. Der Schritt von dem weit verbreiteten sehr beliebten System antik-christlicher Kunstverglasung zur figürlichen Glasmalerei scheint jedoch erst in dem Herrschergebiete Karls des Großen gemacht worden zu sein. Zwei Voraussetzungen waren dazu notwendig. Es mußte möglich sein, einzelne Glasstücke in leicht biegsame, mit Bogen versehene Stücke zu schließen, und außerdem ein Gemisch herzustellen, das auf Glas gemalt, im Brande mit der Oberfläche zusammenschmilzt. Die früheste Verwendung des Bleies zeigt ein Reliquienschrein, der auf dem Friedhof von Sery-les-Mézières bei St. Quentin gefunden wurde. Dieser Reliquienschrein dürfte in der zweiten Hälfte des 9. Jahrhunderts entstanden sein und bildet jenes Stadium der Entwicklung, in dem das Blei nicht bloß dienendes Verbindungsmittel, sondern motivführende Kontur darstellt. Gesellte sich dazu das Bedürfnis nach einer bescheidenen Modellierung, nach einer mäßigen Andeutung von Licht und Schatten, und war das dazu nötige Malmittel (in dem Schwarzlot) gefunden, so war von selbst der Schritt zur Glasmalerei gemacht. Es versteht sich leicht, daß dieser Übergang, trotzdem er die bedeutende Grundlage der gesamten viele Jahrhunderte geübten Glasbemalung bildet, doch, nach rückwärts betrachtet, ein verhältnismäßig kleiner Schritt ist. Denn die Entwicklung war auf jenen hohen Punkt angelangt, auf dem das an sich so unkünstlerische Mittel wie die Bleirute eine vollständige Zeichnung ersetzen konnte und auch tatsächlich ersetzt hat. Das 9. Jahrhundert war offenbar die Zeit jener Weiterbildung. Aus diesem Säkulum ragen verschiedene Nachrichten von Glasgemälden in die Geschichte dieses Kunstzweiges herein, die, in ihrem Gesamtwert betrachtet, einen ziemlich sicheren Schluß auf die Tatsache wirklicher Glasmalerei zulassen. Zwar ist die viel 
zitierte Stelle aus dem Festgedicht des Mönches Ratpertus, das ęr anläßlich der Weihe des Frauenmünsters in Zürich an seinen Mitbruder Notker in S. Gallen sandte, etwas unklar. Sie lautet: Sicque fenestrarum depinxit plana colorum pigmentis laquear pigmentaque arte manuque artifici et fucis, quadrato ex orbe petitis.

„Sie ließ auch die Fensterflächen mit farbigen Zeichnungen bemalen, auch die Decke, und zwar den Farbenschmuck mit kunstfertiger Hand, sowie mit Rötel, den man allenthalben hervorgeholt hatte." Es handelte sich um Bertha, die Tochter Kaiser Ludwig des Frommen, die den Bau des Kleinmünsters vollendet hat. Während nun die einen, z. B. Sepp, in dieser Stelle höchstens eine Bemalung der Scheiben nach Art der Kaltmalerei erblicken, sehen andere in ihr ein vollgewichtiges Zeugnis für eigentliche Glasmalerei. Jedenfalls konnte sich fucus (die aus Seegras gewonnene, hauptsächlich zur Rotschminke gebrauchte Farbe) sowie das pigmentum (Farbe) nicht, wenigstens nicht im wörtlichen Sinne des Ausdruckes, auf die Fenster beziehen, da die Glasmalerei, wenn sie schon in dieser Zeit geübt wurde, nur die eine Farbe, das sogenannte Schwarzlot kannte. Wahrscheinlich wollte Ratpertus die Wirkung der farbigen Fenster nach Art der Deckenund Wandgemälde beschreiben. Wie dem auch sei, jedenfalls kommt diesem ungenauen Bericht eine andere Stelle sehr geschickt zu Hilfe. Die von Nordhoff ${ }^{1}$ ) publizierte Vita II Sancti Ludgeri, episcopi Monasteriensis (entstanden kurz nach 864; Ludger starb 809), erzählt von einem blinden Mädchen, das auf Fürbitte des h1. Ludger in der Abteikirche zu Werden geheilt wurde und bemerkt: aurora iam rubescente et luce paulatim per fenestras irradiante imagines in eis factas monstrare digito coepit ${ }^{2}$. "Schon rötete sich der Morgen und allmählich erstrahlte das Licht durch die Fenster, da begann sie mit dem Finger auf die Bilder zu zeigen, die auf ihnen dargestellt waren." Wenn der Verfasser der Vita auf die Glaubwürdigkeit des Wunders Wert legte, so mußte er an äußere Punkte anknüpfen, die dem Leserkreis von vornherein bekannt waren. Hätten also die Scheiben der Stifts-

1) Repertorium für Kunstwissenschaft III, S. 460.

2) Urkunde für S, Amand. Bouquet Rec. VIII, 587 . 
kirche zu Werden nur Buntverglasung enthalten, so hätte der Autor statt imagines in eis factas wohl colores in eis micantes oder wenigstens figuras gesagt, da figura im Gegensatz zu imago geometrische und höchstens stilisierte Pflanzenmotive bezeichnet, niemals menschliche Darstellungen, für die der Ausdruck imago angewendet wurde. Der Übergang von der Kunstverglasung zur Glasbemalung ist demnach um die Mitte des 9. Jahrhunderts vollzogen. Wir vermögen uns nicht die geringste Vorstellung $\mathrm{zu}$ machen, wie diese Glasmalereien der karolingischen Epoche ausgesehen haben. Dagegen dürfen wir das forschende Auge auf die noch erhaltenen Wandmalereien z. B. in Goldbach, auf der Reichenau, im Schweizerischen Landesmuseum hinweisen, da der glasmalerische Schmuck nichts als eine Fortspinnung der künstlerischen Motive der Wanddekoration war. Wohl haben auch Teppiche, mit denen einstens die Lichtöffnungen behangen waren, befruchtend auf die Entwicklung der Glasmalerei eingewirkt, indeß bleibt es angesichts des völligen Mangels an derlei Arbeiten aus der romanischen Zeit beim bloßen Zitat der beiderseitigen Verwandtschaft. Nur die noch erhaltenen Miniaturen, die allen dekorativen Künsten $\mathrm{zu}$ Grunde lagen, dürften am relativ vollständigsten andeuten, in welchen Bahnen die Glasmalerei während ihrer ersten Entwicklungsstufe gewandelt ist.

Aus dem Gesagten erhellt, daß die Entstehung der Glasmalerei durch eine örtliche Definition nicht zu bestimmen ist. Denn sie bildet einen, für das was vorausging unbedeutenden, für die Folgezeit allerdings sehr wichtigen Punkt in der Gesamtentwicklung des buntfarbigen Fensterschmucks, der durch die Anwendung des einbrennbaren Schwarzlots markiert wird. Dagegen habe ich schon in der Gelegenheitsschrift: „Vierzig Jahre Glasmalkunst" darauf hingewiesen, daß alle Kirchen, für die uns in der Frühzeit Glasmalereien bezeugt waren, Stiftungen der Benediktiner sind: Das Kleinmünster in Zürich, in dem Bertha, Ludwig des Frommen Tochter, Äbtissin war, Werden, St. Denis, Reims, Sanct Gallen, Reichenau, Tegernsee sind von den Söhnen des hl. Benedikt gegründet. Die Benediktiner haben die antike und byzantinische Technik und Kunstübung innerhalb ihres Ordens, dessen Regel der Kunstpflege äußerst günstig war, weitergegeben und gebildet. Leichte Beweglichkeit und 
Ideenzirkulation wurde durch die Praxis der Zentralkapitel und des Scholarenaustauschs ermöglicht und sorgte für eine prompte Ausbreitung der einzelnen Kunstzweige. Da sich aber innerhalb. des gemeinsamen Ordensrings einzelne Klöster zu Kongregationen zusammenschlossen, so war von vornherein die Möglichkeit einer Schulenbildung im kunstgeschichtlichen Sinn gegeben, was wir auch an der Entwicklung der Glasmalerei bestätigt sehen. Der Faden reicht also zurück bis in das christliche Altertum, so daß bei der stetigen Weiterbildung der alten Idee buntfarbigen Fensterschmucks eine sprunghafte Erfindung von vornherein ausgeschlossen ist. Darum hat die lange über Gebühr aufgebauschte Mitteilung, daß um das Jahr ıooo die Glasmalerei in dem bayrischen Kloster Tegernsee erfunden worden sei, ihren Nimbus verloren. Die alten Tegernseer Mönche haben auch niemals den Anspruch erhoben, die Erfinder und Begründer der Glasmalerei $\mathrm{zu}$ sein, vielmehr sagt der Abt Gozbert in seinem Briefe $^{1}$ ) an einen adeligen Gönner, es möge dem Konvent vergönnt sein, die Scholaren, die mit der neuen Kunst nach dem Kloster gekommen seien, zu prüfen und wenn sich ein Mangel an ihrer Kunst zeigen sollte, zurückzusenden. - Wohin? Hören wir zunächst den Abt Gozbert: Dem Erlauchten Grafen. Arnold, dem durch den Ruhm seiner vielfachen Eigenschaften überall berühmten Herrn, senden Abt Gozbert und der Konvent der ihm unterstellten Brüder den Ausdruck anhaltender Fürbitten und Gruß im Herrn. Die Dienste frommer Andacht, die Ihr solange Zeit uns und den unsrigen unaufhörlich durch die mannigfaltigen Leistungen und großen Dienste erwiesen habt, möge Gott, der alles lohnt, auf die Bitten seines heiligen Zeugen Quirinus, mit seinem Lohn unzähligemal vergelten vor der ganzen himmlischen Heerschar! Mit Recht bitten wir Gott für Euch, die Ihr unser Kloster mit solch ehrenden Werken verherrlicht habt, wie wir weder früher geschaut haben, noch in Zukunft zu sehen hoffen durften. Die Fenster unserer Kirche waren bisher mit Tüchern verhängt, in Eueren glücklichen Zeiten aber strahlte die goldhaarige Sonne zum erstenmal durch verschiedenfarbige Gläser von Gemälden auf den Fußboden, und alle die dies sehen

1) Petz, Thesaurus anecdotum, Tom VI, Pars I, pag I 22. 
erfüllt große Freude, die sich über die Mannigfaltigkeit des ungewohnten Werkes wundern. Weil nun dieser Ort durch einen solchen Schmuck ausgezeichnet ist, wird Euer Namen dem Tagund Nachtgebet einverleibt. Damit in der Folge das Gedächtnis aller Eurer Verwandten hier begangen werde, laßt die Namen, soviele Ihr wollt, auf Pergament aufsetzen und uns durch gegenwärtigen Boten übermitteln. Eurem Gutdünken stellen wir die Prüfung der jungen Männer anheim, ob sie zu dem genannten Werk schon derart geeignet sind, wie es für Euch ehrenvoll, für uns aber nötig ist, oder wenn ich irgend einen Mangel an ihnen entdecke, so möge es mir erlaubt sein, sie zwecks Vervollkommnung zurückzusenden. Lebet wohl!

$\mathrm{Daß}$ „die verschiedenartigen Gläser von Gemälden“ discoloria picturarum vitra" wirkliche Glasmalereien darstellen, kann als einwandfrei gelten. Jedoch bietet der Brief sonst eine Reihe von Unklarheiten. Woher kamen die Fenster? Woher die noch nicht erprobten Glasmaler? Warum soll der Graf prüfen? Wie kann Abt Gozbert seinerseits untersuchen, ob die Künstler noch irgendwie einen Mangel aufweisen, wenn er doch selbst von der neuen Kunst keine Ahnung hatte? Endlich, wohin dürfen die Scholaren gesandt werden, um die letzte Ausbildung zu bekommen? Eines steht von vornherein fest: Tegernsee kann nicht der Ursprungsort der Glasmalerei sein, vielmehr ist diese Kunst an einem anderen Ort gepflegt worden, und zwar schon so intensiv, daß Schüler an andere Klöster abgegeben werden konnten. Daß das Kloster S. Emmeram zu Regensburg diese Herberge der Kunst war, ist sehr wahrscheinlich. Abt Gozbert wie sein Nachfolger Beringer waren vordem Mönche in S. Emmeram. In den Regensburger Klosterstuben gedieh und blühte eine hochberühmte Miniatorenschule und eben der Zusammenhang zwischen Miniatur und Glasmalerei, den wir für die entwickelte Tegernseer Glasmalerschule nachweisen können, läßt auch auf die Beziehung der Tegernseer Filiale zu dem Regensburger Mutterkloster im Falle der Glasmalerei einen Schluß zu. Dazu kommt, daß Regensburg der feste Punkt war, über den der Levantehandel, der Import byzantinischer Kunstwerke und Kunstformen wanderte. In Münchener Privatbesitz befinden sich Reste von Glasmalereien, die auf dem Dachboden der alten Emmerambasilika verborgen 
lagen. An ihnen ist mit Sicherheit zu erkennen, daß sie in die allererste Zeit der romanischen Periode gehören. Das zeigt die Eigenart der Glasfärbung und der breite Auftrag des Schwarzlots. Wir hören nun von Regensburger Glasmalerei nichts. Offenbar hat S. Emmeram die Führung auf diesem Gebiet dem Kloster Tegernsee überlassen, und somit erscheint es wahrscheinlich, daß jene Glasmalereireste aus dem Io. Jahrhundert stammen. Nur für den Fall, daß Regensburg die Heimat der Tegernseer Glasmalerschule ist, erklärt sich Gozberts Äußerung, er wolle die Scholaren prüfen. Als ehemaliger Mönch von S. Emmeram hatte er die Übung der Glasmalerei stets vor Augen und die Vorbedingungen, überhaupt prüfen zu können; jedenfalls hat ihn diese Kunst besonders interessiert und er hat dann als Abt, den Gönner des Klosters, den Grafen Arnold gebeten, wenn er dem Kloster ein Geschenk machen wolle, so würden Glasfenster dem Abt und Konvent eine besondere Freude bereiten. Auch muß zwischen Regensburg, dem Grafen Arnold, dem Abt Gozbert bereits ein Meinungsaustausch stattgefunden haben, ob man die Zentrale der Glasmalerei nicht nach Tegernsee verlegen solle, ähnlich wie den Glockenguß nach Freising, und es war offenbar schon zu einer Einigung gekommen. Der letzte Satz des Briefes se:zt vieles voraus und wäre für sich allein betrachtet, dem Grafen Arnold nicht recht verständlich. Auch die unmittelbare Folgezeit beweist die Richtigkeit unserer Annahmen: Sofort nach der Gründung der Tegernseer Glasmalerschule laufen Bestellungen von Freising und einer (unbekannten) Äbtissin ein. Freilich hat Gozbert sehr mit Schwierigkeiten zu kämpfen. Er kann die Lieferzeit nicht einhalten und nur Teile senden, weil es an Glas fehlt. Ein Mönch des Klosters Tegernsee, namens Godehard, verlie $\beta$ um Iоo2, also zu einer Zeit, in der die Glasmalerei mit Begeisterung im Kloster aufgenommen worden war, Tegernsee und gelangte nach einem langen Aufenthalt in Heersfeld und Kremsmünster, I 022 auf den bischöflichen Thron von Hildesheim. Aus der Zeit dieses Godehards stammen ein paar Notizen, die allenfalls auf Pflege der Glasmalerei in Hildesheim gedeutet werden können. Es ist die Rede von ,pictoribus et eis qui vitro fenestras componebant", sowie von einem „Glaser und Maler Liudiger". Ob damit die ersten Regungen glasmalerischer Tätigkeit in Hildesheim zum 
Ausdruck kommen, oder ob schon unter Godehards Vorgängern die Kunst in der alten Bischofsstadt geübt wurde, wissen wir nicht, jedenfalls steht fest, daß die Regierung eines ehemaligen Tegernseer Mönches einen besonderen Einfluß auf die Entwicklung der Glasmalerei ausübte.

Daß von den genannten Orten glasmalerische Tätigkeit bezeugt ist, von anderen dagegen nicht, hängt lediglich vom Zufall ab. Nur das Ereignis in Tegernsee ist zu dem eigenen Thema eines Briefes gewählt worden, während alle übrigen Erwähnungen Gelegenheitsnotizen sind. Darum ergibt sich für das I. christliche Jahrtausend folgendes Bild: Die Kunstverglasung hat sich auf dem Boden des römischen Imperiums entwickelt; sie erscheint sofort nachdem das Edikt von Mailand im Jahre 3 I 3 eine gesteigerte Bautätigkeit für die christlichen Gotteshäuser geschaffen hat. In die außeritalischen Gebiete kam die Sitte hauptsächlich durch Vermittlung des Benediktinerordens auf dem Boden des fränkischen Reiches. Von da aus gelangt sie durch Vermittlung französischer ,,vitri factores“ im letzten Drittel des 7. Jahrhunderts nach England und die übrigen nordischen Gebiete, so daß man die Regierungszeit Karls des Großen als jene Periode bezeichnen kann, in der sich die Sitte buntfarbigen Fensterschmucks über alle Kulturreiche des Abendlandes verbreitet hat. Das 9. Jahrhundert bildet den mittleren Zeitpunkt, an dem die Entwicklung von der Buntverglasung zu der mit Schwarzlot arbeitenden Glasmalerei fortgeschritten ist.

\section{B) Das Zeitalter des reinen Flächenstils.}

\section{Die frühromanisch=deutsche Schule.}

Die ältesten, heute noch erhaltenen Glasmalereien befinden sich, wie bekannt, im Dome zu Augsburg. Dieses ehrwürdige Gotteshaus, das mit seinen ältesten Bauteilen noch in die frühromanische Zeit hineinragt, berühmt durch sein Portal, birgt in den Hochschiffenstern den kostbarsten Schatz, den uns die Glasmalerei hinterlassen hat, fünf Fenster mit Figuren von alttestamentlichen Personen. Freilich war die Hochschätzung der Fenster nichts weniger wie allgemein. Im Gegenteil, sie werden häufig 
als primitive, fast rohe Erstlingsarbeiten angesprochen. Diese niedrige Einschätzung hängt zunächst mit dem sehr verbreiteten, aber irrigen Vorurteil zusammen, die Glasmalerei sei eine spontane Erfindung des Io. Jahrhunderts, weswegen die Augsburger Fenster selbstverständlich den Charakter des Primitiven, Unfertigen an sich tragen müßten.

Die ungenügenden Reproduktionen der Fenster auf dem Wege des lithographischen Verfahrens, die sich durch alle kunstgeschichtlichen Werke hindurchzogen, haben der gerechten Beurteilung ebenfalls sehr geschadet. Erst vor einigen Jahren hat der Verfasser dieses Buches die Glasgemälde auf Grund erstmaliger photographischer Aufnahmen bekannt gegeben (siehe die Gelegenheitsschrift: Vierzig Jahre Glasmalkunst, Festschrift der Hofglasmalerei Zettler, München I9I2). Daß auch nach dieser Bekanntgabe von einer ,,unbeholfenen Haltung“ und einer „,schwerfälligen Technik" gesprochen wird, muß befremden. Auf den ersten Blick vermag der Beobachter an Ort und Stelle zu erkennen, daß er es nicht mit primitiven Erstlingswerken, sondern mit Höhęnpunkten glasmalerischer Entwicklung zu tun hat. Es sind fünf Figurenfenster mit einer Durchschnittshöhe von ca. $230 \mathrm{~cm}$ und einer Breite von $54 \mathrm{~cm}$, so daß die Figuren selbst die Höhe von ungefähr $210 \mathrm{~cm}$ haben. Der Rahmen, der sie umkleidet, ist spät. Wahrscheinlich sitzen die Scheiben noch an ihrem ursprünglichen Platz, nur daß die Scheiben bei einer späteren Erweiterung des Fensterraums umrahmt werden mußten. Die ganze Technik dieser überlebensgroßen Figuren ist, wie wir später sehen werden, für Höhenwirkung berechnet. Sie stammen aus einem größeren Programm, von dem noch erhalten sind:

I. Moses. Mit Leibrock, Mantel, Judenhut, den beiden Tafeln, darauf . X ..P. (decem praecepta) und Spruchband; darauf -AUDI - ISRL - PRECEPTA - DN. (audi, Israel praecepta Domini). Über dem Kopf die Umschrift ...OYSES (Moyses).

2. König David. Mit Krone und Zepter, und Spruchband, darauf BEATI $\cdot \mathrm{Q} \cdot \mathrm{HAB}$... I $\cdot$ DOMO . TVA . DNE. (Beati qui habitant in domo tua, Domine. Über dem Kopf die Umschrift DAVID - REX.

3. Der Prophet Daniel. Auf dem Spruchband die Schrift: OSTENDE - DNE - FACIẼ - TVÃ - SVP - SEVRIṼ TVṼ. (Ost- 


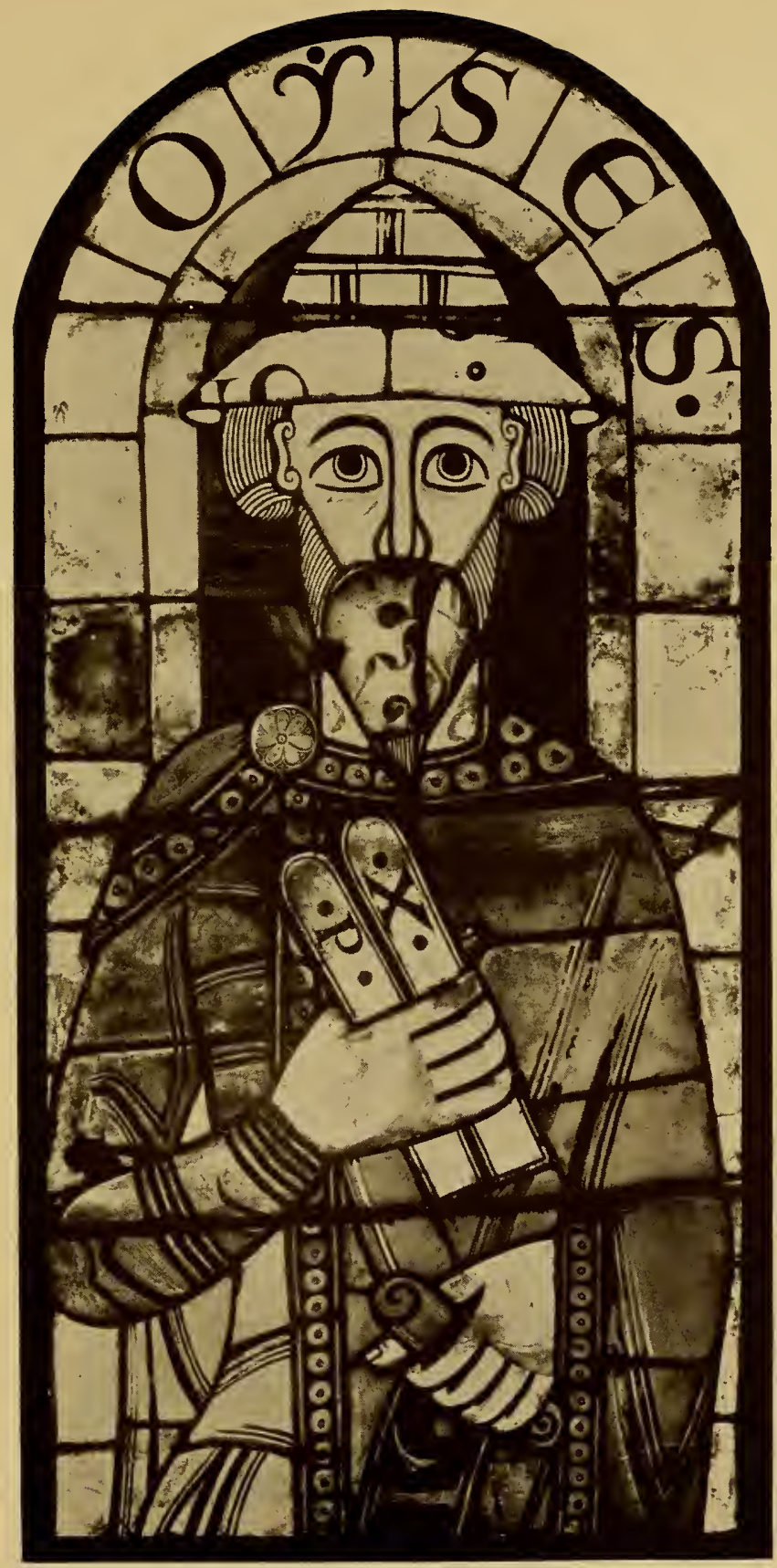

Teil einer Prophetengestalt. Dom zu Augsburg. Mitte des I I. Jahrhunderts. 

ende domine faciem tuam super servum tuum). Das Wort SER V ist während einer späteren Restauration verdorben worden. Über dem Kopfe die Umschrift: DANIEL . PP. Daniel propheta.

4. Der Prophet Osee. Auf dem Spruchbande die Schrift: EC . . ERVDITOR - OMNIṼ.DS. (ecce eruditor omnium dominus). Über dem Kopfe die Umschrift OSEE.PP. Osee propheta.

5. Der Prophet Jonas. Auf dem Spruchband die Schrift RVRSVM - VIDEBO - TẼPL $\tilde{V} \cdot S \tilde{L} \tilde{V} \cdot \widetilde{D I} \cdot \widetilde{M I} \cdot$ rursum videbo templum sanctum domini mei. Diese Stelle findet sich in dem Buch des Propheten Jonas Kap. 2, Vers 5, so daß die Reste der Umschrift richtig auf IONAS ergänzt sind. Bei einer Restauration sind die Schriftteile, wie der Judenhut in Unordnung gekommen. (Tafel I-4.)

Die Scheiben waren im Lauf der Zeit verschiedenen Restaurierungen unterworfen. So erscheinen besonders die Hüte zum größten Teil aus späterem Glase hergestellt, wobei Fragmente von den anderen, leider verlorenen Scheiben verwendet wurden. Aus den letzten Jahrhunderten mit seinem glatten Glase sind nur wenige Stücke zu bemerken. Die alte Bleifassung, das sog. gehobelte Blei, ist noch an drei Flügeln (den beiden Flügeln der Mosesscheibe und dem unteren Flügel der Danielscheibe) notdürftig erhalten. Die Bleiruten erscheinen hoch und stark, sind aber nur $5 \mathrm{~cm}$ breit. Auf der Jonasscheibe ist das Blei ungefähr I 50 Jahre alt, während die übrigen Teile um I 870 mit Zinnruten versehen wurden.

Es ist erstaunlich, wie gut erhalten der größte Teil des Glasmaterials und der Konturen noch heute ist; diese stehen frisch auf dem Glase und selbst der zu einer bescheidenen Modellierung und einer leichten Angabe von Licht und Schatten verwendete dünne Auftrag hat die zerstörenden Einflüsse langer Jahrhunderte prächtig überstanden. Die außerordentlich einfache Technik, die sich zurLinienführung undErklärung derForm auf die notwendigste Schwarzlotmalerei beschränkte, hat die gute Erhaltung begünstigt.

Was künden uns die stummen Prediger über die Verhältnisse ihrer Entstehung? Wann haben sie zum erstenmal den Blick der Gemeinde auf sich gelenkt? Wer sind die Künstler, unter deren Händen sich so einfache Mittel zu so großen Wirkungen gestaltet haben' Nachdem über sie keinerlei literarische Kunde auf uns 
gekommen ist, können sie nur selbst und etwa noch der Bau, den sie zu schmücken bestimmt waren, Aufschluß geben. Nach Schildhauer sind am Dom hauptsächlich drei Bauperioden zu unterscheiden, deren mittlere für uns in Betracht käme. Im Jahre 995 wurde mit einem Neubau begonnen und im Jahre 1006 fand eine feierliche Weihe statt. Sechs Jahrzehnte später (1065) hören wir abermals von einer Domweihe. Darum haben jene Autoren, die den Fenstern eine relativ frühe Entstehungszeit zubilligten, auf die Mitte des I I. Jahrhunderts, etwa I $50-60$ erkannt. Im Jahre Io I 2 kamen unter Abt Reginbald Mönche von Tegernsee zu den Gräbern der hl.Afra und des hl. Ulrich in Augsburg. Diese Siedlung brachte eine große Blüte für das Kloster. Im Jahre Io64 wurde der Neubau aufgeführt und bereits I07 I fand die feierliche Weihe statt. Es wäre nun sehr seltsam, wenn die Tegernseer Kolonie nicht alle Traditionen der Heimat nach dem neuen Wirkungskreis mitgebracht hätte, darunter vor allem die schöne Kunst der Glasmalere1. Nicht minder seltsam, wenn man in S. Ulrich auf den Schmuck verzichtet hätte, den man so reichlich in dem naheliegenden Dom anwandte. Tatsächlich hat S. Ulrich einst Glasmalereien besessen, wie uns Prior Wilhelm Witwer in seinem catalogus abbatum monasterii St. Ulrici et Afrae (um I 500) erzählt. Ich habe in der "Zeitschrift für alte und neue Glasmalerei“ (I9I2, S. 4) die betreffende Stelle ins Deutsche übertragen, um die Beurteilung des Fensters einem weiteren Kreise zugänglich zu machen. Witwer sagt: „Im Chor der Kirche befindet sich ein Fenster, das mit verschiedenen Figuren und Farben nach altem Brauch hergestellt und bemalt ist. In der Mitte, und zwar im oberen Teil des Fensters, ist ein Kreis, in dem die selige Jungfrau Maria dargestellt ist mit folgender Inschrift: Omnibus ecce modis ornat me gracia prolis. Auf der nördlichen Seite des Fensters aus dieser Bezeichnung ergibt sich, daß das Fenster nach Osten schaute, dementsprechend in der Mitte des Chores sich befand; für den Beschauer war die linke Seite der Fenster gegen Norden, die rechte gegen Süden gewendet und in diesem Sinne: links und rechts vom Beschauer, sind die Ausdrücke nördlich und südlich $\mathrm{zu}$ verstehen - ist ein Engel mit Spruchband: Que est ista que ascendit, auf der südlichen ebenfalls ein Engel mit Spruchband: Pulchra ut luna, electa ut sol. Ferner sind beim unteren Teile- 


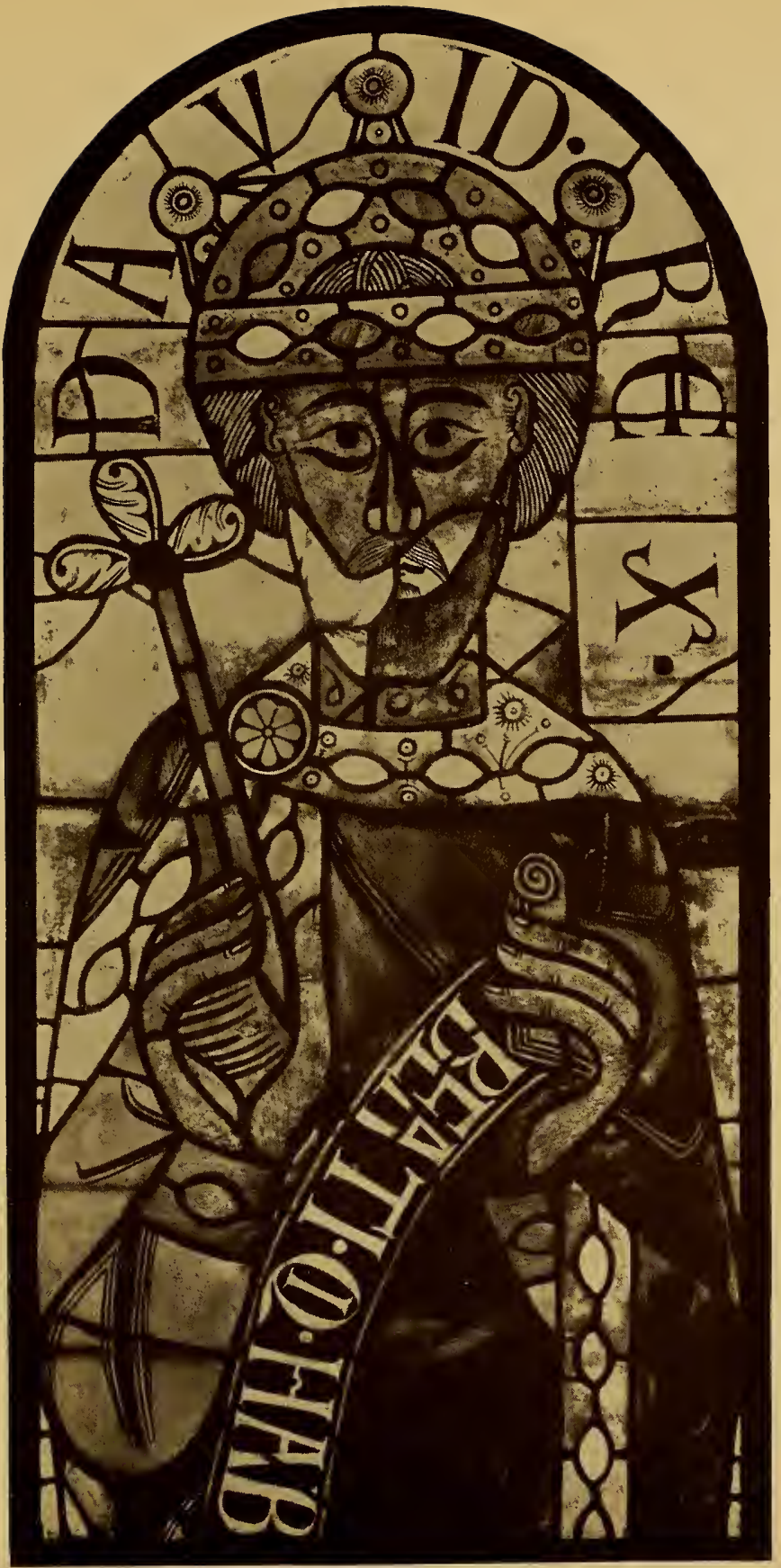

Teil der Gestalt des Königs David. Dom zu Augsburg. Mitte des I I. Jahrhunderts. 

jenes Kreises zwei andere Kreise, der eine gegen Norden, in dem ein Bild dargestellt ist, Virginitas benannt, mit einem Spruchband quer über die Brust: Veni de Libano, und mit einer dreiblättrigen Rose in der Rechten. Gegen Süden ist ein gleicher Kreis mit dem Bilde Daniels und folgender Inschrift: Veni coronaberis. Ferner ist in der Mitte des Fensters ein anderer Kreis, ähnlich dem vorher erwähnten, in dem drei Bilder von Frauen enthalten sind, in der Mitte die heilige Afra, unsere Patronin, mit dem Spruchband: Est in sorte bona michi reposita iusta corona; gegen Norden ein Bild mit dem Spruchband : Unus accipit pravium, in der Linken ein kleines Kistchen; gegen Süden ein Bild mit dem Spruchband: In tribulacione pascentes. Sodann befinden sich hier ebenfalls zwei kleine Kreise: im. ersten, dem nördlichen, ist ein Bild, Martirium, mit der Schrift: Plantacio rose in Jericho, in der Rechten das Zepter des Martyriums, in der Linken ein Strauß von drei Rosen; im andern, dem südlichen, ist das Bild Jobs, in der Rechten ein Stab, in der Linken das Spruchband: Odientes malum. Schließlich aber ist im unteren Teile des Fensters in der Mitte ein dritter Kreis, gleich groß wie die vorher beschriebenen; in ihm sind drei Bilder heiliger Bischöfe, des Dyonisius, des ersten Bischofs dieser Stadt, des Narzissus und des Ulrich. Von ihnen hat nur der heilige Ulrich eine Schrift, die folgendermaßen lautet: Officio fungor, quo sanctis ordine iungor. Sodann sind wiederum zwei Kreise bei den Füßen der Bischöfe, rechts und links; nördlich ist ein Bild, die Perseverancia, im Kreise auf der südlichen Seite ein Bild, die Patientia, beide ohne Schriften. Am Rande des Fensters sind zwei Halbkreise: nördlich das Bild Sacerdotium, mit dem Spruchband in der Hand: Qui docet in doctrina, in der Linken eine dreiblättrige Lilie; südlich das Bild Noes mit der Schrift: Qui preest in solicitudine - doch halten es einige für das Bild des Apostels Paulus. Am unteren Rande des Fensters ist das Bild des Abtes Heinrich, kniend und mit erhobenen, nach Art einesBetenden gehaltenen Händen, der diesesFenster renoviert, bzw. ausgebessert und geschmückt hat. Ferner sind enthalten folgende Verse, bzw. eine Schrift auf dem Fenster im Kreise an den Seiten:

Ordo beatorum sub ymagine ponitur horum.

Dum Noë rectores, Job sanctus signat angores, Daniel et mores castos niveosque pudores." 
Nach dieser Beschreibung dieses Buches ist vom Verfasser dieses Buches eine Rekonstruktion des Fensters versucht worden (s. Abb. I). Mit den Domfenstern hat dieses Glasgemälde scheinbar nun nicht

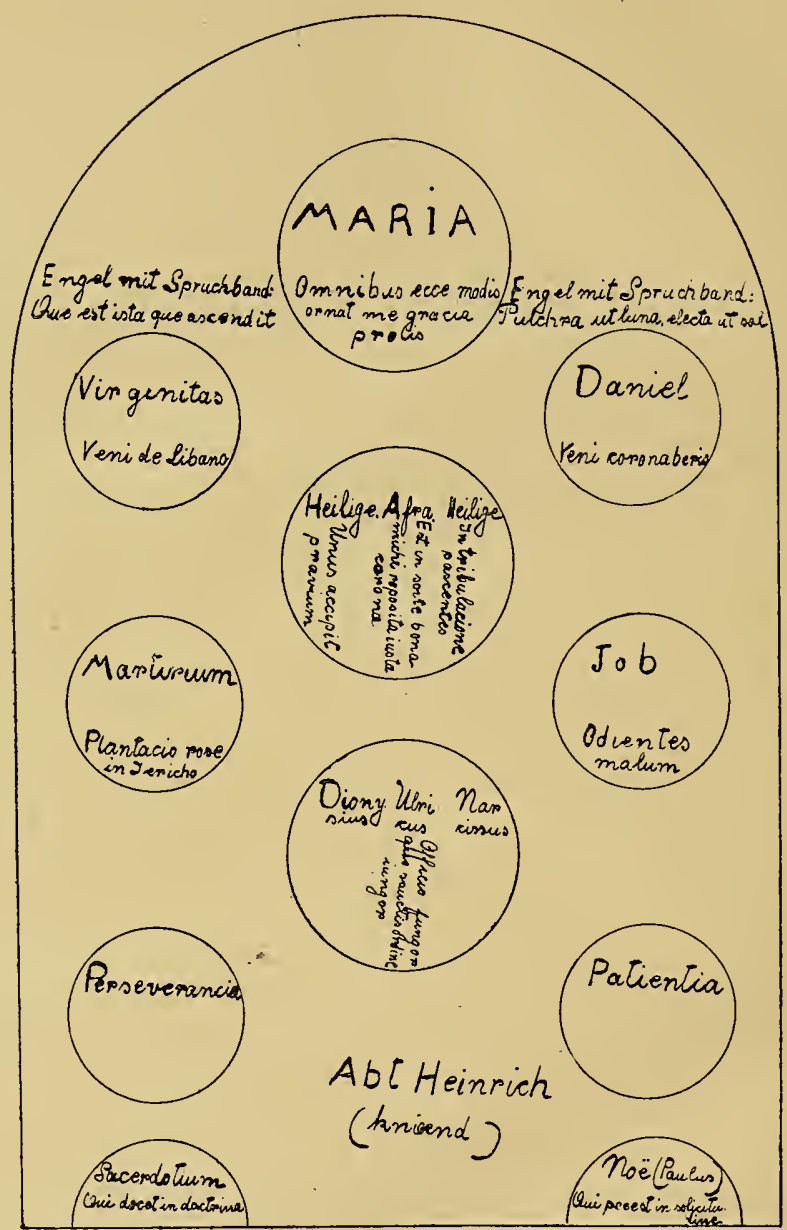

Abb. I. Rekonstruktion eines Fensters aus dem Chor der Sankt U'richskirche zu Augsburg. Ir. Jahrhundert.

die geringste Verwandtschaft, dagegen eine um so innigere mit einem Blatt des Uta-Evangeliars, das im Jahre 1002 angefertigt wurde. Hier wie dort findet sich die Einteilung in Kreise, 'n denèn allegorische oder heilige Gestalten mit Spruchbändern einge- 
zeichnet sind. Geradezu parallel erscheinen die das Knie beugende und betende Äbtissin Uta und der das Knie beugende und betende Abt Heinrich. Betrachtet man den durch Mauerwerk und eingebleite Kreise gegebenen Grundriß des Fensters von St. Ulrich,

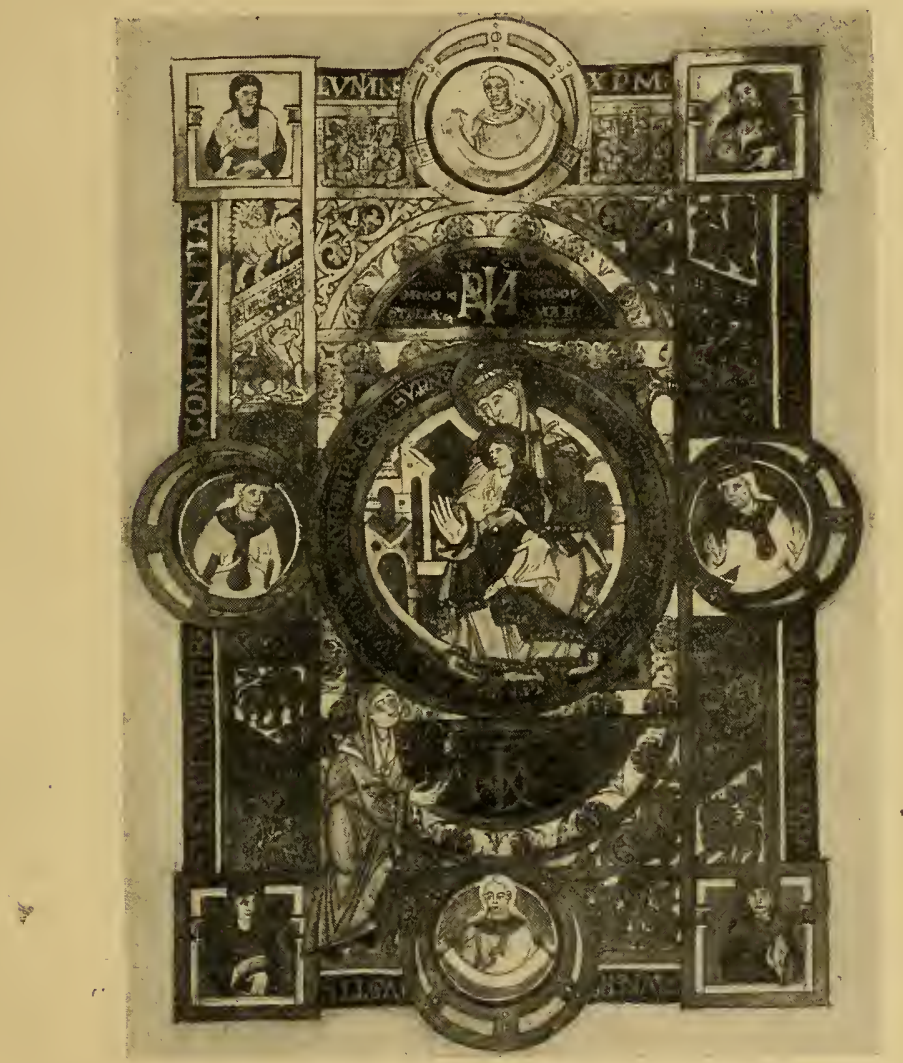

Abb. 2. Blatt aus dem Evangeliar der Äbtissin Uta aus Regensburg. Um IOO2.

so erkennt man darin sofort eine von den Urformen frühchristlicher Fensterverschlüsse. Miniatur und Architekturglied sind sich so auf halbem Wege begegnet, um den Rest bis zur Entstehung eines Glasgemäldes gemeinsam zurückzulegen. Über die Ents'- - jungszeit des Fensters haben wir außer dem Vergleich mit der eben genannten Handschrift, den Baudaten der Kirche, noch 
eine Notiz Witwers zu befragen. Der Prior sagt von dem Abt Heinrich III. (II83-II87) : renovavit hanc fenestram, sive melioravit ac decoravit. Im Jahre I 83 hatte nämlich ein Brand das. Kloster und die Kirche heimgesucht, durch den das Fenster nicht zerstört, sondern nur beschädigt wurde. Die Entstehungszeit des. Glasgemäldes liegt also zwischen I002 und I 83. Nun heißt es, wie oben bemerkt, am unteren Teil des Fensters sei das Bild des. Abtes Heinrich angebracht. Mit Namen Heinrich gab es drei Äbte, Heinrich I. (IO3I-I044), Heinrich II. (II7I-II77) und der eben genannte Heinrich III. Wahrscheinlich kann nur Abt Heinrich III. in Betracht kommen. Sein Bild wäre also, wie das. eines Stifters, in die untere Fläche des restaurierten Fensters gekommen. Es spricht kein Grund gegen die Annahme, daß das. von Heinrich III. restaurierte Fenster aus der Zeit des ersten Kirchenbaus nach Einwanderung der Tegernseer Benediktiner, also. spätestens in die Zeit unmittelbar vor I07 I, fällt.

Wie dem auch sei, der von selbst sich ergebende Hinweis. auf die Buchmalerei muß die Untersuchung des Stils beider Arbeiten auf diesen Gesichtspunkt hin veranlassen. Äußerlich bietet eben das unter Abbildung 2 wiedergegebene Blatt des Uta-Evangeliars eine direkte Parallele zu dem nicht mehr erhaltenen Fenster aus S. Ulrich. Für die Domfenster vermag aus der noch vorhandenen Miniaturengruppe der Regensburger Schule nichts als unmittelbares Spiegelbild in Betracht zu kommen. Wenn wir aber auf der Miniatur die streng linear geführten Federstriche, durch die die Konturen angegeben sind, mit den Schwarzlotkonturen der Domfenster vergleichen, so werden wir ohne weiteres zum Schlusse gedrängt, daß beiden Arbeiten das gleiche stilistischePrinzip zugrunde liegt. Swarzenski hat in seinem ausgezeichneten Buche „Die Regensburger Buchmalerei usw.“ die Ottonische Buchmalerei einer eingehenden Analyse unterzogen. Dabei stellte er fest, daß sich noch am Ende der Antike in der Buchmalerei eine Scheidung vollzog. Der antike Buchschmuck entlehnte seine Stilistik der Monumentalmalerei, so daß die Miniaturen auf plastischeGestaltung im Raum und impressionistische Gesamtwirkung hinzielten. Da dieser Eindruck dem eigentlichen Wesen der Buchmalerei nicht entsprach, bildete sich noch in den Zeiten der Antike ein mehr zeichnerischer Stil, der zur bewußten Herausent- 
wicklung einer spezifischen Kodexillustration führte. Der mehr malerische, aus der Antike geradlinig übernommene Stil herrschte vornehmlich in Lothringen und Frankreich, während der zeichnerische seine Pflege in Süddeutschland in Fulda, auf der Reichenau, später in Regensburg fand. S. Emmeram hat den Charakter der rein zeichnerischen Kunstdarstellung im Gegensatz zu den dramatisch bewegten Kompositionen Westdeutschlands (Triers) bewahrt und an seine Filiale Tegernsee weitergegeben. Trotz der kompositionell reichen Ausstattung des Utaevangeliars, wie des Fensters von S. Ulrich, ist auf dem Blatt durchweg jener rein zeichnerische, fast nur mit Greraden arbeitende Stil deutlich zu erkennen. Am strengsten sind die Fenster im Dome gehalten. Bringt die Übertragung einer Miniatur auf Glas an sich schon eine Verschärfung des Zeichnerischen und eine Minderung des Malerischen mit sich - wofern der Charakter der Glasmalerei als einer reinen Flächenkunst nicht alteriert wird - so haben die Künstler der Domfenster in weiser Berechnung des Zwecks die Monumentalität noch besonders betont. Die Glasgemälde waren von vornherein auf Höhenwirkung, auf monumentalen Eindruck berechnet. Darum der breite Auftrag des Schwarzlots, der fast völlige Verzicht auf die Angabe von Details : Geringe Verzierungen auf den Schuhen, kleine Kreise an den Gewandsäumen, Palmetten auf dem Boden, Rosetten als Gewandschließen waren mit Schwarzlotmalerei dargestellt. Nur die Tunika Osees, die Beinlinge des Moses tragen durchweg Verzierung, aber in geometrischer Einfachheit, ein in Rauten gestelltes Vierblatt, das,"wie die darunter befindlichen Kreise, in Radiertechnik ausgeführt ist. Wo sonst ein Ornament angezeigt schien, wie an der Krone und den Gewandsäumen Davids, da griff der Künstler zu dem ebenso einfachen, wie kräftigen Mittel der Einbleiung verschiedenfarbiger Glasstücke, einer deutlichen Anleihe von der Emaillierungskunst.

In der Handschrift lassen sich bestimmt zwei Künstler unterscheiden. So stammen die Figuren des Daniel, Moses, Osee von einer Hand, während die Figuren des David und Jonas im Charakter des Strichs auf einen anderen Künstler schließen lassen. Entgegen der streng zeichnerischen Schwarzlotführung biegt die Kontur an den Knien der Jonas- und Danielfigur plötzlich in eine dreigeschwänzte Spirale um. Man hat diese Seltsamkeit nie beachtet, 
da sie offenbar als stilistische Spielerei angesehen wurde. Nur Greiges kommt in seinem gründlichen Werke: „Der alte Fensterschmuck des Freiburger Münsters" darauf zu sprechen und zieht zum Vergleich einzelne Werke der Plastik (in Vézelay), der Malerei (in Montmorillon), des Emails (im ungarischen Nationalmuseum und in der Reichen Kapelle zu München) heran und hält sie für eine „starr schematische Darstellungsweise des Knochengerüstes“, die sich bei den Augsburger Fenstern ,zu einer vollständigen Loslösung von der eigentlichen Gestalt der Körperteile auswächst“" Geiges hat mit diesen Vergleichen völlig recht. Allein, da die Augsburger Fenster als älteste Arbeit am Anfang der Entwicklung stehen, erhebt sich die Frage: Aus welchem Kunstempfinden heraus ist dieses seltsame Motiv entstanden? Meines Erachtens hat erst die „Ausstellung von Meisterwerken mohammedanischer Kunst" Licht in die dunkle Herkunft jener Kunstsprache gebracht. Die Fenster des Domes zu Augsburg waren auf meine Veranlassung hin eben photographiert, da öffneten sich die Tore der Ausstellungshallen in München und zahlreiche, bisher kaum oder gar nicht bekannte Kunstwerke konnten zum Vergleich und zur Hilfe beigezogen werden. Am reinsten fand sich das Spiralmotiv auf einem Stoff, der zwei Löwen darstellte. Die Knöchel zeigten die nämliche Spirale, wie wir sie auf den Fenstern des Augsburger Doms erblicken. Dieser Stoff aber stammte aus dem sassanidischpersischen Kunstkreis. Daß diese Tatsache nicht vereinzelt oder wenigstens nicht ohne inneren Zusammenhang mit der Augsburger Formensprache erscheint, geht daraus hervor, daß sich die gesamte Formgebung und das gesamte Empfinden für Ornament und Zeichnung der Augsburger. Fenster aus dem sassanidischpersischen Kunstkreis erklären läßt. Man braucht nur die Bronzegefäße zu betrachten, die auf der Ausstellung zu sehen waren und jetzt in dem prachtvollen Werk Sarre-Martin, Meisterwerke mohammedanischer Kunst, München 1912, abgebildet sind. Siehe z. B. Tafel 129. In Persien hat sich das Spiralmotiv erhalten und in die byzantinische, wie mohammedanische Kunst eingenistet. So begegnen wir ihm auf einer Bronzekanne des 6. Jahrhunderts, (siehe Tafel I 29), auf dem Bruchstück einer Fließe (Tafel r Io), auf Elfenbeinstücken (Tafel 253). Es wurde beibehalten auf spanischmaurischen Brokaten, wie einer im Domschatz zu Würzburg sich 


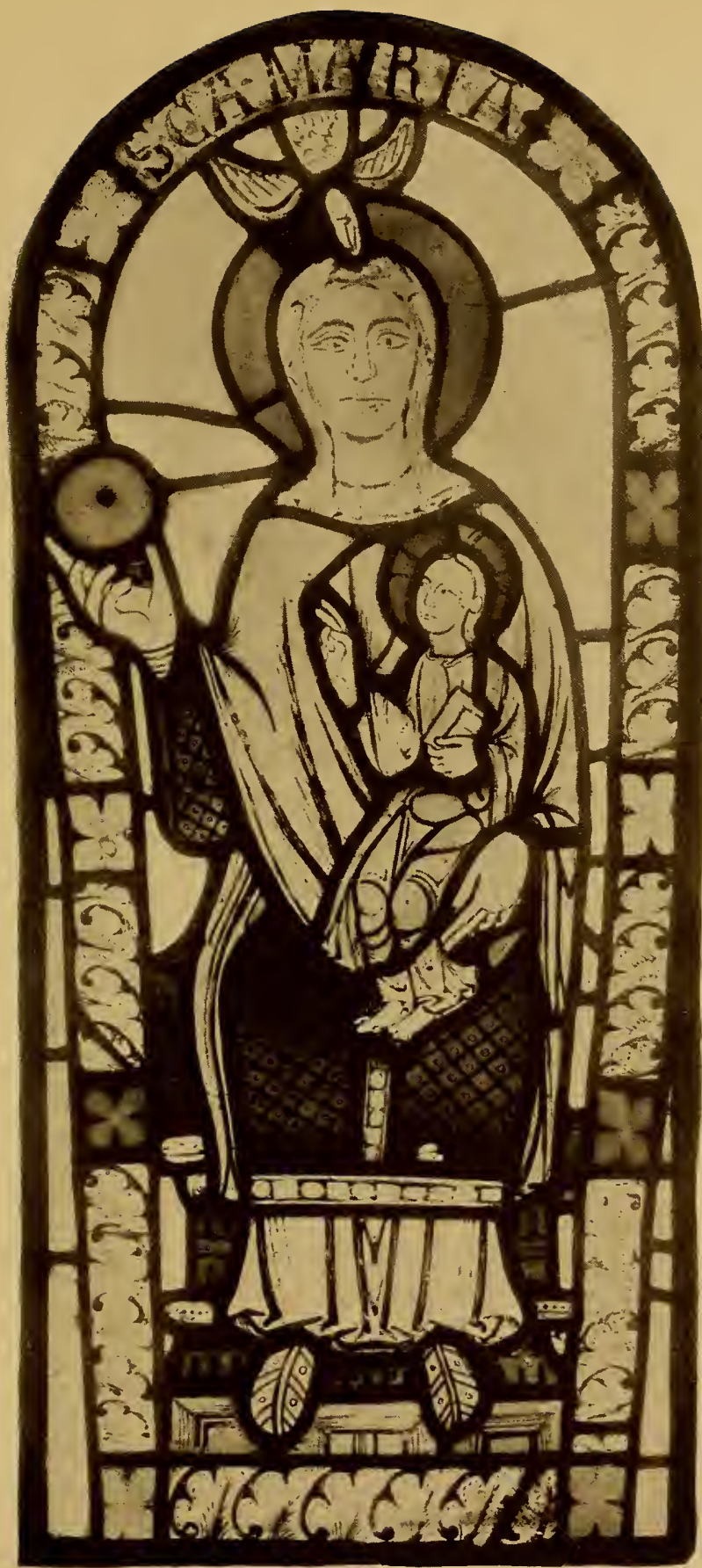

Madonna. Glasgemälde im Schweizerischen Landesmuseum zu Zürich. Aus Flums. Anfang des I 2. Jahrh. 

befindet, auf sarazenischen Brokaten (Tafel I87), auf der Schließe eines deutschen Kaisermantels (Geiges, S. 47). Die Kunst des Ostens ist also auf dem Weg über Byzanz nach dem Westen in die Glasmalerstuben gedrungen. Für Süddeutschland kommt als Vermittlungsstation die alte Zentrale des Levantehandels, Regensburg wie auch Salzburg in Betracht. An die Salzburger Miniaturenschule erinnert die eigentümliche Ausbiegung der Faltenkonturen, von der noch im folgenden Kapitel die Rede sein wird.

Ein besonders gütiges Geschick hat noch zwei Glasgemälde der Nachwelt überliefert, die dem Charakter der Augsburger Scheiben nahe stehen. Das eine ist das Timotheusfenster aus Neuweiler im Elsaß, das andere eine Madonnenscheibe im Schweizerischen Landesmuseum zu Zürich (siehe Tafel 5). Das Timotheusfragment befindet sich jetzt im Clunymuseum $\mathrm{zu}$ Paris und ist von Robert Bruck (Elsässische Glasmalerei) bekannt gemacht worden. Die Madonnenscheibe im Züricher Landesmuseum aber war bis zum Jahre I834 an ihrem ursprünglichen Aufstellungsort, der S. Jakobkapelle zu Flums unweit Walenstadt. Es bildet die nächste uns bekannte Stufe nach den Augsburger Fenstern und stellt vor farblosem Hintergrund die sitzende Maria mit Kind dar. Das Kind schaut nach einem großen roten Apfel, den Maria in der Rechten hält. Über dem Haupte Marias schwebt der Heilige Geist in Gestalt einer Taube. Das Ganze ist in eine mäßig breite Girlande von stilisierten weißen Blättern auf schwarzem Grunde gerahmt. Marias Kleid zeigt, ähnlich wie die Figur des Propheten Osee, durchgehende Musterung. Auch sonst tritt die Verwandtschaft zwischen den Augsburger Fenstern und der Flumser Madonna offen zutage. Über das Timotheusfenster in Neuweiler handelt ausführlich Robert Bruck, und bemerkt, daß dasselbe in die Zeit zwischen den Augsburger Domfenstern und der Entstehung des Hortus deliciarum der Herrad von Landsberg, einer Handschrift aus der zweiten Hälfte des I2. Jahrhunderts, falle. Wir können Bruck recht geben und halten die Timotheusscheibe für eine Weiterentwicklung gegenüber der Flumser Madonna, wobei wir die Frage zunächst unerörtert lassen können, wo sich die Weiterentwicklung vollzogen hat und ob nicht der Meister des Timotheusfensters von S. Denis beeinflußt war. Davon im nächsten Kapitel. Die Faltenzeichnung, trotz ihrer freien Linienführung, die Stellung 
und Ausführung der Hand, die Einbleiung der Nacktpartie des Kopfes in die Haare, das Ornament der Palmette - das alles beruht auf dem Prinzip der Augsburger Domfenster, dem, wie gezeigt, auch die Flumser Madonna folgt. Diese steht entwicklungsgeschichtlich zwischen Augsburg und Neuweiler. Der Auftrag des Schwarzlots ist völlig identisch mit dem Stil auf den Augsburger Fenstern. Breit und massig steht es auf dem Glas. Fast keine Spur von Modellierung oder Andeutung von Licht und Schatten. Demgegenüber versucht der Meister des' Timotheusfensters bereits eine zielbewußte Modellierung, z. B. in der Handfläche, am Hals, um die Nase; mit leicht aufgetragenem Überzug deutet er starke Schatten an.

Man kann die Fenster zu Augsburg, Flums in gewissem Sinn als Arbeiten der Tegernseer Schule bezeichnen, insofern sie denselben Gestaltungsprinzipien folgen. Es ist die älteste Gruppe, die wir kennen, und wir nennen sie am ehesten die frühromanische deutsche Schule; damit soll selbstverständlich nicht behauptet werden, daß das Fenster zu Flums in Tegernsee angefertigt wurde, obwohl der Betrieb daselbst sehr ausgedehnt und der Versand fertiger Glasgemälde außerordentlich weite Gebiete aufsuchte. Einmal in Übung gekommen, erfreute sich die Glasbemalung großer Beliebtheit, und begreiflicherweise bildeten sich an Kulturund Kunstzentren des Benediktinerordens Filialen der Tegernseer Schule. Im wesentlichen beschränkt sich der Kanon der Tegernseer Schule auf die bayrisch-alamannischen Gebiete. Elsaß, das Bindeglied zwischen Deutschland und Frankreich, öffnete sich sehr bald französischen Einflüssen. Diese überstiegen sogar den Schwarzwald, wie die im Museum zu Stuttgart erhaltene Scheibe aus dem ehemaligen Kloster Alpirsbach lehrt. (Abgebildet bei Balet, Schwäbische Glasmalerei). Die frühromanische deutsche Schule liebte die Einzelfigur und zog sie der in Frankreich geschätzten Szenendarstellung vor. Das erklärt sich zum Teil aus einer besonderen ästhetischen Neigung für das Monumentale, Architektonische in der Glasmalerei. Es ist oft bemerkt worden, daß die deutsche Kunstübung die Vertikale bevorzuge. Diese Beobachtung trifft für die Glasmalerei vollkommen zu. Die Fenster erzielen ihren gewaltigen, monumentalen Eindruck eben durch diese Betonung der Vertikalen, durch die Füllung des ganzen 


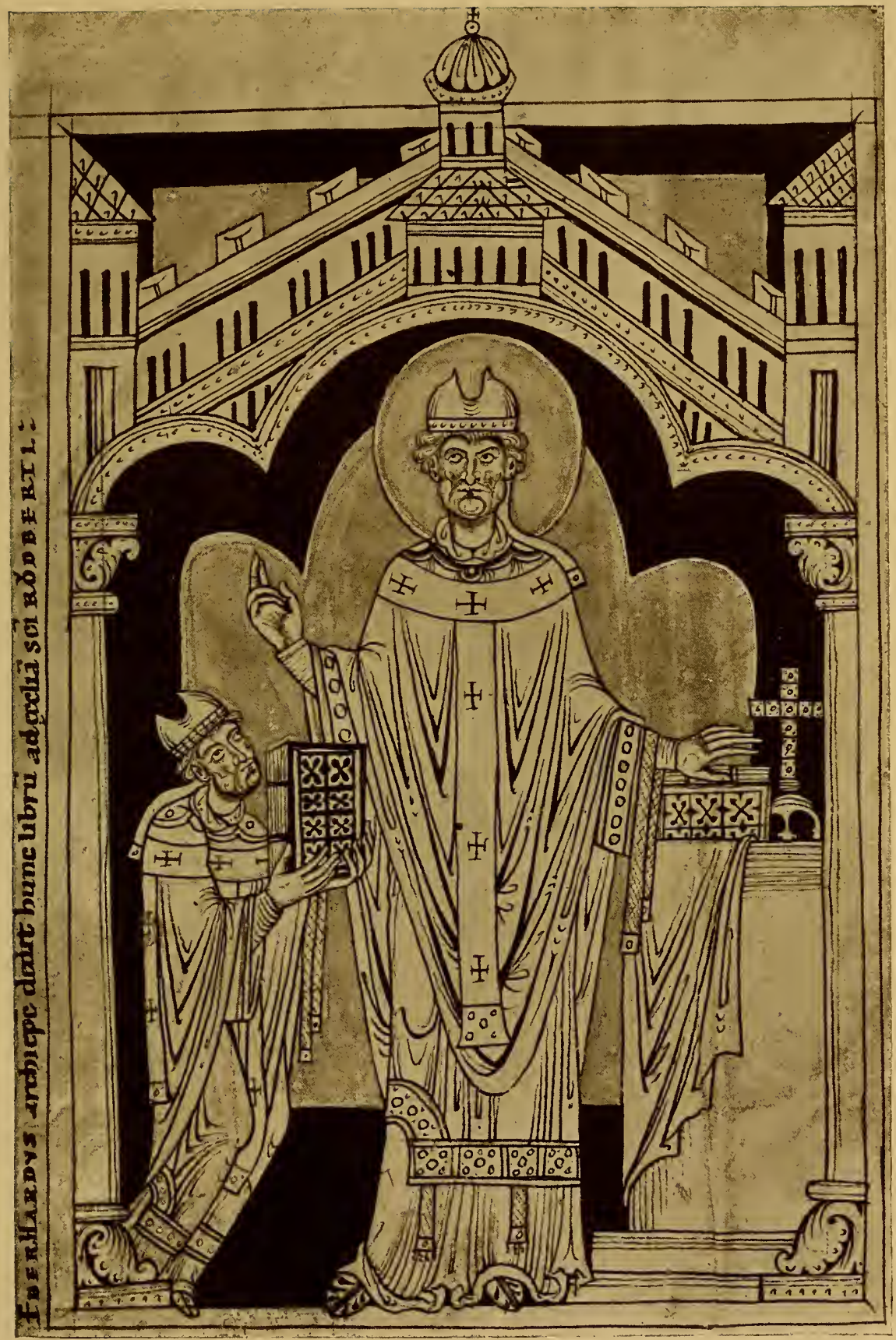

Miniatur aus einer Salzburger Handschrift; codex lat. 1581 2 der Münchener Hof- und Staatsbibliothek. Um I I 50. 

Fensters mit einer ein..gen Figur. Es ist möglich, daß um die Figur ein ornamentaler Rahmen, wie in Flums und Neuweiler, gezogen war. Immerhin aber wollen die Fenster durch Gesamteindruck, durch Monumentalität wirken, nicht bloß, ja nicht einmal in erster Linie, durch augenerfreuende Buntfarbigkeit, wie die französischen Glasgemälde. Die Farben sind im Gegenteil höchst einfach und im Gegensatz zu den französischen Glasmalereien in großen Glasflächen wiedergegeben. Die deutschen Glasfenster ordnen sich streng dem tektonischen und religiösen Ziel des Gebäudes unter, das sie zieren, sie erbauen und lenken auf das Wort des Predigers und die Symbolik des Gottesdienstes; die französischen ergötzen und lenken ab. Darum die große Feindschaft des heiligen Bernhard und der Cisterzienser gegen die französische Glasmalerei, überhaupt gegen die figürliche Glasmalerei. Wir wissen wohl, daß auch auf französischem Boden Einzelfiguren dargestellt wurden, ja direkt in ein festes Ausstattungsprogramm gehörten, das Emile Mâle (L'art religieux du XIII. siècle en France) im einzelnen gezeigt hat. Allein aus den ersten Jahrzehnten der französischen Glasgemälde, die zudem reichlich nach den bayrischalamannischen Arbeiten entstanden sind, findet sich stets die Szene an Stelle der Einzelfigur. Dieser Beobachtung widerspricht auch nicht das oben gekennzeichnete Fenster von S. Ulrich und S. Afra, da dieses auch im zeichnerischen Charakter der Tegernseer Miniaturen gehalten war.

Es ist ein kleiner Bruchteil, der sich aus dieser ersten, der frühromanischen deutschen Schule erhalten hat. Daß sehr viel verloren gegangen ist, besagen uns nicht nur vereinzelte Nachrichten über Feuersbrünste, Zerstörungen durch Hagelschlag, sondern noch beredter die Tatsache, daß zu Beginn des I2. Jahrhunderts kleine Pfarreien wie Neuweiler, ja sogar einsame Bergkirchlein wie Flums, glasmalerischen Schmuck aufwiesen. Sollte eine Kathedrale, ein Münster buntfarbiger Fenster entbehrt haben, wenn sich die bescheidensten Gotteshäuschen im Dorfe bereits eines solchen Schmuckes erfreuten? Von diesem Gesichtspunkte aus gewinnen die paar zerstreuten Notizen über alte Glasmaler, so über den vitrearius Stracholfus, servus Sancti Galli, dem Ludwig der Fromme einen Anzug schenkte, über den Fenestrator Otto in Köln um I I 40 und einige andere neue Bedeutung. Wie frei- 
lich die ältesten Glasmalereien Kölns ausgesehen haben, läßt sich nicht einmal vermuten; denn bis zu dem ältesten erhaltenen Werk sind es noch mehr wie hundert Jahre.

\section{Die frühromanisch:französischen Schulen.}

a) Die Schule von Chartres.

Zwei bis drei Menschenalter mögen seit der Entstehung der Augsburger Fenster verflossen sein, als die bischöfliche Kirche zu Châlons-sur-Marne einen großen Glasgemäldeschmuck bekam und damit die lange Reihe noch erhaltener französischer Glasmalereien eröffnet. Síe stehen nicht mehr, wie die Augsburger Domfenster an ihrem ursprünglichen Platze, sondern sind verschiedene Male versetzt worden. Dabei mag manches verloren gegangen sein. Immerhin aber ragen die 19 erhaltenen Überreste als mächtige Zeugen französischer Primitive in die Gegenwart herein. Um nicht mißverstanden zu werden, möchten wir betonen, daß die Glasgemälde zu Châlons-sur-Marne natürlich nur insofern französische Primitive genannt werden, als sie die ältesten erhaltenen Arbeiten auf französischem Boden darstellen, denen vielleicht zahlreiche, aber nicht mehr vorhandene Glasgemälde vorangegangen sind. Der Unterschied zwischen diesen Glasmalereien von Châlons und der deutschen frühromanischen Schule springt sofort in die Augen. An die Stelle der Einzelfigur ist die Szene, an die Stelle der Vertikalen'das Medaillon getreten. Auf dem einen Medaillon sehen wir in vier Szenen die Legende Gamaliels und des Priesters Luzian, ein anderes zeigt die symbolischen Gestalten der Kirche und Synagoge, ein drittes enthält die Kreuzigung während von einem vierten Glasgemälde nur mehr die linke Seitenfigur erhalten ist. Gegenüber der von allem Wirklichen abgewendeten Übersinnlichkeit der deutschen Schule, deren eisernen Ruhe, zeichnet die französischen Arbeiten ein bemerkenswertes. Streben nach Realismus, insbesondere nach Versinnlichung des. inneren Lebens, aus. Dies geschieht aber nicht etwa durch den Gesichtsausdruck, als vielmehr durch Aktionen und Körperbewegungen, die gerne bis zu unnatürlichen Verdrehungen ausarten, wie auf den Glasgemälden zu Le Mans zu erkennen ist. Die Gewänder sind an 'den unteren Teilen faltiger und bewegter, Hände 


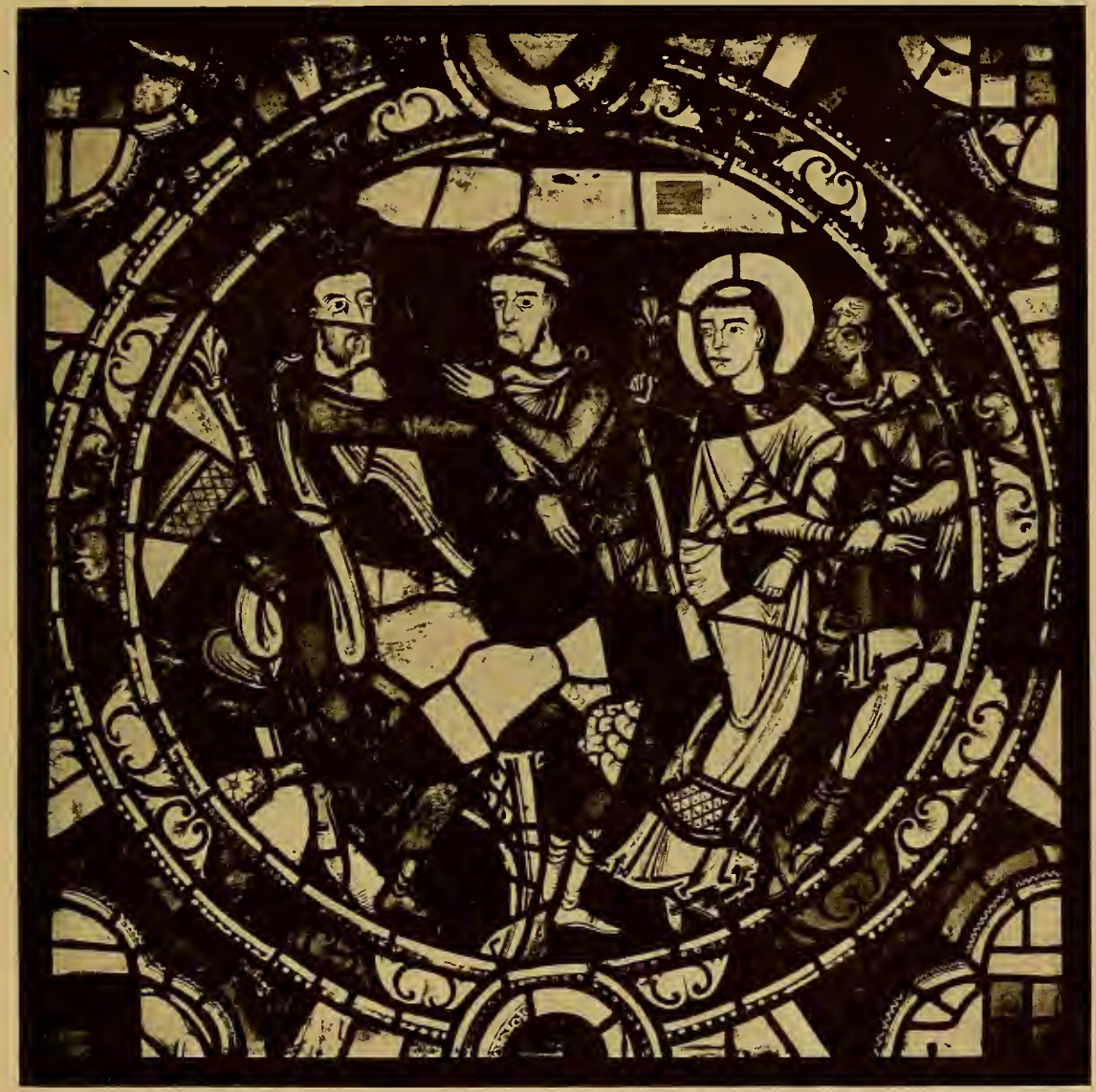

Detail aus einem Glasgemälde der Kathedrale zu Poitiers. Zweite Hälfte des I 2. Jahrhunderts. 

werden nicht sklavisch streng auf der Brust gehalten, sondern entfernen sich vom Leibe. Dies alles soll dem Streben nach Veräußerlichung des Pathos, dem frischeren Naturalismus dienen. Ganz besonders fällt die Wiedergabe anatomischer Kenntnisse an dem Körper Christi auf. Trotz dieser gewaltigen Unterschiede in der Auffassung finden sich andererseits sehr viele Berührungspunkte zwischen der deutschen und französischen Schule. Die Führung des Schwarzlots, die charakteristische Verlängerung des einen Schenkels bei in Winkelform zusammenstoßenden Schwarzlotstrichen, die Schraffierung der Haare ist dieselbe geblieben. Diese merkwürdige Verlängerung des einen von zwei zusammenstoßenden Schwarzlotstrichen über den Schnittpunkt hinaus ist ein Überbleibsel aus der Technik der Miniatur zur Andeutung gebrochener Falten und führt uns in die Schreibstuben der alten Mönche. Insbesondere die Salzburger Schule liebt diese Gewohnheit (siehe Tafel 6). Modellierung und Angabe

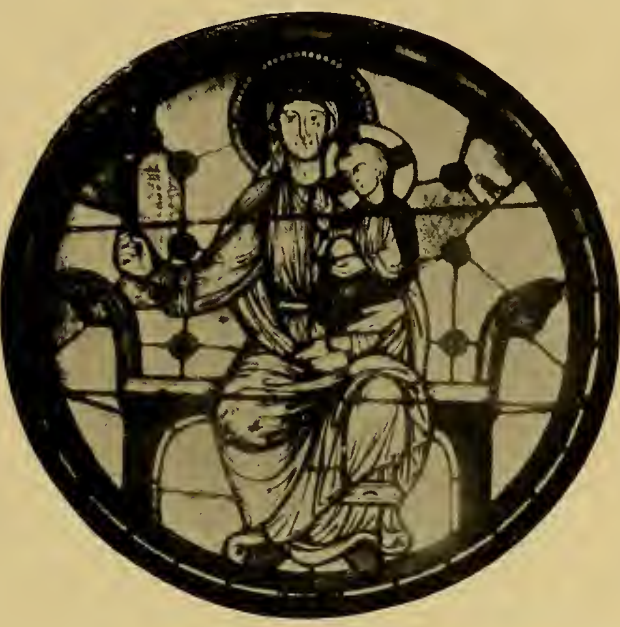

Abb. 3. Mittelpunkt der großen Rose in der Kathedrale zu Lyon. I3. Jahrhundert. von Licht und Schatten sind kaum über die Technik des Timotheusfensters hinaus geschritten. Dagegen erscheint die Zeichnung freier und lebhafter. Was wollen wir mit unseren Hinweisen auf die deutsche Schule und gar auf die Schreibstube in Salzburg sagen? Wollen wir damit indirekt behaupten, daß die frühromanisch-französische Schule von der deutschen Technik beeinflußt gewesen sei? Gewiß, das wollen wir. Deutschland und Frankreich sind gemeinsam von dem byzantinischen Formenschatz bedient worden, der seinerseits wieder eine Weiterbildung der sassanidisch-persischen Kunst ist. Das meint auch jene Legende, die sagt, byzantinische Emailleure seien die Lehrer der Glasmalerei gewesen. Entsprechend dem verschie- 
denen Nationalcharakter verarbeiteten die beiden Länder den gleichmäßig überkommenen Bestand in verschiedener Weise weiter. Deutschland liebt den zeichnerischen, Frankreich den malerischen Stil. Die Technik aber und die Ausdrucksmittel blieben während der frühromanischen Periode hüben wie drüben gleich. Darum aber, nur darum ist 'es erklärlich, wie eine Lieblingsgewohnheit der Salzburger Schreibstube auf fast allen Glasgemälden des I I. und I2. Jahrhunderts wiederkehrt und der Gedanke gewinnt große Wahrscheinlichkeit, daß sich in der Südostecke des deutschen Reiches die Technik und Stilistik der Glasmalerei zu einem festen Kanon ausgebildet hat, der auch im Westen Europas unbeschadet der Eigenart des keltoromanischen Naturells Eingang gefunden hat. Darum ist es auch erklärlich, daß sich die uns aus der persisch-byzantinischen Kunst, dann auf den Augsburger Fenstern geläufige Spirale an den Knieen, auch auf dem Himmelfahrtsfenster der Kirche zu Champ (Isère) (Tafel 8), allerdings in einer freieren Form wiederfindet. Eben dieses Fenster, auch ein Medaillon, zeigt eine Umrahmung, die auf denselben Palmettenmotiven beruht, wie das Neuweiler Glasgemälde. Es ließe sich also daran denken, daß die frühromanisch-französische Schule eine direkte Weiterbildung der frühromanisch-deutschen Schule in national-keltoromanischen Sinn ist ${ }^{1}$ ). So wie die Verhältnisse sich aus dem jetzt noch vorhandenen Material erfassen lassen, hat sich die Entwicklung der Glasmalerei in folgender Weise vollzogen: Formenschatz und Technik stammen von Byzanz, indirekt noch weiter von Osten, wie wir im vorausgehenden Kapitel gezeigt haben, - Rom kann bei dem gänzlichen Mangel originaler Glasmalereien während des Ir. und 12 . Jahrhunderts nicht in Betracht kommen. - Je weiter die Kunst nach Westen vordringt, desto mehr verblaßt die byzantinische Eigenart; zudem trifft sie fast überall in ihren natürlichen Haltepunkten, den Klöstern, auf entwickelte, mit eigenen Stil arbeitende Schreibstuben, so Salzburg, Regensburg. Dadurch reift eine neue Formensprache für die Glasmalerei heran, die die Elemente der byzantinischen Ein-

1) Mâle sagt, die Schule von Reims, l'école champenoise, habe etwas „Byzantinisches, Germanisches an sich". Ursprung und Chronologie dieser Schule seien nicht erklärbar. Die Beobachtung Mâles, daß die école champenoise etwas Germanisches an sich hat, ist richtig und erklärt gleichzeitig die Provenienz der Schule. 


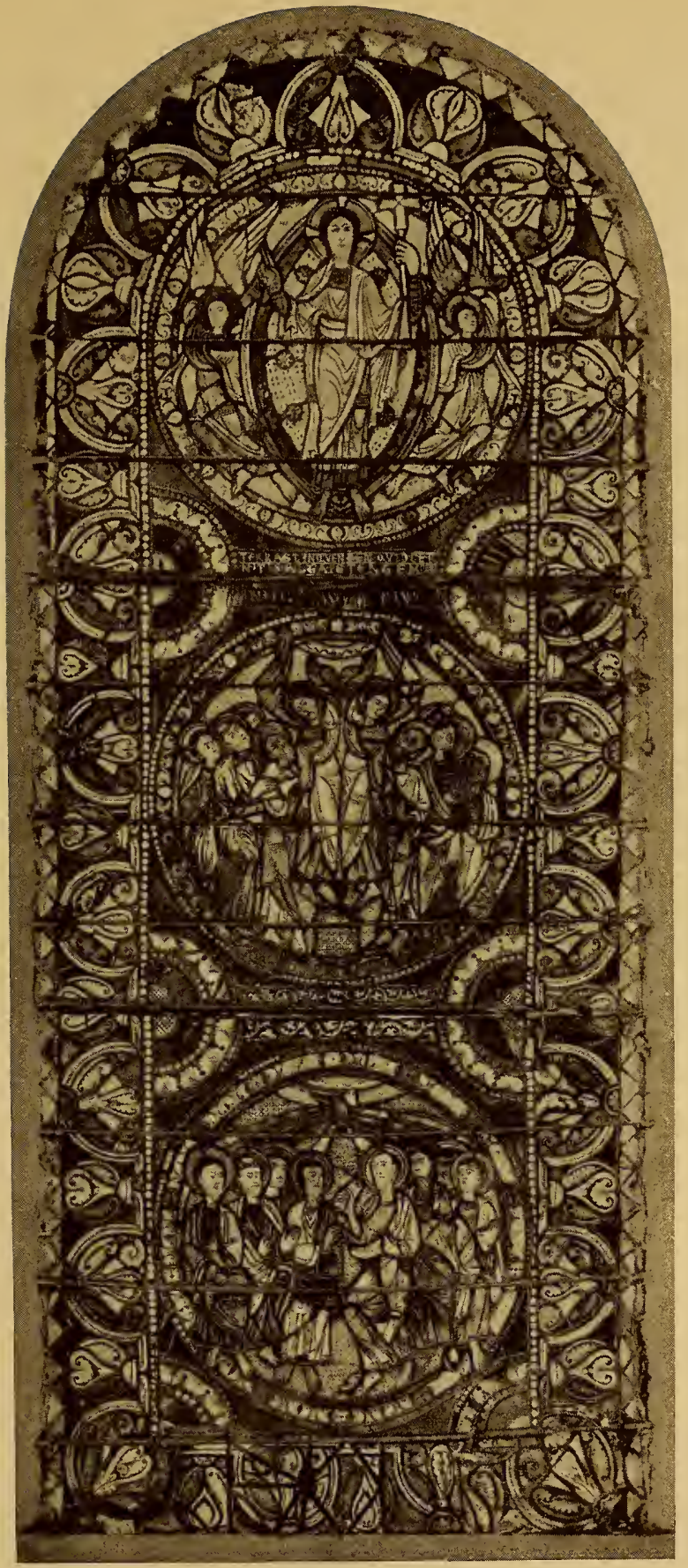

Fenster in der Kirche zu Le Champ (Isère). Zweite Hälfte des I 2. Jahrhunderts. Nach einer Photographie von L. Bégule. 

wanderung mit den Grundsätzen der lokalen Schreibstube organisclı verbindet. Es entsteht ein Kanon von festen Formen über den Auftrag des Schwarzlots, der einzigen spezifischen Neuheit der neuen Kunst, und dieser Kanon greift bei allen Ausstrahlunge. von den östlichen Zentralen nach den verschiedenen westlichen Punkten über. Auch in diesen Klosterschulen trifft dieser Kanon auf bestimmte Lokaltraditionen in Auffassung der Kunst im allgemeinen, und so entstehen gleich von Anfang, trotz aller gemeinsamen Ursprungsmerkmale, scharf von einander unterschiedeneGlasmalerschulen. Wir lesen zwar in dem berühmten Buch von Hucher: "Ce qui est admis par tout le monde c'est que la peinture sur verre est un art tout français; que c'est en France qu'il a pris naissance ou au moins son plein accroissement", und dieser Gedankengang hat sich bis zur Stunde in fast allen französischen Werken unversehrt und mackellos erhalten. „L'art du vitrail est un art aussi français que 1'architec-

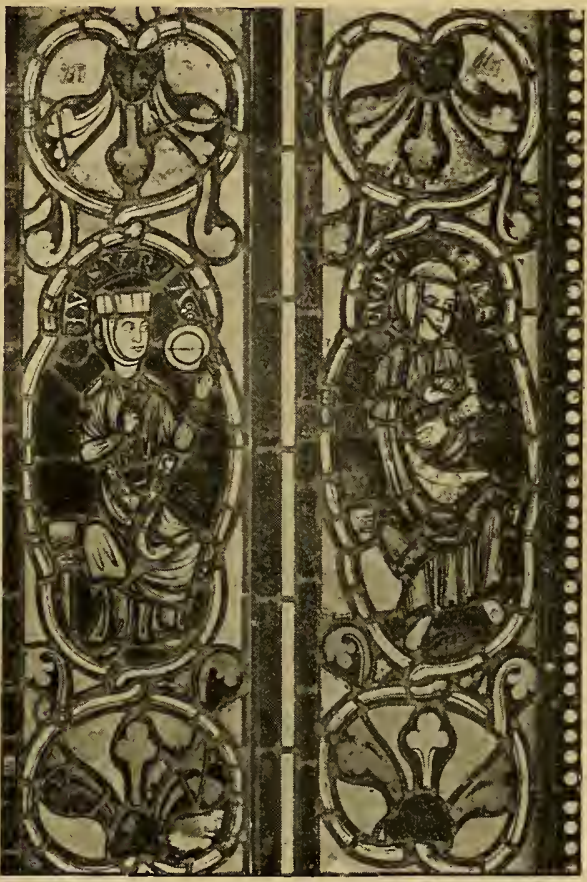

Abb. 4. Detail aus einem Fenster der Kathedrale zu Lyon. I3. Jahrhundert. ture dite gothique." Mit diesem Glaubensbekenntnis eröffnet L. Bégule im Jahre I9 I I sein sonst sehr verdienstliches Werk über die Glasgemälde der Gegend von Lyon. Allein, wenn auch noch so oft wiederholt, hält dieser Satz vor der Wahrheit nicht stand. In der spätern, besonders gotischen Periode, gingen von Frankreich viele Anregungen auf dem Gebiete der Glasmalerei aus, allein in der frühromanischen Zeit konnte Frankreich nichts bieten, da es nichts hatte. Vergleicht man die frühromanisch-deutsche Schule mit der frühromanisch-französi- 
schen Schule, so fällt der Vergleich in Hinsicht auf die Qualität entschieden zugunsten der deutschen Glasmalerei aus. In Deutschland wurde man mit dem monumentalen, alles Detail, alle Auf'regung vermeidenden Stil, dem Charakter der Glasmalerei weit mehr gerecht, als in Frankreich mit dem unbeholfenen, mißglückten Versuch, Lebenswahrheit und Temperament auf den Glasfenstern wiederzugeben. Zwar hatte man in Frankreich eine schärfere Witterung für die unbeschreiblichen koloristischen Möglichkeiten, die der Glasmalerei innewohnten, allein der Kolorismus war erst dann in der richtigen Bahn, wenn er einer der Eigenart des Materials entsprechenden Zeichnung diente. Die Legende von Frankreich, als Lehrmeister der Glasmalerei, mag zum Teil sich aus der Tatsache erklären, daß die Franzosen als Stamm den bezaubernden Wohllaut farbiger Glasfenster mit größerer Lebhaftigkeit aufnahmen, als der etwas bedächtigere Deutsche, daß daher während des I 2. und I3. Jahrhunderts Glasmalerschulen wie eine Kadmossaat aus dem Boden sproßten, und daß französische Arbeiten hart an, ja über die Grenzen des bayrisch-alamannischen Gebiets gedrungen sind, werden wir in den nächsten Kapitel sehen.

\section{b) Die Schule von S. Denis.}

Ungefähr zu gleicher Zeit, wie die Glasgemälde zu Châlonssur-Marne entstanden sind, hat Abt Suger von S. Denis seine neue Abteikirche mit einem Fensterschmuck versehen lassen. (Zwischen I 140-I I 44.) Von diesem Schmuck ist nicht mehr viel erhalten geblieben; dagegen besitzen wir eine genaue Beschreibung, die der Abt selbst in seinem berühmten Buch de rebus in administratione gestis aufgezeichnet hat: „Wir haben auch die herrlichen neuen Fenster von dem ersten mit dem Stammbaum Jesse im Chor der Kirche bis zu đem, das über dem Hauptportal steht, durch die kundige Hand vieler Meister aus verschiedenen Nationen malen lassen. Eines von ihnen, das vom Sinnlichen zum Übersinnlichen aufruft, stellt den Apostel Paulus dar, wie er eine Mühle dreht, während die Propheten Säcke zur Mühle tragen." Darunter befindet sich eine erklärende Inschrift. Diese Szene will sagen, daß das Aite Testament nach der Lehre des heiligen Paulus sich ganz ins Neue auflösen mußte, und während es sich umbildete, 
wurde es gereinigt; die Spreu, die Unvollkommenheiten des alttestamentlichen Gesetzes ist verschwunden, geblieben ist nur das reine Mehl. Diese Szene war in ein Rundmedaillon komponiert und bildete noch mit drei anderen ein Fenster. Nach Sugers Bericht enthielten die drei Medaillons, mit einer einzigen Ausnahme, Darstellungen aus dem Leben und Lehren des Moses, dem noch ein zweites, ebenfalls mit vier Medaillons ausgestattetes Fenster, gewidmet war. Unmittelbar an die Gesetzesmühle schloß sich die symbolische Szene, wie von dem Gesichte des Moses der Schleier genommen wird. Das nächste Medaillon ist noch erhalten und stellt dar, wie das Kreuz aus der zum Triumphwagen erweiterten Arche herauswächst und vom Vater gehalten wird. Auf dem anderen Fenster ließ Suger aus der Mosesgeschichte anbringen: Moses im Binsenkörbchen, Moses vor dem brennenden Dornbusch, den Untergang der Ägypter im Roten Meer und endlich die Gesetzgebung auf dem Berge Sinai. Außerdem war noch ein Stammbaum Jesse dargestellt. Emile Mâle hat in seiner geistreichen Abhandlung über die französische Glasmalerei ${ }^{1}$ ) Saint-Denis als Ausgangspunkt aller französischen Glasmalerschulen des I2. und I3. Jahrhunderts bezeichnet. Woher aber stammt die Schule von Saint-Denis? Suger sagt, er habe die Glasmaler aus verschiedenen Nationen zusammenkommen lassen. Man dürfte unter anderen wohl an Deutschland denken, wenngleich der Begriff nationibus nicht im heutigen Sinn zu fassen ist. Für S. Denis bildeten Burgunder, Bewohner des Lyonnais ebenso diversas nationes, wie etwa Rheinländer oder Alamannen. Aber daß deutsche Meister an den Glasgemälden von S. Denis mit beschäftigt waren, kann als ebenso wahrscheinlich gelten, als die Mitarbeit von Künstlern aus Châlons-sur-Marne und Le Mans. Mâle sagt über die Künstler von S. Denis nur, daß sie auf den Schultern von hervorragenden Meistern der Technik gestanden sein müßten. Wir werden darauf später zurückkommen. Von S. Denis ging die Schule zunächst nach Chartres, wo die drei Fenster der Westfassade (Stammbaum, Kindheit und Passion) angefertigt wurden. Auch nach York in England schlug ein Strahl aus mit den Fenstern des Jahres I 59, wobei dahingestellt sein mag, ob die Yorker Fenster ein-

1) In André Michel, Histoire de l'art I, 2 S. $783 \mathrm{ff}$. 
fach Import aus S. Denis oder Chartres sind. Für Vendôme schufen die Künstler von S. Denis eine Kopie der Scheibe wie Gott Vater den Sohn trägt. Auch Le Mans weist nach Mâle eine große Verwandtschaft mit S. Denis auf. Über Chartres gehen die Traditionen von S. Denis nach Angers und Poitiers. Die Windeisen auf den Fenstern von Poitiers gehen noch gerade mitten durch die Fenster, während die Schule von Chartres die Windeisen mit den Medaillonkonturen zusammengehen läßt. Es wäre also möglich, daß die Schule von S. Denis direkt auf Poitiers gewirkt hat.

\section{Die deutschen Glasgemälde der späteren romanischen Schule.}

Oidtmann ${ }^{1}$ ) und Schmitz $^{2}$ ) stellen eine rheinische Gruppe von Glasgemälden zusammen, die aus der zweiten Hälfte des 12. und dem Anfang des r3. Jahrhunderts stammen. Dazu gehört ein kleines Rundbogenfenster in S. Segolena zu Metz, zwei solche Fenster von Peterslahr (jetzt in Bonn), eine Kreuzigungsgruppe im Kgl. Kunstgewerbemuseum zu Berlin und als Glanzpunkt die Glasgemälde von Cappenberg-Nassau. Als Hauptcharakteristikum dieser Gruppe wird vor allem der fein ausradierte Damast angegeben, der auf Hintergründen, Bordüren, Kreuzesstamm, Thron Gottes angebracht ist und in der Ausführung mit den Rugerus-Vorschriften über die Radiertechnik übereinstimmt. Die Kreuzigungsszene in S. Segolena steht am Anfang der genannten Gruppe, was wir allerdings nur mit der Einschränkung behaupten, daß uns nichts älteres erhalten ist. Sie stellt im üblichen Sinn Christus am Kreuze mit Maria und Johannes dar. Über dem Kreuz sind Sonne und Mond eingebleit. Nach Oidtmann haben wir in dieser Kreuzigungsgruppe echt deutsche Arbeit. Und doch besteht eine so innige Verwandtschaft mit den Glasmalereien in S. Denis, daß sie kaum zu übersehen ist. Der feine Damast kommt oftmals auf den Fenstern des Sugerus vor. Man betrachte den Rand und das Innere der zum Triumphwagen erweiterten Arche, sowie die Balken des aus der Arche wachsenden Kreuzes. Dazu kommt die merkwürdige

1) Rheinische Glasmalerei I, S. $70 \mathrm{ff}$. Dort sind auch die entsprechenden Abbildungen einzusehen.

2) Die Glasgemälde des Kgl. Kunstgewerbemuseums in Berlin, S. $6 \mathrm{ff}$. 


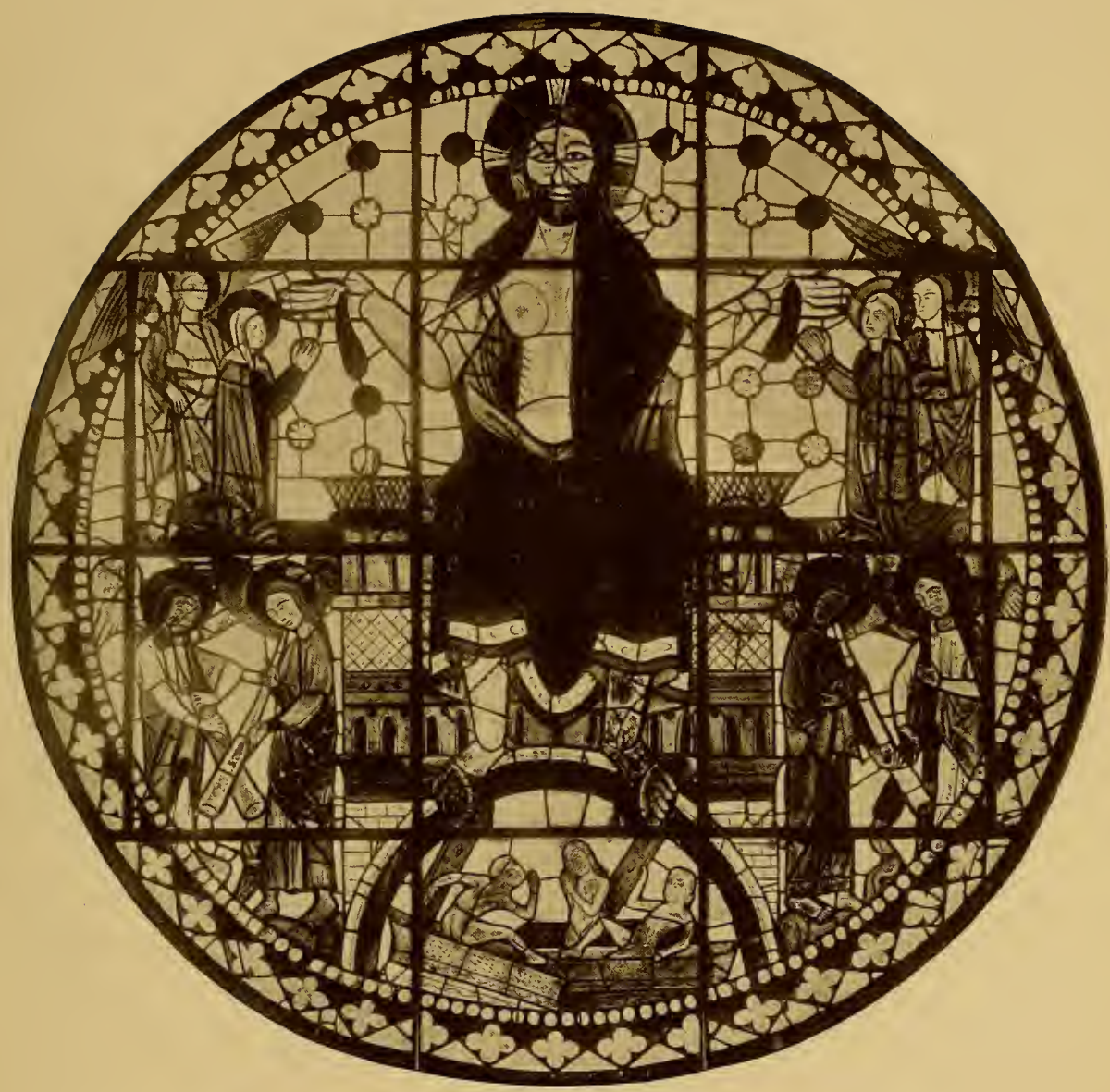

Glasgemälde in der Kirche zu Chateauroux. Anfang des I 3. Jahrhunderts. 

Führung des Schwarzlots, die Verlängerung des einen von zwei zusammenstoßenden Schenkels, was eine Rückerinnerung an die frühromanische Schule bedeutet. Ferner beachte man die eigentümliche Ikonographie. In Peterslahr finden wir den thronenden Vater zwischen den vier Symbolen der Evangelisten, was unverkennbar an die Rundscheibe von S. Denis erinnert, auf der das aus der Arche wachsende Kreuz dargestellt ist. Noch mehr. Die Cappenberger Fenster weisen einen Stammbaum auf, in dem Christus zwischen den sieben Gaben des hl. Geistes sitzt, ähnlich wie wir es auf dem Jessefenster in Chartres, ebenfalls einem Abkömmling der Schule von S. Denis, sehen. An S. Denis erinnern ferner die drei Mosesszenen, die in Cappenberg erhalten sind. Wir haben also in den Cappenberger Fragmenten Teile eines Zyklus, der nach Mâle lediglich in S. Denis vorkommt und wahrscheinlich den gelehrten Abt Sugerus selbst zum Urheber hat. Stil und Technik der skizzierten rheinischen Gruppe weisen also auf S. Denis. Wohl führt Schmitz zum Vergleiche eine Reihe von Miniaturen an, die in Deutschland entstanden sind, so das Evangeliar aus Hardehausen in Kassel, das Evangeliar des Mönches Heriman von Helmwardshausen an der Diemel, endlich das Fraternitätsbuch von Corvey bei Höxter. Allein bei der Stileinheit, die ebenso den Illuministen wie Glasmaler, wie überhaupt alle Insassen eines Klosters beherrschte, muß man diese Übereinstimmung als gemeinsame Stämme aus derselben Wurzel bezeichnen. S. Segolena steht, wie gesagt, am Anfang der Gruppe. Die Personifikation der auf dem Fenster dargestellten Sonne ist männlichen, die des Mondes, wie man deutlich aus dem Schleier sieht, weiblichen Geschlechts, was den französischen Worten le soleil und la lune entspricht, während auf deutschen Scheiben, wie wir später sehen werden, das Verhältnis umgekehrt ist, wobei die Möglichkeit offen bleibt, daß sol und luna dem Künstler vorschwebte. Die rheinische Gruppe, die mit S. Segolena in Metz, dem Übergangspunkt, beginnt, geht von der Schule S. Denis' aus und entfaltet am Rhein eine reiche und eigenartige Tätigkeit. Wie weit die von Suger zusammengerufenen Künstler deutsche Stilelemente mitgebracht haben und wie weit daher die Abwanderung nach dem Rhein eine Zurückleitung des Heimatlichen darstellt, ist nicht mehr zu er- 
mitteln. Schmitz weist endlich noch, mit Recht, auf die koloristische Verwandtschaft dieser Rheingruppe mit einigen Rundscheiben hin, der Simsonscheibe aus Alpirsbach und den zwei im Kgl. Kunstgewerbemuseum zu Berlin befindlichen Glasgemälden. Diese Scheiben sind jedoch wie einige im Germanischen Museum in Nürnberg (M. M. I-3) unseres Erachtens ebenfalls von Frankreich aus beeinflußt, wenn nicht direckt von dort importiert.

Was nun die einzelnen Glieder dieser rheinischen Gruppe betrifft, so hat sich der Meister der Cappenberger Fenster am höchsten und selbständigsten entfaltet. Oidtmann hat diese herrlichen Arbeiten um die Mitte der neunziger Jahre im Steinschen Schloß zu Nassau aufgefunden, restauriert und in der Zeitschrift für Christliche Kunst, später in seinem Werk „Die Rheinische Glasmalerei" veröffentlicht. Die Fenster sind in einem von Ranken gebildeten Saum eingerahmt, der in vielem an das Timotheusfester von Neuweiler, und an das Fenster zu Champ (Isère) erinnert. Auch in der Zeichnung des Schwarzlots an den Knieen der sitzenden Figuren des Jessefensters wiederholen sich leise, unseres Erachtens, Motive des Meisters, der das Timotheusfenster geschaffen hat. Auf einem der Cappenberger Fenster, das den brennenden Dornbusch darstellt, ist das höchst interessante Brustbild des Stifters Gerlach, der nach den Attributen, die er trägt, Maler war; ob er auch Glasmaler und daher Verfertiger der Fenster war, erscheint sehr wahrscheinlich. Da das Brustbild ein unverkennbares Streben nach Ähnlichkeit, nach Selbstporträtierung aufweist, ist Gerlach, wenn wir in ihm tatsächlich den Verfertiger der Cappenberger Fenster vor uns haben, seiner Kleidung nach (weißer Habit und schwarzer Mantel) Prämonstratenser, was zu Oidtmanns Vermutung, die Glasgemälde würden der ehemaligen Prämonstratenserabtei Arnstein an der Lahn entstammen, sehr gut passen würde. Der Kopf ist ein prachtvolles Beispiel, wie sich in der Glasmalerei innerhalb der Grenzen der Stilisierung das Proträt verwenden läßt.

Wir haben im vorhergehenden Kapitel gesehen, wie die von S. Denis nach Chartres berufenen Künstler an ihrem neuen Wirkungsort auf starke byzantinische Kunstwellen stoßen. Dasselbe gilt von Le Mans, überhaupt der gesamten Maine. Auch 


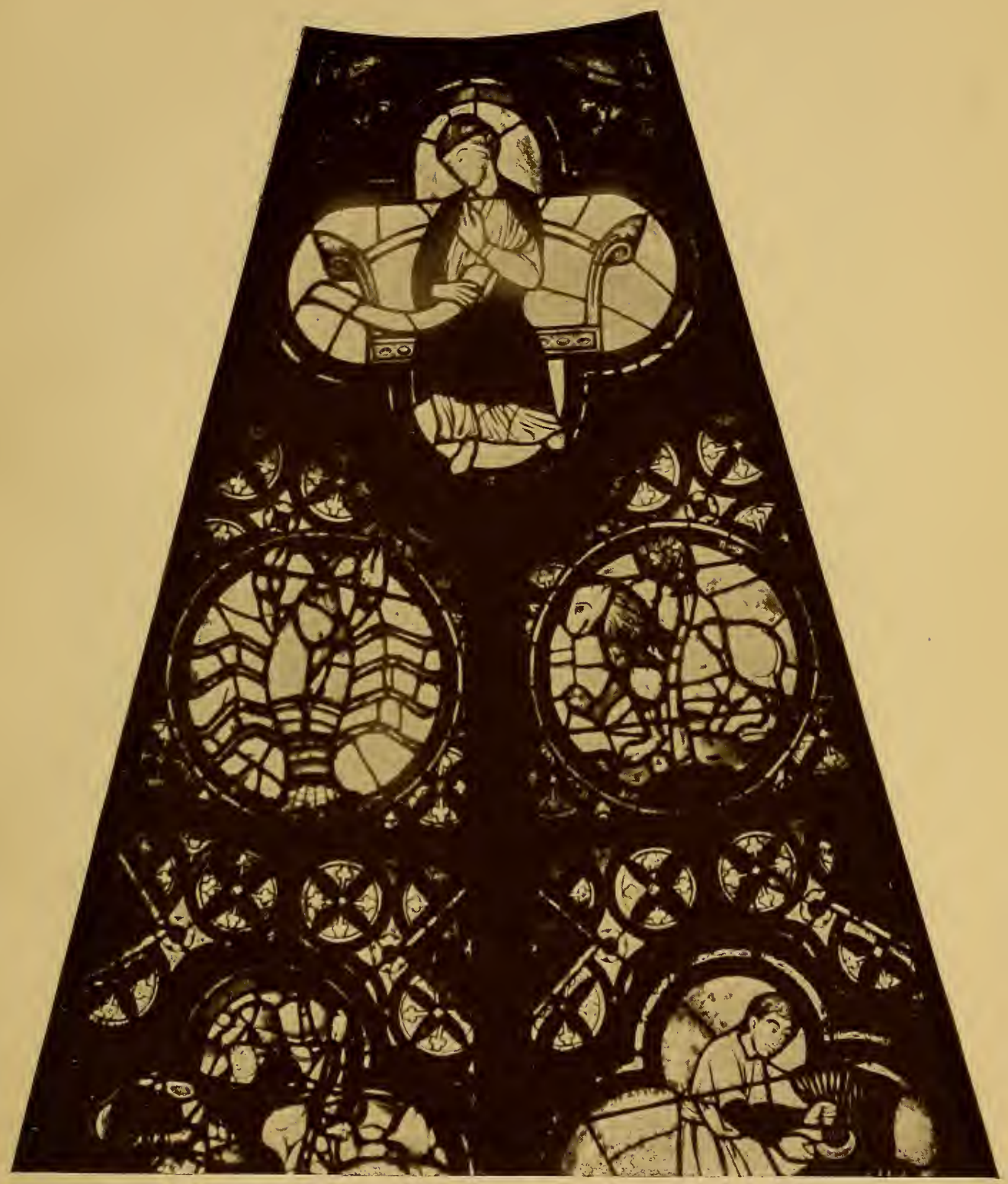

Detail aus der großen Rose (mit Monatsbildern) in der Kathedrale zu Lyon. I3. Jahrhundert. 

in Deutschland ist die rheinische Gruppe, die sich aus den Anregungen von $\mathrm{S}$. Denis zu einem eigenen Stil entwickelt hat, sehr rasch den byzantinischen Einflüssen erlegen. Unseres Erachtens kamen diese Einflüsse über Frankreich; denn auf dem Donauweg oder über die Alpen sind sie nicht nach Deutschland gedrungen, da die süd- und ostdeutsche Glasmalerei der ersten Hälfte des I 3. Jahrhunderts völlig darniederliegt und also keinesfalls in führender Eigenschaft Einflüsse vermitteln konnte. Schmitz stellt Soest in den Mittelpunkt dieser byzantinisierenden Schule in Nordwestdeutschland. Die Fenster aus Lohne, die sich jetzt im Münsterer Landesmuseum befinden, stellen einen Übergang von der rheinischen Schule zu den neuen Stilelementen dar. Noch sind die Schwarzlotkonturen, die als Ausdruck der Gewandfalten dienen sellen, in zeichnerischer Manier gehalten; sie endigen stets in verdünntem meist umgebogenen, einem Schwänzchen ähnlichen Strich. Dagegen verraten sie freiere Linienführung und größere Annäherung an die Wirklichkeit. Die Art, wie der Künstler an den unteren Gewandteilen das Flattern der Kleider andeutet, entspricht noch genau dem System, das der Meister der Cappenbergerfenster auf dem Flügel mit der Gesetzgebung auf dem Berge Sinai anwendet. Auch die Scheibe im Darmstädter Museum gehört noch in diesen Übergangsstil.

Da ändert sich plötzlich die Lage. Im Jahre I237 wurde der Dom zu Bamberg eingeweiht. Wer immer von weltlichen und geistlichen Fürsten konnte, nahm an diesen Festen teil. Auch Bischof Engelhard von Naumburg war nach der fränkischen Bischofstadt gepilgert. In seiner Residenz wurde eben an dem prachtvollen Dome gebaut, einem Meisterwerk des spätromanischen Stils. Nach der Rückkehr des Bischofs wurde mit einem Schlage der romanische Stil verlassen und der durch französischen Einfluß in Bamberg bereits zu einer gewissen Blüte gediehene gotische Stil angewandt. In diese letzten fünf Jahre Naumburger Bautätigkeit fallen auch die daselbst noch zahlreich erhaltenen Glasgemälde (Abb. 5). Sie sind die ersten und zugleich kräftigsten Äußerungen des von der französischen Portalund Reliefplastik beeinflußten Stils in Deutschland. Der Glasmaler deutet die Falten nicht mehr in zeichnerischem Sinne an, er führt sie aus. Das Schwarzlot ist nicht mehr allein Kontur, 
es wird in hervorragendem Grad Angabe von Licht und Schatten. Die in Frankreich sehr beliebte Medaillonform, eigentlich als

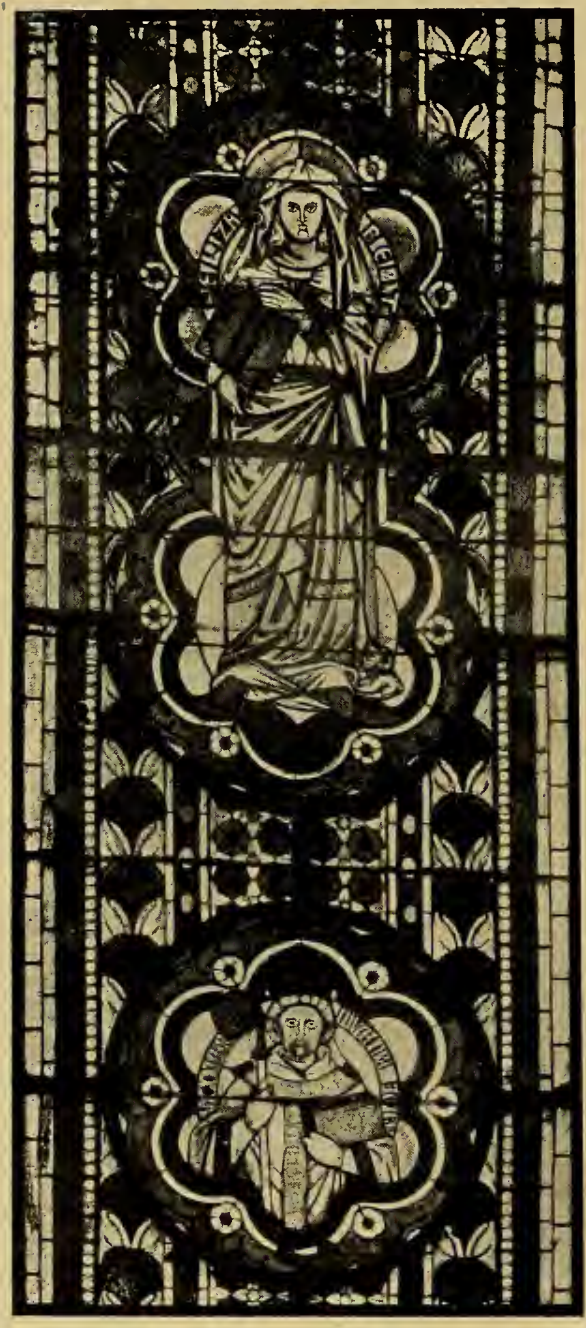

Abb. 5. Detail aus einem Fenster des Westchors zu Naumburg. Mitte des I 3. Jahrhunderts.
Einrahmung von Szenen bestimmt, hat nunmehr auch die Darstellung der Einzelfigur ergriffen und sich auf die verschiedensten Abwandlungen paßförmiger Gebilde erweitert. Auch die Farbenskala ist um ein beträchtliches gewachsen. So lassen sich an den Naumburger Fenstern beiläufig fünf verschiedene Grün, drei Violett feststellen. Das paßförmige Medaillonsystem wird nunmehr so beliebt, daß es selbst da Verwendung findet, wo noch die alte Fenstereinteilung herrscht, wie in den Fenstern von S. Kunibert in Köln mit der Darstellung der hl. Cäcilia Katharina, Kordula, Ursula. Die von Frankreich importierte Paßform ist seit za. I240 eine so strenge Mode, daß sie der Künstler der genannten Fenster von S. Kunibert verwendet,obwohlsienamentlich auf dem Kordula- und Ursulafensters nichts weniger als gut aussieht. Im übrigen hat die deutsche Empfindung trotz des modischen Beiwerks in den Fenstern von S. Kuni-
vertieft, so daß man von dem bert den Ausdruck außerordentlich vertieft, so daß man von dem
französischen Einfluß nicht mehr viel merkt, und daß man mit Recht von einer westfälisch-rheinischen Schule um I 245 sprechen 


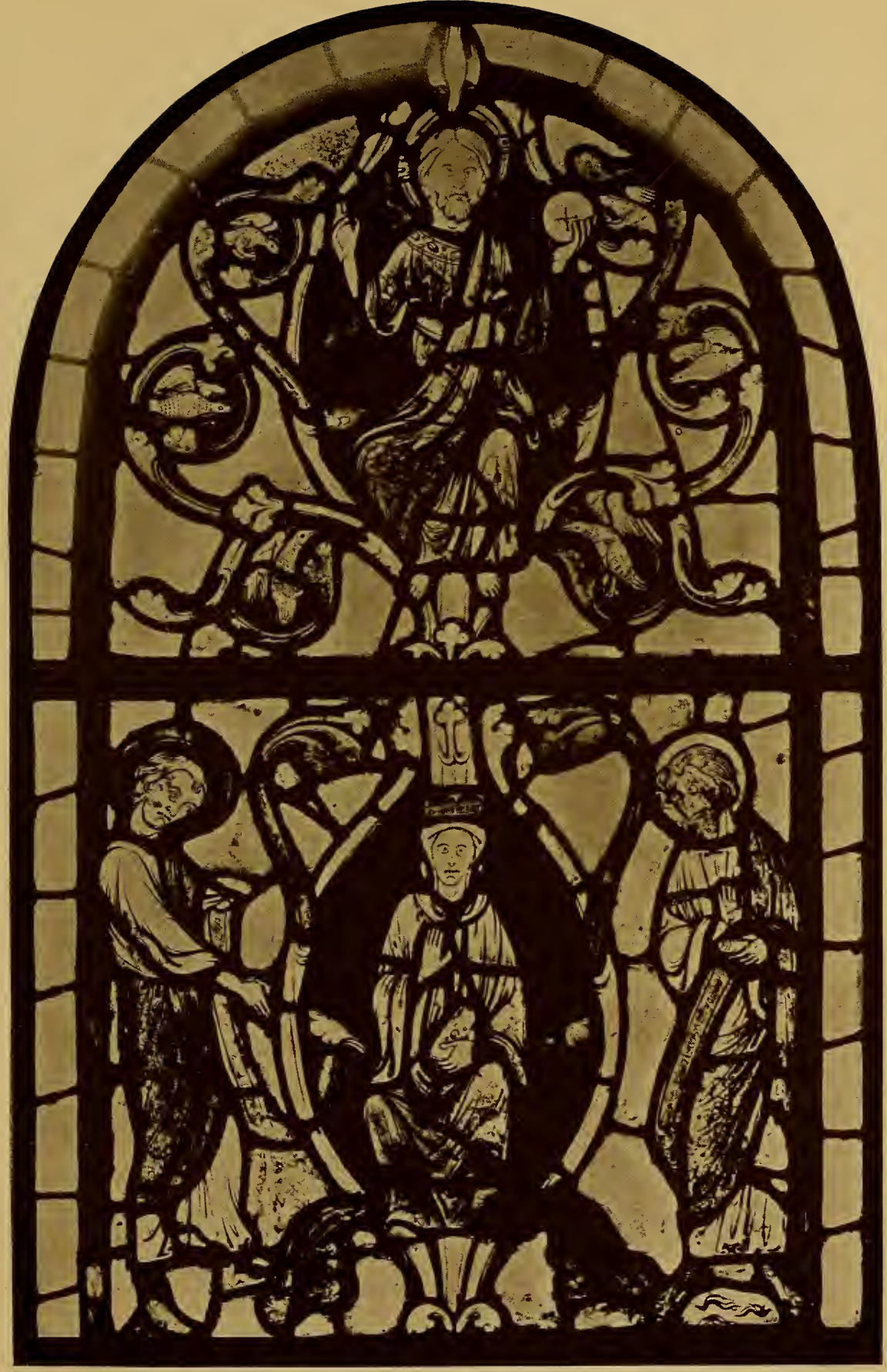

Glasgemälde in Varennes. I 3. Jahrhundert. 

kann, deren Hauptleistung eben in den Standfiguren von Kunibert $\mathrm{zu}$ erblicken ist. Im Süden wird Regensburg in der 2. Hälfte des 13. Jahrhunderts Sitz eines weithin arbeitenden Exports, soweit der eigene Bedarf befriedigt ist. Im Jahre 1275 wurde am Regensburger Dom der Bau des Chors in Angriff genommen und aus der sich daran anschließenden Bauperiode stammen eine Reihe von Glasgemälden, die im Stil der Naumburger Fenster gehalten sind. Ein jeder Flügel enthält in einer länglich gezogenen Paßform eine Heiligenfigur. Von Regensburg aus wanderte um I 290 ein Glasmaler Eberhard nach Heiligenkreuz im Wiener Wald, wo in den folgenden Jahren die Babenberger Fenster entstanden. In zwei Fenstern sind die Bildnisse des Stifters, Georg Leopolds III., seiner Gemahlin und seiner sechs Söhnen dargestellt. Für diese mit den Chorfenstern in Naumburg zum erstenmal greifbare Schule der länglichen Paßformen ist auch charakteristisch, daß sie die lange, bis dahin unbestritten herrschende, stilisierte Ranke in das natürliche Blatt aufgelöst hat. In die Regensburger Gruppe gehören verschiedene auf österreichischem Boden entstandene Glasgemälde, so die jetzt im Germanischen Museum zu Nürnberg befindlichen Tafeln aus Graz (Katalog Nr. I6-20).

\section{Das Auftreten von Architekturgliedern in der Glasmalerei.}

Bereits auf den Fenstern, die unmittelbar nach S. Denis von den eingewanderten Künstlern in Chartres angefertigt worden waren, finden sich zahlreiche Architekturteile, die in die Rundmedaillons hineinkomponiert sind. Nicht daß allen solchen Szenen, bei welchen ein städtischer Hintergrund verlangt ist, ausgedehntes Häuserr- und Bauformenmaterial zuteil wird, auch andere Darstellungen bekommen nicht selten Architekturteile, die keineswegs von der Szene selbst gefordert werden. Könige sitzen unter säulengetragenen Rundbogen, Maria sogar (bei der Anbetung der Magier) in einem leicht vertieft gezeichneten Raum. Diese Beiziehung des Architektonischen war in S. Denis noch nicht bekannt. Sie drang durch den byzantinischen Geist, der in der Maine und den angrenzenden Gebieten herrschte, in die Glasmalerei ein. In Deutschland gelangt die Sitte erst in dem 
zweiten Viertel des dreizehnten Jahrhunderts zur Anwendung. Wo von Frankreich unbeeinflußte Lokaltraditionen fortleben, kommt sie noch später in Übung. $Z \mathbf{u}$ den ältesten erhaltenen Arbeiten mit Architektur gehören die Prophetenscheiben aus Lohne, von denen wir im vorigen Kapitel gesprochen haben. Mit großer Ausführlichkeit tritt die neue Mode auf den Legendenfenstern der rheinisch-westfälischen Gruppe auf, insbesondere auf

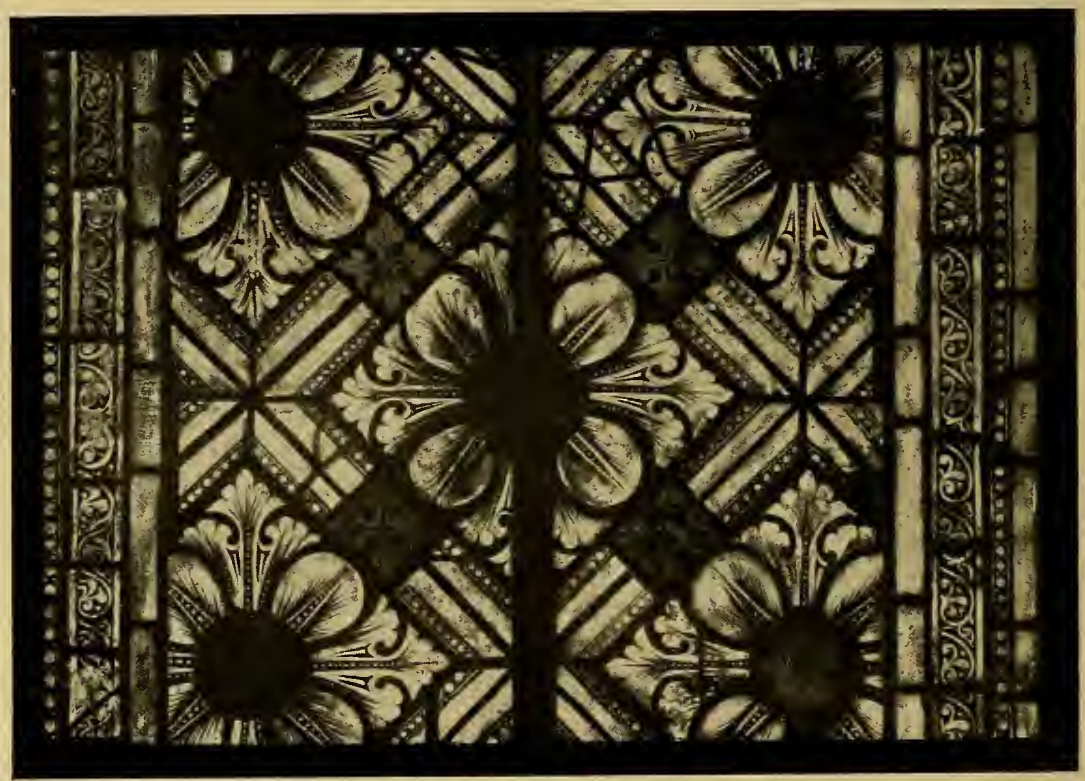

Abb. 6. Detail aus einem spätromanischen Fenster der Elisabethkirche zu Marburg. Zweite Hälfte des I3. Jahrhunderts.

den von französischem Geist beeinflußten Fenstern mit der Kunibert- und Klemenslegende in S. Kunibert zu Köln, und den Fenstern der Maternianikirche zu Bücken an der Weser. Ein lehrreiches Beispiel bieten drei prachtvolle Scheiben im Historischen Museum zu Frankfurt (Taf. 12), die Geburt, Geißelung und Auferstehung darstellend. Christus, der an die Geißelsäule gebunden ist, steht unter einem Bogen. Rechts und links tragen zwei mit zierlichen Laubkapitälen versehene, schlanke Säulen den Bogen. Hier ist also die Langpaßform mit Architekturgliedern verbunden. Dieser Sitte begegnen wir seit dem zweiten Drittel 


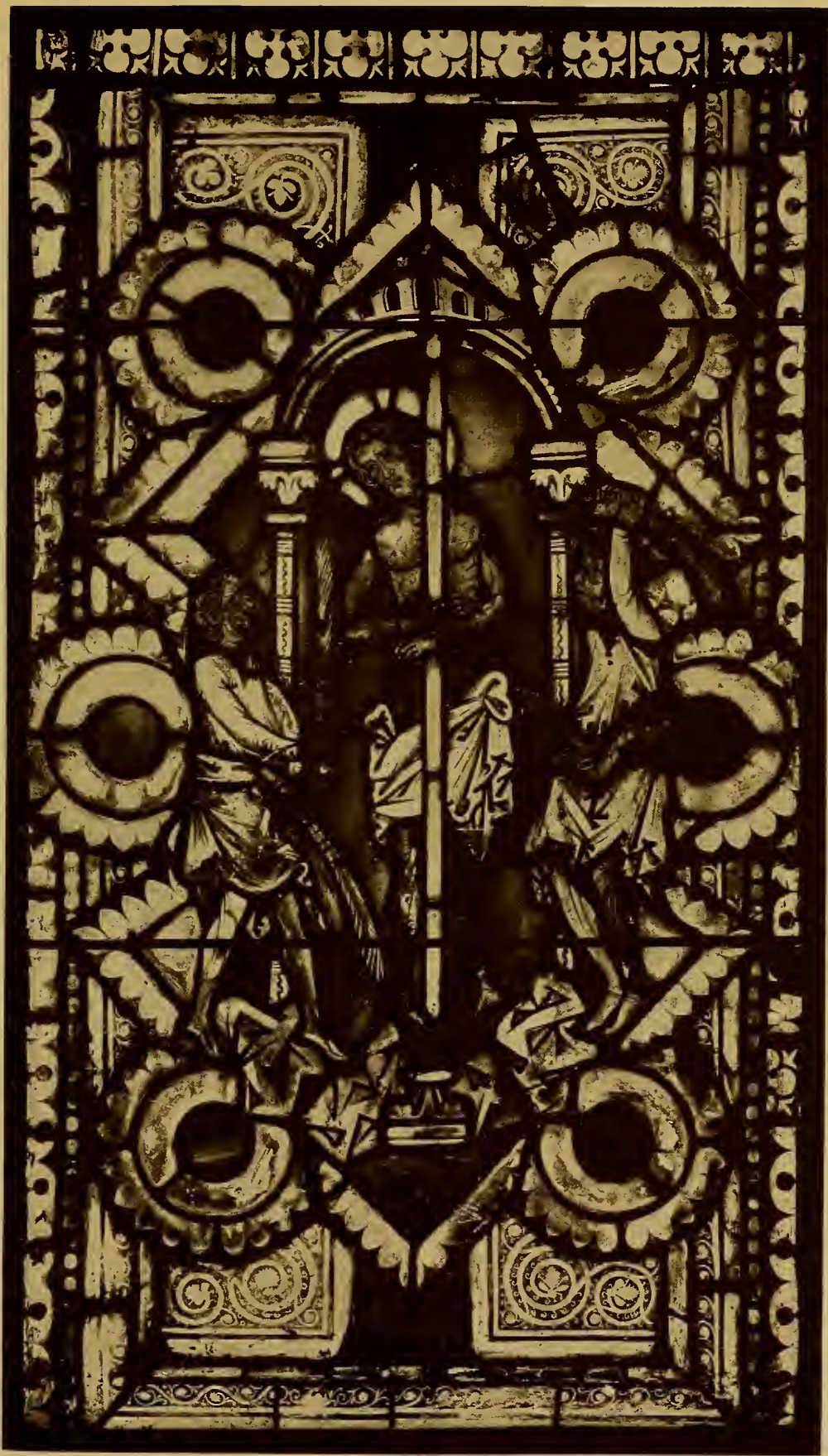

Glasscheibe im Historischen Museum zu Frankfurt. Drittes Viertel des I 3. Jahrhunderts. 

des I 3. Jahrhunderts zu wiederholten Malen. In der Ausführung sind die Frankfurter Scheiben mit den Naumburger Fenstern verwandt. Der Schwarzlotauftrag auf dem Lendentuch und den Gewändern Marias erscheint der Naumburger Formsprache so

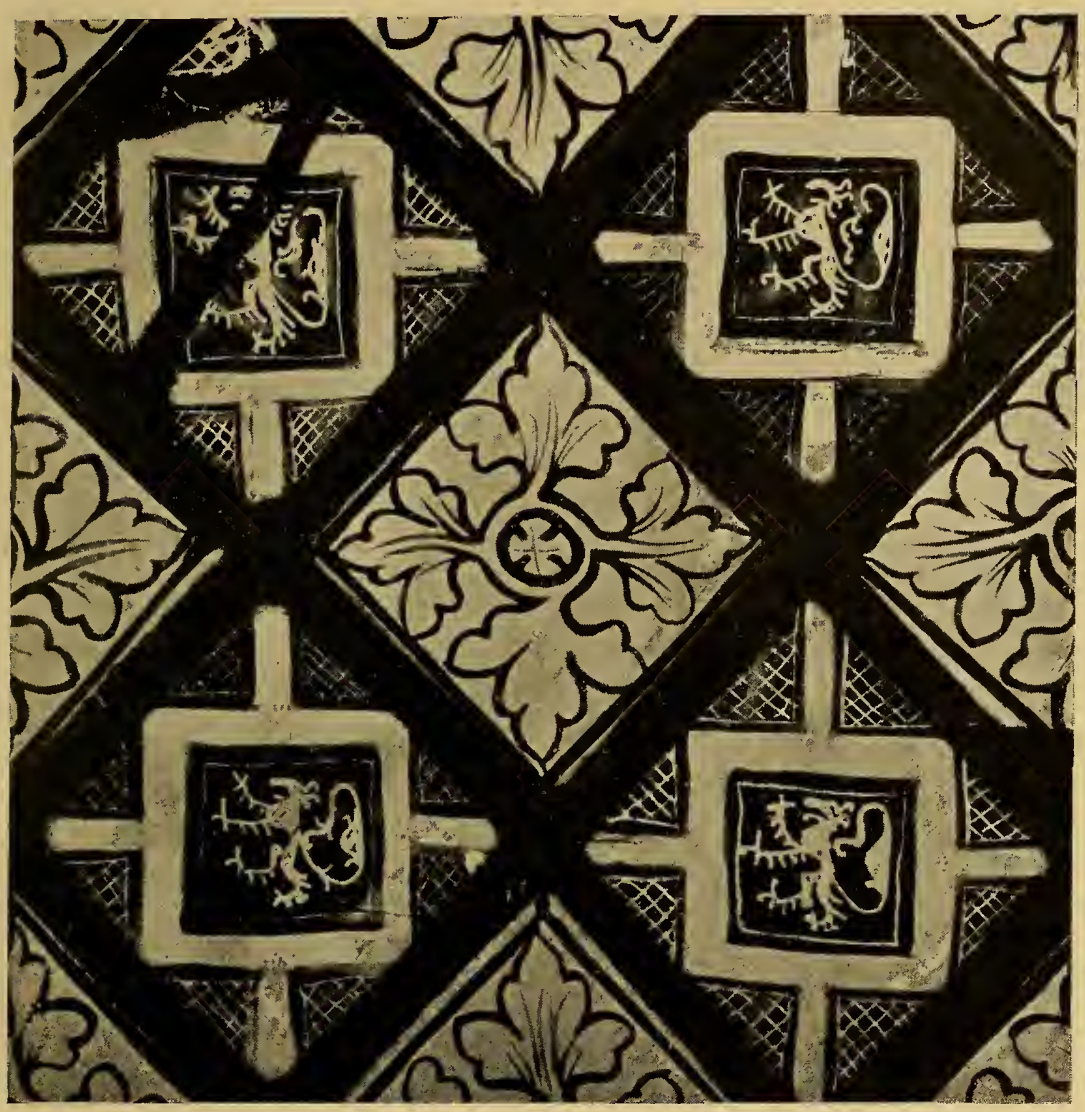

Abb. 7. Detail aus einem Flügel in dem Archiv der Elisabethkirche zu Marburg.

ähnlich, daß man versucht ist, die Frankfurter Scheiben dem Künstlerkreis der Naumburger Domfenster zuzuschreiben.

Eine eigene Gruppe bilden die Glasgemälde der Elisabethkirche zu Marburg (Abb. 6, 7). Der Bau dieser Kirche wurde im Jahre I235 begonnen und wie die, um diese Zeit noch unvollendeten Bauglieder des Naumburger Domes, in frühgotischem Stil ausgeführt. Haseloff weist darauf hin, daß die ältere Gruppe der 
Marburger Glasgemälde im Gegensatz zu dem französischen Charakter des Baues, noch völlig ungotisch sei, vielmehr dem eigentümlichen Stil der deutschen Malerei und Plastik des frühen i 3. Jahrhunderts angehöre, die durch den engen Anschluß an byzantinische Vorbilder und besonders reiche Ausbildung des Faltenentwurfs charakterisiert werde. Die Heimat dieses Stils, so sagt Haseloff, sind die thüringisch-sächsischen Lande. Die bekannten Werke der Malerei sind die Illustrationen des Psalters des Landgrafen Hermann von Thüringen und des Gebetbuches seiner Schwiegertochter, der hl. Elisabeth. $\mathrm{Zu}$ den ältesten Werken der Marburger Glasmalerei gehören einige Standfiguren und vier Legendenfenster mit Szenen aus der Schöpfungsgeschichte und aus dem Leben der hl. Elisabeth. Auf diesen Glasgemälden offenbart sich der architektonische Gedanke der französischen Glasmalereien am mächtigsten. Diese allgemeine Anregung sowie die Anlehnung an byzantinische Vorbilder haben die sächsisch-thüringischen Glasmaler gleichmäßig wie alle anderen Schulen des I3. Jahrhunderts von Frankreich aus-bekommen, dagegen haben sie sich in der Ausführung und insbesondere im Detail vielleicht am selbständigsten von allen deutschen Schulen entwickelt. Mit der rheinisch-westfälischen Gruppe haben die Marburger Fenster die Rankenmotive gemein. In den Standfigurenfenstern wird dieses Prinzip zugedrängt und durch Mäanderund Damaststreifen ersetzt, wie es zum erstenmal auf den Glasmalereien von Lohne zum Ausdruck kommt.

Im Südosten Deutschlands, den altbayrischen Stammlanden, scheint die Glasmalerei ziemlich rasch von der Blüte abgefallen zu sein, die sie mit der Tegernseer Schule des I I. und I2. Jahrhunderts erreicht hat. Das bayrische Nationalmuseum besitzt Reste eines Glasgemäldezyklus, der angeblich aus dem Kloster Tegernsee stammt. Wir erkennen auf ihm einen in langer handwerklichen Tradition erstarkten, ohne fremde Einflüsse erfrischten Provinzialismus. Merkwürdig, wie sicher auf diesen Glasgemälden die Technik gehandhabt ist, die für den armseligen Formenschatz mehr wie entschädigt! Diese Tradition erstreckt sich noch weit in das Zeitalter der Frühgotik hinein. Gegen Neuerungen ist die bayrische Schule bedächtig. Man vergleiche z. B. den Glasgemäldezyklus, der aus dem Kloster Seligen- 
thal bei Landshut stammt und sich jetzt im Bayrischen Nationalmuseum $\mathrm{zu} \cdot$ München befindet (Abb. 8).

Straßburg und Freiburg sind bis zur Zeit der Spätgotik die beiden wichtigsten Zentren der südwestdeutschen Glasmalerei geblieben. Was den heutigen Bestand an altem Material in Straßburg betrifft, so bietet er für die kunstgeschichtliche Erfassung

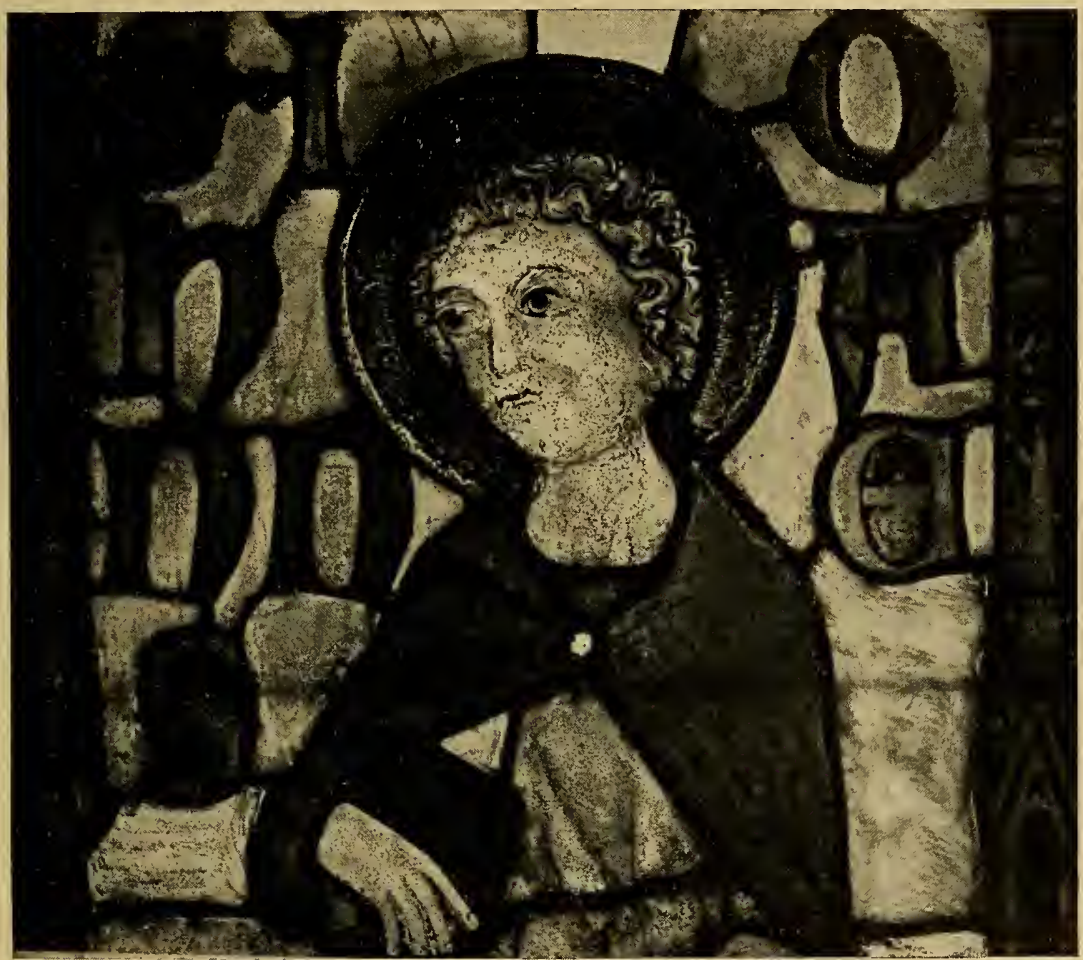

Abb. 8. Detail aus einem Zyklus des Klosters Seligenthal bei Landshut, jetzt im Bayrischen Nationalmuseum zu München. Um I330. Landshuter Schule.

einige Schwierigkeit, da in der zweiten Hälfte des vorigen Jahrhunderts eine entscheidende Änderung in der Anordnung und eine durchgreifende "Restauration “ einen heillosen Wirrwarr geschaffen haben. Das romanische Münster war im Jahr I 75 ein Raub der Flammen geworden, und genau ein Jahrhundert später setzte jene gewaltige Bautätigkeit ein, die den ersten ganz gotischen Bau auf deutschem Boden schuf. Aus der Zeit bis nach 
Mitte des I3. Jahrhunderts sind noch verschiedene Reste erhalten. $\mathrm{Zu}$ den ältesten, aus dem romanischen Bau übernommenen Arbeiten gehören die Glasgemälde, die im südlichen Querschiffarm ihren Platz haben. Es sind drei das salomonische Urteil darstellende Szenen in dem bekannten Stil der französischen Medaillonfenster. An S. Denis erinnert der Damastgrund, soweit er noch alt ist, an Chartres die Gruppierung und Ausführung der Szenen. An Chartres gemahnen ferner die beiden Gruppen David und Salomo, Salomo und die Königin von Saba. Die zwei von einer Säule getragenen Rundbögen, unter denen die königlichen Personen stehen, bzw. sitzen, sind zum erstenmal auf den Fenstern zu Chartres verwendet worden. Von dem Fenster mit dem Urteil Salomos abgesehen, hat die Straßburger Schule durchweg an der Einzelfigur festgehalten und zwar in streng zeichnerischer Fassung. Von irgend welcher Neigung zu Paßformen hat sich nichts bemerkbar gemacht. Am vollständigsten ist das Christophorusfenster im südlichen Querhaus erhalten. Es hat allerdings durch einen "Restaurator" argen Schaden genommen. Da dieser nach der Zahl der reparierten Stücke bezahlt wurde, zerschnitt er die alten Stücke in viele Teile. Das Fenster gehört in die Zeit um I 240 und damit noch der alten Münsterperiode an. Aus dieser Epoche sind außerdem erhalten eine Verkündigung, ein Engel, jetzt in der Krypta, sowie die beiden Fensterrosen, die eine gewisse Verwandtschaft mit dem hortus deliciarum der Herrad von Landsberg aufweiser. Um diese Zeit muß auch jene Gruppe entstanden sein, die sich durch Anwendung eines von kräftigen Säulen getragenen Rundbogens charakterisiert, ferner die alten Teile der Matthias- und Bartholomäusscheiben im südlichen Querhaus, der beiden Johannes im nördlichen Querhaus, des Königs Heinrich des H1. in der Apsis. Den eigenartigsten Schmuck des Straßburger Münsters bildet die in der romanischen Zeit begonnene und während der gotischen Zeit weitergeführte Reihe der deutschen Könige und Kaiser. Dehio hat gemeint, daß diese Königsreihe als eine Manifestation der Straßburger Bürgerschaft gegen die bei Oberhausbergen im Jahre 1262 gebrochene bischöfliche Macht zu erkennen sei. Wir können nicht glauben, daß der Bischof von Straßburg ausgerechnet das ihm am eigensten gebliebene kirchliche Gebäude der Bürgerschaft 
zur Verfügung stellte, um sich darin verspotten zu lassen. Daß in so früher Zeit weltliche Personen auf Glasgemälden dargestellt wurden, ist ohne $Z$ weifel etwas sehr Seltenes und jedenfalls durch einen besonderen Anlaß hervorgerufen. Wir kennen eine so vollständige Serie nur in Reims, wo wir die französischen Könige in langer Reihe dargestellt finden ${ }^{\mathbf{1}}$ ). Allein da sie alle in der Szene wiedergegeben sind, wie sie eben mit Ö1 gesalbt werden, so ist die Ursache der Darstellung als Beziehung auf die Krönungsstadt Reims von vornherein klar. Mâle erblickt darin den Hinweis, daß die mit Ö1 gesalbten Könige nicht mehr gewöhnliche Menschen seien, sondern einen Teil der göttlichen Weltregierung zum Ausdruck brächten. Wir bezweifeln, ob rein weltliche und gar noch vom bischöflichen Standpunkt so wenig ideale Gründe die Schaffung dieser eigenartigen Königsserie veranlaßt haben. Aus der älteren Reihe ist nicht mehr viel erhalten. Die Figur König Heinrichs I., der Rumpf Friedrichs II., der Kopf Ottos I., Teile des Königs Heinrich II. des Heiligen, sowie der Torso mit Kinderfigur, die jetzt in das Fenster des sogen. Conrads und Heinrichs III. eingefügt sind. Nach dem Brande von 1298 und leider auch im I9. Jahrhundert wurden diese alten Teile neu montiert, so daß jetzt altes und neues, wie Karten untereinander gemischt ist. Jedenfalls gehören die alten Teile der spätromanischen Bauperiode an. Hans Kurze hat darauf hingewiesen, daß die Köpfe dieser älteren Serie über dem Nimbus mit einem Halbkreis versehen sind, wie an den beiden einzigen alten Köpfen, dem des heiligen Laurentius und des Königs Heinrich I. beobachtet werden kann. Außerdem macht Kunze ${ }^{2}$ ) in hohem Grade wahrscheinlich, daß zu der älteren Königsreihe auch noch ein Phrophetenzyklus gehörte, von dem sich ein von Kunze zum erstenmal publiziertes Stück erhalten hat. Es stellt den Propheten Ezechiel dar und stimmt in Maßen und Ausführung mit dem Königszyklus völlig überein; zu dem im südlichen Seitenschiff als Gegenstück zu der Königsserie des nördlichen Seiten-

1) Fischer, Königsdarstellungen auf romanischen und frühgotischen Glasgemälden. Zeitschr. f. alte u. neue Glasmalerei, Jahrgang I913, S. 73 ff. Die in Köln (Hochschiffenster des Doms) dargestellten Könige sind Repräsentanten der jüdischen Könige und darum in den religiösen Symbolismus einzubeziehen.

2) Straßburger Münsterblätter I 9 I 3 . 
schiffs hat nach Kunze auch der Rumpf des heute mit dem Kopf des Henricus Babinbergensis versehenen Figur gehört, die den König David darstellte. Der Bestand an romanischen Glasmalereien im Straßburger Münster ist also nicht groß, aber er reicht hin, um zu beweisen, daß auch die Straßburger Schule zweimal enge Verwandtschaften mit Frankreich, das eine Mal mit S. Denis, das andere Mal mit Chartres aufweist. Je mehr sie sich dem Ende der romanischen Periode nähert, desto selbständiger wird sie und betont, vielleicht am stärksten von allen deutschen Schulen, den monumentalen zeichnerischen Charakter der Glasmalerei. Darin liegt ihre Eigenart, die sie auch beibehielt als seit dem Jahre I275 und seit dem Brande des Jahres 1298 die gotische Baubewegung mit Macht einsetzte.

\section{Die Glasmalerei während des Zeitalters der Frühgotik.}

Um die Wende des I3. Jahrhunderts taucht plötzlich eine Gruppe von Glasmalereien auf, die durch ihre eigenartige Architektur ein gemeinsames Band umschlingt. Es ist ein mit Krabben versehener Kielbogen, der auf zierlichen Säulchen ruht und vor einer Fensterbank in eine Kreuzblume endigt. Diese Fensterbank konnte ich mir nie recht erklären, da sie keinen rechten Sinn zu haben schien. Betrachten wir aber den Psalter Ludwigs des Heiligen, der ca. I 260 entstanden ist, so erhalten wir hinreichend Licht, um diese dunklen Punkte zu erfassen (s. Abb. 9). In der genannten Handschrift finden sich ca. Ioo Szenen aus dem Alten Testament, die fast sämtlich unter die gleiche Architekturbekrönung komponiert sind. Diese Architektur besteht in der Hauptsache aus zwei wimpergartigen Bögen, die an den Rändern von zwei Halbsäulen und in der Mitte von einer sehr dünnen Säule getragen werden. Jeder Bogen teilt sich in zwei Dreipaßbögen, über denen eine Fensterrose steht. Die beiden durch eine Fiale von einander getrennten Hauptbögen heben sich von einem Hintergrund ab, der das Dach, die Hochschiffwand und Strebepfeiler eines kirchlichen Gebäudes darstellt. Kein Zweifel, dieses Architektursystem ist aus der Portalskulptur hervorgegangen, indem der Künstler seinen Standpunkt vor dem Seitenportal eines Domes dachte. Der Psalter Ludwigs des 


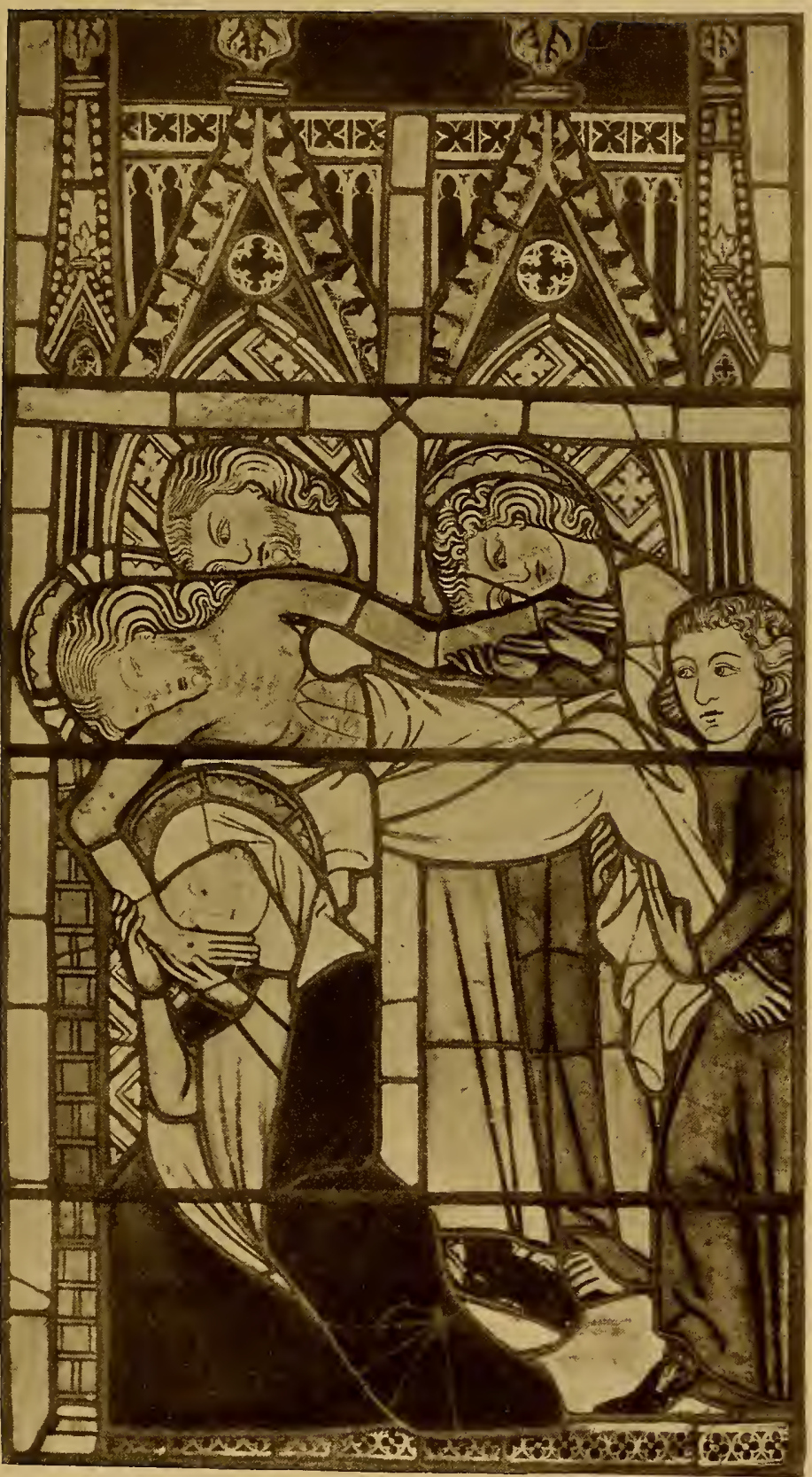

Flügel aus einem Glasgemälde in Schloß Heiligenberg. Gegen I 330. Nach einer Photographie von Frl. Dr. Hertha Wienecke. 

Heiligen ist gleichzeitig mit der Entwicklung der französischen Hochgotik entstanden, so daß wir wohl in dieser Handschrift die erste Verwendung des genannten Architektursystems sehen dürfen. Es wurde rasch sehr beliebt, drang in die französische und mit der Jahrhundertwende in die deutsche Glasmalerei ein. Insbesondere die Schweiz, der

Oberrhein, Schwaben, aber auch Köln nahmen die neue Mode mit Begeisterung auf. In Deutschland war die Erinnerung an die Entstehung des Systems rasch vergessen, und es entstehen Gebilde, die das Architektonische um das Lebenswahre verkürzen und einen einfachenRahmen übrig lassen, wie z. B. auf den Fenstern zu Blumenstein (Kant. Bern), Köniz (Kanton Bern), Kappel, Eßlingen, Köln (Kunstgewerbe-

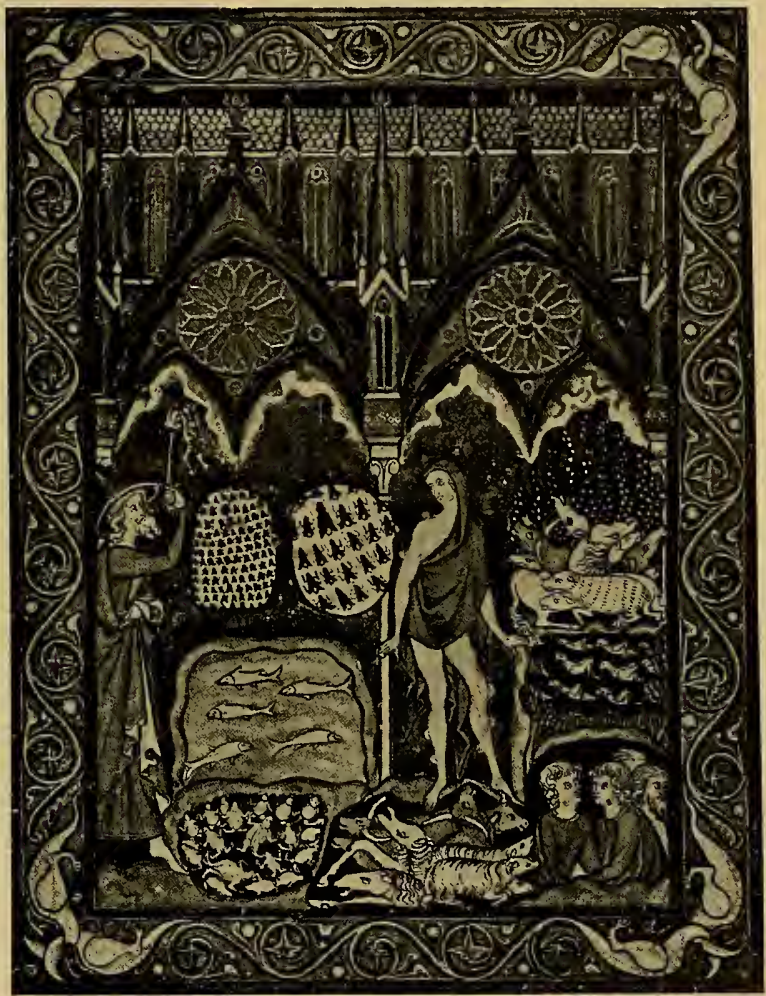

Abb. 9. Die ägyptischen Plagen. Miniaturblatt aus dem Psalter Ludwigs des Heiligen. Ms. lat. der Bibliothèque Nationale Paris. Um 1260. museum),Freiburg

i. B. Konstanz hebt sich mit den Fenstern von Oberkirch bei Frauenfeld, einigen Scheiben in dem Großherzoglichen Museum zu Karlsruhe und den Fenstern' in der Schloßkapelle auf dem Heiligenberg (Tafel I3, I4) als eigene Schule ab. Sie wird durch die eigentümlichen Kleeblättchen, die an Stelle von Krabben die Bögen besetzen, durch helle Töne 


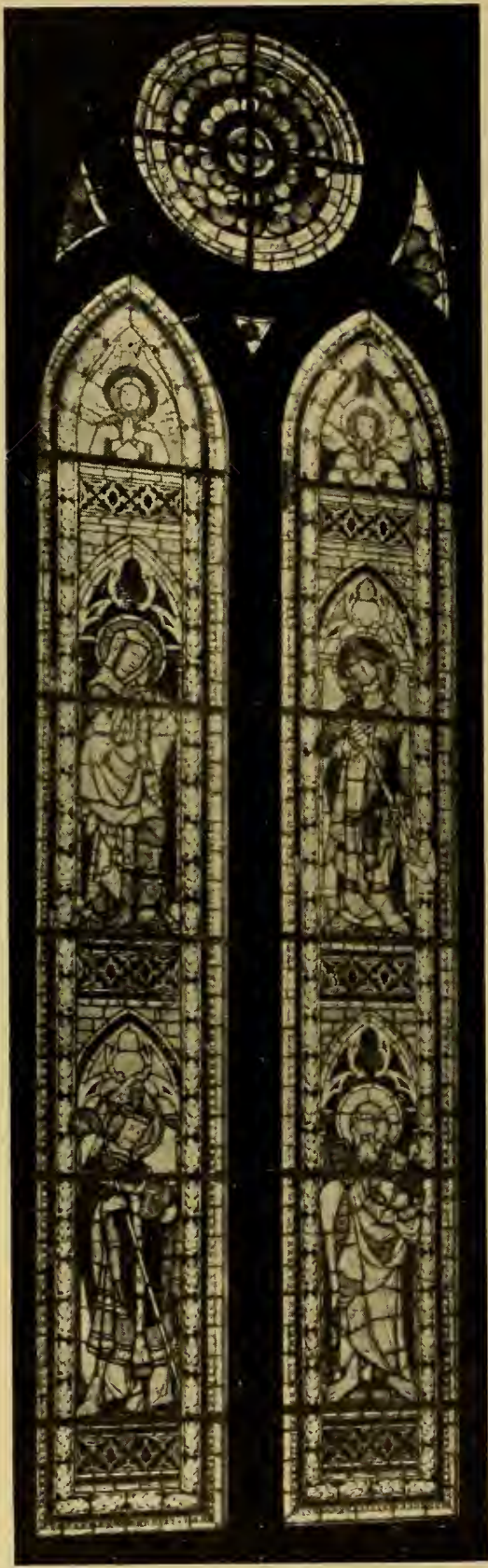

Abb. Io. Standfigurenfenster in der Elisabethkirche zu Marburg. Anfang des 14. Jahrh. charakterisiert. Ein im gleichen Stil hergestelltes Fenster befindet sich heute im Freiburger Münster und soll nach Geiges aus Konstanz stammen. Die Konstanzer Schule scheint im dortigen Dominikanerkloster ihren Sitz gehabt zu haben ${ }^{1}$ ). Übrigens ist $\mathrm{zu}$ beachten: Je weiter die französische Architekturmode nach Osten dringt, desto mehr verliert sie den horizontalen Charakter der französischen Gotik und macht sich den vertikalen Charakter der deutschen Gotik zu eigen. Darum verschwindet mehr und mehr die Rose aus den Baldachinen, die in französischen Arbeiten, z. B. in den Riches heures du duc de Berry stets in Übung blieb. Die Verteilung der einzelnen Szenen auf ein ganzes Fenster findet sich schon seit Anfang des I4. Jahrhunderts, am frühesten in Köln, später in der Freiburger und Konstanzer Schule.

Den ganzen Reichtum gotischer Architekturornamente bringt zum erstenmal die Kölner Schule in Anwendung. In Köln war in dem zweiten Jahrzehnt des I4. Jahrhunderts nach dem Muster von Amiens der Chor vollendet worden. Um ihn würdig

1) H. Wienecke hat diese Schule in ihrer Dissertationsschrift (Konstanzer Malereien des I4. Jahrhunderts. Halle I9I2) sehr gründlich behandelt. 


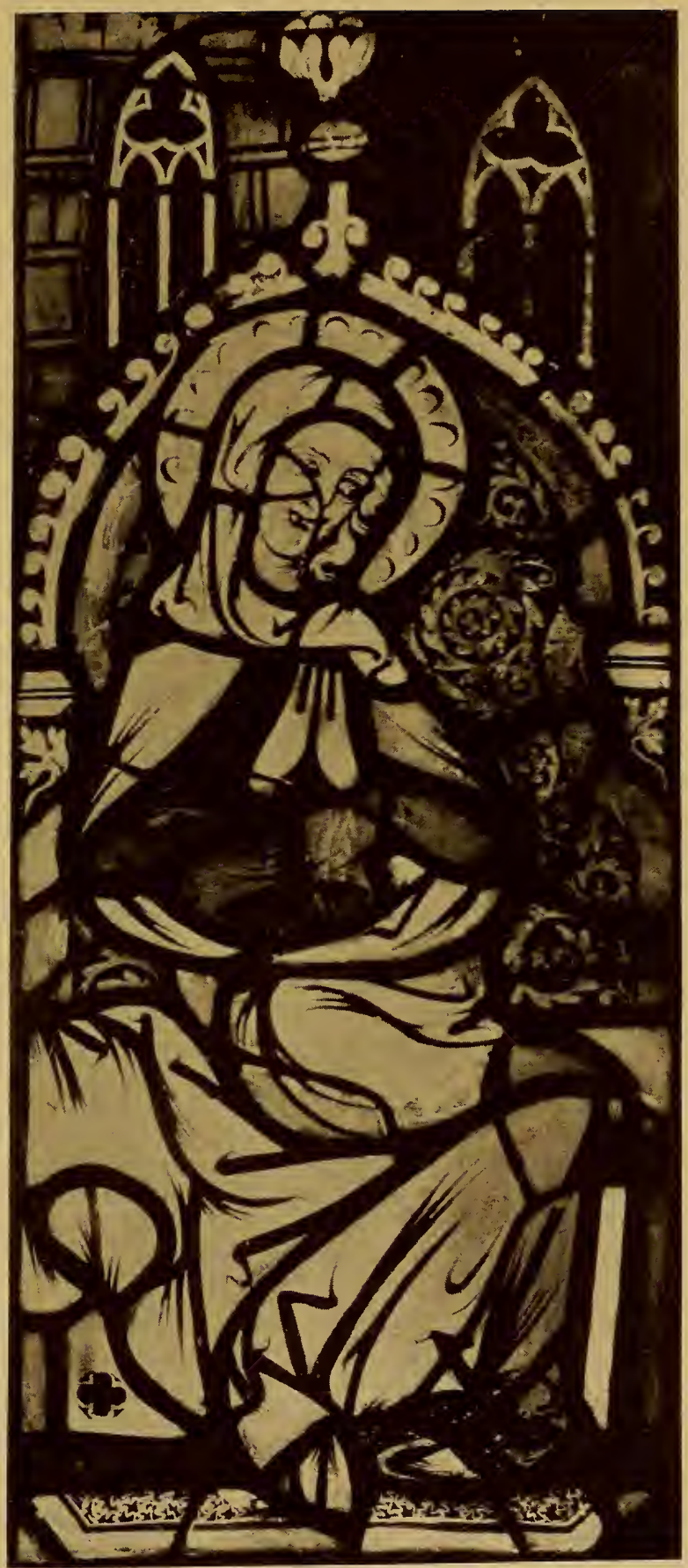

Flügel in der Altertümersammlung zu Karlsruhe. Gegen I 33 . Photographiert von W. Kratt, Karlsruhe. 

zu schmücken, überboten sich die ersten Geschlechter Kölns an Fensterstiftungen. Vermutlich nahmen die Stiftungen mit der Verlobung des Grafen von Jülich mit der Tochter des Grafen von Holland im Jahre 1317 ihren Anfang. Daran schlossen sich die alten Patrizier Kölns, so daß der Chor in kürzester Frist einen reichhaltigen Schmuck von Glasgemälden bekam. Zunächst interessiert an ihnen ihr Inhalt. Wir finden nämlich auf den Fenstern eine Anzahl von Königen dargestellt. Oidtmann ist geneigt, in ihnen deutsche Könige und Kaiser zu sehen. „Die Gestalten tragen unverkennbar deutsches Gepräge: Deutsch ist die Farbe, deutsch der Schnitt des Haars. " $\left.{ }^{1}\right)$ Wir hätten also $\mathrm{zu}$ der Straßburger Königsreihe eine Parallele. Auch die Straßburger Könige schlossen sich an eine Anbetung der Magier an, wie diese Szene im Mittelpunkt der Kölner Königsweihe steht. Der Hinweis auf Amiens lehrt uns indessen etwas anderes. Auch an dieser Kathedrale waren Könige dargestellt. Aber es sind keine christlichen Könige, sondern die jüdischen Könige, als Stammväter Christi. Wahrscheinlich verhielt sich die Sache in Köln wie in Straßburg; der aus Frankreich herbeigerufene Bauleiter brachte auch die Ideen für das Ausstattungsprogramm mit. Darum auch die reichliche Verwendung des gotischen Architekturornaments. Andererseits traf der vom Westen gekommene Architekt auf feste Schulen, und so ist es begreiflich, daß französische Anregungen Annahme fanden, daß aber die Ausführung nach den überkommenen Lokaltraditionen erfolgte. Die Glasgemälde des Kölner Domes bilden nicht bloß in der gleichzeitigen Entwicklung der Glasmalerei, sondern selbst in der niederrheinischen Schule eine eigene Gruppe. Ihr ungewöhnlicher Reichtum an architektonischen und Pflanzenornamenten hebt sie aus allem heraus. Auch die Zeichnung weicht von den näheren und entfernteren Schulen ab. Die Kölner Figuren sind bis zu einem gewissen Grade lebenswahrer und malerischer, während der Süden an dem streng stilisierten Ideal der zeichnerischen, den Irdischen entrückten Gotik festhält. Den Domfenstern gegenüber charakterisieren sich die übrigen Kölner Arbeiten durch größere Einfachheit, durch reinere Gotik in der

1) Die rheinische Glasmalerei I, S. I8I. Vergleiche auch oben Seite 75 . 
Zeichnung. Man vergleiche die Glasgemälde im Hause Oppenheim und die Glasfenster in der Viktorskirche zu Xanten, die in den Jahren I350-I360 von dem Vitrifex Jacobus in Köln gefertigt wurden.

Ohne jeden Zusammenhang mit den Kölner Glasmalereien steht das überaus prächtige Westfenster in der Zisterzienserabtei Altenberg. Es ist eine Stiftung des Grafen Wilhelm von Berg und seiner Gemahlin Anna von Pfalz-Bayern. Nach einer erstmals im Jahre 1640 aufgetauchten Notiz hat Bruder Raynold "super omnes lapicidas rex" das Fenster gefertigt. Oidtmann hält auf Grund dieser Notiz den Bruder Raynold für den Architekten des Baues, der gleichzeitig das Westfenster mindestens gezeichnet, wenn nicht direkt auch ausgeführt hat. Andererseits besteht eine nicht zu leugnende Verwandtschaft mit den Glasmalereien im Dome zu Metz, die dem I 398 gestorbenen Hermann von Münster ihre Entstehung verdanken. Wahrscheinlich war der Altenberger Meister der Gebende und Hermann der Empfangende. Ohne Beeinflussung wäre die eigentümliche Behandlung der Architektur auf den Metzer Fenstern nicht zu erklären. Es ist jedoch $z u$ bedenken, daß in Frankreich verschiedentliche Anregungen vorhanden waren, und daß die Technik weißer Figuren, wie sie auf den Altenberger Fenstern zum erstenmal auf einem Glasgemälde zu Chartres 1328 vorkommt.

\section{Das System des gotischen Medaillonfensters.}

Es bedarf wohl keines Beweises, daß dieses System seine erste Ausbildung in Frankreich bekommen und von diesem Lande aus seinen Weg nach Deutschland gefunden hat. Die früheste Verwendung der Medaillons findet sich auf den Fenstern zu Hauterive, die der oberrheinischen Schule zugeschrieben werden, die aber Ausläufer südfranzösischer Arbeiten sind. Die Form des Medaillons, eine Art Mandel, ist sehr selten und kommt gegen Mitte des Jahrhunderts in der Liebfrauenkirche zu Eßlingen und zu Westhofen im Elsaß und gegen Ende in Niederhaslach vor. Im Laufe des I4. Jahrhunderts wandeln sich die Medaillons zu den merkwürdigsten Rund- und Paßformen und es entstehen über ganz Deutschland hin die verschiedensten Schulen. 


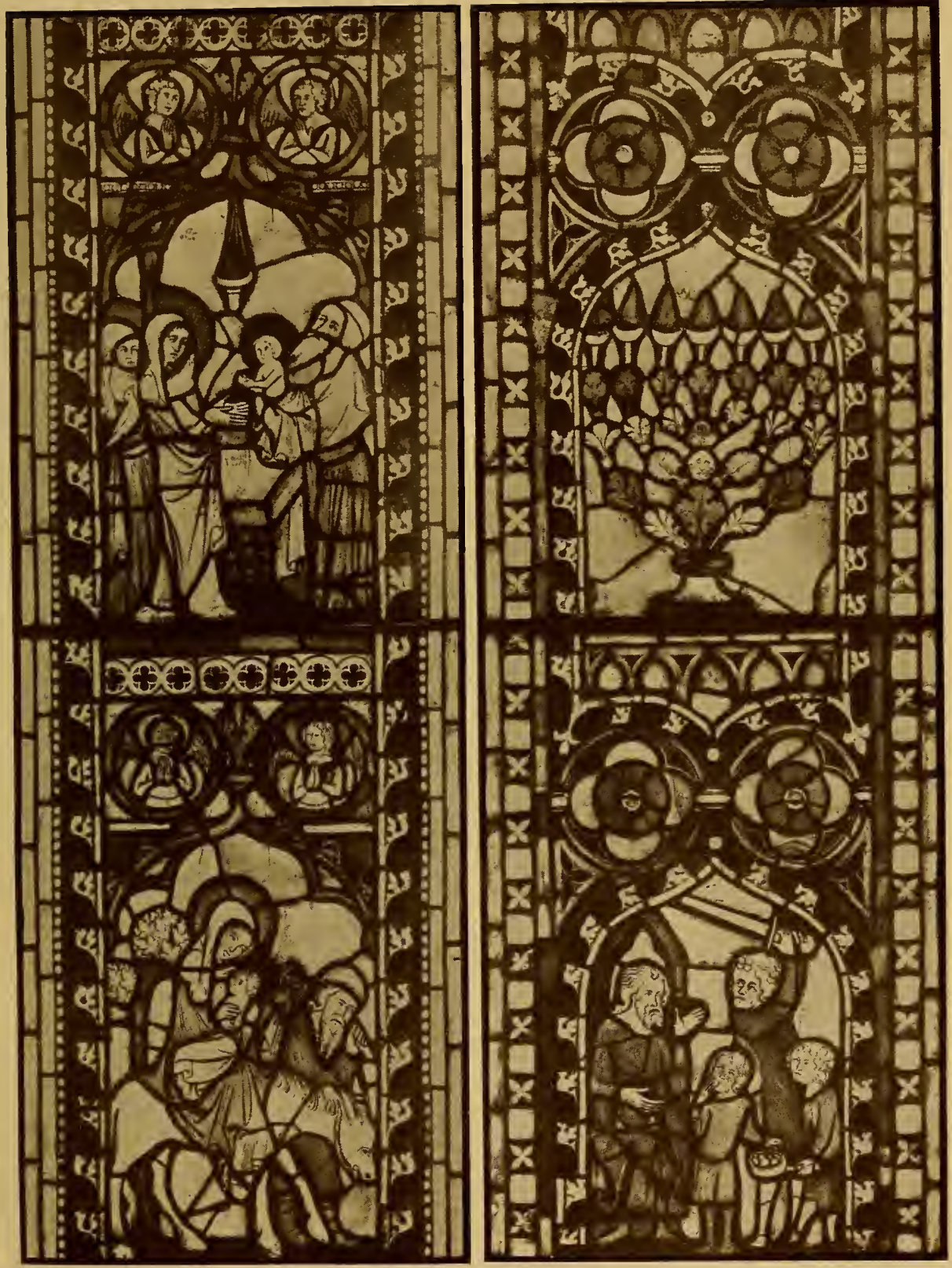

Detail aus einem Fenster der Stephanskirche zu Mülhausen i. E. Um I 340. 


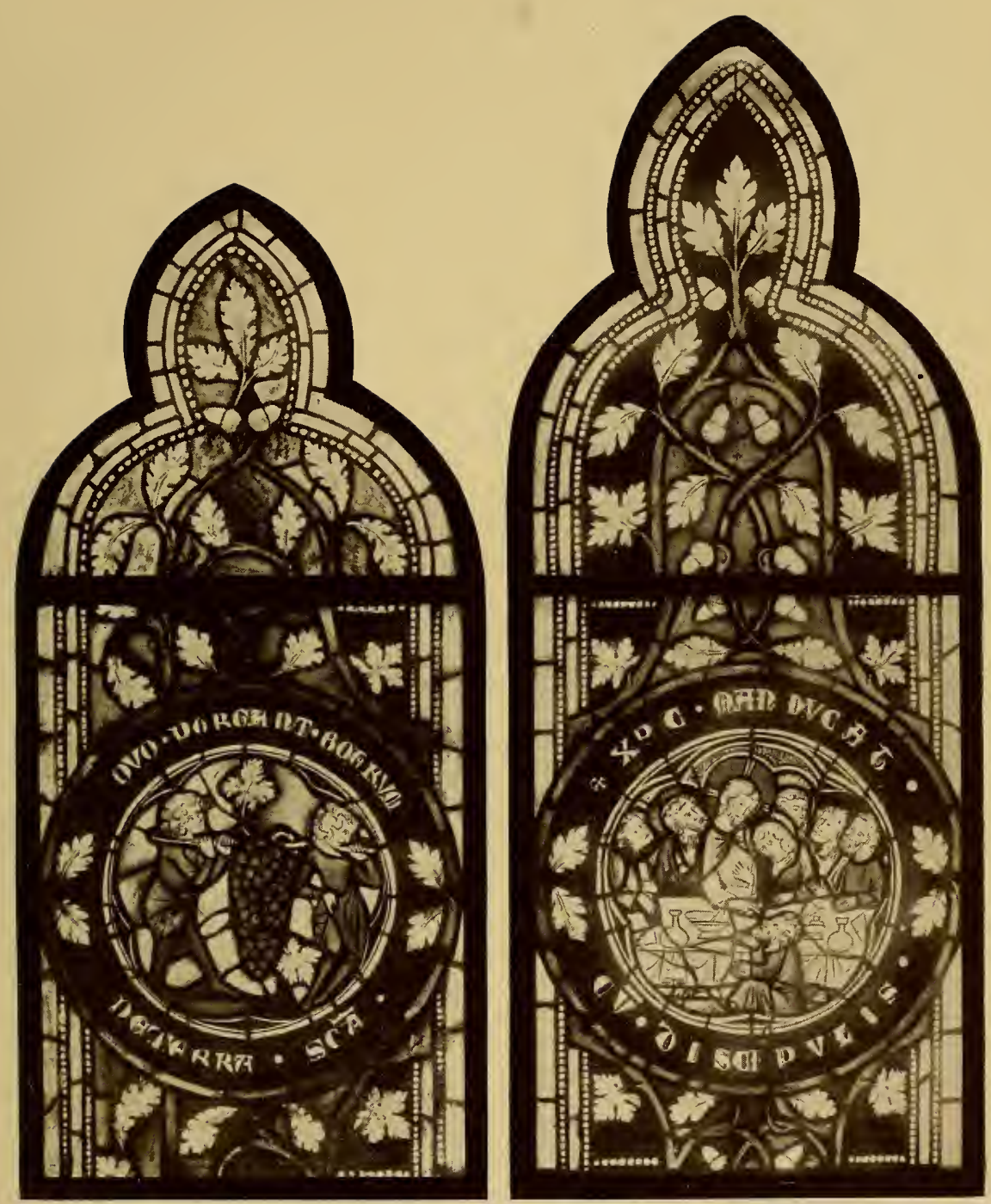

Detail aus einem Glasgemälde der Stephanskirche zu Mülhausen i. E. Um I 340. 

Die oberrheinische Schule ist nur noch spärlich vertreten. Das älteste dürfte das Fenster zu Weißenburg im Elsaß sein, das seine Verwandtschaft mit französischen Arbeiten nicht verleugnen kann. Vielleicht hängt das spärliche Vorkommen von Medaillonfenstern am Oberrhein mit der Tatsache zusammen, daß daselbst schon sehr früh eine Modifikation des Systems vorgenommen wurde, die in der Mitte zwischen den Architekturfenstern und Medaillonformen steht; während das höchst wahrscheinlich aus dem Dominikanerkloster in Konstanz stammende und jetzt im Schloß Heiligenberg befindliche Fenster die Szenen aus dem Leben Jesu unter die im vorigen Kapitel charakterisierte Architektur stellt, erscheint in Mülhausen und im Münster zu Straßburg ein neues System. Der Spitzbogen wird zwar zunächst noch beibehalten, aber in sehr feinem Geäst vor einer Fensterwand. Sehr rasch wird der Ast in ein breites Band erweitert, das $a b$ und $z u$ über die Spitze hinausgeführt wird und in zwei Kreise endigt. Dieses System scheint von den Dominikanern erfunden worden zu sein. Wir begegnen ihm in der Eßlinger Schule wieder (Taf. I5-I7).

Die schwäbische Schule hat die Glasmalerei über Wimpfen bekommen und wurde wie die übrige gotische Kunst durch die Bettelorden importiert. Sie hat ihre Abhängigkeit von Frankreich weniger verleugnet als andere Schulen. Ihr Hauptsitz ist Eßlingen. In dieser Stadt haben sich noch erhebliche Reste erhalten, die über verschiedene Jahrzehnte hin verteilt sind. Wahrscheinlich brachten die Dominikaner die Kunst der Glasmalerei nach Eßlingen. Wir finden daselbst alle möglichen Paßformen vom einfachen Rundmedaillon bis zum komplizierten Achtpaß. Die kräftigen Farben des Westens sind verblaßt, namentlich das Blau und das Grün. Je weiter die Schule in das Fränkische vordringt, desto verwaschener werden die Farben, desto provinzartiger der Stil. Vergleiche dazu die Fenster der Katharinenkirche zu Hall. Balet hat den Zusammenhang der EBlinger Schule mit Frankreich richtig vermerkt, es ist aber zu konstatieren, daß die Einwanderung über Straßburg ging, da in dieser Schule die eigenartige Umrahmung einzelner Szenen geschaffen worden ist, die wir oben beschrieben haben, und die sich auch auf einem Fenster in EBlingen findet.

Fischer, Handbuch der Glasmalerei. 
Am Niederrhein hat sich eine eigene Richtung ausgebildet, die in den Legendenfenstern in der Stephanskapelle des Kölner Doms, in München-Gladbach und in Xanten ihren Ausdruck gefunden hat. In der äußeren Anordnung treffen wir bei all diesen Fenstern auf ein festes System. Die Fenster sind zweiteilig, enthalten auf der linken Seite Szenen aus dem Alten und auf der rechten Seite Szenen aus dem Neuen Testament. Während nun die Szenen der linken Seite in Teppiche gestellt, keinen engeren $\mathrm{Zu}$ sammenhang miteinander aufweisen, sind die auf rechter Seite befindlichen Medaillons in ein sich über jedem Medaillon kreuzendes Geäst, in dessen Gezweig nach Art der Jessefenster Propheten angebracht sind, komponiert. Bei dem Fenster in der Stephanskapelle des Kölner Doms wird das Geäst an einen durch das ganze Fenster sich ziehenden Stamm angeschlossen. Diese niederrheinische Gruppe, zu der noch verschiedene Reste in rheinisch-westfälischen Kirchen gehören, hat ihren Ausgang vom Elsaß genommen. Denn das mittlere Chorfenster zu Weißenburg im Elsaß hängt aufs engste mit der genannten Gruppe zusammen. Die Weißenburger Fenster enthalten in Stil und Ausführung noch viel Romanisches, während die niederrheinische Gruppe vollständig gotisch ist. Ausläufe dieser Schule sind die Glasgemälde zu Limburg an der Lahn.

Mitteldeutschland wird hauptsächlich durch die Regensburger und thüringische Schule bedient. Es ist mir wiederholt aufgefallen, wie eng verwandt diese beiden Gruppen sind und wie sehr Erfurt in diese Verwandtschaft einzubeziehen ist. Man betrachte z. B. die Fenster aus der Minoritenkirche im Bayrischen Nationalmuseum und die Glasgemälde in der Blasiuskirche zu Mühlhausen in Thüringen. Diese Verwandtschaft zieht sich auch in die Entwicklung des neuen (perspektivischen) Stils der zweiten Hälfte des I 4. und des I 5. Jahrhunderts hinein.

Um die gleiche Zeit regt sich auch in Italien das glasmalerische Leben. Man hat Italiens Glasmalereien nie so recht in den allgemein-geschichtlichen Entwicklungsgang der Glasmalerei einbezogen. Fern von der Vergleichung mit den Arbeiten Deutschlands und Frankreichs hielten die italienischen Gelehrten ihre heimischen Glasmalereien für bodenständig. $\mathrm{Zu}$ den ältesten Glasgemälden gehören die Fenster in der berühmten Basilika des 

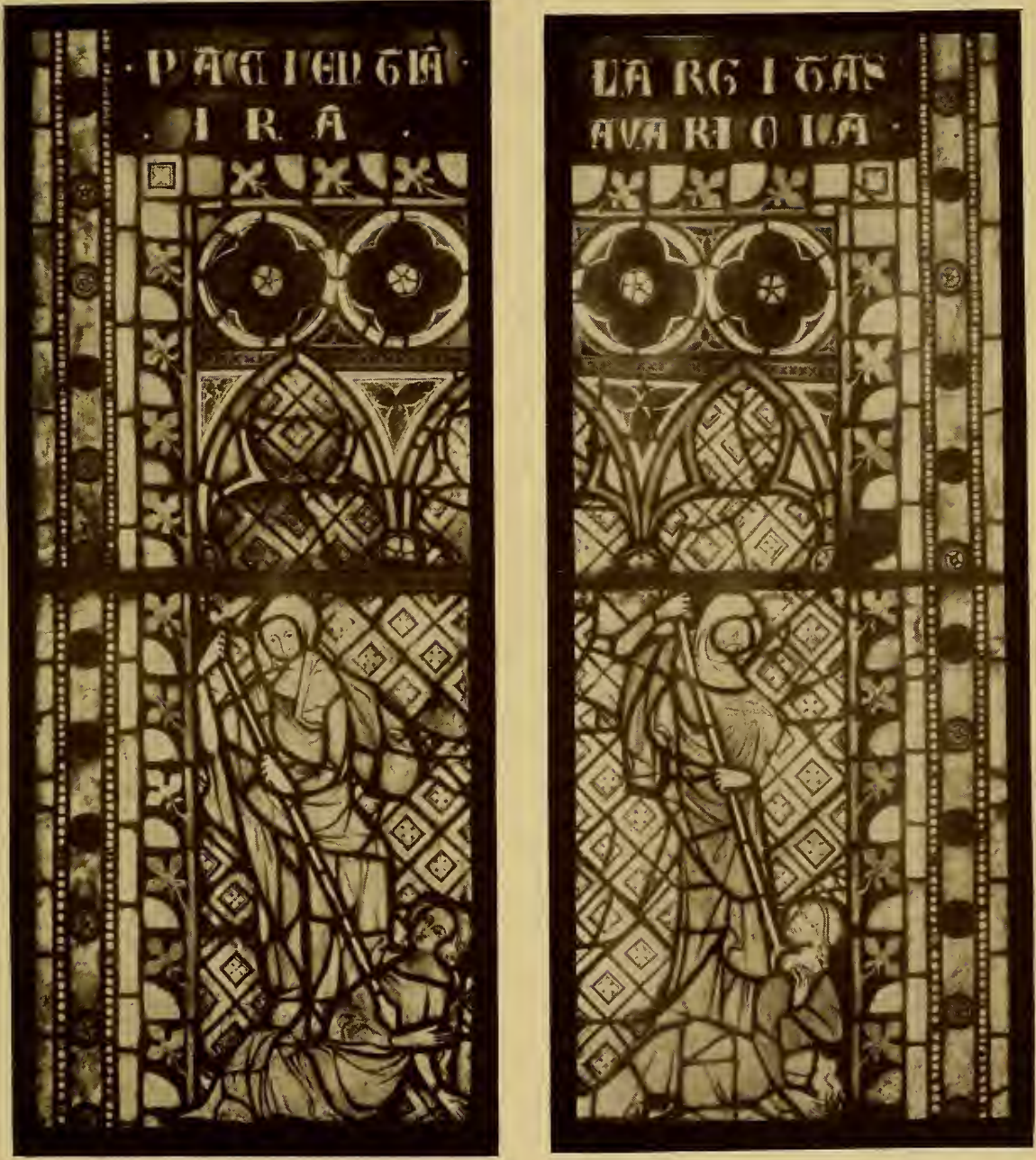

Detail aus dem Fenster der Tugenden und Laster in der Stephanskirche zu Mülhausen i. E. Um I 340. 

hl. Franziskus zu Assisi. In einer jüngst erschienenen Monographie über diese Fenster erklärt sie der gelehrte Verfasser P. Egidio Giusto für Arbeiten Cimabues und seines Kreises. Die eigentlichen Glasmaler, fast durchweg Mönche des Franziskanerordens, hätten in Murano und Venedig das Glasmalen erlernt und nach den Kartons von Cimabue die alten Kirchen und Klöster Italiens mit Fenstern geschmückt. Nichts hindert uns zu glauben, daß Venedig tatsächlich als früheste Pflegestätte der Glasmalerei in Betracht kommt. Allein wenn wir das Medaillonsystem, die Anordnung usw. der Fenster von Assisi betrachten, so können wir uns der andern Tatsache auch nicht verschließen, daß deutsche Einflüsse es gewesen sind, die den italienischen Glasgemälden ihr Aussehen gegeben haben. Ist nicht ein "Frater Theutonicus“ in hervorragender Stellung als Glasmaler um die Wende des I3. Jahrhunderts in Venedig tätig gewesen? Er hat, wie wir wissen, die Kirche dei Frari mit Glasgemälden geschmückt. Auch Venturi ${ }^{1}$ ) sagt: „Die ältesten Glasmalereien Italiens sind deutsche Arbeiten." Das rechte Apsidenfenster in der Basilika zu Assisi erinnert direkt an das Weißenburger Fenster. Freilich haben die Italiener die herbe Gotik der deutschen Figuren in die weichere Modellierung der italienischen Frührenaissance aufgelöst(Taf.6o, 6 I).

Spanien hat seine Impulse zusammen mit der gotischen Baukunst von Frankreich, teils auch von Belgien und Köln bekommen. $\mathrm{Zu}$ den ältesten Glasfenstern in Spanien ${ }^{2}$ ) gehören sicherlich einige der 230 Scheiben der Kathedrale von León. Diese Fensterscheiben, die, durch feines Steinstabwerk geteilt, in den Seitenschiffen vom Sockel bis knapp unter die Gewölbekappe reichen, sind im Hauptschiff, zwischen aufs Äußerste reduzierten Bündelpfeilern durch ein zartes Netzwerk aus Stein gefaßt und füllen, über dem Scheitel der Mittelschiffbogen beginnend, bis zu I 2 Meter Höhe Triforien und Hauptschiffwände. Was zum erstenmal im Chor der Kathedrale von Amiens erscheint, ein mit bunten Fenstern versehenes Triforium an Stelle eines einfachen, ist hier in Spanien bald nachher, etwa am Ende des I3. Jahrhunderts

1) La basilica d'Assisi pag. 143

2) Für die Bearbeitung der spanischen Glasmalerei hat mir Herr Architekt A. L. Merz, Stuttgart, sein reiches in Spanien gewonnenes Studienmaterial in dankenswerter Weise zur Verfügung gestellt. 
wiederholt worden. Schon bei Betrachtung der Außenarchitektur des Domes von León, die zum Zerissensten gehört, was je zu sehen ist, ahnt man das lichte Innere. Alles hier scheint wie nirgends nur für die Glasgemälde gemacht und wir müssen es in Kauf nehmen, daß der außergewöhnlichen Steigerung eines untergeordneten Architekturgliedes zulieb, das Bauwerk - im Ganzen - eine äußerst schlechte unstatische Wirkung ausübt.

An diesem Dom in León ist das Unarchitektonische das Interessanteste: Das ist's, was dem Beschauer schon von Außen auffällt. Und tritt er dann aus der grellen spanischen Sonne hinein und fühlt sich zurückgeschlagen und angezogen zugleich von der Fülle farbigen Lichts, die ihm entgegenquillt, nachdem er den dunklen Vorraum durchschritten hat, dann weiß er, daß einiger Wert darin steckt, auf Kosten der Gesamtheit die Wirkung eines einzelnen Teils zu steigern.

Die noch erhaltenen ältesten Fenster, die der "Capilla de Santiago" und einige andere sind ihrer Entstehungszeit nach nicht genau zu datieren, da alle Angaben fehlen. Sie stammen aber ihrem Stil nach sicherlich aus dem I3. Jahrhundert. Andere sind im I4., I 5. und I6. Jahrhundert entstanden. Neben den Fenstern der Hauptkapelle, der "Capilla de Santiago", und den anderen noch erhaltenen ältesten Fenstern sind besonders bemerkenswert die großen Rosenfenster der Westseite des Hauptschiffs und die im nördlichen Querschiff. Hervorzuheben sind noch die Fenster der Seitenschiffe, die alle mehr romanischen Charakter haben. Während die ebengenannten Fenster mit Ausnahme der Rosenscheiben mehr figürlichen Charakter zeigen, treten bei den Fenstern der Seitenschiffe Eichenlaub, Weinlaub und andere Pflanzenmotive frei stilisiert in köstlich satter Farbtönung auf. Obgleich diese seitlichen Fenster eine Ergänzung später Zeiten sind, gehören sie doch zu den besten in ganz Spanien.

\section{c) Die allmähliche Auflösung des Flächenstils in Bild= wirkung unter dem Einfluß des italienischen Trecentos.}

7. Der Kunstkreis zu Königsfelden.

Der Stoß, den Italien von Deutschland empfing, blieb nicht unbeantwortet. Ein paar Dezennien nach den Arbeiten zu Assisi. 


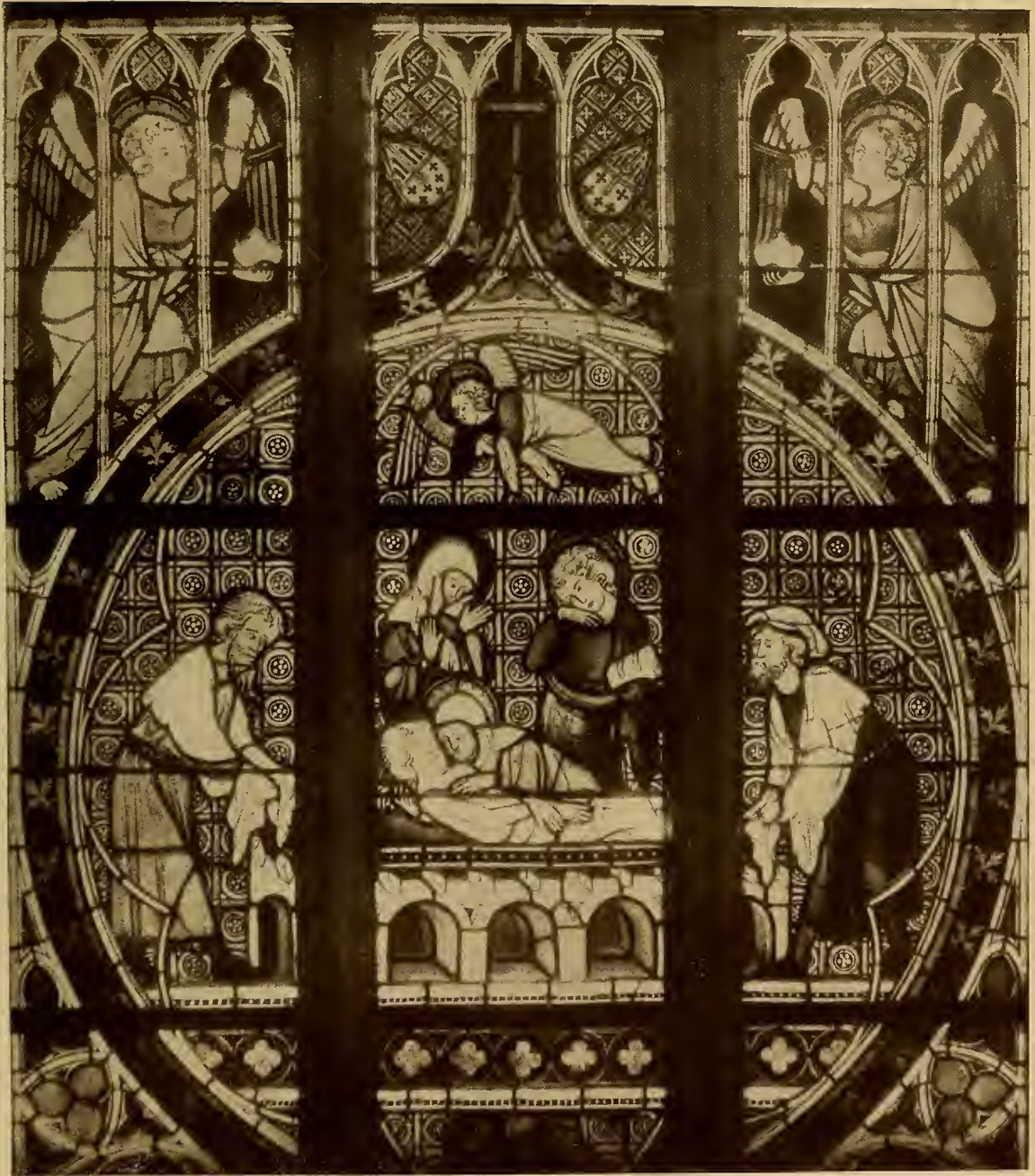

Teil aus dem Passionsfenster in der Klosterkirche zu Königsfelden. Erstes Viertel des I 4. Jahrhunderts. 

mit dem ersten Flügelschlag des I4. Jahrhunderts, setzt eine Richtung in der Glasmalerei ein, die mit dem bisher geübten Prinzip der Glasmalerei als Flächenkunst bricht und die Perspektive in die Glasmalerei einführt. Das hängt hauptsächlich mit dem Aufkommen der Tafelmalerei zusammen. Seit der Aufstellung der französischen Primitive zu Beginn dieses Jahrhunderts ist der Streit über die Priorität Frankreichs bzw. Italiens auf dem Gebiete der Tafel- und auch Miniaturmalerei nicht verstummt. Am schärfsten vertritt Bouchot in seinem Buche „Les primitifs français I292-I500" den französischen Standpunkt. Bouchot unterscheidet drei Hauptschulen, die Schule von Paris seit Beginn des I3. Jahrhunderts mit den Hauptnamen Jean Pinon, Jean d'Orléans, Etienne d'Auxerres, Evrard d'Orléans. In diese Schule gehören der Psalter Ingeburgs, das Skizzenbuch des Villard von Honnecourt, die Manuskripte Ludwigs des H1., die Glasfenster der Sainte Chapelle. Als zweite Schule führt Bouchot die Gruppe von Hesdin auf, genannt nach den Arbeiten für Hesdin, einem Sitz der Mathilde von Artois ( $\dagger$ 1 329). Die Glasmaler dieser Schule sind in Arras seit I299, Othon, der wahrscheinlich von Burgund kam, Hue d'Arras, Noël d'Arras, Jeanets Coquelés, Huart. Auf diese Schule führt Bouchot auch den Meister E. S. zurück. "Au nombre des orfévres en I 329 figure un certain Etienne de Salins dont la descendánce fut illustre, je crois. Je conseillerais en tout cas aux historiens du célèbre Maitre E.-S. de 1466 - dont on fait un allemand, mais que des gens plus avisées ont dit être de Salins - 1a recherche approfondie dans ce sens. Les ascendances soi-disant flamandes, mais surtout bourguignonnes, du célèbre graveur seraient plus facilement, explicables par Mahaut d'Artois (78). Von den anderen Schulen wird im nächsten Kapitel zu reden sein. Unter diese für Bouchot sehr klaren Ereignisse fällt die merkwürdige und etwas mysteriöse Reise eines französischen Hofmalers nach Oberitalien, sowie der Aufenthalt verschiedener italienischer Künstler in Frankreich. Die durch solche Berührung von selbst sich ergebende Verwandtschaft der italienischen und französischen Primitive weist Bouchot mit der Bemerkung ab, daß die Italiener höchstens die Lernenden gewesen seien. Uns könnte dieser Prioritätsstreit an sich gleichgültig sein, wenn er seine Schatten nicht auf die Glas- 
malerei der ersten Hälfte des I 4. Jahrhunderts werfen würde. Königsfelden, unweit der Habsburg, der Ort schmerzlindernder Sühne für die Schreckenstat des Jahres I 308, besitzt eine Reihe herrlicher Glasgemälde, Stiftungen der Habsburger an ihren durch Mörderhand gefallenen Ahn, Albrecht. Nach Lehmann sind sämtlicheFenster spätestens bisEnde des 4. Jahrzehnts, vollendet worden, während Lübke, dem auch Schmitz folgt, eine successive Entstehung bis über die Mitte des Jahrhunderts (etwa bis I 368) verteidigt (Taf. I 8-20). Nach äußeren Anhaltspunkten 1äßt sich das Klarafenster (Fenster L nach Lübke) am genauesten datieren. Es trägt die Aufschrift: Domina Katherina dvcissa Avstrie pro Leopoldo dvce Avstrie. Dieser Herzog Leopold ist im Jahre I 326 gestorben, während seine Frau, die genannte Herzogin Katharine, noch bis zum Jahre I337 gelebt hat. Das Klarafenster ist also spätestens in der 2. Hälfte der dreißiger Jahre des 14. Jahrhunderts entstanden. Man müßte somit von der Technik und dem Stil dieses Fensters ausgehen, wenn man Schlüsse auf die Entstehungszeit der übrigen Fenster ziehen wollte. Es ist dem Beschauer viel zugemutet, wenn er auf den ersten Blick hin glauben soll, sämtliche I I Fenster seien in dem kurzen Zeitraum von höchstens zwei bis drei Jahrzehnten entstanden. Im wesentlichen stehen sich zwei Gruppen von Fenstern gegenüber, die Fenster C, E, G, L als Repräsentanten des in der üblichen Kirchengotik komponierten Flächenstils und die übrigen Fenster, die bereits den perspektivischen Gedanken in Verbindung mit der Profanarchitektur zur Anwendung bringen. Die Fenster mit Szenen aus dem Leben Jesu und die Apostelfenster, die den Konstanzer Arbeiten, in manchem sogar den frühgotischen Glasmalereien der Kölner Schule ähnlich sehen, scheinen einen unüberbrückbaren Gegensatz zu den malerisch-plastisch gehaltenen Fenstern mit den Legenden des hl. Franziskus und der hl. Klara $\mathrm{zu}$ bilden. Eines steht jedenfalls fest: auch wenn Lübke und Schmitz mit ihrer Datierung Recht haben, so muß mindestens ein einheitlicher Ausschmückungsplan vorhanden gewesen sein. Denn die Fenster bieten nicht bloß in der allgemeinen Anordnung, in der Verteilung der koloristischen Grundakkorde eine auffallend korrespondierende Wechselwirkung, sie weisen vielmehr auch in Einzelheiten geradezu überraschende Ähnlichkeiten 

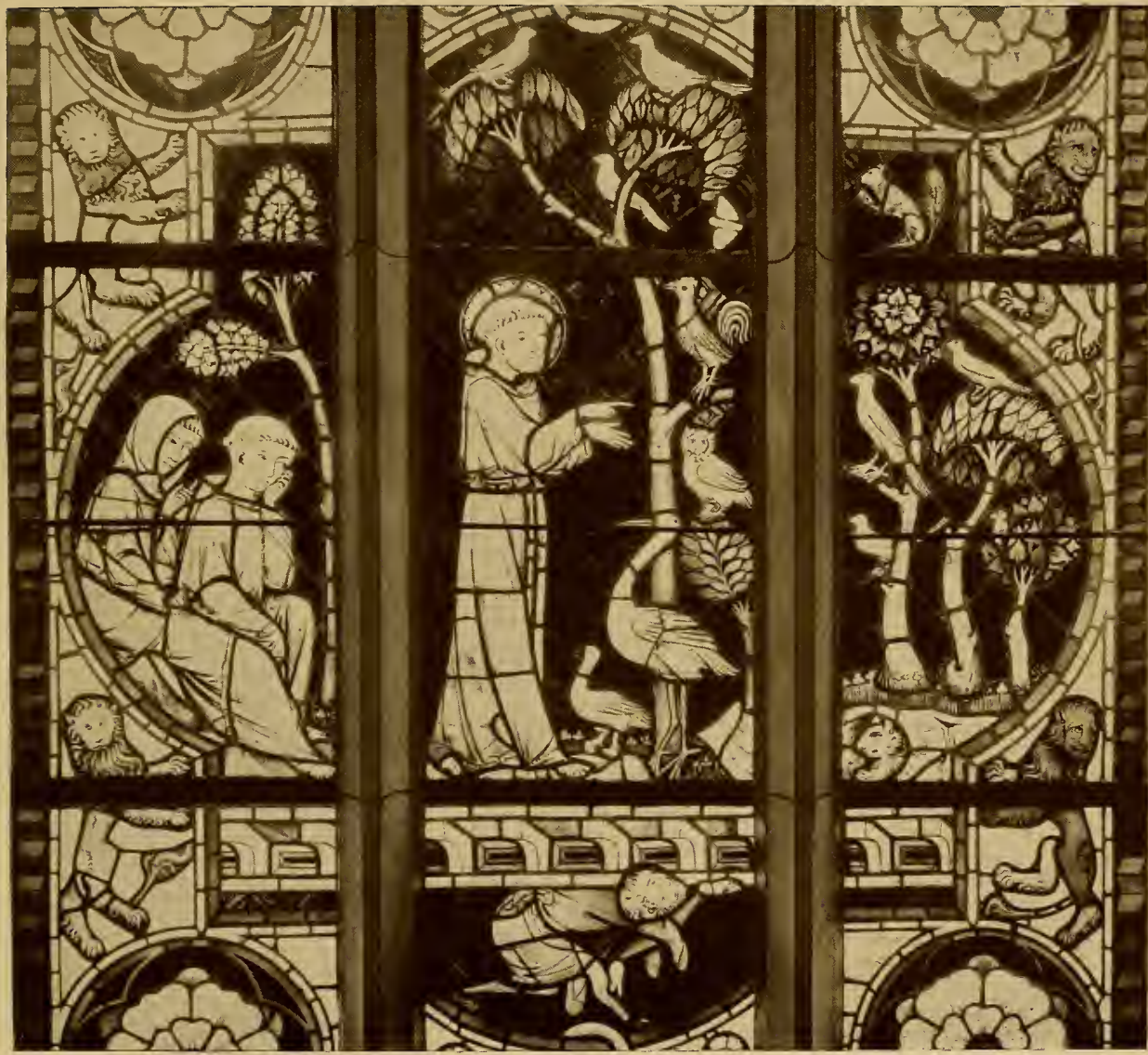

Teil aus dem Franziskusfeǹster in der Klosterkirche zu Königsfelden. Erstes Viertel des I 4. Jahrhunderts. 

auf. Zunächst stimmen die Farbenskalen auf allen Fenstern unter sich überein. Sie bestehen aus einem Weiß, einem Kohlengelb, zwei Rot, zwei Grün, einem Rotviolett, einem Blauviolett, einem Rotbraun, zwei Fleischtönen und einem Blau. Das Silbergelb wird sehr sparsam verwendet, kommt aber bezeichnender Weise fast auf allen Fenstern vor und zwar im gleichen Ton und in der schulmäßig gleichen Behandlung. Durchweg in schwefelgelbem Kolorit tönt es Beinschienen, Armreife (Fenster G, H, L), Umschläge von Büchern (Fenster F, I), eine Agraffe (Fenster D), einen Schwertknauf (Fenster I 4), eine Harfe (Fenster L). Auf dem Schweißtuch eines Schergen (Geißelung Christi in Fenster F) ist es sogar in höchst feiner und origineller Weise $\mathrm{zu}$ einer leichten Modellierung und Schattierung verwendet. Die beiden Apostelfenster C und I zeigen die fortschrittlichere Anwendung des Silbergelbes: weitgehende Tönung der Architektur und insbesondere der Haare. Der Gebrauch des Silbergelbes schließt sich also genau an die Technik an, die Lehmann auf dem um I 300 entstandenen Fenster zu Blumenstein bei der Tönung von Fischen mit Silbergelb festgestellt hat. Die Verwendung des Silbergelbes zur ergiebigen Tönung der Haare auf den Königsfeldener Fenstern steht in der Entwicklung dieser Farbe einzig da. Würde also diese Tatsache die Vermutung auf relativ späte Entstehungszeit der beiden Apostelfenster wachrufen, so ist andererseits $\mathrm{zu}$ bemerken, daß gerade diese Glasgemälde ihrem Charakter nach zu den unbestritten ältesten Bestandteilen des Chorschmuckes in Königsfelden gehören. Die Farben der Hüttengläser und die Verwendung des Silbergelbes lassen also bis jetzt den Schluß zu: Sämtliche Fenster müssen unter denselben Werkstattsbedingungen entstanden sein. Dazu kommt die auffallende Übereinstimmung in der Zusammenstellung von Farbenakkorden namentlich von den Zweiklängen Rot-Grün (einer nicht häufigen Kombination in dieser Zeit), Rot-Gelb, Rotviolett-Grün. Auf dem Fenster A ist Anna, auf Fenster D Katharina, auf E Maria je als Hauptperson gleichmäßig in grünes Kleid und rotvioletten Mantel gekleidet, eine Zusammenstellung, die wir auch auf Fenster $\mathrm{L}$ finden. Und doch bilden Fenster A und $\mathrm{E}$ so ziemlich die Grenzpunkte der Datierung von Lübke. Daß diese Tracht nicht eben auf religiöse, sondern nur auf ge- 
meinsame Werkstattradition zurückzuführen ist, möge nur nebenbei bemerkt sein und darauf hingewiesen werden, daß auch Jesse auf Fenster $A$ in den gleichen Farben gekleidet ist.

Der architektonische Aufbau der Fenster ist für die Datierung ebenfalls sehr lehrreich. Der Fußboden wird auf allen Glasgemälden durch eine mit gotischen Vierpässen gezierte Bank abgetrennt, an sich ein ziemlich unbeholfener aber in seiner schlichten Originalität um so charakteristischerer Ausweg. Auf dem Mittelfenster $(F)$, den Fenstern $A$ und $L$ ist diese Bank rein zeichnerisch, flächig dargestellt, während sie auf den Fenstern B, $\mathrm{E}, \mathrm{H}, \mathrm{I}$, auf perspektivisch angebrachten Balken ruht, also eigentlich das Gegenteil, was man nach Lübkes Datierung erwarten muß. Auch in der Ausstattung der unter der Bank freiliegenden Fläche ist Wechselwirkung erstrebt. Diese Zwickel füllt im Mittelfenster ein schreitender Löwe, auf B eine grün gekleidete Figur, auf A und L die Halbfigur eines Engels. Schließlich mag noch auf die Darstellung des Grabes auf Fenster $G$ hingewiesen sein. Das Grab wird durch einen langen, frontal gestellten und mit gotischen Fenstern versehenen Kasten gebildet, dessen Deckel auf der Vorderseite dachschuppenartig vorgelagert und von perspektivisch gezeichneten Balkenkonsolen getragen wird. Derselbe Aufbau des Grabes findet sich aber auch auf dem Mittelfenster. Wäre die Entwicklung des Kostüms und der Waffen in lückenloser und chronologisch auch nur annähernd genauer Weise erforscht, so ließe sich aus den interessanten Kriegs- und Friedenskleidern, die auf den Königsfeldener erscheinen, manches über die Datierung ermitteln. Zwar zieren die Trachten des Klarafensters in farbigen Nachzeichnungen die Tafel IV (Nr. I-4) von Hottenroths bekanntem Werke über die "Trachten etc. der Völker“. Allein in der Anmerkung fügt der Verfasser bei: „Nach den I358-1364 entstandenen Glasgemälden von Königsfelden“ (S. 310). Auf Grund dieser durch nichts bewiesenen falschen Datierung werden nun die weiteren Schlüsse über die Entwicklung der Tracht gezogen. Die Trachten auf dem Klarafenster bestehen aus der enganliegenden Hose, dem bis an die Knie reichenden und halbseitig aus zwei Farben zusammen gesetzten Wams, einer Kragenkapuze (Gugel) mit lang herabhängender Spitze und einem Lendengürtel mit Tasche 

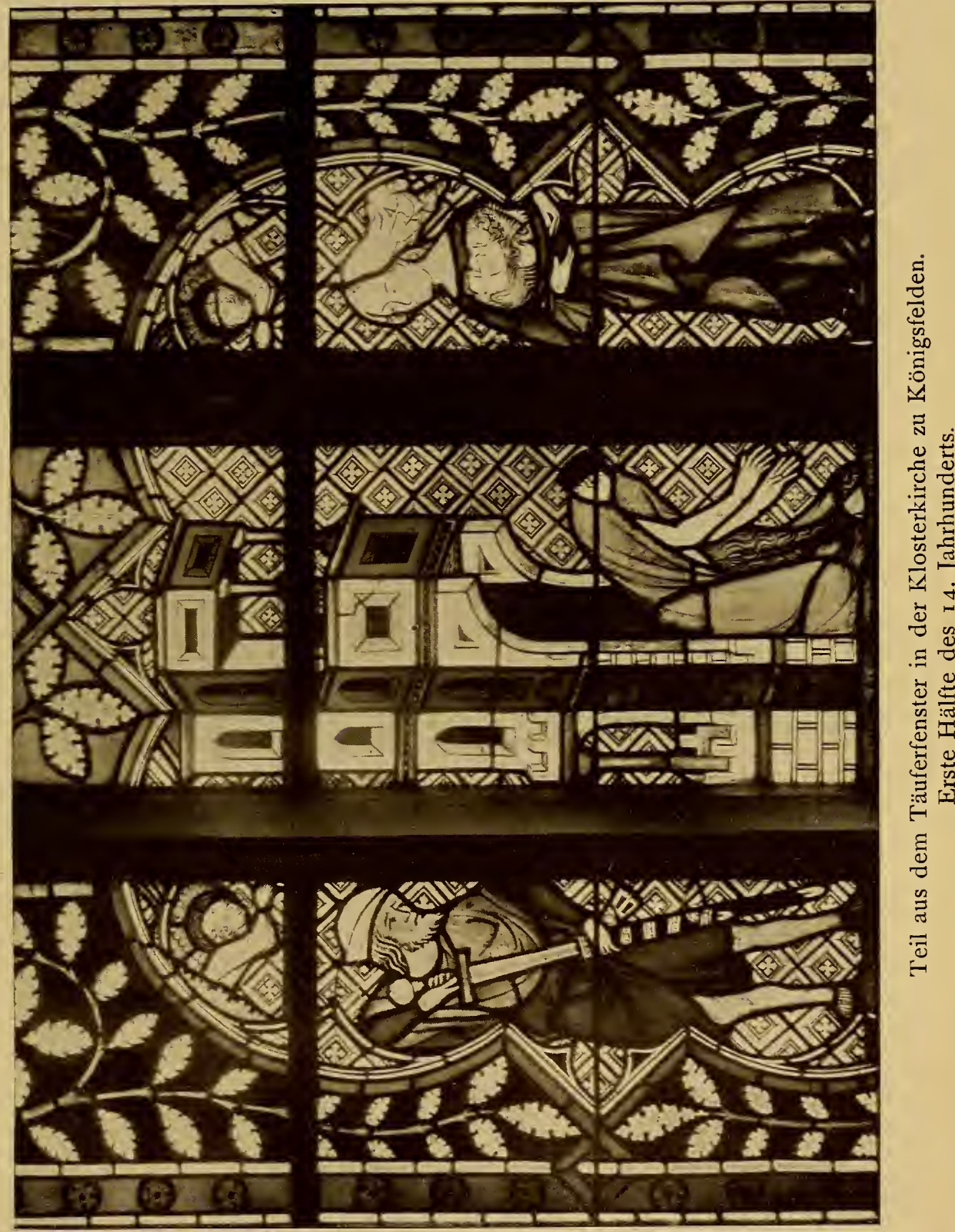

(Dusing). Unter den weiblichen Gewändern tritt nur das Gebende (auf dem Annafenster) besonders hervor. Die Waffenbekleidung aber setzt sich aus den Kettenrüstungen zusammen, über die ein Waffenrock aus Tuch gezogen ist, teils mit Kniekappen und Beinschienen, teils ohne dieselben, sowie Beckenhauben oder Eisenhüten und Dreiecksschilden, die an den oberen Enden gerundet sind. Solche Krieger finden sich auf Fenster G, H, L also wiederum auf den zeitlich am weitesten auseinander datierten Fenstern. Die Mode der Kürzung aller Oberkleider soll nach den Darlegungen in Trachtenbüchern in Burgund zu Beginn des I4. Jahrhunderts aufgekommen sein. Indeß führt Hottenroth (2. A. Tafel 83, 7) einen italienischen Edelmann auf, der in ähnlicher Mode, wie die Eltern der hl. Klara gekleidet ist. Zu Beginn des I4. Jahrhunderts macht sich in der vornehmen Welt der romanischen Länder das Bestreben geltend, das Oberkleid zu kürzen, die Beinlinge zu verengen. An dem Grad, in dem sich die Kleider den Körperformen anschmiegen, läßt sich der Verlauf der neuen Mode im einzelnen fixieren. In dem um I 350 entstandenen Gebetbuch der Herzogin Blanca von Mailand hat sich die Mode bereits zu den bekannten karnevalistischen Auswüchsen spitzer Schuhe, korsettartigem Schnitt in die Taille bei Waffenrock und Wams, Verkürzung des Oberkleids bis knapp über den Oberkörper entwickelt. Diese Auswüchse kennt der Königsfeldener Zyklus noch nicht, er steht vielmehr am Anfang der Mode, so daß nichts hindert, die Glasgemälde in das erste Drittel des Jahrhunderts zu verlegen, denn daß Künstler, die im Dienst eines so hohen und natürlich mit der Mode gehenden Fürstengeschlechts stehen, nicht in provinzieller Weise Altes nachschleppen, sondern jeweils das Neueste sehen und kopieren, ist selbstverständlich.

Wenn nun der Befund der Königsfeldener Fenster auf eine allerdings reiche und unter dem Drängen der fürstlichen Bauherren, sowie dem unausgesetzten Flu $\beta$ von Stiftungen zu raschem Arbeiten gezwungene Gesamtwerkstatt schließen läßt, so weisen doch die Fenster trotz der zahlreichen Ähnlichkeiten große stilistische Unterschiede auf. Da ist es zunächst die erste Hauptgruppe, die im großen und ganzen im System der flächigen Kirchengotik arbeitet und die Fenster E-G, C-I umfaßt. Die 
Fenster $\mathrm{E}$ und $\mathrm{G}$ sind Arbeiten eines Künstlers, der in den trühgotischen Traditionen gelernt und geschaffen hat, der ebenso die Konstanzer, überhaupt oberrheinischen Glasgemälde kennt, wie 'die niederrheinischen speziell die von Köln. Die Geburt Christi ist noch ganz nach dem byzantinischen Kanon dargestellt. Das andere Fensterpaar C-I mit der Wiedergabe der Apostel, bedeutet gegen die beiden genannten eine Fortentwicklung zum System der Hochgotik. Freilich ist dieser Schritt unbedeutend im Hinblick auf die Kluft, welche die andere Hauptgruppe scheidet, die den neuen perspektivischen, aus der Malerei Giottos und seiner Schule hervorgequollenen Stil mit Profanarchitektur, in die Glasmalerei Königfeldens und überhaupt in die glasmalerische Praxis einführt. Und zwar muß der ganze Ideenkreis am Platz gewesen sein, noch bevor die Meister der Fenster E-G, des Fensters $F$ ihre Arbeiten zum Abschluß gebracht haben. Anders läßt sich die Zeichnung des Grabes nicht erklären, die eine Konzession an die neue Richtung darstellt. Am zwanglosesten deutet sich das Königsfeldener Problem dahin: Infolge der Beschleunigung des Chorbaues und der zahlreichen Stiftungen der Habsburger wurde von der Bauleitung nach den besten Kräften ausgesandt. Das zunächstliegende war der Oberrhein und Konstanz. Bezeichnenderweise findet man auf einem Fenster eine Umrahmung einzelner Figuren und Szenen, die in dem ersten Drittel des I4. Jahrhunderts im Elsaß (näherhin wohl in Straßburg) ausgebildet und auf den Fenstern von S. WilhelmStraßburg, auf den Fenstern von S. Stephan (gegen I340) zu Mülhausen (Bruck, Tafel 35-38, 4I) häufig verwendet wurde. Wir müssen daher auf Grund des stilisch-technischen Befunds, der trotz der weitgehenden Restauration mit Leichtigkeit abgelesen werden kann, jene Datierung für richtig halten, zu der Lehmann durch seine chronologisch-biographischen Untersuchungen der Stifter gekommen ist und sämtliche Chorfenster der Kirche zu Königsfelden in die ersten vier Dezennien des I4. Jahrhunderts verlegen.

Innerhalb der neuen - nennen wir sie bis zur näheren Charakterisierung mit Perspektive und Profanarchitektur - arbeitenden Schule von Königsfelden spalten sich verschiedene Kräfte, denen eine Übertragung der giottistischen Körper- und 
Kompositionslehre in deutsches Empfinden gemeinsam ist. Auf dem Mittelfenster herrscht eine Beschränkung der Figuren vor, der Hintergrund (getüpfeltes Kreismuster von blauem Hüttenglas) nimmt mindestens zwei Drittel des gesamten Raumes ein. Die Körper sind noch schlank, die Gesichter von trockenem, monotonem Ausdruck. Diesem Fenster stehen am nächsten das Fenster mit der Legende der hl. Katharina und des hl. Johannes des Täufers (D) und das korrespondierende Fenster mit den höchst originellen Darstellungen von Szenen aus dem Leben des Apostels Paulus (H). Daran schließt sich das Klarafenster (L) an. Die Personenzahl vermehrt sich, wie auch die Figuren selbst größer gezeichnet sind. Das Fenster besteht aus fünf Rundmedaillons, deren Kreis im unteren Teil des Fensters in eine Gerade ausgezogen wird, die ihrerseits Stifter und Stifterin, sowie zwei musizierende Engel trennt. In die Zwickel sind ebenfalls Engel komponiert und in den drei unteren Medaillons hat der Künstler noch eine besondere Teilnahme von Engeln an der Szene eingefügt, die aus einer Wolkenumrahmung eine Krone herabreichen. Die Zeichnung dieser Engel stimmt mit dem en face gehaltenen und perspektivisch verkürzten Engel überein, der die (neue) Verkündigungsszene auf Fenster E (unterste Zeile) bekrönt. Das Klarafenster ist am reichlichsten mit ornamental angebrachten Engeln ausgestattet und bildet so einen merkwürdigen Vorläufer des später in Bayern, Schwaben und dem Elsaß wirkenden sogenannten Medaillonmeisters um I400- I420. Im übrigen wird auf dem Klarafenster mit den Grundsätzen der Perspektive voller Ernst gemacht, wenn auch die Zeichnung und Ausführung des Figürlichen noch stark an den gotischen Schematismus erinnert. Der Künstler, der die Figuren des Klarafensters gezeichnet hat, war auch an den Zwickelfiguren des Annafensters (A) beteiligt. Diese Figuren, die eine Reihe weiblicher Heiligen darstellen, scheiden sich von denen, die innerhalb der Medaillons Aufnahmen fanden und einen weicheren, von italienischen Vorbildern angeregten Gesichtsausdruck, rundlichere Formen und natürlichere Körperhaltung aufweisen. Während die Architektur des unteren Medaillons genau wie jene auf dem Medaillon der Enthauptung des Johannes in profanem Charakter gelöst ist, erscheint auf den übrigen der höchst interessante Versuch, das 
perspektivische italienische Motiv mit den Formen der deutschen Gotik zu vereinen. Am stärksten ist das Franziskusfenster von italienischem Geist beeinflußt. Die Szene mit der Basilika zu Assisi konnte nur ein Künstler zeichnen, dem jene Atmosphäre in und um Assisi genau bekannt war, und einen so lebenswahren Charakterkopf, wie ihn der im Gefolge des Papstes Innozenz befindliche Kardinal zeigt, konnte nur ein Künstler entwerfen, der sich im Leben und Treiben italienischer Prälaten genau umgesehen hatte.

Wenn nun in Niederhaslach (Johannesfenster, Bruck Tafel 42, Marienfenster Tafel 43, III, Passionsfenster 44, V, die Fenster mit dem Meßopfer, den Werken der Barmherzigkeit und der Darstellung des Apostels Johannes Tafel 44, II u. III) eine stilverwandte Gruppe zu den Königsfeldener Fenstern erscheint, so ist es nicht notwendig, den Sitz und den Ausgang der ganzen Schule in Straßburg zu suchen. Frankreich bietet nichts, was der Königsfeldener Schule hätte als Vorbild dienen können. Die Szene der Hinrichtung des Johannes Baptista auf dem Niederhaslacher Fenster hat allerdings in dem Miniaturblatt einer französischen Handschrift (Grandes Chroniques de France. Bibl. nat. man. fr. 28I 3) eine gewisse Parallele ${ }^{1}$ ). Allein die Niederhaslacher Fenster stammen aus den Jahren I360-I370, während die betreffende Handschrift erst 1375-1379 hergestellt wurde. Der Hinweis auf die Altardecke von Narbonne, die mit der Kreuzigungsgruppe des Niederhaslacher Fensters Ähnlichkeit hat, wirkt im entgegengesetzten Sinne, denn die Narbonner Altardecke ist erst in den siebziger Jahren, also wiederum erst nach den Niederhaslacher Fenstern entstanden. Man beachte ferner die merkwürdige Verwandtschaft, die zwischen den rautenförmig gemusterten Hintergründen der Königsfeldener Fenster und den genau so gemusterten Teppichhintergründen besteht, die sich auf Fresken A. Lorenzettis im Palazzo pubblico zu Siena finden. Diese Fresken sind ungefähr I 338 entstanden. Ähnliches suchen wir auf französischen Miniaturen und Gemälden vergeblich. Auch weisen die überhängenden Baldachine, die vorspringenden Konsolen, kurz

1) Für die hier und im folgenden genannten Miniaturen vgl. A. Michel, Histoire de l'art III, I. 


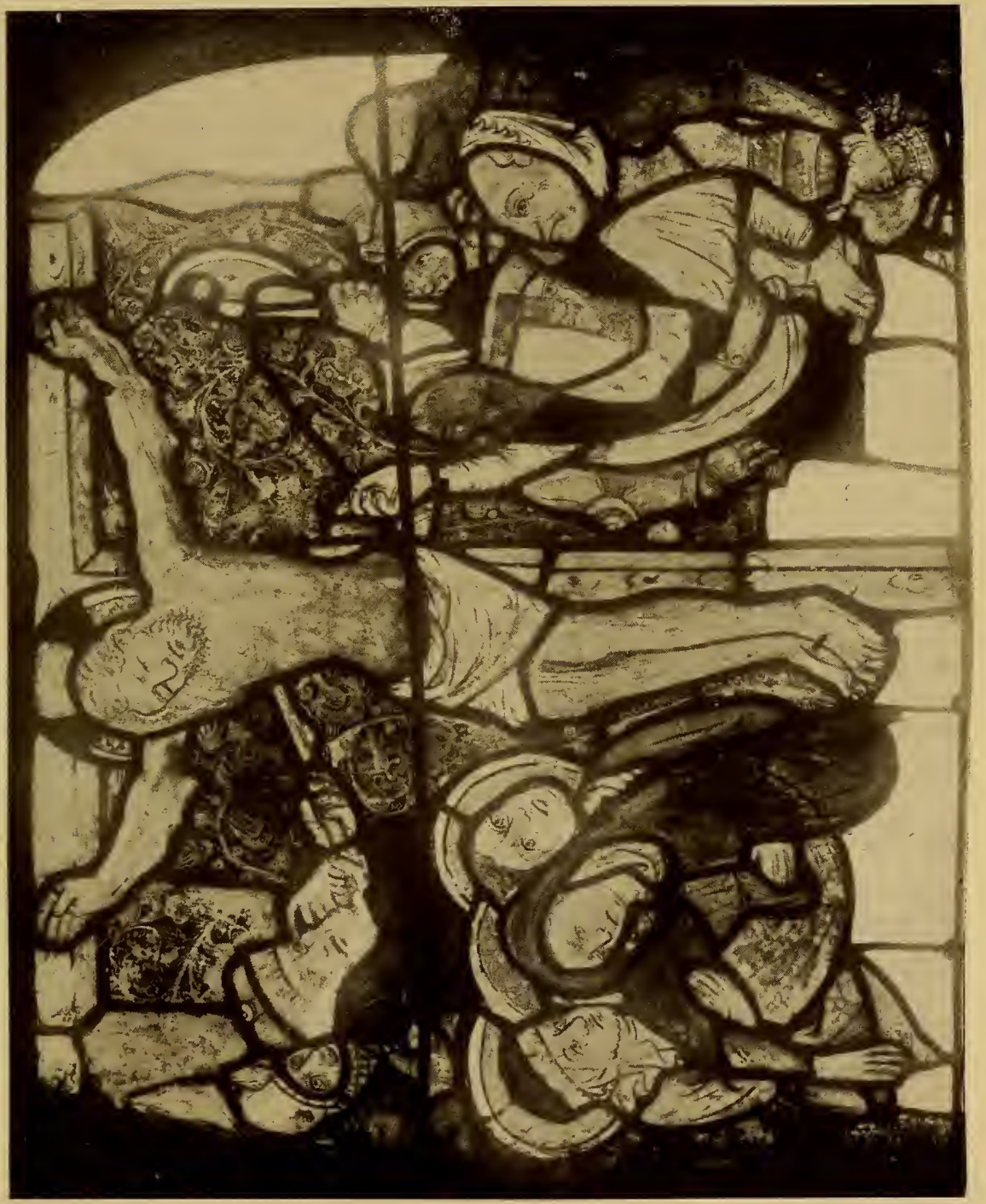

章 

die ganze Weisheit der Perspektive, die uns auf den Königsfeldener Fenstern zum erstenmal begegnet, eine weitgehende Übereinstimmung mit den Gemälden der oben angeführten italienischen Trecentisten auf. Ich möchte endlich auf eine scheinbar unbedeutende, aber gleichwohl interessante Tatsache hinweisen. Auf dem Bibelfenster der Südseite in Niederhaslach findet sich in der untersten Reihe die Szene der Verkündigung, aber nicht in der gewohnten Art und Weise. Es ist vielmehr die Idee des Ausgehens des Sohnes vom Vater versinnbildlicht. Vom Munde des Vaters geht der Sohn als Knäblein aus, um in einem Strahl in den Schoß Mariae hinabzusteigen. Eine gleichartige Darstellung fand ich auf dem Rundmedaillonfenster der Benedictuskirche in Freising, ebenso in der Frauenkirche zu München, dem Verkündigungsfenster der Nordseite des Augsburger Domes, das dem Hans Wild zugeschrieben wird, wie in etwas erweiterter Form auf einem Glasgemälde zu Friedersbach in Österreich. Hermann von Fritzlar, der im Jahre I 349 eine Legende der Heiligen schrieb, sagt, diese Sitte komme von Italien. (Das Nähere siehe Bruck S. 74.) Ein Glasgemälde zu Pistoja soll dieselbe Darstellung enthalten, und ich fand sie jüngst auch in einer italienischen Handschrift der Münchener Hof- und Staatsbibliothek (cod. 1at. 232 I5). Es ist ein Gebetbuch, das um I 350 für Branca von Savoyen, die Gemahlin Galeazzo II. Visconti in Mailand, gemalt wurde. Ähnliches hat die französische Kunst so früh nicht aufzuweisen, so daß auch diese Erscheinung für Beeinflussung der Königsfeldener Künstler durch italienische Trecentisten spricht. Die Schule nahm also in Königsfelden ihren Anfang mit Künstlern, die Giotto und seinem Kreis angehört haben. Sie wurde von dem Hause Habsburg berufen, wanderte nach Erledigung ihrer Arbeiten zu Königsfelden nach dem Oberrhein und natürlich in die neuen Habsburger Lande an der Donau (z. B. S. Florian, Wien). Auch nach Regensburg schlug ein Strahl aus, wie die Fenster zeigen, die einst die dortige Minoritenkirche schmückten und nunmehr im Bayrischen Nationalmuseum verwahrt werden.

In Prag auf der Burg Karlstein ist noch ein Rest alter Glasmalereien, die sehr zahlreich und bedeutend gewesen sein müssen (Taf. 2I). Kaiser Karl IV., ein Verwandter des franzö- 
sischen Königshauses, hat für Prag eine besondere Kunstblüte geschaffen. Als Maler wirkten an seinem Hof hauptsächlich Thomas von Modena, der unter dessen Einfluß stehende Theoderich und Nikolaus Wurmser aus Straßburg. Schmitz glaubt, daß die Berufung des Nikolaus Wurmser für die Glasgemälde der Burg Karlstein von Bedeutung gewesen sei, da sich Ähnlichkeiten zwischen dem Prager Glasgemälde und dem Florentiusfenster in Niederhaslach (Bruck, Tafel 42) feststellen ließen. Das Prager Glasgemälde, die Kreuzigung darstellend, hat Verwandtschaft mit einem ebenfalls auf der Burg Karlstein befindlichen Wandgemälde, das nach Neuwirth ${ }^{1}$ ) nicht von Thomas von Modena stammt. Darum glaubt Schmitz, daß das gegen I 380 entsțandene Glasgemälde über die Straßburg-Königsfeldener Schule nach Frankreich führt. Eine Ähnlichkeit mag ja zwischen der Altardecke von Narbonne und den Prager Bildern wohl bestehen; wenn aber aus dem Auftreten des Damastgrundes (Kar1steiner Glasgemälde) Schlüssę zugunsten einer Beeinflussung von französischen Miniaturen, die seit der zweiten Hälfte des I4. Jahrhunderts den Karrohintergrund durch Damaste ersetzt hätten, gezogen werden, so muß konstatiert werden, daß das sogenannte Gebetbuch Ludwigs des Bayern bereits den Damasthintergrund kennt. Diese mit zahlreichen Miniaturen geschmückte Handschrift ist in Italien, wahrscheinlich auf dem Römerzug des Kaisers, I327/28 angefertigt worden. (Codex lat. 6I 6 der Münchener Hof- und Staatsbibliothek.) Auch Thomas von Modena verwendet bereits den Damast als Hintergrund wie in Heiligenscheinen, während der Meister des Prager Tafelgemäldes für den Hintergrund fliesenartige Musterung, in den Heiligenscheinen aber die alten Motive der gotischen Formenwelt gebraucht. Auch ist dieser Meister von den Erinnerungen an die deutsche Gotik noch nicht frei, wie die Haltung Marias und insbesondere die des Johannes zeigt. Der Prager Glasmaler aber beherrscht die italienische Freiheit der Haltung und Bewegung der Körper, ahmt in seinen rundlichen Formen den Thomas von Modena nach. (Vg1. Zeitschrift für alte und neue Glasmalerei I914, S. I 7.)

1) Mittelalterliche Wandgemälde und Tafelbilder auf der Burg Karlstein S. 47, Taf. I8. (Siehe Taf. 2I.) 


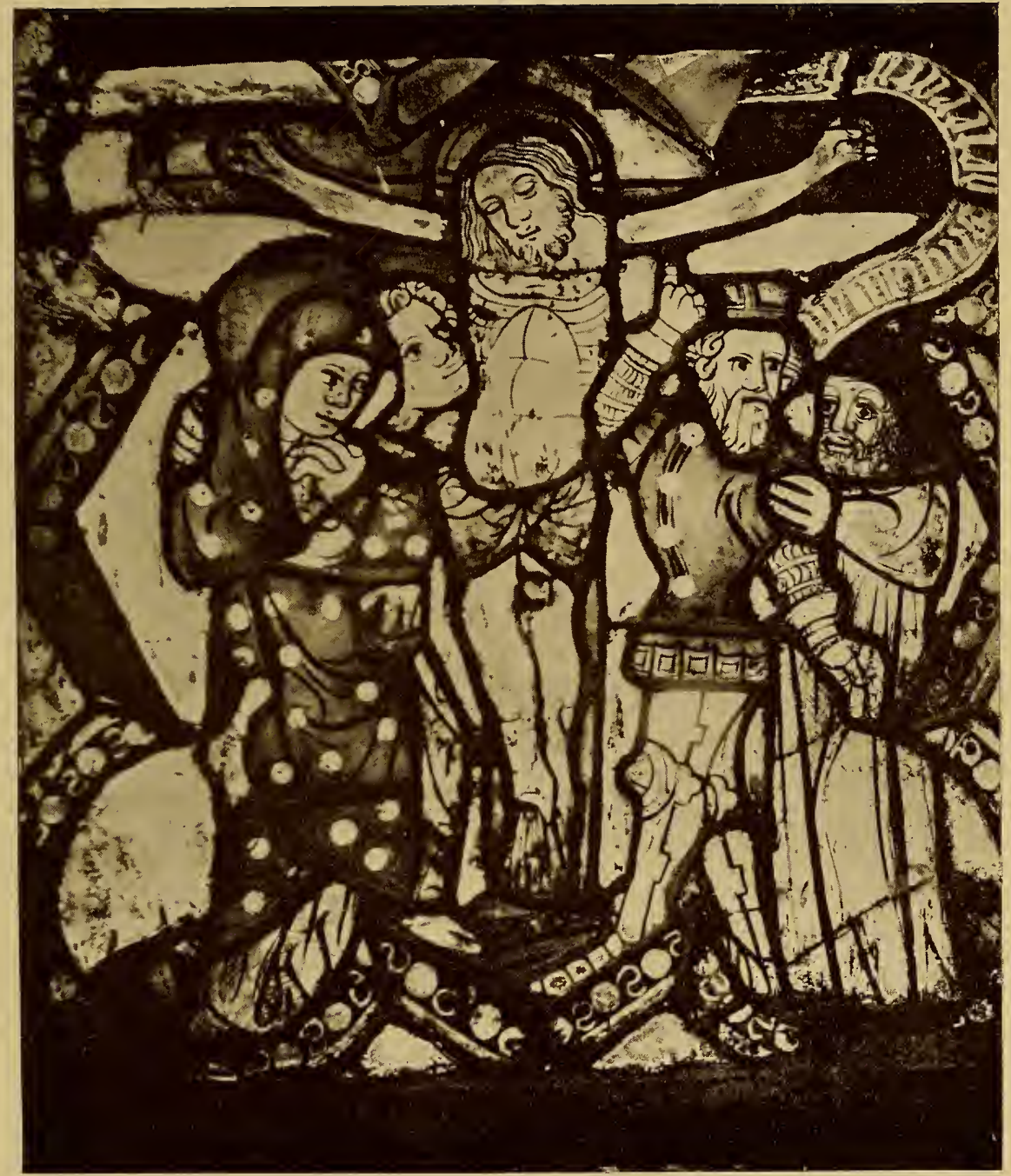

Glasgemälde einst in der Pfarrkirche zu Culm, jetzt in der Marienburg. Ende des I 4. Jahrhunderts. 

Die Arbeiten des Thomas von Modena siehe bei Neuwirth a. a. O., Tafel $\mathbf{1}, \mathrm{ff}$.

In der Pfarrkirche zu Kulm befanden sich alte Glasgemälde, die in neuer Zeit restauriert und in die Marienburg übertragen wurden. Es sind Reste eines Zyklus des Lebens und Leidens Christi, in Paßform komponiert. Unseres Erachtens hängen sie mit den Fenstern in Prag zusammen und sind eine provinzielle, aber in der Wirkung sehr rassige und kräftige Verarbeitung des in der Metropole Gesehenen. Ihre Entstehung dürfte dem Ende des 14. Jahrhunderts angehören (Taf. 22). Auf Prager Einfluß gehen auch die polnischen Glasgemälde des Domes zu Krakau zurück (Taf. 23, 24).

Die Fenster der Regensburger Minoritenkirche (Taf. 25-27) haben ihre Ausführung höchstwahrscheinlich in der Glasmalerschule bekommen, die für den Dom arbeitete. Wenigstens findet sich noch heute im südlichen Seitenschiff des Domes ein Fenster, das in vier Medaillons das Martyrium der hl. Katharina darstellt und ein bis zwei Dezennien jünger sein dürfte als die Glasgemälde der Minoritenkirche (Taf. 28). Die Hauptsache ist, daß dieses Fenster unverkennbar Verwandtschaft mit dem Stil der Fenster der Minoritenkirche hat, und andererseits wieder zu einer Gruppe von Glasgemälden weiter leitet, deren Urheber man neuerdings mit dem Sammelnamen „Medaillonmeister “ bezeichnet ${ }^{\mathbf{1}}$ ). In die Gruppe dieses Meisters bezieht Frank1 je ein Glasgemälde zu Freising, im Dome zu Augsburg, in der Frauenkirche zu München, im Münster zu U1m und in der Kirche von Altthann; als Ausgangspunkt der Schule ist nach Frankl eben Regensburg anzusehen, und zwar der Glasgemäldeschmuck der Minoritenkirche. Unseres Erachtens steht das Katharinenfenster im Dom, eine Fortentwicklung der Glasgemälde der Minoritenkirche, jener Gruppe näher. Die Paßform ist in den großen Kreis aufgelöst, den wir auf allen Fenstern der genannten Gruppe finden. Der Kreis auf den Medaillons des Katharinenfensters wird von einem Rosettenband gebildet, das wir auch auf einem Ulmer Medaillon antreffen. Man betrachte ferner die noch durch und durch fließenartige Behandlung des Hintergrundes. Das

1) Die Glasmalerei des I 5. Jahrhunderts in Bayern und Schwaben S. 7 ff. 
Klarafenster in Königsfelden weist zum erstenmal jene auffallende Beteiligung von Engeln an der Szene auf, die im Laufe der Entwicklung zu den Engelskränzen des Medaillonmeisters geführt haben mögen. Am nächsten steht der Idee des Medaillonmeisters ein Tympanonfries an dem Portal der Kirche zu Vicenza, das im Jahre I 344 ausgeführt wurde: Um das Tympanon zieht sich ein breiter mit Engeln und Heiligen ausgefüllter Halbkreis genau in der Art des Medaillonmeisters. Das Tympanon hat, nebenbei bemerkt, bereits jenen sternbesäten Grund, den wir auf so vielen Glasgemälden des I 5. Jahrhunderts finden. Es ist daher nicht unmöglich, daß der Medaillonmeister durch eine italienische Reise über Königsfelden zu seinen Entwürfen angeregt wurde.

Wir konnten bereits feststellen, daß die Fenster der Regensburger Minoritenkirche von der Königsfeldener Schule beeinflußt sind, und daß das Katharinenfenster des Doms eine Weiterentwicklung der Minoritenfenster bedeutet. Wenn nun nach Frank1 Regensburg den Ausgangspunkt für den von ihm benannten Medaillonmeister bildet, so kann das zunächst nur in dem Sinn verstanden werden, daß der Medaillonmeister Stilformen verwendet hat, die von Königsfelden nach Regensburg gelangt sind. In den Heiligen, die auf dem Annafenster in Königsfelden die Rundmedaillons umgeben, erkenne ich eine Anregung für den späteren Medaillonmeister. Vor Freising steht immer noch Rosenweiler (Bruck, Tafel 47). Girodie hat dieses gegen I 400 zudatierende Glasgemälde einer „école d'Alsace vers I400, sous l'influence de l'école de Cologne" zugeschrieben, wobei er die Verwandtschaft des Rosenweiler Fensters mit den Königsfeldener und Niederhaslacher Fenstern übersah und den italienisierenden Charakter der Rosenweiler Glasgemälde, den er sich nicht erklären konnte, für Kölner Einfluß hielt. Schon die Logosdarstellung allein auf dem Freisinger Fenster spricht für dessen Ableitung aus italienischen Anschauungen. Die letzten Wurzeln des Freisinger Fensters und seiner nächsten Verwandten liegen also bloß da und es bleibt nur die Frage offen, ob der einmalige Stoß, den die Regensburger Schule (Minoritenkirche und Katharinenfenster im Dom) von der Königsfeldener Schule erhielt, stark genug war, um bis nach Freising usw. weiter zu wirken, oder ob ein zweiter dazu notwendig war. Der Engelkranz, der 


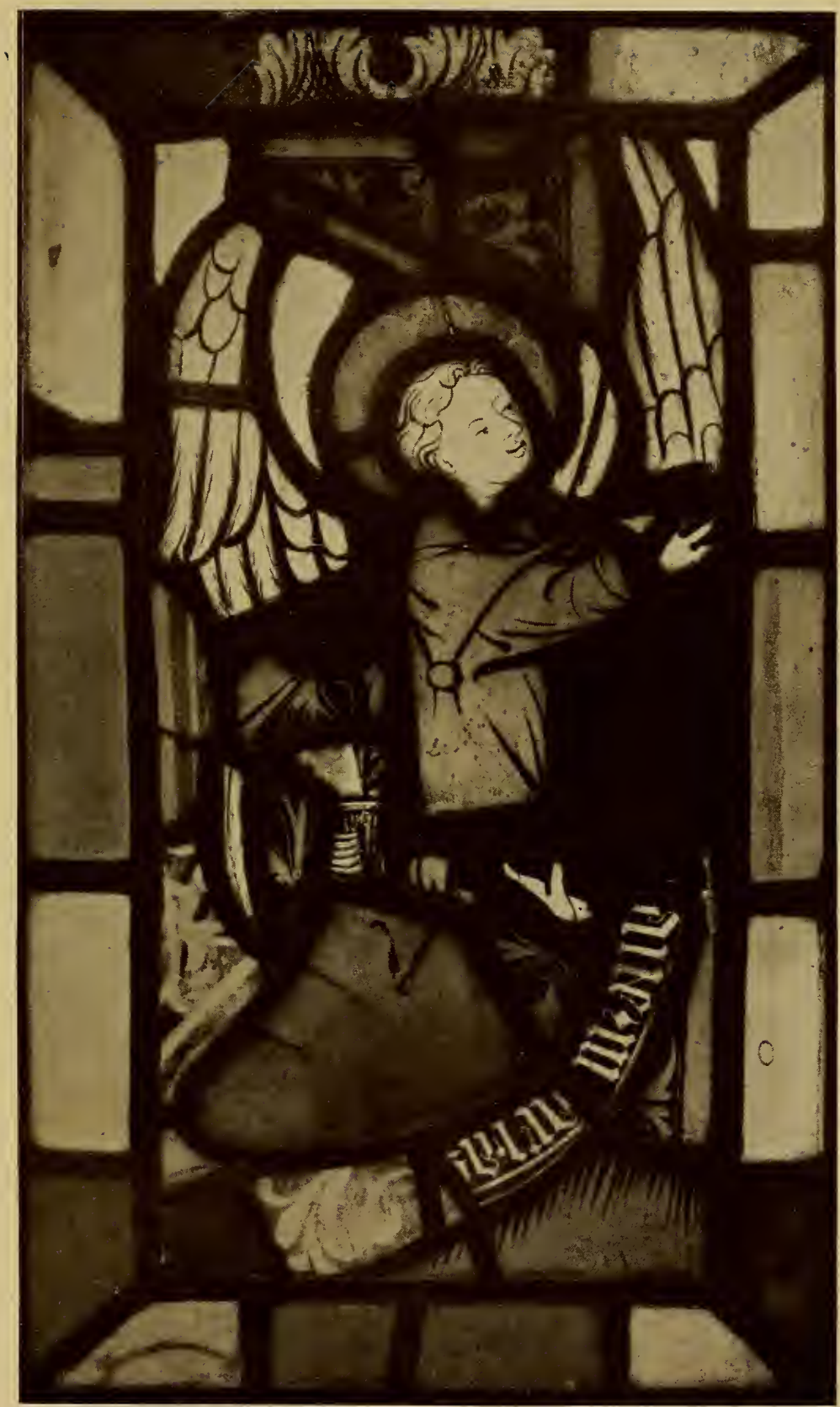

Teil einer Verkündigung. Nationalmuseum zu Krakau. Ende des I 4. Jahrhunderts. Zu Tafel 24 gehörig. 



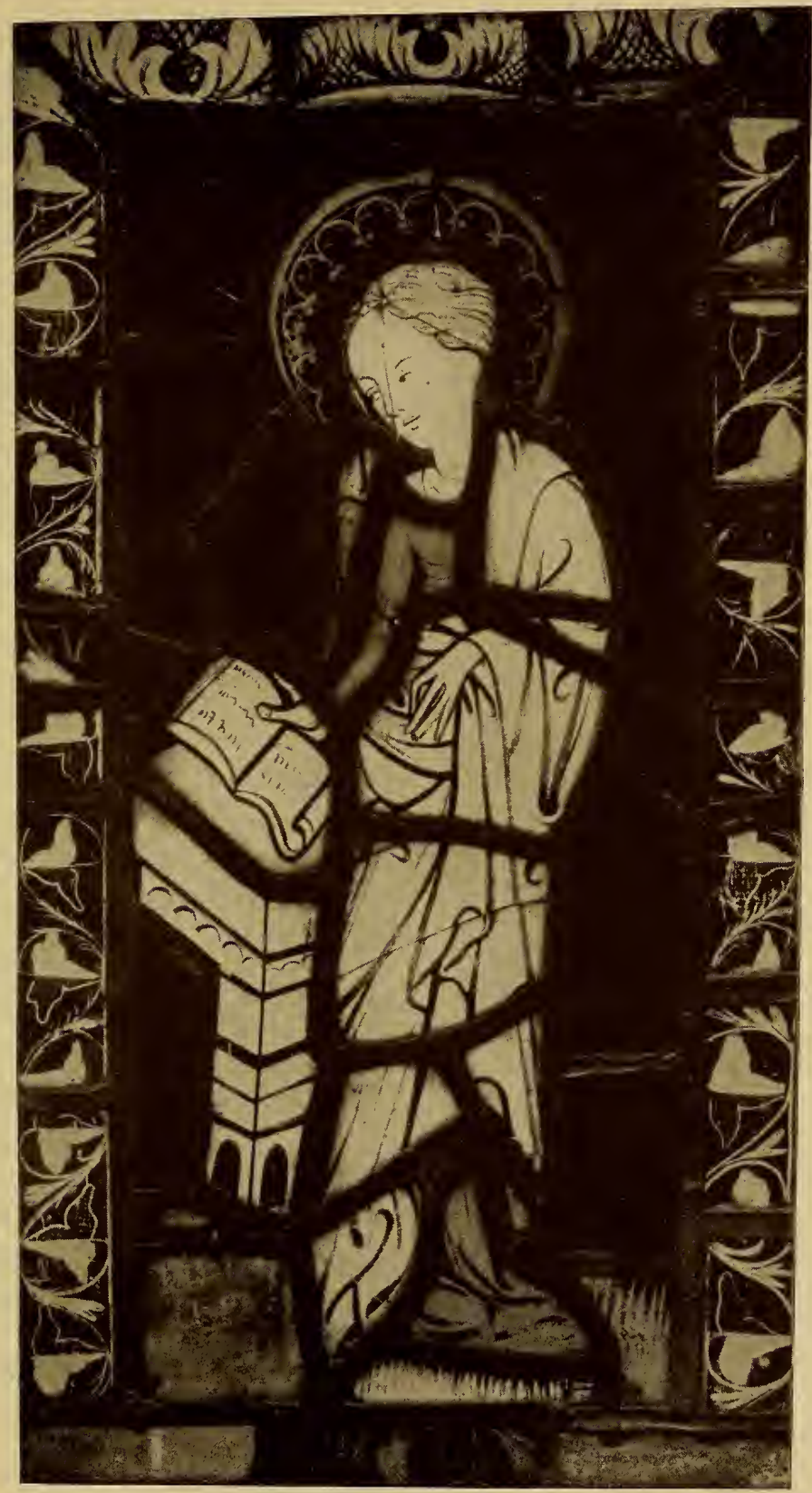

Teil einer Verkündigung. Nationalmuseum zu Krakau. Ende des I 4. Jahrhunderts. Zu Tafel 23 gehörig. 



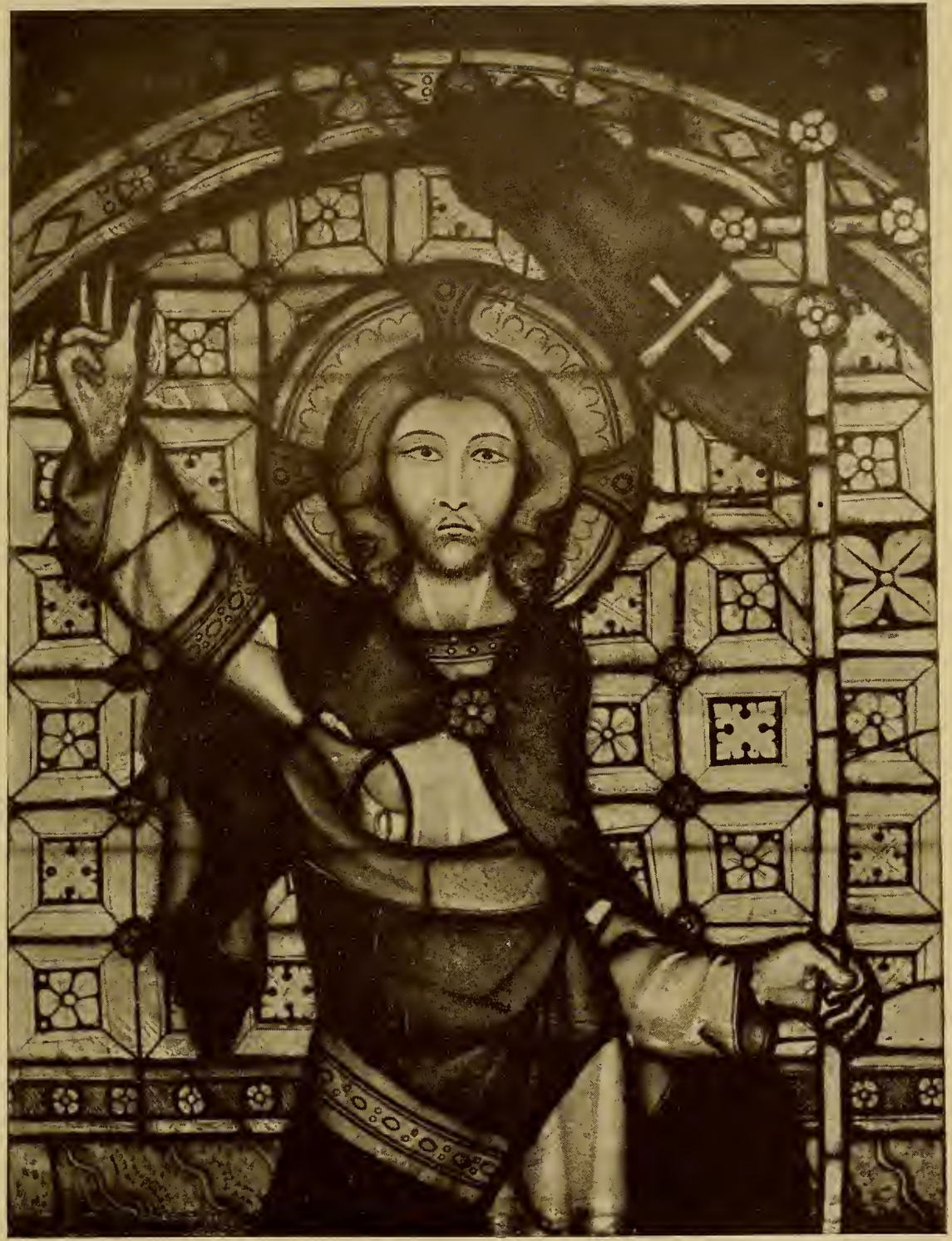

Detail aus einem Glasgemälde der Minoritenkirche zu Regensburg, jetzt im Bayrischen Nationalmuseum zu München. Um I 360. 



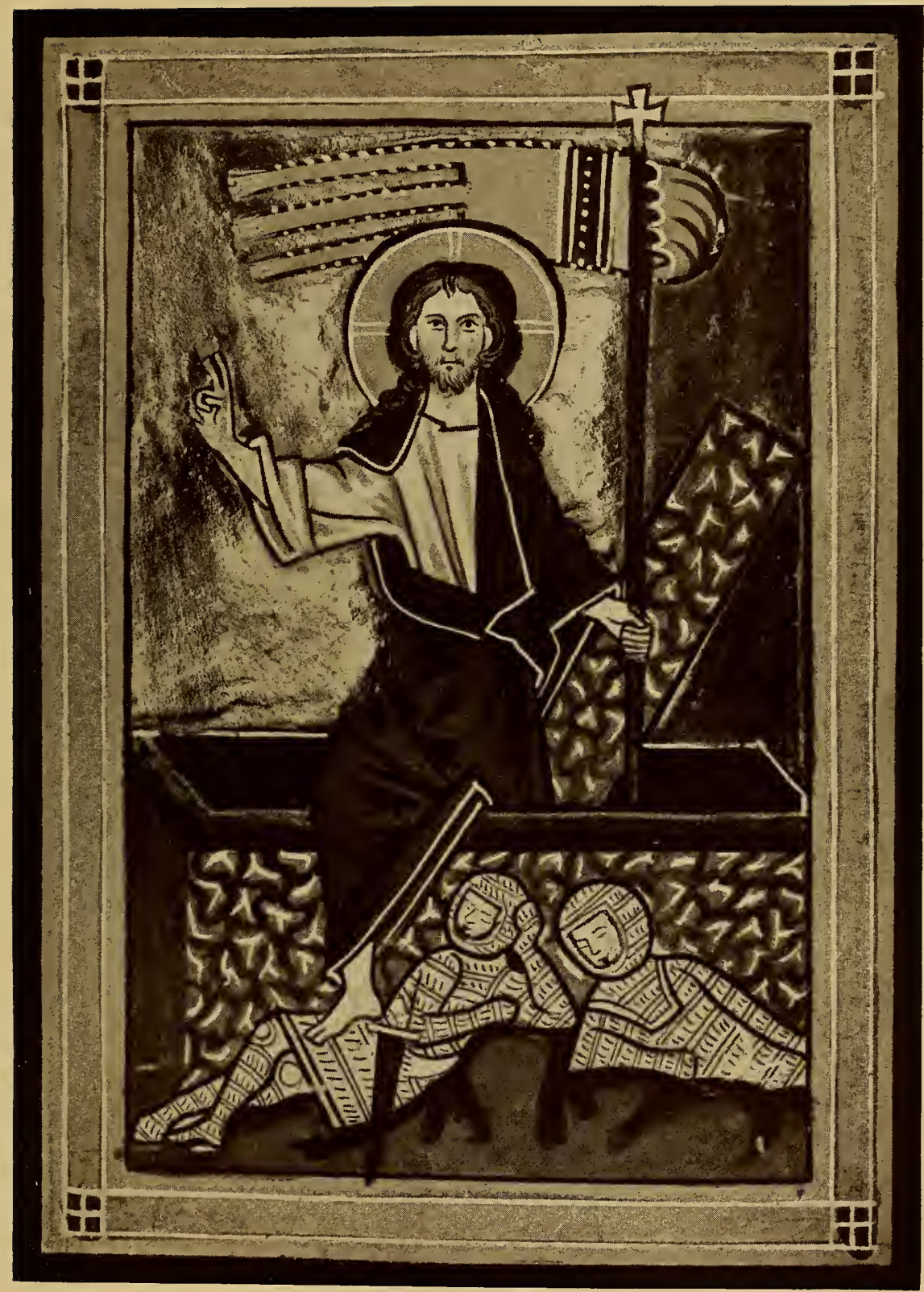

Einzelblatt aus einer Regensburger Handschrift. Hof- und Staatsbibliothek zu München. Um I350. 


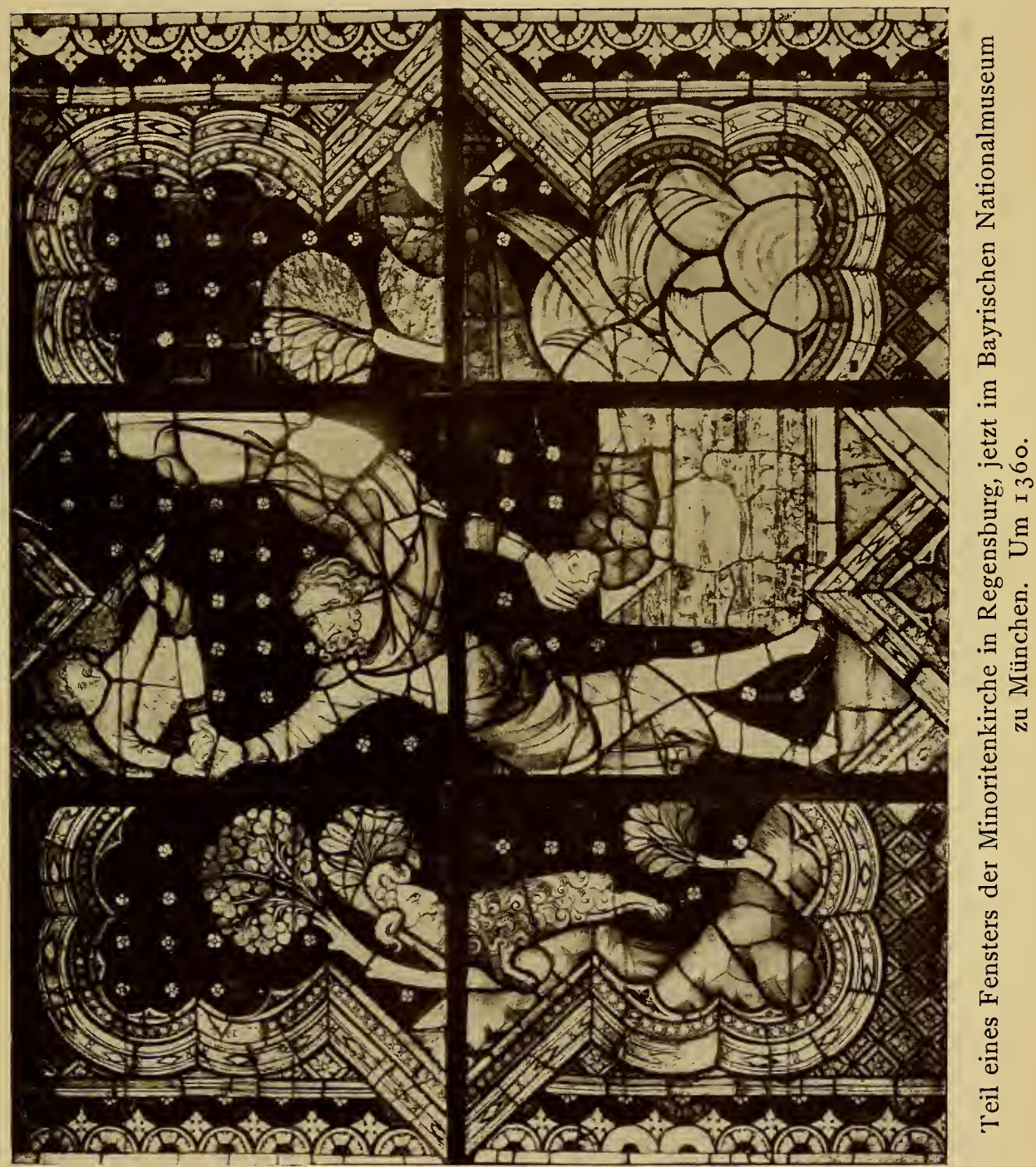



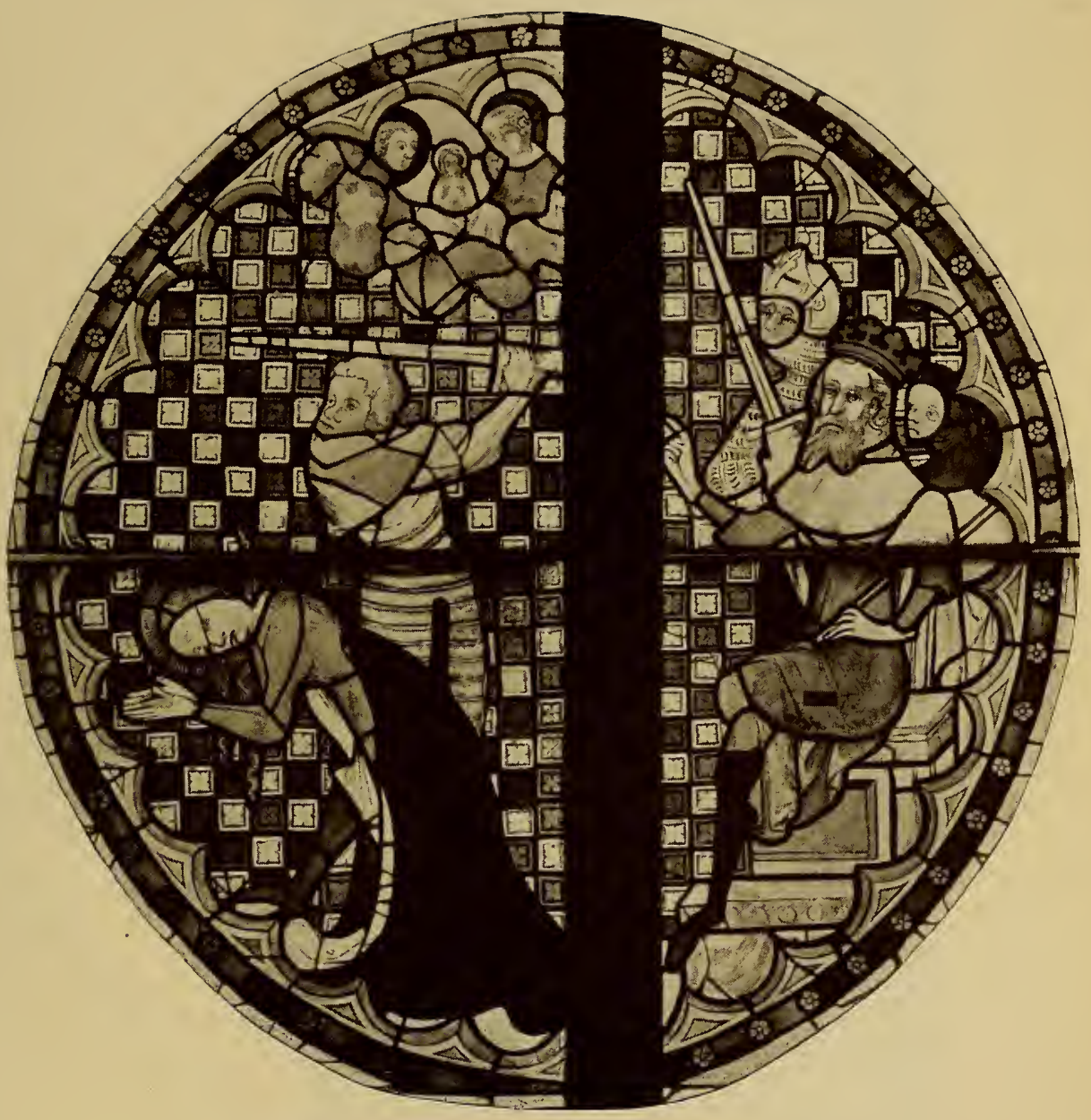

Teil des Katharinenfensters im Dom zu Regensburg. Letztes Viertel des I 4. Jahrhunderts. 

die Medaillonkreise umgibt, hat eine Parallele in dem elsässischen Hang für dramatische Belebung. Man beachte, wie die Dominikanerschule seitAnfang des I4. Jahrhunderts in Straßburg auf ihren Bibelfenstern in die Kreise der Architekturbögen Engel- und Prophetenbüsten komponierthat (z.B. Bibelfenster in der Laurentiuskircheim Straßburger Münster, vordem in der Dominikanerkirche, ferner in der Stephanskirche zu Mühlhausen, in der Frauenkirche zuEßlingen, die von Straßburg aus beeinflußt ist). Diese Fenster konnten zu dem Medaillonfenster ebenfallsweiterleiten. Zweierlei ist für die Kompositionsweise des $\mathrm{Me}$ daillonmeisters charakteristisch: Der schon genannte Engelkranz und die

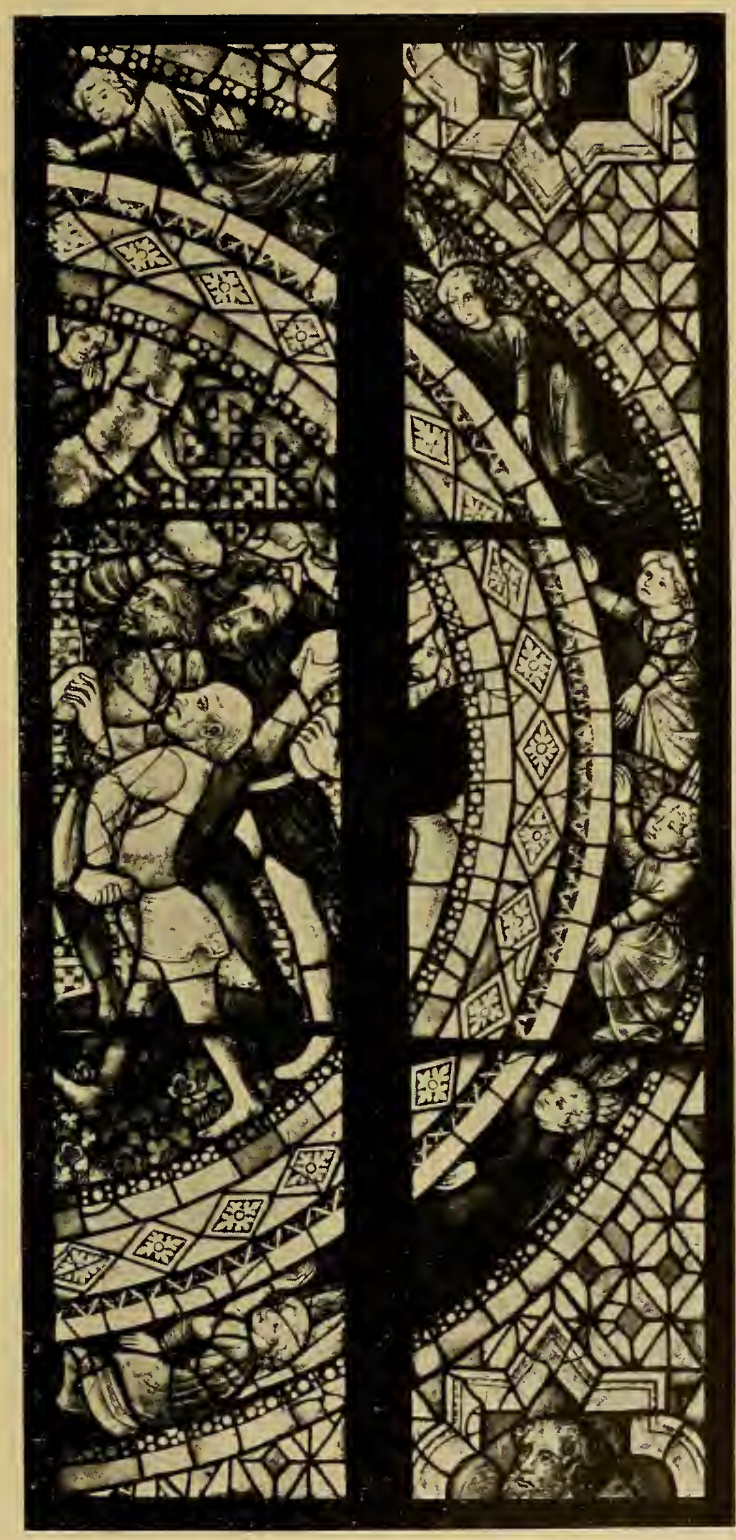

Abb. I I. Teil eines Medaillonfensters im Chor des Ulmer Münsters. Anfang des I 5. Jahrhunderts. 
auf allen Medaillons wiederkehrende Wolkenbank am Scheitel des Medaillons, von der Engel oder meistens Gott Vater in sehr bewegter Weise ihre Teilnahme an den Ereignissen bekunden. $\mathrm{Zu}$ beidem konnte Königsfelden namentlich das Klarafenster als Anregung dienen. In einem für $\mathrm{S}$. Emmeram in Regensburg I 406 hergestellten Missale (München, Hof- und Staatsbibl. cod. 1at. I 445) findet sich eine ähnliche Wiedergabe der Wolkenbank mit Gott Vater. Der Stil weist trotz seiner Verwandtschaft mit den übrigen Werken der Regensburger Lokalschule auf den Oberrhein, überhaupt den Westen, wie schon die perspektivische Fließenverkleidung der Baldachine zeigt.

Auf dem Schriftband des Münchener Rundmedaillons steht zu lesen: anno dni mccclxxxxv, vii diis octobris. obit. ... paravit hoc vitra(?)m. Mit dem Tod des (unbekannten) Stifters ist also dieses Glasgemälde einigermaßen datiert und zwar auf die Zeit nach 1395. Das Fenster enthielt mehrere Medaillons, ein weiteres Fragment von ihnen ist vielleicht in den von Schinnerer unter Nr. 97 seines Katalogs aufgeführten Scheibenresten im Bayrischen Nationalmuseum enthalten (Taf. 29). Daß diese einen anders gefärbten Hintergrund haben als das Medaillon in der Frauenkirche, beweist nicht gegen ihre Zusammengehörigkeit, da die Tinktur des Hintergrunds erfahrungsgemäß sehr häufig in korrespondierender Weise gewechselt wurde. An die Medaillons von München schließen sich die Scheiben der Benedictuskirche in Freising zwischen I 400-I4IO, daran die von Augsburg. Leider sind nur noch zwei letzte Repräsentanten des Zyklus erhalten, ein Fenster in U1m und eines in Thann. Mit diesen Konstatierungen sind wir bei den höchst merkwürdigen Beziehungen zwischen Ulm und Thann angelangt (Abb. I I). Zum erstenmal tauchen diese in den letzten Dezennien des I4. Jahrhunderts auf und zwar in der Reliefplastik. Das Südwestportal des Münsters zu Ulm weist bei Darstellung der Dreikönigslegende Szenen auf, die nur noch in Thann, im Dreikönigsfenster zu Bern und zum Teil am Tympanon des Westportals in Haßfurt vorkommen. Es sind die drei Wunder, durch die jeder einzelne der drei Könige zu seiner Reise nach Jerusalem angeregt wurde. Diese Wunder sind in dem Gedichte des alamannischen Dichters Walther von Rheinau auf Grund einer aus Italien stammenden Bearbeitung in metrische Form gefaßt worden 


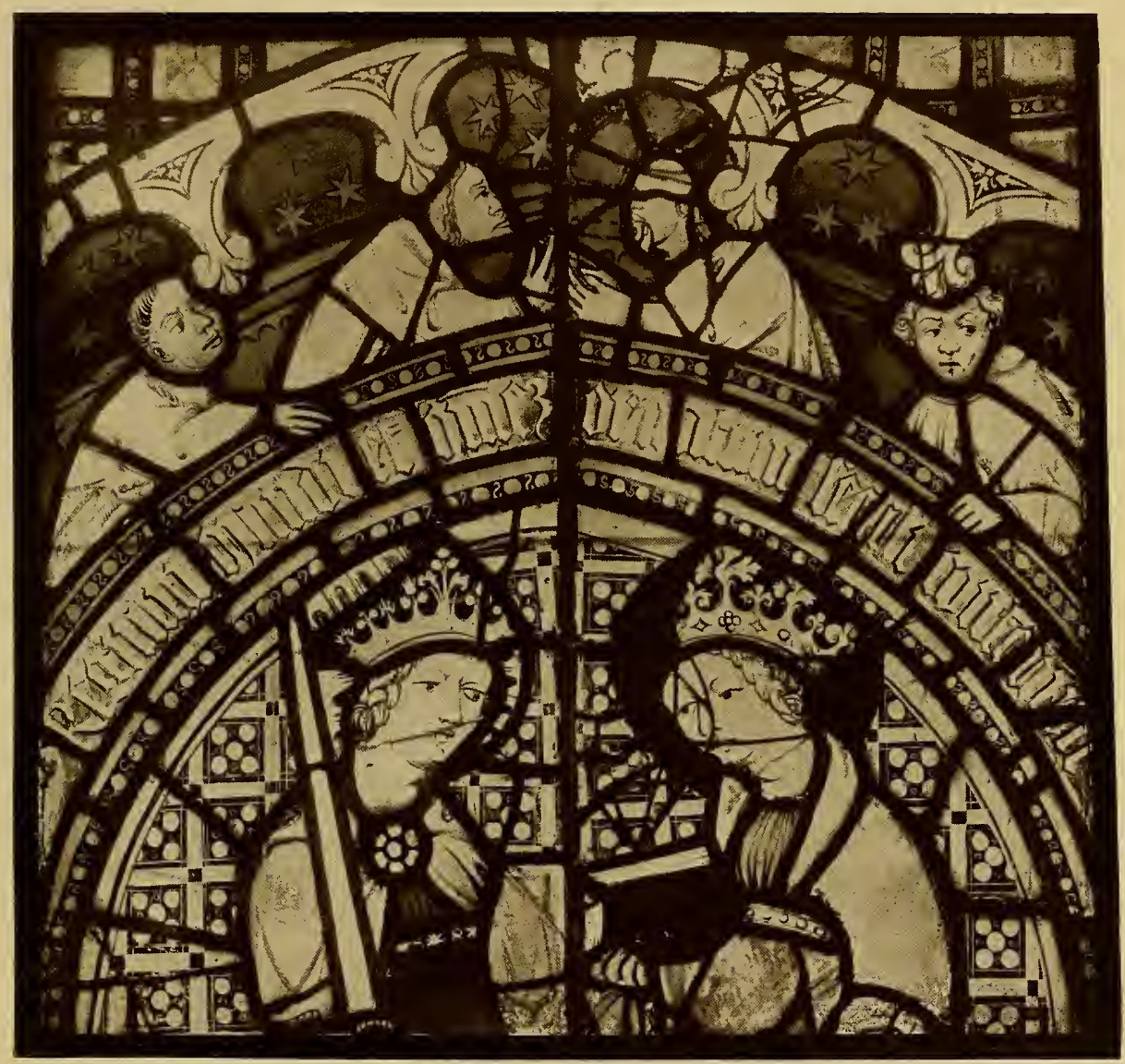

Teil eines Medaillonfensters im Bayrischen Nationalmuseum zu München. Anfang des I5. Jahrhunderts. 

und bilden die Quelle, aus der der Bildhauer von Thann und U1m geschöpft hat. Im Stil schließen sich die beiden Reliefplastiken direkt an Giovanni Pisano (Pisaner Domkanzel) an. Wir begegnen also auch hier dem italienischen Einfluß, den ich seit der Königsfeldener Schule, die u. a. nach Regensburg Ausläufer sandte, während des I4. Jahrhunderts auf oberrheinischen und schwäbischbayrischen Glasmalereien fand. Ob nun Ulm oder Thann zuerst sein Medaillonfenster bekommen hat, müßten urkundliche und baugeschichtliche Funde lehren, da eine stilkritische Untersuchung schon deswegen $\mathrm{zu}$ keinem Ziele führt, weil von beiden Fenstern viel zu wenig erhalten ist. Jedenfalls hat das Ulmer Fenster, wie schon die Umrahmung und der Hintergrund zeigt, in einem Achtpaß-Fenster der Frauenkirche zu München einen letzten Ausläufer gefunden, dessen Meister allerdings auch schon die Glasgemälde der Bessererkapelle im Ulmer Münster kennt (Taf. 30). Frankl erklärt dieses Münchener Fenster für die Darstellung der fünf Freuden Mariae und rechnet zu den vier erhaltenen Szenen noch eine in einem anderen Fenster eingesetzte Verkündigung - die bezeichnenderweise wieder mit der Logosdarstellung ausgeführt ist. - Nun gibt es allerdings nicht fünf, sondern sieben Freuden Mariae, als Pendant zu den sieben Schmerzen Mariae, und wenn Frankl etwa die fünf Geheimnisse des freudenreichen Rosenkranzes gemeint haben sollte, so würde zwar die Zahl, nicht aber der Inhalt (Verkündigung, Heimsuchung, Geburt, Aufopferung im Tempel, Wiederfinden des zwölfjährigen Knaben gegen Verkündigung, Geburt, Anbetung der hl. drei Könige, Darstellung im Tempel, Mariae Tod) auf den Münchener Fenstern stimmen. Wahrscheinlich handelt es sich um die Reste eines mariologischen Fensters. In den Kreis dieses Meisters gehört auch die Dreikönigsscheibe, die sich in Garmisch befand. Ich möchte auch auf die merkwürdigen Berührungen des Fragments im Nationalmuseum mit einer Scheibe hinweisen, die sich heute im Museum zu Genf befindet. Lehmann, der diese Scheibe bespricht und abbildet (Nr. 83, a. a. O., S. 428, (274), hält sie für eine burgundische Arbeit.

Das I4. Jahrhundert war, wie wir im Vorausgehenden gesehen haben, die Periode stärksten Einflusses des italienischen Trecento auf die süddeutsche Glasmalerei. Dadurch bekommt sie eine gewisse Frische gegenüber der in Köln allmählich ein- 
setzenden Gleichmäßigkeit und Langweile. Bouchots Ausführungen, die in dem Versuch gipfelten, die Priorität der trecentistischen Ideen und Formen für Frankreich zu Ungunsten Italiens in Anspruch zu nehmen, haben uns nicht überzeugt, da die ganze perspektivische Neuheit samt dem übrigen Realismus in Italien seinen Ausgang genommen hat. Damit soll nicht übersehen werden, daß sich die französische Hofkunst des I4. Jahrhunderts außerordentlich kräftig und selbständig entwickelt hat. Wie dem auch sei, bis zum Ausgang des I4. Jahrhunderts hat die süddeutsche Glasmalerei ihre Impulse von Oberitalien bekommen. Das änderte sich mit der Jahrhundertwende.

\section{Die oberrheinischen und ostdeutschen Schulen des}

\section{Jahrhunderts.}

Die überaus glücklichen Verhältnisse, die den gesegneten Landen rechts und links vom Oberrhein während des I 5. Jahrhunderts eine so außerordentliche Blüte der Kunst und Kultur gebracht haben, sind schon oft von kundiger Hand dargestellt worden. Übereinstimmend weisen die Schriftsteller dieses schönen Säkulums auf die günstige wirtschaftliche und exponierte politische Lage, die Verbindungslinie zwischen Italien und Frankreich hin, die ja auch den Städten Konstanz und Basel die stattliche Heerschau von Prälaten und Fürsten auf zwei Konzilien zugeführt hat. In der Isle-de-France und in Burgund war die Kunst Luxusund Hofsache geworden. Die Künstler führten außer Pinsel und Meißel in der Regel den goldenen Schlüssel eines Kammerherrn; diese Einbeziehung in den Hofdienst brachte den Künstlern viele Reisen, auf denen sie gaben und nahmen, wie dadurch andererseits eine Zentralisierung und Schule, ja sogar die Ausbildung einer starkgefärbten Persönlichkeit gefährdet war. Die Bedürfnisse der Fürsten an künstlerischer Arbeit waren, eben weil es sich um höfischen Luxus handelte, sehr groß, man denke an die verschwenderischen Ausstattungen der Mathilde von Artois, des Herzogs von Berry, man denke an die Kartause von Dijon, um nur das Bekannteste zu nennen. Kein Wunder, daß die Fürsten alles an ihren Hof zogen, was künstlerisch irgendwie bedeutend war; so treffen wir an französischen Höfen nicht nur niederländische Namen, sondern auch gut deutsche, wie den des 


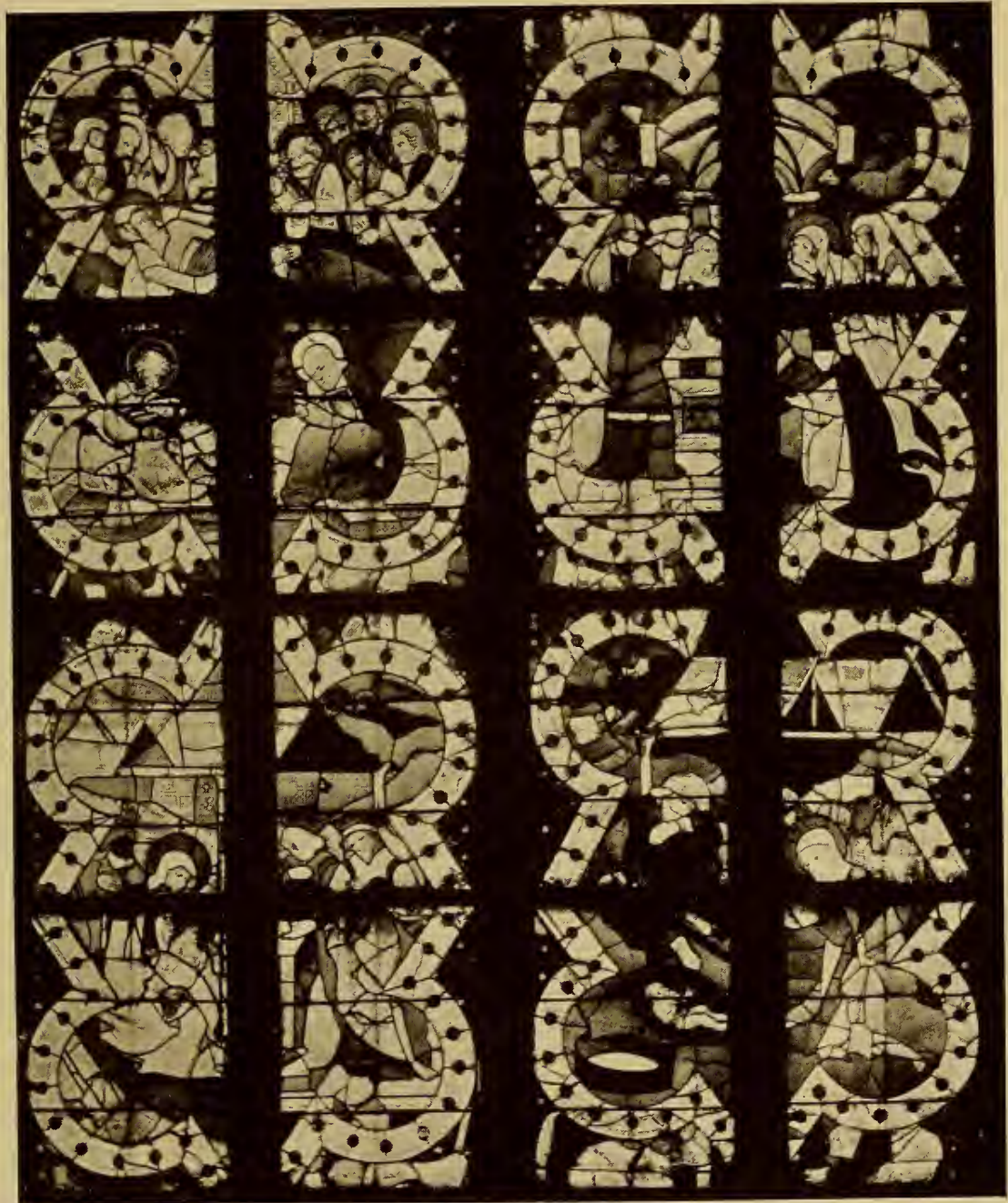

Zusammengestellte Szenen aus einem mariologischen Fenster. Frauenkirche zu München. Um I 430. 

Hänslein von Hagenau und Hermann von Köln. Die Folge ist, daßsich vom Rheinknie bis Straßburg abwärts ein künstlerischer Meinungsaustausch entwickelt, daß alle Fortschritte der Kunst, mögen sie in den blühenden Städten Oberitaliens, an den Höfen prachtliebender Fürsten oder auf den breiten Märkten aufstrebender Reichsstädte gemacht werden, sich über die Geleitstraße vermitteln. Den größten Nutzen aber hat derOberrhein. Wohin sich die neuen Männer mit ihren großen Anregungen wenden, überall streuen sie den Samen zu Lokalschulen aus, sofern sich ihnen großeZiele bieten. Aber diese Lokalschulen bleiben nicht zurück, wie dies früher des öfteren der Fall war, sie entwickeln sich vielmehr so kräftig, daß sie manches an den Oberrhein zurückgeben, was sie an der Stätte ihres Wirkens herausgebracht haben. Die

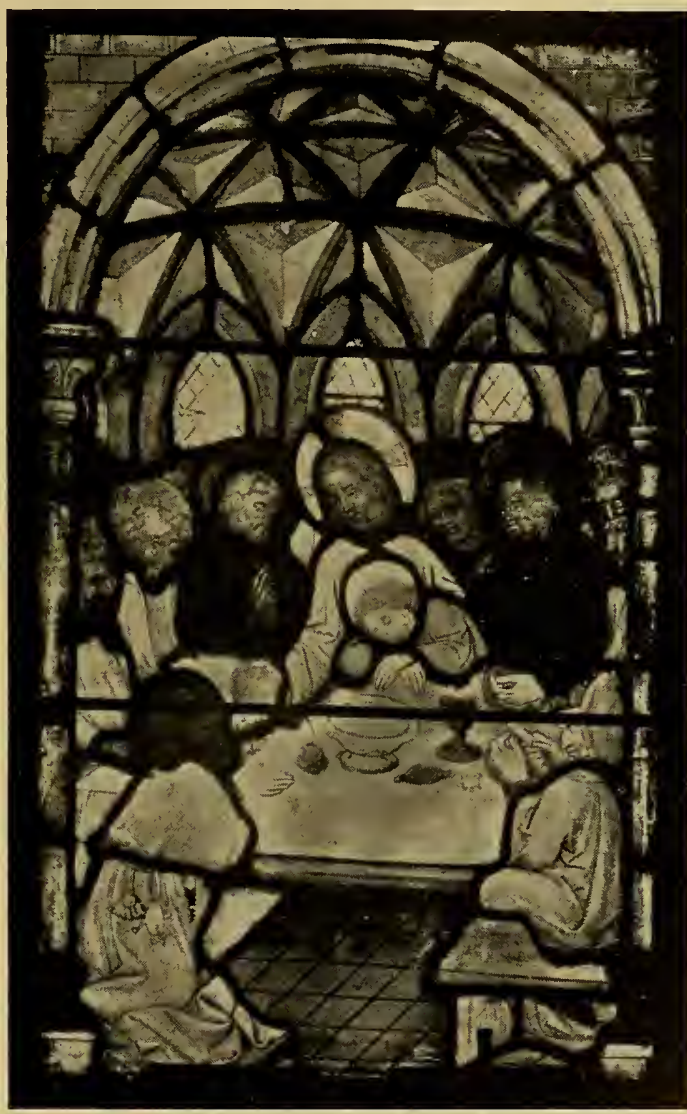

Abb. I2. Scheibe aus den Fenstern der Bessererkapelle im Münster zu UIm. Um I 420.

\section{Entwicklung der}

Städte und des Zunftwesens, der vermehrte Bedarf an Kunstwerken förderte jenes künstlerische Schaffen, so daß das Kunstleben einem Blutkreislauf glich, der alle neuen Impulse an die Peripherien führte. Schon beginnt auch der Einfluß der Tafelmaler auf die Glasmaler, natürlich im Verein mit 
der Einwirkung der Illuministen (enlumineurs). Von Moser und den beiden Witz, von Tiefenthal und von dem Meister Hermann von Köln gingen auf die Glasmalerei Einflüsse aus, die zwar aktenmäßig nicht zu belegen, aber stilistisch ohne Mühe nachzuweisen sind. Man hat der französisch-niederländischen Miniatur des ausgehenden I4. Jahrhunderts den größten Anteil an der Entwicklung der oberrheinisch-elsässischen Glasmalerei zugeschrieben und weist zur Stärkung dieses Satzes auf die zahlreichen Miniaturen, die aus den Ateliers der Jean d'Orléans, Jean Petit, Jean d'Artois, Jean de Beaumetz, Jan Malouel, Melchior

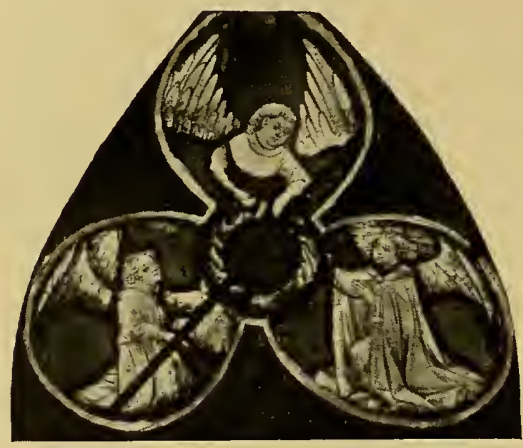

Abb. 13. Maßwerk aus einem Fenster der Bessererkapelle im Münster zu Ulm. Um 1420 .

Broederlam, lauter Vertreter der seit ca. I 370 blühenden Burgunderschule hervorgegangen sind, sowie auf den Kreis um den Herzog von Berry. In diesen Ateliers wurden zah1reiche Livres d'heures Stundenbücher (Gebetbücher) auch Illustrationen von lateinischen und italienischen Dichtern, sowie von Kalendern geschaffen, die sich in einer relativ hohen Anzahl erhalten haben. Auch ich würde diese Abhängigkeit der Glasmalerei von der französischen Miniatur ohne weiteres anerkennen, wenn nur nicht das Gebetbuch der Blanca Maria von Mailand wäre, das um I 350 alle wesentlichen Eigenschaften des neuen Stils in behaglicher Fülle Seite für Seite ausbreitet. Es soll damit nicht behauptet werden, daß die französische Kunst ohne Einfluß auf die Glasmalerei gewesen wäre. Aus dem französischen Kunstkreis stammen insbesondere die Fliesenbekleidung von Fußböden und Plafonds, die sich bereits in einer Handschrift des Klosters S. Emmeram in Regensburg finden, die im Jahre 1406 , also zur Zeit des sogenannten Medaillonmeisters angefertigt wurde. Aus Frankreich stammt auch jener kräftige Realismus, der bei der Zeichnung nichtheiliger oder gar roher Personen sich keineswegs an der Wahrheit stoßt, sondern ins Häßliche und Abschreckende über- 


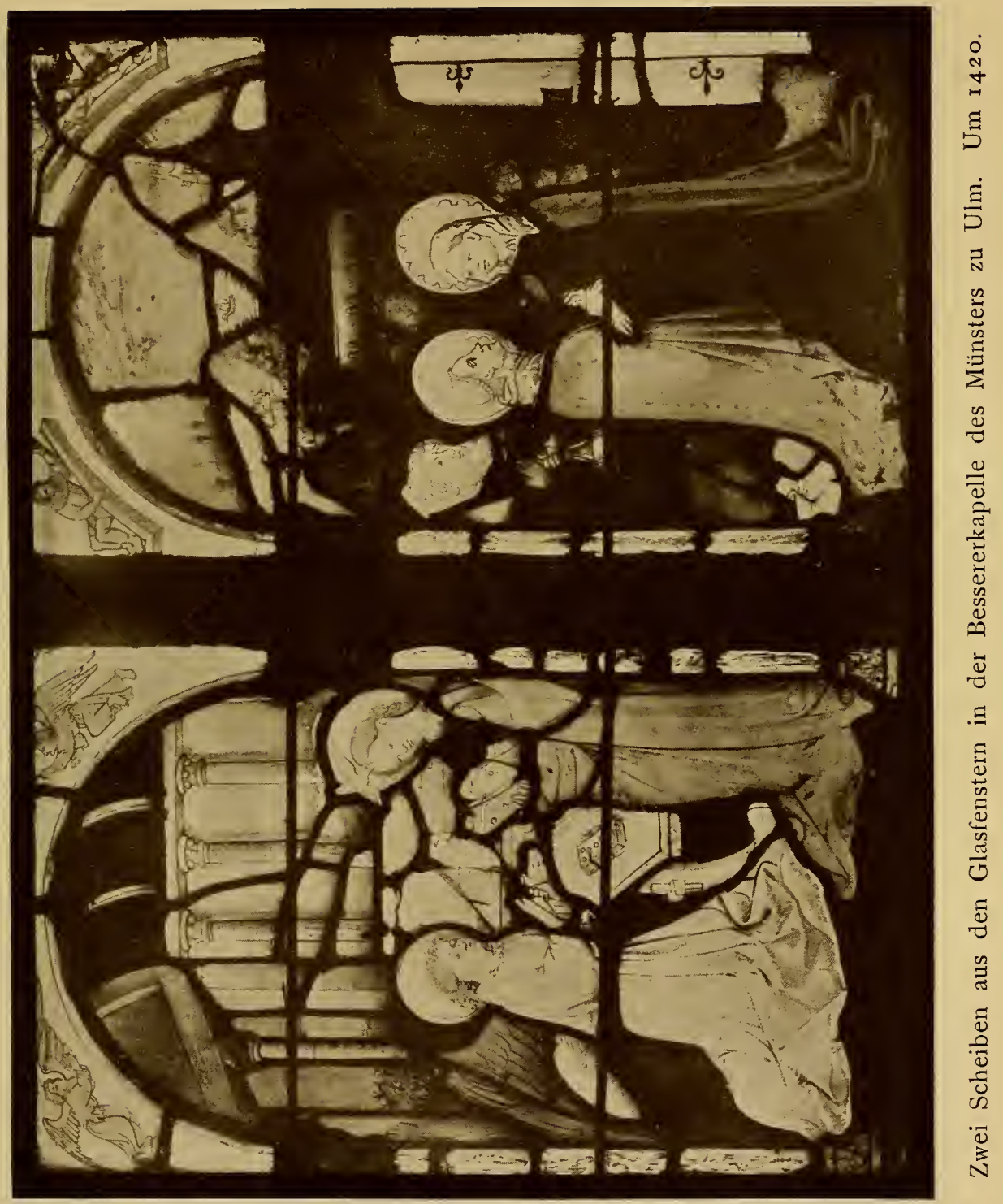



treibt. Dazu hat vor allem die Kunst des Claus Slüter mitgewirkt, die wir in Glasmalerei umgesetzt, auf verschiedenen Fenstern $\mathrm{zu}$ Thann finden. Indes hat der Realismus erst durch deutsche Meister seine volle Entfaltung bekommen. Aus der französischniederländischen Schule stammt endlich die kräftige Betonung der Landschaft. In der Beherrschung der Landschaft haben sich unter den Deutschen besonders Konrad Witz und Lucas Moser hervorgetan. Unter der Inspiration des Lucas Moser mögen jene prachtvollen Glasgemälde entstanden sein, die heute noch die Kapelle der Familie Besserer im Münster zu Ulm schmücken (Abb. I2-I4, Taf. 31). Nach Ausweis der Hüttenbücher des Ulmer Münsters bekommen in den Jahren I4I7-I42I "maister Jakob der mauler" und der "mauler Lukas" Zahlungen für Glasgemälde. Einmal steht dabei „von den venster $z u$ bletzen (Plätzen) der Bierbruwer"1). Man hat unter dem mauler Lukas wiederholt den Maler Lukas Moser erkennen und in den Zahlungen die Ausgaben für die Bessererfenster sehen wollen. Das letztere stimmt sicher nicht, da die Bessererfenster als Stiftungen dieser Familie auch von dieser bezahlt wurden. Auch der Hinweis auf Multscher, als den Inspirator der Scheiben, den Stadler in seinem Buch über H. Multscher

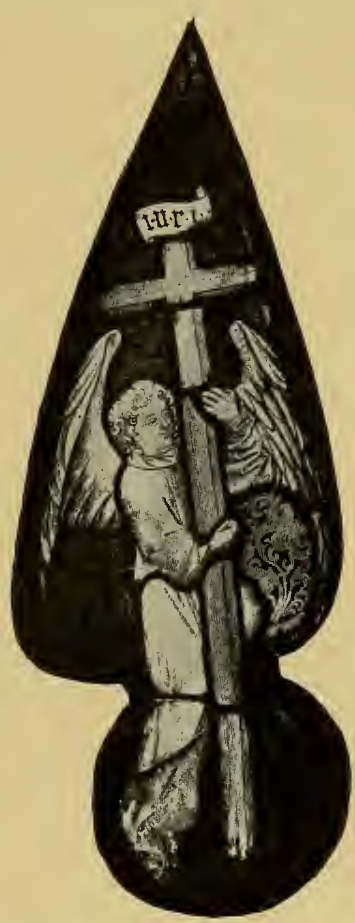

Abb. 14. Maßwerk aus einem der Bessererkapelle im Münster zu Ulm. Um I 420. gemacht, wird, soviel ich sehe, allgemein abgelehnt. Es müßte erst einmal bewiesen werden, daß Multscher wirklich Maler war und wenn er es war, dann würde ich seine Hand im Einklang mit Stadler auch eher in den Glasgemälden der Bessererfenster suchen, als auf den im Wert weit hinter diesen Glasmalereien und den beglaubigten Bildhauerarbeiten des Meisters stehenden Tafeln des Wolfegger und Sterzinger

1) Vgl. K. Habicht in Repertorium für Kunstwissenschaft 1910, S. 446. 
Altars. Mehr Ansprechendes hat der Hinweis auf Lukas Moser. Wenn man den Hintergrund der Anbetung der heiligen drei Könige oder der Szene Christus als Gärtner auf dem Freiburger Fenster, das, wie wir später sehen werden, ebenfalls von dem Meister der Bessererfenster stammt, mit dem Flügel des Tiefenbronner Altars vergleichen, der die Meerfahrt der Heiligen darstellt, so müssen wir die nahe Verwandtschaft beider Arbeiten ohne weiteres anerkennen. Auch in der Behandlung perspektivisch gezeichneter Räume berühren sich Tiefenbronner Altar und die Glasgemälde der Besserer Kapelle. Ob aber Moser mit jenem "lukas“ direkt identisch ist, scheint gleichwohl zweifelhaft. Für den Ausgangspunkt des Meisters der Bessererfenster bietet Melchior Broederlam einen Anhalt und zwar näherhin seine Altarbilder für Dijon. Bei ihm erscheinen zum erstenmal perspektivisch vertiefte Frontansichten gotischer Kirchenräume, wie dies auch auf den Scheiben des Abendmahls, der Fußwaschung, Kreuztragung, Geißelung und den Wappenscheiben der U1mer Glasgemälde $\mathrm{zu}$ beobachten ist. Man vergleiche ferner die Zeichnung der Mutter Anna auf dem Gemälde Broederlams mit der Anna auf der U1mer Heimsuchungsscheibe. Von weiteren Werken des Meisters der Bessererfenster ist mir nur ein Fenster in Freiburg i. B. bekannit geworden. Es enthält drei biblische Szenen: Christus als Gärtner, die Auferstehung und Himmelfahrt, sowie Christus als Weltenrichter. Es sind kleine Varianten zu den Ulmer Fenstern, von demselben Meister ausgeführt (Taf. 32).

Seit dem dritten Dezennium des I 5. Jahrhunderts dringt in die Glasmalerei ein außerordentlicher Reichtum von Architekturformen ein. Dabei scheiden sich zwei Klassen. Die eine übernimmt aus der italienisch-französischen Buchmalerei Elemente und Raumdarstellungen, die sich mehr an profane Bauten anschließen, während die andere mit der monumentalen Kirchengotik arbeitet und die in große Dimensionen erweiterten Architekturen mit zahlreichen Engeln bevölkert. Bis ein besserer Beweis gelungen ist, halten wir Giotto für die Quelle, aus der die Glasmalerei Perspektivenzeichnung und Raumvertiefung geschöpft hat ${ }^{1}$ ). Unter den französischen Primitiven, die jetzt in

1) In dem „Handbuch der Kunstgeschichte“ unternimmt Fr. Burger den Versuch, die südfranzösische Kunst (Avignon) als das anregende Element in Anspruch zu nehmen. 


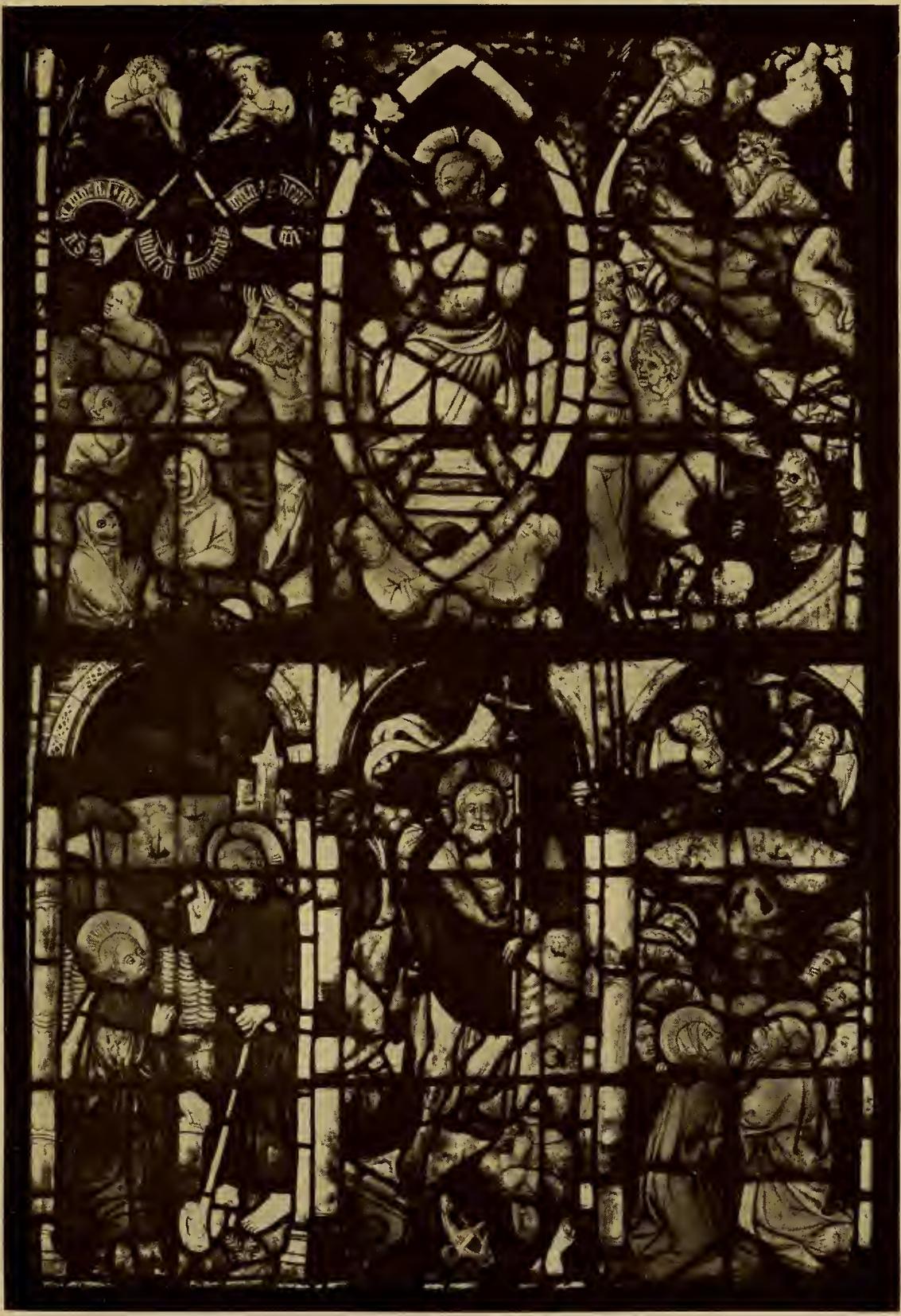

Glasgemälde vom Meister der Bessererfenster in Ulm. Münster in Freiburg. $\mathrm{Um} \mathrm{I} 420$. 

einer Prachtausgabe vorliegen, fand sich nichts, was diese Anschauung erschüttern könnte. Andererseits war die Verbindung mit Italien nicht so stark, daß sie allein vermocht hätte, die Glasmalerei des 15. Jahrhunderts zu befruchten. Darum stand der Oberrhein, das Hauptzentrum glasmalerischen Schaffens, den Einflüssen der französischen Miniatur völlig offen. Seltsamerweise hat die französische Miniatur und Malerei die heimische Glasmalerei nicht in gleicher Weise angeregt, wie den Entwicklungsgang der deutschen Glasmalerei $\left.{ }^{1}\right)$. Das hängt mit dem ausgesprochen höfischen Charakter der französischen Kunst zusammen. Die Prachtliebe der Fürsten, das Bestreben sich vor den übrigen Volksgenossen hervorzutun, die enge Verflechtung der Künstler in den Hofdienst, läßt die Vermutung aufkommen, daß die Fürsten nicht wünschten, daß ihre Künstler auch noch für Gemeinwesen, oder sonstige Auftraggeber, arbeiteten. Damit würde denn auch der schon besprochene Mangel einer eigentlichen Schulbildung zusammenhängen. Wie dem auch sei, jedenfalls hat der Oberrhein von den Franzosen wiederholt Anregungen empfangen, diese verarbeitet und nach den schwäbischen, bayrischen und österreichischen Landen weiter gegeben. Nach Girodie $^{2}$ ) hat sich diese Beeinflussung im einzelnen folgendermaßen abgewickelt: Um I4IO wurden die Glasgemälde in Thann auf Kosten der Katharina von Burgund, der Tochter Karls des Kühnen, begonnen. Möglicherweise verdanken sie ihre Entstehung den Ateliers des Hans Witz und Hans Tieffenthal, Künstlern, die unter dem Einfluß der französischen-niederländischen Vorläufer van Eycks standen. Wenn Girodie Recht hat, daß während des Konstanzer Konzils an den Thanner Fenstern gearbeitet wurde, so wäre damit auch die auffallende Verwandtschaft des von den Montforter Grafen gestifteten Glasgemäldes zu Eriskirch, mit dem zwar späteren, aber allgemein dem Hans Tieffenthal zugeschriebenen Katharinenfenster zu Schlettstadt

1) Dagegen hat diese französische Hofkunst, getreu den alten Beziehungen, dic englischen Künstler angeregt. Vergleiche z. B. dic Fresken im Westminster Palast. Diese Kunst hat dann wieder auf die nördlichen Gebiete Deutschlands zurückgewirkt, wie dịe Glasgemälde im Rathaus zu Lüneburg zeigen. Siehe Abbildung I 5.

2) Martin Schongauer et l'art du Haut-Rhin. 
erklärt. Der Meister des Eriskircher Fensters hat die Kompositionsart und teilweise auch die Ausführung aus verschiedenen, deutlich zu scheidenden Meistern entlehnt. So kennt er sicher 'die Glasgemälde in Königsfelden, das Medaillon- und Marner-

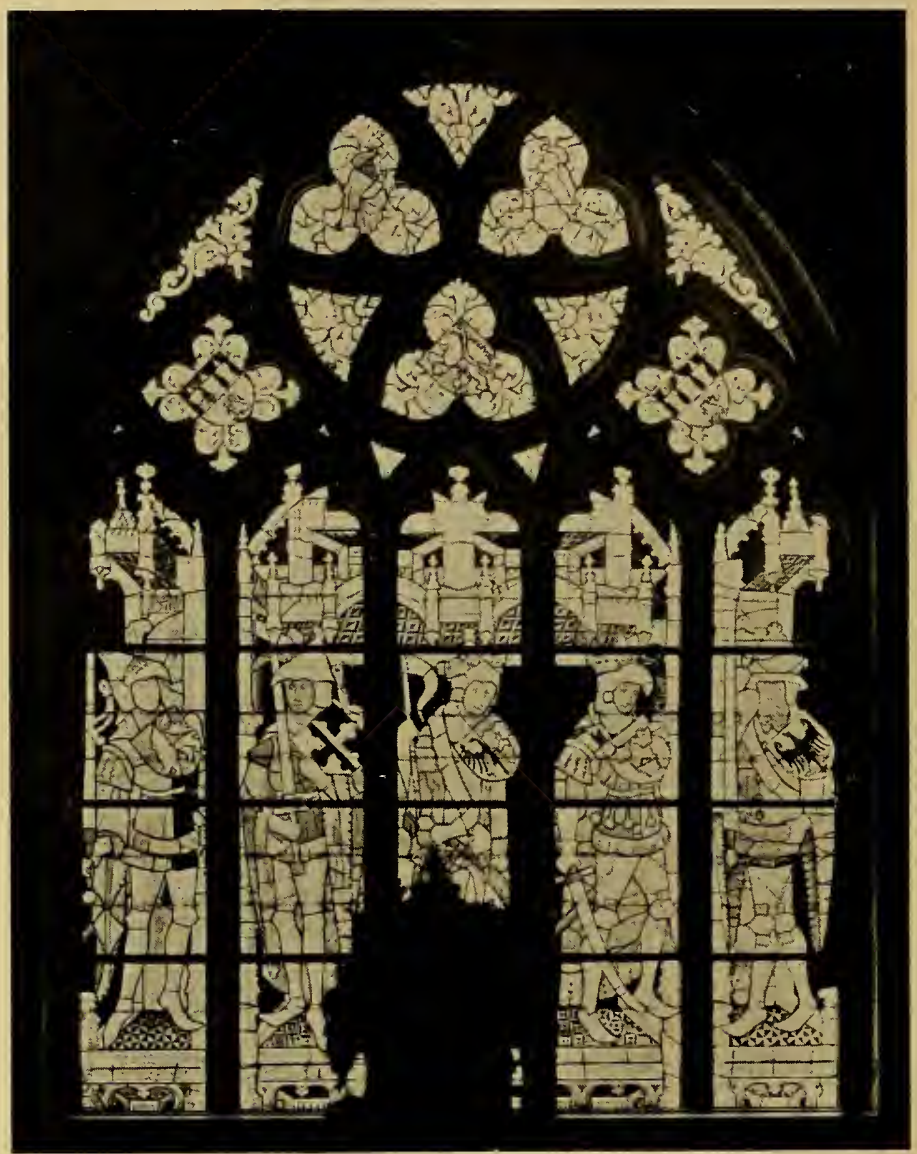

Abb. I 5. Glasgemälde im Rathaus zu Lüneburg. Erste Hälfte des 15. Jahrh.

fenster in Ulm, wie schon der Hintergrund des Scheibenpaares zeigt, auf dem der Stifter vor Maria kniet. Auch die Kunstweise der überhängenden perspektivisch gezeichneten Baldachine, die seit Beginn des Jahrhunderts am Oberrhein gepflegt wurde, ist ihm geläufig. Wenn von verschiedenen Seiten Konstanz als die 


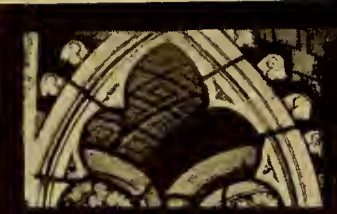

Axing Bars

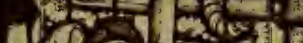
- 3 (3) A N 2 서

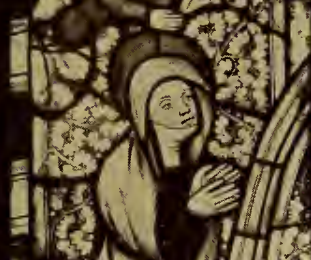
- for Fines 42.15

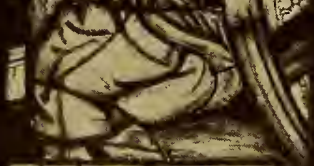

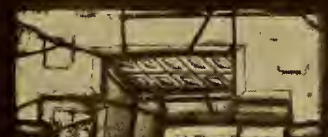

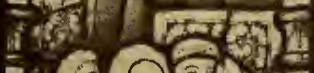
b) $\Rightarrow$ a in $\rightarrow$ a $18(-3) \times-3=\frac{3}{3}$ $y=10=2$

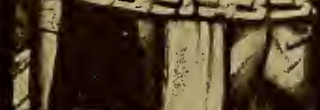<smiles>C#CC1CC(C=C)CC1C</smiles>
f 1010 is

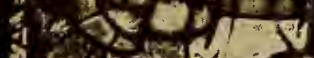

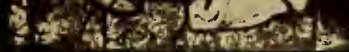
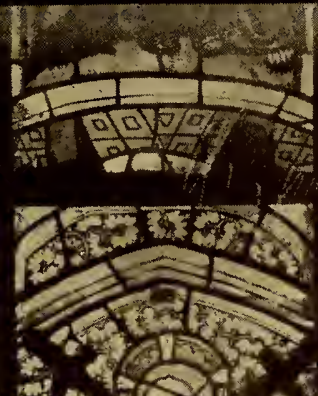

4 D. (⿻) 20 32 \% 50

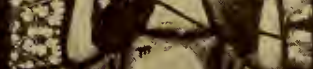

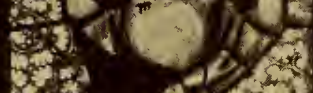

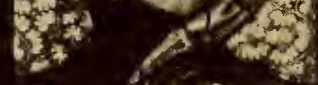

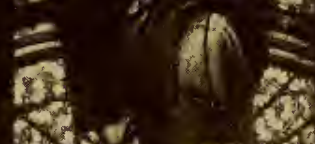

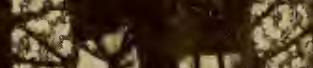

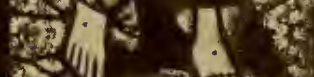
35 iा m min है
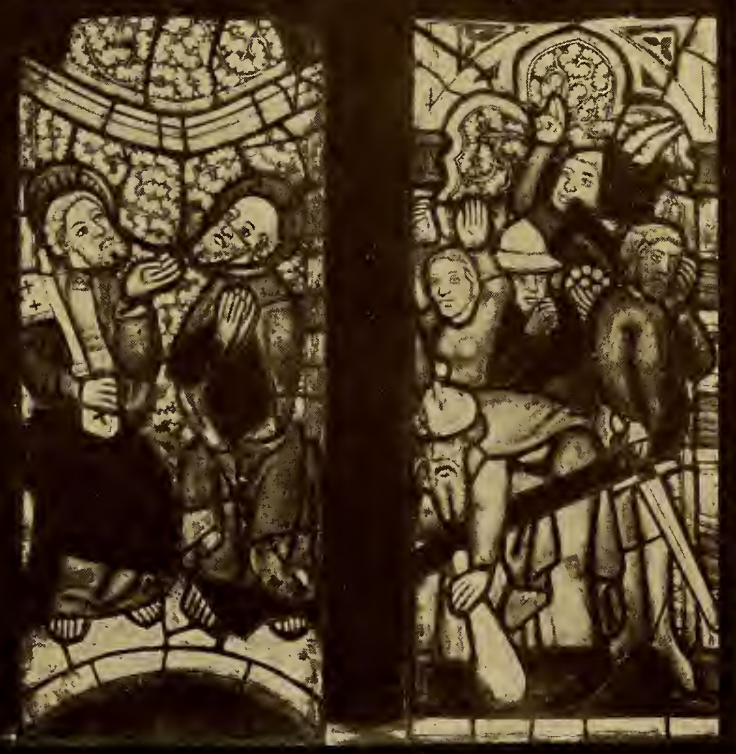

Teil eines Glasgemäldes in der Kirche zu Markterlbach. Letztes Viertel des I 4. Jahrhunderts. 

Heimat des Eriskircher Meisters angesprochen wird, so kann dies höchstens mit der Einschränkung gelten, daß dieser Künstler sich zufällig während des Konzils in Konstanz aufgehalten hat. Von einer Bodenständigkeit der Kunst dieses Meisters in Konstanz kann keine Rede sein.

Unter dem Einfluß van Eycks soll Tieffenthal nach Girodie im dritten Dezennium des I 5. Jahrhunderts die Glasgemälde in Thann, hernach in Schlettstadt und endlich gegen I435 die Glasfenster ausgeführt haben, die von der Gemahlin Philipps des Guten von Burgund, von Isabella, der Kartause in Basel zum Geschenk gemacht wurden. Das Katharinenfenster in Schlettstadt ist vor mehreren Jahren restauriert worden, jedoch so, daß sich aus dem Fenster noch sehr vieles für die Entwicklung der oberrheinischen Glasmalerei erschließen läßt. Die Baldachine erweitern sich $\mathrm{zu}$ völligen Hallendecken, die natürlich ebenfalls perspektivisch gezeichnet sind. Das ganze Interesse ist auf diese Raumdarstellung konzentriert, darum sieht der Meister von allem Landschaftlichen ab und gibt auch für Szenen im Freien einen Tapetenhintergrund. Das Figürliche ist im Stil der französischniederländischen Miniatur gehalten. In den Kreis des Schlettstadter Fensters gehören auch zwei Glasgemälde in der Stadtpfarrkirche zu Ravensburg. In dieser Kirche befinden sich drei alte Fenster; eines enthält sechs Vierpaßmedaillons mit je zwei Aposteln und ist datiert (auf das Jahr 1415). Es hat im Aufbau Ähnlichkeit mit den Resten eines Fensters in der Liebfrauenkirche zu Eßlingen, weicht aber im Detail und in der Ausführung erheblich davon ab. Die Jahreszahl I4I5 stimmt natürlich nur für dieses Paßformfenster, die beiden übrigen sind mindestens zehn Jahre jünger und gehören in den Kreis des Schlettstadter Katharinen- und Agnesfensters. Auch dieser Kreis bevorzugt die aus den Miniaturen bekannten Profanarchitekturen, kleidet bereits auch heilige Personen nach der neuesten Mode und kann so seinen Ursprung aus der höfischen Kunst der französischburgundischen Residenzen nicht verleugnen. Nur in beschränktem Maße werden Bauformen der ausgesprochenen Kirchengotik zugelassen, zuerst in der Art des Melchior Broederlam. Bereits bei dieser Richtung läßt sich eine merkwürdige Neuerung bemerken, die gegen Mitte des Jahrhunderts unglaublich übertrie- 
ben wird. Loggienartig bauen sich auf den Baldachinen Geschoße auf, die sich immer mehr mit Engeln, seltener auch Heiligen bevölkern. Am stärksten wird diese dramatische Belebung auf Fenstern angewandt, die ihre Architektur aus der Kirchengotik holen. Woher stammt diese eigenartige, in der Regel unangenehm wirkende Sitte. Man könnte daran denken, daß es eine realistische Auflösung der auf Altären, einzelnen Miniaturblättern, Goldschmiedearbeiten (Monstranzen) zahlreich dargestellten Heiligenfiguren ist, die unter Baldachinen und Fialen stehen. Die Miniatur hat keinen Geschmack an dieser der Glasmalerei eigenen Sitte gefunden. Man kann allenfalls auf die Federzeichnung: Hieronymus von Paul von Limburg hinweisen, die ähnliches, aber in maßvoller Haltung zeigt (Bibl. Nat. zu Paris ms. fr. I66). Die dramatische Lebhaftigkeit und theatralische Pose, die sich in Körperhaltung und Handbewegungen ausdrückt, läßt mich die Vermutung aussprechen, daß diese Regie auf Glasgemälden aus den geistlichen Spielen stammt, die von den Künstlern besucht, ja zum Teil arrangiert waren. Man betrachte z. B. die Ulmer Fenster aus der Mitte des Jahrhunderts und man wird erkennen, wie jede Aktion als Umdeutung einer Regievorschrift aufzufassen ist. Auch die französische Glasmalerei hat sich der Mode nicht entzogen, in den Architekturoberteilen Engel und Heilige anzubringen; allein sie hielt sich an eine schlicht ornamentale Verwendung und vermied, diese Figuren in eine so enge, theatralische Teilnehmerrolle zu zwingen. Man vergleiche z. B. die unter französischem Einfluß entstandenen Glasgemälde für die S. Peterkathedrale in Genf, die in den Architekturteilen reich mit Figuren ausgestattet, aber frei von allen erregten Aktionen sind.

Gegen Ende des I4. Jahrhunderts entstanden für die Kirche Markterlbach bei Nürnberg eine Reihe von Glasgemälden, die von dem Nürnberger Burggrafen Friedrich I. († I 398) gestiftet waren (Taf. 33). Sie leiten eine Gruppe ein, die man bequemer Weise als fränkisch bezeichnet hat. Der Aufbau der Markterlbacher Fenster stellt eine Verbindung fortgeschrittener Kirchengotik mit italienisierenden Bauformen dar. Es sind die gewundenen Säulchen, die wir auch auf den Karlsteiner Fresken finden, die perspektivischen, - fliesenartig gemusterten 


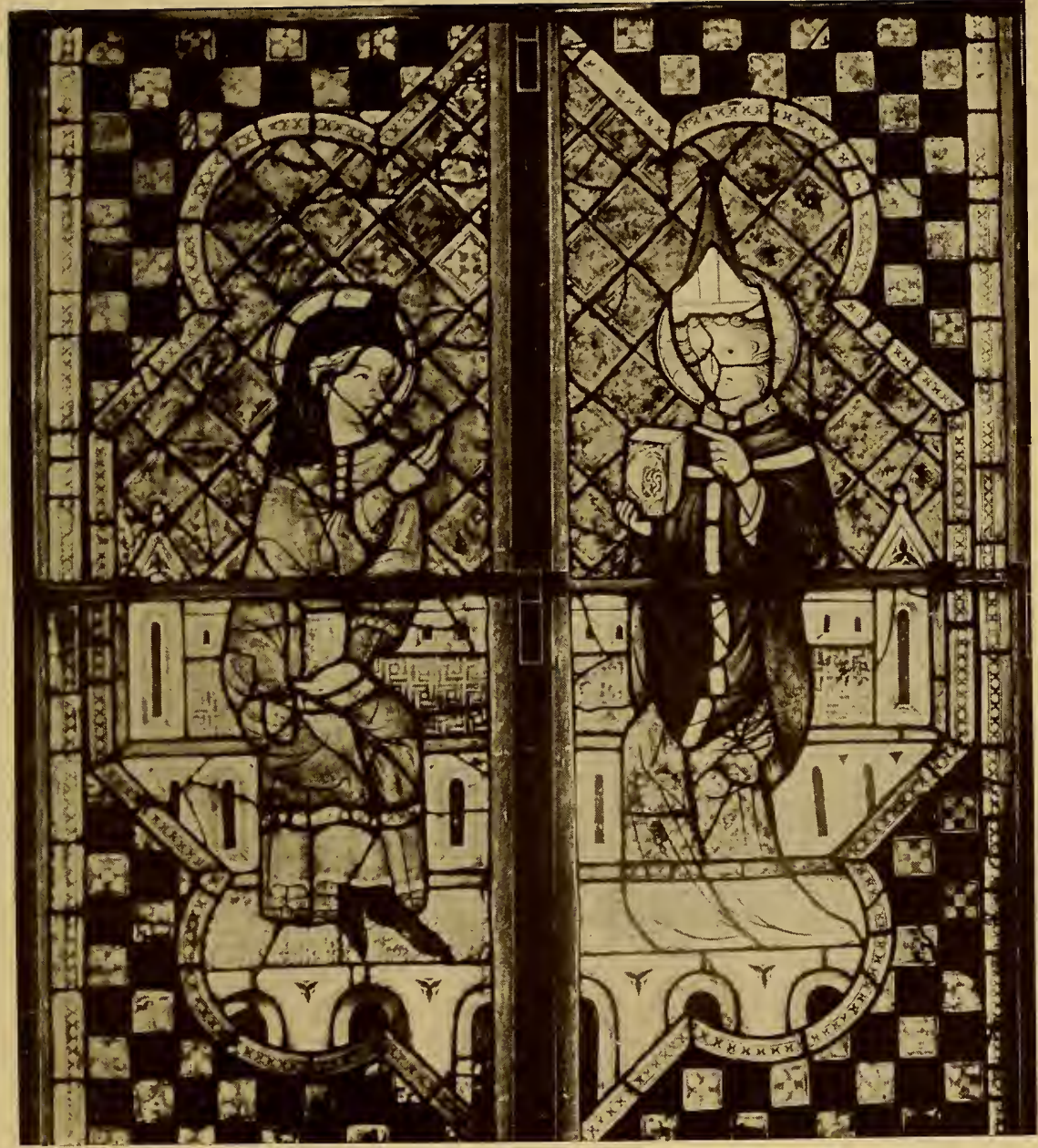

Teil aus einem Glasgemälde in der Blasiuskirche zu Mühlhausen in Thüringen. Zweite Hälfte des I 4. Jahrhunderts. 

Decken, denen andererseits, namentlich nach der Höhe der Fenster zu, ein ganzes System von Baldachinen, Fialen, Fenstermaßwerken gegenübersteht. Den Hintergrund ziert feiner Damast, die Figuren aber erinnern an südliche Vorbilder. Den Markter1bacher Fenstern folgt die Serie des Patriarchen-, der Passionsund Josefsfenster im Erfurter Dom, die der gleichen Schule angehören, wie die Markterlbacher Fenster ${ }^{1}$ ). Im Jahre I 408 entstand das Marnerfensterim Ulmer Münster, dessen noch vorhandene Reste ebenfalls nahe Verwandtschaft mit Markterlbacher Fenstern aufweisen. Teile eines Passionsfensters(um 1420) finden sich in der S. Jakobskirche zu Straubing, zwar zur Hälfte erneuert, inde $\beta$ noch deutlich als

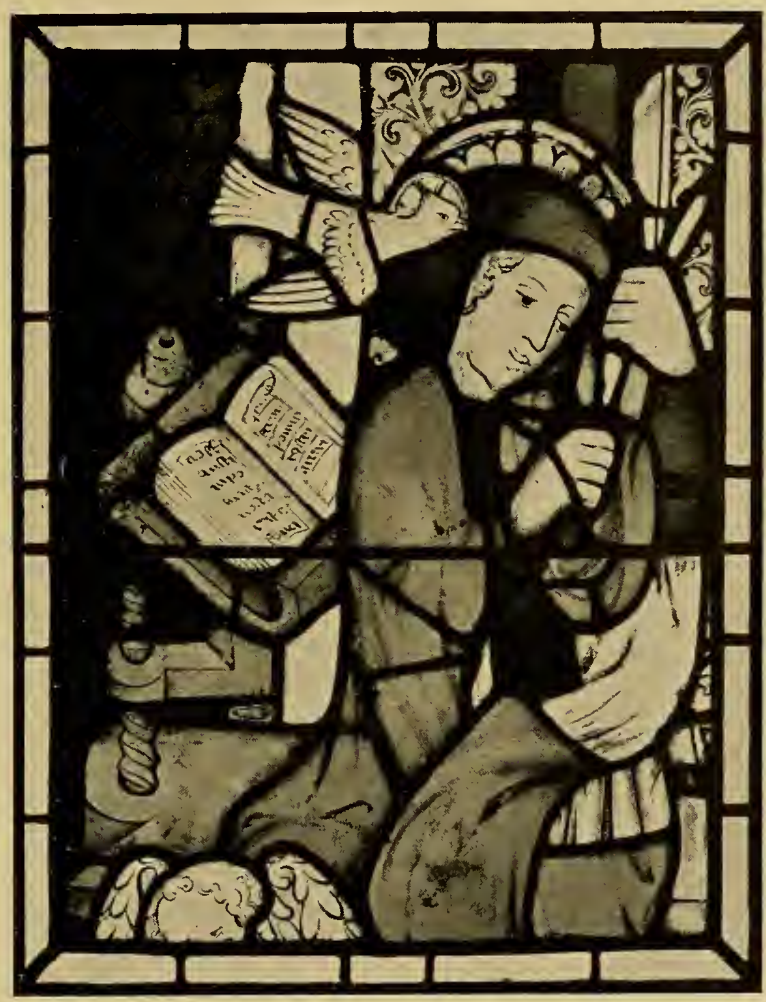

Abb. I6. Evangelist. Wohl aus Ulm stammend. Gegen Mitte des I5. Jahrhunderts.

Glied der. eben

besprochenen Gruppe erkennbar. Von wichtigeren Arbeiten schließen wir noch die Chorfenster in der S. Jakobskirche in Rothenburg und die gegen Mitte des Jahrhunderts entstandenen

1) Die Fenster zu Mühlhausen in Thüringen zeigen deutlich die Wanderung der Elemente der Regensburger Minoritenfenster über Nördlingen, Rothenburg, nach Erfurt und Stendal (siehe Taf. $34-36$ ). 
Arbeiten im Ulmer Münster und einige Fenster in Stendal an (Taf. 37-39, Abb. I6).

Die genannten Glasgemälde verteilen sich auf den Zeitraum von ungefähr einem halben Jahrhundert. Trotz der Entwicklung, die daher innerhalb der Gruppe vor sich gegangen sein muß, gehören sie doch eng zusammen; denn sie weisen alle Merkmale auf, die bei der Beschreibung der Markterlbacher Fenster eben skizziert wurde. Es fragt sich nur: Wo ist der Punkt, von dem aus diese Gruppe in die allgemeine Entwicklungsgeschichte der Glasmalerei eingereiht werden kann, wo ist das Zentrum dieser Schule? Man spricht gerne von einer Nürnberger Schule, obwohl von der Existenz einer solchen im weiteren nichts bekannt ist. Zwar verwahrt das Germanische Museum eine Reihe von Scheibenresten, die aus Nürnberg und Umgebung stammen, allein sichere Schlüsse können daraus nicht gezogen werden. Jedenfalls ist von Interesse, daß in Ulm zahlreiche Fenster aus dieser „fränkischen Schule " vorhanden waren ${ }^{1}$ ), von denen sich ein beträchtlicher Rest erhalten hat. Der auf allen Fenstern der Gruppe mehr oder weniger deutliche böhmische Charakter ist bei dem weiten Einflußgebiet der böhmischen Schule nicht weiter verwunderlich. Er drang über Regensburg, Nürnberg, Gmünd bis Mülhausen a.N. vor; während des Konstanzer Konzils ist er in Konkurrenz mit der burgundisch-französischen Hofkunst; starke Ausläufer hat er nach dem Maingebiet (Altar zu Schotten), nach den Deutschordensburgen des Nordens, überhaupt nach Brandenburg entwickelt. Andererseits blieb die deutsche Kunst des Südens wie Nordens in steter Berührung mit Oberitalien, da die geistlichen wie auch weltlichen Berufe ihre Ausbildung zum großen Teil an den italienischen Universitäten nahmen, was auf den Geschmack und den Rückschlag auf die Künstler nicht ohne Einwirkung blieb. Darum verschwinden auch die italienischen Reminiszenzen nicht, obwohl sich die Glasmaler alle Mühe gaben, die Kirchengotik den Gesetzen der aus der italienischen Profanarchitektur entlehnten Perspektive anzupassen. Während das Straubinger Fenster im figürlichen Teil Anklänge an österreichische Arbeiten aufweist, entwickelt sich auf den übrigen Fenstern der

1) Einige prachtvolle Scheiben sind im Besitz des württembergischen Königshauses. 


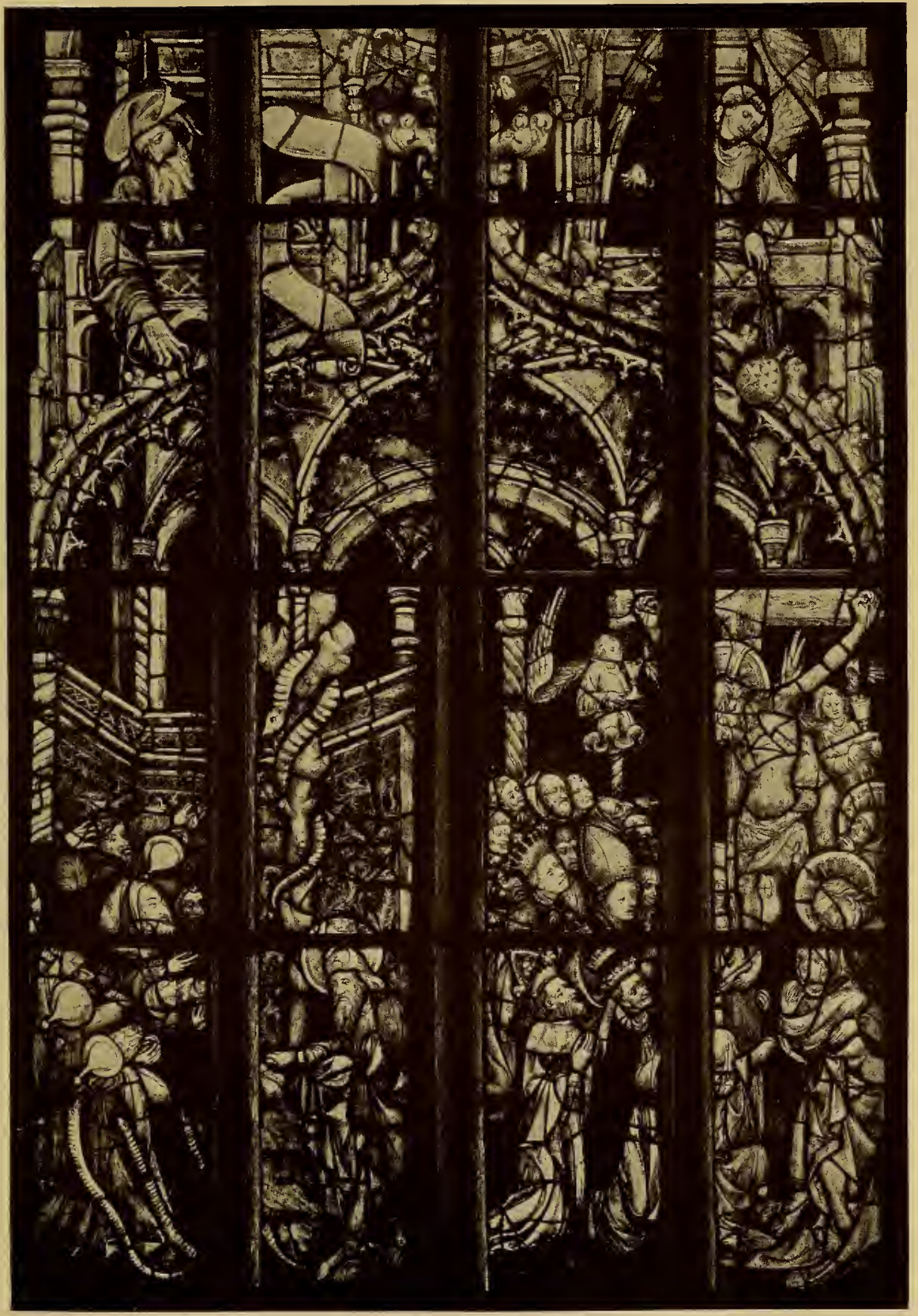

Teil aus dem Helenafenster im Dom zu Erfurt. Um 1400. 

Schule eine gewisse Selbständigkeit, die um so mehr wächst, je weiter die Schule nach Westen wandert. Die Köpfe werden länger, die Einzelformen rundlicher, was den scharfen Zeichnungen der Regensburger Richtung gegenübersteht und $z$. B. auch auf den Erfurter Fenstern zu beobachten ist. Die Schule ging jedenfalls von Regensburg aus. Man vergleiche z. B. die enge Verwandtschaft der Rothenburger Fenster mit dem Katharinenfenster im Regensburger Dom. Allmählich bildet sich für den Aufbau ein System. Es ist die perspektivisch gezeichnete Innenansicht eines gotischen Kirchenraumes, bei dem besonders die Gewölbe und die bekrönenden Teile betont sind. Die Rippen der sternbesäten Gewölbefelder laufen gerne auf einer Mittelsäule zusammen. Esmögedaran erinnert werden, daß der Reliefgrund des Portals zu Vicenza (I 344) ebenfalls mit Sternen besät ist. Die gedrehten oder umwundenen Säulen brachte zum erstenmal

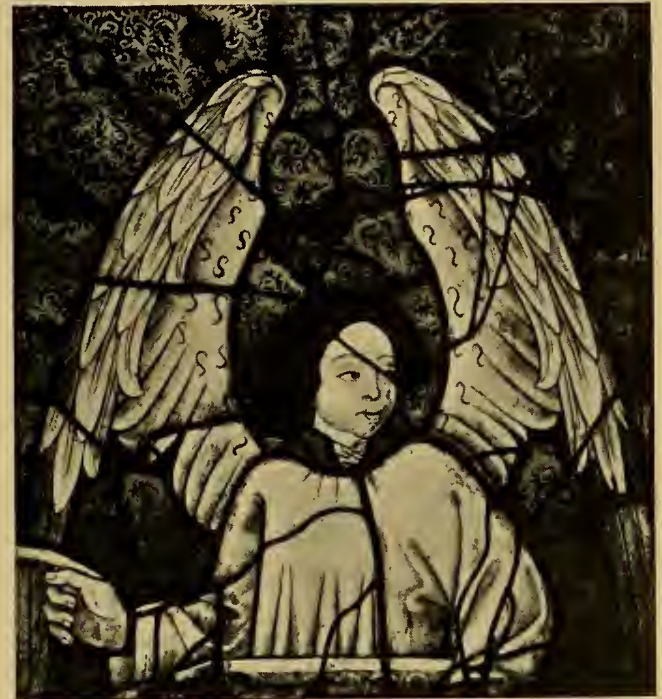

Abb. I 7. Detail aus einem Glasgemälde der Stadtkirche zu Friedberg.

Thomas von Modena nach Deutschland, wo sie sich lange großer Beliebtheit erfreuten. Eben dieser eklektische Charakter macht es schwer, die Schule irgendwo zu lokalisieren. Alles fließt ineinander. Da nun U1m und in Abhängigkeit davon Thann (siehe Bruck, Tafel 53) besonders reichlich mit derlei Fenstern versehen wurden, möchte man den Sitz der Schule dort suchen, wo sich Beziehungen zu Ulm nachweisen lassen; das ist aber nur die Stadt Nördlingen, so daß Nördlingen als Zentrum dieses Mischstils in Betracht kommen könnte. In alten Notizen fand sich ein Conrad dictus Fugelin pictor $\mathrm{r} 386$. „Ein Maler, Friedrich Walther von Dinkelsbühl, wurde I460 Bürger allhier. Er war 
Zeichner von zwar steifen Figuren in die Armenbibel. Er zog von hier wieder ab nach Bern, wo in der dasigen Münsterkirche und zu Freyburg ${ }^{1}$ ) auf Glas gemalte Fenster von ihm zu sehen sind, seine Nachkommen florieren noch in Bern als angesehene Kaufleute." Diese kurze Notiz in der Literatur scheint auf Beyschlag zurückzugehen, der über die Kunstgeschichte Nördlingens (Beyträge zur Kunstgeschichte Nördlingens von der Formschneiderey I798) eingehende Untersuchungen über diesen Maler Walter macht. Beyschlag sagt, daß er aus handschriftlichen Nachrichten vernommen habe, Friedrich Walter „der Glasmaler" sei mit dem Jahre 1472 aus Nördlingen verschwunden und nach Bern gewandert. Des weiteren führt Beyschlag eine Wappenscheibe der Stubengesellschaft an, die um I430 in Nördlingen entstanden ist. In dem Nekrolog der Franziskanermönche findet sich zu Beginn des I5. Jahrhunderts der Eintrag obut O. Fr. L. Luger laycus optimus incisor lignorum. Beyschlag unternimmt im Anschluß an diese Notiz den Nachweis, daß sich Nördlingen während des ganzen I 5. Jahrhunderts im Holzschnitt und den verwandten Gebieten, also auch Rissen für Glasmalerei hervorgetan habe ${ }^{2}$ ). Sighart ${ }^{3}$ ) erweitert die von Beyschlag gegebene Liste um ein Beträchtliches. Angefangen mit Heinz dem Maler, genannt Schüttenhelm (I400-I432) setzt eine ununterbrochene Reihe von mehr denn einem Viertelhundert Malern ein und zwar während des einzigen I 5. Jahrhunderts. Im Jahre I4I4 tritt zum erstenmal die Glasmalerfamilie Deckinger auf, später hören wir von Ulrich Glaser von Dünkelsbühl; um die Mitte des Jahrhunderts tauchen die schon genannten Acker und Deckinger auf, hernach die Familie der Daig, Martin und Bastian Daig, aus deren Schule der Meister von Meßkirch, Jerg Ziegler,

1) Auch der Sohn des Hans Schäufelein geht später nach Freiburg i. Üchtgau, ein Zeichen, daß die Nördlinger Künstler stets enge Beziehungen zu dieser Stadt hatten.

2) Es darf auch darauf hingewiesen werden, daß die Bistümer Bamberg und Freising bis tief in Kärnthen und Steiermark Besitz hatten, was an die kleine Grafschaft Görz, die unmittelbare Grenznachbarin Venedigs, grenzte. Der Weg ging stets über Salzburg, an dessen Südostgrenze Bamberger Besitz stieß, Nördlingen, Rothenburg. Tatsächlich hatte Nördlingen seit $\mathbf{1} 400$ mit Salzburg regen Künstleraustausch, so daß der eklektische Charakter der spätgotischen Glasmalerei hinreichend erklärt ist.

3) S. 604 und 643 . 


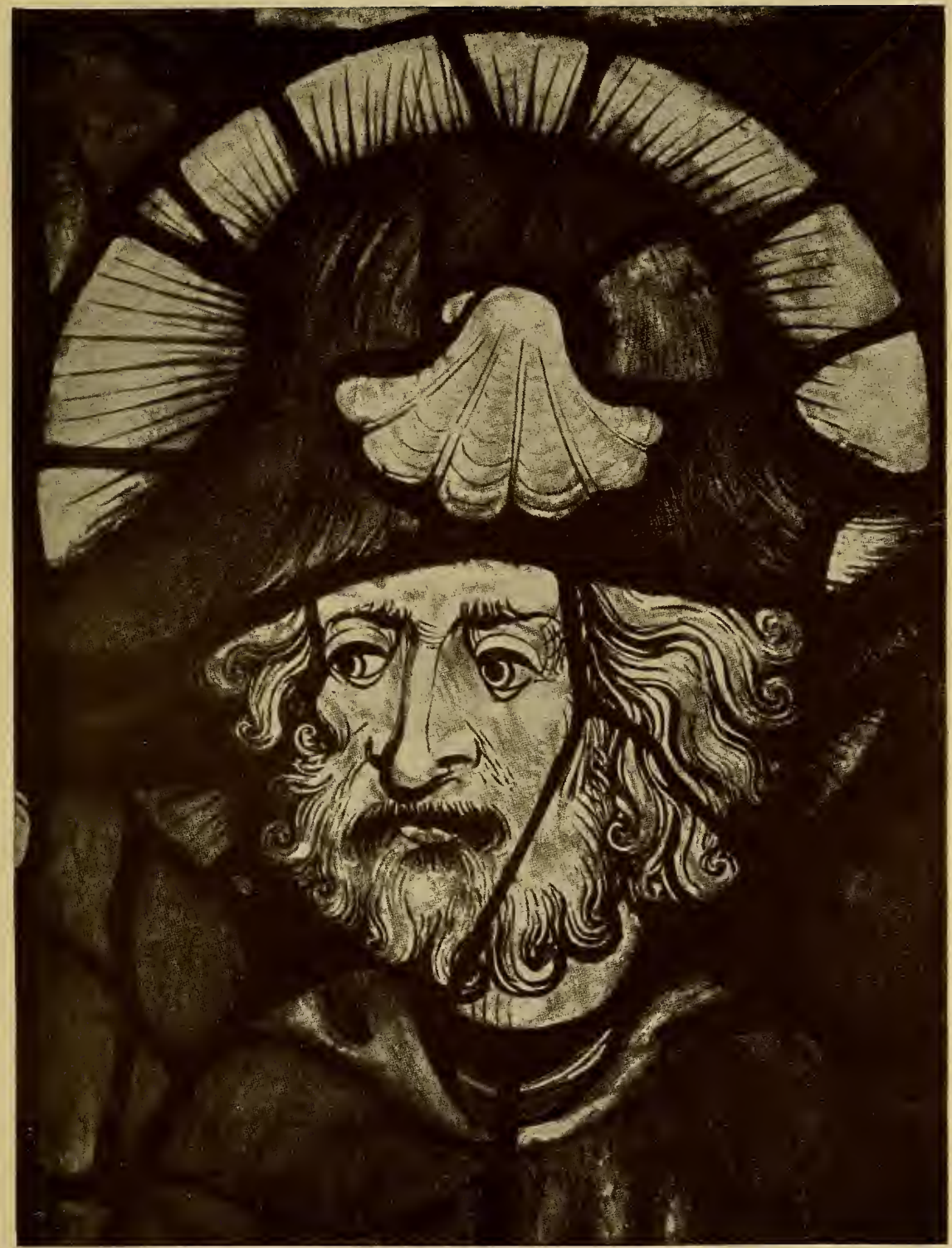

Apostelkopf in einem Fenster des Domes zu Erfurt. Nach 1400. 



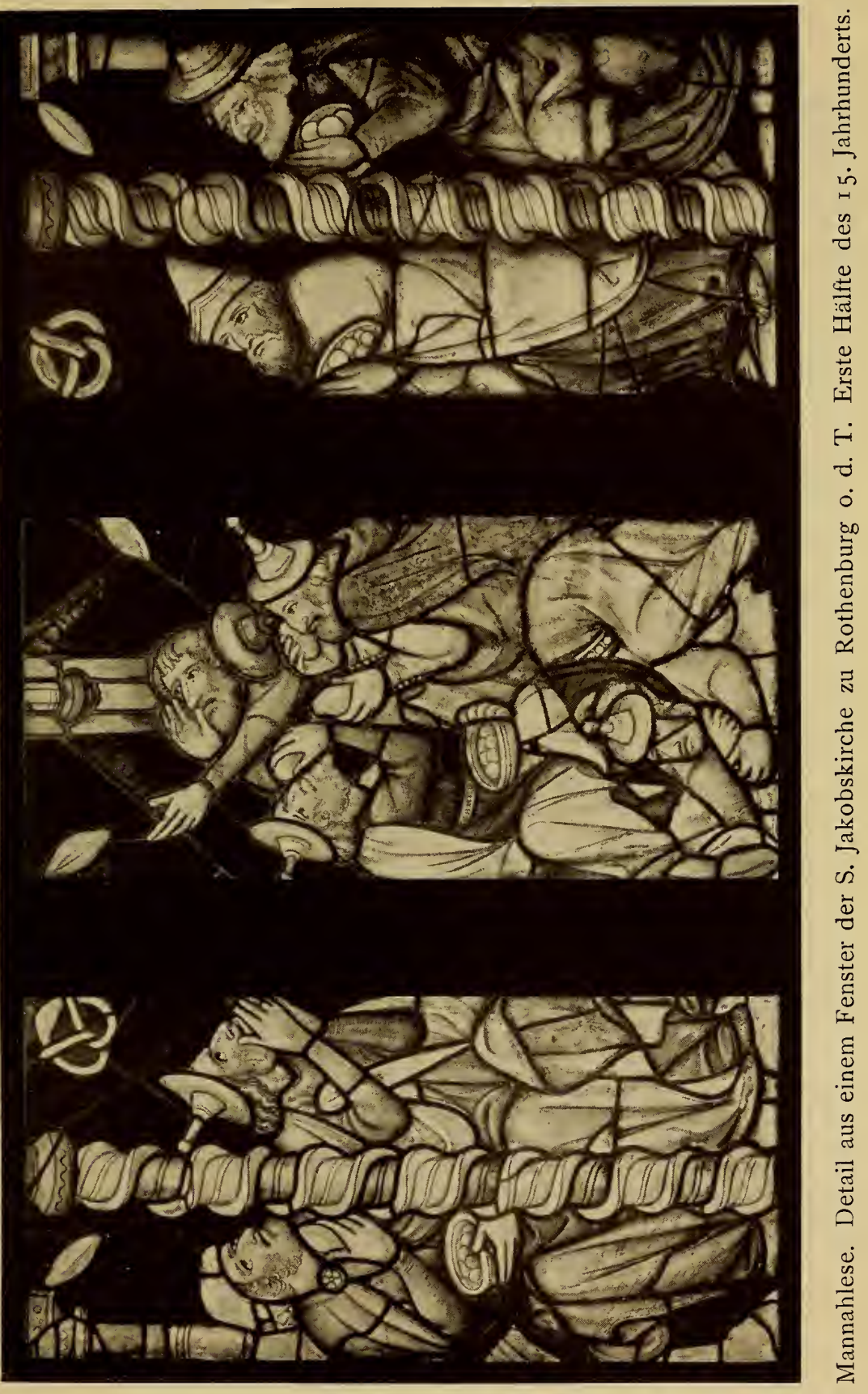





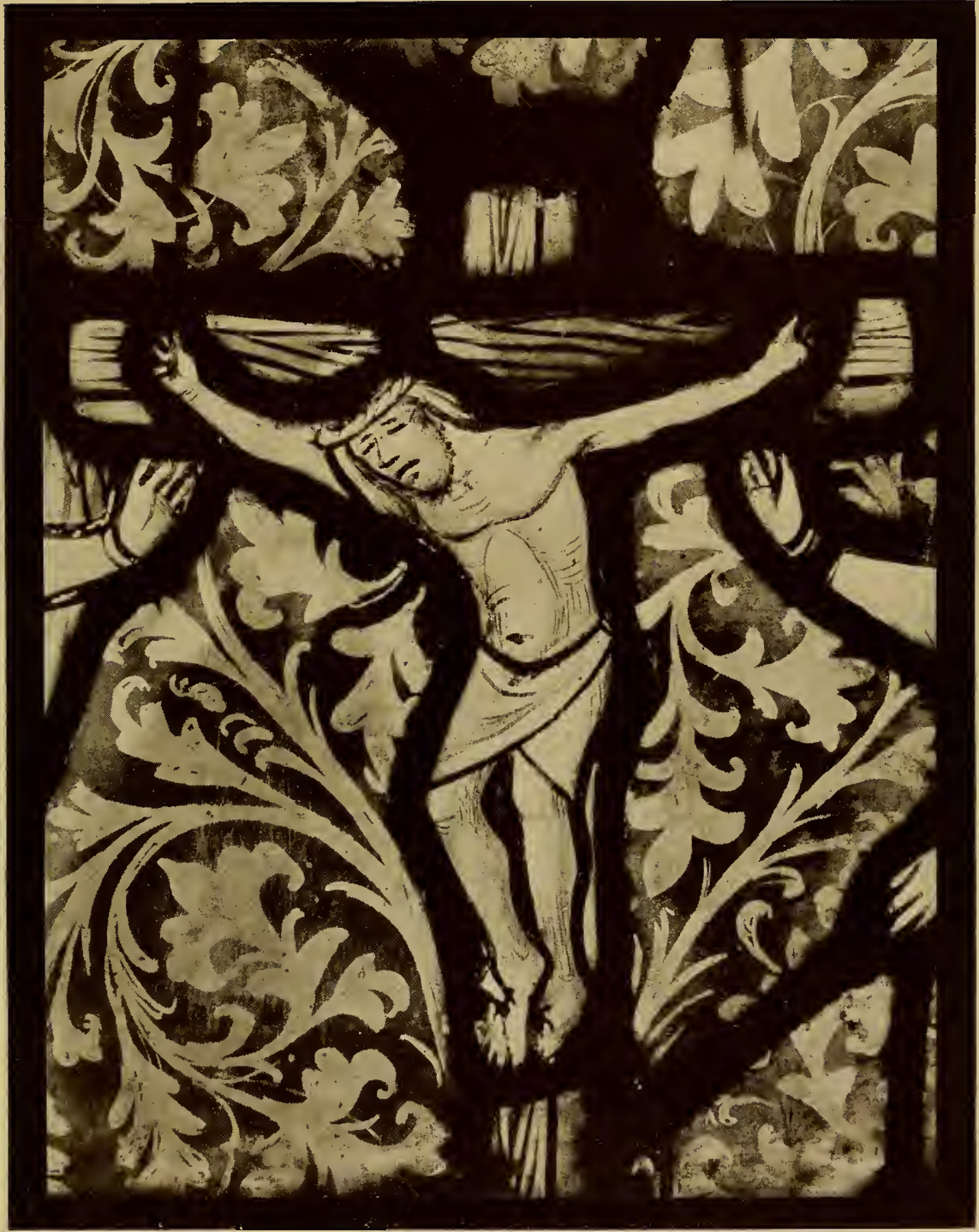

Detail aus einem Glasgemälde der S. Jakobskirche zu Rothenburg o. d. T. Erste Hälfte des I 5. Jahrhunderts. 



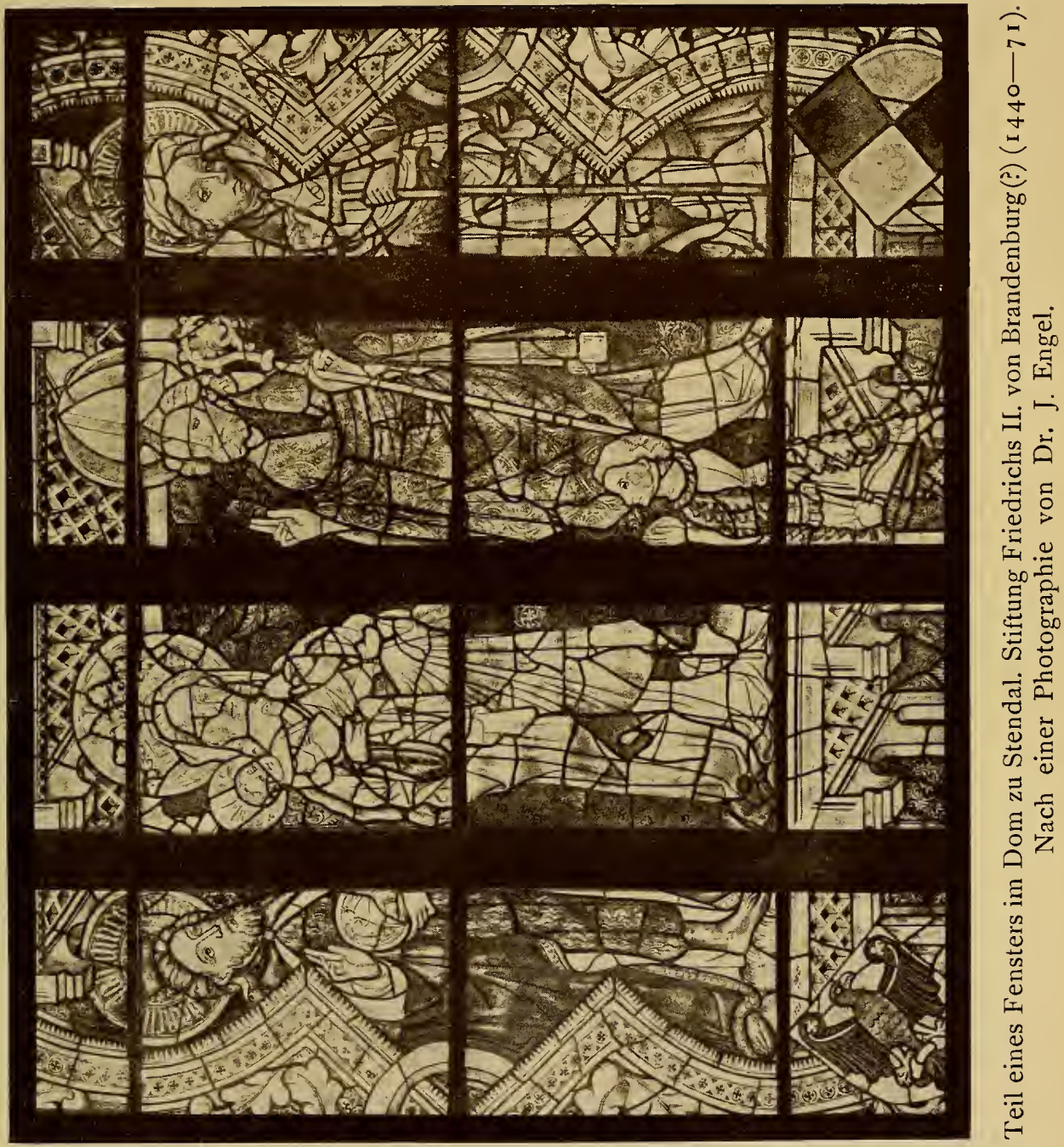



hervorgeht. Dazu kommt die Schäuffeleinschule, deren letzte Ausläufer ich in einem Glasgemäldezyklus aus den Jahren I 572 bis 1577 gefunden habe, der einst für das Kloster Urspring bei Blaubeuren angefertigt wurde. Mit Beginn des I6. Jahrhunderts treffen wir den Haimerand Daig und laut den Forschungen von Ansgar Pöllmann ${ }^{1}$ ) in den Rechnungsbüchern Nördlingens den Conntz Mayinger, Baltasar Vennd, Matthys Freyhart, Lorenntz Wattenhofer, Bastian Schnitzer, Martin Mülhofer und Lenhart Müller. Freyhart und Wattenhofer üben Malerei und Glasmalerei gleichzeitig aus, ganz im Einklang mit der oben charakterisierten Entwicklung der spätgotischen Glasmalerei. Von Daig fand Pöllmann Glasgemälde in der Nähe von Nördlingen. Größer als der Lehrer wurde der Schüler, der schon genannte Jerg Ziegler, der Meister von Meßkirch ${ }^{2}$ ). Von ihm stammen laut Pöllmann eine kleine Scheibe auf Schloß Heiligenberg, die berühmten Heiligkreuzthaler Scheiben im Stuttgarter Museum der Vaterländischen Altertümer, und jüngst fand ich ein unvergleichlich schönes Stück in der Sammlung des Königs von Württemberg ${ }^{3}$ ). Seinen Einfluß, bzw. seine Nachwirkung, glaube ich auch in den prachtvollen Fensterresten auf Reichenau-Mittelzell $\mathrm{zu}$ erkennen, die im Jahre 1556 entstanden sind und das letzte Zeugnis süddeutschen Kunstschaffens auf dem Gebiet der monumentalen Glasmalerei darstellen. Der Chor der genannten Kirche wurde in den Jahren I 5 55-56 von dem Straßburger Baumeister Jakob Roß aufgeführt. In dieser Zeit herrschte am Oberrhein ein aus Baldung- und Jerg Zieglerelementen herausgewachsener Stil in der Glasmalerei.

Der Einfluß der böhmischen Schule nach Westen ging wahrscheinlich, wie oben bemerkt über Regensburg. Die im Chor des dortigen Doms erhaltenen Fenster mit der Geburt Christi, den drei Königen, und Mariae Tod gehen auf das böhmische Dekorations- und Architektursystem zurück. Die zahlreichen Konsolen und Plafonds findet man in den Fresken der Karlsteiner Marienkirche wiederholt vorgebildet. Dieses System ist

1) Zeitschrift für alte und neue Glasmalerei I $9 \mathrm{I} 3, \mathrm{~S} .32 \mathrm{ff} ; 4 \mathrm{ff}$.

2) Siehe über ihn Pöllmann in den Historisch-Politischen Blättern I908, Heft 6 und in der Zeitschrift für christliche Kunst I 908 , S. $263 \mathrm{ff}$.

${ }^{3}$ ) Vgl. das unter der Presse befindliche Werk des Verfassers dieses Buches, über Schwäbische Glasmalerei.

Fis cher, Handbuch der Glasmalerei. 
aus italienischen Motiven herausgewachsen. $\mathrm{Ob}$ freilich der durch Thomas von Modena nach Prag gebrachte italienische Formenkreis für die Entwicklung der Regensburger Miniatur und Glasmaler hinreichend war, oder ob es neuer, direkter Verbindungen mit dem Süden bedurfte, ist nicht festzustellen. Trotz des äußerlich sehr veränderten Bildes der drei genannten Chorfenster bestehen doch noch unverkennbare Ähnlichkeiten mit dem Medaillon-(Katharinenfenster).

In der Pfarrkirche S. Jakob zu Rothenburg finden sich Fenster, auf denen der Medaillongrund des Regensburger Katharinenfensters mit dem Architektursystem vereinigt ist, das wir zum erstenmal auf den Chorfenstern zu Erfurt und U1m wahrnehmen. Dieses System ist eine genaue Kopie der Kirchengotik und betont im Gegensatz zu den früheren Frontansichten nunmehr die Darstellung des perspektivisch gezeichneten Innern, sowie der Gewölbekappen, deren Rippen wie schon erwähnt, häufig auf eine Mittelsäule zusammenlaufen. Die Felder der Gewölbekappen schmückt im Gegensatz zu den Fliesenplafonds der italienischfranzösischen Kunst, ein sterngeschmückter blauer Grund. Allerdings könnte auch diese Idee in italienischen Vorbildern begründet sein. Denn das Tympanon über dem Portal der Kirche zu Vicenza, das I 344 angefertigt wurde, weist ebenfalls einen sternbesäten Hintergrund auf.

Rothenburg bildet übrigens den Übergang zu einem besonders prächtigen Fensterschmuck, den Glasgemälden zu Münnerstadt. Sie wird als eine eigene Gruppe, als Mainschule, ausgeschieden. Dabei ist aber zu beachten, daß der Charakter der Fenster keineswegs einheitlich ist, daß vielmehr Meister aus verschiedenen Schulen an den Glasgemälden tätig waren. So hat das Katharinenfenster unverkennbar Ähnlichkeit mit den Arbeiten, die dem Hans Noll in Bern zugeschrieben werden. Auch von Regensburg ist ein kräftiger Strahl der heimischen Kunst nach Münnerstadt gefallen. Das System der Kirchengotik bleibt bis über die Mitte des Jahrhunderts, um welche Zeit es von dem System der Spätgotik abgelöst wird. Im äußersten Südosten Bayerns dauert der italienische Einfluß entlang der Innstraße ungeschwächt fort, wie das 1426 von Hans (S?)ponhaumer gestiftete Fenster für die Tillykapelle, das unter dem frischen Eindruck 


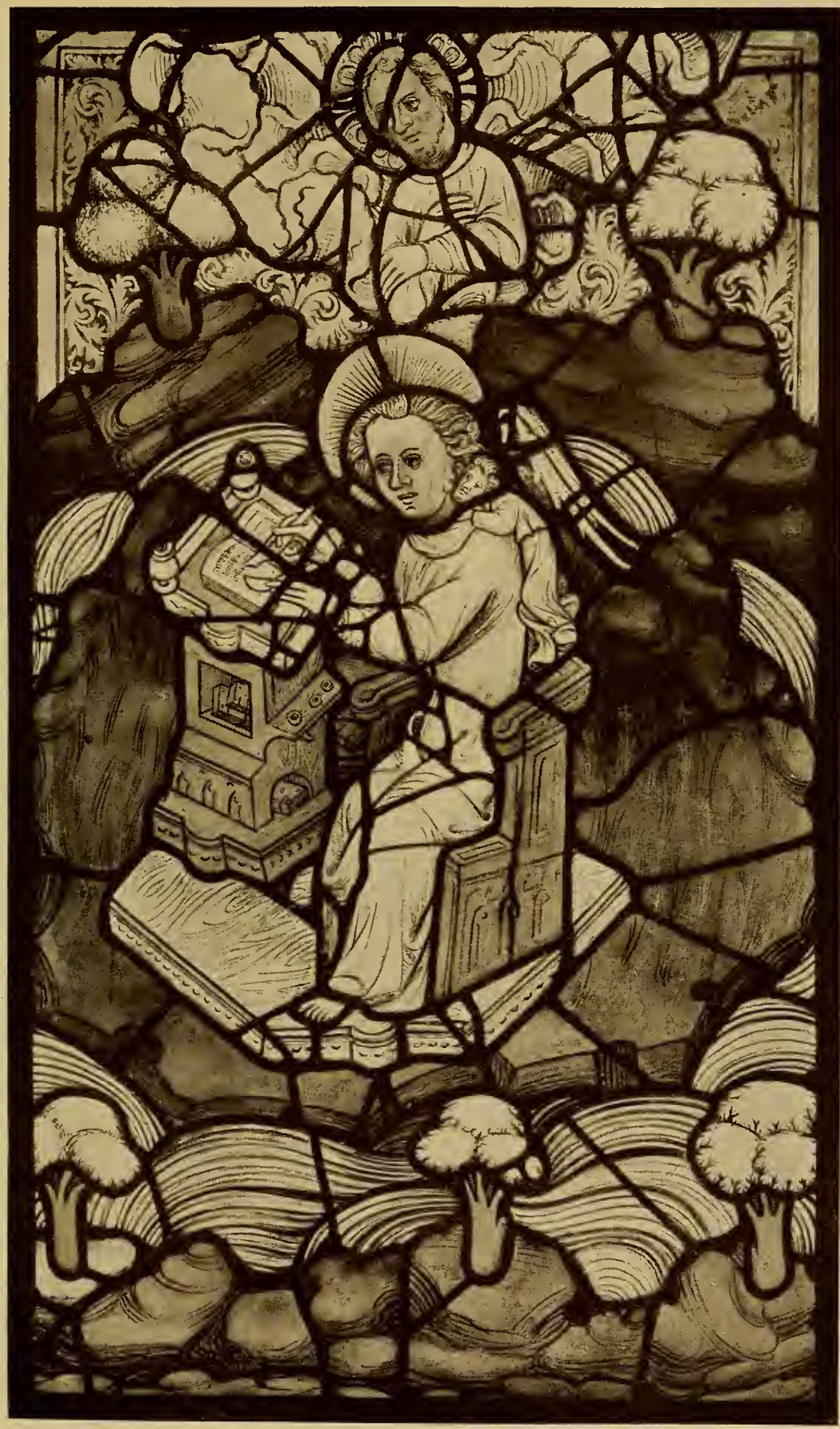

Evangelist Johannes. Detail eines Glasgemäldes im Dome zu Halberstadt. Anfang des I 5. Jahrhunderts. 

der italienischen Frührenaissance gezeichnet wurde, beweist (Taf. 41).

Durch die stä̀ndige Verbindung mit der französisch-niederländischen Kunst hat sich am Oberrhein eine Glasmalerschule entwickelt, deren Arbeiten allerdings nur mehr in wenigen Kirchen vorhanden sind, die aber das Eigenartigste während des I 5. Jahrhunderts geschaffen hat und nur von dem Meister der Bessererkapelle überholt wird. Unter dem Einfluß Dierick Bouts entstand das Fenster zu Zabern, das von Bruck dem Kaspar Isenmann zugeschrieben wird. Isenmann war anscheinend ein Schüler des Hans Tieffenthal und hatte sich auf seinen Wanderungen durch Flandern eine genaue Kenntnis der niederländischen Kunst erworben. Bruck kommt durch Vergleichung der Zaberner Scheiben mit den Altarbildern im Museum zu Kolmar zu seiner erwähnten Zuschreibung. Unter dem Einfluß des Roger van der Weyden bildeten sich die Schüler des Moser und Witz zu jener eigentümlichen Gruppe, die hauptsächlich durch den Meister E S charakterisiert wird. $\mathrm{Zu}$ dem szenischen Realismus gesellt sich das Bestreben, das modische Benehmen und Sichkleiden der vornehmen Welt getreu $\mathrm{zu}$ kopieren. Es sind dies die Umdeutungen der fürstlichen Hofkunst Frankreichs und Burgunds in den üppigen Luxus des städtischen Patriziats. Dies kam bereits auf dem Schlettstädter Katharinenfenster des Hans Tieffenthal zum Ausdruck. „Le maître E S de 1466 aime la vie élégante des cités du diocèse de Bâle, ses bourgeois habillés à la mode bourguigonne, leur robuste sensualité, l'assurance de leurs gestes comparés à ceux que la joie de vivre suggère aux compagnes des jeux où les surprend le vieux graveur" (Girodie 92). Neben dem Meister E S, den Bouchot zu einem Franzosen, "de Salins", macht, tut sich ein zweiter hervor, dem man die Walburger Fenster zuschreibt (Bruck Taf. 56-59) und den Bruck den Meister von I 46I nennt, weil die Walburger Glasgemälde eben auf dieses Jahr datiert sind. Die Fenster enthalten in Legendenform die Darstellung des Lebens Mariae, des Lebens Jesu, des Johannes des Täufers, der Apostel und der Szene des Weltgerichts. Das Atelier dieses Meisters und jenes des Meisters E S gingen, wie Girodie (S. 200) glaubt, wahrscheinlich aus der Schule des Conrad Witz hervor. Sie haben offenbar das Atelier des Hans 
Tieffenthal im Elsaß und in der Schweiz weitergeführt. Zwischen 1430-1450 ist das Fenster mit dem Leben Jesu zu Altthann gemalt worden. In Schlettstadt entstand das Agnesfenster, in der Kathedrale zu Thann das Marienfenster und die Stifterscheiben, in der Kirche S. Wilhelm zu Straßburg um I460 das Katharinenund Wilhelmfenster, die Fenster mit dem Leben Mariae und mit den Aposteln, in Altthann endlich die auf 1466 datierte Stiftung des Pfarrers Johannes Müller und des Gutleutpriesters Nicolaus Wolffach. Girodie fügt bei: „Das Leben Jesu und die Legende des hl. Benedikt zu Biel, datiert auf 1457, weisen Analogien mit den Fenstern zu Bern, einer gemeinsamen Schöpfung des Hans Tieffenthal und des Meisters E S. Einige Figuren des Lebens Jesu leiten sich von der Kunst des Hans Witz ab, die sich mit der des Roger van der Weyden vermischt hat. Die Fenster zu Staufberg, nahe bei Lenzburg (Schweiz), endlich sind eine Nachahmung der Fenster von Altthann" (S. 2OI). Dieser Anteil der Meister Hans Tieffenthal usw. an den Berner, Bieler und Staufberger Fenstern ist jedoch auf die Vorlagen oder höchstens den Karton einzuschränken, da Lehmann (S. I 29-278) den Meister Hans von Ulm, Meister Niclaus, Peter und Hans Noll und endlich Urs Werder als ausführende Künstler nachweist ${ }^{\mathbf{1}}$ ).

Infolge der reichen Beschäftigung, die den Künstlern am Oberrhein zuteil wurde, beschränkte sich der Schulzusammenhang nicht auf Vererbung fester Traditionen. Jeder Meister hatte vielmehr das Bestreben, das auf der Wanderschaft Gesehene zu einer eigenen Formensprache $\mathrm{zu}$ verarbeiten, wobei freilich die Herrschaft der Mode keineswegs alteriert wurde. Das gemeinsame Ziel war die Verdeutschung der jenseits der Alpen und jenseits des Rheins gewonnenen Eindrücke. Und da man die Eindrücke nicht in Glasmalerstuben, vielmehr in den Ateliers der Ölmaler bekam, überwog immer mehr der Charakter des plastisch-malerischen über das flächig-zeichnerische. Nur eines konnten die Visierer nicht von den Tafelmalern absehen, nämlich die Art, wie man verhältnismäßig kleine Szenen in großangelegte Rahmen fügen könne. Von Italien hatten frühere Generationen

1) Siehe Lehmann, die Glasmalerei in Bern am Ende des 15. und Anfang des I6. Jahrhunderts. Anzeiger für schweizerische Altertumskunde I9I2-I9I4. 


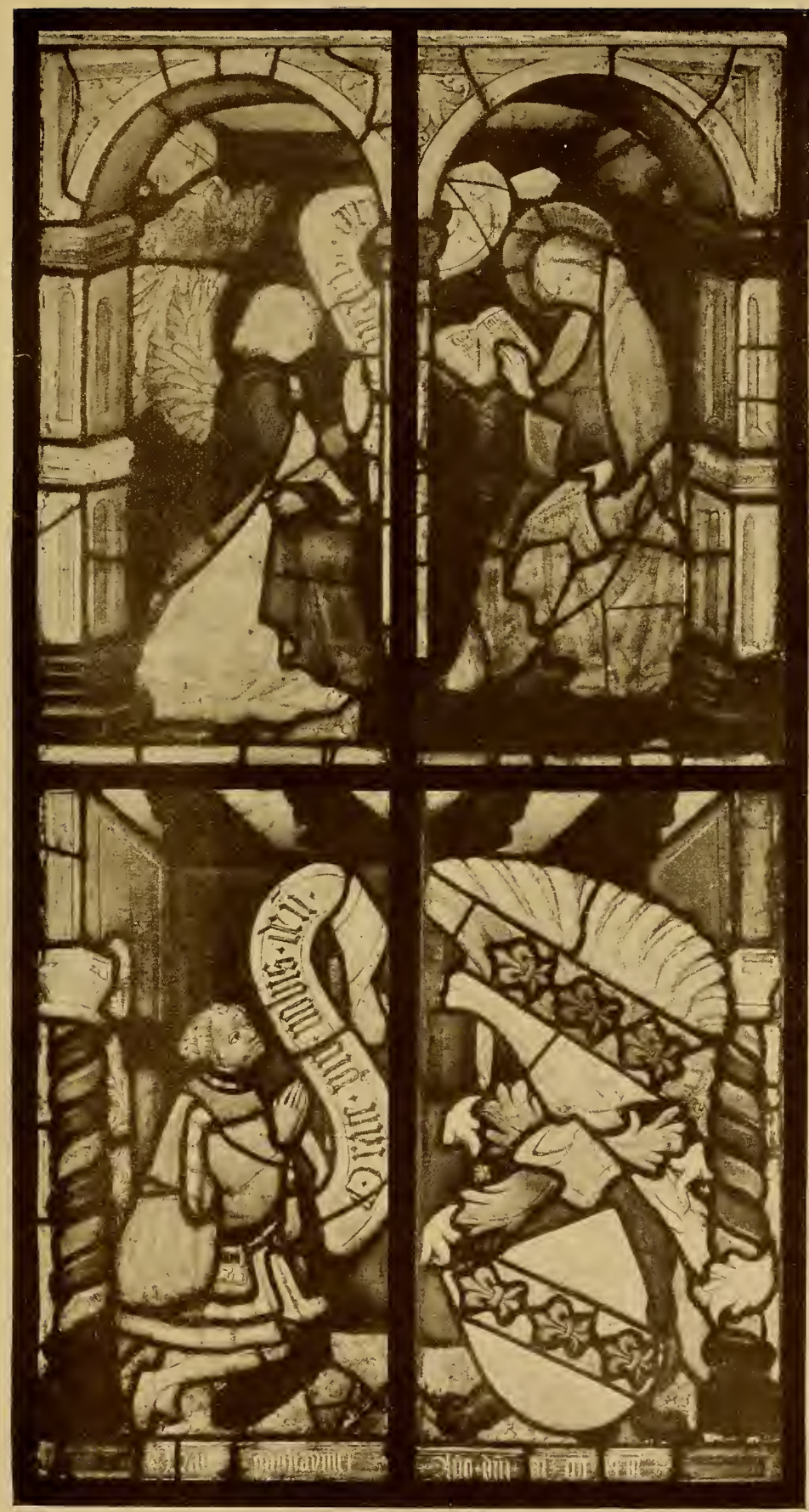

Detail aus einem Glasgemälde in der Tillykapelle zu Altötting. Datiert I 426 . 

die perspektivisch gezeichneten Architekturen nach Königsfelden gebracht und von da aus waren diese neuen Gedanken, ein Erbe Giottos, peripherisch nach Norden und Westen ausgestrahlt und an verschiedenen Orten (Prag, Regensburg) durch neue Zuflüsse aus dem Süden verstärkt. Daß sich aber die deutsche Glasmalerei vom ersten Augenblick an nicht begnügte, diese italienische, durch Frankreichs höfische Miniatur verstärkte, Architekturzeichnung beizubehalten, sondern mit der Kirchengotik zu verbinden, ist ein Beweis für die unendlich mächtige Bedeutung der Glasmalerei, als eines integrierenden Bestandteils des Bauprogramms. Nur wenige Fenster (Eriskirch, Ravensburg, Thann, Bruck, Tafel 48), blieben an der italienischen Profanarchitektur haften, alle sonst bekannt gewrordenen Glasgemälde suchen mit mehr oder weniger Geschick den Gedankengang des Baumeisters mit den importierten Moden zu verbinden. Dem Meister der Markterlbacher Fenster ist dies am frühesten und verhältnismäßig gut gelungen. Eine vollständige und systematische Überwindung des italienischen Prinzips zugunsten der Übereinstimmung mit dem Charakter des zu schmückenden Baus fand in der eben charakterisierten oberrheinischen (schweizerischen) Schule seit der zweiten Hälfte des I5. Jahrhunderts statt. Auf den Fenstern der Pfarrkirche zu Zabern, und zwar auf den Scheiben der Geißelung und Dornenkrönung kann man vortrefflich studieren, wie der italienische Baldachin in den gotischen gewandelt worden ist. Auf anderen Scheiben derselben Fenster hat Isenmann den Baldachin durch einen von zwei schlanken Baumstämmchen als Säulen getragenen Rundbogen ersetzt, der, ähnlich wie die zahlreichen gotischen Friese, mit Laubwerk belegt ist. Mit diesen Glasgemälden ist das Zeitalter der Spätgotik eingeläutet. Im Figürlichen machen die Glasmaler alle Moden der Tafelmaler mit, was bei der nunmehr häufigen Trennung des Visierers vom Techniker nicht verwunderlich sein darf, im Architektonischen suchen sie ebenfalls alle Spielarten des spätgotischen Baustils zu kopieren. Aus diesem Milieu ist der letzte große Meister des ausgehenden Jahrhunderts hervorgewachsen, der Glasmaler Hans Wild $^{1}$ ). Girodie, der die Identität des Meisters der Fenster in S.

1) Frankl, P. der Ulmer Glasmaler Hans IVild, Jahrbuch der Königlich Preußischen Kunstsammlungen 19 I 2, S. 3 I ff. 
Magdalena zu Straßburg mit dem Meister der U1mer Chorfenster, auf denen er sich verewigt hat, also den Hans Wild noch nicht kannte, erklärt: Unter dem Einfluß M. Schongauers hat der Meister der Passion in Alt Sankt Peter die Glasgemälde der Magdalenenkirche gemacht (S. 205). Zum erstenmal wurde von der Hofglasmalerei F. X. Zettler erkannt, daß die Kartons von S. Magdalena in Straßburg fast genau mit den Chorfenstern
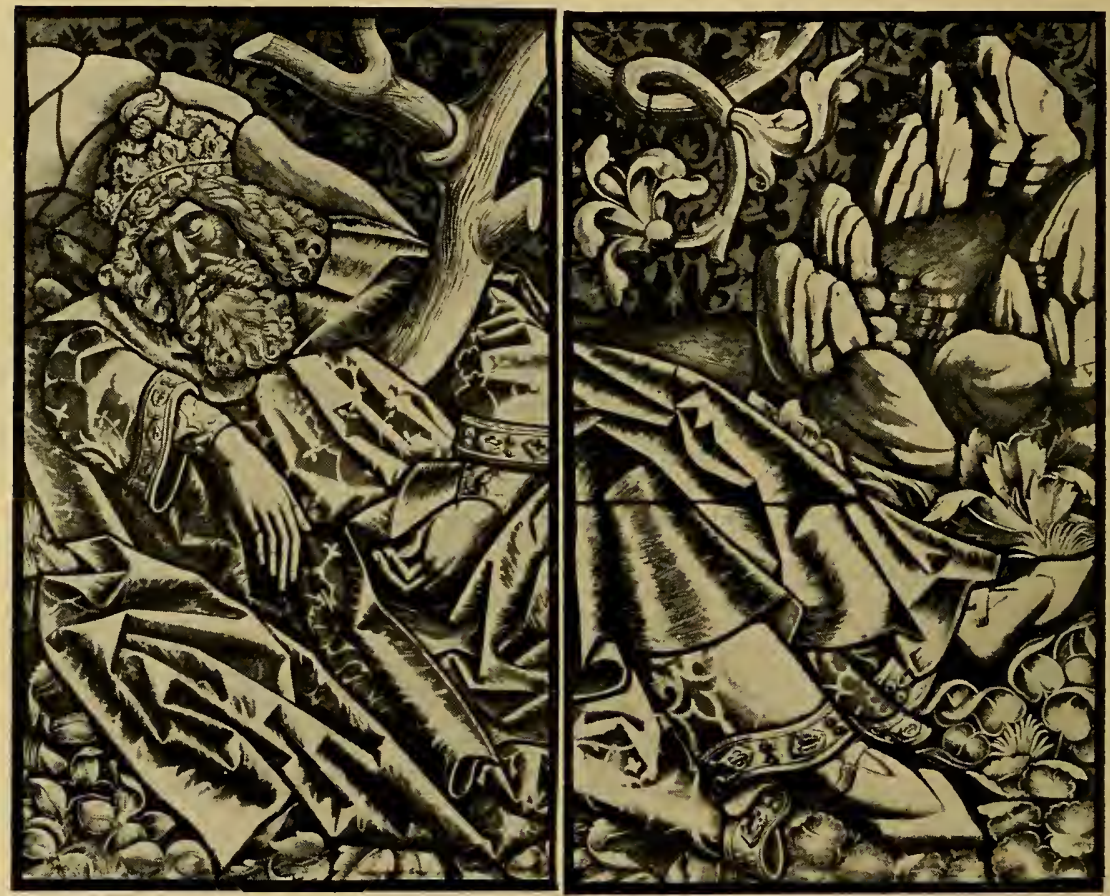

Abb. 18. Detail aus dem Stammbaumfenster des Münsters zu Ulm.

gleichen Inhalts in U1m übereinstimmen. Diese Anstalt hat auch genaue Aufnahme von beiden Zyklen machen lassen. In neuester Zeit ist von Paul Frankl das umfangreiche Material gesammelt worden, das eine Stileinheit mit den Ulmer Chorfenstern bildet und daher unter dem Namen des Glasmalers Hans Wild geht (Taf. 42-46, Abb. I8). Das älteste Werk befindet sich in der Stiftskirche zu Urach aus dem Jahre I47 I. Von da an umfaßt das Tätigkeitsgebiet des Meisters Schwaben, Bayern bis Salzburg, Franken 

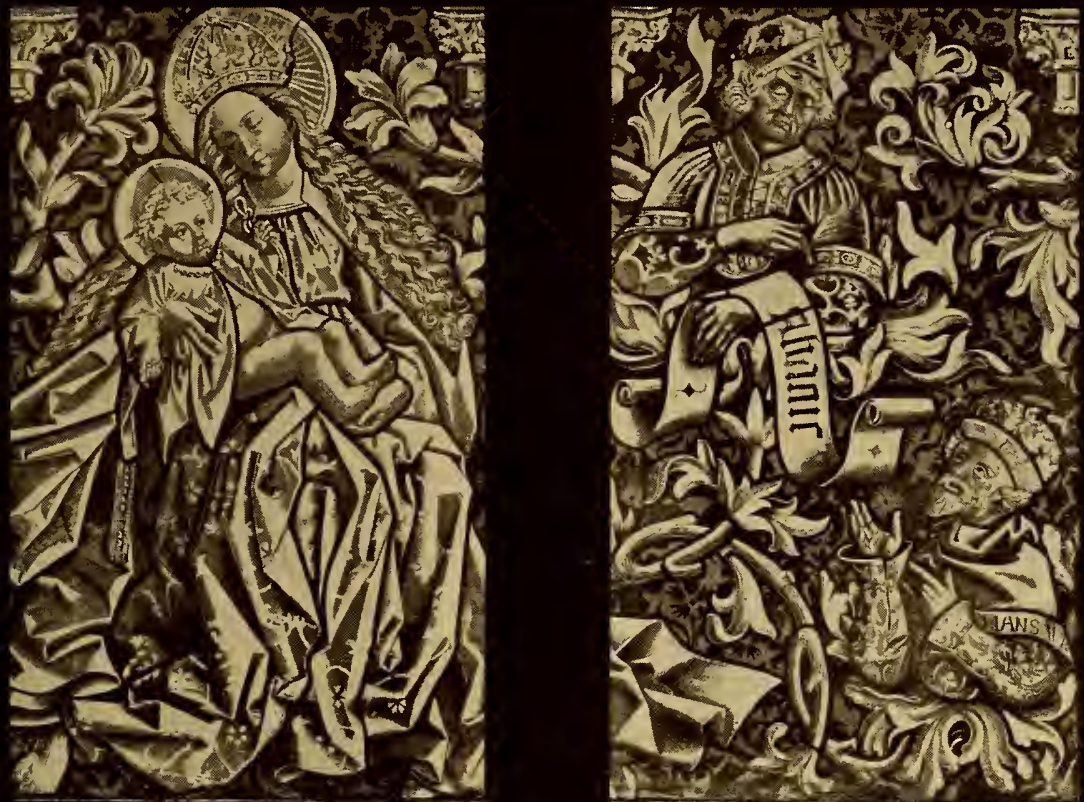

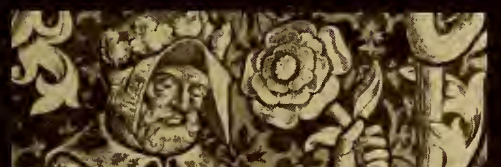
군. ind (4) की (e) 1 . 2 Cis 015

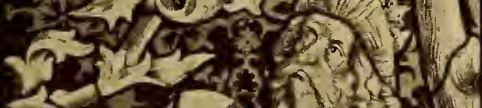
1)

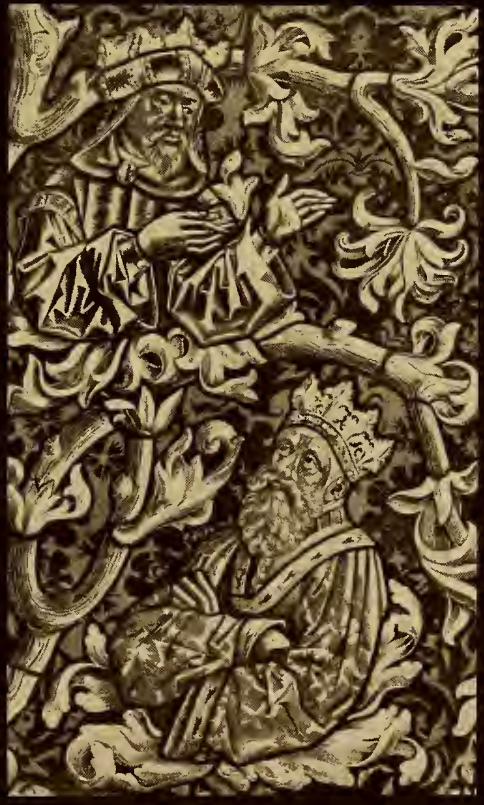

Detail aus dem Stammbaumfenster im Münster zu Ulm. Signiert Hans Wild. I 480. 

bis Nürnberg und nach Lehmann auch die Schweiz. Chronologisch folgen sich auf das Fenster in Urach die Glasgemälde in der Stiftskirche zu Tübingen (I477), das Kramerfenster zu U1m (I 480), das Ratsfenster ebendort, die Glasgemälde auf dem Nonnberg zu Salzburg ( ( 480) ${ }^{1}$ ), in der Magdalenenkirche zu Straßburg (I48I), im Dome $z u$ Augsburg, das Scharfzandtfenster in der Münchener Frauenkirche, das Volkamerfenster zu St. Lorenz in Nürnberg. Außer diesen großen Arbeiten sind an verschiedenen Orten kleine Reste erhalten, die man ebenfalls bei Frankl aufgezählt findet. Obwohl nun die ältesten Arbeiten auf württembergischschwäbischen Boden sich befinden, ist damit doch noch nicht gesagt, daß Hans Wild aus Ulm hervorgegangen ist. Um ảie Mitte des 15. Jahrhunderts haben die Acker und Deckinger in Ulm gearbeitet und Lehmann macht einen "Hans von Ulm" bekannt, der im Jahre I44I das Passionsfenster im Chor des Berner Münsters anfertigte und dem Lehmann eine Scheibe in der Erlachkapelle desselben Münsters zuschreibt(Abbildung 44 bei Lehman11 ${ }^{2}$ ). In der Tat weisen sowohl die Passionsfragmente, als das Dreikönigsfenster, das ebenfalls aus der Mitte des Jahrhunderts stammt, wie die genannte Scheibe Ähnlichkeiten mit dem Wildschen Fenster des Ulmer Münsters auf. Dazu gehört besonders der eigenartige aus Rotviolett geschliffene Damastmantel und ein ganz pikantes Farbspielchen. Auf dem Stammbaumfenster im Chor des Ulmer Münsters und auf der Scheibe in der Erlachkapelle erscheint in einer weiten Fläche von ganz dunklen Farben als besonderer Farbenreiz ein kleines Stück Rot (Mütze). Diese eigenartige Wirkung läßt sich weder mit Worten beschreiben

1) In Salzburg gab es um die genannte Zeit allerdings auch einheimische Glasmaler. So bezahlt Probst Ludwig Ebner von S. Zeno-Reichenhall Glasgemälde nach Salzburg: „ich hab an Meister Paulsen maler zu saltzburg ein glaß in mein capellen angeben als geprannt von gueten Farben und pildwerch" ... (Urkunde im Reichsarchiv zu München, nacl Mitteilung von Fr. Wolter).

2) Dieser Hans von Ulm war sehr wahrscheinlich im Gefolge des Vinzenz Ensinger, der um I 440 am Konstanzer Münster beschäftigt war. In einer Kapelle dieser Kirche befindet sich der Rest eines Glasgemäldes mit dem Wappen des Bischofs Heiurich von Höwen (1436-1462), das außerordentlich viel Ähnlichkeit mit den von Lehmann dem Hans von Ulm zugeschriebenen Glasgemälden im Berner Münster hat. Offenbar ist also Hans von Ulm mit Vinzenz Ensinger über Konstanz nach Bern gewandert. (Vgl. auch Diözesanarchiv von Schwaben 1896, S. 142). 
noch auf einer Abbildung ablesen, ist aber so charakteristisch, daß sie bei dem Ulmer Fenster nur aus Abhängigkeit von dem Berner Meister erklärt werden kann. Hans Wild hat, konkret gesprochen, die Schule und Tätigkeit des Hans von Ulm gekannt. Von dem Passionsfenster ist nur sehr wenig erhalten und auch dieses Wenige stark restauriert. Trotzdem läßt sich die Ulmer Provenienz noch heute erweisen, auch wenn die urkundliche Notiz, die Lehmann veröffentlicht hat, nicht erhalten geblieben wäre. Um die Ölbergszene zieht sich ein Halbkreis, der den Umrahmungen von Portalreliefs entspricht; in ihm befinden sich sitzende mit Lesen beschäftigte Figuren. Diese allgemein gleiche Tätigkeit ist bei den verschiedenen Figuren außerordentlich fein variiert, so daß man unwillkürlich an den Archivoltenzyklus des Ulmer Hauptportals erinnert wird, in dem die Schreibtätigkeit der I2 Apostel ebenfalls reich variiert erscheint. Auf dem Dreikönigsfenster findet sich in der Architektur die Wiedergabe der Episoden, in denen das die drei Könige zum Aufbruch nach Bethlehem mahnende Wunder geschildert wird, jener Episoden, die uns am Südwestportal des Münsters zu Ulm begegnen. Die Darstellung dieser Szenen, die auf das Gedicht des Walther von Rheinau über das Leben Mariae zurückgeht, ist so außerordentlich selten, daß man unbedingt an Abhängigkeit denken muß, wenn man sie in Bern wiederfindet. Aber auch technisch-stilistische Gesichtspunkte weisen auf Ulm. Es sind jene landschaftlichen Hintergründe, ein eingenartiges Rotbraun, das wir auf den Fenstern der Bessererkapelle im U1mer Münster kennen gelernt haben. Noch einmal taucht also die Meistergestalt jenes Künstlers auf, dem wir den prachtvollen Schatz der Bessererkapelle verdanken. Die Berner Glasgemälde bilden den Übergang von diesem Meister zu Hans Wild. Jener Hans von Ulm, mag er nun in die Familie der Acker oder Deckinger gehört haben oder nicht, bildet neben den Meistern der Ulmer Chorfenster eine eigentümliche Erscheinung. Er steht auf dem Boden der großen Traditionen des Künstlers der Bessererkapelle und nimmt von seinen Kollegen, die mehr im Stil der Nördlingen-Nürnberger Schule arbeiten, nur wenig an. Von ihm hat sich im Münster zu U1m nichts erhalten.

So sehr also diese Momente dafür sprechen, daß Hans Wild 


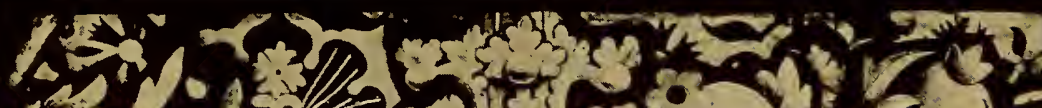

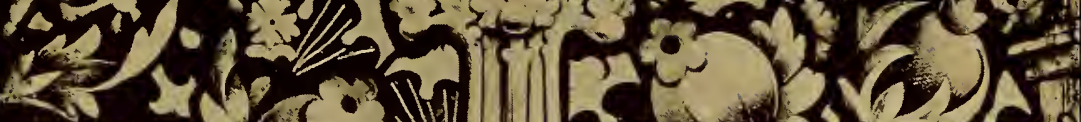

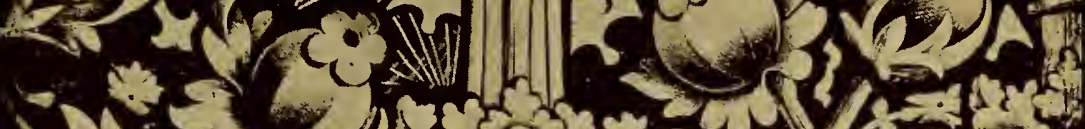
I.

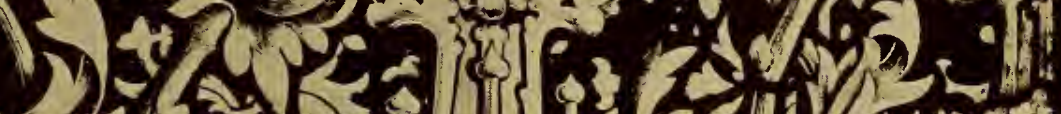
$12 x-1$.

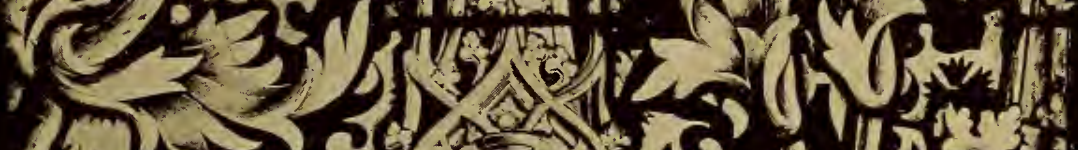

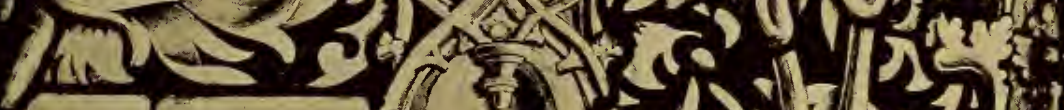

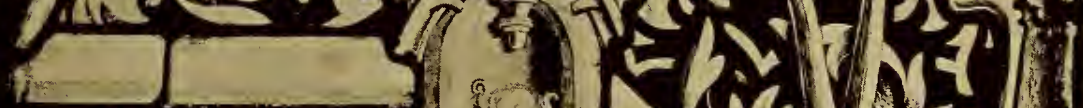
nes 7 .

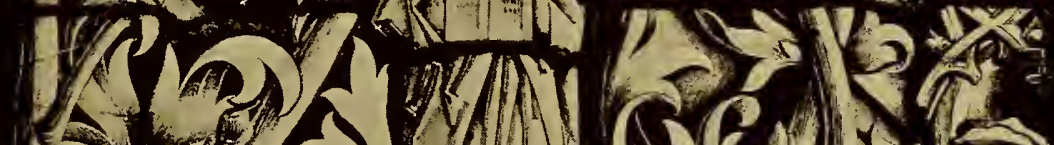
$2 \frac{25}{201}$

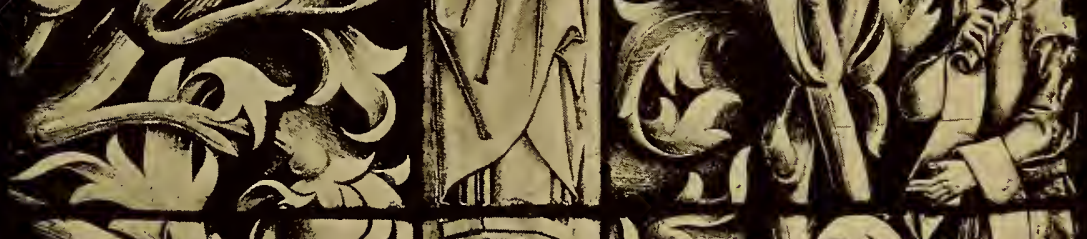

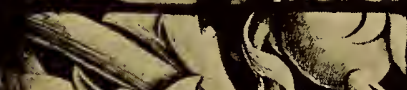
Nits
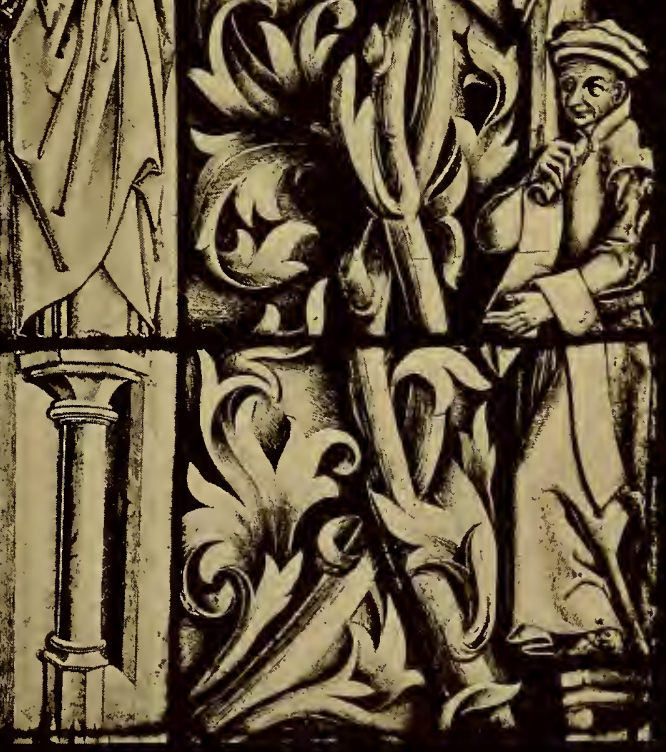

Detail aus einem Glasgemälde von Hans Wild im Ulmer Münster. U'm I 480. 



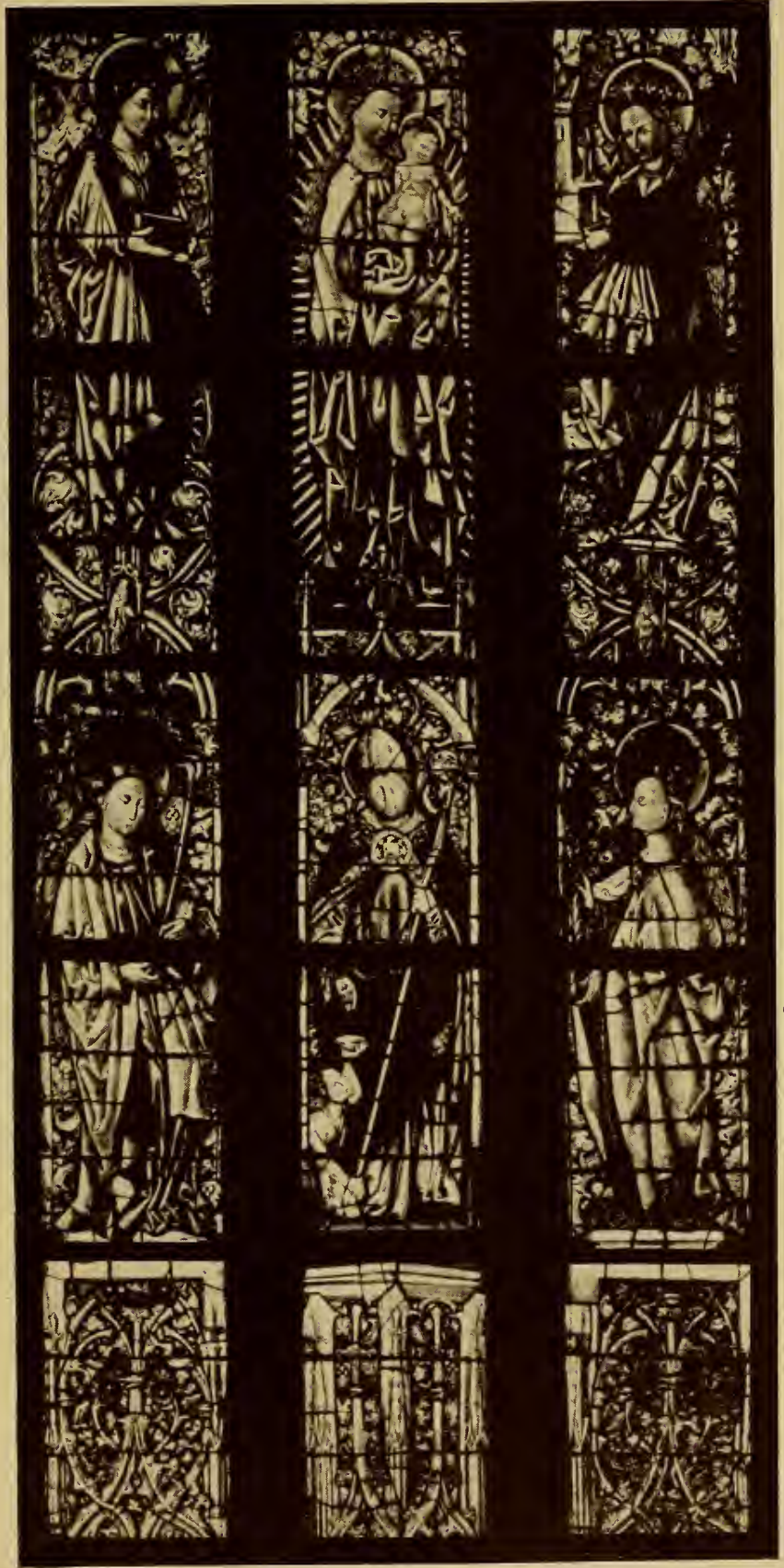

Teil eines Glasgemäldes in der Stadtkirche zu Friedberg. Ende des I 5 . Jahrhunderts. 



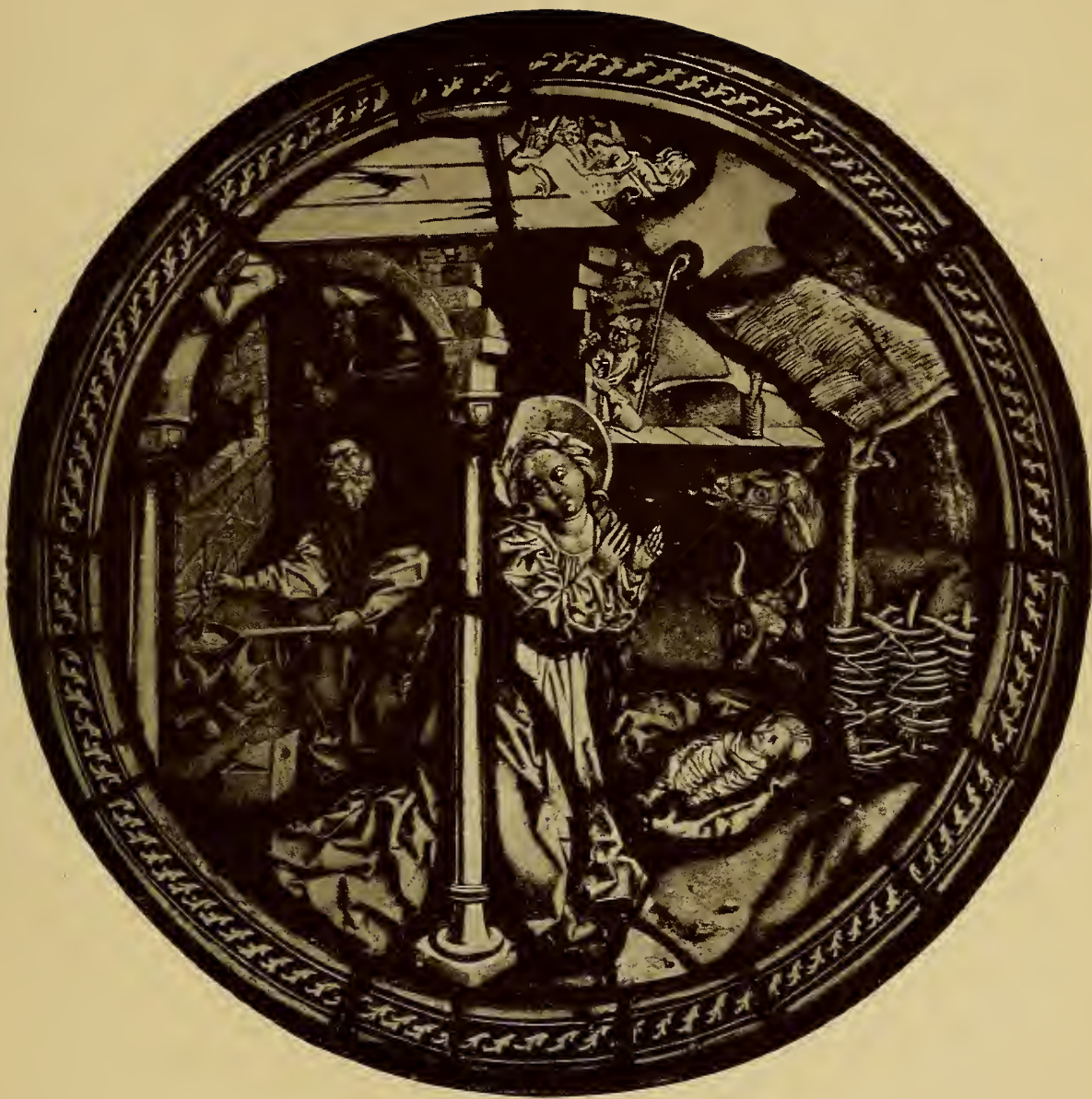

Rundscheibe in farbigem Hüttenglas. Schloß zu Erbach. Ende des I 5. Jahrhunderts. 



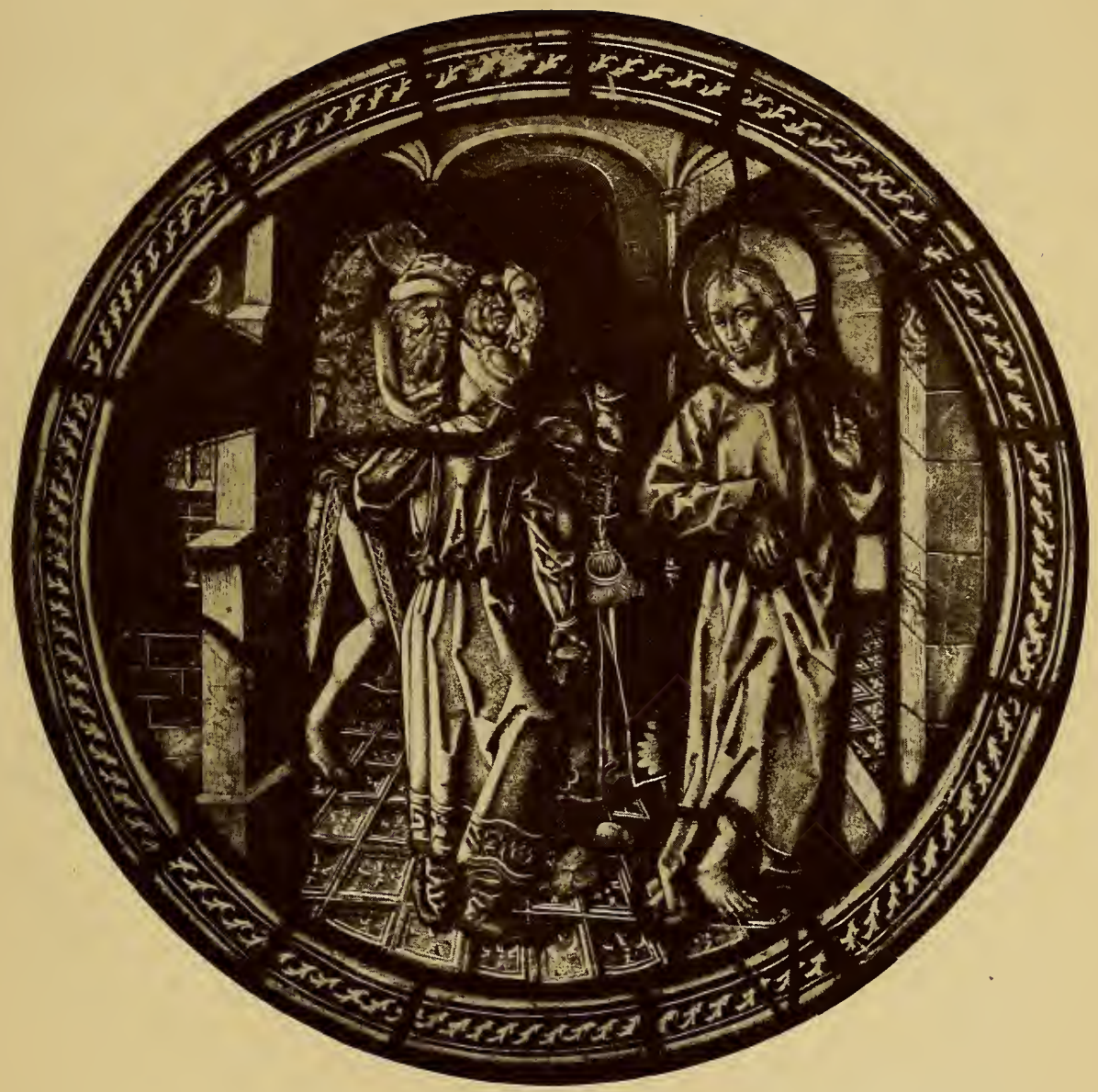

Rundscheibe in farbigem Hüttenglas. Schloß zu Erbach. Ende des I 5. Jahrhunderts. 

aus der U1mer Glasmalerschule hervorgegangen ist und in einem besonderen Verhältnis $\mathrm{zu}$ dem in Bern genannten „Hans von Ulm " steht, so lassen sich doch auch viele Gesichtspunkte feststellen, die auf das Elsaß deuten. Vor allem ist der Einfluß Schongauers und anderer oberrheinischer Ateliers auf Hans Wild unverkennbar. Wild hat dort zu visieren und stilisieren gelernt, wo der Sieg der deutschen Kirchengotik mit dem uns unter dem Namen Spätgotik bekannten Resultat, über die Mischung deutscher Kirchengotik mit verzopftem Giottismus völlig entschieden war. Man kann sich nun die Lernzeit Wilds zusammen reimen, wie man will, jedenfalls steht fest, daß er in seinen technischen Kunstgriffen an die Traditionen des Hans von U1m anknüpft, während er im Stil auf dem Boden der oberrheinischen Kunstrichtung steht. Dabei mag unbeanstandet bleiben, daß Hans Wild seine dauernde Wrerkstätte sehr frühzeitig in dem zentraler gelegenen und große Aufgaben bietenden Ulm aufschlug. ${ }^{1}$ )

\section{Die französische Glasmalerei im Zeitalter der Gotik.}

Die zum erstenmal im Psalter Ludwigs des Heiligen angewandte architektonische Überdachung der Einzelfigur hat für die französische Gotik der Glasmalerei während zweier Jahrhunderte das Leitmotiv gegeben. Sie ist, wie gezeigt, in weite Gebiete Deutschlands eingedrungen, ohne allerdings selbständige Weiterbildungen zu veranlassen. Dem System der Kirchengotik blieb Frankreich treu, selbst in dem Moment, als die Trecentomalerei Oberitaliens für Süddeutschland und das benachbarte Elsaß neue Ziele brachte, ja selbst in dem Moment, als die französische Miniatur ihren Einfluß auf die deutsche Glasmalerei ausübte. Das hängt damit zusammen, daß sich die kirchlichen Kreise

1) Mit der Auflösung des hebraisierenden Ornaments auf einem Gewandsaum eines Hohenpriesters auf dem Scharfzandtfenster zu München in Wilt sind wir nicht einverstanden. (Siehe Abb. 22 in dem Aufsatz Frankls in dem Jahrbuch der preußischen Kunstsammlungen). Um zu diesem Leseresultat zu gelangen, muB das Wort verkehrt und aus der Reihe heraus gelesen werden. Es ist zudem nicht einzusehen, warum Wild seinen Namen mit Thau, das immer wie aspiriertes S gesprochen wurde, schrieb, während ihm doch die richtigen Buchstaben Daleth und Thet zur Verfügung standen, wenn er bzw. sein Gewährsmann je hebräisch konnten. Wir halten das Ganze für einen neckischen Zufall eines völlig ornamentalen Zwecken dienenden Buchstabenspiels. 


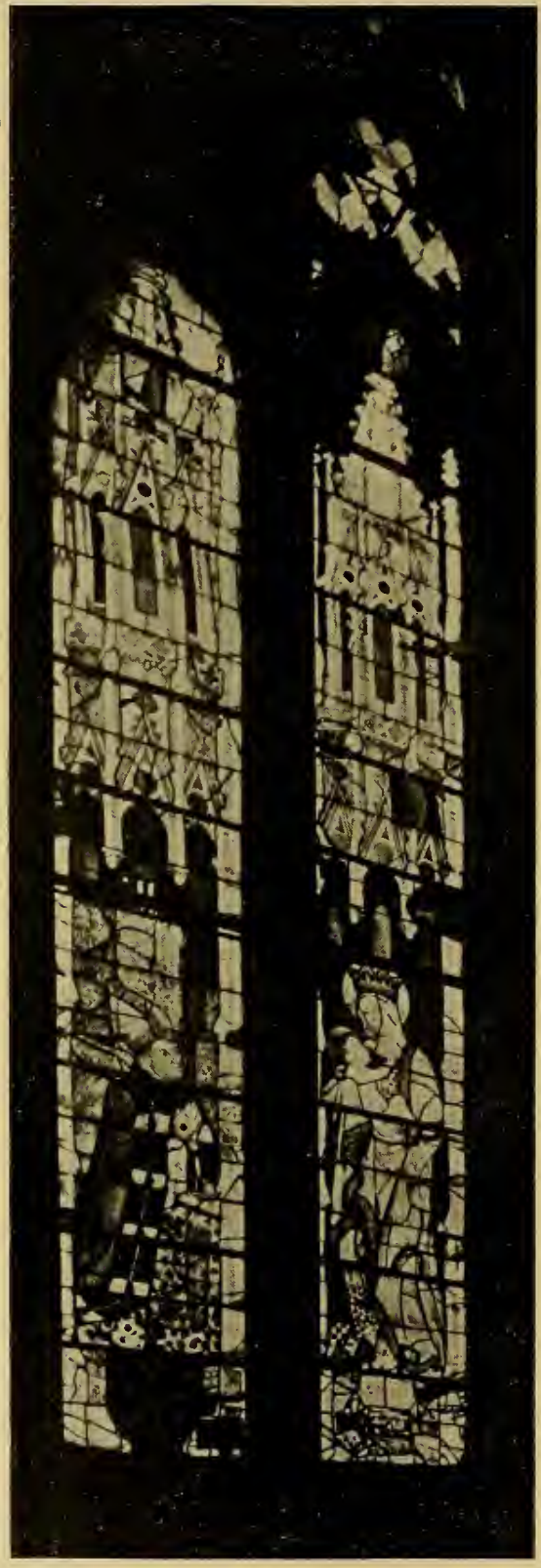

Abb. 19. Chorfenster in der Kirche zu Evreux. Zweites Viertel des I4. Jahrhunderts.
Frankreichs um so weniger an der französischen Hofkunst beteiligten, je mehr sie von den einzelnenHöfen entfernt waren. Die französische Glasmalerei entwickelte sich daher gleichmäßig mit den Stilwandlungen der Gotik. Den noch einfachen gotischen Übergangsarbeiten in Châlons-sur-Marne folgt die Periode der französischen Frühgotik, vertreten durch das Beispiel zu Esconnes, der Hochgotik mit den Fenstern zu Evreux, denen die Glasgemälde der Kathedralen zu Limoges und Beauvais anzuschließen sind (Taf. 47, Abb. 19, 20). Die architektonische Umrahmung und insbesondere Bekrönung dieser Fenster entspricht zwar durchweg wirklichen Bauformen, allein sie sind rein flächig, zeichnerisch gehalten und gleichen dem Aufriß eines Baumeisters auf Pergament. Gegen Ende des Jahrhunderts aber wird der bekrönende Flachbogen zum perspektivisch festgehaltenen Baldachin. Die Fläche weicht dem Räumlichen, die einerFederzeichnung ähnliche Konturierung breiter Plastik und malerischer Behaglichkeit. Daß dies unter dem direkten Einfluß der italienischenTrecentomalereigeschah, muß stark bezweifelt werden, 

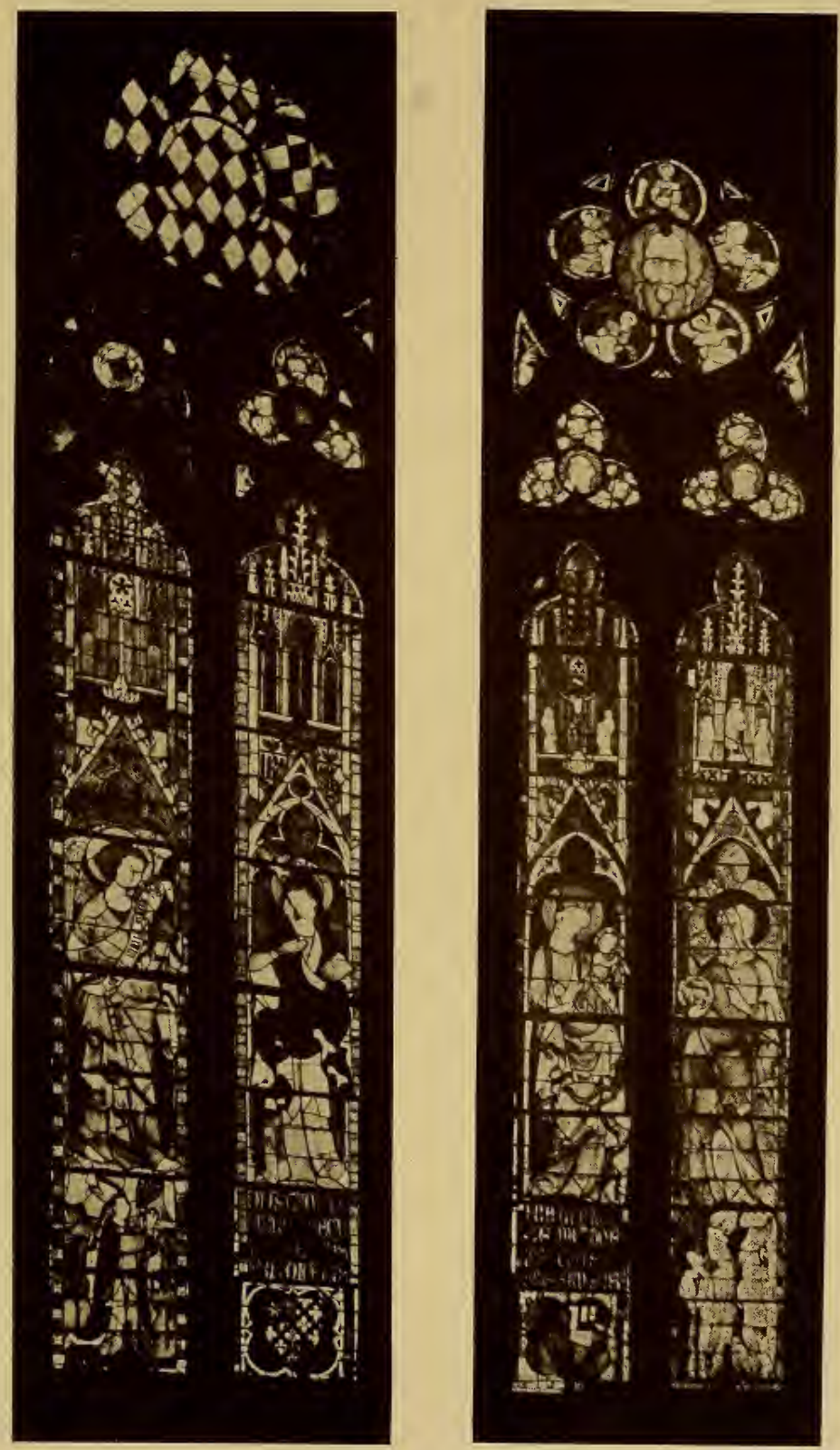

Chorfenster in der Kirche zu Evreux. Zweites Viertel des r4. Jahrhunderts. 

da die Giottisten ganz andere Ziele verfolgten als die französischen Glasmaler. Wenn man sieht, wie selbst Broederlam die giotteske Kleinarchitektur in die Kirchengotik umzusetzen sucht, wie selbst Paul von Limburg in dem Federblatt „Heiliger Hieronymus" die perspektivische Behandlung der Kirchengotik versucht, so muß man darin die starke Kraft der monumentalen Glasmalerei erkennen, die sich nicht so leicht von der Kleinkunst der Miniatur verdrängen ließ. Man darf sogar noch einen Schritt weiter gehen und annehmen, daß die perspektivisch-plastische Behandlung der Kirchengotik eine selbständige, unbeeinflußte Entwicklung in den französischen Glasmalerateliers darstellt. Wohl weist ein Blatt der Loipeauhandschrift in der Gestaltung des Baldachins, der entgegen der trecentistischen Architektur im Stil der französischen Kirchengotik gehalten ist, überraschende $̈$ hnlichkeit mit den eben geschilderten Glasmalereien auf. Allein in diesem Fall ist nicht die Glasmalerei von der Miniatur, sondern die Miniatur von der Glasmalerei beeinflußt. Die Beispiele aus Ambierlé und Chailly mögen die perspektivisch-plastische Gestaltung der französischen Glasmalerei im I 5. Jahrhundert zeigen. Aus dem Jahre I 440 stammt ein Glasfenster in der Kirche zu Egmoutiers, das die Kirchengotik der französischen Glasmalerei mit den Idealen der höfischen Miniatur zu verbinden strebt. So tief ist der kirchlichen Glasmalerei ihre ererbte Tradition eingefleischt, daß sie von dem gotischen Architekturprinzip nicht abgegangen ist. Nur der Fußboden bekam die perspektivische Fliesenmusterung und die beiden Seitenpfeiler, die der Baldachin $\mathrm{zu}$ tragen hatte, wurden in Kleinarchitektur mit Baldachinen aufgelöst, wie wir sie aus italienischen Bildern, italienischen und französischen Miniaturen kennen. In ähnlicher Weise ist ein Fenster gehalten, das sich in S. Maurice zu Lyon befindet, während ein Fenster in der Kathedrale zu Tours die Verbindung der Fußbodenperspektive mit der Kirchengotik zeigt. Die französischen Glasmaler haben den architektonischen Gedanken der Glasmalerei treuer bewahrt als die süddeutschen Meister, die sich an italienischen Malereien und französischen Miniaturen inspirierten. Entgegen den mit vielen kleinen Szenen gefüllten Fenstern der romanischen Periode liebt die französische Glasmalerei der gotischen Periode die Einzelfigur oder die Darstellung einer einzigen 


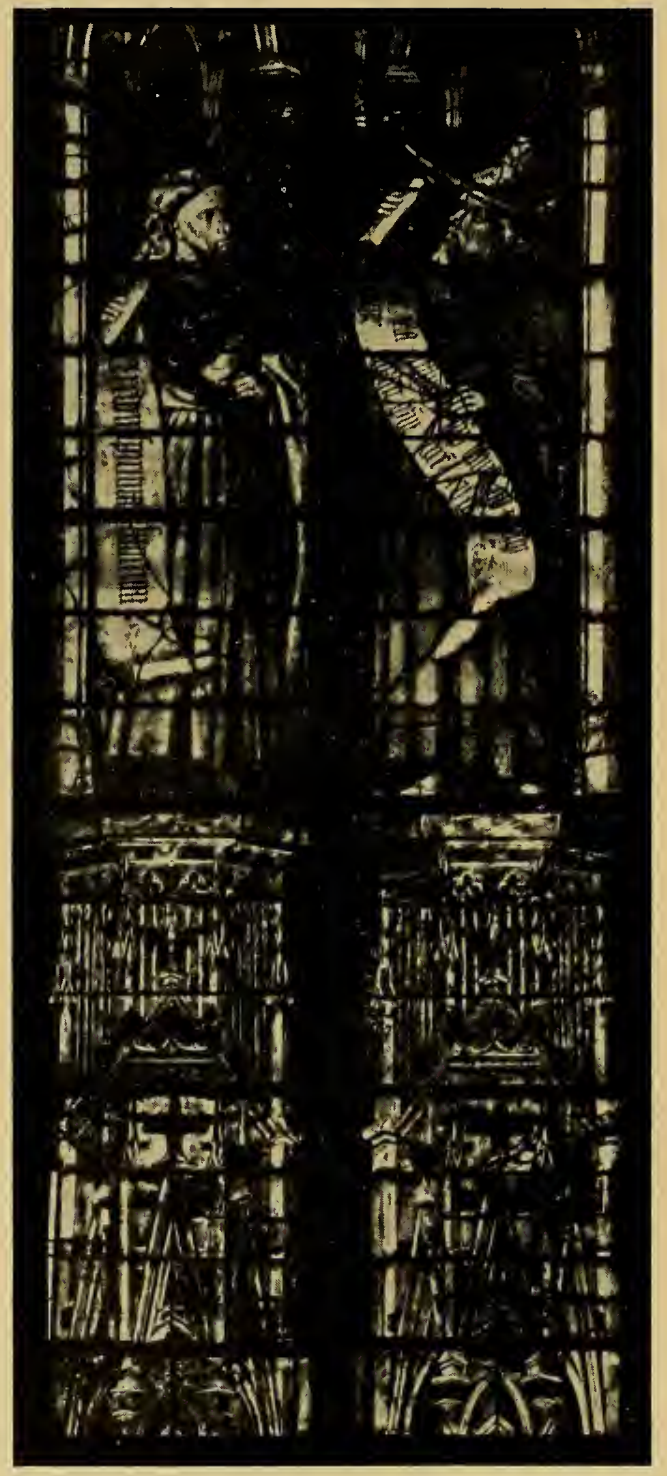

Abb. 20. Detail aus einem Glasfenster der St. Chapelle zu Riom. Um I 350. über das ganze Fenster verteilten Szene. Durch den Holzschnitt und Kupferstich kam die süddeutsche Glasmalerei immer mehr in das System der Legendenfenster hinein, während Frankreich nur den kleineren Teil seiner Fenster in diesem System komponierte. Beispiele davon finden sich in der Kirche zu Rosnay, Berulles, St. Parre-lesVaudes, St. Julien-duSault. Sämtliche Kirchen liegen wie das Zentrum dieser Schule, Troyes, in der Aube und sind der burgundischen Einwirkung am meisten ausgesetzt. Dengenannten Fenstern ist eigentümlich, daß sie für die Darstellung der Szenen entweder auf jede architektonische Umrahmung verzichten oder sich auf dürftige, sehr flach gezogene Bogen beschränken.Imübrigen geht die Zeichnung im Stil der Kleinkunst, der Buchmalerei. Die Mehrzahl der französischen Glasmalereien des I 5. Jahrhunderts setzt, wie gesagt, das System der Kirchengotik fort. Mit dem Eindringen der italienischen 
Renaissance suchte man den herkömmlichen Baldachin den neuen Kunstformen anzupassen, wie noch ein sehr interessantes Glasgemälde aus dem Jahre $155 \mathrm{I}$ in der Kathedrale von Beauvais zeigt (angefertigt von dem Maler Nicolaus Lépot) (siehe Taf. 48-5I).

Um vor Stagnation bewahrt zu werden, blieb der französischen Glasmalerei nur der eine Weg, der einer Anleihe bei der Tafelmalerei offen. Soweit die heimische Malerei nicht kräftig genug war, ließ man das Ausland auf sich wirken und dabei kamen besonders die Niederlande, der Mittelrhein und Süddeutschland in Betracht. In Anvers befindet sich ein Glasgemälde mit den beiden Johannes, das nach Vorlage eines Schülers van Eycks ausgeführt wurde. Da die Holzschnitte und Kupferstiche leicht $\mathrm{zu}$ transportieren waren, bildeten sie für die französische Glasmalerei eine reiche Vorlagenquelle. In der Kirche zu Brou erstrahlt die Stiftung Philipps des Schönen und der Margarethe von Österreich in verschiedenen prachtvollen Fenstern. Auf einem von ihnen ist als Hauptthema die Himmelfahrt Mariä dargestellt, darüber ein triumphus Christi. Schon Nodet ${ }^{1}$ ) hat erkannt, daß der Triumphzug auf Tizian zurückgeht. Ungefähr I 5 ro entwarf Tizian einen solchen triumphus Christus, der dann von Nicollo Boldrini und Andrea Andreani in Holz geschnitten wurde und als Holzschnitt den Glasmalern Jean Brachou, Jean Orquois und Antoine Noisin, den Meistern der Fenster von Brou als Vorlage diente. Das Hauptbild aber, die Himmelfahrt, bestimmte Nodet als Kopie eines Stiches von Albrecht Dürer und zwar aus der I5IO entstandenen Holzschnittfolge des Lebens der Jungfrau Maria \%. Die Himmelfahrt war für den Helleraltar, der durch Brand zugrunde gegangen ist, in Ö1 ausgeführt. Beim Übertrag des Stiches auf das Glasgemälde wurde die frische Kraft Dürers völlig verwischt und ins Weiche aufgelöst. Außer diesem Stich verwendeten die Glasmaler noch zwei andere, nämlich Christus und Magdalena, Christus als Gärtner, die im „Kupferstichkabinet" von Bartsch unter Nr. 46 und 47 aufgeführt sind. S. $96 \mathrm{ff}$.

3) Nodet, V. Un vitrail de l'église de Brou, Gazette des Beaux Arts XXXV,

2) Die Abbildungen siehe bei L. Bégule, Les vitraux du Moyen-âge et de la Rénaissance dans la région Lyonnaise. Paris I9II. 
Was Nodet von Brou, das weist Lafond ${ }^{1}$ ) von einem Glasgemälde nach, das sich heute in der Kirche S. Romain zu Rouen befindet und nach einem Stich Dürers aus der "Großen Passion“ (Bartsch Nr. I I) gezeichnet ist. Der Karton des Fensters in der Kapelle Notre dame de Loretto der Kathedrale zu Beauvais wird von Lasteyrie einem Kopisten Raphaels, zugeschrieben. Was immer nach Stichen deutscher oder italienischer Meister an Glasgemälden entstanden ist, alles weist eine Umdeutung der kräftigen Kontur in die weichen Formen der französischen Malerei auf, die den ganzen Verlauf der französischen Glasmalerei des I6. Jahrhunderts nachhaltig beeinflußte. Die Glasmaler hießen in den Rechnungsbüchern bezeichnender Weise fast stets peintre statt verrier, was dem schon genannten Gelehrten, Jean Lafond, anfänglich Bedenken bereitet hat (S. 6). Diese starke Abhängigkeit der französischen Glasmalerei von der Tafelmalerei trug den Keim vorzeitiger Auflösung der Glasmalerei in sich. Die wenigen großen Meister des I6. Jahrhunderts, die ebenfalls mehr Maler waren, Jean Lequier, Engrand le prince, Fauconnier, Pierre Vilatte und Nicolas Froment zu Avignon, Nicolas Cordonnier zu Troyes, Jean Barbe, Robert le Court, Guillaume le Vieil zu Rouen, wurden mit Aufträgen überhäuft, so daß die kleineren immer mehr zurückgedrängt waren. Wo man diesen noch einige Aufgaben zuwies, da hielt man sie an, die Großen zu kopieren, wie Lafond an einem interessanten Beispiel aus der Normandie nachweist. Der Glasmaler Mausse Heurtault war laut eines noch vorhandenen Kontraktes vom Jahre I 535 verpflichtet, für die Kirche Saint-Ouen de Pont-Audemer Glasgemälde nach dem Vorbild des Engrand le prince, des Haupts der Schule von Beauvais, dem Lucien Magne in seinem Werke über die Glasmalereien zu Montmorency ein Denkmal gesetzt hat, anzufertigen. Heurtault hielt sich getreu an sein Vorbild und verzichtete nur einmal auf Engrand, nämlich als er es für nötig erachtete, einen Stich des Lukas von Leyden (Bartsch Nr. 40) sklavisch zu kopieren. Unter solchen Umständen waren dem Einfluß auswärtiger Künstler

1) Lafond, J. Arnoult de la Pointe et les artistes etrangers à Rouen, Bulletin de la Société des amis des monuments rouennais I9II. Un vitrail d'Engrand le prince ebendort 1908 . 


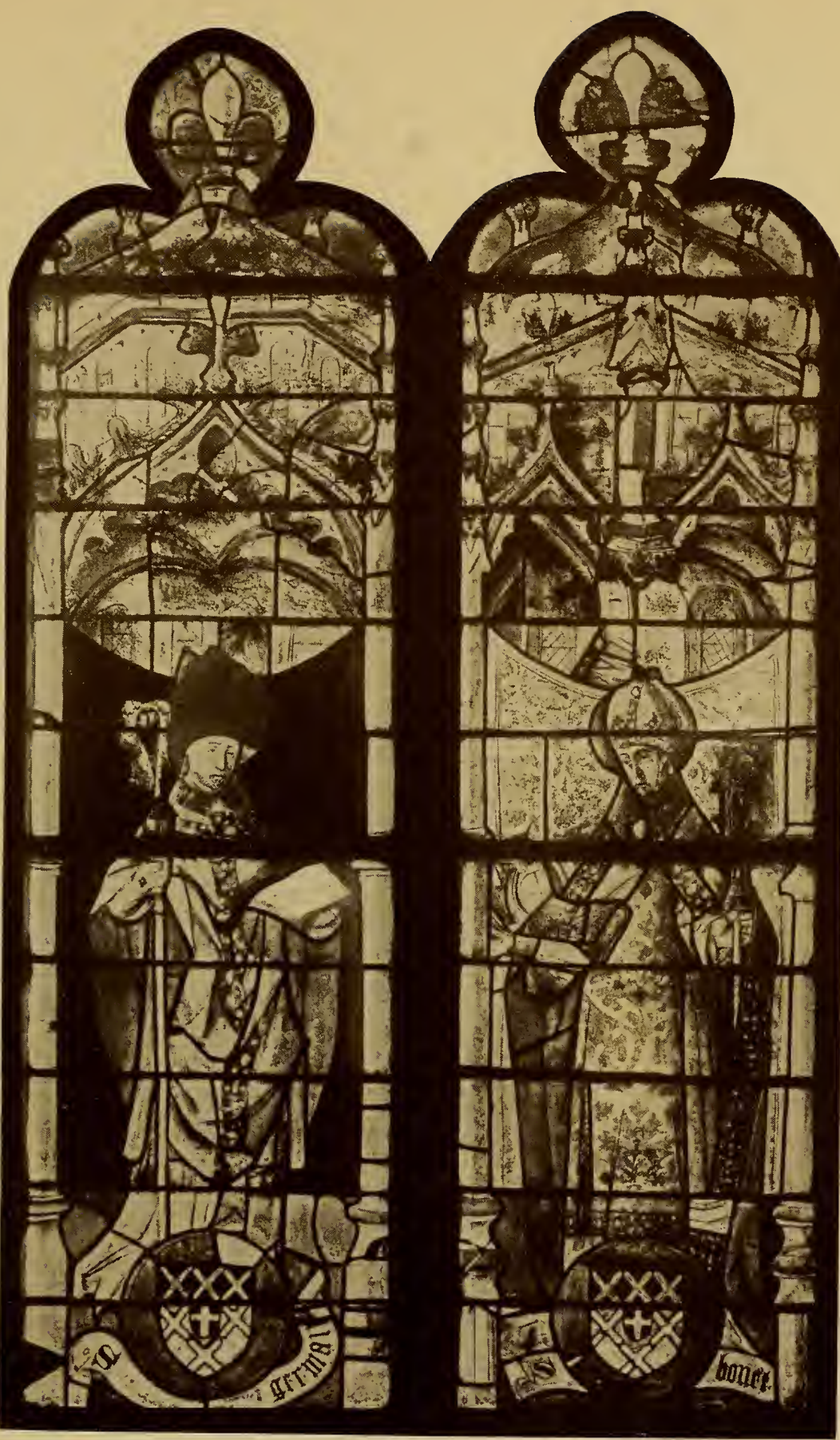

Teil eines Fensters in der Kirche zu Ambierlé. Stil der französischen Spätgotik. 

immer mehr die Tore geöffnet. Nicht, daß man sich begnügt hätte, fremde Stiche nachzumachen. Die Künstler wurden direkt nach den Zentren der französischen kirchlichen Kunst gerufen. Auf Grund einer gründlichen Untersuchung über „les peintres sur verre", "les artistes et les maîtres de méties à Lyon du XV. au XVI. siècle" kommt Natalis Rondot zu dem Resultat, daß zehn Prozent aller Künstler Ausländer sind, von denen ein schwaches Drittel auf Italien, das übrige auf Holländer und Deutsche trifft, die hauptsächlich aus Utrecht, Nimwegen, Leyden Mainz und Köln kommen. So ist ein Hans von Wesel seit 1457 bis zu seinem Tode dauernd in Rouen tätig, ferner ein Arnold von Cronberg (Mainzer Gegend). Mit diesen urkundlichen Resultaten stimmen die stilistischen Befunde völlig überein. Auf dem Stephanusfenster in S. Romain zu Rouen, das aus S. Etienne-desTonneliers stammt, ist zu lesen Arnoult de Niemeg peii... Es ist derselbe Meister, der unter dem Namen Arnoult de la Pointe als Meister des Stammbaumfensters in S. Godard (Rouen) in den Rechnungen vorkommit (S. 7) und auf dem genannten Glasgemälde signiert hat. Seit der Mitte des I6. Jahrhunderts gerät Frankreich immer mehr in die Abhängigkeit von den holländischen Glasmalern. Neue technische Mittel müssen über den Mangel an Erfindung hinwegtäuschen, wie beispielsweise das bekannte Rotbraun des Jean Cousin, das neuerdings wieder hergestellt wird.

Was die englische Glasmalerei betrifft, die stets im $\mathrm{Zu}$ sammenhang mit den französischen und besonders normannischen Schulen zu behandeln ist, so läßt sich die Entwicklung in ähnlicher Weise charakterisieren, wie sie eben für Frankreich festgestellt worden ist. Die aus der ersten Hälfte des I4. Jahrhunderts stammenden Glasgemälde zu Exeter, in der Beer Ferrers Church zu Devon gehen parallel mit den Glasgemälden zu Evreux und Esconnes, während die Katharinenscheibe in der Exeter Kathedrale ( 1389 ) den Stil der plastisch-breiten Kirchengotik wiedergibt, den wir an vielen Glasgemälden Frankreichs kennen gelernt haben (Siehe Taf. 52). 


\section{D) Die Vorherrschaft des Malerischen infolge Trennung zwischen Visierer und Techniker.}

\section{Die kölnische und niederländischen Schulen.}

Die Werkstatt des Hans Wild bildet den Ausklang eines selbständigen Kunsthandwerks. Wenn auch Wild nur einen kleinen Teil der aus seiner Werkstatt hervorgegangenen Glasmalereien persönlich ausgeführt hat, so hat er gleichwohl allem den bestimmten und für immer kenntlichen Eigencharakter aufgedrückt, indem fast alle seine Glasmalereien von der gleichen Hand, nämlich von dem Meister selbst visiert wurden. Wild bedeutet daher das interessanteste Beispiel für die künstlerischen Vorzüge einer organischen Verknüpfung von Visierer und Techniker. Obwohl Wilds Stil aus einer maniriert entarteten Kunst, die mit dem Meister E S beginnt, hervorgewachsen ist, obwohl sein Stil alles Flächige verabschiedet und eher vom Holzbildhauer gelernt hat, entstanden in seiner Werkstatt doch noch Arbeiten, die sich in Riß und Ausführung ein großes Stück echten Glasmalertums erhalten und daher den Glasmalern des I9. Jahrhunderts in besonderer Weise als Vorbild gedient haben. Außer Wild ist keine andere Werkstätte bekannt geworden, die eine derartig markante Stellung eingenommen hätte. Schon die sehr bedeutende Hirsvogelwerkstatt ist keine stilistische Einheit mehr. In ihr wird ausgeführt, was die großen Künstler am Platze visiert haben.

Mit dieser Trennung des Visierers von der Werkstatt tritt die Glasmalerei in eine völlige Abhängigkeit von der zeitgenössischen Tafelmalerei. Die Glasmaler sehen sich gezwungen, die feinen Modellierungen und Schattierungen auszuführen, die den Ölgemälden der Visierer eigen sind. Nur der starke Nachhall großer glasmalerischer Traditionen hat verhindert, daß die spezifischen Eigenschaften der Ölmalerei als störende Mißklänge in der ihnen an sich wesensfremden Glasmalerei erscheinen. Unter dem Einfluß der Ölmalerei tritt auch für die Glasmalerei eine besondere Betonung des Modells auf. Wenn auch schon auf dem Franziskusfenster zu Königsfelden der gelungene Versuch gemacht wurde, einen italienischen Prälatenkopf nach der Wirklichkeit zu zeichnen, so tritt Porträt und Charakterkopf doch 


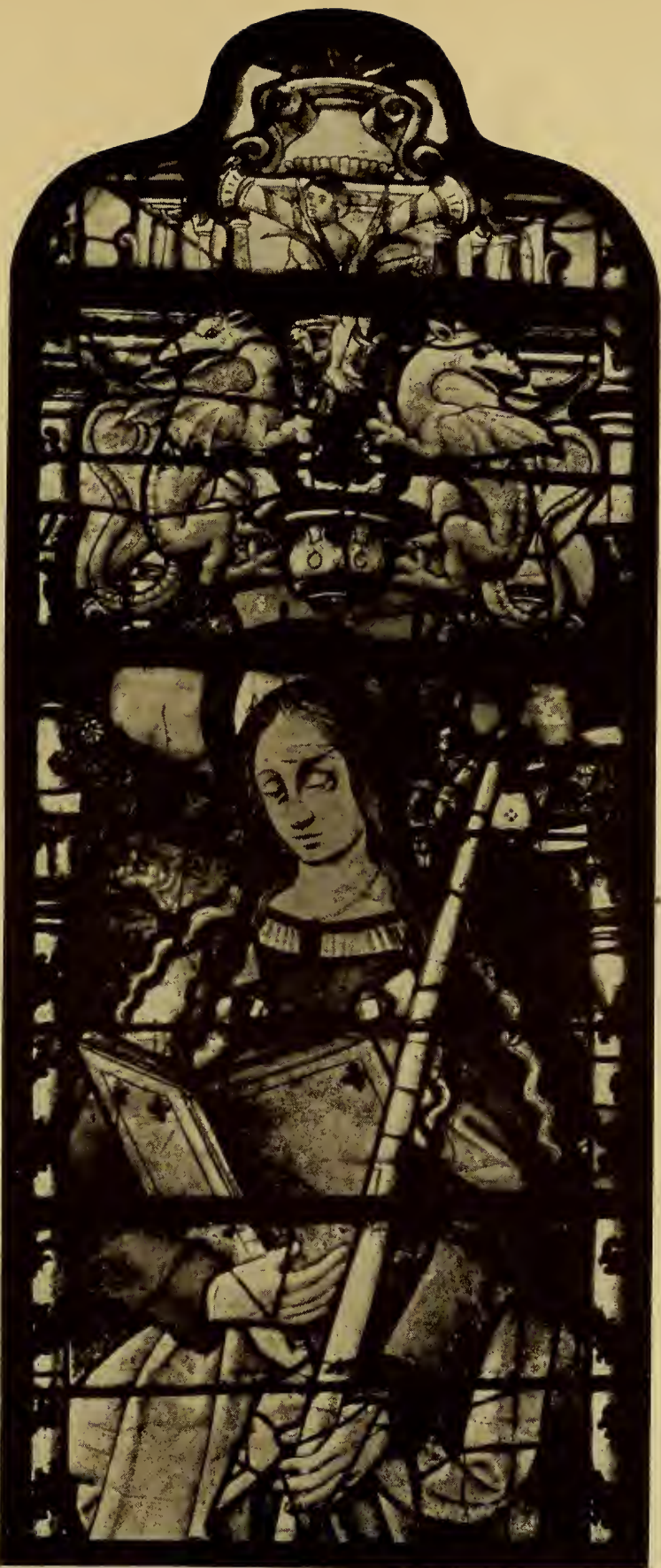

Detail eines Glasgemäldes in der Kirche zu Montmorency, im Stil der französischen Frührenaissance. 



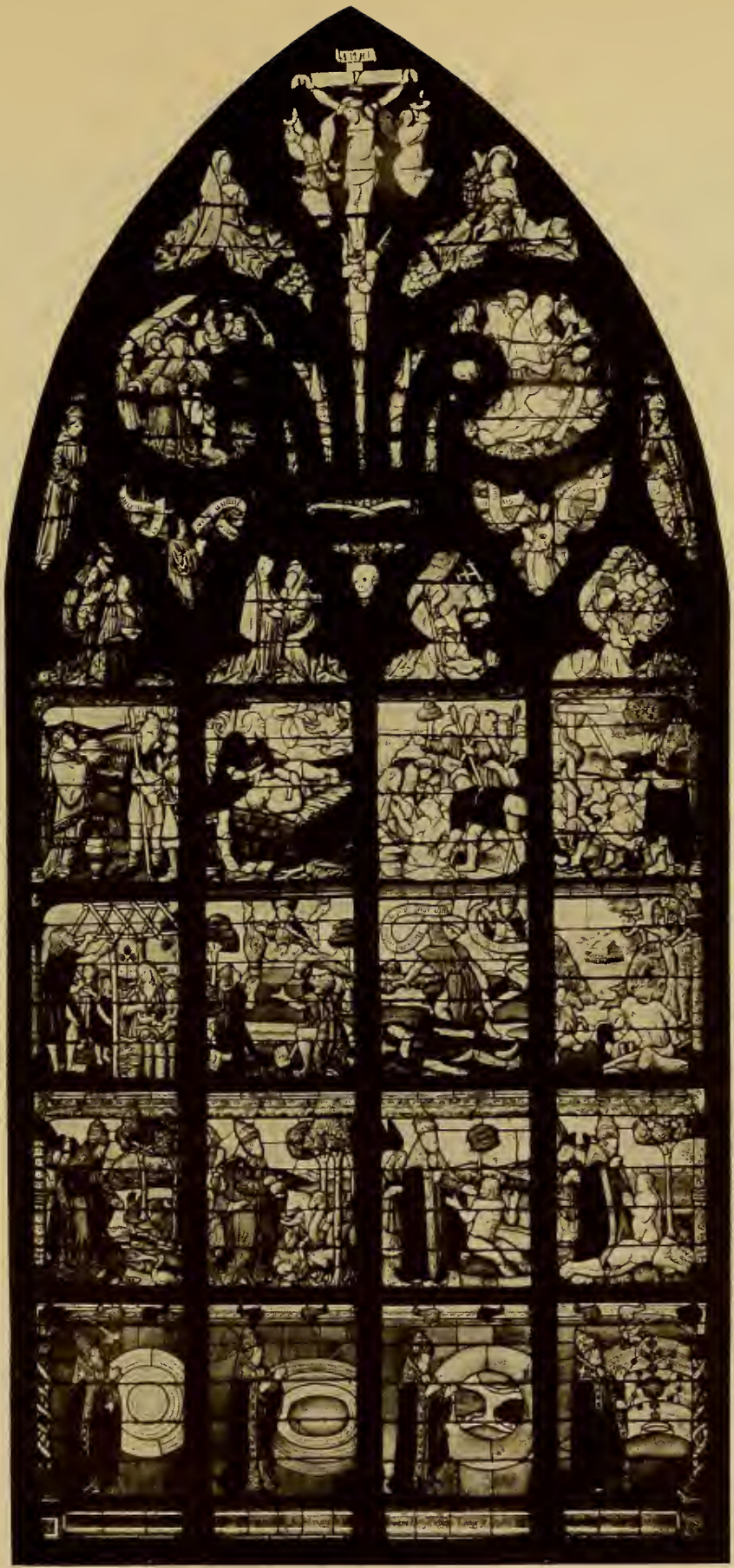

Fenster im Dom zu Troyes. Anfang des I 6. Jahrhunderts. Nach einer Photographie von G. Lancelot. 



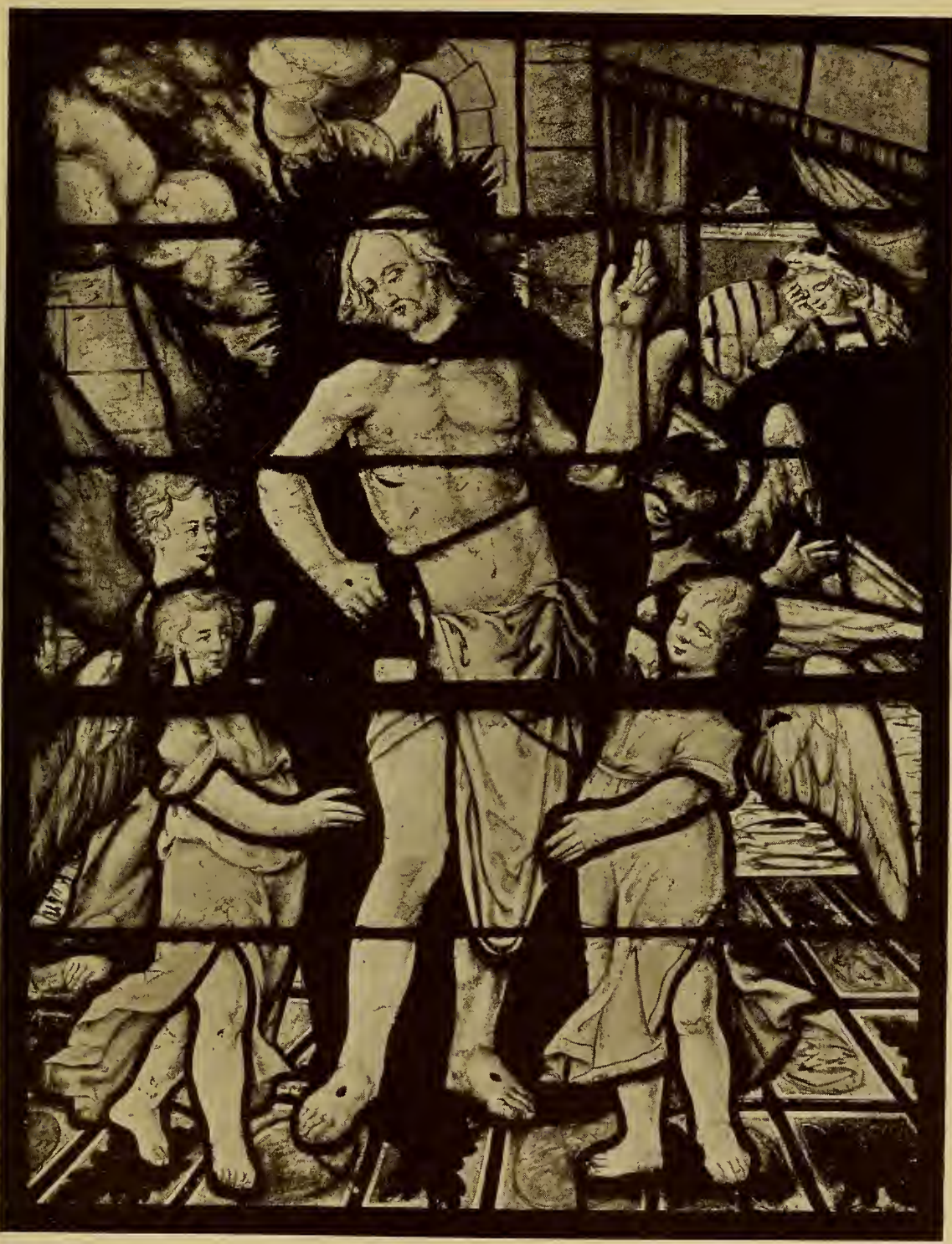

Detail aus einem französischen Renaissancefenster. 



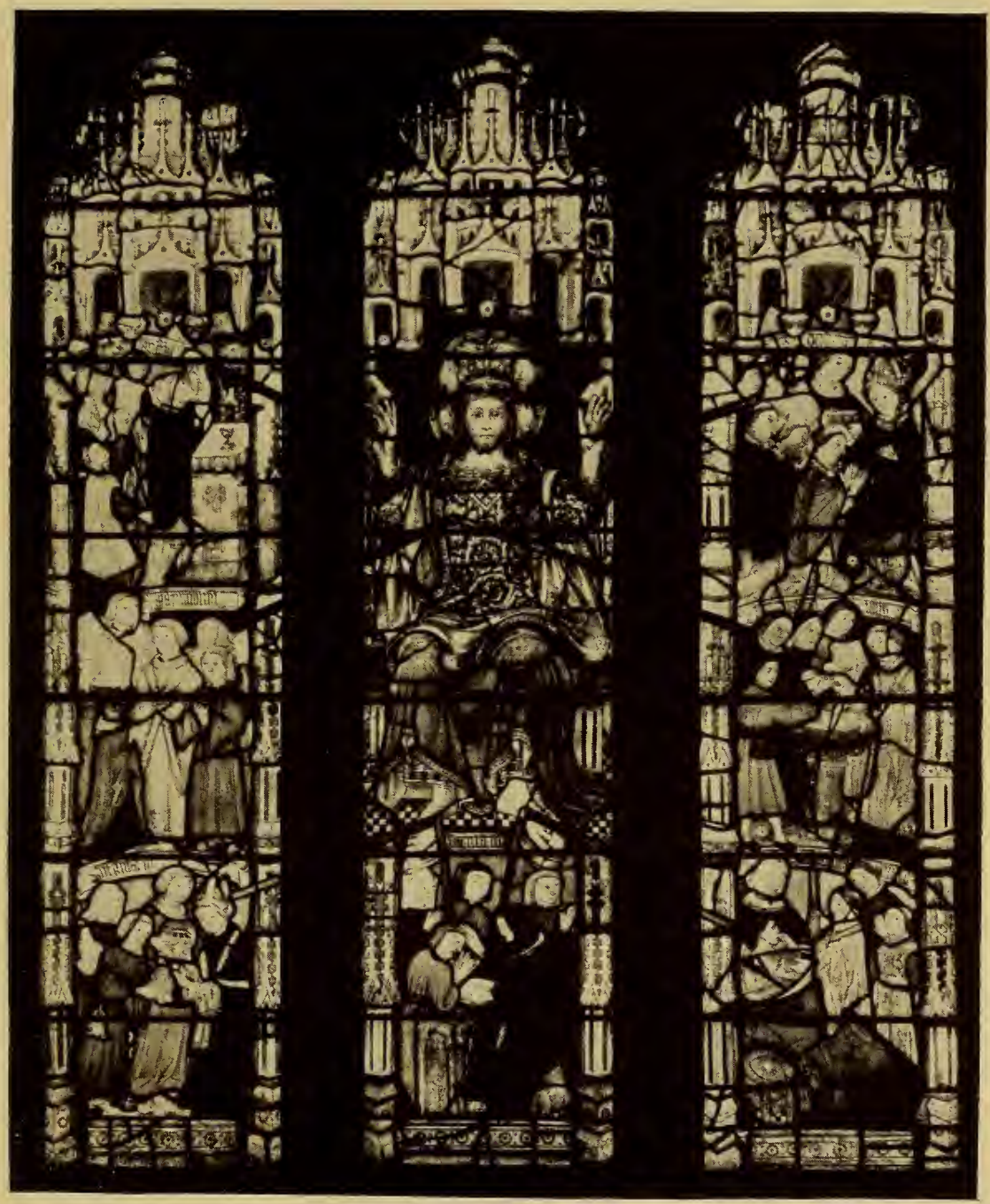

Glasgemälde aus einer englischen Kirche. I5. Jahrhundert. Mittelbild restauriert. 

Tafel 53
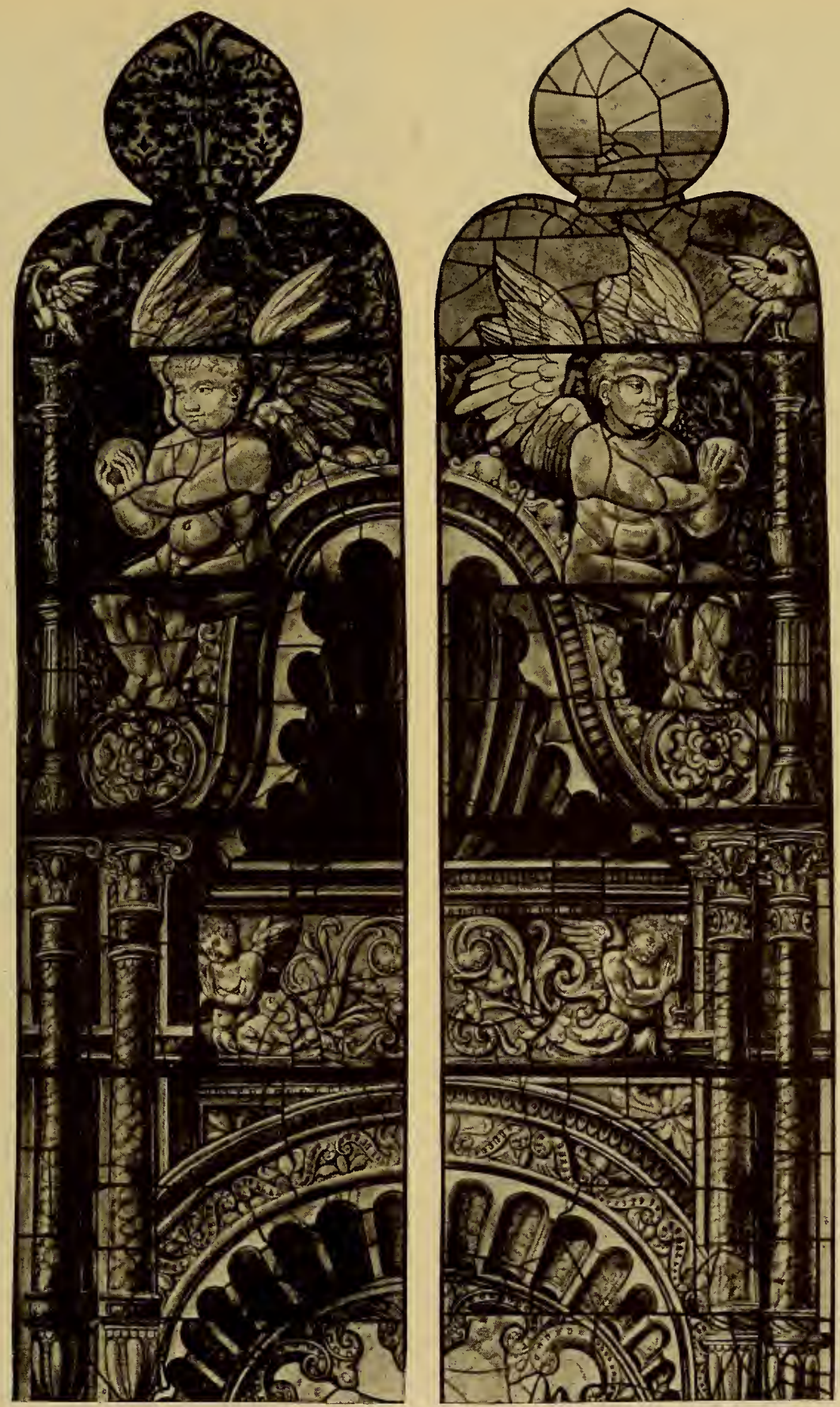

Teil eines Glasgemäldes im Dom zu Metz, von Valentin Busch. 


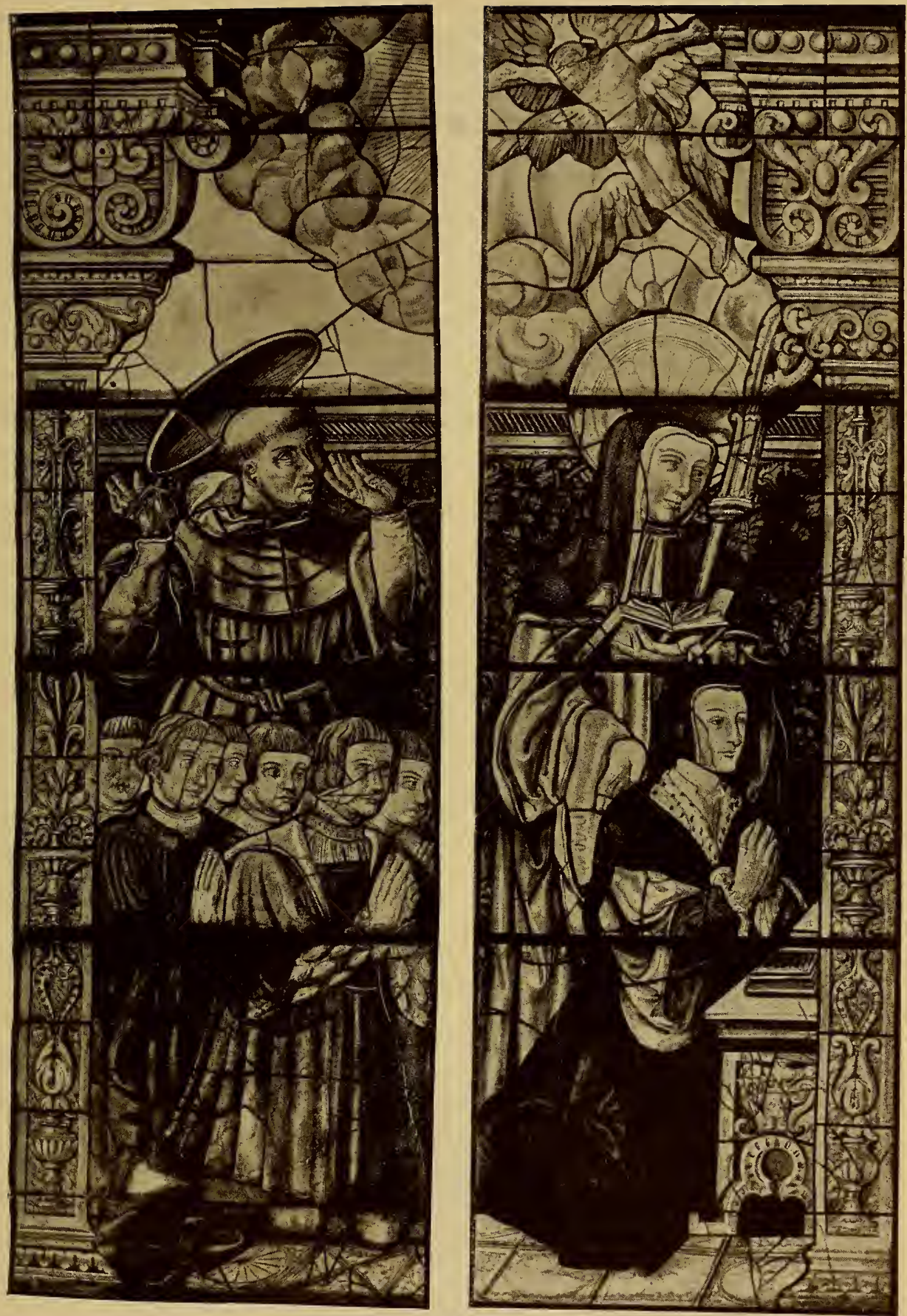

Teil eines Glasgemäldes im Dom zu Metz, von Valentin Busch. 



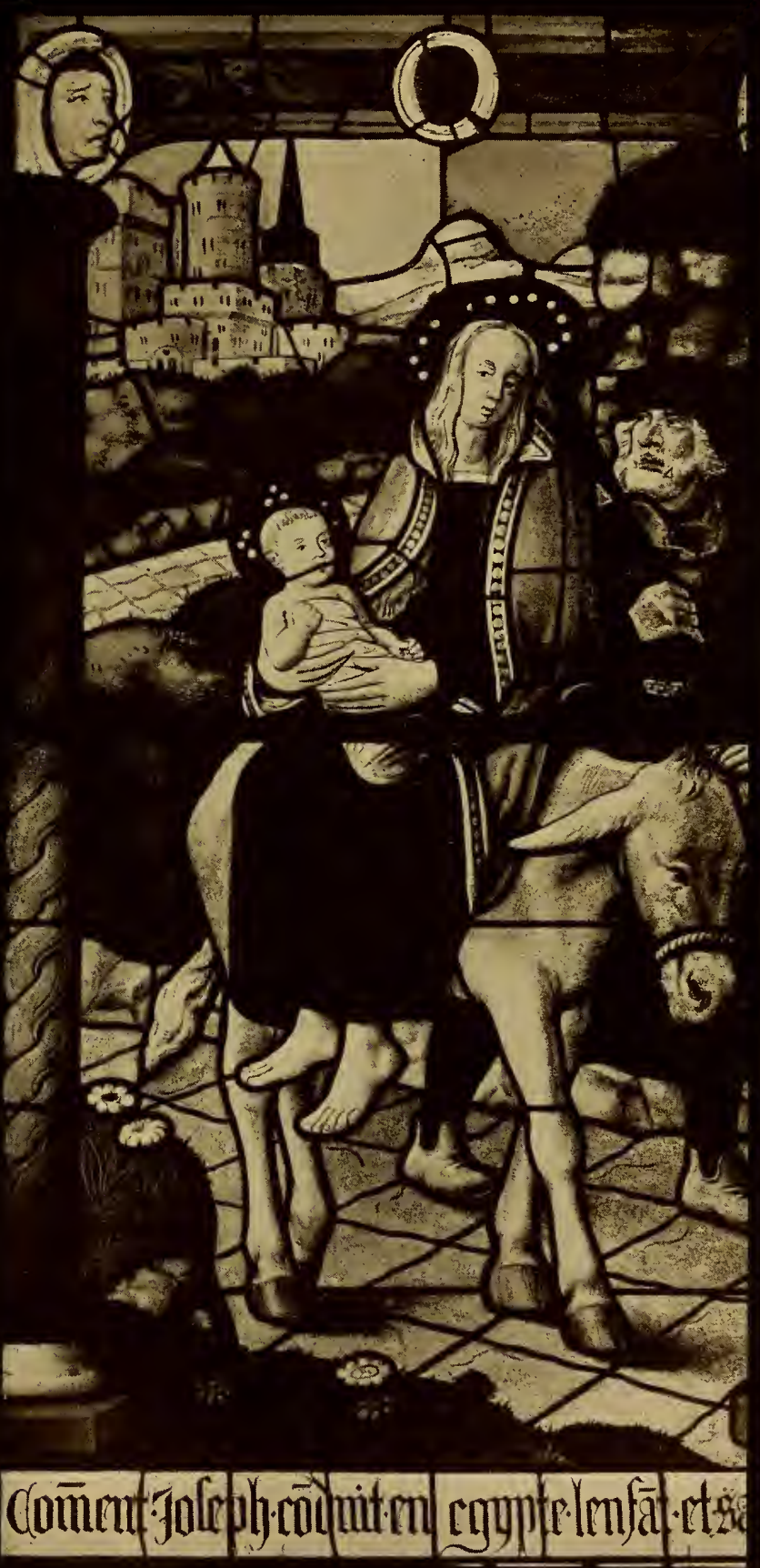

Detail aus einem Glasgemälde in der Kathedrale zu Chalons. Ende des I 5. Jahrhunderts. 



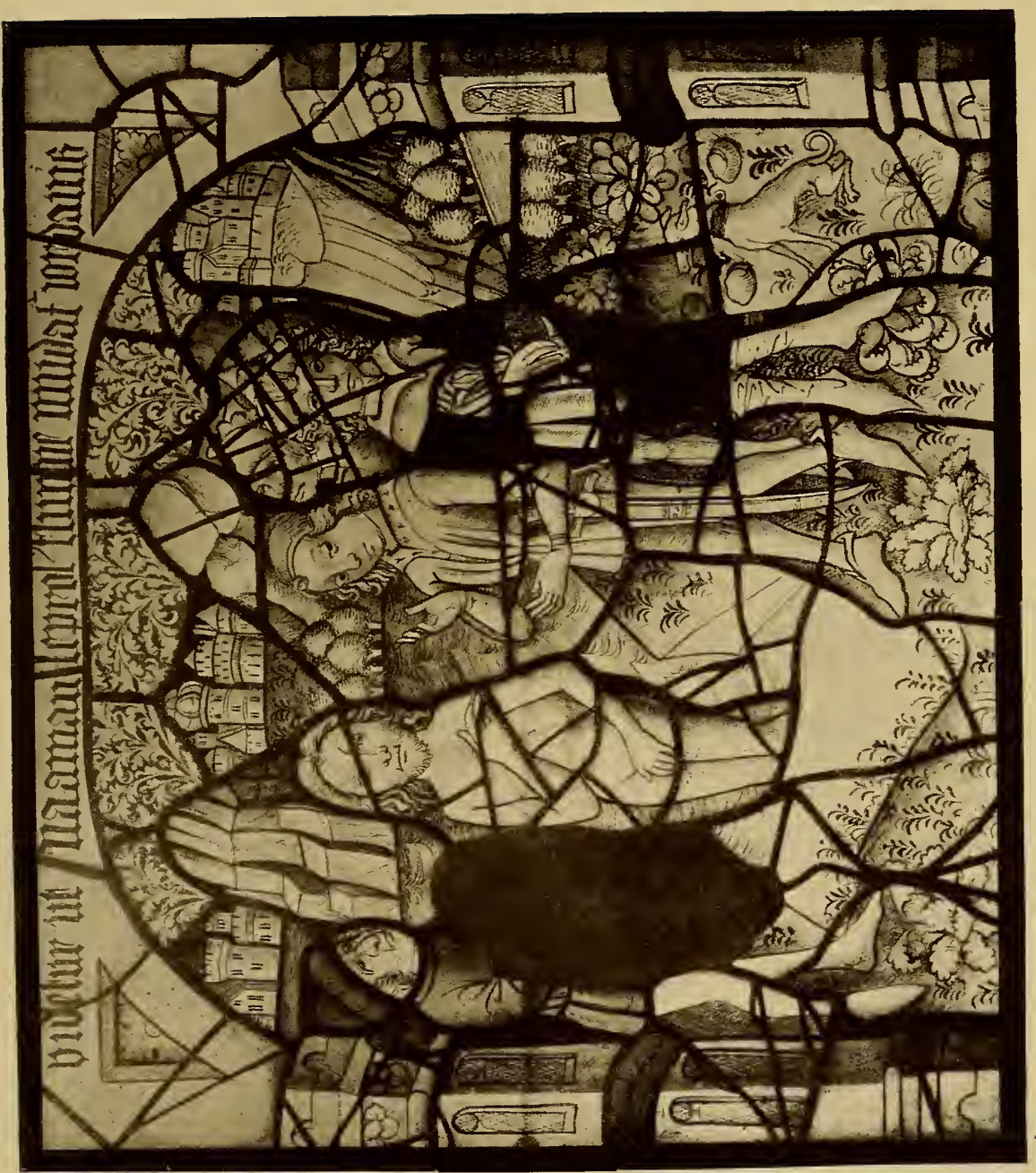

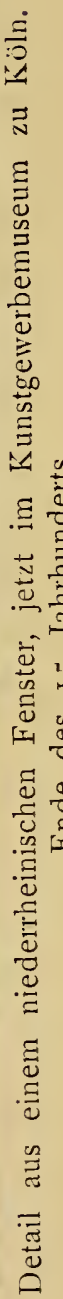



hinter den traditionellen Typen zurück, die nur deswegen keine blutleeren Schemen sind, weil die gläubig-naive Zeit einen tiefen Inhalt echten religiösen Empfindens in die Zeichnung zu gießen hatte. Erst die Zeit des Humanismus und der Renaissance zieht auch in der Glasmalerei die heiligen Gestalten aus den typischen Höhen der Gottheit in die faßbare Nähe deș Menschentums herab und deutet dies schon äußerlich an, indem sie die meisten heiligen und insbesondere nichtheiligen Personen in das Zeitkostüm kleidet. Hand in Hand damit geht die Betonung des Landschaftlichen und die Bezeichnung des Details.

Am frühesten hat sich die Kölner Glasmalerei der Abhängigkeit von der Tafelmalerei ergeben und blieb bei diesem Prinzip, weswegen allen Arbeiten die frische Unmittelbarkeit und eine gewisse Rassigkeit mangeln. Zu Lochners Zeiten steckten die Kölner noch voller Beziehungen zur französischen Kunst, und des Künstlers Einfluß auf die Glasmaler war gering. Bezeichnenderweise ist es nicht die interessante höfische Mliniatur, vielmehr die wulstige Gotik der im vorigen Kapitel genannten Glasgemälde Frankreichs, von denen Köln im Bann gehalten wird. Man vergleiche nur zum Beispiel die Wechselbeziehungen zwischen einem Prophetenfenster in Germanischen Museum zu Nürnberg, einer Geißelungsscheibe in Gondorf, sowie einer Evascheibe im Kaiser-Friedrich-ILuseum zu Berlin und andererseits dem Zyklus in Châlons-sur-Marne (Taf. 55, 56). Es ist dieselbe Architektur, dieselbe Zeichnung des Fußbodens, derselbe Typus der Figuren. Auch die Einfügung einzelner Szenen in rechteckig angelegte Architekturen (siehe z. B. die Athaljascheibe, die Naamanscheibe im Kölner Kunstgewerbemuseum) entbehrt nicht eines Gegenbildes auf französischem Boden, wic eben die Darstellung des Lebens Jesu zu Châlons oder der Julianuslegende in der Kirche zu S. Julien-du-Sault zeigt. Seit der Mitte des Jahrhunderts werden die Zusammenhänge mit der Tafelmalerei so eng, daß die Kölner Glasmalerei weit eher einen Bestandteil der Tafelmalerei bildet, als daß sie in einer Darstellung der Glasmalerei Anrecht auf breitere Behandlung hat. Im einzelnen ist nun freilich nicht immer leicht, die erhaltenen Glasgemälde mit gewissen Tafelmalern zu identifizieren, da zu viel verloren ist und eine so feste Gesamttradition herrscht, daß man nur unter größtem Vorbehalt bestimmte Zuschreibungen 
machen kann. Im allgemeinen läßt sich folgender Entwicklungsgang feststellen: Die Glasmalerei Kölns verläßt nach Mitte des Jahrhunderts die Bahnen einer Architekturkunst fast vollständig. Der breite Anteil, den die gotischen Bauglieder auf den Fenstern eingenommen, verschwindet wie mit einem Schlag (d. h. für unser Erkennen, da zwịschen dem System des Gondorfer Merodenfensters und der Kreuzigung in der Hardenrathkapelle der Kirche S. Maria im Kapitol, die man mit dem Meister des Marienlebens in Zusammenhang bringt, vielleicht verschiedene uns heute nicht mehr erkennbare Zwischenstufen liegen). Dafür erscheint die bühnenmäßig stilisierte Natur; die Szene nimmt womöglich das ganze Fenster ein, wodurch manchmal sehr ungeschickte Überschneidungen durch Steinrippen und Windeisen entstehen. Der Übergang von der Spätgotik in die Renaissance vollzieht sich daher in kaum merklicher Weise. Als Vorlagen für Visierungen dienen hauptsächlich der Sippenmeister, der Meister des hl. Bartholomäus, der Meister von S. Severin, der die Kölner Frührenaissance vertretende Bartholomäus Bruyn und der Meister der Kölner Hochrenaissance Anton Woensam von Worms. Mit dem Sippenmeister werden die drei mittleren Fenster der Nordwand des Kölner Doms in Zusammenhang gebracht, die nach Merlos Forschungen allem Anschein nach der Kölner Glasmaler Hermann Pentelynck d. Ä. angefertigt haben dürfte. Auf Vorlagen des Meisters von S. Severin wird ein Zyklus, Leben des hl. Bernhard, zurückgeführt, der im Jahre I 505 für den Kreuzgang des Klosters Altenberg gestiftet war. Reste befinden sich im Kölner und Berliner Kunstgewerbemuseum. Bartel Bruyns Vorlagen sollen Fenster im Chor von S. Peter in Köln ihre Anregung verdanken, während die Hand des Anton Woensam von Worms in einigen Scheiben des Berliner und Kölner Kunstgewerbemuseums erkannt wird. Da Köln von den Wirren der Reformation verschont blieb, erlitఓ die monumentale Glasmalerei daselbst keine Unterbrechung, ein Zeichen, daß das Ende des monumentalen Stils in anderen großen Glasmalerzentren (Ulm, Nürnberg) tatsächlich auf Rechnung der im Gefolge der Reformation befindlichen Unruhen zu setzen ist.

Der Eintritt der Renaissance in die Kölner Glasmalerei vollzog sich auf ähnliche Weise, wie die Entwicklung dieser Schule 


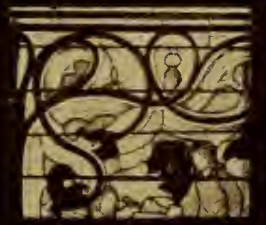

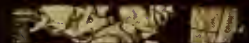

s.

*ै

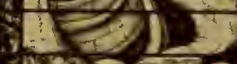

(es $\Rightarrow$

19.5

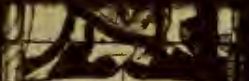

लिm

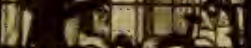
$720 \%$ 政

II $₹ *$ yezull

Ues is ind

IE G

at-enilt

$17 x=-15 s$

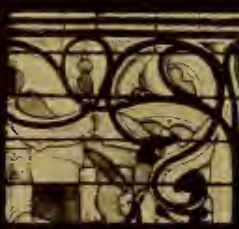

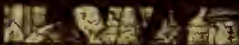

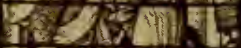

Hay il ? s. arearser. 1

लmest

A

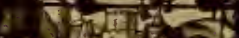

S 댐 18 100 ine?

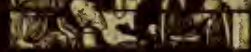

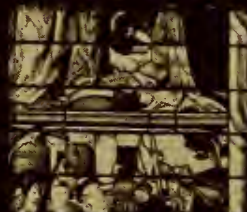

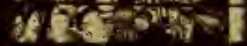

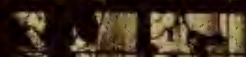

5.

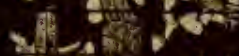

y. मक खो।

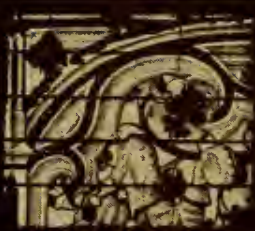

Fanis

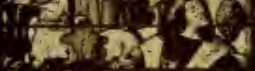
in $\mathrm{x}=1$ is 10 3. 2. wes? अरिप ) 1 (15 $>11$

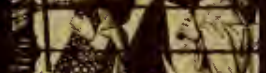
ath ory

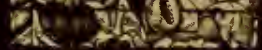

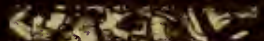

X्र. B vitu Cx-2 तो d 4 दहर

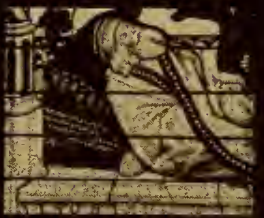

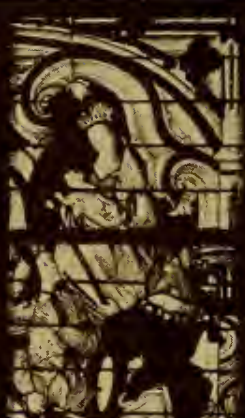

sonts

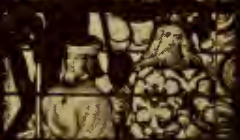
ares as

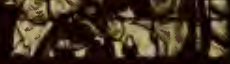
VE (1)⿺廴

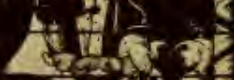
क. 1 हैते है ㄴ. (주에 (2)

Teil eines Fensters im Dome zu Köln. Anfang des r 6. Jahrhunderts. 

während des Zeitalters der Hoch- und Spätgotik, nämlich in steter Übereinstimmung mit den westlichen Nachbarn. Aber wiederum ist es nicht die burgundische Hofkunst, die Anregung gibt, vielmehr das nordwestliche und nördliche Kunstgebiet. Im Gegenteil, niederländische Künstler arbeiten im Dienste der burgundischen Herzöge. Laborde führt ein Register auf, nach der ein Glasmaler Joris van Pourse im Jahre I 467 Geld bekommt, „la somme de IoO livres en prest à luy fait sur les veyrières que du commendement de M. d. S. il fait présentement pour mettre en l'église de Notre Dame de Bouloiogne". Dieser Joris van Pourse stammt aus Brüssel und führt I 456 ein Glasgemälde für Notre Dame de Grâce près Bruxelles aus. Seit der zweiten Hälfte des 15 . Jahrhunderts werden die Niederländer Träger der glasmalerischen Entwicklung. Sie, die in stetem Kontakt mit der italienischen Renaissance sind, vollenden die Metamorphose der flächigen, im zeichnerischen Zuschnitt gehaltenen Glasmalerei in einen $\mathrm{Z}$ weig der Tafelmalerei. In Nordostfrankreich, am Niederrhein trifft man allenthalben auf holländische Glasmalerei. Aus dem Gedenkbuch Kaiser Maximilans I. erfahren wir, daß ein Jörg van Delft die Fenster in der Kirche der Wiener Neustadt zu restaurieren und zu ergänzen berufen war. Die Geschichte der kölnischen und niederrheinischen Glasmalerei seit der Spätgotik ist also ein Abschnitt der Geschichte der Malerei. Immerhin haben die Fenster der Kölner und Niederländer Glasmaler noch eine kräftige Tradition der Technik. Das rührt daher, daß neben den Visieren offenbar noch sehr tüchtige Glasmaler am Platze waren, wie z. B. die schon genannten Pentenlyncks in Köln. So sehr die Glasmaler den Anforderungen der Kartons in Farbton und Konturierung gerecht wurden, so stimmt doch der Gesamtcharakter der noch erhaltenen Glasgemälde jener Periode so sehr überein, daß, speziell in Köln, die Visierer aus den Kreisen der zünftigen Tafelmaler in einer tüchtigen Glasmalereiwerkstätte ihren künstlerischen und wirtschaftlichen Mittelpunkt haben mußten. Die damalige Zeit hat eine gewisse Verwandtschaft mit dem bis zur Gegenwart geübteı System des Unternehmertums in der Glasmalerei. Kleinere oder größere Werkstätten übernehmen der Kirchenfabrik gegenüber den Auftrag und geben die Ausführung des Kartons an den entsprechenden Künstler weiter, der dann in der Werkstätte des 
Glasmalerunternehmers ausgeführt wird. So erklärt sich die allgemeine Werkstattübereinstimmung und andererseits die koloristische Eigenart der einzelnen Kölner Glasgemälde (Taf. 57-59) ${ }^{\mathbf{1}}$ ).

\section{Die süddeutschen Meisterschulen.}

Die großen Aufgaben, vor welche die Glasmalerei Süddeutschlands in den letzten Dezennien des I 5. Jahrhunderts gestellt war, fanden fast allgemein in Wildscher Art ihre Erledigung. Noch I 487 wird nach Frank1 bei Hans Wild das Volkamerfenster der Lorenzkirche in Nürnberg bestellt. Und wenn, wie von Schinnerer einleuchtend nachgewiesen wurde, auch die Wolgemutwerkstätte mit Glasmalerentwürfen beschäftigt war, so gehen diese Arbeiten, das Kaiserfenster in S. Lorenz, in dem holzschnittmäßigen Stil, der neuerdings etwas merkwürdig ,der sandig-trockenen, von Föhren spärlich bewachsenen Nürnberger Gegend" zugeschrieben wird, wobei ohne Berücksichtigung bleibt, daß dieser Stil in den geckenhaften Moden der damaligen Zeit weit eher seine Erklärung findet. Würde sich die seltsame Notiz, daß im Jahre I 465 ein Maler Michel Wolgemut nach Wiener-Neustadt kommt und sich als achtzehnjähriger Sohn ${ }^{2}$ ) der Hans Wolgemut und seiner Frau Kristina ausweist, auf den Nürnberger Michel Wolgemut beziehen, so wäre auch erklärt, warum gerade Wohlgemuts Werkstätte im Gegensatz zu Wild mit der Visierung zu einer Stiftung Kaiser Friedrichs III. beauftragt war. Sowohl die Arbeiten der Wildwerkstätte, als jene, die der Wohlgemutschule zuzuerkennen sind, weisen den glasmalerischen Formenschatz der Spätgotik in der Stilistik wie in der Technik auf. Das Glasgemälde ist ein Architekturglied, ebenso mit der Logik der Gotik entworfen, wie das Bauwerk selbst. Das Detail verschwindet in der Unterordnung unter das Ganze, das hauptsächlich durch seine Farben wirken soll. Man konnte lediglich in der Kombination der Farben, in den Dimensionen der Komposition, bei der man aber von

1) Italien ist natürlich viel schneller, als irgend ein anderes Land dem beherrschenden Einfluß der Tafelmaler, seinen Quattrocentisten crlegen. (Siehe Taf. 6o, 6r). Vgl. auch W. Bombe, Die Peruginer Glasmalerei vom I4. bis I6. Jahrhundert, Zeitschrift $f$. alte $u$. neue Glasmalerci I9I4.

2) Darnach wäre Michel Wolgemut I 447 geboren, was der allerdings nicht einwandfreien Inschrift auf dem Porträt, das Dürer auf den Meister gemalt hat, widersprechen würde, die $\mathbf{I} 434$ als Geburtsjabr angibt. 


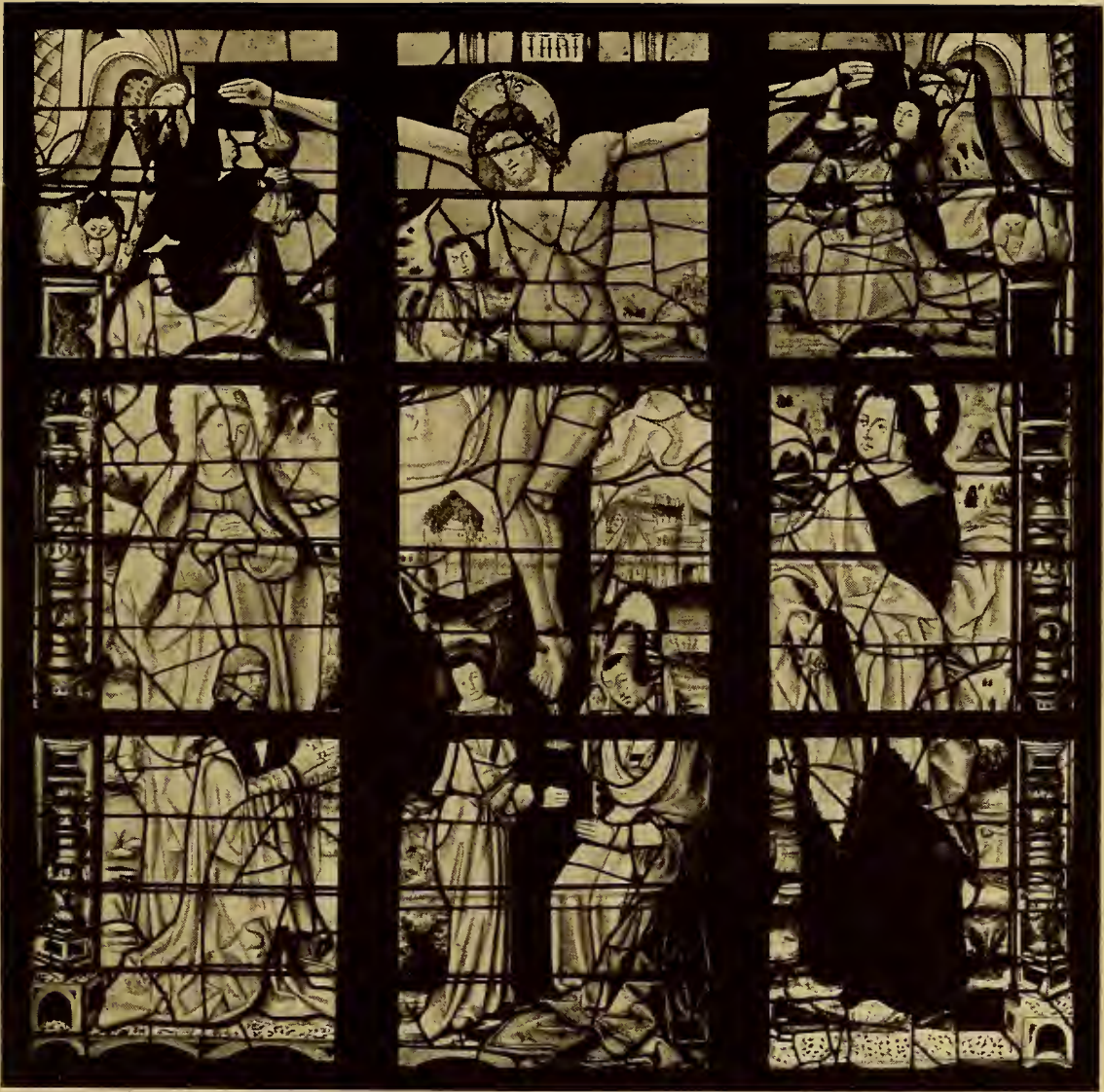

Teil eines Glasgemäldes in der Kirche zu Xanten. Anfang des r 6. Jahrhunderts. 

dem Baumeister abhängig war, Steigerungen erzielen, die allerdings nicht zum Heil der Glasmalerei ausfielen und es ist bezeichnend, daß der Geschmack sich sofort jenen Meistern zuwandte, die eine Neuerung brachten und mochten sie auch so umstürzend sein, wie ein Baldung im Elsaß, ein Grünewald am Main, ein Dürer in Nürnberg. Es verdient aber zunächst festgestellt zu werden, daß der Umschwung sich lediglich auf den Karton bezieht und daß sich die Technik noch vollständig in den Bahnen der alten Werkstätten bewegt. Dafür gibt es keine andere Erklärungals die Annahme, daß die Glasmalerwerkstätten noch fest im Kunstleben wurzelten und als gleichberechtigte Faktoren gegenüber den Visierern dastanden. Und in der Tat leuchtet trotz der spärlichen Nachrichten aus dem archivalischen Dunkel für jedes Zentrum glasmalerischer Tätigkeit wenigstens ein großer Werkstattsinhaber auf, so die Pentenlyncks in Köln, die von Rapolstein (Ropstein) in Freiburg, die Hirsvogel in Nürnberg, und darum ist auch die Annahme verfehlt, die glaubt, daß die Visierer stets aktiv in die Ausführung ihres Entwurfs eingegriffen hätten.

Der große Sprung, den die Entwicklung der Glasmalerei in Süddeutschland mit dem Auftreten Dürers macht, besteht in der Verselbständigung des Glasgemäldes. Die Szene ist um ihrer selbstwillen da, sie bildet die Hauptsache, während, was bisher die Hauptsache war, der architektonische Bestand wie mit einem Ruck ins Nebensächliche gedrängt wird. Bereits die im Städelschen Institut (Schmitz, Abbildung 230) befindliche Visierung Dürers zeigt diesen kecken Eingriff in die Tradition, der auch ein Hans Wild noch gläubig und gutmütig gefolgt war. Vergleicht man diesen Riß mit den ziemlich zahlreichen Glasgemälden, die auf Grund der Arbeiten Schinnerers und Lossnitzers, von Schmitz Dürer und seiner Schule zugeschrieben werden, so findet man, daß keines der letzteren, auch nicht die von Schmitz Dürer selbst zuerkannten drei Scheiben der Landauer Kapelle, die sich jetzt im Berliner Kunstgewerbemuseum befinden, an die ungeheure Kraft heranreichen, die in dem genannten Scheibenriß und den übrigen Dürerstichen zum Ausdruck kommt. Das rührt davon her, daß, wie gesagt, die ausführende Werkstatt auch ihren Anteil an den Glasgemälden hat. Schmitz ist zwar geneigt, dem Künstler die Kenntnis der Glasmalpraxis zuzu- 
billigen. „Daß Dürer von Glasmalerei etwas verstand, geht aus seinen Beziehungen zu den Antwerpener Glasmalern, speziell zu Dirick Vellert hervor, von dem er sich im Jahre I520 eine rote Farbe aus Ziegelsteinen, das Eisenrot, schenken ließ" (S. I42). Die Beziehungen zu den Antwerpener Glasmalern beweisen für diese Frage nichts, da Dürer zu allen angesehenen Künstlern Beziehungen hatte, und was die rote Farbe betrifft, so konnte dieser Rötelstein auch zur Herstellung für eine zur Wandmalerei verwendbaren Eisenrotfarbe dienen. Das aber darf als sicher gelten, Dürer hat ihn zur Glasmalerei wohl ebensowenig benützt, wie das Kesselbraun, das er in Antwerpen gekauft hat ${ }^{1}$ ). Seitdem die Kunst Dürers Gemeingut des kunstaufnahmefähigen Publikums geworden war, konnten sich die Nürnberger Glasmaler dem Stil dieses Mannes nicht mehr entziehen. Wahrscheinlich haben Dürerschüler eine Reihe von Kartons im Sinne ihres Meisters entworfen, die dann in den Werkstätten der Glasmaler ausgeführt wurden. Darum sind die Arbeiten, die in Dürernachfolge entstanden, oft so ungleich. $\mathrm{Zu}$ den besten gehören die aus der Lorenzkirche in die Sammlung der Veste Koburg verschleppten Scheiben, die M. Lossnitzer in einer gründlichen Untersuchung bekannt gemacht hat (Taf. 62, 63). Sie sind einer Gruppe zuzuteilen, die außerdem die Fenster der Kirche in Gründlach, die sieben Tafelbilder aus dem Marienleben aus Wittenberg, jetzt in der Dresdener Galerie, umfaßt. Lossnitzer stellt fest, daß sich diese Gruppe mit dem sogen. Benediktmeister berührt, der sich von Dürer abhebt und dessen Stil in einer Benediktuslegende am deutlichsten erkennbar wird. Daß Dürers Vorlagen für Glasmalereien sehr beliebt waren, zeigt der schwunghafte Handel, der mit seinen Stichen getrieben wurde, so daß in Brou und Rouen Glasgemälde nach Dürers Vorlagen entstanden. Auch in der kunstgewerblichen Sammlung des Hofmuseums in Wien befindet sich ein Glasgemälde, das nach der im Jahre 1650 fixierten Tradition von Albrecht Dürer stammen soll. Glück, der die Arbeit gesehen hat, erklärt dazu: „Daß diese Glastafel, eine Kreuzabnahme darstellend, nicht von Dürer herrühren kann, beweisen trotz der sehr geschickten Nachahmung der Helldunkeltechnik

1) Siche Geiges in den „Freiburger Münsterblättern“ I 908, S. 68. 

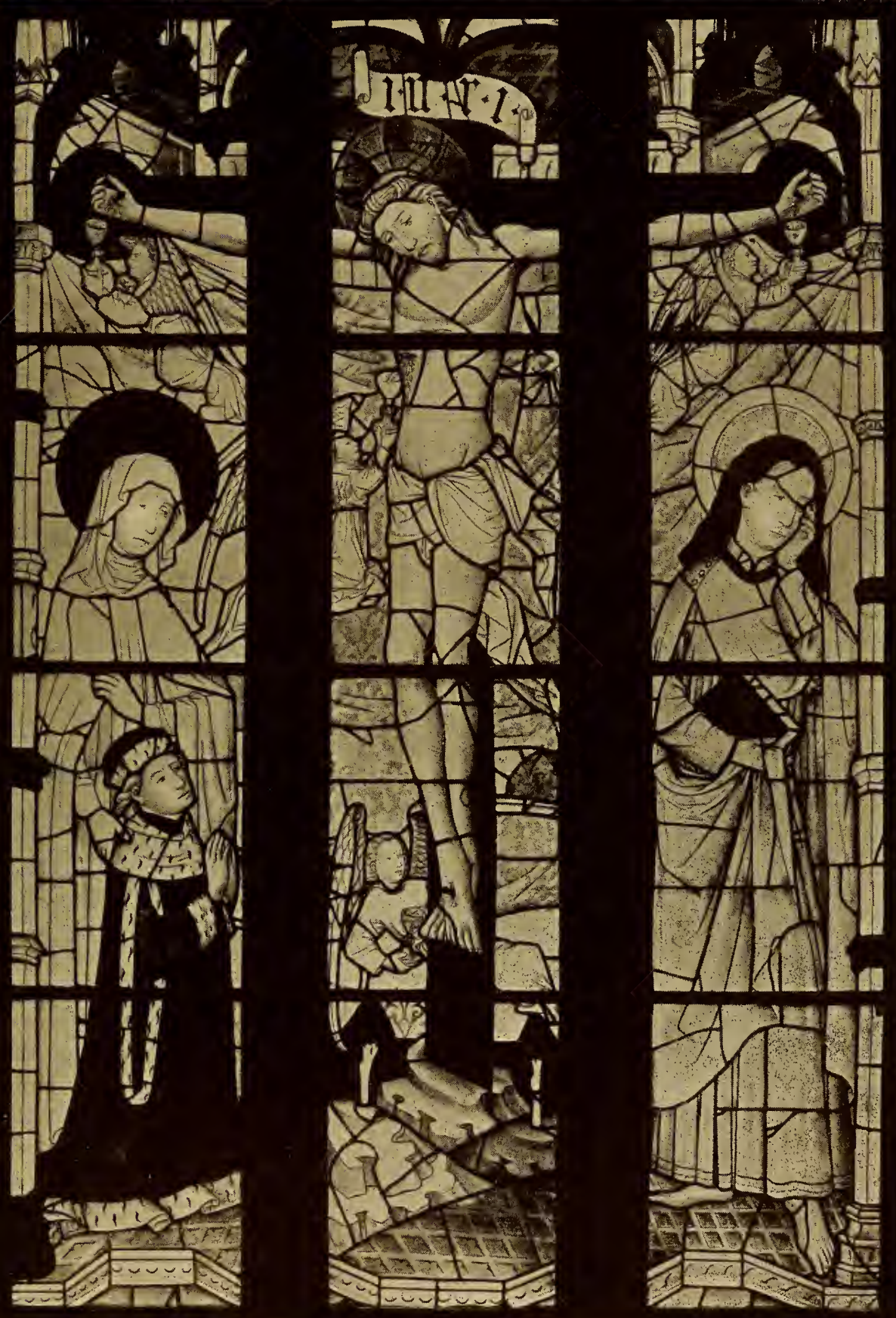

Teil eines Fensters in der Wallfahrtskirche zu Wilsnack, im Stil der niederrheinischen Spätgotik. Nach einer Aufnahme von Dr. J. Engel. 

des Meisters die Formen, die nur ganz allgemein Dürer folgen, keineswegs aber in das Jahr I 504 passen würden. Doch steht manches Dürers Empfinden so nahe, daß man eine verhältnismäßig frühe Entstehung nicht sehr lange nach Dürers Tod annehmen darf ". ${ }^{1}$ )

Nach allgemeiner Annahme ist der Meister, in dessen Hände Dürer seine Entwürfe zur Ausführung gelegt hat, Veit Hirsvogel oder genauer dessen Werkstatt. Ein absolut sicherer Beleg für die Arbeiten dieser Werkstatt ist nur einmal vorhanden, aber erst aus dem Jahre $\mathrm{I} 520$, wie wir später sehen werden, und die Vorsicht gebietet zu beachten, daß um die Jahrhundertwende Martin Krinaberger, Johann Brechtl (I 52 I) und Albrecht Glockenthon in der Pegnitzstadt als Glasmaler tätig waren. Auf den Glasgemälden der Imhofkapelle auf dem Rochusfriedhof, die ungefähr aus dem Jahre I 520 stammen, ist das Monogramm A. H. (Augustin Hirsvogel) zu erkennen. Nun läßt sich aber, wie Karl Friedrich mitteilt ${ }^{2}$ ), aus den Familienpapieren der Imhofs nachweisen, daß eine Reihe von Einträgen Veit Hirsvogel als Honorarempfänger für diese Fenster nennen. Man sieht also, gegenüber der Zuschreibung an die Hirsvogelwerkstatt ist große Vorsicht geboten, um so mehr, als sie kein untrügliches Kennzeichen an sich trägt. Schmitz ${ }^{3}$ ) nennt zwar "markige Schwarzlotzeichnung und meisterhaften Überfangausschliff" untrügliche Kriterien, wobei $z u$ beachten ist, daß diese Eigenschaften auf allen Glasgemälden der ausklingenden Spätgotik und Frührenaissance zu bemerken sind. Als Hauptarbeit wird von Schmitz nach Neudörfers Vorgang die Reihe von drei Fenstern angegeben, die im Jahre I5I4/I5 für den Chor von S. Sebald angefertigt wurden. Bock $^{4}$ ) hat nachgewiesen, daß die Visierung zu dem von Markgraf Friedrich von Brandenburg gestifteten Fenster von Hans von Kulmbach stammt, während für die beiden anderen, namentlich für das Pfinzingfenster Dürer mindestens die Oberleitung ge-

1) Jahrbuch der Kunstsammlungen des allerhöchsten Kaiserhauses $28, \mathrm{~S}$. 6 .

2) Karl Friedrich, Augustin Hirsvogel als Töpfer; seine Entwürfe für Öfen und Glasgemälde.

3) a. a. O. S. 147 .

4) Zeichnungen von Hans von Kulmbach für ein Kaiserfenster, Monatshefte f. Kunstw. 1909. S. 401 . 
habt haben soll. "Der Kaiser, der in diesen Jahren alle Aufträge an den größten Nürnberger Künstler gab, wird auch eine solch kostspielige Stiftung nicht an einen Gesellen Dürers, der Kulmbach, was die Erfindung angeht, trotz seiner malerischen Begabung blieb, vergeben haben" (Schmitz, S. I 49). Am 5. Februar I5I4 schreibt Maximilian I. an den Rat der Stadt Nürnberg: "nachdem unser vorfarn am reich, Romische Kaiser und khönig, got $z u$ lob ein venster in Sant Sebolt khirchen bei Euch zu Nuremberg vor verschiner Zeit machen haben lassen, das aber durch Alter etwas zerprochen und schadhaft worden sein soll; dieweil wir nun geneigt sein, die gedechtnis unser und derselben vorfaren zu meren und aufzuhalten, haben wir uns fur genommen, bemalt venster wiederum machle zu lassen." Darum soll der Rat sofort 200 Gulden an den Probst Melchior Pfintzing zahlen, was ein Darlehen des Kaisers bei der Stadt bilden solle. ${ }^{1}$ ) Von Seiten des Kaisers war also über den Meister nichts bestimmt. Uns will scheinen, daß Hans von Kulmbach die Visierung zu allen drei Fenstern geliefert hat. Das Markgrafenfenster ist eine "Kabinettscheibe“ großen Stils. In fünf Zeilen, also weitaus dem Hauptteil, wiederholen sich fürstliche Persönlichkeiten mit Wappenschilden, was eher der Befriedigung persönlichen Ehrgeizes als der Erfüllung eines religiösen Zweckes diente. Dieses Fenster hat zweifellos zu einem über I25 Jahre jüngeren Fenster, nämlich zu dem Imhofschen Wappenfenster gleichfalls in Nürnberg Veranlassung gegeben. Mit dem Beginn der Reformation hat die kurze durch Dürer in höchste Blüte gebrachte Glasmalerei sofort ihre Kelche für immer geschlossen. Von Köln abgesehen ist Nürnberg die Stadt, in der die Glasmalerei am raschesten und gründlichsten ihr Aussehen gewechselt hat. Die bedeutendste Neuerung, die Dürer brachte, besteht in der Erweiterung der Komposition auf große Fensterflächen, in dem Realismus der Formen, in der Helldunkeltechnik und in der schweren Wucht opaker Farben. Dürer zwang die Glasmalereiwerkstätten, ihm mit allen Fortschritten auf dem Fuße zu folgen. Darum kann man die letzte Periode der Nürnberger Monumentglasmalerei

1) Kreisarchiv zu Nürnberg. Jahrb. der Kunstsammlungen des allerhöchsten Kaiserhauses 10, Regest 5797, 5798. 


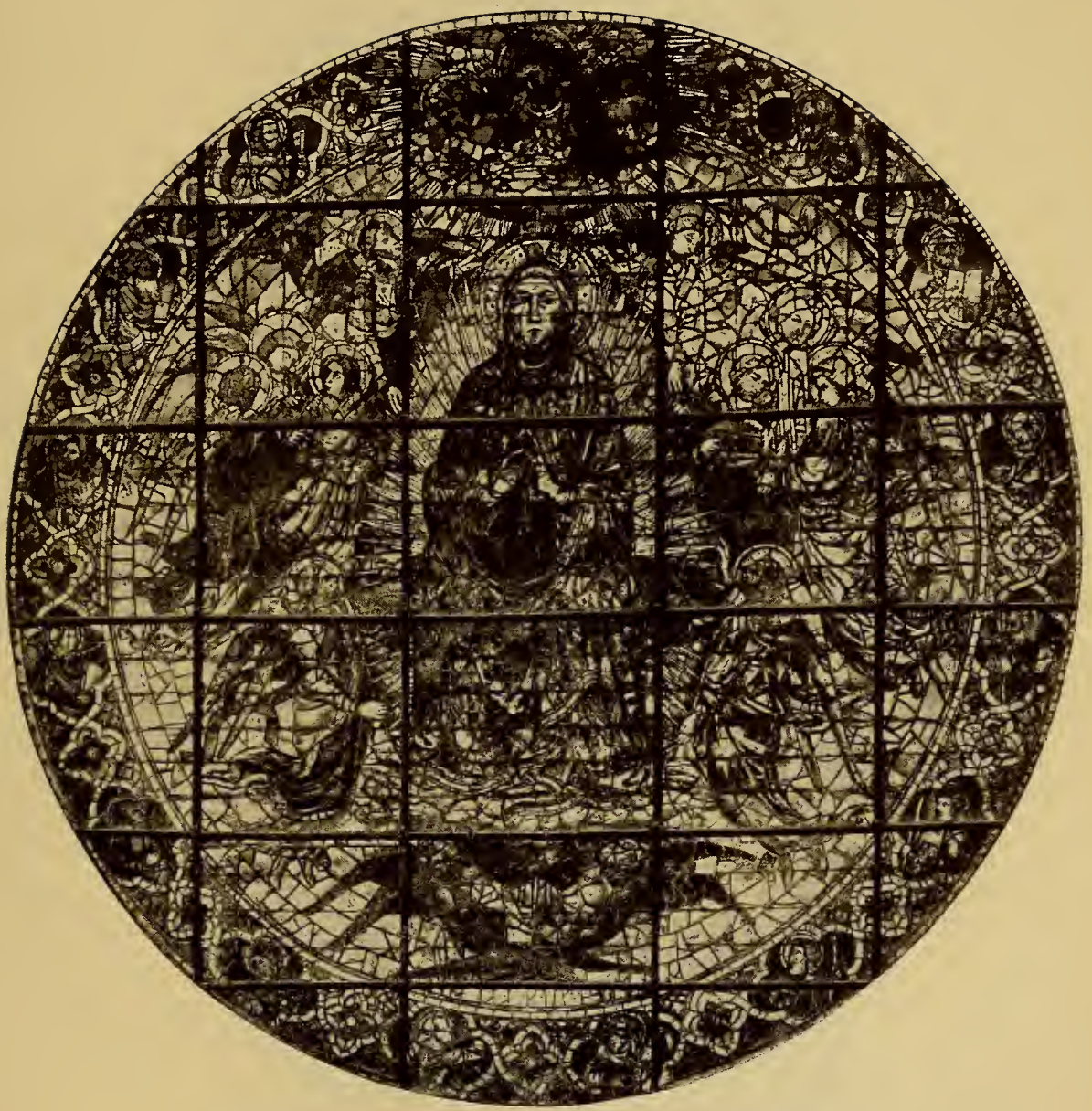

Rundfenster im Dom zu Florenz. Nach einer Zeichnung von L. Ghiberti. 


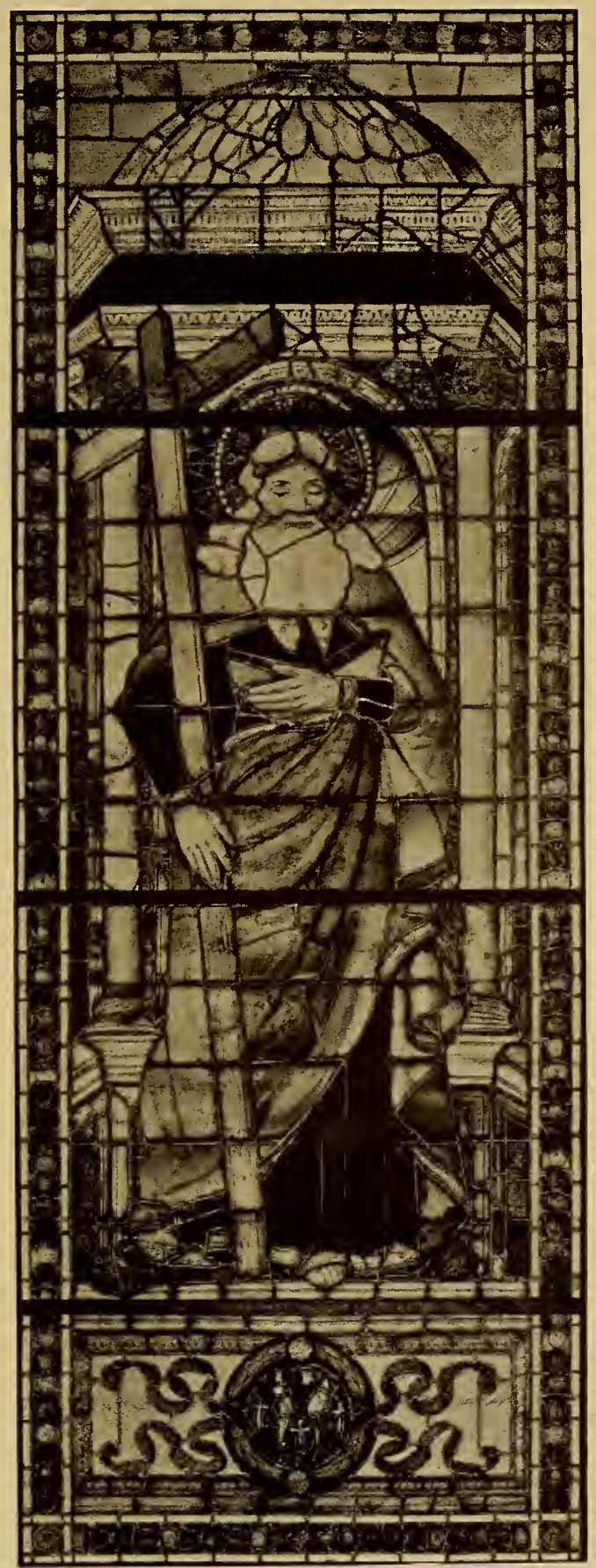

Glasgemälde im Kloster S. Croce zu Florenz. Erste Hälfte des I 5. Jahrhunderts. 



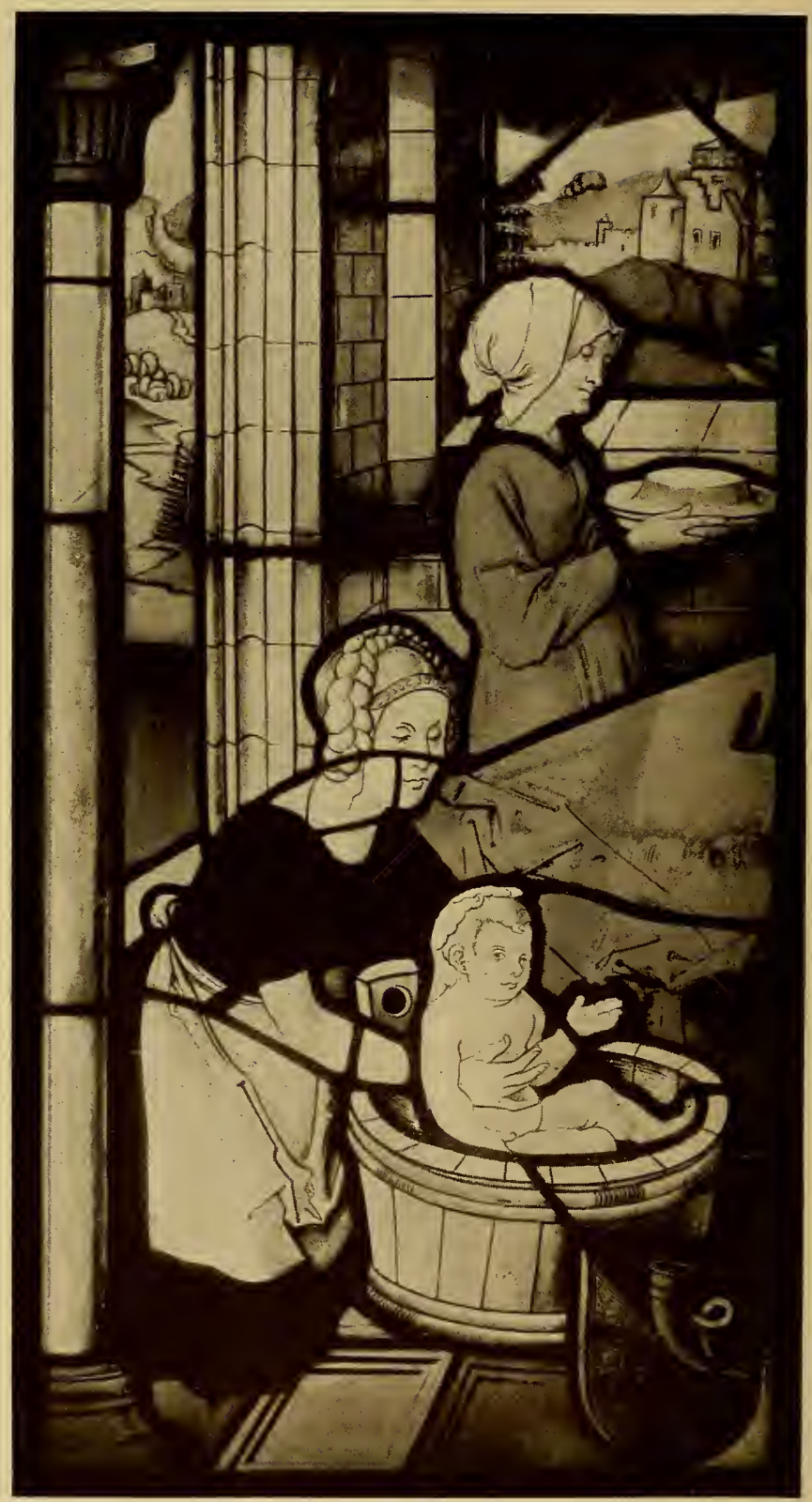

Glasgemälde auf der Veste Koburg. Hirsvogelwerkstatt. Anfang des I 6 . Jahrhunderts. 


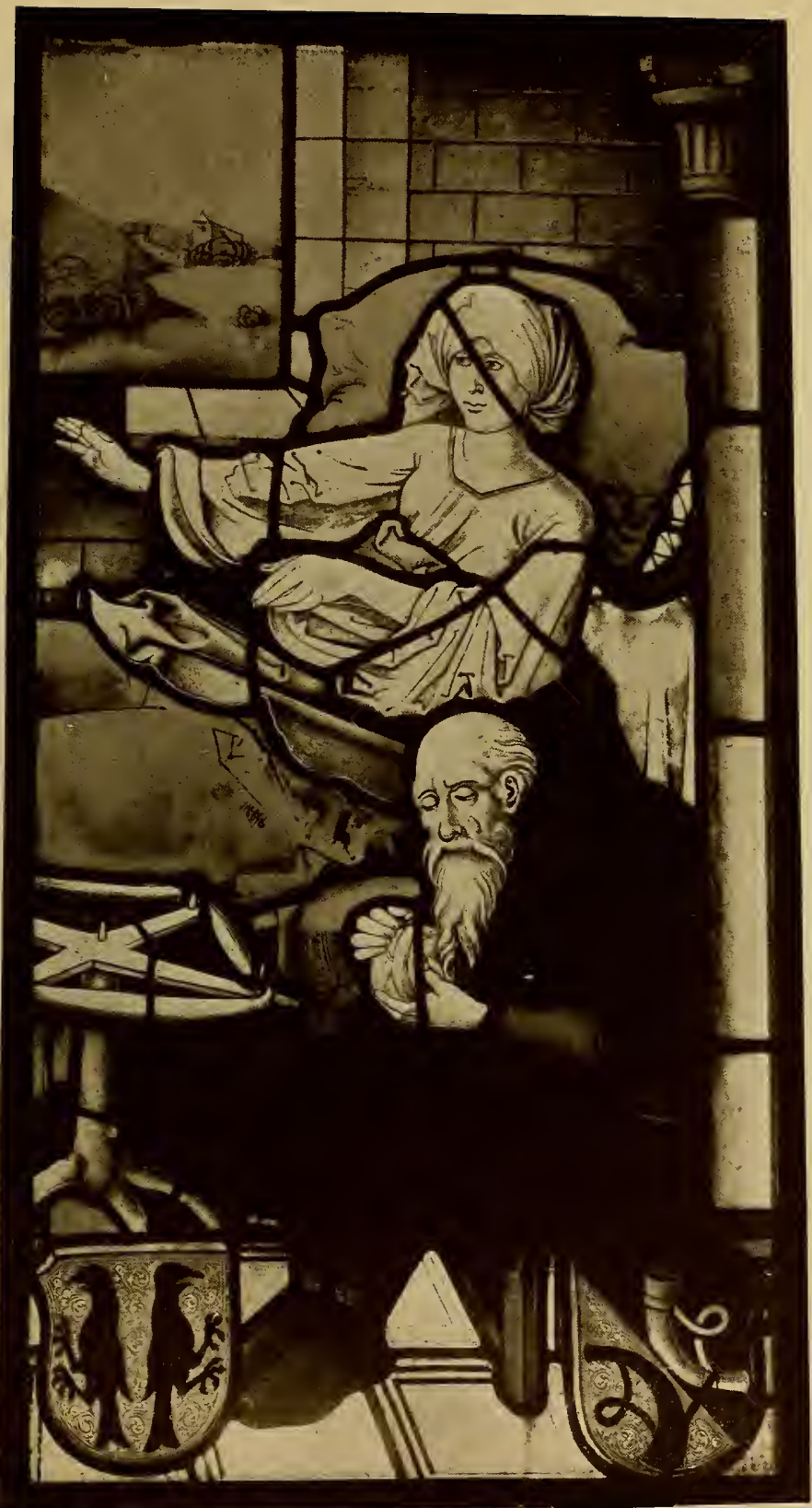

Glasgemälde auf der Veste Koburg. Hirsvogelwerkstatt. Anfang des I 6 . Jahrhunderts. 



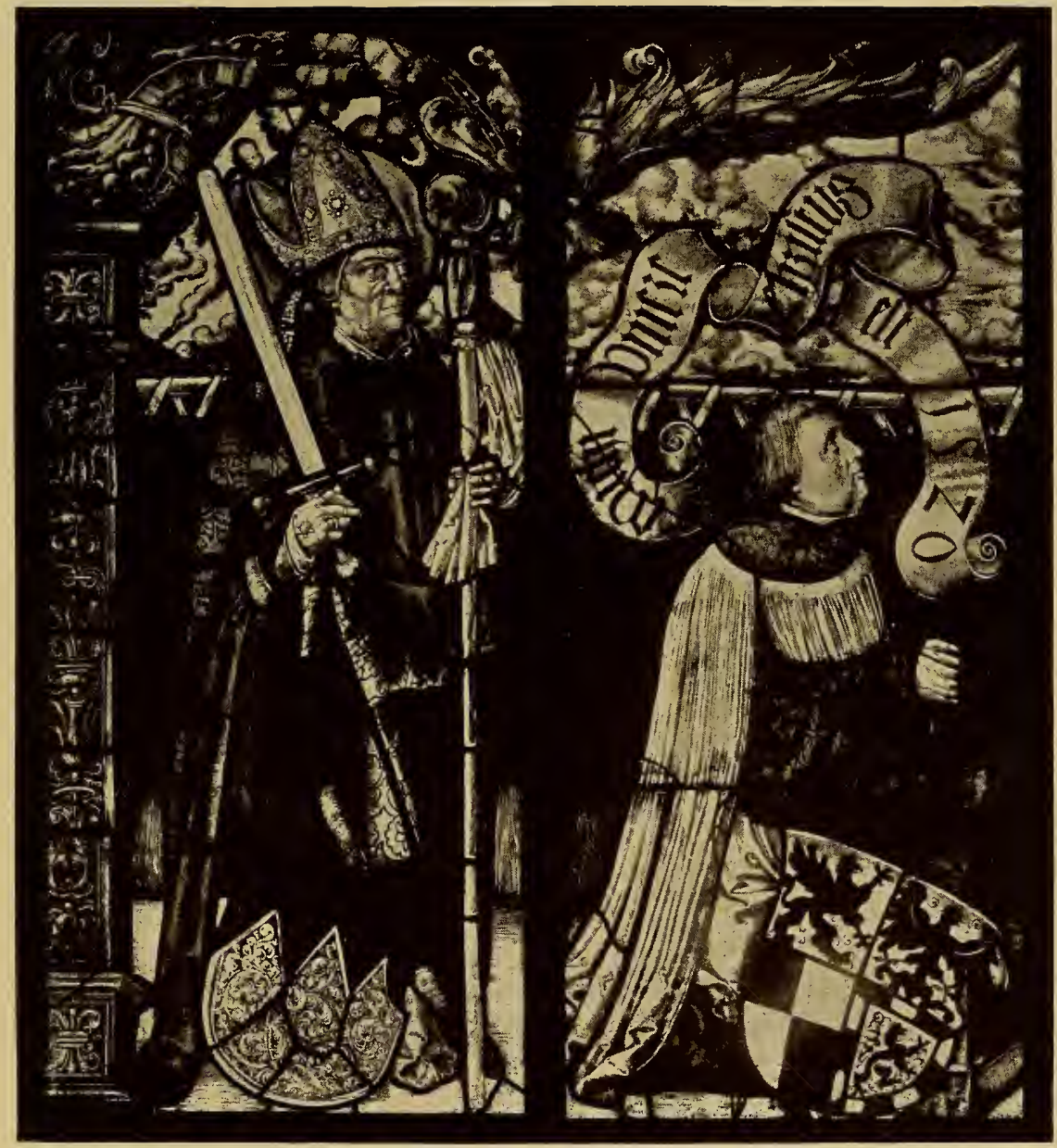

Detail aus einem Glasgemälde in der Schwanenritterkapelle zu Ansbach. Dürer-Hirsvogelwerkstatt. I 520 . 

mit vollem Recht die Periode Albrecht Dürers nennen, wenngleich für kein einziges der erhaltenen Glasgemälde nachgewiesen werden kann, daß bei ihm mehr von Albrecht Dürer stammt, als die Skizze, höchstens noch Korrektur einzelner Kartondetails, in allem aber der auf die Schüler ausgegangene Geist des Meisters.

Nürnberg, Augsburg, Straßburg! Für die Periode der deutschen Frührenaissance bedeuten diese drei Namen die Mittelpunkte jenes tatenfrohen Schaffens, das Deutschland seither nicht wieder in dem Umfang gesehen hat. Das Bürgertum hatte sich aus den Modetorheiten und den geckenhaften, von Westen kommenden Sitten erholt und wie mit dem einen Ruf: "Wach auf" in eine Erregung versetzt, der Ulrich Hutten jubelnden Ausdruck verlieh. Geradezu unvermittelt setzt sich an die Spätgotik diese herrliche, glanzvolle Zeit, die kaum ein Menschenalter dauernd, unter den zerstörenden Tendenzen der Glaubensspaltung für immer verschwand. Knüpft Dürer in seiner Sprache auch zunächst noch an die Kunst der Vergangenheit an, deren ungeheuren Kräfte er durch sein gewaltiges Genie zu einer letzten großen Entfaltung bringt, so stehen Baldung und namentlich Grünewald der gotischen Vergangenheit fern (Taf. 65, 66). Baldungs Gestalten sind echte Menschen und weisen alle Stufen des seelischen Affekts auf. Daher seine Neigung, die Köpfe der dargestellten Heiligenfiguren durch Beiziehung des Porträts stark $\mathrm{zu}$ individualisieren. Baldung hat die elsässische Glasmalerei in ähnlicher Weise beeinflußt, wie Dürer die Glasmalereiwerkstätten Nürnbergs. Er tritt in bewußten Gegensatz zu der Formensprache und auch zu der Technik des Hans Wild. Selbst die frühesten Arbeiten weichen aufs schärfste von der knittrigen, manirierten Art der Wildschule ab. Baldung bildet, selbstverständlich unbewußt, eine Verschmelzung der Dürerischen Formenschärfe mit Grünewaldischer Glut des Ausdrucks. Dem Aschaffenburger Meister gleicht Baldung in der veristischen Kraft der Farben, die sich durch ihr blendendes Feuer und durch ihre sichere Verteilung von der akademischen und sehr oft unausgeglichenen Art der Wildschule wesentlich abheben. Hans Baldung muß zusammen mit seinen glasmalenden Mitarbeitern als der vollkommenste Ausdruck der Straßburger Kunst bezeichnet werden. Durch die gründlichen Studien von H. A. Schmid, Terey und 
insbesondere von Fritz Geiges ist der Anteil, den Baldung an der Freiburger Glasmalerei hatte, ziemlich genau festgestellt. Der Schreiber dieser Zeilen kann der Baldungschule noch fünf weitere Scheiben zuweisen, die zum Teil auf Taf. 67-7I abgebildet sind. Professor Fritz Geiges ${ }^{\mathbf{1}}$ ) hat das Verdienst, die Zusammenhänge der Freiburger. Glasmalerwerkstätte mit den elsässischen Meistern dargelegt zu haben. Er macht in hohem Grade wahrscheinlich, daß eine aus Raperstein stammende Glasmalerfamilie seit der zweiten Hälfte des 15. Jahrhunderts bis nach Mitte des I6. Jahrhunderts in Freiburg tätig war. Allerdings muß auch hier bemerkt werden, daß außer dieser Werkstätte noch einige andere Glasmaler in den Urkunden vorkommen. Da aber durch eine von Geiges entdeckte Inschrift an einem Hochchorfenster im Freiburger Münster des Meisters Hans von Ropstein (andere Lesart für Raperstein) Stil authentisch bekannt ist, so hält es nicht schwer eine Reihe von weiteren Arbeiten, die im Stil mit jenem Hochchorfenster übereinstimmen, eben an diese Werkstätte anzugliedern. Äußerlich ist die Werkstatt schon an dem breiten Damasthintergrund erkennbar, der in der Regel mit einer Renaissanceguirlande gekrönt ist. Zum erstenmal tritt der Baldungstil in den herrlichen Figurenscheiben auf, die im Jahr I 897 als Hauptbestandteil der Douglas'schen Sammlung versteigert worden sind. Lehmann hat nachgewiesen, daß diese Scheiben nicht, wie der Bearbeiter des Katalogs F. J. Mone glaubte, für die Carthause zu Basel, sondern jene bei Freiburg angefertigt wurden. Die Scheiben stammen aus der Zeit gegen I 5 I 5 und zeigen bereits einen so fertigen Stil, daß nur ein ganz großer Meister sie schaffen konnte. Für die Ropsteinsche Werkstätte war es nicht schwer, auf der Visierung stark modellierte Köpfe in Glasmalerei zu übertragen; der Überschuß der Wildschen Modellierung war schon allein für ein rationelles Maß von Durcharbeitung mehr wie hinreichend.

Die Männerköpfe gelingen weit besser als die weiblichen; für sie muß Baldung ausgezeichnete Modelle gehabt haben. Unter allen Scheiben ragt die prachtvolle Darstellung des Johannes des Täufers hervor; der Kopf ist ein Meisterwerk der

1) Freiburger Münsterblätter I 908, S. 4I ff. 



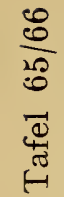

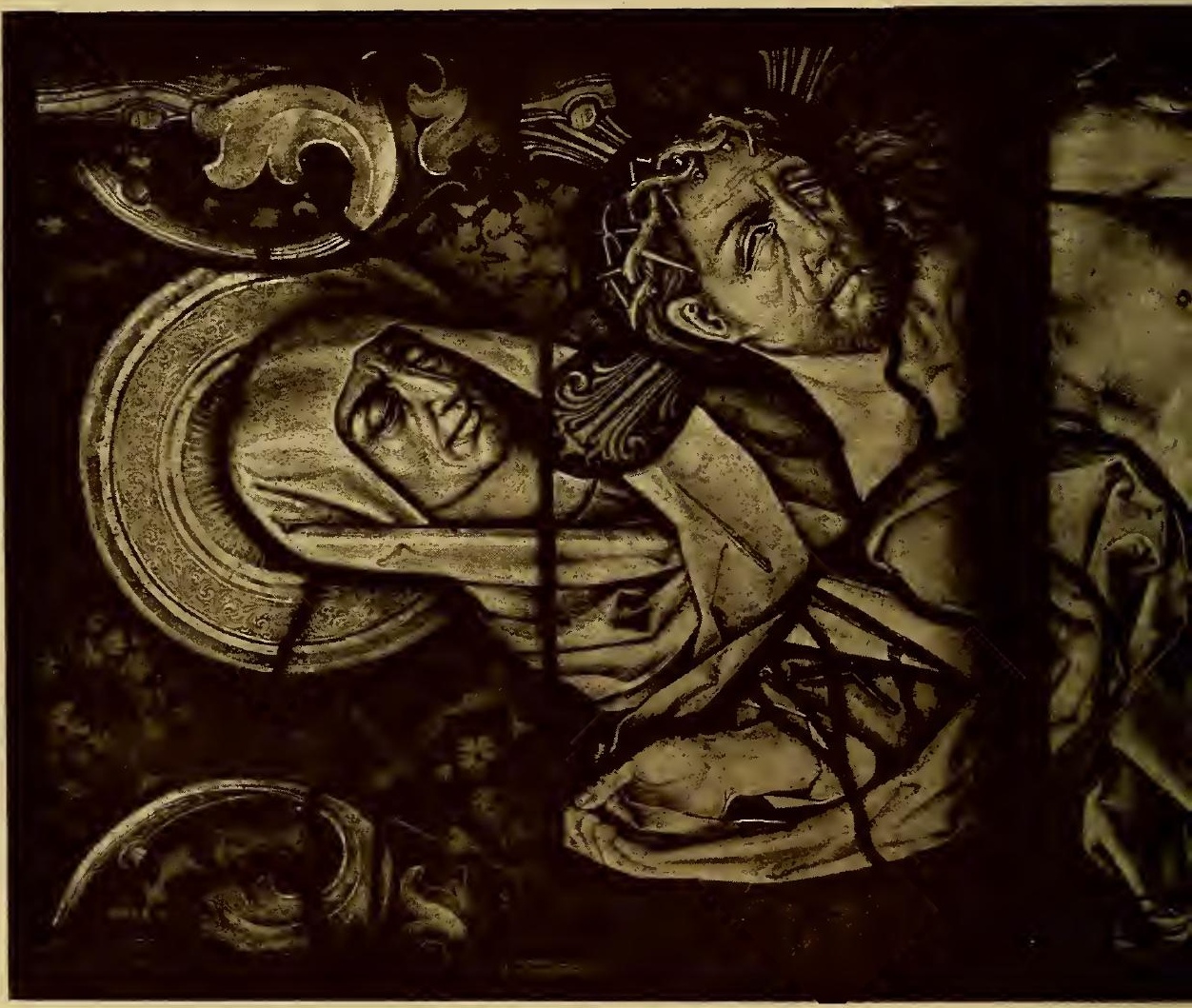





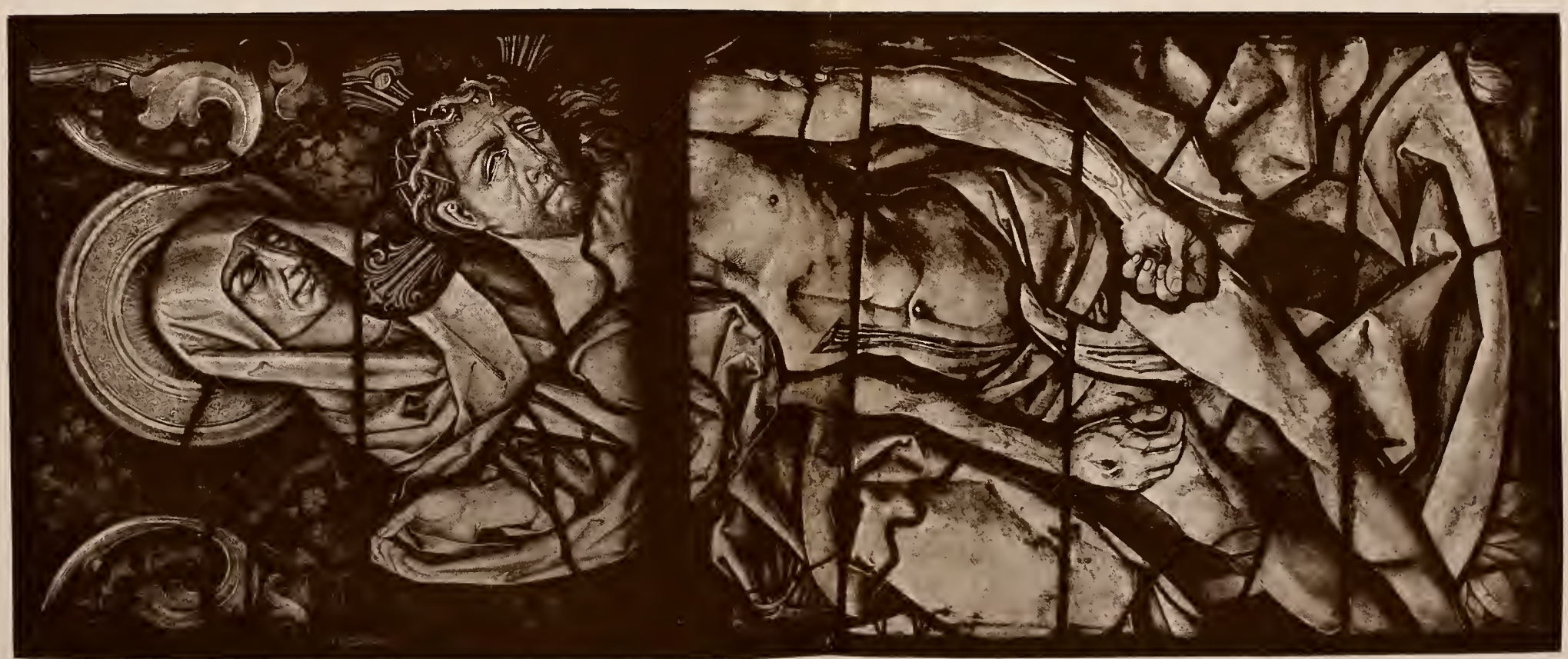



Charakteristik. Johannes, der Asket der Wüste, mit den scharfen Zügen und dem überquellenden Haupt- und Barthaar, hat wohl selten eine so prägnante Darstellung seiner Persönlichkeit gefunden. An diese Scheibe reicht etwa noch die Darstellung des h1. Georg heran. Als Wappenherold des Hauses Habsburg steht dieser Heilige in voller Ausrüstung und Frisur der Georgsritter da. Man hat in dem ausgezeichnet wiedergegebenen Kopf ein Selbstporträt Baldungs erkennen wollen, wie dies auch für die Jörg Ziegler, dem Meister von Meßkirch, zugeschriebene und jetzt in Stuttgart befindliche Sankt Georgsscheibe angenommen wird. Wie dem auch sei, beide Köpfe sind Kabinettstücke von Porträtköpfen, denen die Köpfe der h1. Elisabeth und des hl. Ludwig (Douglas No. 2 I und 22), die unverkennbar Porträts für Kaiser Maximilian und seine Gemahlin, Maria von Burgund, darstellen, zwar nahe aber nicht gleichkommen. Die größten Werke von Baldungs Hand besitzt das Freiburger Münster. Ihre Publikation durch die kunstverständige Feder des Herrn Professor Fritz Geiges steht bevor. Eines von ihnen, das St. Annafenster in der Alexanderkapelle, ist bereits veröffentlicht. Es stellt die am Ausgang des Mittelalters hochverehrte hl. Anna im Kreis ihrer gesamten Familie dar, ist also ein sogenanntes Sippenbild. Geiges macht darauf aufmerksam, daß die Art der Stiftung, eine Gabe der Gewerken der Todtnauer Silbergruben I515, noch besonders auf die Mutter Anna gewiesen hat, da die Heilige als Patronin der Bergleute weithin Verehrung fand. Auch auf diesem Fenster begegnen wir den mit Renaissancegirlanden bekrönten Damasthintergründen und der für die Baldungscheiben charakteristischen Art der Schriftbandverschlingungen. Daran wären drei Scheiben zu schließen, die sich in der königlichen Residenz zu München befinden. Wiederum ist es ein Evangelist Johannes mit der für Grünewald und Baldung so charakteristischen Handbewegung, und ein Apostel Andreas. Die knienden Stifterfiguren sind Heinrich von Handschuhsheim und Margarethe von Staufenberg. Beide Geschlechter stammen aus Baden. Handschuhsheim liegt in der Nähe von Heidelberg und Staufenberg in der Nähe von Oberkirch. Der Kopf des Andreas hat am meisten Ähnlichkeit mit dem Kopf des Salomas aus dem Annafenster. Auch die äußeren Kennzeichen, Damasthintergrund, 
Renaissancegirlande und Schriftbandverschlingung deuten auf die Baldungschule. Endlich sei auf die merkwürdige Eigentümlichkeit hingewiesen, den Namen der beiden Heiligen im Nimbus anzugeben. Diese Namensbeifügung hat, wie auch Geiges bemerkt, rein dekorativen Wert, da über die einzelnen Persönlichkeiten bei derartig groß beigefügten Attributen ein Zweifel nicht bestehen konnte. Auf dem einen Schriftband steht: Sant.andras. bit.vir.vns, ihesum crist. dorum $\mathrm{dz}$ du sein erster iunger bist., auf dem anderen: Hilf . heliger . Johannes . baptist . von . frowen kein . gröler..geborn . ist:. Durch diese Inschriften ist die Zusammengehörigkeit der drei Scheiben außer Zweifel gestellt.

Wie verhält sich nun das ausführende Glasmaleratelier zu den Entwürfen Baldungs? Schon Geiges hat für das Annafenster nachgewiesen, daß der Glasmaler wohl nichts weiteres als eine im kleinen Maßstabe hergestellte Skizze Baldungs vor sich gehabt haben kann. Bei einem Vergleich der ehemaligen Glasmalereien in der Magdalenenkirche zu Straßburg, mit den Glasgemälden im Chor des Ulmer Münsters, konnte der Schreiber dieser Zeilen feststellen, daß für beide Arbeiten derselbe Entwurf vorlag ${ }^{1}$ ). Trotz der Übereinstimmung im Ganzen, zeigten sich in Einzelheiten zahlreiche Verschiedenheiten. Beidesmal stand den Glasmalern nicht, wie dies heute der Fall ist, ein genau ausgeführter Karton zur Verfügung, sondern eine in kleinem Maßstab entworfene Werkzeichnung. Das entsprach der mittelalterlichen Meisterprüfung für Glasmalerei: Ein Geselle, der Meister werden wollte, mußte imstande sein, ein Glasgemälde selbständig zu reißen und auszuführen. Baldung hat also die Entwürfe gezeichnet und die Ausführung anderen Kräften überlassen. Es mag dahingestellt bleiben, ob dies Schüler seiner Werkstatt oder Angehörige des Glasmalerateliers waren. Es ist auch nicht unwahrscheinlich, daß Baldung einzelne Teile, wie gewisse Köpfe, selbst ausgeführt hat. Was nun die Technik der Ropsteinwerkstatt betrifft, so sind als spezifische Eigenschaften angesprochen worden: „Die feurigen Gläser, roter Überfang mit Ausschliff, kräftig gestupfte Modellierung mit feiner Nadel- und Federkielradierung, glänzende Silbergelbbehandlung

1) Siehe Zeitschrift für alte und neue Glasmalerei r913, S. 86. 


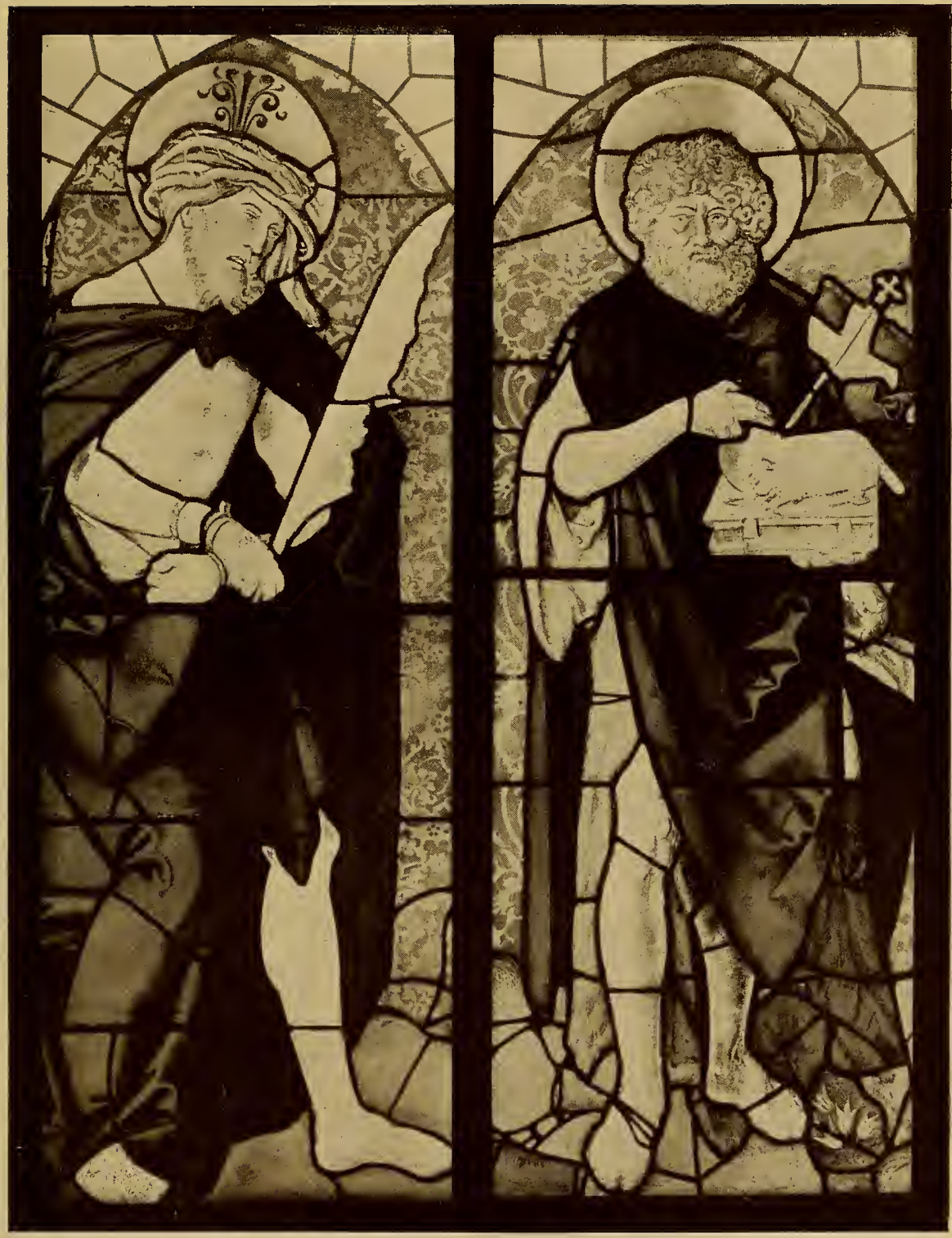

Glasgemälde aus der ehemaligen Kartause bei Freiburg. Stil Hans Baldung Griens. Zwischen I 5 Io und 1520 . 

der Haare. "1) Diese Kennzeichen sind jedoch Gemeingut aller Glasmalerschulen um I 500 am Oberrhein, wie an der Pegnitz, in Mitteldeutschland, wie in Bayern. Dagegen unterscheidet sich die Ropsteinwerkstatt in der Behandlung der Lichter. Gemeinsam ist um jene Zeit folgende Technik: Auf das blanke Glas wird ein dünner Schwarzlotüberzug aufgetragen, darauf die breite Schwarzlotkontur. Aus dem Überzug werden die höchsten Lichter ausgewischt und stärkere Schatten in Strichelmanier nachgegangen. Während nun die Nürnberger Glasmalereien die kleineren Schatten mehr betonen, überhaupt mehr modellieren und daher plastischer wirken, hat die Ropsteinwerkstatt größere Lichtflächen und etwas sparsamere Modellierung. Auch sind die Strichelchen nicht so holzschnittmäßig scharf, wie bei den Nürnberger Arbeiten.

Die südbayrische $S c h u 1 e^{2}$ ) hat in den Arbeiten für die Münchener Frauen- und Salvatorkirche ihren Mittelpunkt. Der jetzige weithinbekannte spätgotische Backsteinbau der Münchner Kathedrale wurde im Jahre I468 begonnen. Was in der alten Frauenkirche an Glasgemälden vorhanden war, wurde in den Neubau übetragen. Auf Seite $98 \mathrm{ff}$. haben wir von einem Teil dieser alten Glasgemälde gesprochen. Aus der Mitte des I 5. Jahrhunderts stammen bedeutende Reste eines Lebens Jesu, die in der Anbetung der Könige und der Szene: Der zwölfjährige Jesus im Tempel ihre wichtigsten Teile haben. Diese Arbeiten hängen mit der von uns bereits charakterisierten und der Einfachheit halber Nördlinger Richtung genannten Schule zusammen. Da diese Schule sich ebenso über fränkisches, wie elsässisches Gebiet erstreckt hat, darf man sich nicht wundern, daß die Münchener Glasgemälde in Einzelheiten mit Arbeiten anderer Orte Ähnlichkeit haben, wie die gedrehten Säulen, das eigenartige Fliessenmuster auf dem Hintergrund der Dreikönigsdarstellung verglichen mit dem Eucharistiefenster zu Rothenburg ob der Tauber (Taf. 72). Wie weit jenes Fenster beim Neubau der Frauenkirche gediehen war, läßt sich nicht sagen. Um I460 erscheint in den Steuer-

1) Schmitz a. a. O. S. II 9 .

2) Frankl, die Glasmalerei des XV. Jahrhunderts in Bayern und Sehwaben, Straßhurg 1913 . 
büchern ein Meister Martin glaser, I 462 ein Franz glaser, I465 ein Jörg Schaffer glaser. Dies ist ein Zeichen, daß für die alte Frauenkirche noch viel gearbeitet wurde. Der Neubau brachte eine Menge großer Aufgaben. Tatsächlich tauchen zahlreiche Glasmaler in den Steuerbüchern auf, deren Namen von Herrn Dr. Buchheit auf Grund des Studiums der Steuerlisten eruiert worden sind. In höchst dankenswerter Weise hat der genannte Kunsthistoriker jene Namen dem Schreiber dieser Zeilen mitgeteilt. Wir geben im folgenden die ganze Reihe und lassen sie bis zur Mitte des I6. Jahrhunderts weitergehen. Daran wäre die von R. Paulus in der "Zeitschrift für alte und neue Glasmalerei“ I9I3, S. Io9 ff. gegebene Reihe ab I550 zu knüpfen, so daß wir für München eine einigermaßen vollständige Serie der Glasmaler besitzen von dem Moment an, in dem die dortige Glasmalerei als eigene Schule aufzutreten beginnt. Die den folgenden Namen beigegebenen Zahlen sagen, daß der genannte in dem betreffenden Jahr zum ersten- bzw. letztenmal vorkommt, wobei $\mathrm{zu}$ beachten ist, daß die Jahrgänge I5IO-I 52 I, I529, I 530, I 53 I, I 533-39 der Steuerbücher fehlen. Die Reihe lautet folgendermaßen:

Martin glaser $1460-I 480$.

Franz Karlstatter I462-I 479.

Jörg Schaffer I 465 .

Hans Kaiserslauterer I 469.

Hans Winhart I485-I 539.

Hans Olein I 48 I-I 500 (es sind

wohl zwei dieses Namens).

Hans Klein I $48 \mathrm{I}-\mathrm{I}_{4} 84$.

Hans Schmid I486-I 508.

Hanns Straw 1490.

MichelSengenrieder I 486- I 500 .

Jakob Kistenfeger I496- I 532.

Contz Ässlinger I 496-I 509.
Friedrich Prunner 1496-I52I.

Jakob Prunner I 522-I 532.

Hans Herkommer I 524-I556.

Jörg Stöck1 I527-I 540 .

Wolfgang Schöpl I 528-I 529 .

U1rich Perchtold I 532.

Veit Hamer I 540.

Veit Winhart I 540.

Bastian Ostendorffer 1556 bis I 557.

Hans Hebenstreit I556-I 558 .

Hans Schweind1 I 556 .

Hans Märkl I 557 .

Sighart (Geschichte der bildenden Künste in Bayern, S. 640) sagt: „In München erscheinen als bedeutende Glasmaler des I 5. Jahrhunderts Martin der glaser und Hanns Gleismüller Maler, welche für den Chor der Benediktuskirche in Freising Glasgemälde ausführten und dafür I4 Pfd. Münchener Pfennige erhielten im 


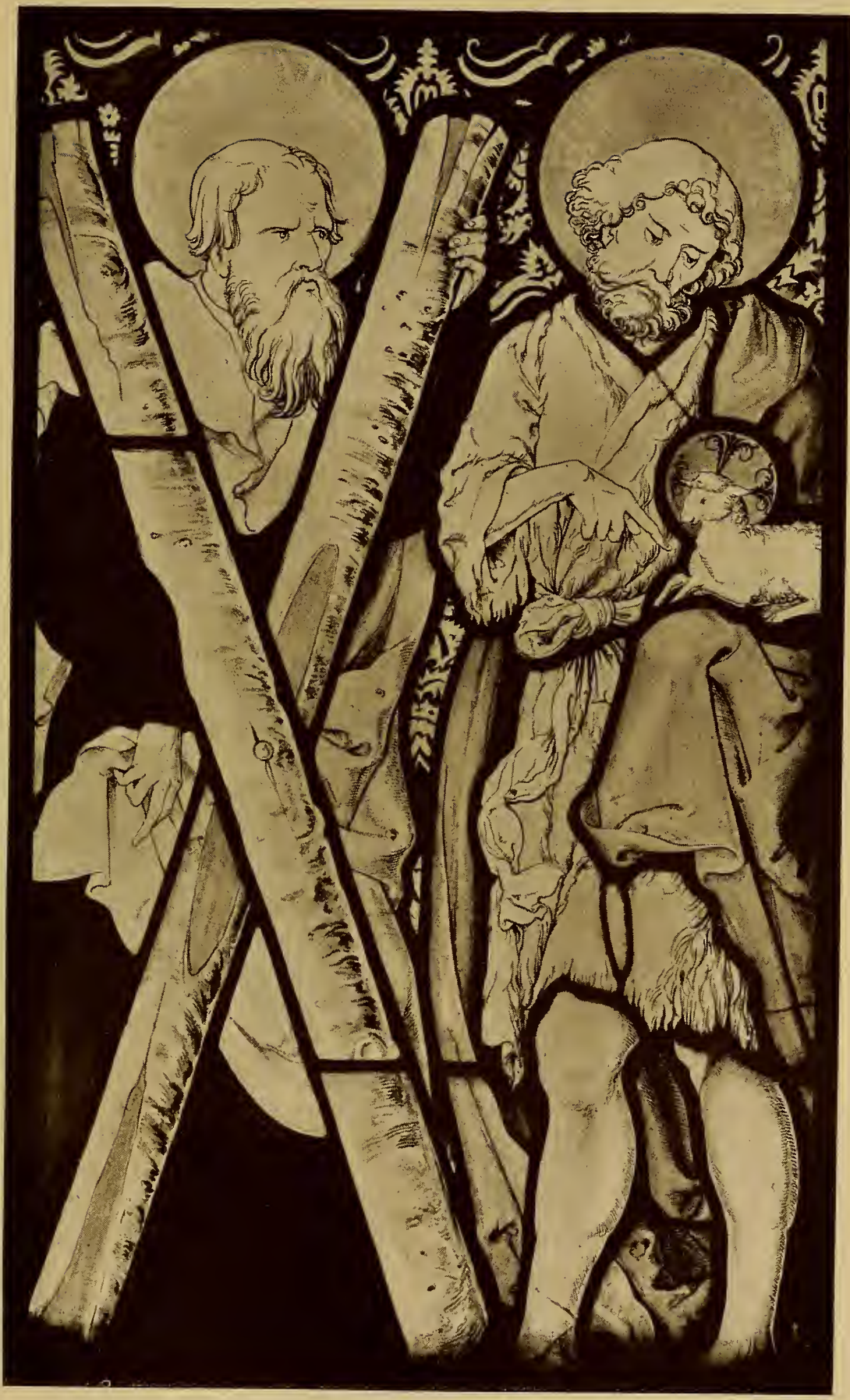

Glasgemälde in der Kgl. Residenz zu München. Stil Hans Baldung Griens. Nach einer Photographie von Oskar Zettler, München. 

Jahre $\left.1436^{1}\right)$. Ob der "Martin der glaser “ mit dem in unserer Liste am Anfang genannten Martin identisch ist, erscheint an sich möglich, ist jedoch nicht näher belegbar. Mit dem Jahre I 485 tritt Hans Winhart ein und steuert ununterbrochen bis zum Jahre I 504, in welchem Jahr er der Statglaser genannt wird. Neben ihm ist Michel Sengenrieder, aber bei weitem nicht so stark, besteuert. I 496 ist abermals ein besonderes Jahr. Es erscheinen als neue Männer Jakob Kistenfeger, Contz Ässlinger und insbesondere fredrich pronner (iuravit I496). Die beiden Jahre I 485 und I 496 bilden wichtige Ereignisse in der Münchener Glasmalerei. Um den ersten Zeitpunkt fällt die Stiftung des sogen. Herzogenfensters; das Jahr I 496 ist das Jahr der größeren Aufträge für die Salvatorkirche, deren erstes Fenster aus dem Jahre I 497 datiert ist. Bei der großen Anzahl von Glasmalern, die seit 1460 in München tätig sind, muß es seltsam erscheinen, daß man eine so umfangreiche Arbeit, wie das Scharfzandtfenster nach auswärts (an Hans Wild in U1m) übertragen haben soll. Nach allem, was wir über den Betrieb der mittelalterlichen Glasmalerei wissen, ist es unmöglich, daß eine einzige Werkstatt so ungeheuer viel bewältigen konnte, wie man dies nach der Menge von Arbeiten annehmen muß, die in Wilds Stil gehalten und erhalten sind, wobei ganz außer Acht bleibt, daß sicher noch ein mindestens ebenso großer Teil verloren gegangen ist. Vielleicht ist das Scharfzandtfenster von einem unter den genannten Glasmalern enthaltenen Münchener Meister nach einer Werkzeichnung Hans Wilds ausgeführt worden. An sich erscheint diese Tatsache ja belanglos, da es sich für uns im allgemeinen nur darum handelt, bestimmte Stileinheiten zusammenzustellen. Außer dem Stil Hans Wilds, der, wie wir bereits gesehen haben, vom Oberrhein beeinflußt ist, tritt uns auf sehr beträchtlichen Resten in der Frauenkirche eine andere ebenfalls vom Oberrhein ausgehende und im Weiterweg von Ulm angeregte Richtung

1) Wolter fand die handschriftliche Notiz im Reichsarchiv zu München: Meister Martein der glaser und meister hanns der Gleißmüller der maler paid burger zu münchen bekennen, daß sie vom hochstift Freising für ihre Arbeiten in dem S. Benediktschor I6 Pfund Münchener Pfenninge erhalten haben. Als Zeugen sind Hanns Sengenrieder und Jörg von Tall, beid burger zu München. Dieser Sengenrieder ist vielleicht verwandt mit den später öfter genannten Glasmalern dieses Namens. 
entgegen. Wir meinen den bzw. die Schöpfer des typologischen Kreises 1480-90 (Taf. 73, 74). Frankl hat in seinem schon genannten Buch (S. I $73 \mathrm{ff}$.) die noch vorhandenen Reste zusammengestellt. Der Glasmaler war bei Zusammenkomponierung der einzelnen Zeilen hauptsächlich von dem speculum humanae salvationis inspiriert, was insofern nicht weiter verwunderlich ist, als in der Heimat seines Stils, im Elsaß, das speculum von jeher besondere Achtung genoß. Wenn Hans Wild auf München Einfluß nehmen

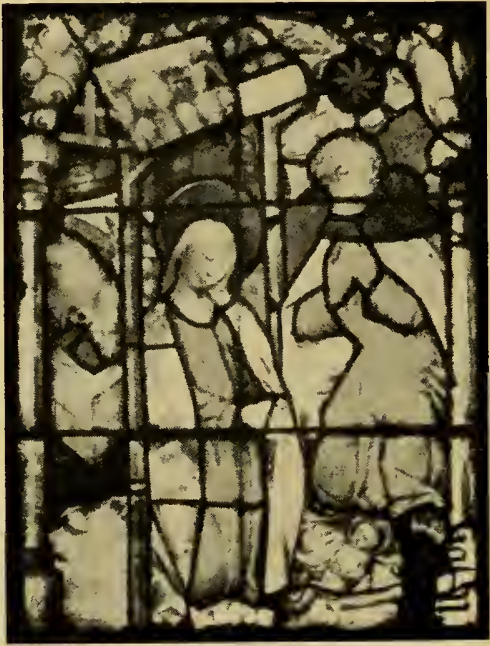

Abb. 2I. Geburt Christi.

Glasgemälde in der Frauenkirche zu München. I 480 - I 490 .

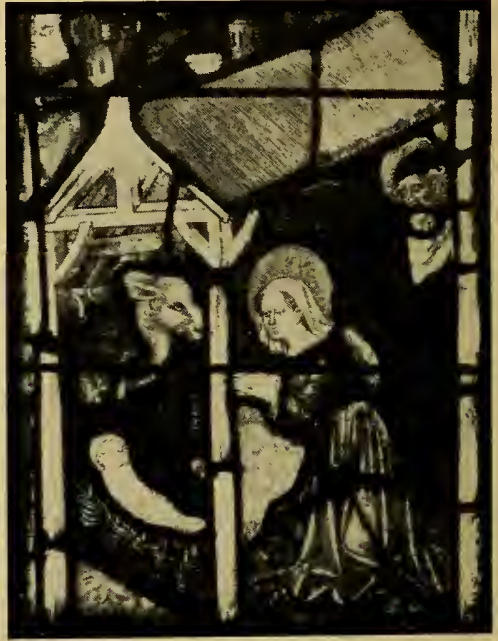

Abb. 22. Geburt Christi. Glasgemälde im Münster zu Ulm. Um 1420 .

konnte, so spricht a priori nichts dagegen, daß auch ein anderer vom Oberrhein ausgegangener und in Ulm tätig gewesener Meister nach der bayrischen Herzogsstadt berufen wurde, um dort eines der schönsten spätgotischen Legendenfenster zu schaffen, das wir überhaupt kennen. Legendenfenster waren ja die Spezialität der oberrheinisch-elsässischen Meister. Schlettstadt, Zabern, die Werkstatt Isenmanns bieten eine Menge Analogien zum Meister des Münchener typologischen Fensters. Es ist derselbe höfische Geist, der mit peinlichster Sauberkeit die Manieren der glanzliebenden westlichen Dynasten, die neuen burgundischen Moden 



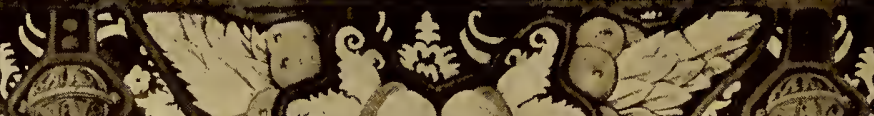

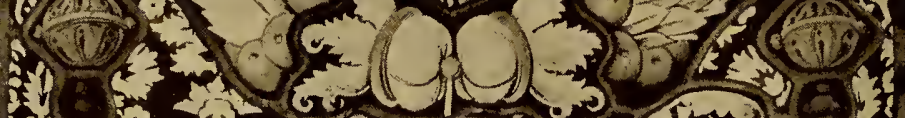

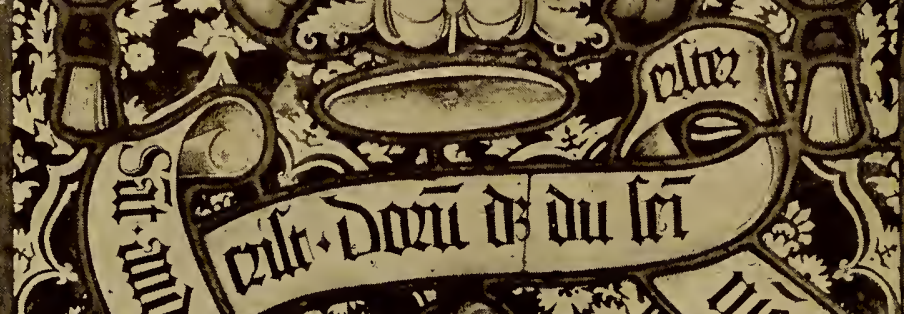
7 D 7 (n)

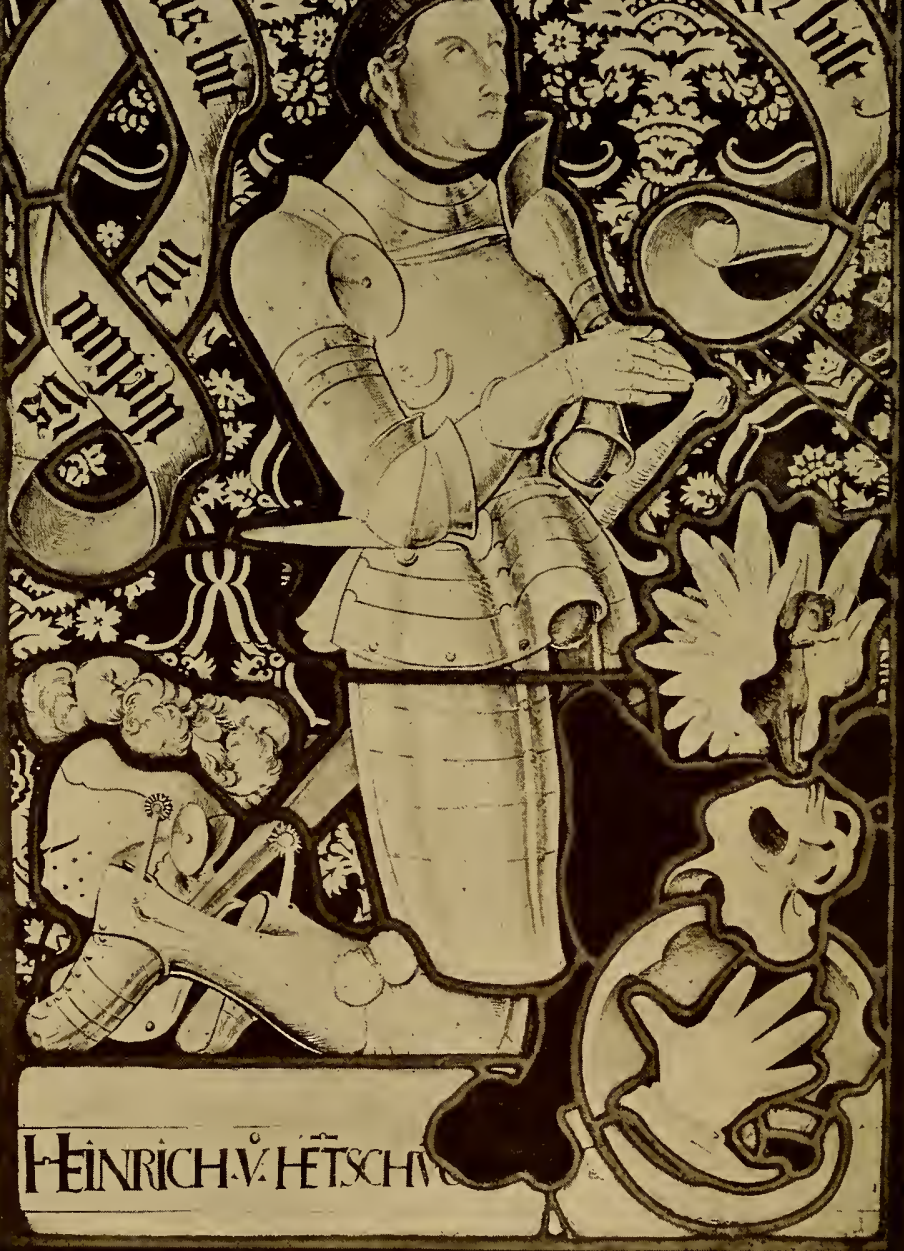

Heinrich von Handschuhsheim als Stifter. Glasgemälde in der Kgl. Residenz zu München. Stil'Hans Baldung Griens. Nach einer Photographie von Oskar Zettler, München. 


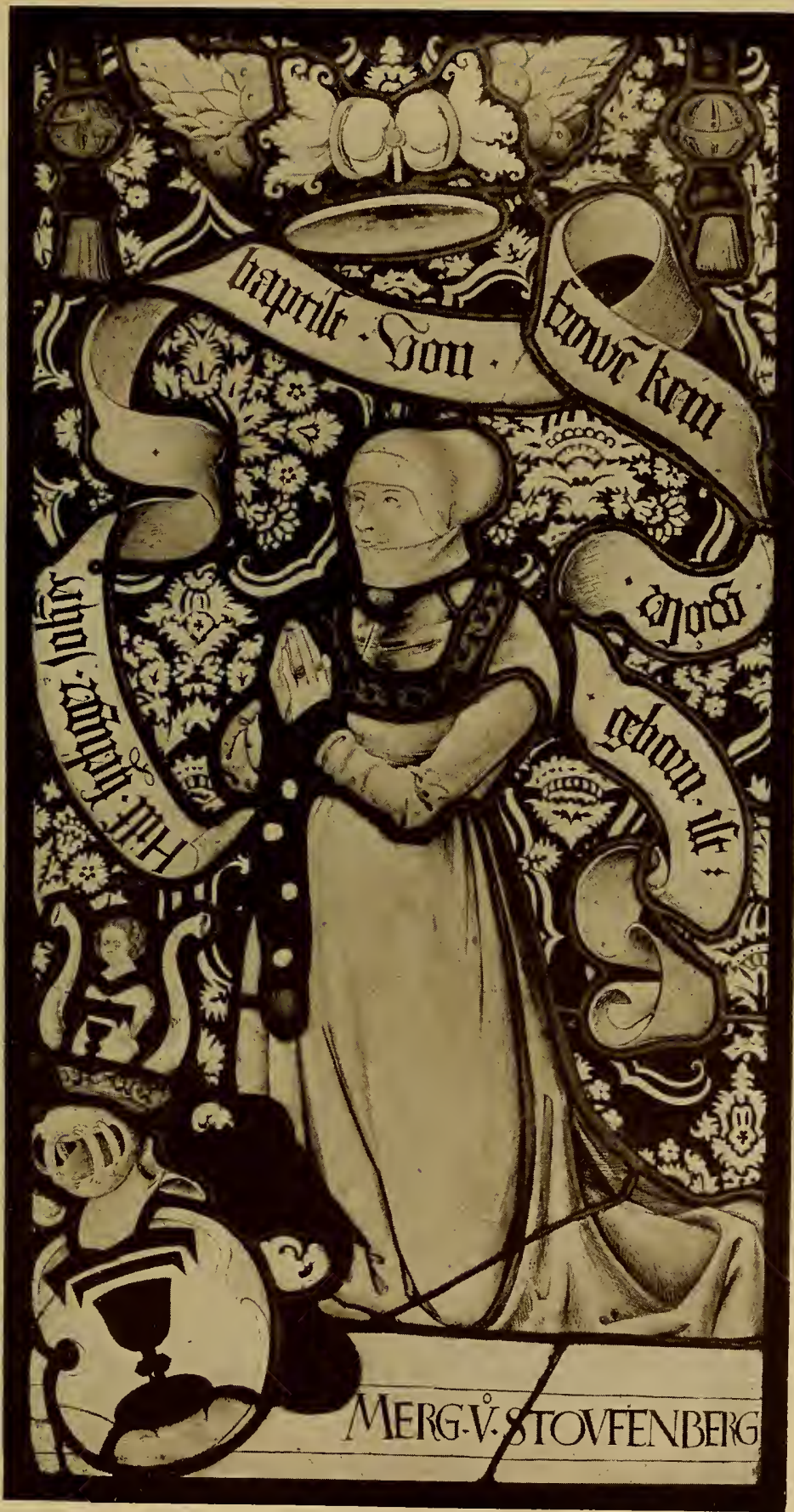

Margarethe von Staufenberg als Stifterin. Glasgemälde in der Kgl. Residenz zu München. Stil Hans Baldung Griens. Nach einer Photographie von Oskar Zettler, München. 



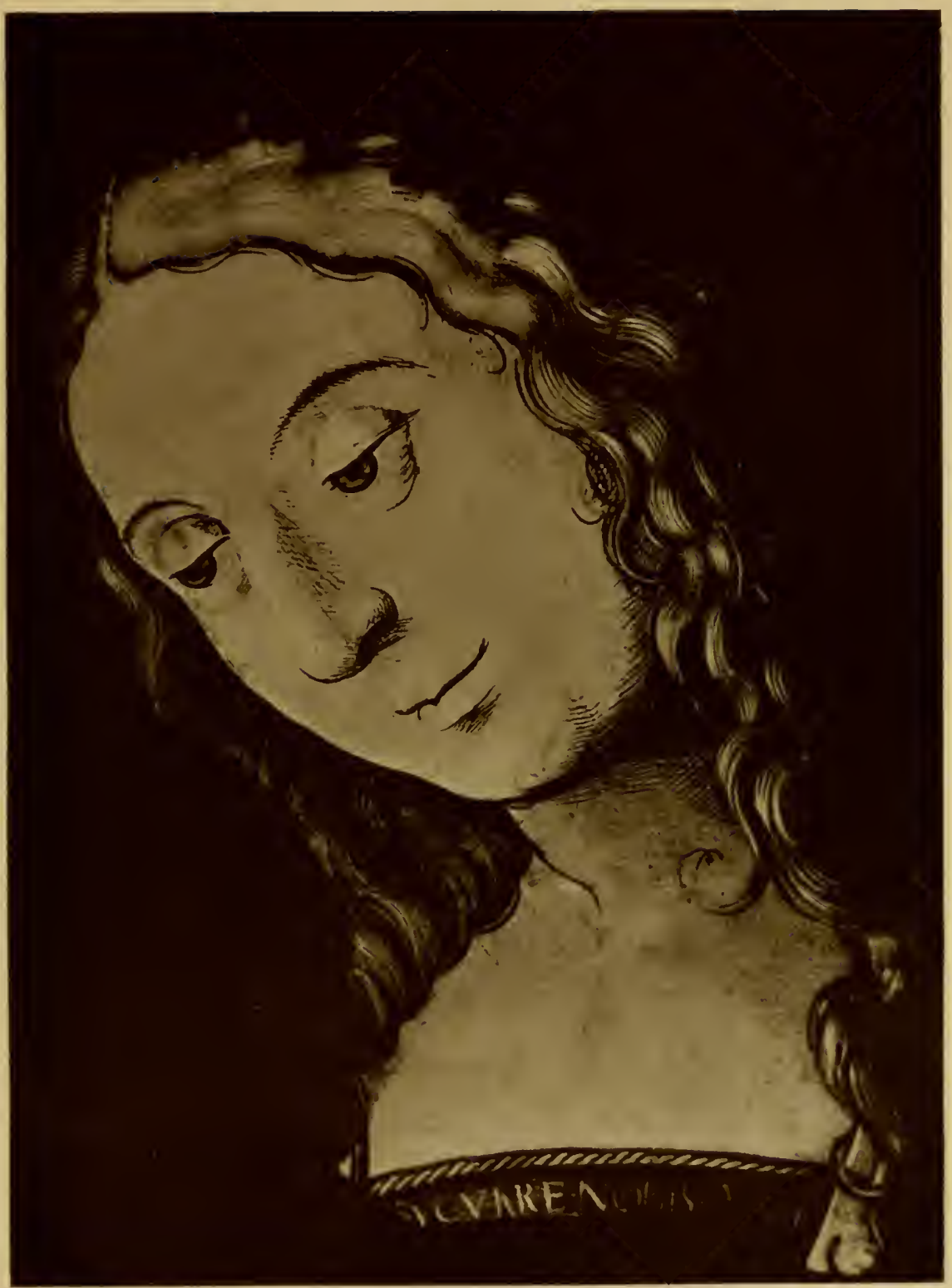

Detail aus einem Glasgemälde in dem Münster zu Freiburg i. B. Stil Hans Baldung Griens. Un $15 \times 5$. Nach einer Aufnahme von Professor Fritz Geiges. 



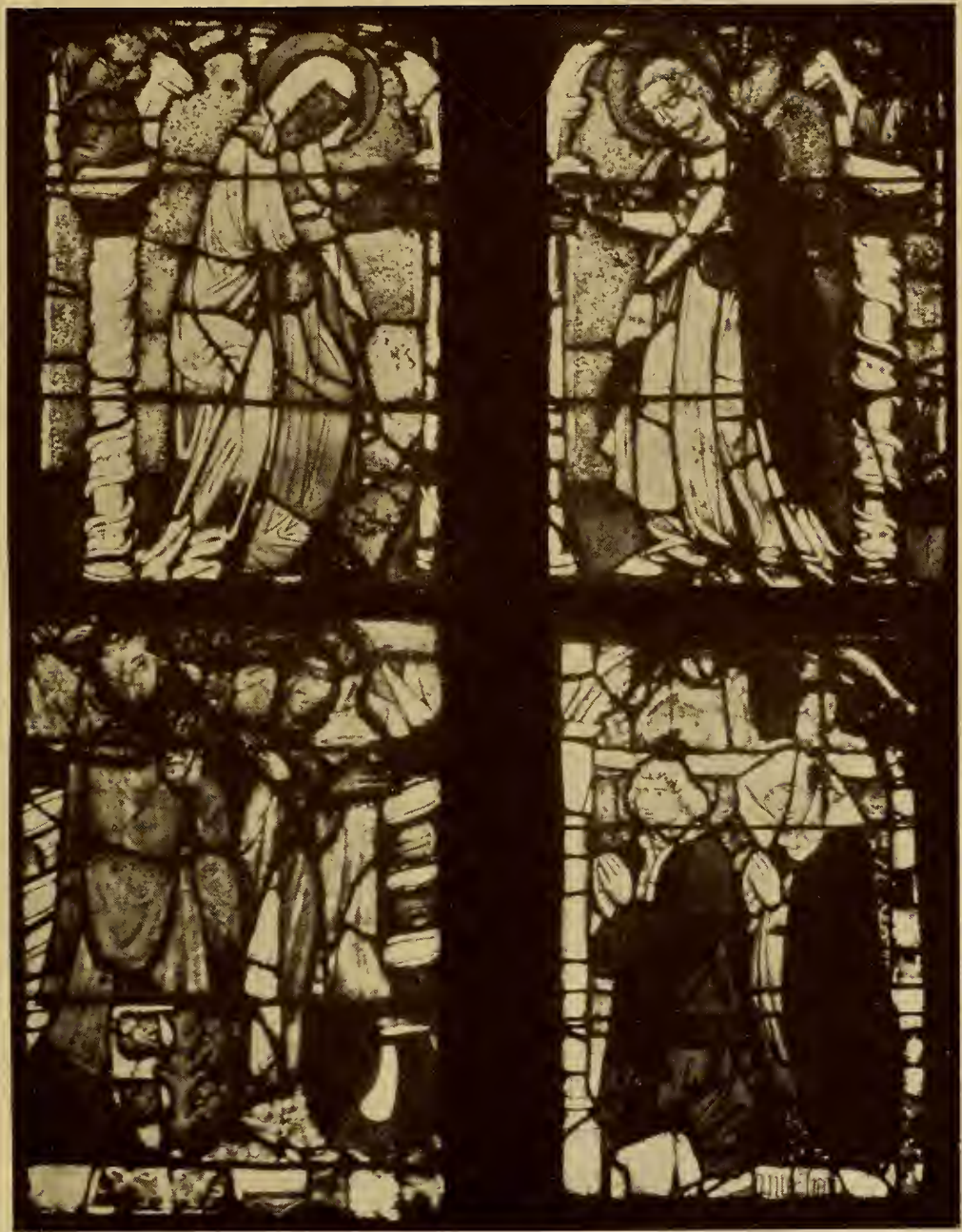

Detail aus einem Glasgemälde der Frauenkirche zu München. Um die Mitte des I 5. Jahrhunderts. 



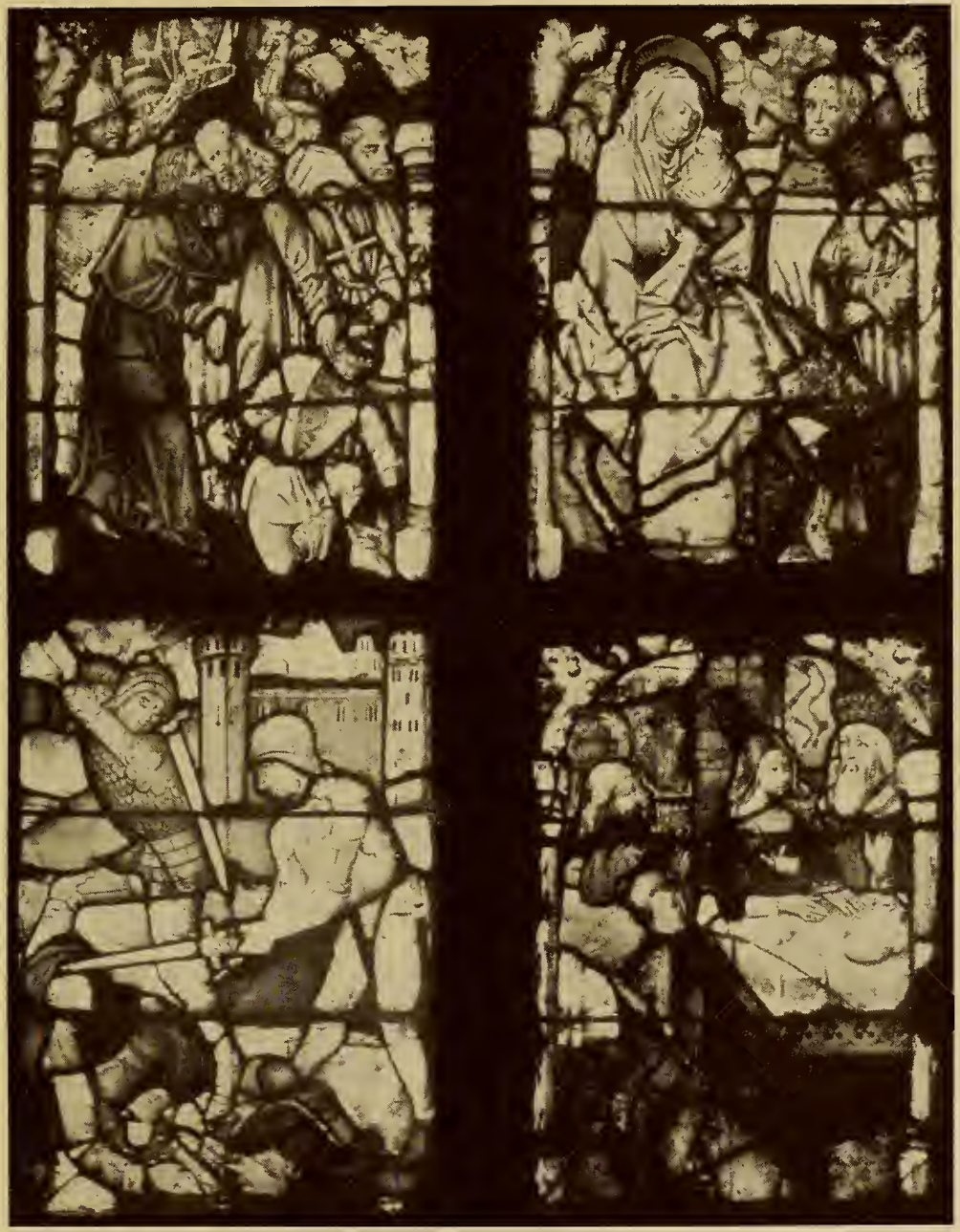

Vier Flügel aus einem typologischen Cyklus in der Frauenkirche zu München. I $480-1490$. 



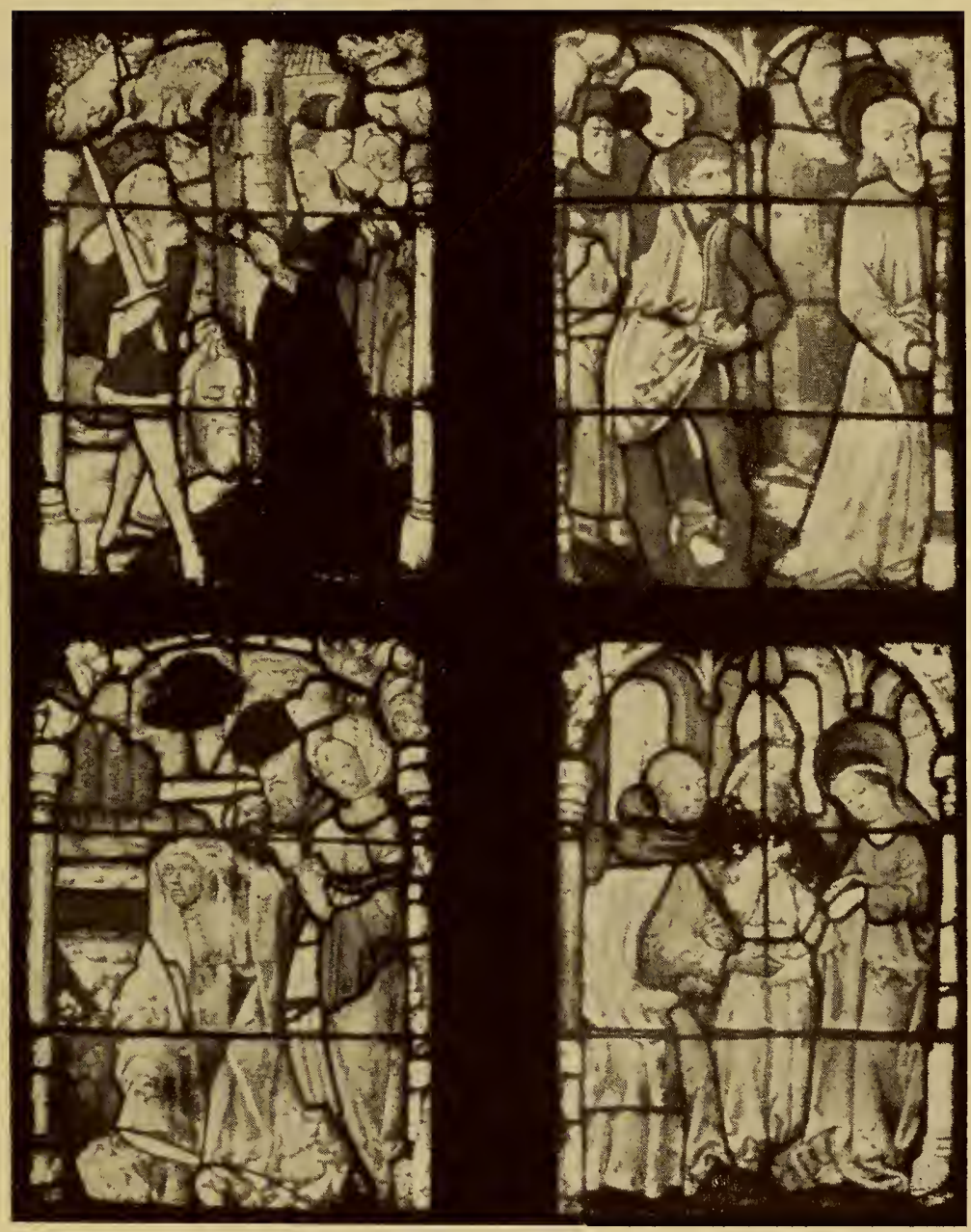

Vier Flügel aus einem typologischen Cyklus in der Frauenkirche zu München. I $480-$ I 490 . 



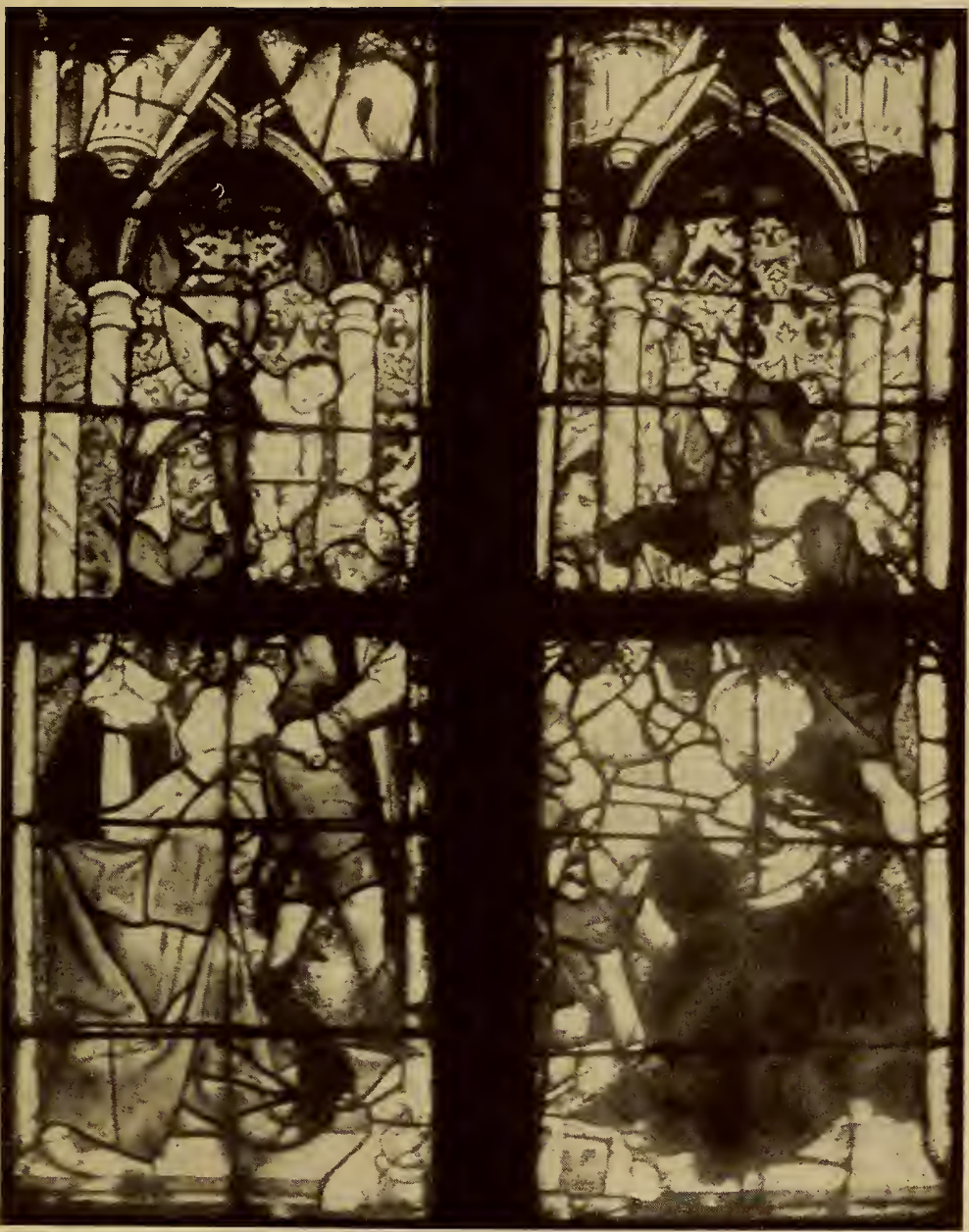

Bethlehemitischer Kindermord. Detail aus einem Glasgemälde in der Frauenkirche zu München. 

registriert und sich in deren Darstellung gefällt. Auch an den Bessererfenstern in Ulm hat er seine Studien gemacht (Abb. 21, 22), wie an jenen Werken, die dem Hans von Ulm zuzuschreiben sind und von denen wir heute nur mehr in Bern eine rechte Probe haben. In der Komposition, in der Farbzusammenstellung, wie in der Technik weist der Münchener Meister wichtige Ähn-

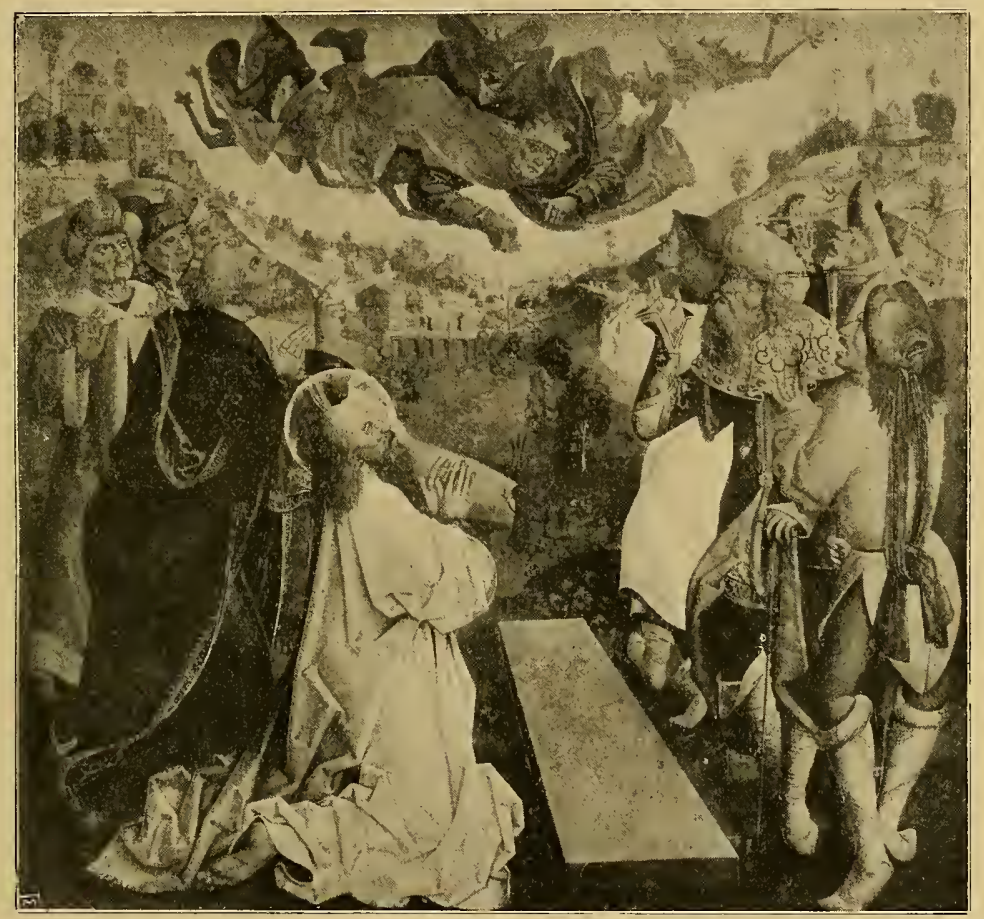

Abb. 23. Gemälde vom Münchener Petrialtar. Von Jan Pollack. Bayrisches Nationalmuseum, München.

lichkeitèn mit den genannten Schulen auf. $\mathrm{Ob}$ er unter den oben genannten Glasmalern enthalten und insbesondere mit dem Hans Kaiserslautrer identisch ist, muß dahingestellt bleiben; Kaiserslautrer kommt in den Jahren I469- I 486 vor; sein Namen, als auf den Rhein deutend, könnte zu der eben genannten Vermutung veranlassen.

Wie dem auch sei, jedenfalls kann von bodenständigem Münchener Stil bei den bisher behandelten Glasgemälden nicht 
gesprochen werden. Das ändert sich mit einem Male, als es sich darum handelt, die schon genannte herzogliche Stiftung und insbesondere die Fenster für die Salvatorkirche auszuführen. Nunmehr treten Meister auf, die zwar die ganze schwäbische und oberrheinische Technik ihrer Zeitgenossen beherrschen, von dem höfischen und kupferstichähnlichen Stil aber erheblich abweichen.

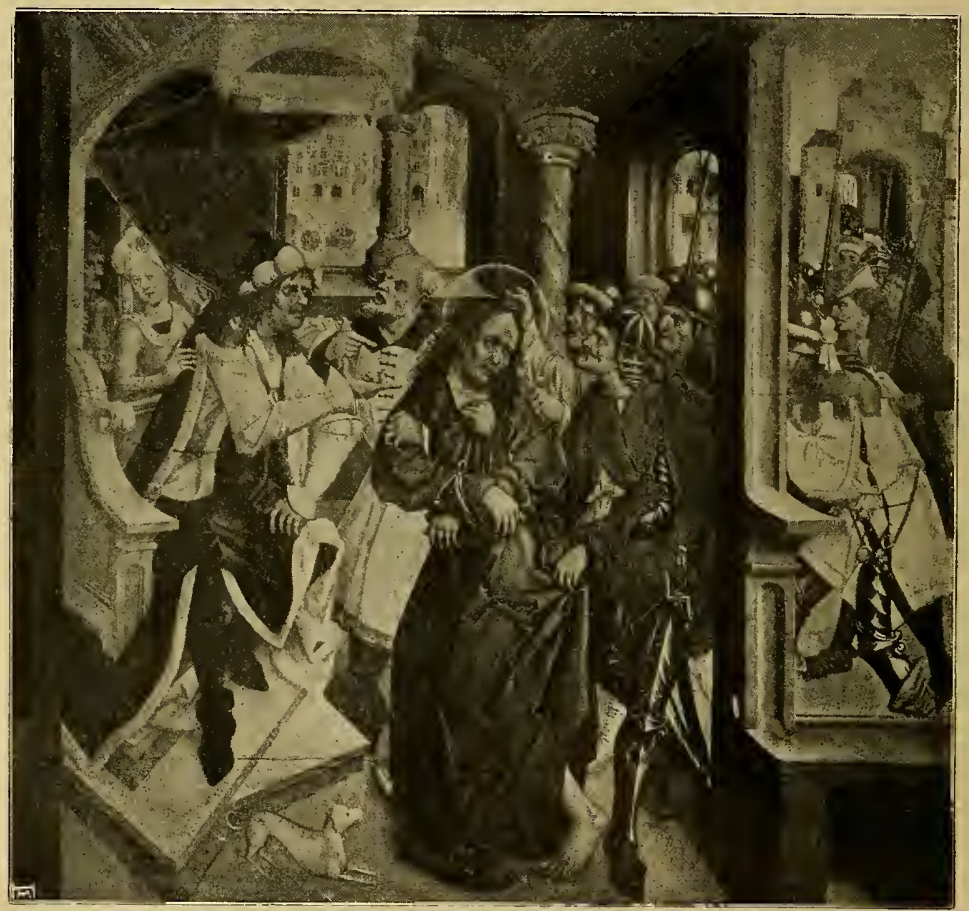

Abb. 24. Gemälde vom Münchener Petrialtar. Von Jan Pollack. Bayrisches Nationalmuseum, München.

Ich habe wiederholt darauf hingewiesen, daß den entscheidenden Umschlag in der Stilistik der Münchener Glasmalerei kein anderer bewirkt hat, als Jan Pollack, der Meister des Münchener Petrialtares. Alles Höfische ist abgestreift, dafür ein kräftiger, überaus derber Realismus mit geradezu fanatischem Eifer durchgeführt. Pollacks Raumgesetze und Perspektiven, die Bewegungen und Gruppierung der handelnden Personen sind überall zu beobachten. $\mathrm{Ab}$ und $\mathrm{zu}$ werden sogar Einzelheiten nachgeahmt, wie beispiels- 


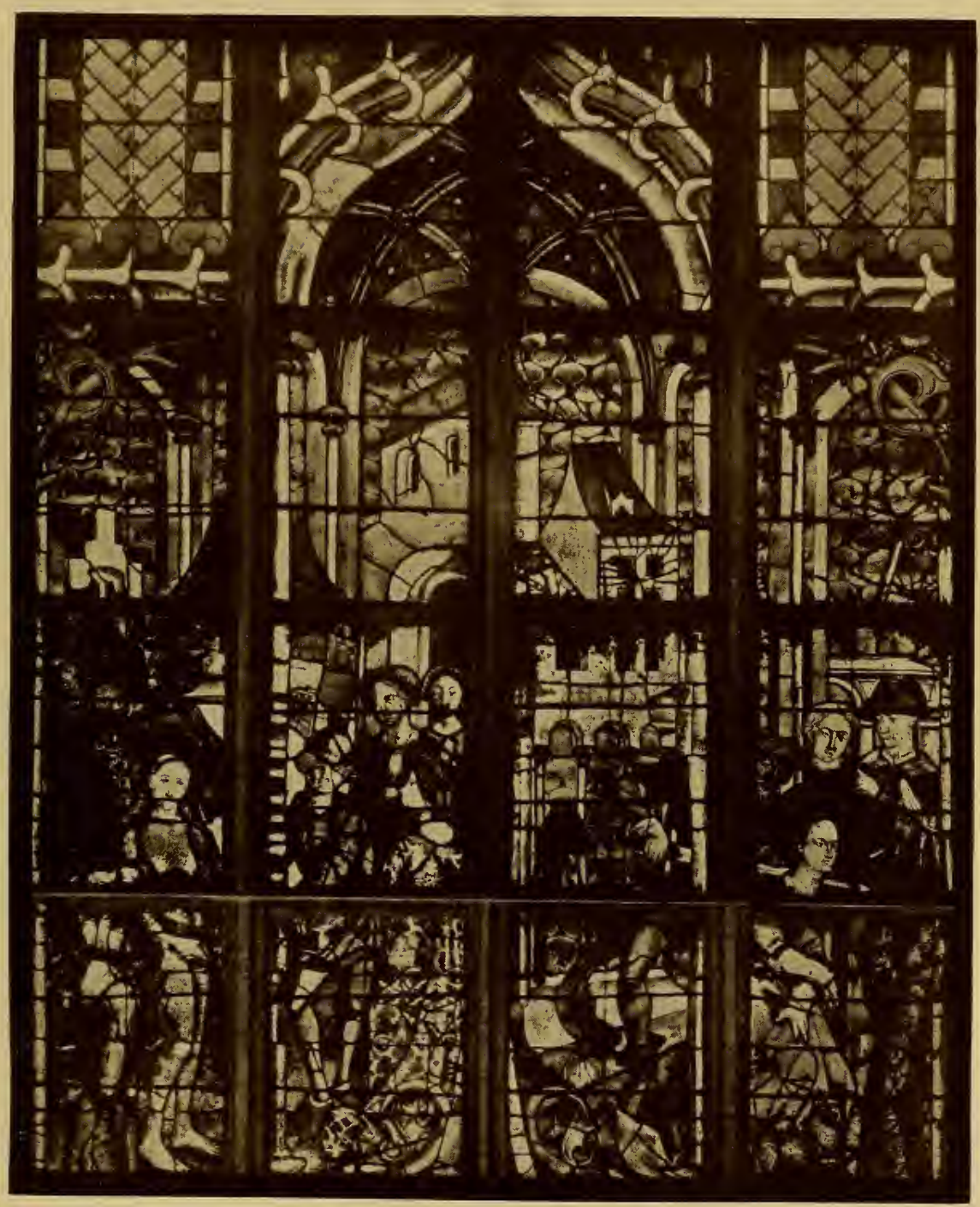

Detail aus einem Glasgemälde in der Frauenkirche zu München, um I 495. 

weise die Säulen auf dem Glasgemälde des bethlehemitischen Kindermords zeigen, die sich genau so auf der Szene Christus vor Pilatus auf dem Petrialtar finden (Abb. 24, Taf. 75). Über Pollack wird in Bälde der beste Kenner dieser Periode, Dr. H. Buchheit,

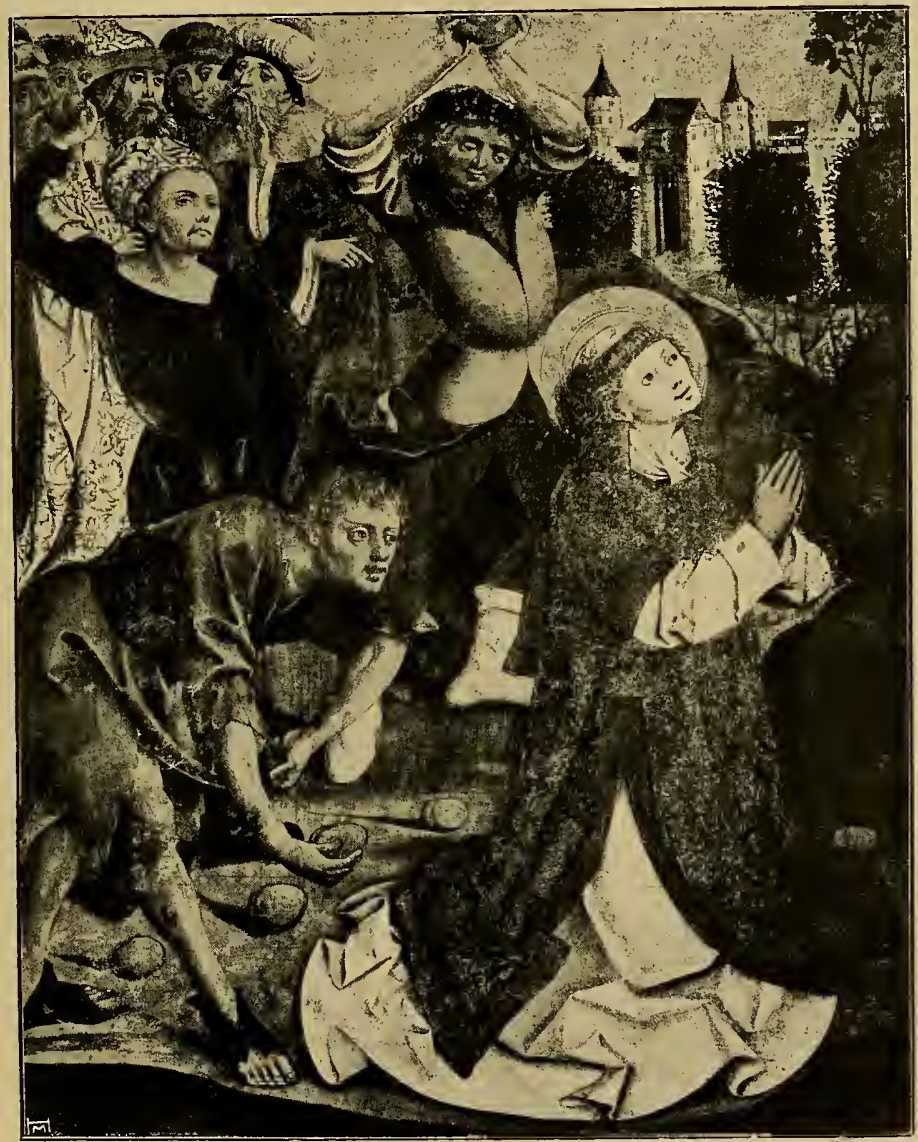

Abb. 25. Gemälde von einem Jan Pollack nahestehenden Meister. Bayrisches Nationalmuseum, München.

umfassende Studien veröffentlichen. Es mochte bisher gewagt erscheinen, Jan Pollack in diesem hohen Grad für die stilistische Neuorientierung der Münchener Glasmalerei verantwortlich zu machen: da fand vor kurzem Herr Dr. M. Hartig in einer Scheyerner Handschrift folgende, mir durch Dr. H. Buchheit 10* 
vermittelte Notiz: "Jan pollack pictor in monacho habet $\mathrm{X} f$. a vitricis ecclie s. martinii." Jan Pollack bekommt also eine Zahlung für Glasge-

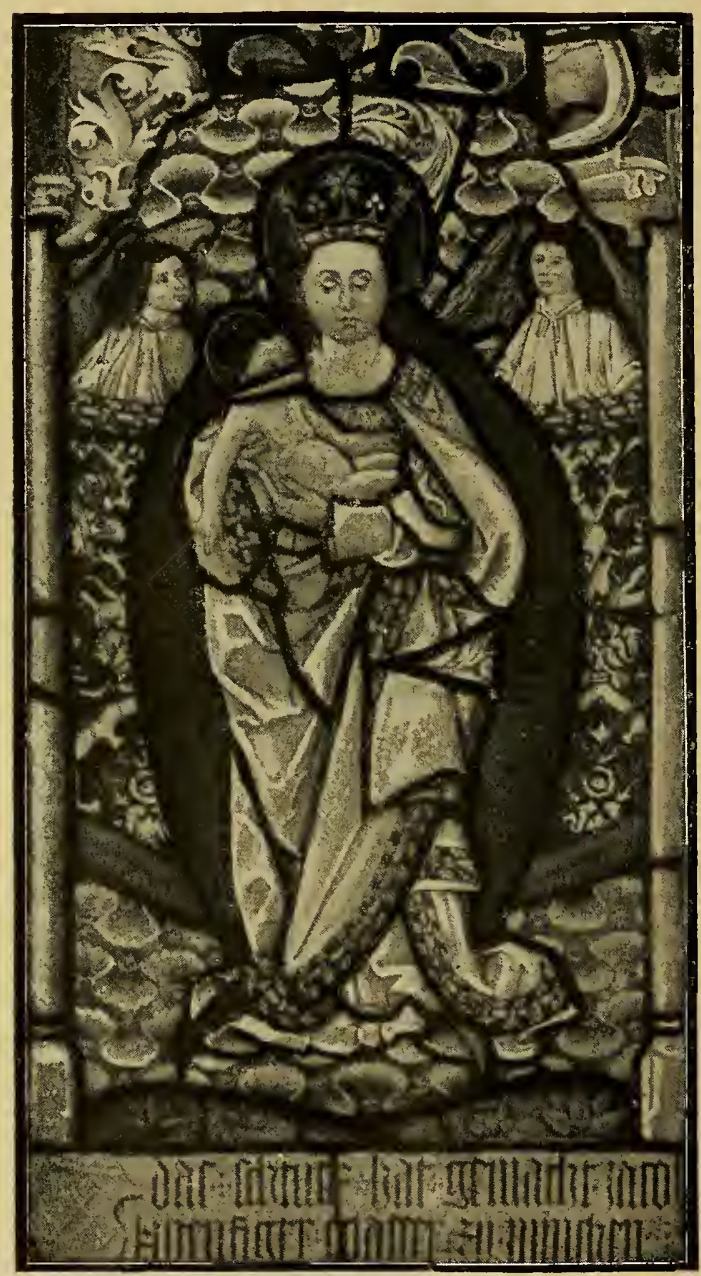

Abb. 26. Scheibe mit der Meisterunterschrift des Münchener Glasmalers Jakob Kistenfeger. I 496-1532. Schloß Erdödy. mälde gerade in dem Jahr, in welchem der Umschwung im Stil der Münchener Glasmalerei sich vollzieht. Nun arbeitet alles, was sich in München "glaser" nennt, im Stile des Jan Pollack. In der Handschrift dagegen macht sich eine große Mannigfaltigkeit geltend, die eine Zusammenstellung einzelner Gruppen bedeutend erschwert, was ja auch mit der Existenz von so vielen Glasmalern, die wir oben angeführt haben, übereinstimmt (siehe Abbildung 23-25, Tafel 75). Auf einer verhältnismäßig kleinen Fläche, z. B. den Fensterstiftungen der Metzgerzunft, sind mindestens zwei verschiedene Handschriften zu konstatieren. Der eine der

Glasmaler konturiert an den Falten der Gewänder holzschnittartig, der andere breit wie ein Bildhauer. Ähnlich verhält es sich mit dem sehr gut erhaltenen Fenster der Verklärung 


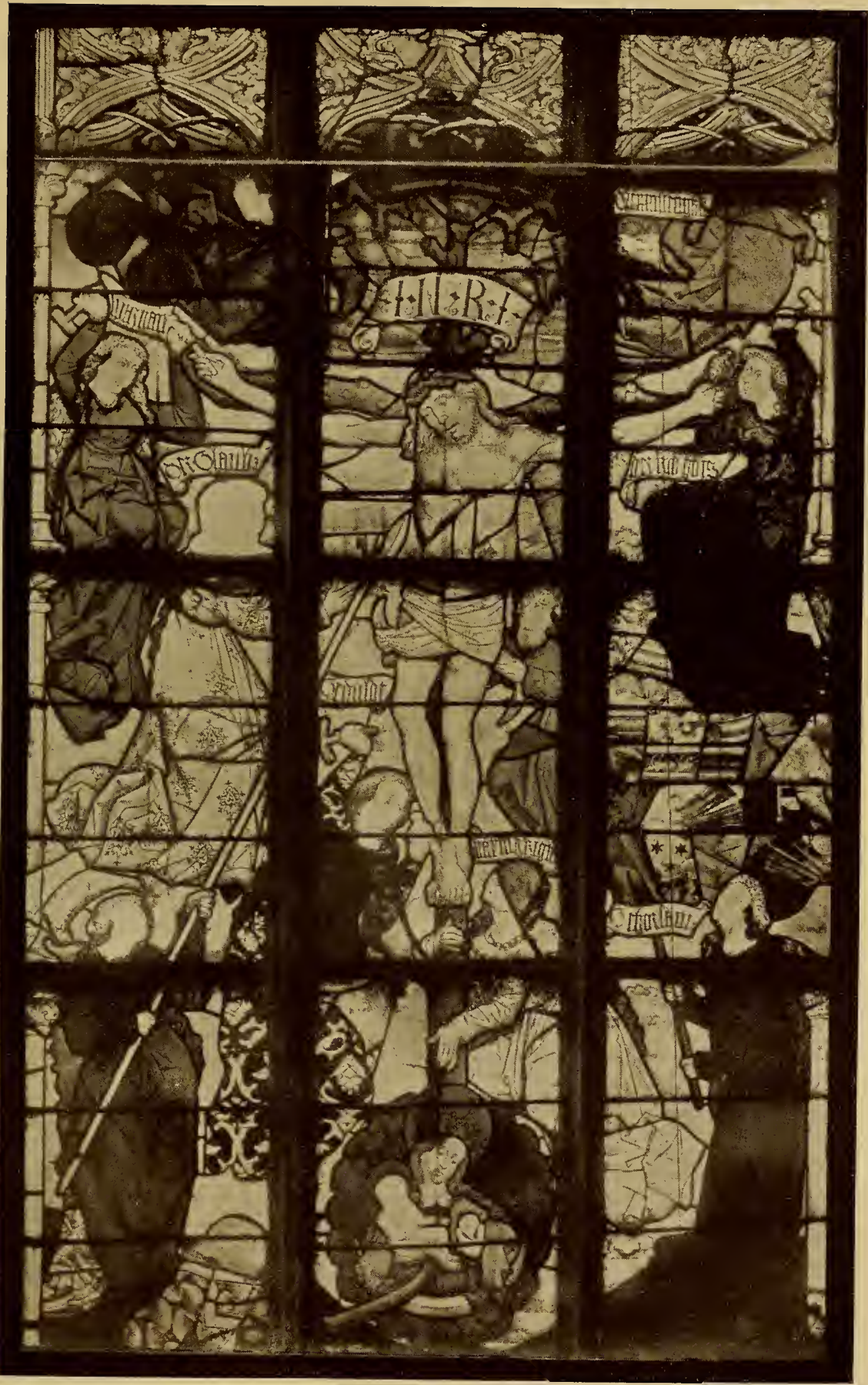

Allegorisches Fenster in der Salvatorkirche zu München. Um I 500. 



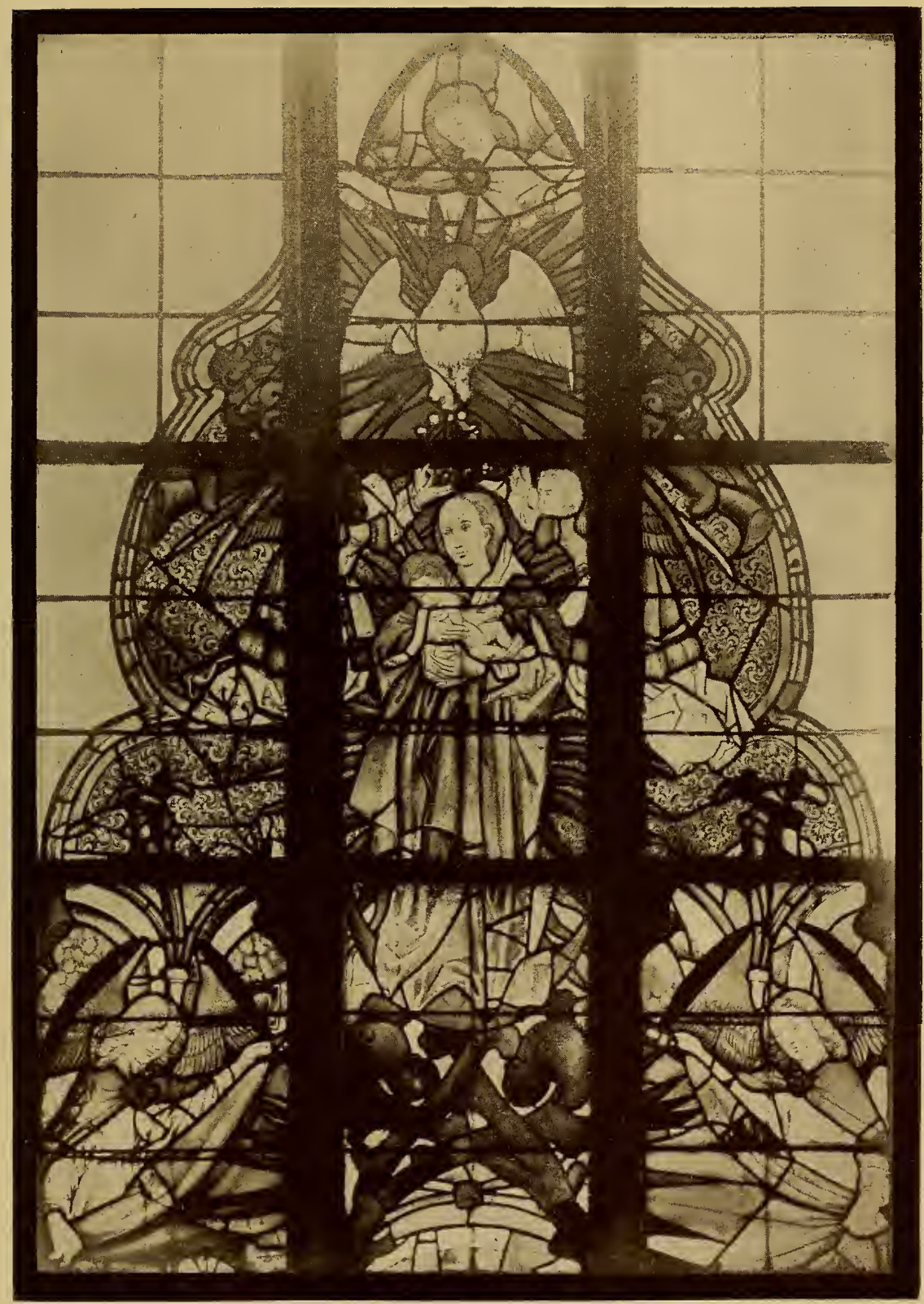

Oberteil eines Fensters in der Salvatorkirche zu München. Um I 500. 

und dem Fenster mit Geburt und Anbetung Christi, die von zwei vollständig verschiedenen Meistern herrühren. Der eine modelliert Licht und Schatten sorgfältig in Radier- und Strichmanier, führt Heiligenscheine mit peinlicher Akribie aus, umsäumt Gewänder mit Schriftbändern. Ganz verschieden ist der andere Meister. Er vergißt alle Heiligenscheine und stellt in seiner Handschrift eine leichte Rückerinnerung an den Formenschatz des Meisters

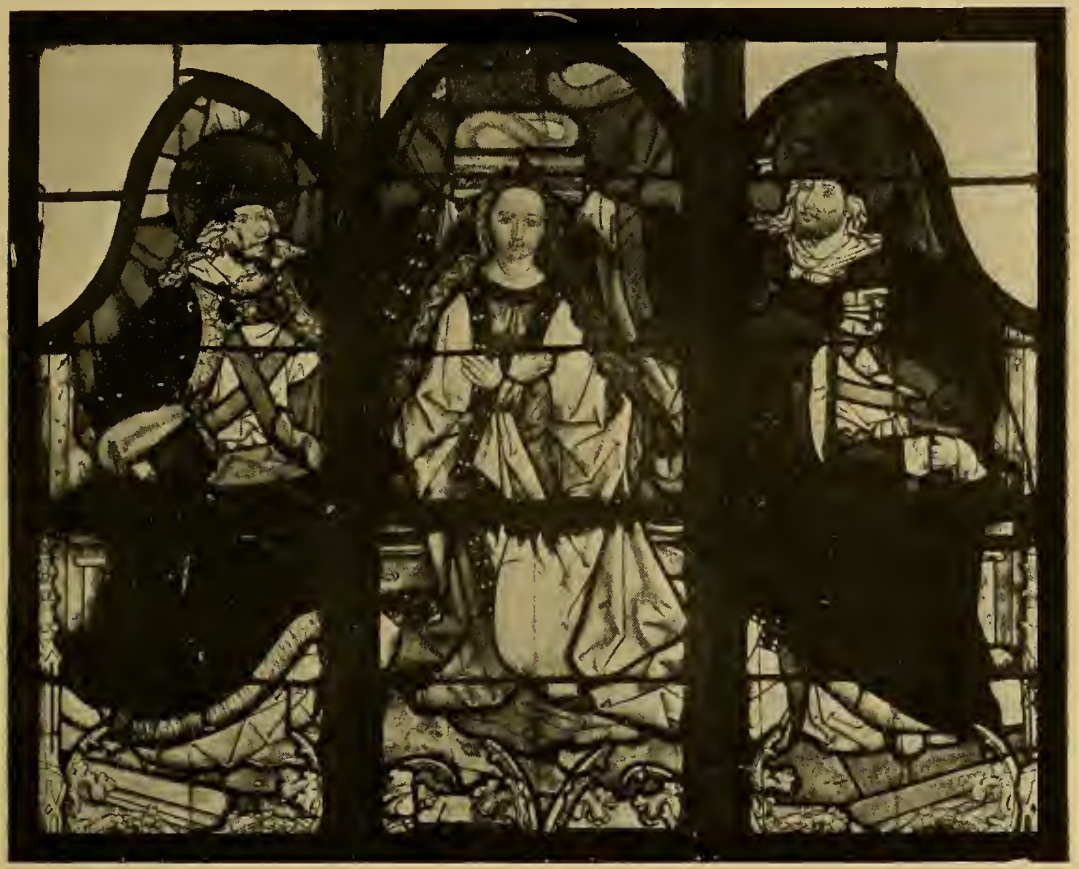

Abb. 27. Oberteil eines Glasgemäldes in der Salvatorkirche zu München. Um I 500.

dar, dem wir das typologische Fenster in der Frauenkirche zuschreiben müssen. Nur die Glasgemälde mit der Ölbergszene und dem Verrat des Judas sind unter sich so verwandt, daß man von einer gemeinsamen Werkstatt sprechen darf. In einen näheren Zusammenhang gehören auch die Reste der Florians- und Sebastianslegende, sodann die Katharinenlegende und die Mannalese in der Salvatorkirche (Taf. 76). Von allen Glasmalern können wir bis jetzt nur den Jakob Kistenfeger fassen, da von ihm eine vollinschriftlich signierte Scheibe erhalten ist und zwar in dem 
Schloß Erdödy in Ungarn (siehe Abb. 26). Am meisten berührt sich der Stil des Kistenfeger mit dem allegorischen Fenster in der Salvatorkirche (Taf. 77, 78; Abb. 27). Dieses allegorische Fenster führt zu den bedeutsamen Glasgemälden weiter, die zu Beginn des 16. Jahrhunderts für Landsberg a. L. entstanden sind

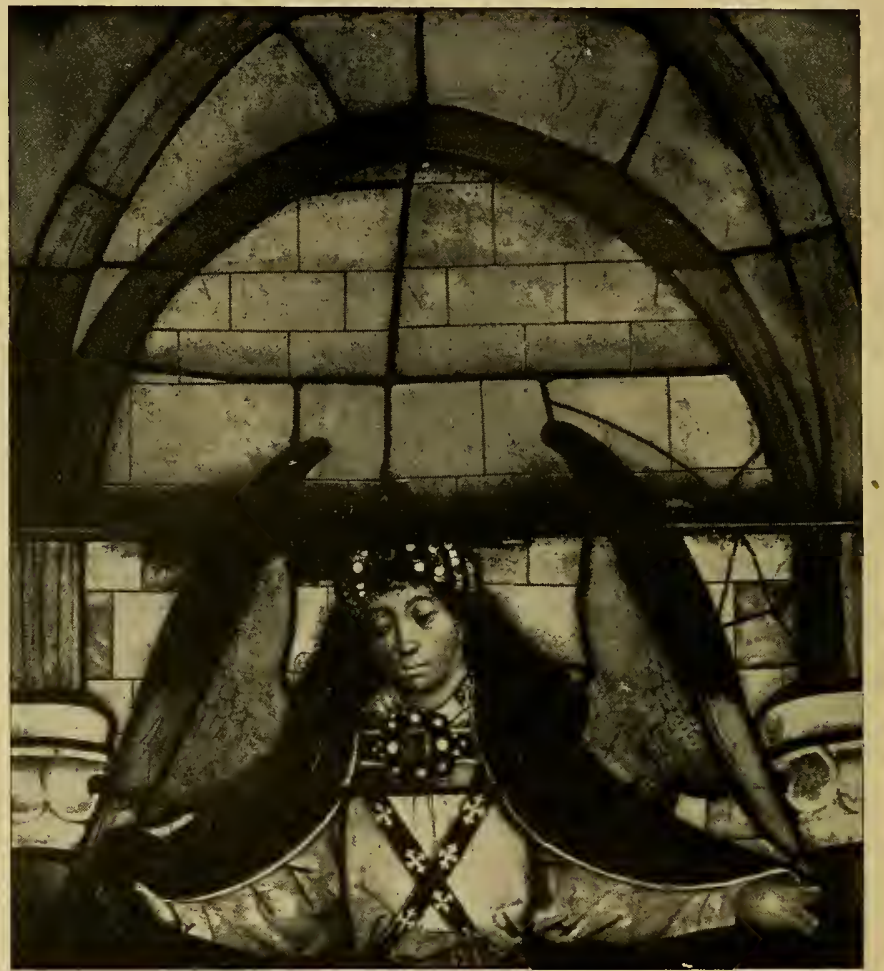

Abb. 28. Detail aus den Chorfenstern der Pfarrkirche zu Landsberg a. L. Anfang des 16 . Jahrhunderts.

(Taf. 79, Abb. 28). Auf dem Ärmel eines Schergen stehen die wohl als Monogramm beabsichtigten Buchstaben K. H. T. und E. A. T. Auch in Blutenburg ist ein Zyklus aus dem Leiden Jesu, beginnend mit dem Einzug (die Verkündigungsszene ist neu) erhalten (Taf. 80) ${ }^{\mathbf{1}}$ ).

1) Die auf dem Lande zerstreuten Reste sind bei Sighart und teilweise auch bei Frankl zusammengestellt. 


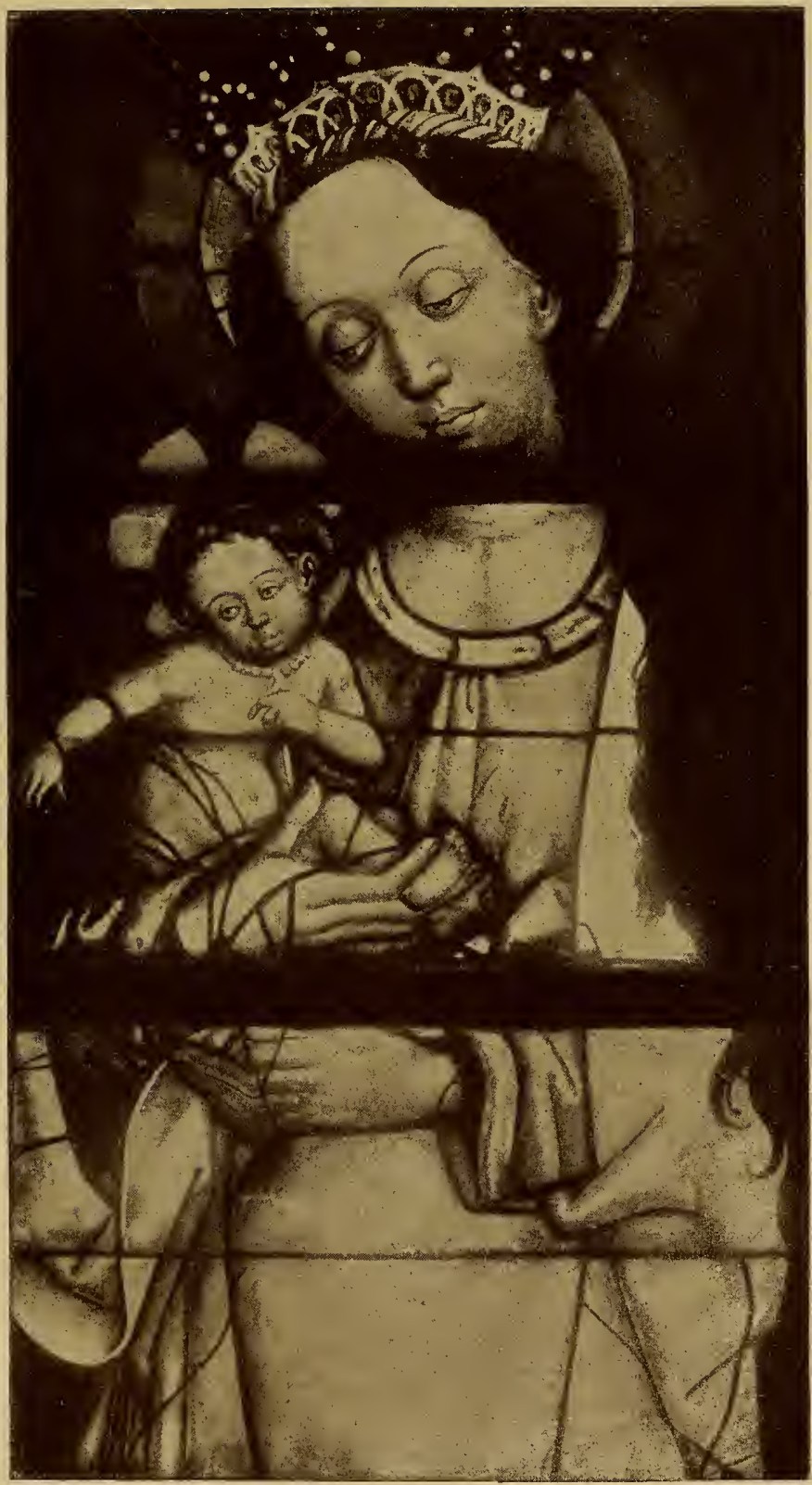

Detail aus den Chorfenstern der Pfarrkirche zu Landsberg a. L. Anfang des 16 . Jahrhunderts. 



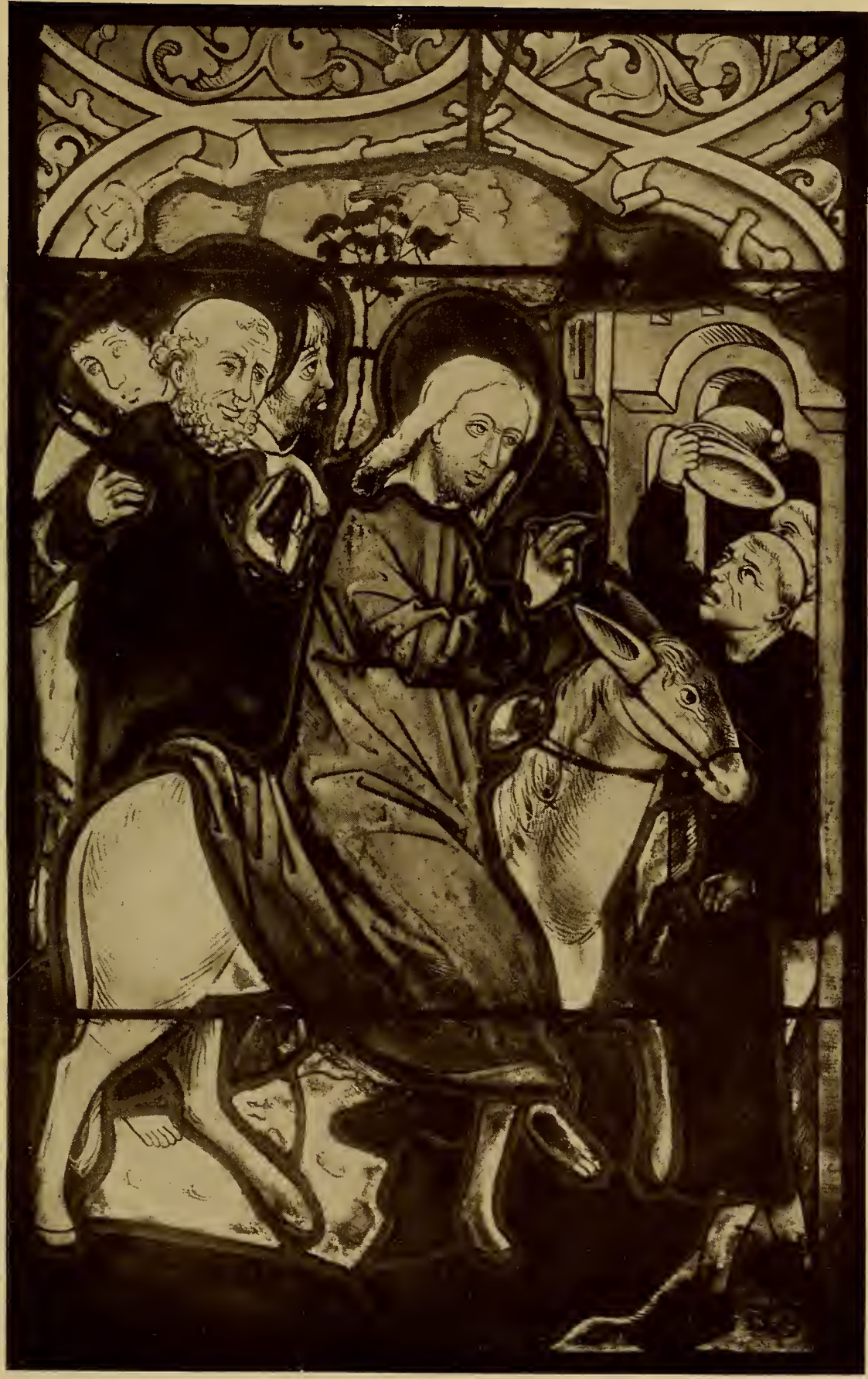

Scheibe aus einem Passionscyklus in der Kirche zu Blutenburg bei München. Gegen I 500 . 

Eine sehr bedeutende Zentrale ist auch Landshut gewesen. Leidinger führt ein aus Landshut verschwundenes Glasgemälde an, das aus dem Jahre 1488 stammt $^{1}$ ). Sighart sagt: „In Landshuter Urkunden wird genannt Arnold der Glaser I400, Marx Glaser, den im Jahre I 4 IO auch die Verbannung traf, besonders aber Hanns Siber, der, ein Freund des Dombaumeisters Andreas Egl in Regensburg, für die Frauenkirche zu Straubing im Jahre I 442 vierzehn gemalte Fenster lieferte, ferner Fenster für die Kartause Prüll malte und wohl auch die zierlichen Fenster in Jenkofen gemalt hat. Dazu kommen noch Jakob Strauß, Glaser (1508), die Hofglaser Georg Bronner, Matthäus von Burghausen ( 1503 ) und Georg Wieland, Glaser ( 1552 ). In Mallersdorf lebte ein Mönch, Mathias Dirnhofer, welcher sich durch Glasmalereien einen Namen erwarb ${ }^{2}$ ). " Aus der Zeit, in der jenes verschwundene Glasgemälde entstand, führt Buchheit einen Hanns weiler glaser an (1493); ferner den Meister Jakob den glaser, der 1512-13 die Fenster in Moosburg malte, I 525 Hanns Glaser (erhält das Bürgerrecht), I 526 den Peter Kreutzperger, I 529 Lorenntz Hernperger, 1536 Wolfgang Kreitzperger, 1546 Bartolome Oberndorffer glaser von Biburg. Im Bayrischen Nationalmuseum befinden sich zwei Scheiben mit Stiftern aus dem Hause der Baumgartner von Fraunstein. Es ist auf Grund von Urkunden festgestellt, daß diese Scheiben von dem Maler Hans Wertinger, genannt Schwabmaler, stammen ${ }^{3}$. Mit ihnen gehören vier Scheiben zusammen, die im Jahre I 5 I 5 für Fürstbischof Philipp von Freising gemalt wurden und sich jetzt im Kgl. Kunstgewerbemuseum zu Berlin befinden. Auf diese Scheiben bezieht sich wohl folgende, jüngst gefundene Rechnung: „Maister Hanns Schwab maler von Landshut hat meinem gn. Herren gemalt iii geschmelzte Scheiben p. 6 fl." Mit Hans Wertinger ist der Übergang zur Renaissance vollzogen. Über ihn vergleiche Hans Buchheit, Der Maler Hans Wertinger, genannt Schwabmaler, Leipzig 1907.

In Augsburg (Abb. 29) wird die Durchdringung der Glasmalerei durch die führenden Tafelmaler in den Ateliers Burgk-

1) Zeitschrift für alte und neue Glasmalerei I9I3, S. 65 .

2) a. a. O., S. 64 I.

$\left.{ }^{8}\right)$ Siehe Schinnerer, Katalog der Glasgemälde des Bayrischen Nationalmuseums, S. 37. 
mairs, Holbeins, später Jörg Breus vollendet. Burgkmair bekommt im Jahre I 5I 5 I 5 Gulden „vmb visier zue glesern“, die dann der Glasmaler Hans Braun für 24 Gulden in Glas schmelzt (der gleichzeitig genannte statglaser Hans Thoma scheint die einfache Glaserarbeit gemacht $\mathrm{zu}$ haben). Während also in diesem Fall noch eine Arbeitsteilung zwischen Visierer und Ausführenden in zwei gleichberechtigten Werkstätten vorhanden ist, hat Holbein

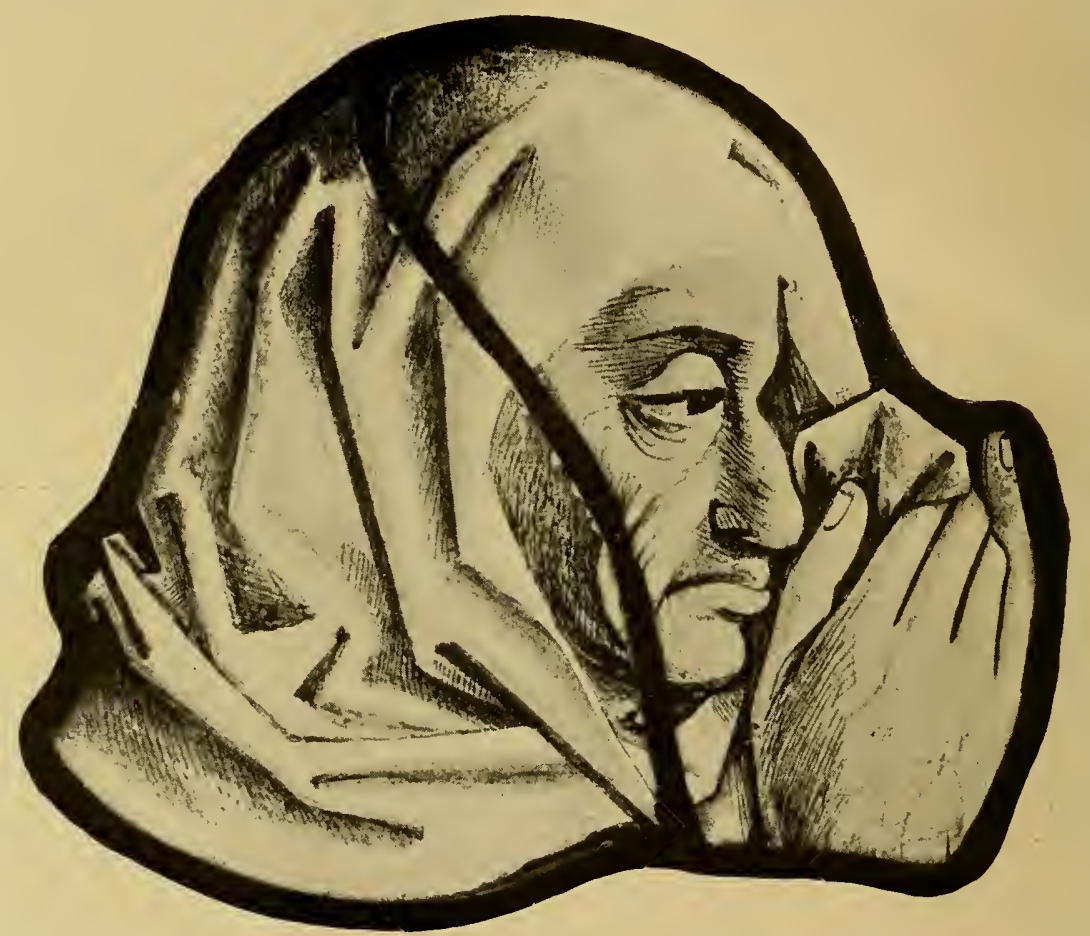

Abb. 29. Fragment eines Glasgemäldes im Bayrischen Nationalmuseum zu München. Ende des 15. Jahrhunderts.

nach Dirrs Ausführungen ${ }^{1}$ ) ein eigenes Glasmaleratelier unterhalten und damit den Sieg des Malerischen über das Glasmalerische zu Ende geführt. Aus der Holbeinwerkstatt gingen unter anderem hervor einige in Eichstätt erhaltene und mit dem vollen Namen Holbeins signierte Glasgemälde, sodann die Glasgemälde in dem

1) Glasgemälde Hans Holbeins im „Münchener Jahrbuch" I 909. 


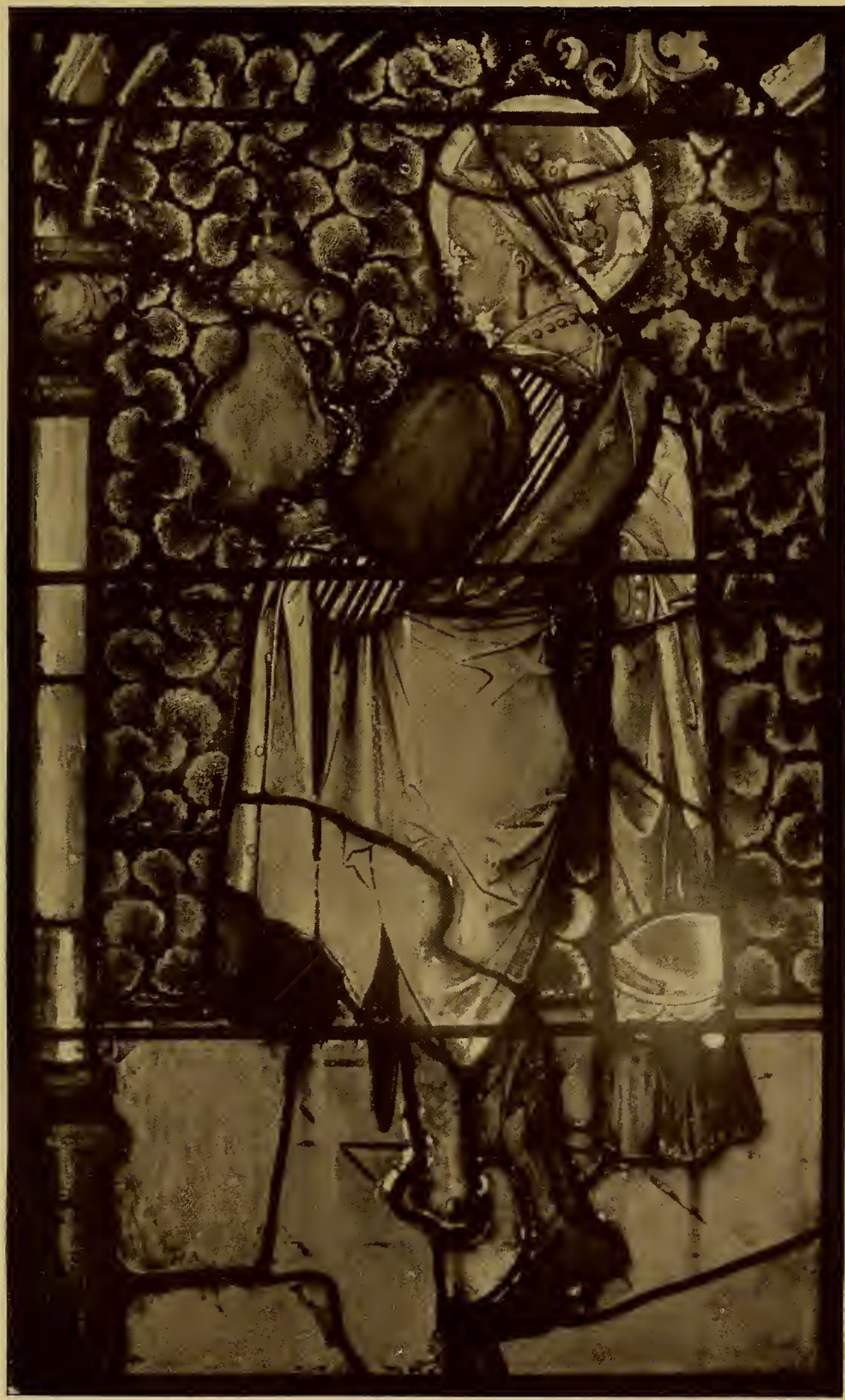

Detail aus einer Anbetung der Könige. Hans Holbein d. Ä. Augsburg. Nach einer Photographie von Höfle-Augsburg. 



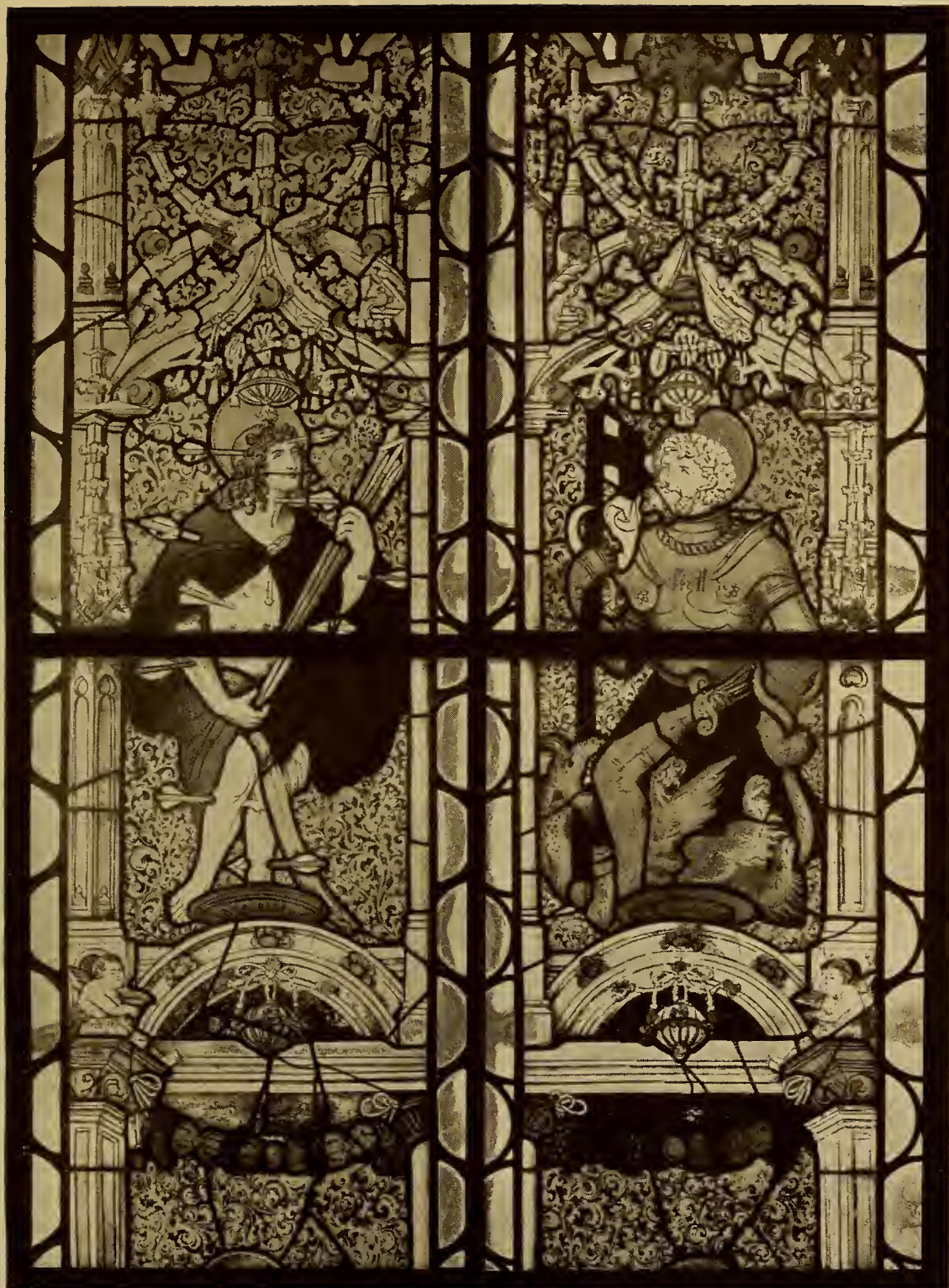

Detail aus einem Fenster in der Kirche zu Tölz. Beispiel für den Übergang der Gotik in die Renaissance. I5IO-I5I5. 

Pfarrhaus des Doms zu Augsburg (siehe Abb. 30, Taf. 81). Seinen Einfluß findet man auch auf einigen Resten in der Kirche S. Ulrich und Afra zu Augsburg. Im Unterschied zu der niederrheinischen Einbeziehung der Glasmalerei in die Tafelmalerei muß bei den süddeutschen Glasmalereien der Spätgotik und Frührenaissance

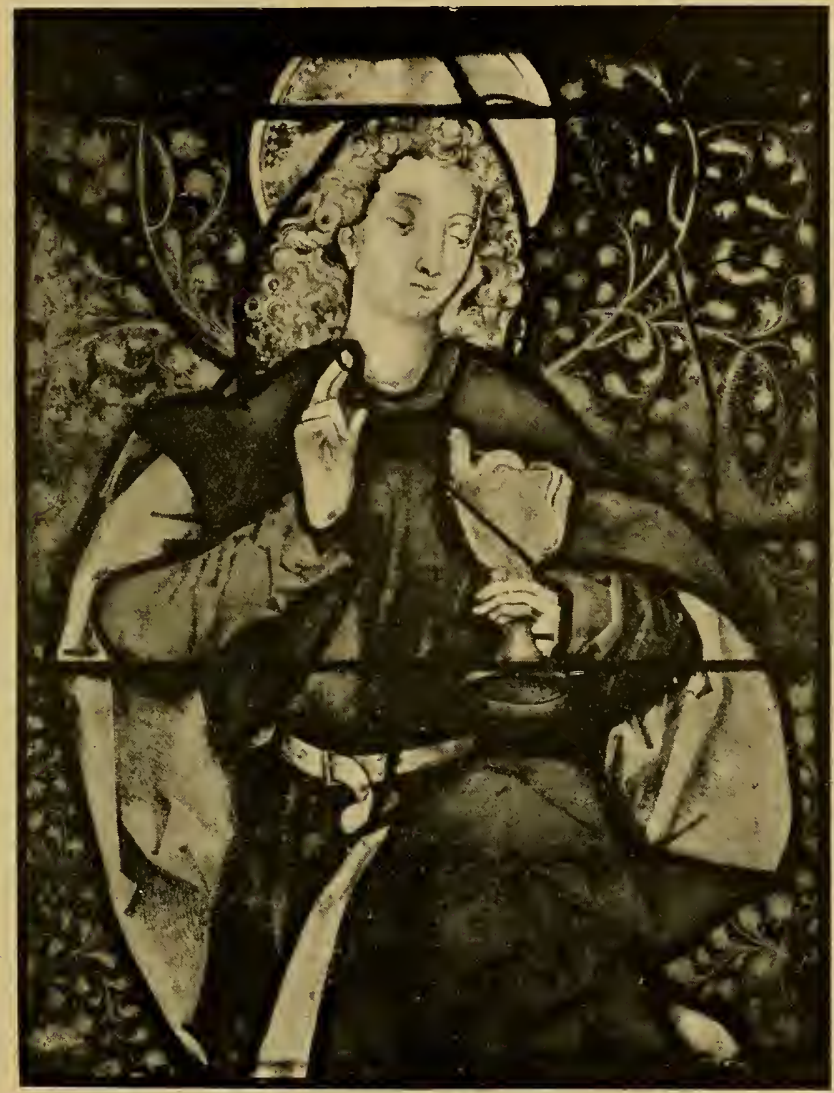

Abb. 30. Detail aus einer Scheibe mit Johannes Ev, Hans Holbein d. A. Augsburg. Nach einer Photographie von Höfle-Augsburg.

konstatiert werden, daß sie sich weit mehr glasmalerische Eigenart erhalten haben. Auch in der Provinz gab es während der Periode der Spätgotik und Frührenaissance zahlreiche Glasmaler. Franz Wolter fand in den Archivalien des Münchener Reichsarchivs viele Notizen, die auf diese Perioden Bezug haben. So sitzt zu 
Altenmarkt ein Glasmaler, der I 460- I 5.09 Bezahlungen für Glasgemälde vom Kloster Baumburg bekommt. Kloster Windberg beschäftigt den Glasmaler Achatz, Niederviehbach den „maler von Dingolfing“. Der rege Austausch zwischen Augsburg und Landshut begünstigt das Anschwellen einer zahlreichen Renaissancekünstlerschar von Glasmalern, was ebenso in den Archivalien zum Ausdruck kommt, als in dem Befund alter Denkmale. Darum ist es beispielsweise möglich, daß in der Karthause Prüll, wie in

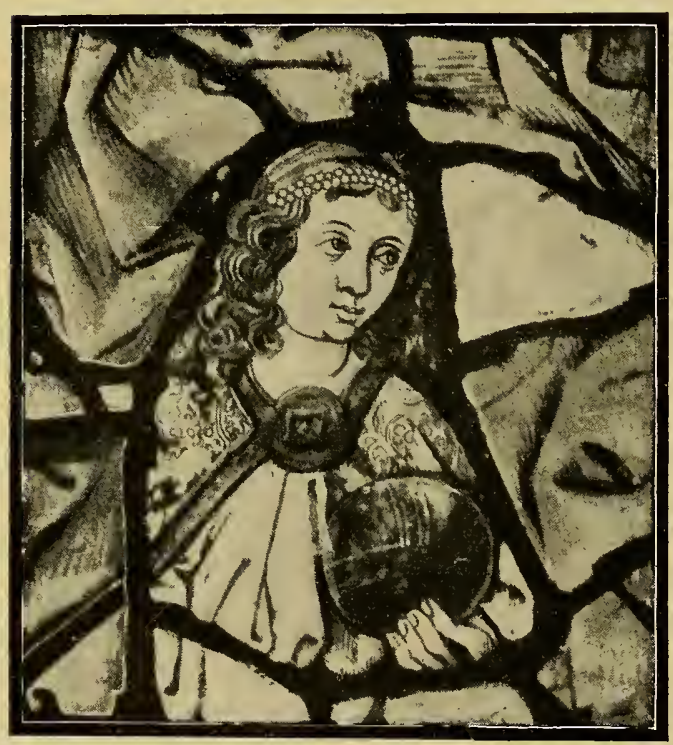

Abb. 31. Ungarisches Glasgemälde. Anfang des I 5. Jahrhunderts. der Kirche zu Tölz (Taf. 82) Glasgemälde verwandten Charakters sich finden, für die Landshut gleichmäßig in der Mitte liegt. Landshut scheint Münchens Blüte gleich nach Beginn des I6. Jahrhunderts übernommen zu haben. Der Einfluß, den die Wirkungsstätte eines Hans Wertinger, eines Hans Leinberger auf die nieder- und oberbayrische Kunst der Frührenaissance genommen hat, ist ganz bedeutend. Wahrscheinlich hat Landshut die Führung in der Glasmalerei der bayrischen Lande bis gegen Mitte des I6. Jahrhunderts innegehabt. Auch die außerdeutsche Glasmalerei machte den Übergang in die Tafelmalermanier mit, da ja alle Länder, in denen noch Glasmalereien gemacht wurden, von Frankreich, Holland und Deutschland beeinflußt waren, so insbesondere Spanien, das seine Glasmaler von den Niederlanden und der Kölner Gegend kommen lie $\left.B^{1}\right)$. In Polen wirken die Einflüsse Prags noch nach, wie der

1) Vgl. darüber A. L. Merz, Die spanische Glasmalerei, Zeitschrift für alte und neue Glasmalerei 19 I4. 


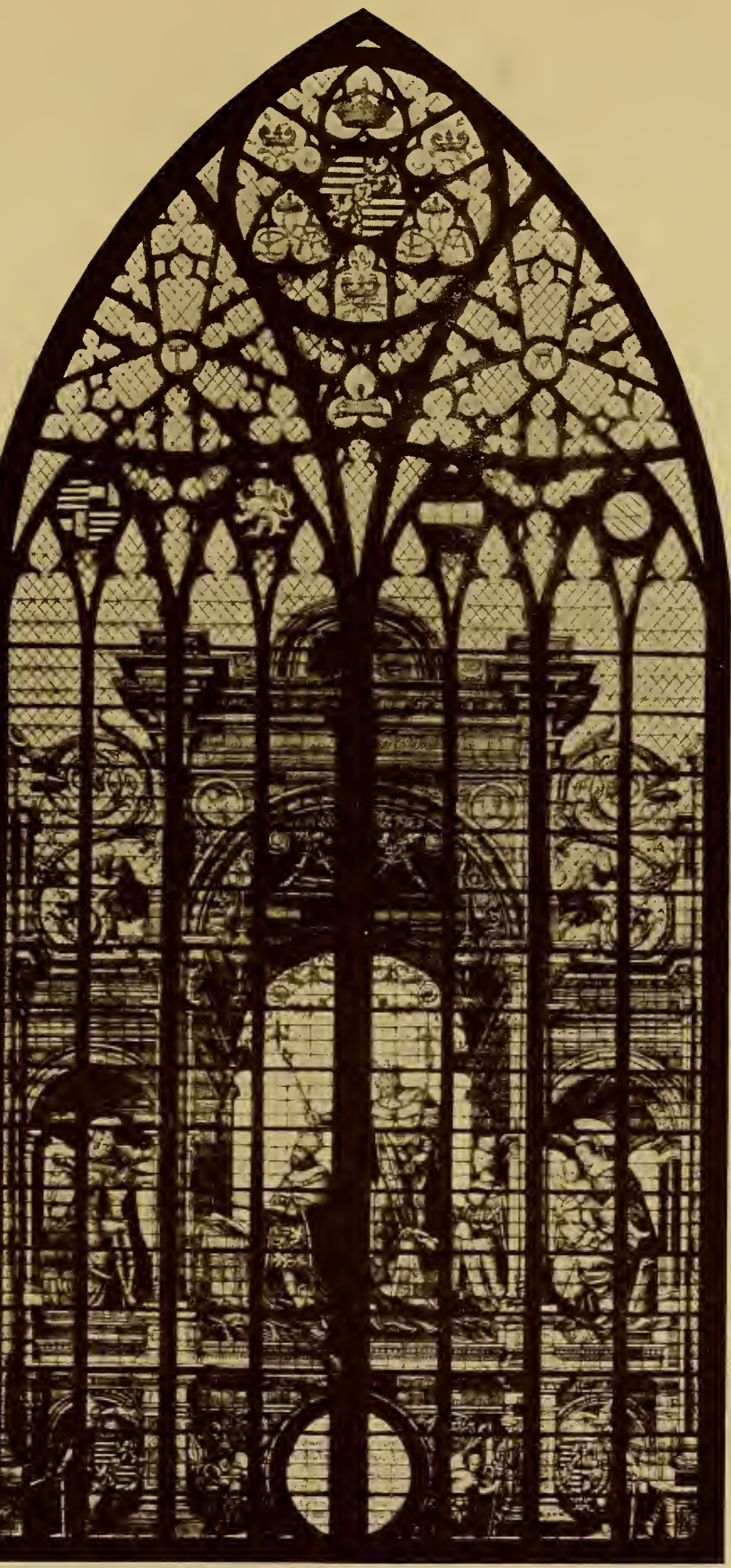

Fenster in der Kirche S. Gudule in Brüssel. 1537. 

Glasgemäldeschmuck in der Dominikanerkirche zu Krakau deutlich zeigt ${ }^{1}$ ). Ungarn wurde von oberrheinischen und niederländischen Meistern heimgesucht. Es scheint jedoch, daß Ungarn wiederholt starke Ansätze zu einer nationalen Schule hatte. Laut einer alten Chronik ließ der Erzbischof Esztergom, Csanád Telegdy, zwischen I 33I-49 das Sanktuarium des hl. Adalbert "mit kunstreichen Fenstern" ausstatten. Vom I4. Jahrhundert an scheint die Stadt Kassa in Oberungarn eine hervorragende Rolle in dieser Kunst gespielt zu haben: I365 schließt Petrus, Probst zu Lelesz, einen Vertrag mit Nicolaus, Maler zu Kassa, wonach dieser für die' Kirche $\mathrm{zu}$ Lelesz vier Fenster für IOO Goldgulden verfertigen soll. Noch in den Jahren 1562 und I 565 ersucht derErzbischof von Eger (Ungarn) wiederholt den Rat der Stadt Kassa, ihm einen Meister, der fünf bis sechs Fenster herstellen soll, zu überlassen. Erhalten blieb, bis auf die wenigen Fragmente in der Dreifaltigkeitskapelle zu Pozsony-Szent-György, nichts mehr. Die von Matthias Corvinus, König von Ungarn, in dem Schloß zu Ofen errichte-

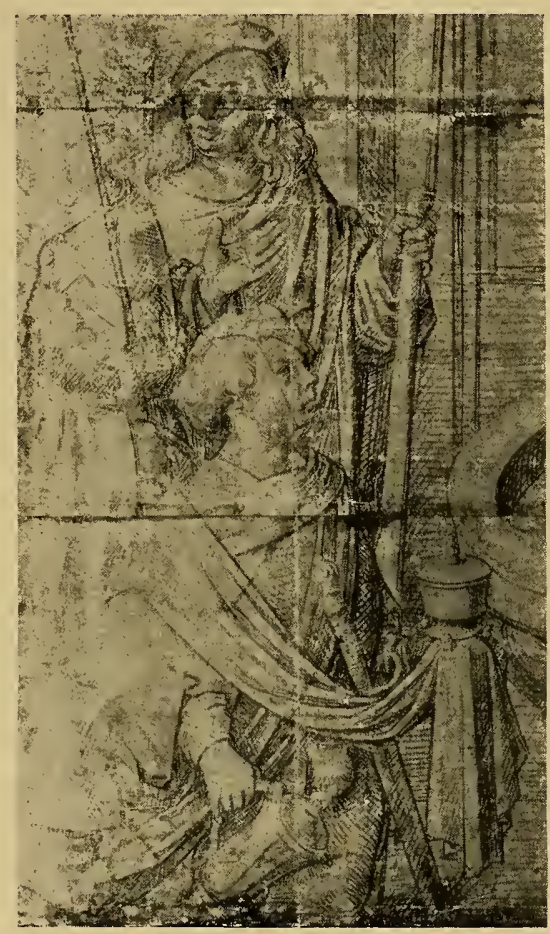

Abb. 32. Kartondetail zu den Glasgemälden in Gouda. Lukas von Leyden? ten Neubauten sollen laut Berichten von Zeitgenossen prachtvolle Fenster geziert haben. Um diese Zeit wird ein Mönch Jacobus erwähnt, der in der Diözese von Széttesfehérvár mehrere Kirchen mit Fenstern von wunderbarer Schönheit schmückte. Der Glasmaler Johann Mikó wanderte um die gleiche Zeit nach Österreich aus. Seine Arbeiten sind jetzt im

1) Kopera, Alte polnische Glasgemälde, Zeitschrift für alte und neue Glasmalerei I9I3, S. 99 ff. 
Museum der Wiener Neustadt aufbewahrt. Eine besondere Stellung nimmt die Kirche zu Aranyos-Marót ein, deren größter Bestandteil an Glasgemälden nunmehr allerdings in das ErdödySchloß übertragen ist. An ihnen läßt sich der Entwicklungsgang der ungarischen Glasmalerei ablesen: Die Schulen des I4. Jahrhunderts scheinen von Heiligenkreuz beeinflußt zu sein, während im I 5. Jahrhundert der niederösterreichische Charakter vorherrscht. Im Zeitalter der Spätgotik dringen deutsche und niederländische Einflüsse ein ${ }^{\mathbf{1}}$ ) (Abb. 3I).

\section{Die Kabinettsglasmalerei.}

\section{Die deutsche Kabinettsscheibe.}

Der Begriff Kabinettsscheibe ist heute der Ausdruck für ein von der monumentalen Glasmalerei verschiedenes kunstgewerbliches Gebiet. Sie hat sich wohl aus der Kirchenglasmalerei entwickelt und verwendet nahezu bis zu ihrem Untergang ebenfalls farbige Hüttengläser, am längsten rot und grün; allein sie folgt ganz anderen Stilgesetzen. Ein monumentales Glasgemälde ist stets für Fernwirkung berechnet. Darum soll es eigentlich nur aus Kontur und Wischen bestehen; alles Modellieren und und alle Angaben von Details lassen ein Glasgemälde, wenn wir auch nur ein paar Meter entfernt sind, bei durchfallendem Licht verschwommen und unklar erscheinen. Die monumentale Glasmalerei ist sonach gezwungen, auf eine realistische Behandlung unter allen Umständen zu verzichten und daher das Figürliche rein ornamental zu zeichnen. Anders die Kabinettsglasmalerei. Sie ist eine Nahkunst. Auch unterscheidet sie sich von ihrer größeren Schwester dadurch, daß das Glasgemälde eines Zimmers außer Beziehung zu dem Bau stehen kann, um so mehr als manches Zimmer überhaupt keinen spezifischen Charakter aufweist. Darum kann die Kabinettsscheibe Stilgesetzen folgen, die der Eigenart der Monumentalglasmalerei direkt zuwiderlaufen.

Die Kabinettsscheibe konnte erst sich voll entwickeln, als eine bedeutendere Nachfrage nach ihr vorhanden war, und das hatte wieder zur Voraussetzung, daß die Fensterverschlüsse über-

1) Vgl. Lyka, Az Üvegfestés in Raths „Az Iparmüvézet Könyve" I 905, S. 257 ff. 


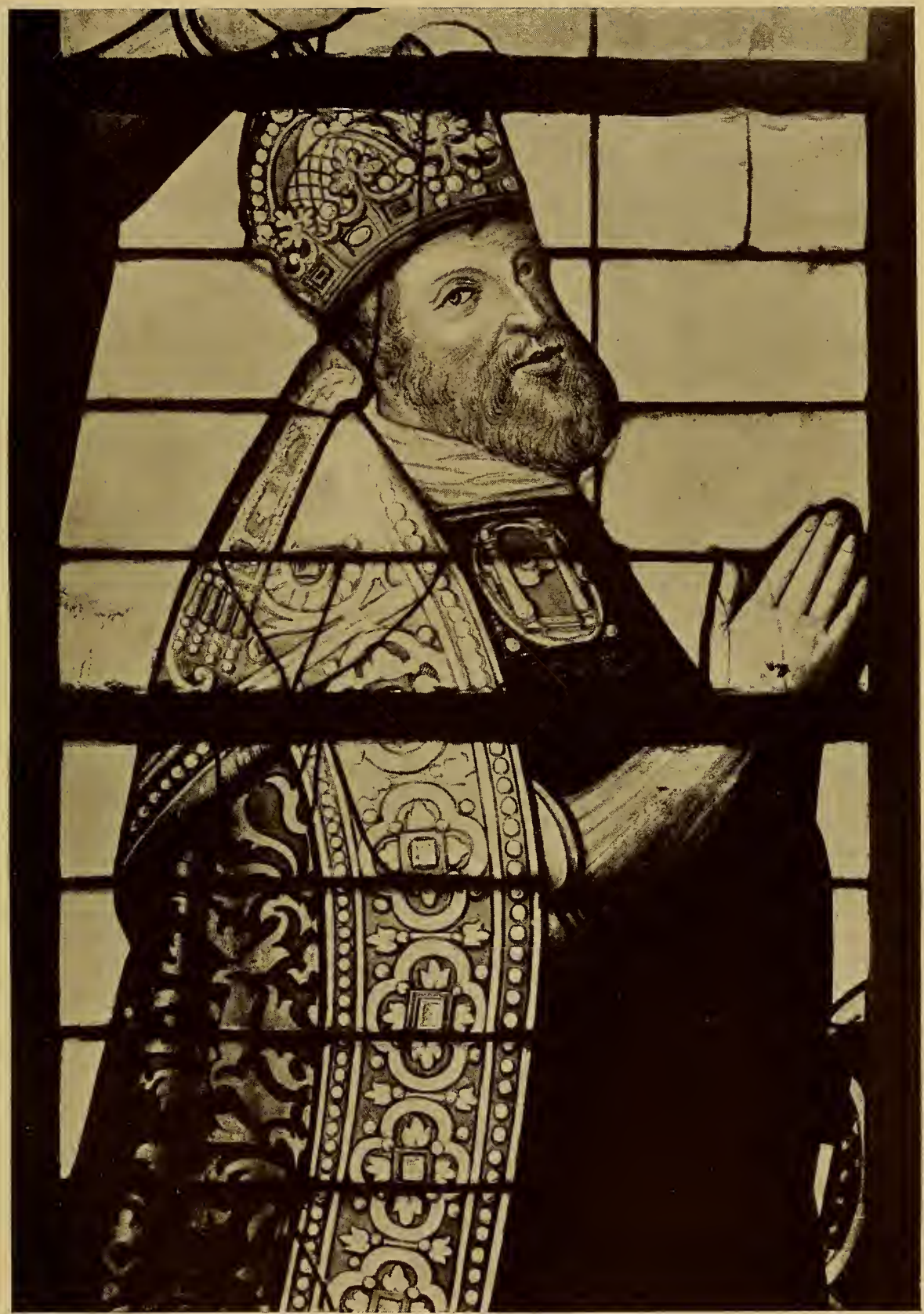

Detail aus der Abbildung Tafel 83 . 

haupt aus Glas hergestellt wurden. Die Sitte, die Fenster von einigermaßen wichtigen Räumen mit Fenster zu verschließen, läßt sich seit der Karolingerzeit ununterbrochen verfolgen. Die Fenster der Schreibstuben in St. Gallen waren, wie aus der Erzählung Ekkehards IV. hervorgeht, mit Glas verschlossen, was schon viel früher französische Äbte in der Regel für Schlafsäle anordneten. Die Zimmer und Säle der Gralsburg waren sogar mit buntgläsernem Fensterschmuck versehen. Wenn auch die Gralsburg im Land Utopia liegt, so muß die Fantasie des Dichters doch durch irgendwelche wirkliche Vorbilder angeregt worden sein. Die Dichter haben also auf jenen Burgen, die sie als Vorlage für die Schilderung Montsalvats nahmen, unter anderem Schmuck auch bunte Glasfenster gesehen. Im Jahre I 340 besaßen die Handwerkerknechte der Grautücher und Rebleute im Spital zu Basel eine Bettstelle mit einem Glasfenster darüber. Wenn nun auch noch in der Mitte des I 5. Jahrhunderts in einer, jedem Kultur- und Kunstfortschritt so offen daliegenden Stadt wie Basel, Teppiche und Papier zu Fensterschlüssen verwendet werden, so mag das für wenig wichtigere Räume und für ärmere Leute gegolten haben und ist ebensowenig ein Beweis gegen die in Blüte gekommene Sitte der Fensterverglasung, wie die Tatsache, daß noch heute in zahlreichen ärmeren Landgemeinden Italiens Ölpapier als Fensterverschluß benützt wird, den gläsernen Fensterverschluß auch im wärmeren Süden beeinträchtigt. Nach Lehmanns gründlichen Forschungen kann man die Wende des I 4. Jaḥrhunderts als die Zeit bezeichnen, in der der gläserne Fensterverschluß bei den einigermaßen vermöglicheren Bürgern in allgemeine Verwendung kam. Die Konzilien zu Konstanz und Basel haben das Wachsen und Erstarken der Sitte beschleunigt, so daß am Ober- wie Niederrhein seit etwa I420 jedes vornehme Haus mit gläsernem Fensterschmuck ausgestattet sein mußte. Wie wir aus den Miniaturen und Kupferstichen zu erkennen vermögen, waren die Fenster niemals mit kunstlosen, quadratischen oder rechteckigen Scheiben verschlossen; sie bekamen vielmehr von Anfang an Musterung in Anlehnung an die alte, dekorative Aufgabe des Glases. Am beliebtesten war das Rautenmuster, das dem vertikalen Streben der gotischen Bauart am besten entsprach. 
Über die Anfänge der Kabinettsscheibe herrscht noch keine völlige Klarheit. Denn die auf 1437 datierte Rundscheibe aus Lindau, die sich nach Angabe von Schmitz im Besitze eines Münchner Antiquars befinden soll, kann selbstverständlich nicht als Kabinettsscheibe angesprochen werden, ebensowenig wie das Medaillonfenster zu Althann oder gar die Serie von Rund-

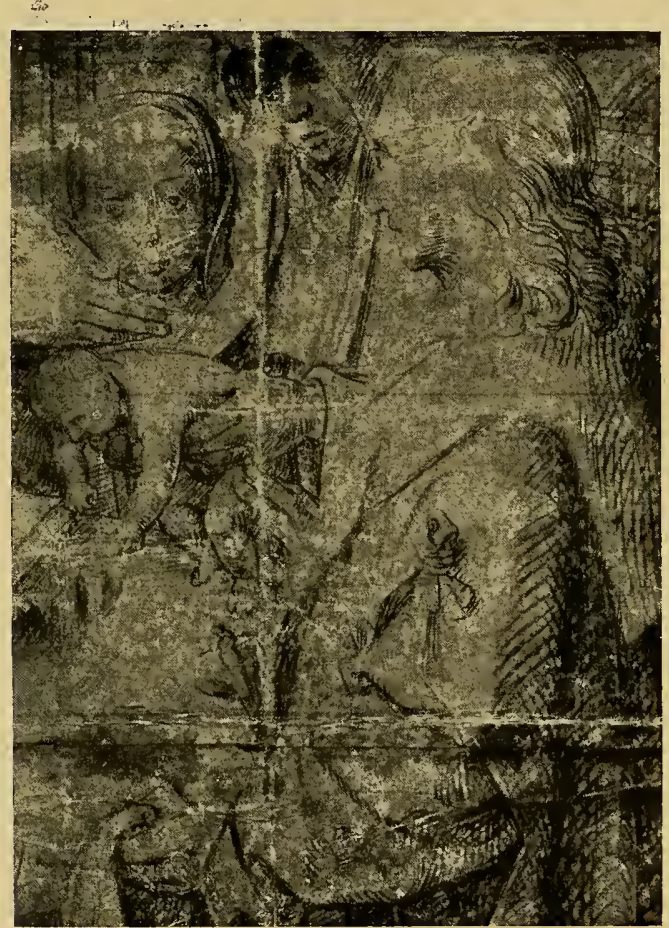

Abb. 33. Karton zu den Glasgemälden in Gouda. Lukas von Leyden(?). scheiben, die sich im Schloß zu Erbach befinden. Diese Rundscheiben sind in monumentaler Arbeit hergestellt, die ersteren im Charakter der Isenmannschule, dieletzteren nach Art Hans Wilds. Ihr verhältnismäßig kleiner Durchmesser $(38 \mathrm{~cm})$ mag mit der Verkleinerung der Fenster in der Spätgotik, insbesondere für Landkirchen, zusammenhängen. Die Sujets der noch vorhandenen nichtheraldischen Kabinettsscheiben zeigen, daß dieSitte, kleinere Räume mit einer oder mehreren Kabinettsscheiben zu schmücken, über Sakristeien, Spitäler und sonstige gemeinnützige Häuser ihren Weg ins Bürgerhaus genommen hat. Die ungemein häufigen Wappenscheiben sind direkte Abkömmlinge der Stifterscheiben in großen Kirchenfenstern.

Im Stil hat sich die Kabinettsglasmalerei im Kupferstich gefunden. Die blühende Werkstatt, fast könnte man sagen, Industrie, die am Oberrhein die zahlreichen Kupferstiche für Einzelblätter und für Illustrationen von Büchern schuf, gab den 


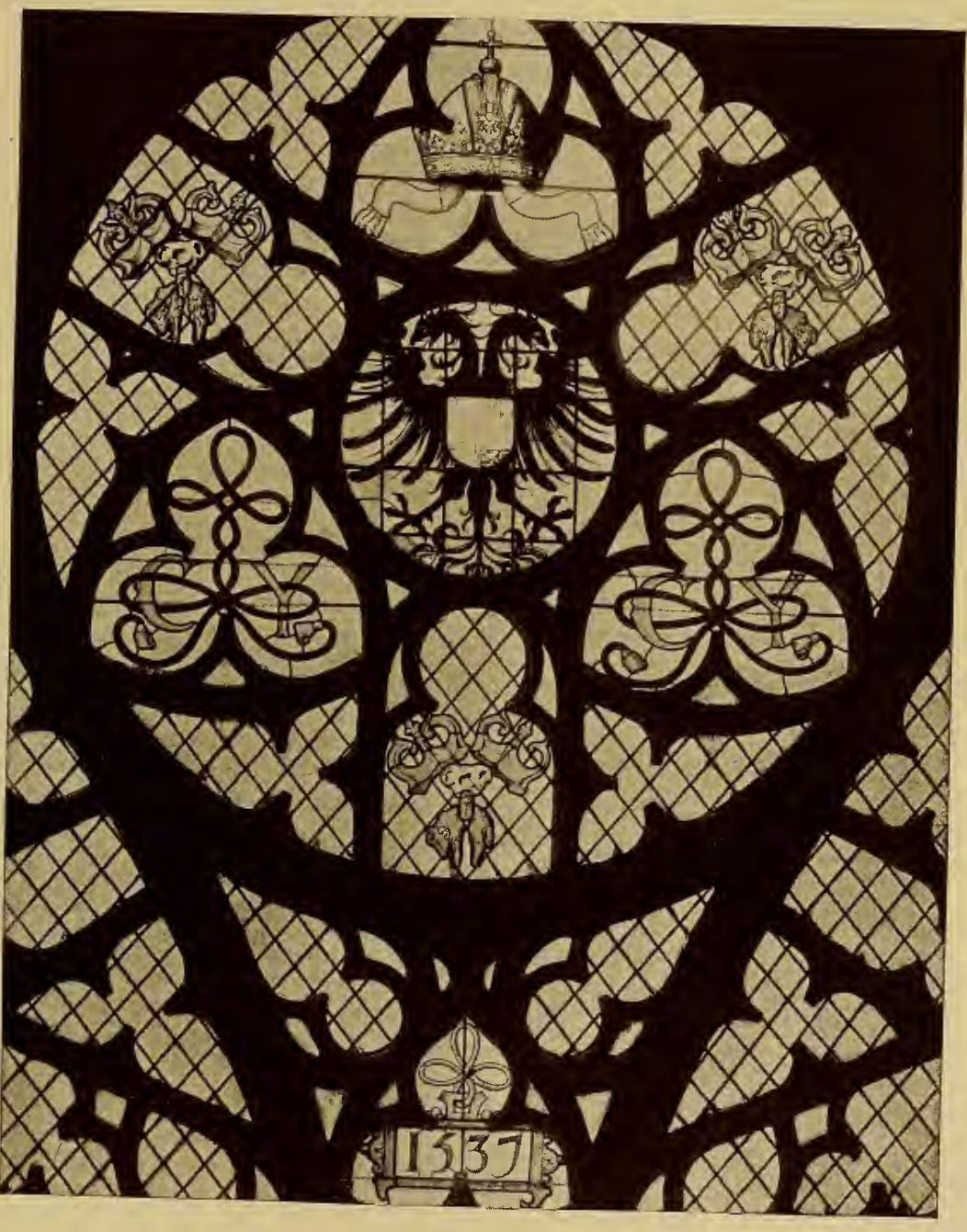

Detail aus der Abbildung Tafel 83 . 

Glasmalern eine Menge von Vorlagen, die man mit geringen Änderungen, ja manchmal direkt wörtlich auf Glas übertrug. Die Erfindung der Schwemmfarben begünstigte die Entwicklung des Kabinettsstils. Von der monumentalen Glasmalerei hatte man das Schwarz- und Rotlot, das Silbergelb, den roten und blauen Überfang übernommen. Damit konnte man bereits sehr viel erreichen. Aber es war immer mühsam, den Überfang auszuschleifen, und zu Farbunterschieden bedurfte es der trennenden Bleie, die für kleine Scheiben eine zu starke Kontur bildeten. Die Schwemmfarben boten daher ein willkommenes Hilfsmittel. Am Niederrhein verlor. sich auch die Kabinettsscheibe sehr bald in völlige Abhängigkeit von der Tafelmalerei und bereits im Anfang des 16. Jahrhunderts trat daselbst eine solche Anarchie der glasmalerischen Stilprinzipien ein, daß die niederländische Glasmalerei nur mehr den Namen des Glasmalerischen hat. Für die Geschichte der niederländischen Malerei bieten sie einen nicht uninteressanten Beitrag, umsomehr als ihre Bestimmung nach Meistern bei dem Zurücktreten des Glasmalers keinerlei Schwierigkeiten macht. Auch können sie durch die lustigen Farbenreize die Aufmerksamkeit fesseln, namentlich wenn es sich um Arbeiten nach Goltzius handelt, der übrigens selbst Glasmaler gewesen ist. Die Schweizer- und süddeutsche Kabinettsglasmalerei hat, trotzdem auch sie von den Kupferstichen und Handzeichnungen berühmter Meister lebte, weit mehr glasmalerisches Gefühl behalten, als die ebengenannten Niederländer.

Der Kupferstich und die Stifterscheibe in Kirchenfenstern bilden also die Quellen für die Kabinettsglasmalerei. Darum hat die vom Kupferstich beeinflußte Richtung am ehesten auf die Verwendung von farbigem Hüttenglas verzichtet und sich gerne auf Schwarzlot und Silbergelb beschränkt. Diese Richtung hatte ja keine Resonanz in der monumentalen Glasmalerei und sproßte als selbständiger Zweig am Baume der allgemeinen Kunstentwicklung hervor. Jene Gruppe aber, die aus der Stifterscheibe entstanden ist, bewahrte bis ins I8. Jahrhundert ihren Zusammenhang mit der monumentalen Glasmalerei, indem sie für Rot, Blau und Rotviolett, Grün bei Architekturteilen fast immer, bei Hintergründen in der Regel das farbige Hüttenglas in Anwendung brachte. Die Kabinettsscheibe scheidet sich da- 
her von selbst in zwei Teile, in die reine Kupferstichmanier, die auf Grisaillen sich auswirkt, und in die monumentalisierende Kabinettsscheibe, die zwar für die Oberlichten den Kupferstich

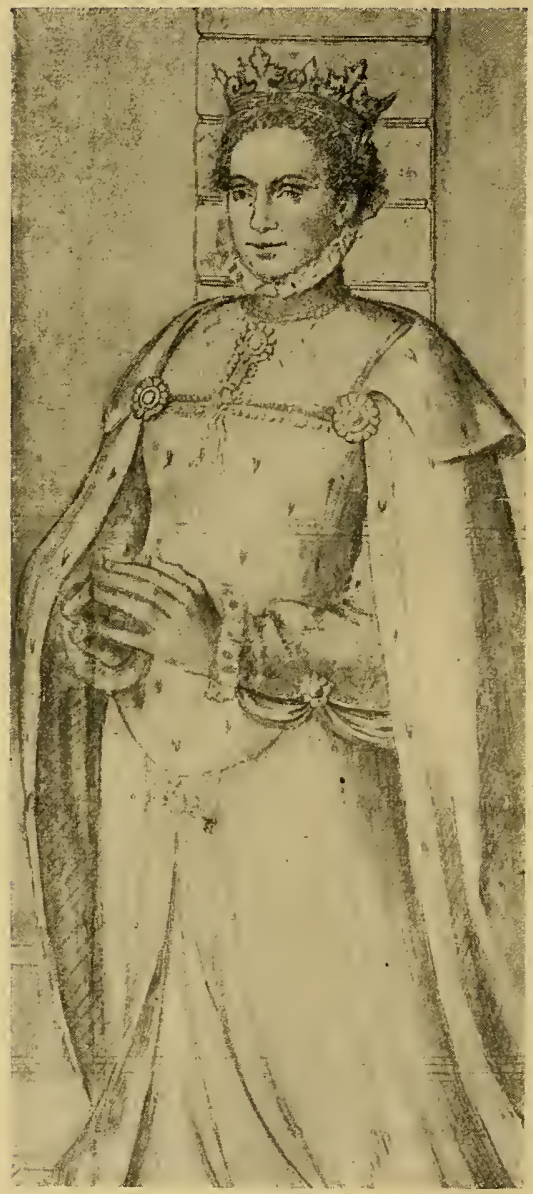

Abb. 34. Karton zu einem Glasgemälde von W. Crabeth (1543-1595).

beizieht, für den größeren Teil der Scheibe aber aus dem Formenvorrat der glasmalerischen Tradition schöpft, die selbstverständlich der Kleinaufgabe, ein Zimmer, ein Kabinett zu schmücken angepaßt ist.

Die reine Kupferstichmanier nimmt am Oberrhein ihren Ausgangspunkt. Der Meister E. S., Martin Schongauer, der Meister des Hausbuchs und deren Schulen sind die fruchtbarsten Vorlagenwerke für die Glasmaler geworden (Abb. 35, 36.) Auf den Hausbuchmeister geht vor allem ein System zurück, das sich über ganz Süddeutschland erstreckt und außerordentliche Verbreitung hat, nämlich die sogen. Vierpaßscheibe. $\mathrm{Ob}$ derHausbuchmeister diese sehr schöne Form aus den Niederlanden bekommen hat, kann nicht festgestellt werden. Um 1420 auf 1430 haben sich in Basel verschiedene Meister mit graphisch gehaltenen Visierungen für Kabinettsscheiben beschäftigt. Paul Ganz hat die einzelnen in Basel noch vorhandenen Blätter publiziert ${ }^{1}$ ). Es ergibt sich daraus, daß der Hausbuchmeister direkt an die oberrheinische Schule anknüpft. Das

1) Handzeichnungen schweizerischer Meister des 15. bis I $\$$. Jahrhunderts, Basel. 


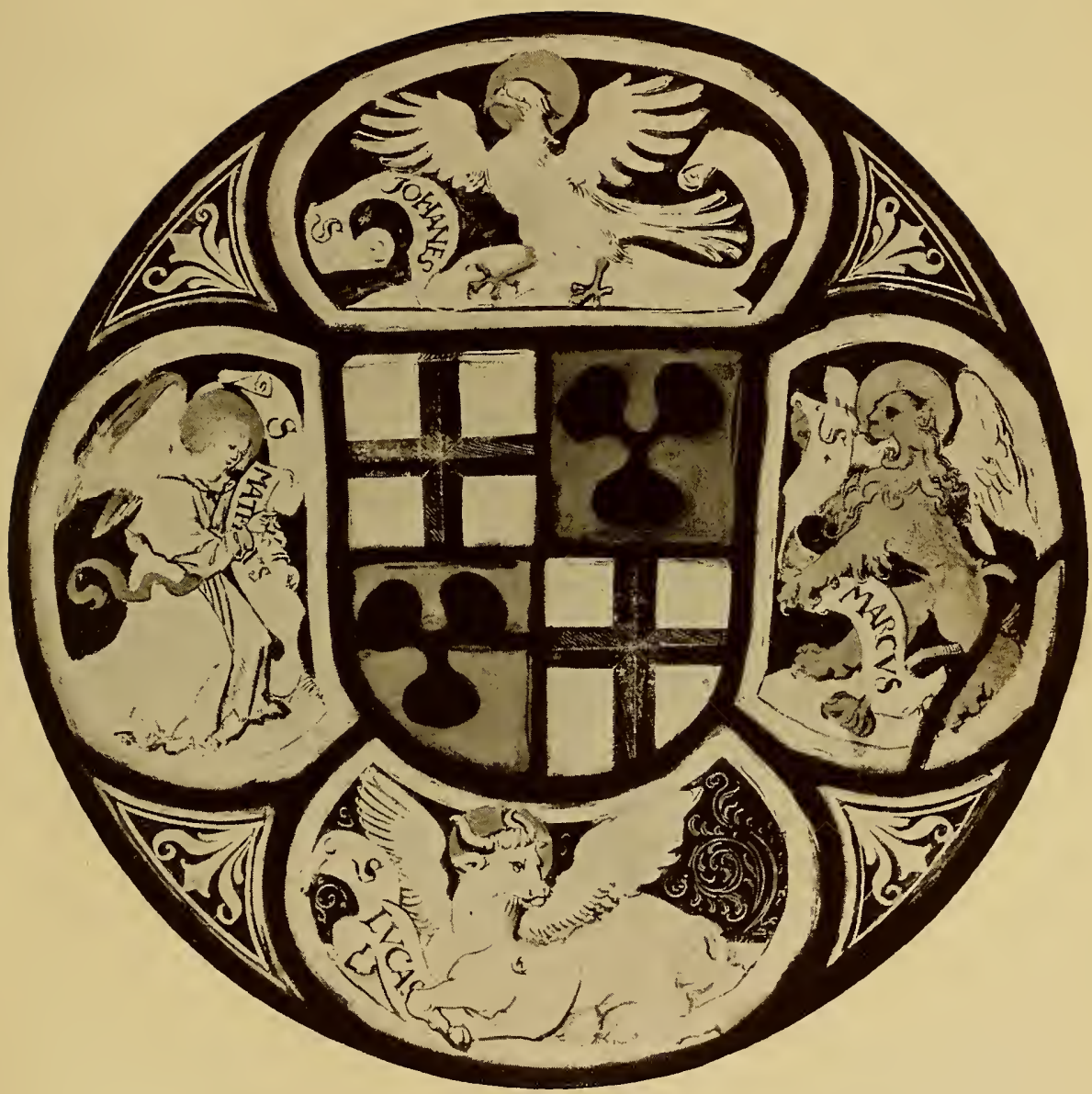

Vierpaßscheibe des Deutschmeisters Dieter von Cleen. Um I 525. Nürnberger Arbeit. 

System der Kabinettsrundscheibe scheint indes erst durch den Hausbuchmeister in Blüte gebracht worden zu sein. Fast ein halbes Jahrhundert läßt sich sein Einfluß verfolgen; zu den frühesten Vierpaßscheiben gehören zwei Scheiben der Schweizer Geschlechter Dittlinger (Schweizerisches Landesmuseum zu Zürich), der Grafen von Wartenberg (Schloß Erbach). Auch die Baldungwerkstatt hat die Vierpaßscheibe, deren Beliebtheit jede Werkstatt zur Kopie zwang, nicht vernachlässigt. In Nürnberg wurde sie von

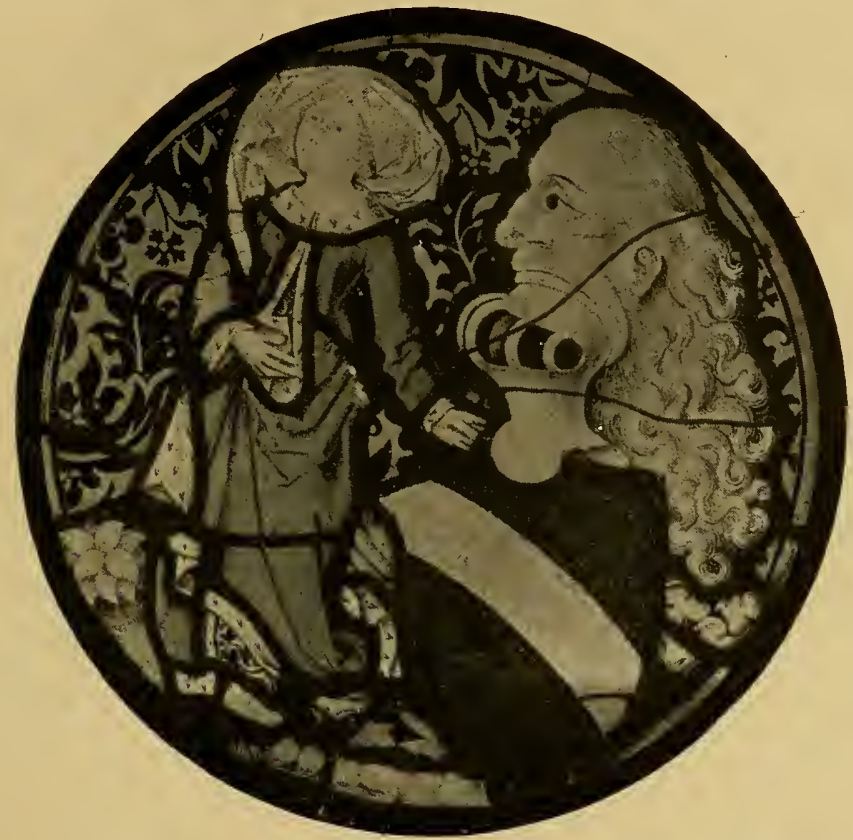

Abb. 35. Scheibe mit dem Wappen von Matzenheim. Dem Hausbuchmëister nahestehende oberrheinische Werkstatt. Um I 480 .

der Dürerschule gepflegt, wie der reiche Bestand des Kgl. Kunstgewerbemuseums in Berlin an solchen Scheiben zeigt. In einer großen süddeutschen Sammlung befinden sich zwei erlesene Vierpaßscheiben der Ordenskomture und Meister des Deutschritterordens Johann Adelmann von Adelmannsfelden (1 5 IO-15 I5) und Dieter von Cleen (I515-I526). Die eine von ihnen haben wir auf Tafel 86 abgebildet. Die andere wird in einer demnächst erscheinenden Monographie über die betreffende Sammlung veröffentlicht werden. Die beiden Scheiben gehören nach Franken, 
vermutlich in die Schule des H. S. Beham. Von dem Wappen abgesehen, das wegen des Wappenbildes (rotes Kleeblatt in weiß), Hüttenglas beiziehen muß, ist alles in Schwarzlot und Silbergelb gehalten und zwar derart, daß die Umrisse der Figuren nicht konturiert, sondern ausradiert sind. In Augsburg verschmäht es auch ein Jörg Breu nicht, im Vierpaßsystem zu entwerfen. Der Schreiber dieser Zeilen konnte eine Wappenscheibe des Bischofs Friedrich von Augsburg aus dem Hause der Hohenzollern bekannt machen (aus dem Jahre I 504), die sich in Schloß Füssen befindet. Sie ist, wie leicht ersichtlich, in der Art Jörg Breus gehalten. Jörg Breu hat im übrigen sein eigenes System gebildet, die Szenen-Monolithscheibe mit Schwarzlot und Silbergelb mit ornamentiertem Rand aus farbigem Hüttenglas. Es gab zwar schon vor Jörg Breu runde Monolithscheiben mit farbigem Rand. Allein sie enthielten lediglich Einzel-(Heiligen-) Figuren im Stil der Schongauerschule. Auch könnte es den Anschein erwecken, als sei Nürnberg mit dem System der szenischen Rundscheibe vorangegangen, nachdem Professor Becker ${ }^{1}$ ) eine Reihe von kleinen Scheibenrissen aus der Nähe des Michel Wolgemut veröffentlicht hat. (Taf. 87). $\mathrm{Ob}$ man es bei diesen Zeichnungen mit Visierungen in Originalgröße (Kartons), oder nur mit Werkzeichnungen (Skizzen) zu tun hat, ist gerade bei diesen Arbeiten schwer zu entscheiden. Professor Becker neigt in seiner verdienstvollen Publikation offenbar der ersteren Annahme zu und stellt die Abhängigkeit des Meisters dieser Visierungen vom Meister des Hausbuches fest. Im ganzen sind es Io Risse, von denen zwei weltlichen Inhalt: Aristoteles und Phyllis, ein Liebespaar, aufweisen. Durch die Publikation des Risses für eine Vierpaßscheibe vom Meister des Hausbuchs hat Becker ${ }^{2}$ ) die Frühzeit der Kabinettsrundscheiben graphischen Charakters wesentlich geklärt. Vom Oberrhein (Basel) ging die Sitte aus, Szenen profanen Inhalts im Stich und in dem von ihm abhängigen Scheibenriß festzuhalten. Der Meister des Hausbuchs hat diese Sitte zur größten Entfaltung gebracht. Von ihm ist der ganze Süden

1) Eine Folge großer Scheibenrisse aus der Nähe Wolgemuts. Zeitschrift für alte und neue Glasmalerei 1912. S. 95.

2) Zeitschrift für bildende Kunst, Juni Heft I9I2. 


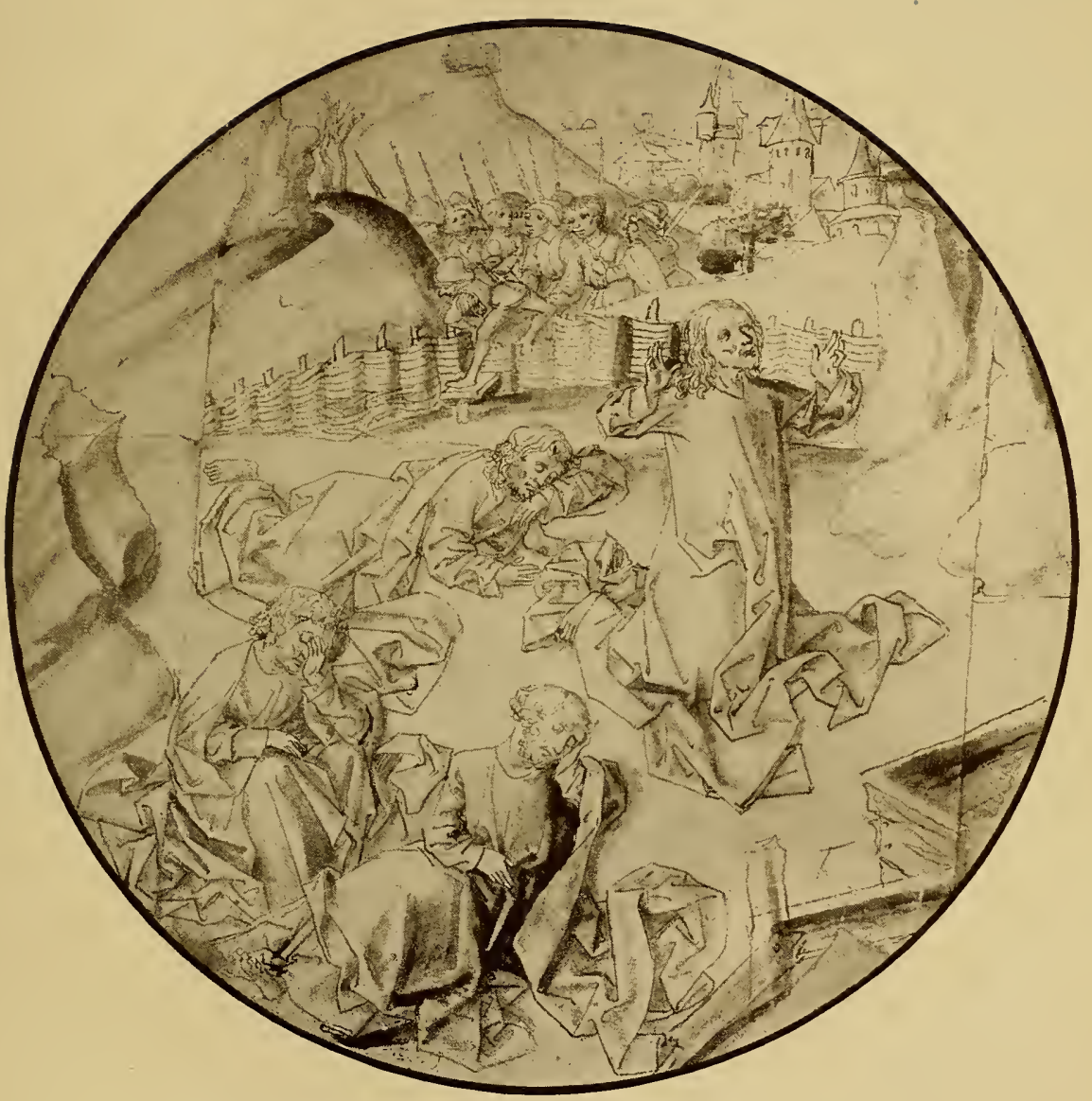

Scheibenriß eines fränkischen Meisters um I 480. 

Deutschlands beeinflußt. Was der Hausbuchmeister in seinen Vierpaßscheiben unternahm, das hat Jörg Breu auf der Monolithscheibe durchgeführt. Was in Nürnberg unter der Einwirkung der oben genannten Scheibenrisse an Rundscheiben in der Art Jörg Breus entstanden, ist jedenfalls verschwindend gegen die Bedeutung, die das Werk Jörg Breus für die Monolithscheibe profanen Inhalts hat. 1502 wurde Jörg Breu Meister und arbeitete so neben seinem Lehrer Hans Burgkmair. Denn auch

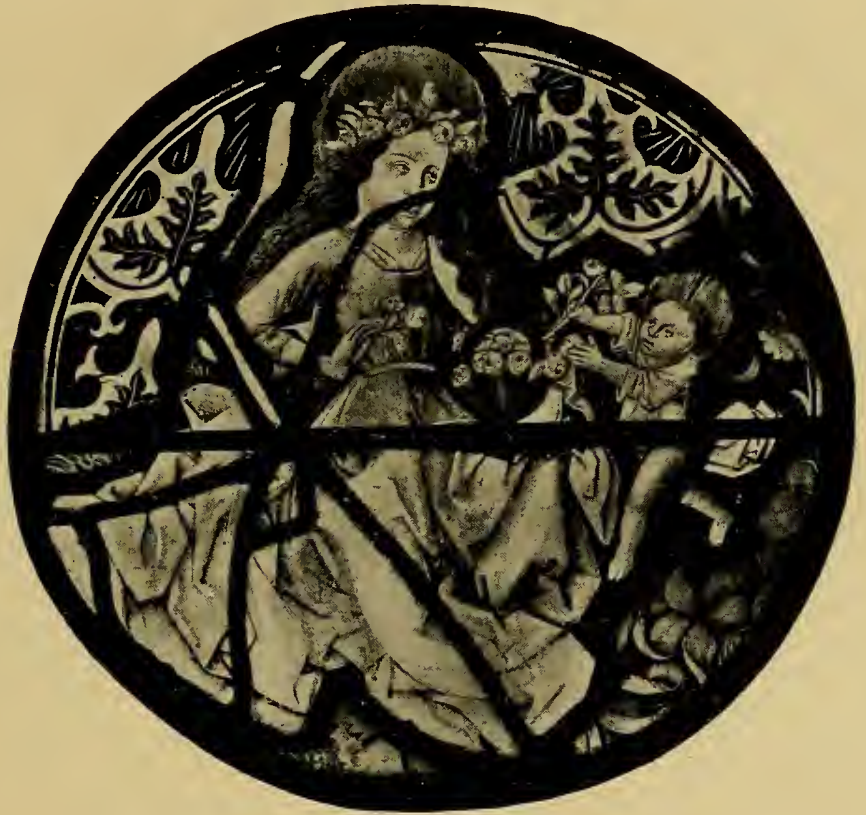

Abb. 36. Rundscheibe aus einer oberrheinischen Werkstatt um 1490.

dieser entwarf Visierungen für Glasmaler. Im Baumeisterbuch der Stadt Augsburg heißt es zu dem Jahre 15 I5: „item I 5 Pfund dem Burgkmaier maler umb Visier zue glesern". Diese "gleser" wurden zum Teil wohl von dem statglaser Hans Braun gemacht, der im gleichen Jahre „24 Gulden umb die fünf gleser“ in die „neuen Stuben des rats" erhält. Aus dem Jahre 1504 stammt die schon genannte Vierpaßscheibe für den Bischof von Augsburg. Nun treten im vorhandenen Material große Lücken auf. Wir hören, daß Kaiser Maximilian I. im Jahre I 5 I6 eine Anzahl 
"geschmelzte Scheiben“ für sein Jagdschloß in Leermoos an der bayrisch-tirolischen Grenze bei dem Hofmaler Hans Knoder bestellt. Die Visierungen dazu hat, wie Stiaßny nachweist, Jörg Breu gezeichnet. Hans Knoder, der Schwager des „Hoffmallers Florian Gumpolt aus Augsburg“ war eigentlich Maler, stammte wohl aus Tirol und war bis 1522 in Augsburg. Er scheint es weder als Maler noch als Glasmaler zu etwas gebracht zu haben. Wenigstens beauftragt Maximilian seinen Rechnungsbeamten Hans Bomgartner "seinem hofmaler hannsen Knoder I 5 guldin rheinisch und ain unserer Hofwinterclait zu geben, so wir ime zu bezahlung seiner schulden und aus Gnaden verordnen “. Neben Knoder sind Hans Thoma und Hans Braun in Augsburg tätig; letzterer bekommt seit I5I9 bis zum Jahre 1553 Zahlungen für Glasgemälde und zwar für den neugebauten Saal in der Burg zu Innsbruck (1539) und 224 fl. für „I 3 stugg geschmelzten glas in die new erbaut khirchen im schlosz zu linz". Man sieht die weiten Beziehungen Augsburgs $\mathrm{zu}$ den tirolischen und österreichischen Landen. Daher rührt es wohl auch, daß sich im Museum zu Salzburg mehrere Scheiben befinden, die unverkennbar Augsburger Ursprung verraten. Wenn die noch erhaltenen Hauptarbeiten Jörg Breus, die 12 Scheiben aus der „Geschichte Josefs", die sich im Nationalmuseum zu München befinden, und zum erstenmal von Joh. Schinnerer als Werke Jörg Breus erkannt worden $\operatorname{sind}^{1}$ ), die vier Scheiben des Berliner Kunstgewerbemuseums aus der letzten Zeit Breus stammen, so sind sie wohl von Hans Braun ausgeführt worden (Tafel 88 u. 89). In den Räumen des "Hist. Vereins für Schwaben und Neuburg“ zu Neuburg befinden sich ebenfalls noch einige Arbeiten im Stil Jörg Breus. Unter der Einwirkung dieses Meisters hat sich in Augsburg die an breiter Behaglichkeit und schwäbischer Erzählungslust reiche Szenenmonolithscheibe entwickelt, die trotz der perspektivischen Verschiebungen noch ein großes Maß Flächigkeit bewahrt und darum, im Gegensatz zu den niederrheinischen Glasgemälden, den Zusammenhang mit den alten Traditionen erhalten hat. Dadurch, daß diese Rundscheiben vorwiegend en grisaille her-

1) Katalog der Glasgemälde des Bayr. Nationalmuseums München, S. 38. Scheibenrisse von Jörg Breu, Zeitschr. f. alte und neue Glasmalerei I912, S. 59. 


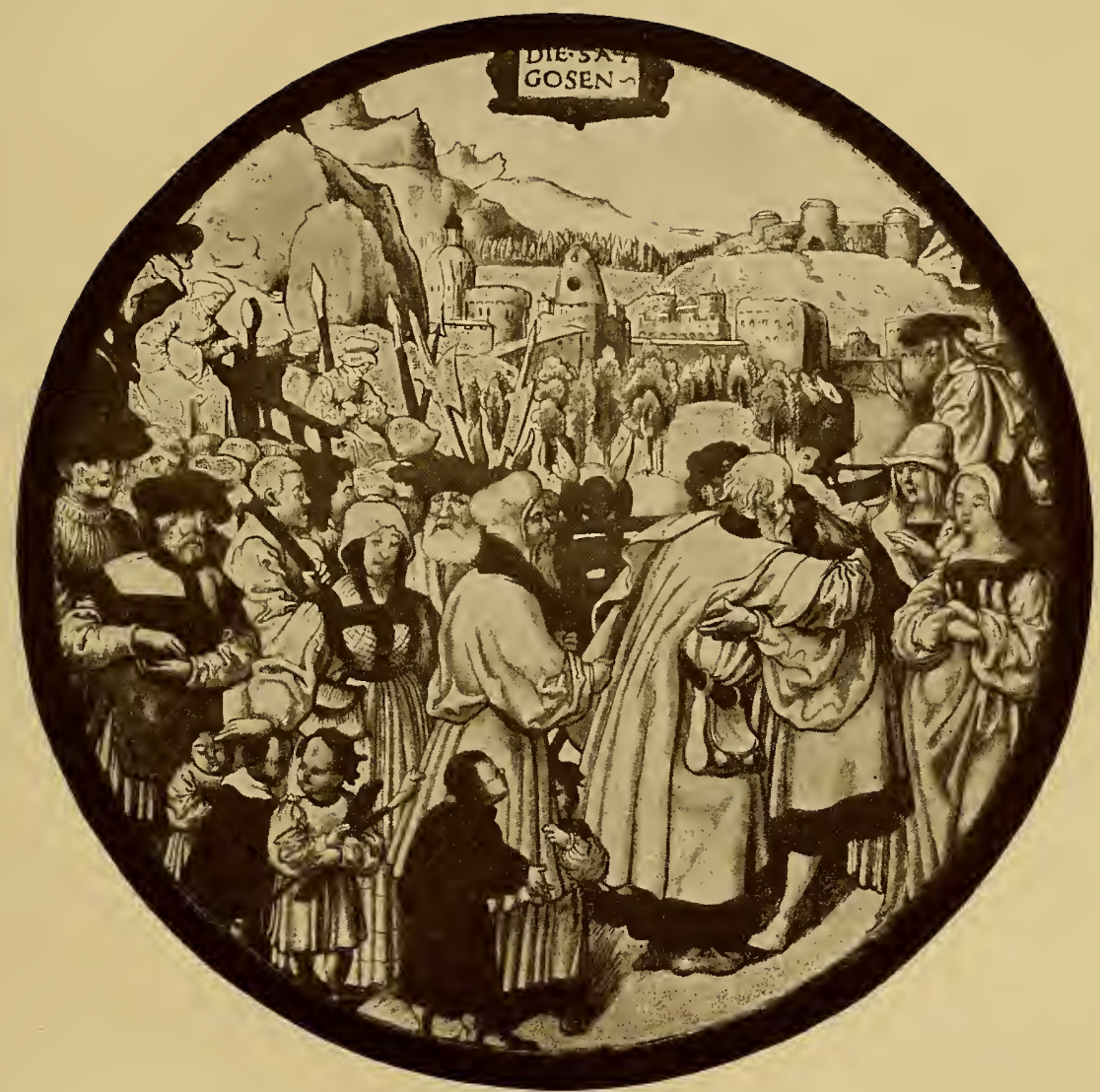

Rundscheibe nach einem Riß von Jörg Breu, vielleicht ausgeführt von dem Glasmaler Hans Braun in Augsburg. München, Bayrisches Nationalmuseum. 

gestellt wurden, blieb ihre Zeichnung wie Ausführung mehr linear. Dieser Charakter erhält sich auch in dem überreichen architektonischen Beiwerk, das, trotz seiner Perspektiven, niemals dem Glasmalerischen zuwiderläuft. Was Jörg Breu vor seinen Nürnberger Kollegen (siehe die Turnierscheibe M. M. 162 des Germanischen Museums um I5IO, zu der übrigens jüngst das Pendant aufgetaucht sein soll) auszeichnet, ist die meisterhafte

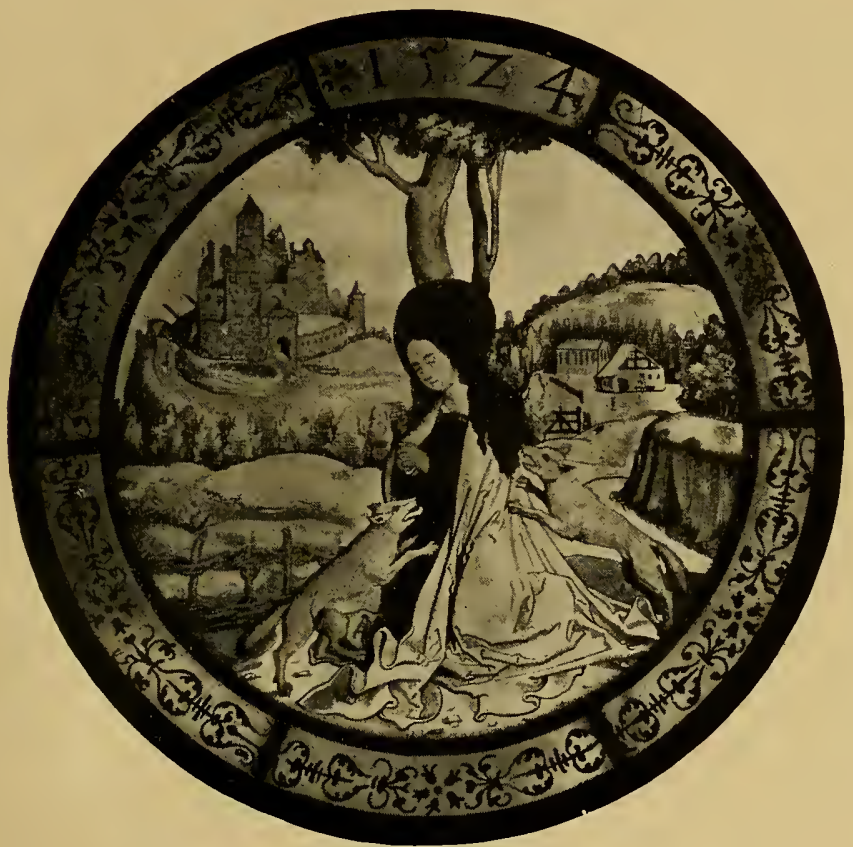

Abb. 37. Rundscheibe mit der hl. Radegundis. Salzburg, datiert I524.

Komposition, die ideale Verbindung des Figürlichen mit dem Raum und die Füllung der ganzen Scheibe mit Inhalt. Demgegenüber haben die Nürnberger große Vorder- und Hintergründe, es gelingt ihnen nicht recht, den Hintergrund, überhaupt den Schauplatz der Szene in lebendigen Zusammenhang mit den handelnden Menschen zu bringen. Mit Jörg Breu hat die graphisch gehaltene Rundscheibe ihren höchsten Stand erreicht, dem in Augsburg niemand mehr, in Nürnberg nur die Scheibenfolgen "Biblische Historien" und die "Lebensalter" nach Stichen Behams 
bzw. Jost Ammans (beide Zyklen im Berliner Kunstgewerbemuseum) gleichkommen. Von ebenfalls graphisch gehaltenen viereckigen Monolithscheiben, die im Charakter der Zeichnung und Ausführung natürlich mit den Rundscheiben völlig übereinstimmen, ist nicht mehr viel erhalten. Die vier Scheiben des Berliner Kunstgewerbemuseums, die nach Behams Stichen gemalt wurden (Schmitz, Taf. 44) sowie zwei Scheiben nach derselben Kupferstichserie in Schloß Friedrichshafen, können als Beispiele gelten. Wenn man sie mit den Rundscheiben der Alexiuslegende (Kölner Arbeiten gegen I 520), mit den Rechteckscheiben des Jan Scoreel von Utrecht um I 530 (Schmitz, Taf. 23, 25) vergleicht, fällt der Unterschied zwischen Niederrhein und den süddeutschen Glasmalereien deutlich in die Augen. Den Süddeutschen lag die große glasmalerische Tradition im Blut, die sie das Verwandte im Kupferstich fühlen und nachahmen ließ; die in Köln und den Niederlanden überließen sich willig den Tafelmalern mit den weichen Linien, schattierten und mattierten Tönen und runden Formen.

Daß die zweite Gruppe von Kabinettsscheiben, die Wappenscheiben, von der monumentalen Glasmalerei abstammen, beweist am besten eine Wappenscheibe des Abtes Adam von S. Peter, auf dem Schwarzwald, aus dem Jahre I 544, die sich in badischem Schloßbesitz befindet. Gleich auf den ersten Blick erkennt man ihren Zusammenhang mit der BaldungRopsteinwerkstatt in Straßburg-Freiburg. Nicht nur der Stil beweist diesen Zusammenhang, sondern auch verschiedene Einzelheiten, so der stark damaszierte Hintergrund, die ornamentale Umschrift und die Ausführung der Heiligenscheine. Das sind Traditionen der monumentalen Glasmalerei in der Baldung-Ropsteinwerkstatt. Auch die prachtvollen Wappenscheiben aus Heiligkreuzthal, die von P. Ansgar Pöllmann dem Meister von Meßkirch, Jerg Ziegler, zugeschrieben werden, sind ein deutlicher Beweis. Aus der Baldung-Ropsteinwerkstatt sind nur mehr wenige Scheiben bekannt. Das System der Wappenscheibe hat sich vom Oberrhein und der Schweiz aus entwickelt: architektonisches Grundprinzip (Schrifttafel als Basis, säulengetragener Bogen, der als Fries ausgebaut wurde, großes zentrales Hauptfeld gleich einem großartigen Portal) und Gliederung des Wap- 


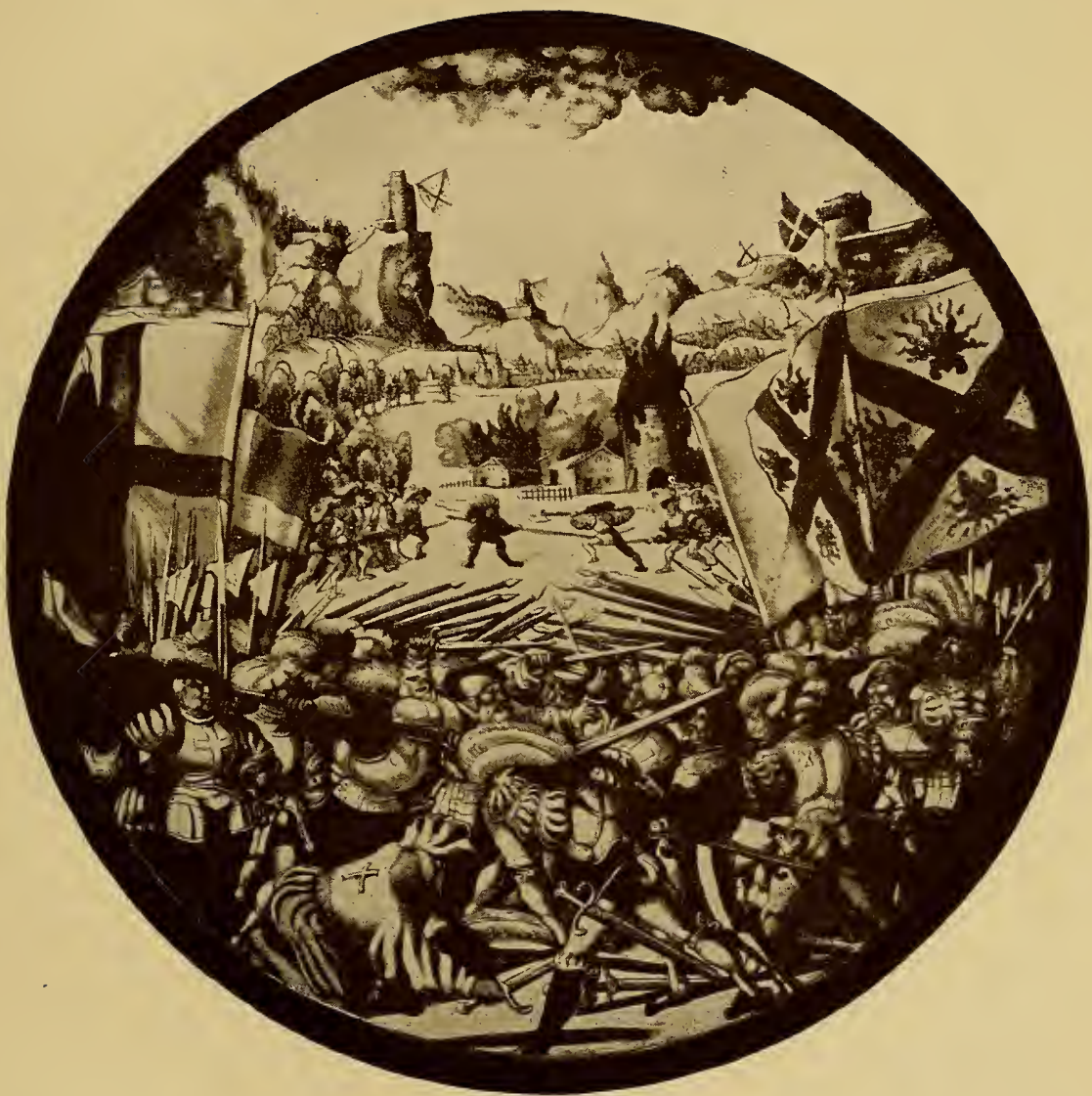

Rundscheibe nach einem Riß von Jörg Breu, vielleicht ausgeführt von dem Glasmaler Hans Braun in Augsburg. Salzburg, Museum. 

pens sind von Anfang bis zu Ende gleich geblieben. An zahlreichen Orten taten sich Schulen und Werkstätten auf, die dem großen Drang nach farbigen Scheiben Verwirklichung bringen sollten. Mittelpunkte sind München, Landshut, Wasserburg (bayrische Gruppe), Reutlingen, U1m, Bodenseestädte (schwäbische Gruppe), Nürnberg, Würzburg (fränkische Gruppe). Dazu kommt Nördlingen, aus dessen Kunstkreis P. A. Pöllmann ${ }^{1}$ ) eine Reihe von Glasmalern bekannt gemacht hat. Fast allenthalben lassen sich Glasgemälde unterscheiden, die einem stärkeren Einfluß der Schweizer Scheibe folgen und solche, die sich den führenden lokalen Größen auf dem Gebiet der Malerei und teilweise Bildhauerei anschließen.

In München und Wasserburg, vielleicht auch Rosenheim war der Schweizer Einfluß gering. Die Werkstätten Hebenstreit, Prielmair, Pöndl, Peich, Loth sind im engen Anschluß an Sustris, Wörle, Peter Candid zu nennen; sie bekamen gelegentlich schwäbische Gesellen. Darum stellen die noch erhaltenen Werke durchaus originelle bayrische Arbeiten dar. Von Hebenstreit stammen die Glasgemälde in der Michaelskirche zu München, die trotz ihrer Größe völlig im Geist der Kabinettglasmalerei gehalten sind. Dem Wolfgang Prielmair können wir ein Glasgemälde zuschreiben, das sich heute in Landsberg befindet und die Familie des Herzogs Albrecht V. von Bayern darstellt. Unter den alten Hofkammerprotokollen, welche im Kreisarchiv zu München verwahrt werden, findet sich unter dem 3 . Sept. I 56 I folgendes Schreiben des Herzogs an den Bürgermeister und den Rat der Stadt Landsberg: „Liebe Getreue! Ihr habt euch zu erinnern, welchermaßen wir euch kurz verschienener zeit das wider das Münzedikt verboten und verfallen gelt zu reinem kirchenpau gnediglich folgen lassen, doch daß ihr uns und unser Gemahel und Kindern in ein Fenster der Kirchen ain gedechtnus machen lasset. So Thr nun söllichs, als uns mit zweifelt zu tun vorhabens, ist unser gnedig begehrn, ihr wöllet dieselb Arbeit unseren Hofglaser alhie Wolfen Prielmair vor anderen Ausländern machen lassen. Daran thuet Ir unseren Gefallen in Gnaden erkennen." J. Schober, der diesen Brief

1) Zeitschrift für alte und neue Glasmalerei I9I3. Heft I, 3, 4. 
Albrechts in den "Landsberger Geschichtsblättern " veröffentlichte (I909, Nr. 3 u. 4), fügt bei, daß im Jahre I 564 der Bürgermeister an den Herzog berichtet, daß sein Wunsch nunmehr erfüllt sei. Mit dem Glasgemälde Prielmairs ist ein etwas späterer Renaissanceflügelaltar in der Liebfrauenkirche zu Ingolstadt verwandt. Auch von Hans Peich hat sich eine Scheibe erhalten. Der Schreiber dieser Zeilen entdeckte endlich in Schloß Hohenschwangau zwei prächtige Wappenscheiben Herzog Albrechts des Leuchtenbergers und seiner Gemahlin ${ }^{1}$ ), die laut archivalischer Notizen dem Paul Loth zuzuschreiben sind. Auf diesen Scheiben erkennt man deutlich die enge Anlehnung der Visierung an die führenden Männer, näherhin an Peter Candid. In München waren die Glasmaler in der Zunft der Maler, was nicht ohne Einfluß auf die Entwicklung des Stils blieb. Aus Wasserburg wird der Glasmaler Abraham Schneider bekannt, der im Stil der Inntalmeister arbeitet und ebenfalls von Schweizer Einflüssen frei ist. Dagegen haben sich in dem Gasteigkirchlein zu München einige Scheibchen erhalten, die ganz den Geist der Schweizer Scheibe atmen.

In Nürnberg wird die Wappenscheibe am stärksten von dem Schweizer Schema losgelöst. Das architektonische Prinzip weicht der Grundvorstellung des gerahmten Bildes. Darum wird die mit Renaissanceornament reichgezierte Umrahmung nicht selten in gleichen Maßen um das ganze Glasbild herumgeführt. Dazu zeichnet Hans Springinklee seine reizenden und in der Bewegung ausgezeichneten Frauen- und Engelsgestalten, die das Wappen halten. Die stichartig gezeichneten Falten und Gewandsäume, der in Strichmanier angedeutete Boden nähert sich dem alten glasmalerischen Prinzip. Behams Kupferstiche sind besonders beliebt, namentlich für Allianzamtsscheiben. Soweit Rundscheiben in Betracht kommen, wird der mit Renaissanceornament reich verzierte Rahmen gern in ein ornamental gehaltenes Girlandenmotiv aufgelöst. Wo immer Hüttenglas sich einfügen ließ, wurde es bevorzugt. Mit der zweiten Hälfte des r6. Jahrhunderts siegt der Schweizer Einfluß. Es sind zwar viele

1) Alte Glasgemälde im Schloß Hohenschwangau S. $20 \mathrm{ff}$, vgl. dazu R. Paulus, der Münchener Glasmaler Paulus Loth, Zeitschr. f. alte u. neue Glasmaler. I9I3 S. 3. 


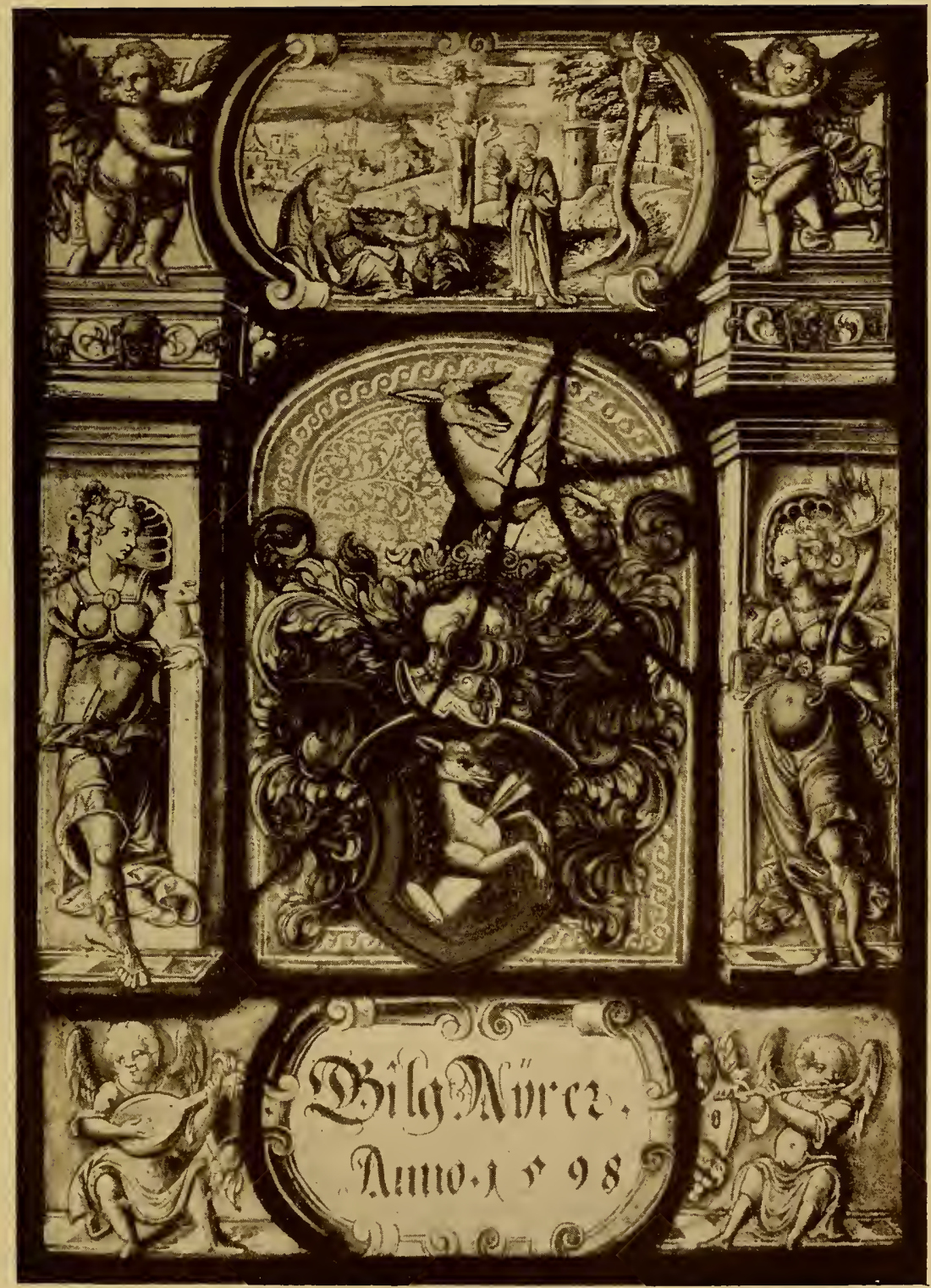

Wappenscheibe aus dem Jahre I598. Nürnberger Arbeit. 

Glasmaler am Platze und es läßt sich sogar eine vollständige Reihe aufstellen: Martin Krinaberger, Johann Brechtl † I52I, Sebald Hirsvogel $†$ I589, Hans Taucher I56I, Gallus Wald, Georg Wiedmann I589, Hans EB 1574. Allein der frische Zug in der Werkstatt muß ebenso verflogen sein, wie die Begeiste-

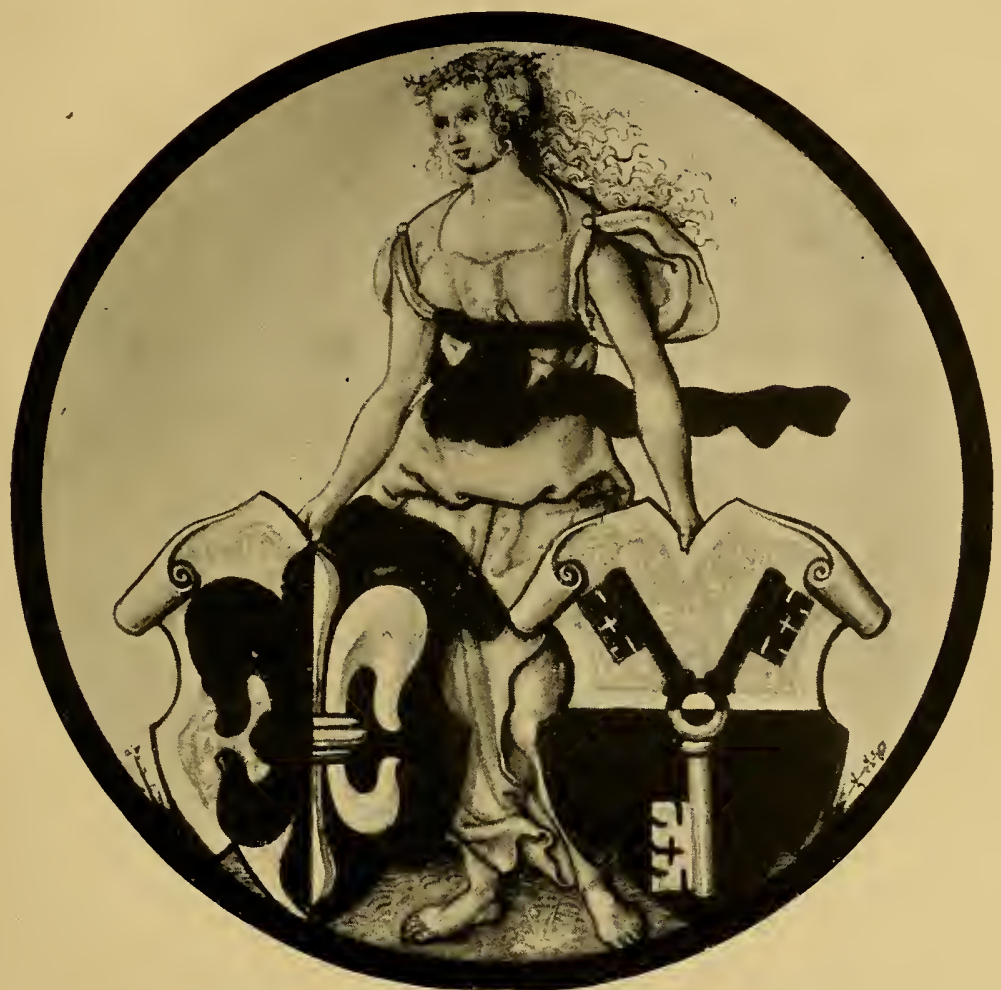

Abb. $3^{S}$. Rundscheibe mit den Wappen Welser und Schlüsselfelder.

Schloß Hohenschwangau. Um 1525. Nürnberger Arbeit (Hans Springinklee).

rung bei den Bestellern. Im Jahre 1603 wird vom Rat der Stadt verordnet: „Hansen Jakob Reutter glaßmaler von Zürich, welcher sich wider die glaser beschwert das ihne allhie nit wollen arbeiten lassen, da er doch ihnen Handwercks halben keinen eintrag thue, soll man anweisen, umb das bürgerrecht anzusuchen, weil dieser zeit wenig glasmaler alhie sein, und ime nichts destoweniger alhie $\mathrm{zu}$ arbeiten $\mathrm{zu}$ lassen, weil die glaser keine glas- 
maler sein. $\left.{ }^{1}\right)^{\star} \quad$ Es muß also recht schlecht ausgesehen haben, wenn der Rat seinen Landsleuten ein so beschämendes Zeugnis ausstellt. Was seit der Mitte des I6. Jahrhunderts angefertigt wurde, ist zwar in der Technik (vgl. die plastische Ausführung der Säulen und sonstige Ornamente) lokale Werkstattradition, allein im Stil sinkt fast alles auf das gewerbliche Niveau. Überraschend bleibt die Güte der Hüttengläser und der Geschmack im Kolorismus. Als Beispiele für die beiden Arten geben wir eine Wappenscheibe nach Hans Springinklee und eine Scheibe des Gilg Ayrer, die im Charakter der von der Schweiz beeinflußten Lokalschule gefertigt ist (Abb. 38, Taf. 90). Seit rund 1600 wurde der Bedarf an Scheiben von auswärts, in erster Linie von Zürich bestellt. In diese Periode fallen die weltbekannten Scheiben der Murerwerkstatt, die sich heute im Germanischen Museum befinden. Um die Mitte des 17. Jahrhunderts erhebt sich noch eine kleine Nachblüte an lokalen Glasmalerwerkstätten. Es tritt ein Georg Unverdorben auf den Plan, wohl in Schatten gestellt von Johann Schaper. Schinnerer hat diese Persönlichkeit in ein helles Licht gerückt, durch den großen Scheibenzyklus, der für die Karthause Prüll angefertigt wurde und sich nunmehr im Bayrischen Nationalmuseum befindet. Von Schaper stammt unter anderen Fragmenten sowie einer Scheibe im Berliner Kunstgewerbemuseum, eine sehr interessante Ulmer Stadtscheibe, aus dem Jahre I663, im Schloß Friedrichshafen. Sie ist nur in Schwarzlot und Silbergelb gehalten (Taf. 9I). Zum Kreis Schapers gehörten Herm. Benkert, Keyll, Faber, Guttenberger † I676, Abraham Helmhack † I 24. Von letzterem Meister ist in Münchener Privatbesitz ein signiertes Glasgemälde von sehr guter Qualität bekannt geworden. Helmhacks Schüler war Herbst, wie von Murr erzählt, Mesner an der Marienkirche und letzter Glasmaler Nürnbergs.

$\mathrm{Zu}$ Beginn des 16. Jahrhunderts hat sich die schwäbische Adelswelt mit Bestellungen an schweizerische Werkstätten gewandt. Aber schon nach Mitte des Jahrhunderts entstehen Lokalschulen und gegen Ende des Jahrhunderts haben verschiedene

1) Quellenschriften zur Kunstgeschichte Neue Folge I2 S. 357, mitgeteilt von Th. Hampe. 


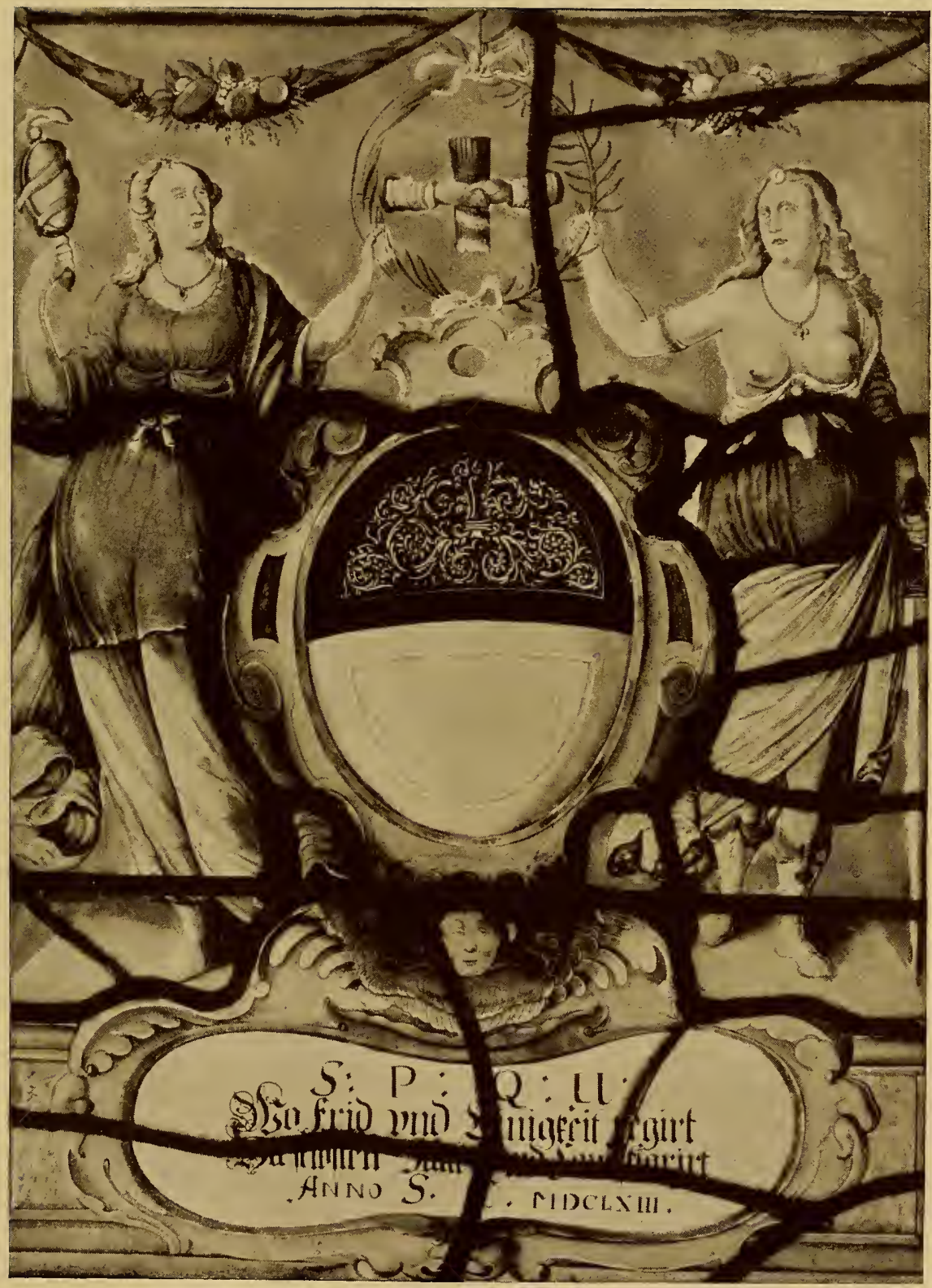

Wappenscheibe mit Wappen der Stadt Ulm. I663, von Johann Schaper in Nürnberg. 

Städte blühende Werkstätten, so Radolfzell, Rottweil, Reutlingen, U1m, Tuttlingen, Lindau. Infolge der Nähe der Schweiz haben die schwäbischen Schulen den Einfluß der Schweizer Scheibe in besonderem Maße erlebt. Das äußere Anordnungssystem wird übernommen, im Stil finden sich zahlreiche Anlehnungen und in der Technik gehen alle Fortschritte der Schweizer Meister sofort in die schwäbischen Werkstätten über. Am deutlichsten kann man dies an dem kostbaren, weil sehr seltenen, Emailgrün beobachten, das sich auf den Scheiben der Reutlinger Maurerwerkstatt in kaum übertroffener Schönheit findet. Nun aber bildet dieses Grün eine besondere Feinheit auf einigen Scheiben im Kreuzgang des Klosters Wettingen, die laut Signierung von dem Glasmaler Christof Brandenberg aus Zug stammen. Dieser Glasmaler, der auf seinen Wanderungen auch nach Reutlingen kam, hat ein sehr interessantes Notizbuch hinterlassen, aus dem wir $\mathrm{zu}$ erkennen vermögen, auf welche Weise sich Werkstattspezialitäten weiter gepflanzt haben. Die Maurerwerkstatt, die eine Reihe prachtvoller Scheiben im Dienst des herzoglichwürttembergischen Hauses geschaffen hat, zeigt den höchsten Blütenstand der schwäbischen Glasmalerei. Außerordentich farbenprächtig, verfügen alle Glasgemälde über leuchtende Schwemmfarben in Blau und Violett, über eine virtuose Anwendung des Silbergelbs, über strahlendes rotes Hüttenglas. Manchmal wird man an die bunte Lebhaftigkeit der Luzerner und Zuger Meister erinnert. In der Zeichnung herrscht plastische Fülle und breite Behaglichkeit vor. Die Säulen der architektonischen Umrahmungen sind fast regelmäßig mit allegorischen Figuren (der Gerechtigkeit, Liebe, Sanftmut, Musik, Geometrie, Arithmetik) belegt, oder es treten Hermen an ihre Stelle. Dazu gesellt sich reiches Kartuschenwerk und in der Mitte des Oberlichts gern größere Masken. Als Oberlichtszenen werden allegorische, religiöse und Jagdszenen bevorzugt. $\mathrm{Ab}$ und $\mathrm{zu}$ findet sich die Lieblingsbeschäftigung der Bürger, Scheibenschießen, wiedergegeben. Von großer Innigkeit und frischem Humor sind Berufsscheiben, von denen allerdings nicht mehr viele erhalten blieben. In der zweiten Hälfte des 17. Jahrhunderts verwässern die Farben, bis man schließlich bei Schwarzlot und Silbergelb ankommt. Aus dem Jahre 1752 stammt noch eine herzogliche Scheibe, ein 
Zeichen, daß der Sinn für Glasmalerei im biederen Schwabenland sehr lange in Pflege stand. ${ }^{1}$ )

\section{Die Schweizer Scheibe\%).}

(Siehe Taf. 92-99, Abb. 39-4I).

Wer kennt und liebt sie nicht, die eigenartige und reizvolle Schweizer Scheibe, die in keiner Sammlung fehlt, die immer wieder auf dem Kunstmarkt erscheint? Mag sie auch manchmal mehr durch ihre frischen Farben, als durch Gediegenheit der Zeichnung erfreuen, mag das Gebiet des Sujets und ihrer Technik eng umschrieben sein, stets ist sie ein Zeichen merkwürdiger und außerhalb der Schweiz nirgends vorkommender Nationalsitte. Daher sehen wir an ihrer Kenntnis und Erforschung ebenso den Kulturhistoriker, wie den Mann der Kunstgeschichte interessiert.

In ihrer schlichten Eigenart ist sie nicht zu verkennen oder $\mathrm{zu}$ verwechseln. Meistens erblicken wir auf ihr ein Wappen: von Ständen, Zünften, Klöstern, Adeligen und Bürgern. Ab und zu finden sich Szenen aus den schweizerischen Befreiungskriegen, nicht selten auch Darstellungen aus der Bibel. „In dem Schießhaus (dem Schützenhaus am Platz zu Zürich) sind der Eidgenossen Siege mit den Wappen sehr schön in den Fenstern mit Farben eingebrannt und abgemalt," sagt der berühmte Topograph Merian ( $16+2)$. Im allgemeinen überwiegt die einfache Wappenscheibe.

Die Freude an buntgläsernem Fensterschmuck setzte bei den Eidgenossen im Laufe des 15. Jahrhunderts ein, erreichte

1) Über die schwäbisclıe Glasmalerei vergleiche das demnächst erscheinende Buch des Schreibers dieser Zeilen (Schwäbische Glasmalerei).

2) Hermann Meyer, Die Schweizerisehe Sitte der Fenster- und Wappenschenkung vom 15. bis 17. Jahrhundert. Frauenfeld 1884. Wichtig Materialien enthalten Schmitz a. a. O. S. I 73 ff.; Fischer, Alte Glasgemälde im Schloß Hohenschwangau. Beide Arbeiten fußen auf den bahnbrechenden Forschungen Hans Lehmanns, der auf reiche Archivalien gestützt, zum erstenmal mit seinem Katalog der Sammlung Sudeley, München 1912, das fast unübersehbare Material nach Meistern und Sehulen geordnet und die Grundlage für die weitere Forschung der Schweizer Scheibe geschaffen hat. Von ihm ist in Bälde der Katalog der Scheiben des Schweizerischen Landesmuseums zu erwarten, in dem die umfassende Behandlung der Schweizer Scheibe enthalten sein wird. 


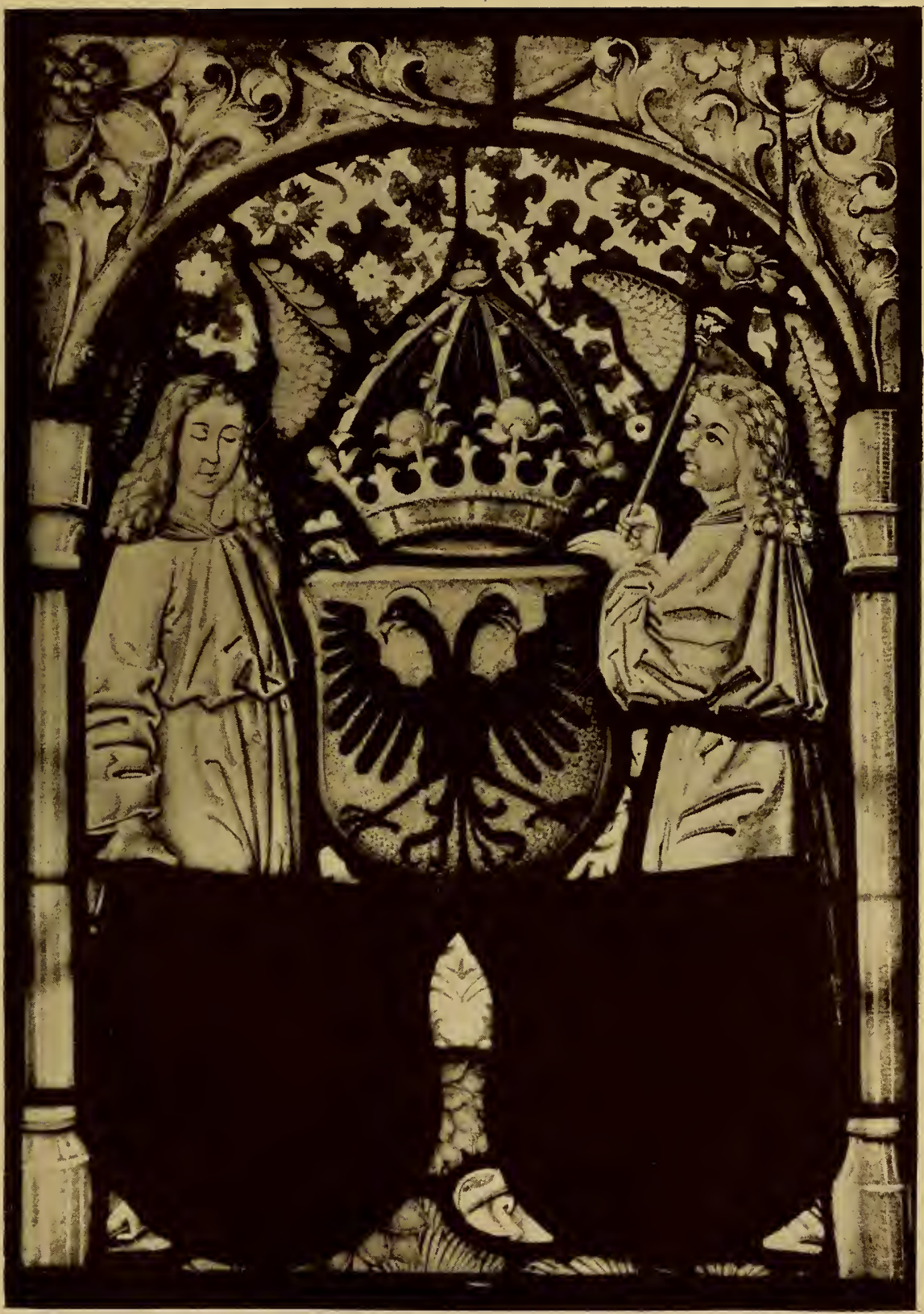

Wappenscheibe des Kantons Schwyz. Gegen I5Io. 

während des I6. ihre höchste Steigerung, um dann im I7. abzuflauen und zu erlöschen. Gleich bei ihrem Beginn erscheint die Sitte in bestimmten Formen, die sich zwar ausgestalteten,

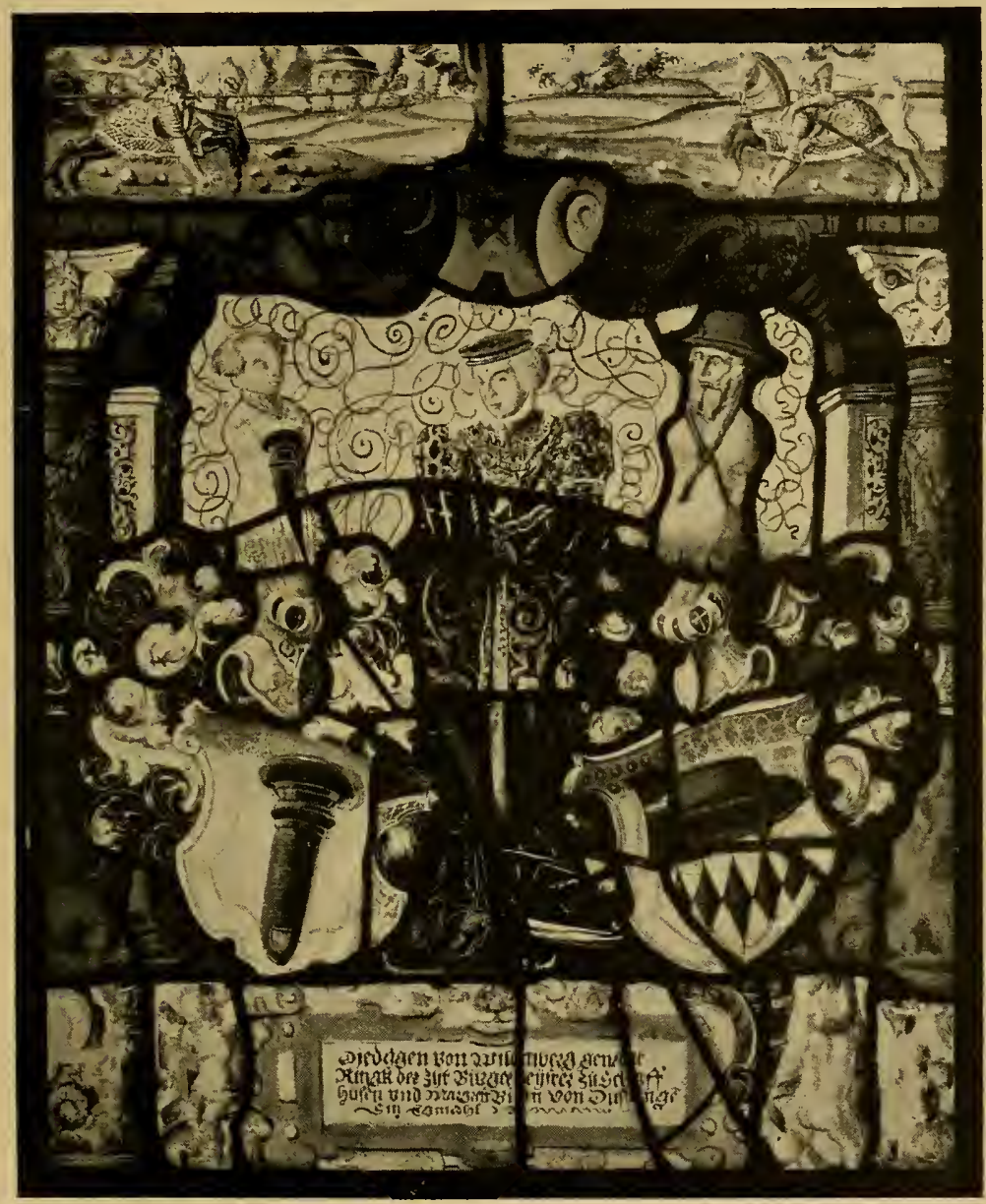

Abb. 39. Wappenscheibe Wildenberg. Arbeit des Daniel Lindtmeyer von Schaffhausen.

im wesentlichen aber bis zum Verschwinden der Sitte konstant blieben. Die Wappenscheiben sind nur ausnahmsweise Besitz derer gewesen, deren Wappen sie tragen. Sie sind fast immer Schenkungen an Eidgenossen. Es schenkt die Tagsatzung, es 
schenken Stände, Städte, Klöster, Adelige, Zünfte und Schützengilden. Zunächst sind es öffentliche Gebäude, denen diese Schenkungen zugute kommen: Rathäuser und Gemeindehäuser, Zunft-, Trink-, Bade- und Wirtsstuben, und wie weitherzig man bei der Auslegung des Wortes Wirtshaus war, zeigen verschiedene interessante Bittgesuche: „Gewirthet soll allerdings nicht werden, aber der Hausherr ist ein so gastfreier Mann, dass wer ihn mit einem Besuche beehrt, auch gelabt werden wird", in einem anderen steht $\mathrm{zu}$ lesen: "gewirthet zwar vorerst wieder nicht, aber das Haus eignet sich ganz vorzüglich für eine Wirthschaft und der Eigentümer behält sich vor, später eine solche darin zu betreiben." Für die Bittgesuche und für die Schenker gibt es gewisse staatsrechtliche Gesichtspunkte, unter denen die Schenkung erfolgt; so schenkt beispielsweise ein Kloster an ein anderes, der Schirmherr an die von ihm beschirmte Anstalt, die Zunft an die Schwesterzunft, der Rat des Standes in seinem Territorium.

Es muß also erheblich mehr hinter einer solchen Schenkung liegen, als was man gewöhnlich unter den Ausdrücken Geben und Empfangen versteht. Hermann Meyer (Die schweizerische Sitte der Fenster- und Wappenschenkung) hat an einer Reihe von Beispielen gezeigt, daß in einer Wappenschenkung zwei verschiedene Seiten auseinander zu halten sind. Der Beschenkte bekommt erstens ein Wappen und zweitens eine Barzahlung "für das Fenster", im Durchschnitt 6 Pfund. Demnach liegt in einer solchen Schenkung die doppelte Eigenschaft der Ehrung und der Unterstützung. Dieses Reichnis von 6 Pfund muß keineswegs zu dem bestimmten Zweck von Glaserarbeiten verwendet werden, sondern es ist schlechthin ein Bauschilling, den der Schenker für den Neubau einer zu ihm in bestimmtem Verhältnis stehenden Person oder Körperschaft leistet. Das andere Moment, die Ehrung, besteht in dem Wappen des Schenkers. Geehrt ist dadurch der Beschenkte wie der Schenker, der Schenker ob seiner Freigebigkeit, der Beschenkte ob seinen guten Beziehungen zum Donator. Es ist begreitlich, daß man sich daher bei allen um ein Fenster bewarb, bei denen man nur im entferntesten eine persönliche Beziehung zu entdecken vermochte. Das oder die Wappen sagten also dem Beschauer, wer den Bau unter- 


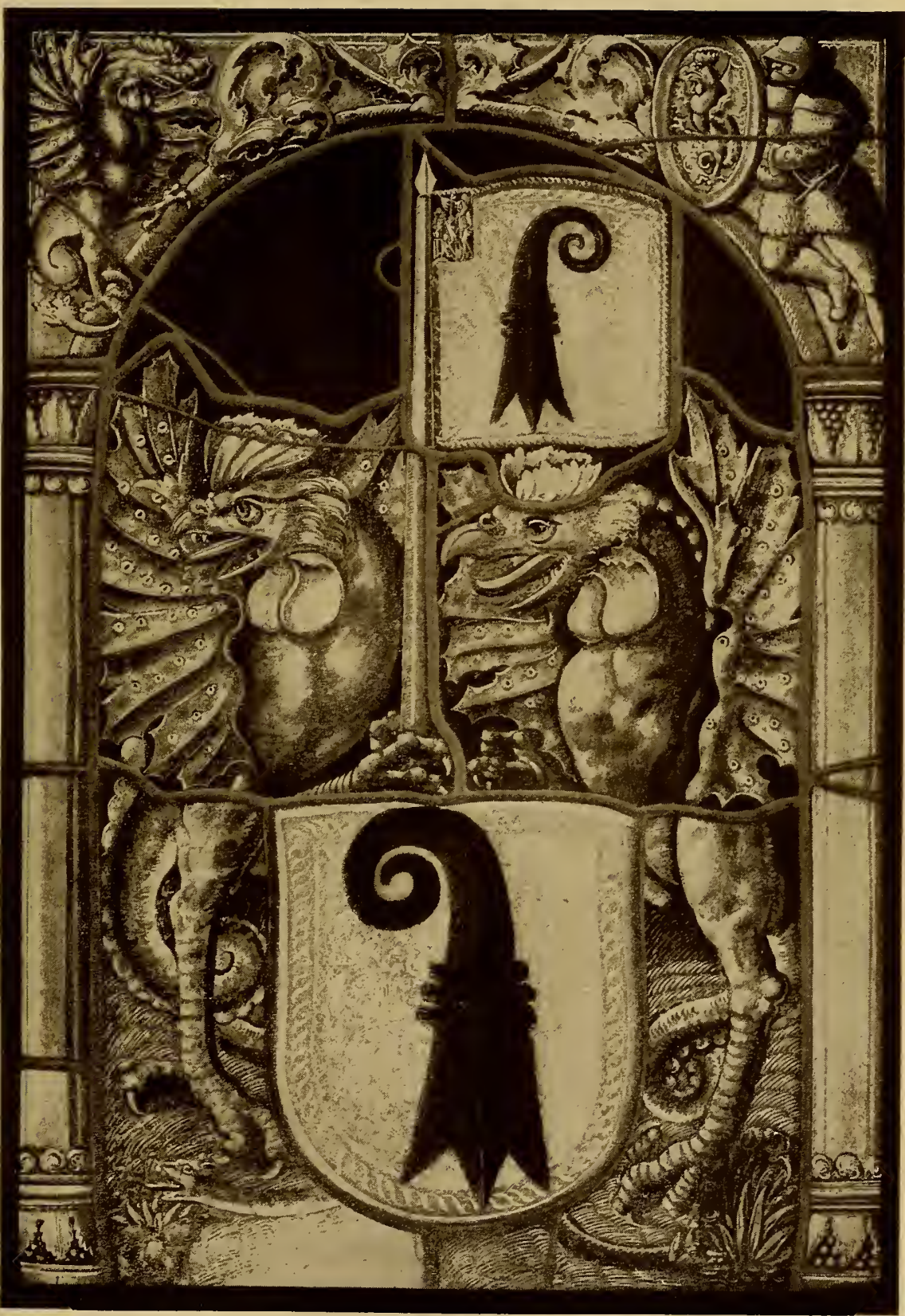

Wappenscheibe Basel. Historisches Museum zu Basel. Anfang des 16 . Jahrhunderts. 

stützt habe. Wenngleich so die Beisteuer zum Bau ein Hauptmotiv bei Bittsteller wie Geber ist, ereignete es sich doch nicht selten, daß bei dem einen oder andern Bittsteller lediglich der Gesichtspunkt der Ehre in Betracht kommt, während er den Gedanken der Unterstützungsbedürftigkeit von sich weist. So lesen wir von einem Bittsteller, "als hablicher Mann bewerbe er sich um die Schenkung von Ehren, nicht der Armut wegen“. Er will also nur das Wappen, nicht auch das Fenstergeld. "In Zürich, als die Schenkungen des Rates flott im Gange sind, läßt sich derselbe die zu verschenkenden Züricher Standeswappen von den dortigen Glasmalern partienweise im Vorrat machen. Das Wappendepot befindet sich auf dem Rathause und wird vom Grosswaibel oder Obristen verwaltet ,als der solche Wappen uff siner Herren Geheiss usszutheilen by Handen hat'. Dort liegen sie nun alle in verschiedenen Größen und Formaten, Geviertete und Runde, anderthalb und zwei Bogen gross bis hinunter zu halbbogen und weggengrossen. Von Zeit zu Zeit werden sie revidiert, zu Schaden gekommene ausgebessert, der unverwendet gebliebene Rest, soweit er Jahreszahlen trägt, bei Beginn des neuen Jahres durch Aenderung des Datums au courant gebracht" (Meyer).

Ursprünglich sollte nur ein Neubau Anlaß für Bittgesuch und Schenkung sein. Man war aber auch hier nicht engherzig in der Auslegung. Jede größere bauliche Veränderung genügte, um an einen Patron heranzutreten. Ja, wenn Feuersbrunst oder sonstiger Schaden einen Bau zwei- dreimal hintereinander zerstörten, jedesmal bewarben sich die Geschädigten mit Erfolg um neue Wappen.

Am üppigsten blühte die Sitte der Wappenschenkung in Zürich. Dort gab es zur Zeit der ausgedehntesten Schenkungen in den Jahren $1580-1600$ allein 27 selbständige Glasmaler. Der letzte Züricher Glasmaler war Hans Conrad Meyer, gest. I766. Von ihm sind nur einige wenige Wappenscheiben bekannt. Die Nachfragen erloschen und Meyer sah sich genötigt, auf anderen Gebieten Tätigkeit zu suchen.

Fragen wir nach den letzten Wurzeln dieser eigentümlichen Sitte, so kommen verschiedene Momente in Betracht. Meyer meint: "Wenn die Scheibe, friedlichen oder kriegerischen Er- 
werbungen auf dem Fuße folgend, in die Rathäuser des neuen Bundesgliedes oder zugewandten Ortes, in die Gemeindehäuser einer der Landschaft kürzlich einverleibten Herrschaft Einzug hält, so stellt sie, in weit von einander gelegenen Gegenden vorkommend, die Fülle der Macht und das steigende Gedeihen des

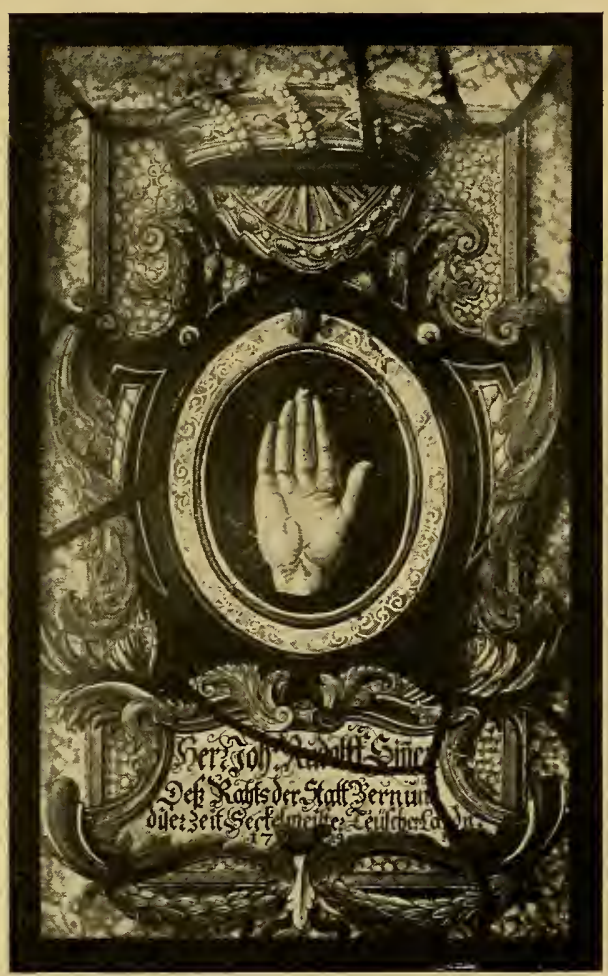

Abb. 40. Wappenscheibe Sinner. I7I9. Historisches Museum zu Bern. Gemeinwesens vor Augen und verkündet das Lob ihrer Herren, der Leiter des Staates. Damit entstanden Denkmale, die edler und sprechender die nationale Macht und Einheit zur Anschauung brachten und geeignet waren, das Lob der Eidgenossenschaft und des einzelnen Standes zu verkünden und im Rathaus der Stände, an den Sammelplätzen der waffenfähigen und stimmberechtigten Mannschaften, den Schützenund Zunfthäusern und Trinkstuben, ebenso auch in der Grenzstadt und im Wirtshause an belebter Heer- und Handelsstraße Platz zu finden. In dieser Ausstattung mußten die Scheiben dem Besitzer ein immer wertvolleres Zeugnis derZugehörigkeit zu dem Verbande, dessen Taten sie schilderten, werden. Die ganze Stufenleiter der Gefühle vom wohlberechtigsten Patriotismus bis zur Prahlsucht findet Nahrung im eigenen Beschauen wie im Vorweisen und in der Überzeugung, daß der Fremde beim Anblick von Achtung und Neid bewegt werde. In der Schenkung an sich und als solcher liegt ein Moment von selbständiger Bedeutung. Die Schenkung ist eine Huld- und Gunstbezeugung." 


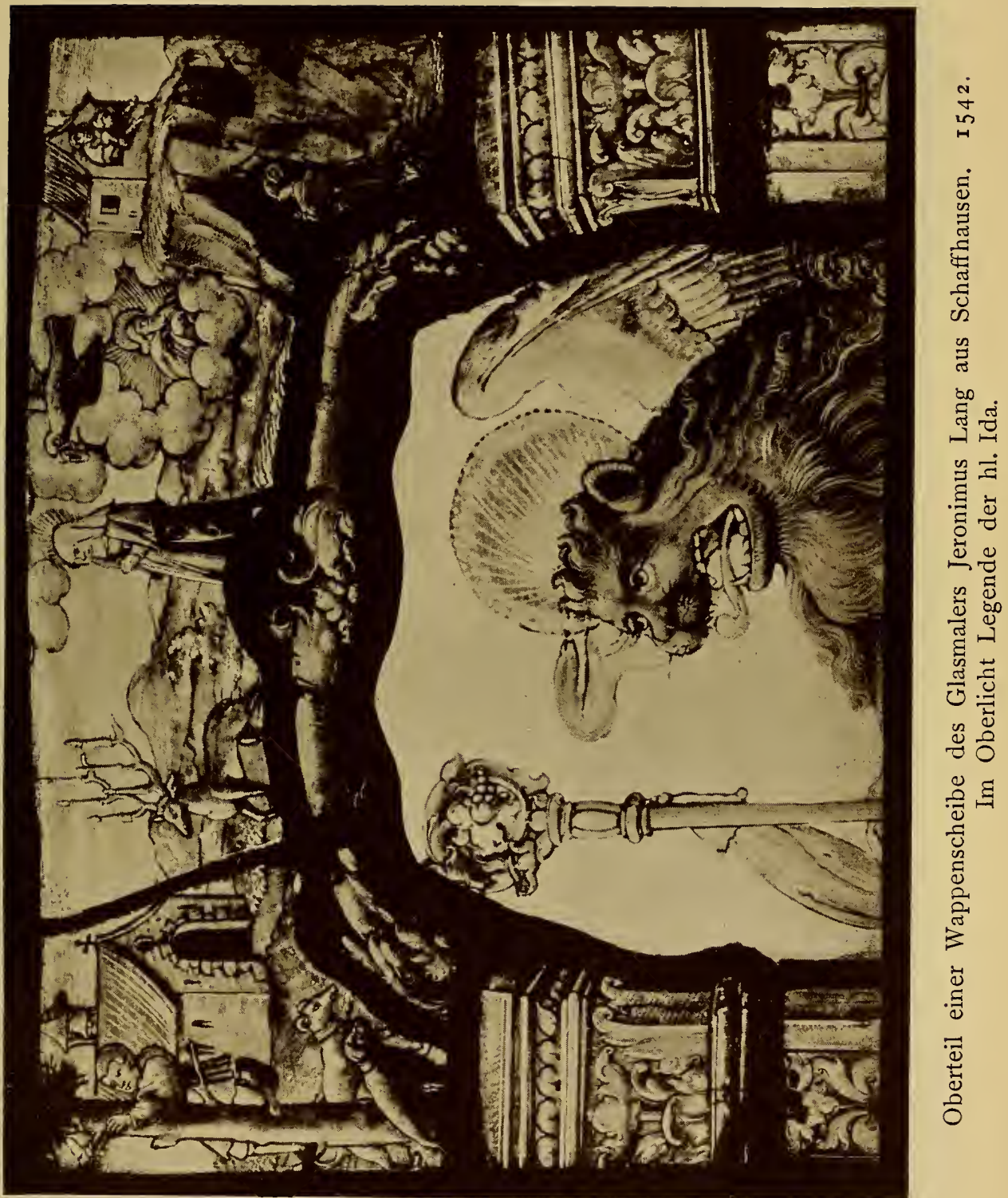





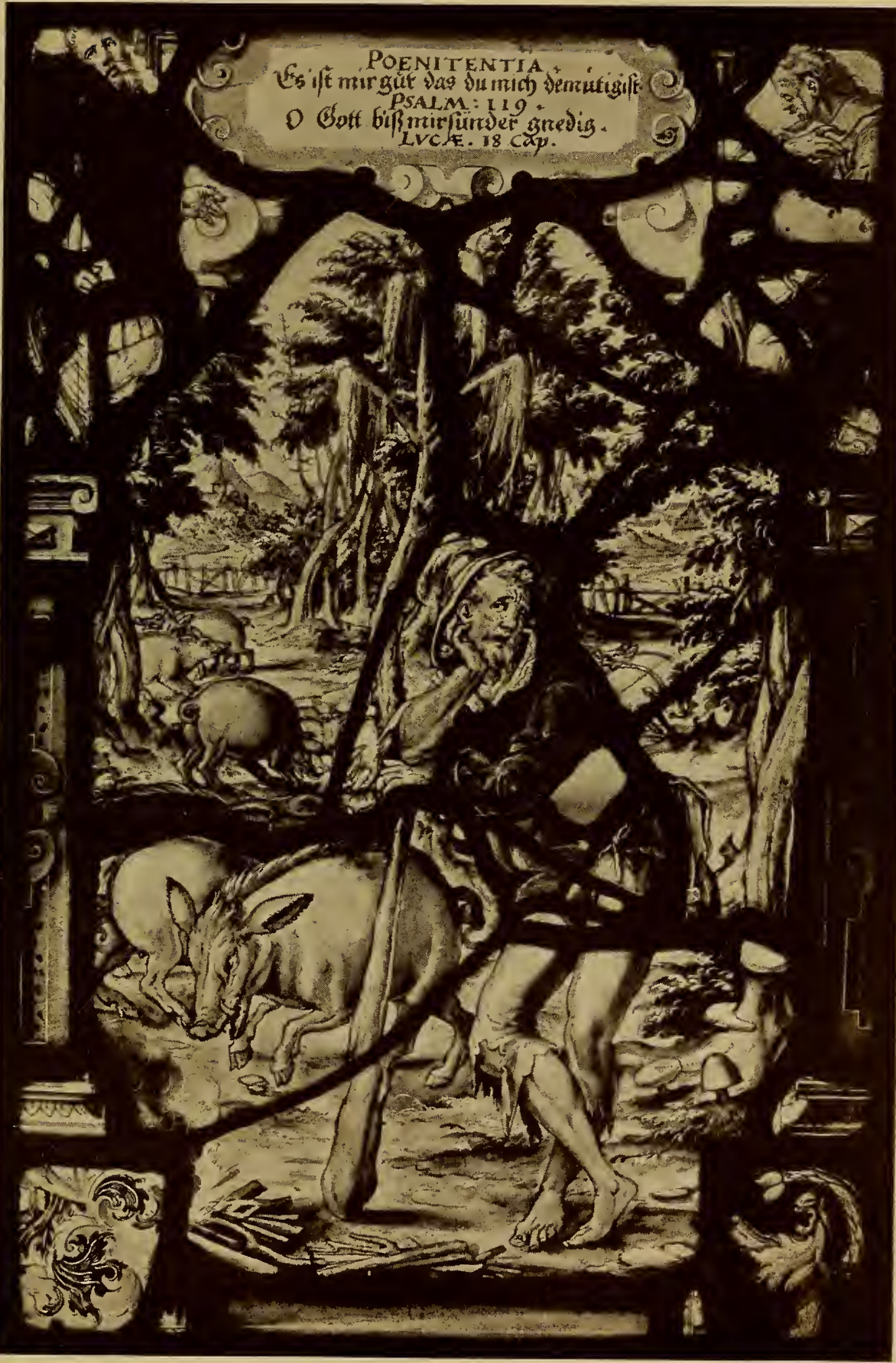

Scheibe aus dem Cyklus: Der verlorene Sohn, von Chr. Murer. 



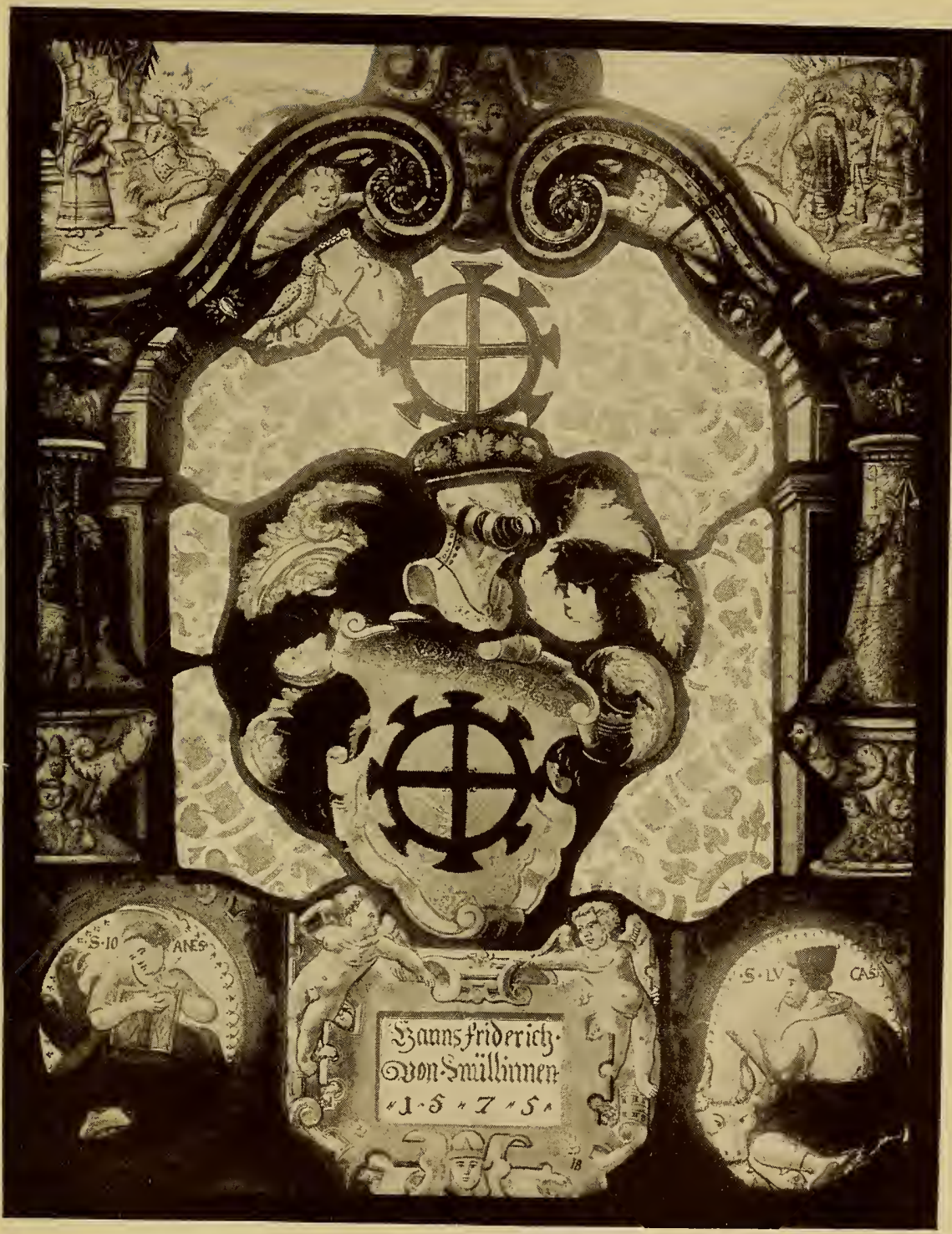

Wappenscheibe Mülinen. Historisches Museum in Bern. Monogramm I. B. 



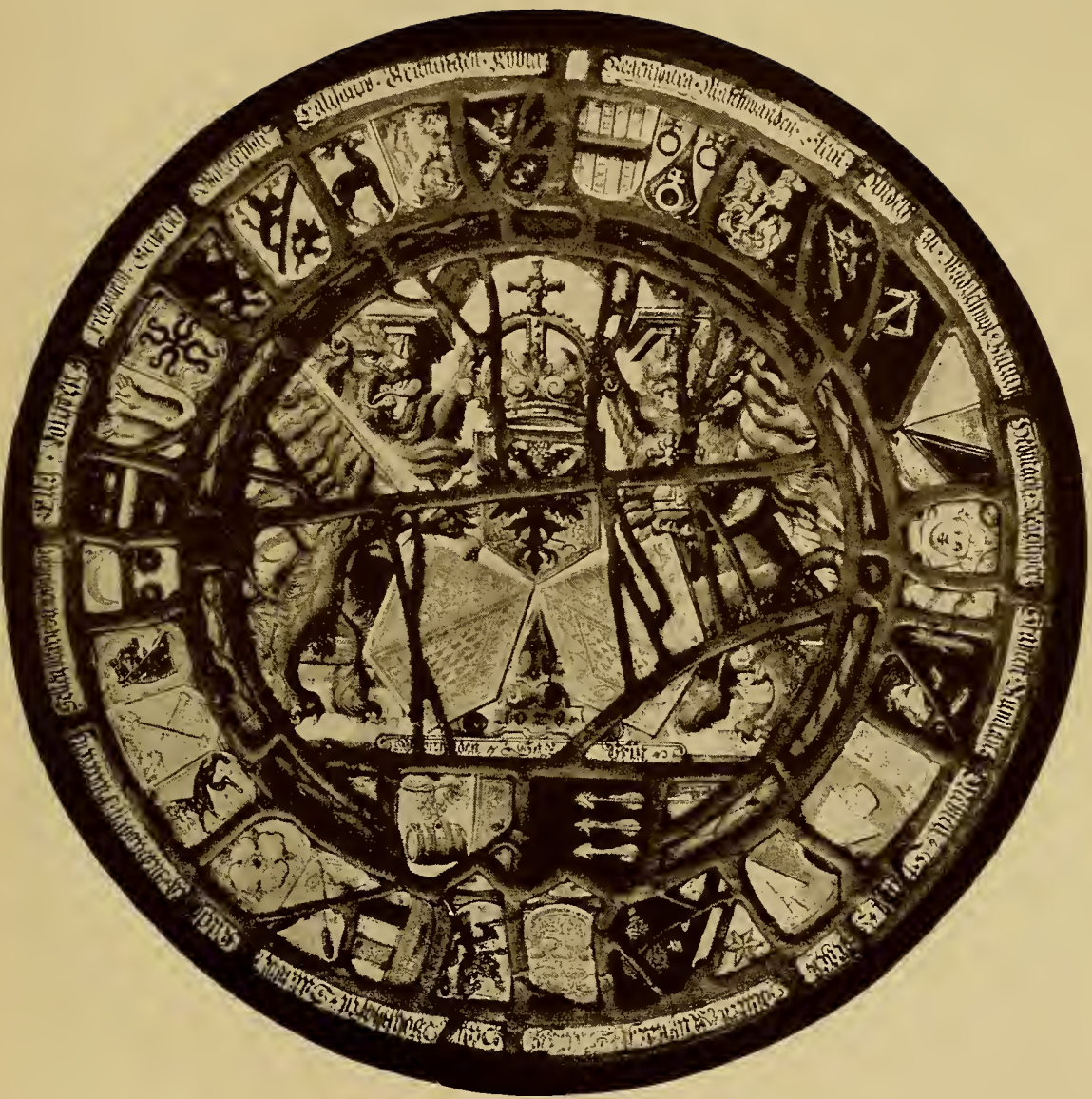

Züricher Standesscheibe. Nüschelerwerkstatt, Zürich. I 628 . 



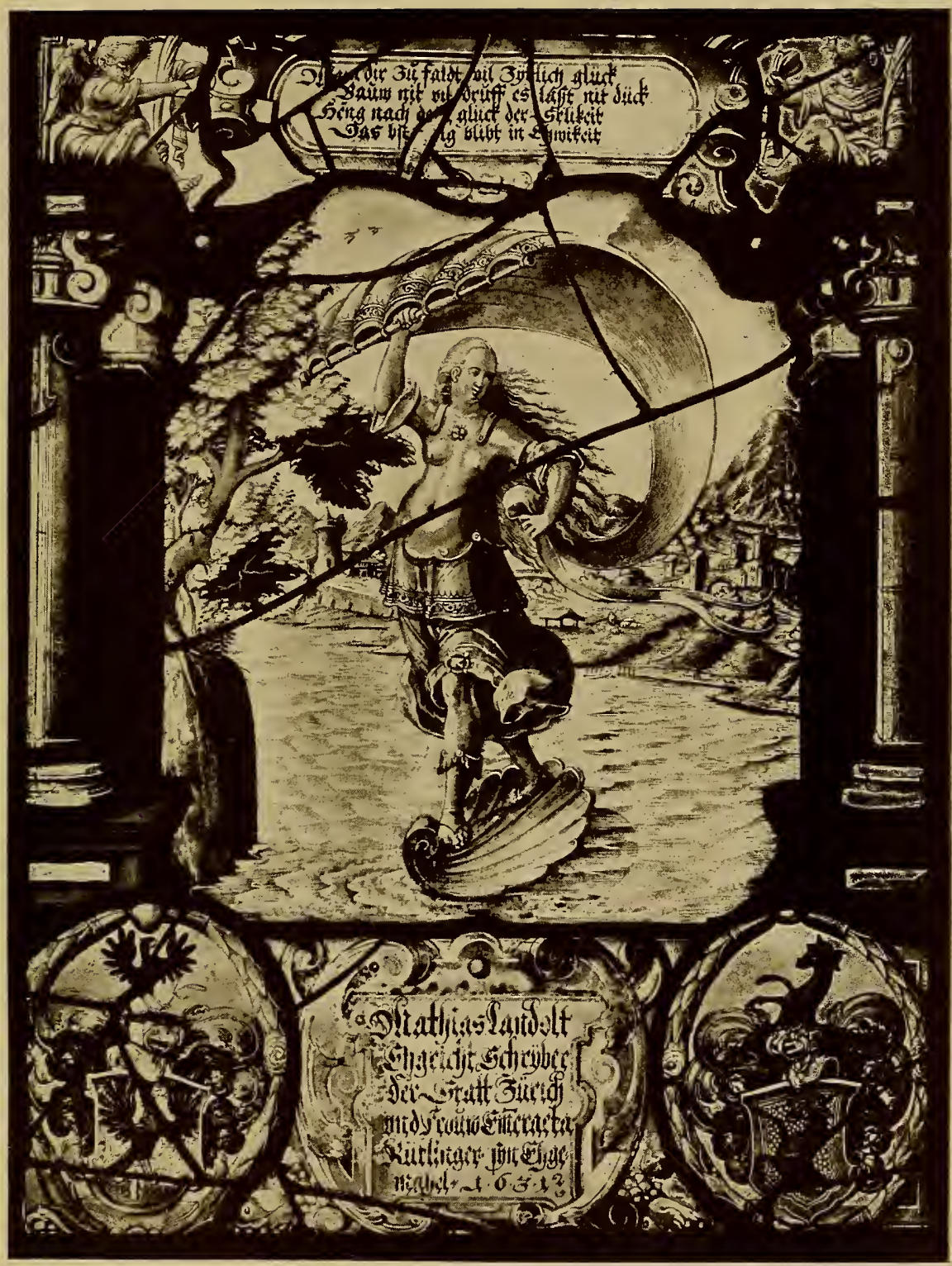

Wappenscheibe mit Fortuna. Nüschelerwerkstatt, Zürich. I631. 



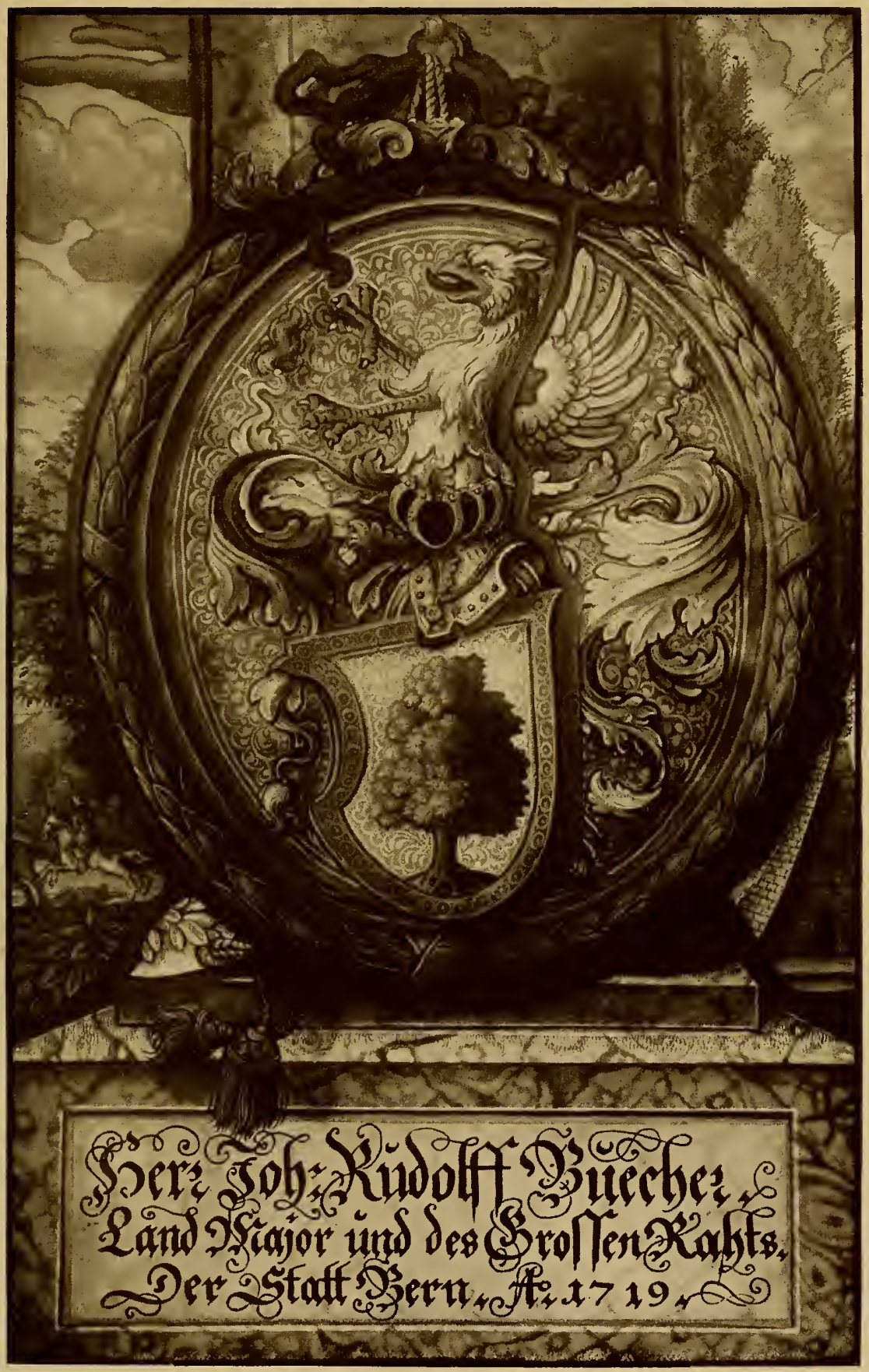

Wappenscheibe Buecher I 7 I 9 . Historisches Museum zu Bern. 

Diese Ausführungen mögen hinreichen, um die einmal entstandene Sitte in ihrer Entwicklung begreiflich zu machen, die letzte psychologische und ästhetische Frage: Wie kommt gerade die Glasmalerei dazu, Trägerin dieser Sitte zu werden? ist damit noch nicht erklärt. Gewiß spielt dabei der Nachahmungstrieb eine große Rolle. Ein oder mehrere angesehene Herren haben sich den ursprünglich noch kostspieligen Luxus von Wappenscheiben geleistet. Dies fiel in die Zeit der größten politischen Blüte der Eidgenossenschaft. Von selbst lenkte sich daher das Interesse auf alles, was einer reicheren Raumausgestaltung diente, vor allem auf die neue Mode buntgläsernen Fensterschmuckes. Freude an dem munteren Spiel der Farbe, Aufnahmefähigkeit für Kunst und Kunstgewerbe befinden sich ja immer im Gefolge politischen oder wirtschaftlichen Aufschwunges. Und, daß schließlich die gesamte Schweiz mit ganzer Macht und Zähigkeit sich auf die Sitte warf, hängt mit dem frischen und unmittelbaren Natursinn des Volkes zusammen, der durch die romantische Schönheit des Landes immer von neuem belebt und genährt wird. Es war eine hohe Stufe von Kultur und Kunstsinn, die in der Sitte der Fensterschenkung sich kundgab, so hoch, wie sie seither niemals mehr erreicht wurde.

Die weite Ausdehnung der Sitte hatte für die Qualität der Scheiben zum Teil unerwünschte Folgen. Man war nicht überall und immer originell genug, um stets Neues zu schaffen. Beliebte Kartons wurden von Werkstatt zu Werkstatt verhandelt. Ja berühmte Meister verschmähten es nicht, die Visierungen anderer Glasmaler ihren eigenen Arbeiten zugrunde zu legen. Nicht selten schnitt man von einer alten Wappenscheibe die Schrifttafel ab, setzte eine neue Jahreszahl und eine neue Beschriftung darunter und fertig war die Stiftung des nachgeborenen Herrn aus der ehemaligen Stifterfamilie. Umgekehrt legte man in späterer Zeit Wert darauf, ein ganzes Geschlecht vollständig vertreten zu haben und ergänzte etwa fehlende Wappenscheiben. Auf diese zwei Anachromismen ist bei der stilkritischen Analyse einer Schweizer Scheibe besonders $z u$ achten. Überhaupt dürfte, t:m dies gleich hier zu bemerken, eine stilistische Betrachtung der Schweizer Scheibe vorderhand noch gar nicht möglich sein. Die Archivforschung fördert außerordentlich reiche Resultate der 
Schweizer Glasmaler zu Tage; es ereignet sich dabei oft, daß eine Zeile alten Urkundentextes ganze Abhandlungen stilkritischen Inhalts von lückenloser Logik über den Haufen stößt.

Die Schweizer Scheibe zeichnet sich vor allen anderen Kabinettsscheiben durch ihre starke ornamentale Kraft aus. Nicht die ziselierte Kleinmalerei ist es, die den Schweizer reizt,

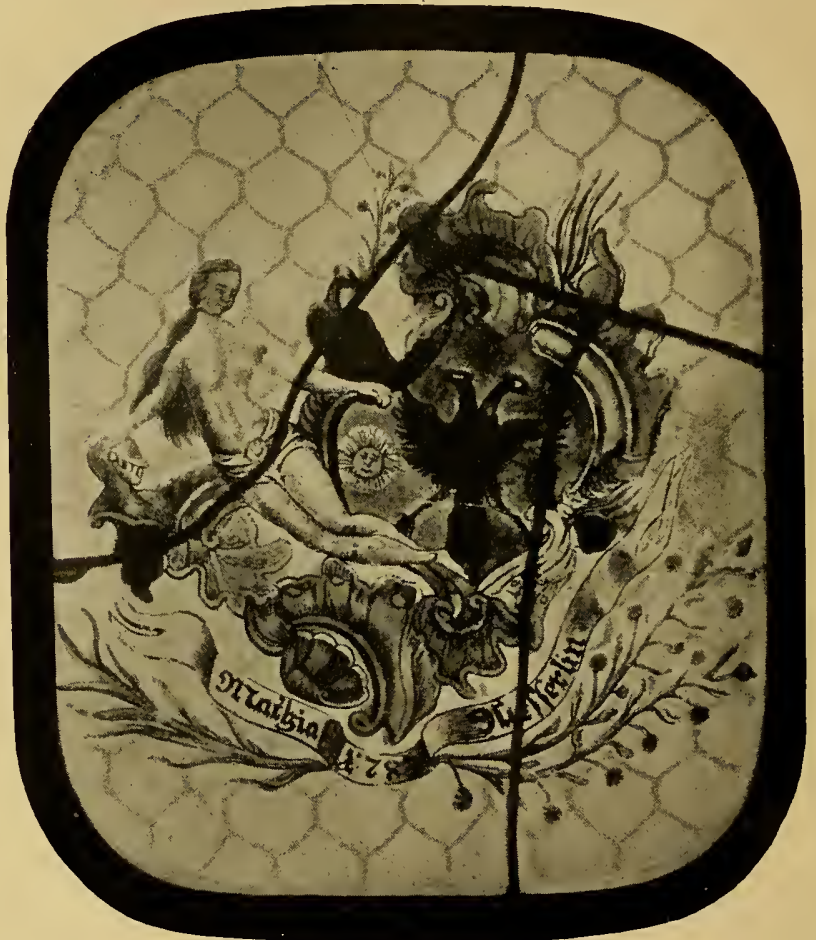

Abb. 4r. Wappcnscheibe Messerlin I 783 . Historisches Museum in Bern.

vielmehr eine in den Maßen reduzierte monumentale Glasmalerei; darum konnten die zierlichen Arbeiten, die am Oberrhein, in den schwäbischen und fränkischen Glasmalerwerkstätten im Anschluß an den Kupferstich des Meisters E. S., des Hausbuchmeisters, Martin Schongauers im Bereich der Eidgenossen nie so recht Wurzel fassen. Wohl brachten süddeutsche Glasmaler sogar Spezialitäten wie die bekannten Vierpaßscheiben in die Schweiz. Lehmann nennt fünf solche Scheiben, von denen er zwei dem in die Schweiz gewan- 


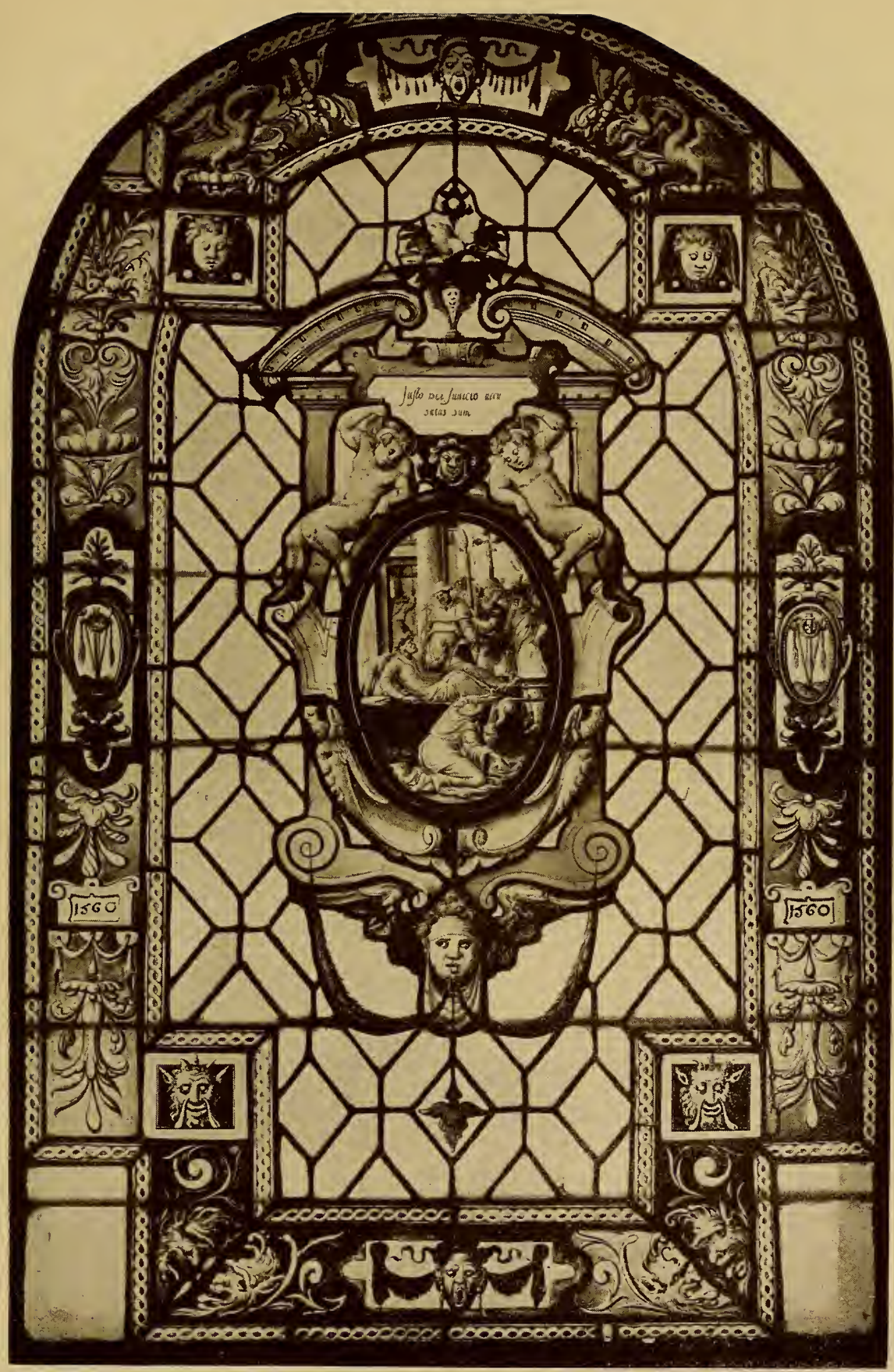

Glasgemälde in der Certosa van Florenz. I560. Giovanni da Udine. 

derten Hans Hänle aus Reutlingen (Württ.) zuschreibt. Allein der zierliche Stil der in Kupferstichmanier gehaltenen Kabinettsscheiben fand in der Schweiz niemals wirkliche Gegenliebe. Es ist bezeichnend, daß die Schweizer Glasmalerei, die (speziell die Berner Glasmalerei) bis Ende des I 5. Jahrhunderts von den Werkstätten des deutsch-alamannischen Vö1kergebiets abhängig ist, gleichwoh1 eine spezifische schweizerische Kunst blieb, ohne ihren Grundcharakter je gegen die oberrheinischen Manieren einzutauschen.

Im Lauf des letzten Jahrzehnts ist es dank der unermüdlichen Tätigkeit der Schweizer Archivare und Hans Lehmanns gelungen eine Reihe von Glasmalern festzustellen und eine große Anzahl von Glasgemälden bestimmten Meistern zuzuschreiben. Indes ist dieses große Werk noch mitten in der Entwicklung. Im Gegensatz zu der deutschen Kabinettsscheibe, die sich stets nach der Qualität der Visierung beurteilen läßt, liegt bei der Schweizer Scheibe das Wesentliche in dem Handwerklichen. Dem Schreiber dieser Zeilen ist eine Paradiesesszene auf fünf verschiedenen Scheiben zu Gesicht gekommen. Sämtliche Scheiben gingen, wie leicht an Details zu erkennen war, auf denselben Riß zurück; gleichwohl wiesen sie durchweg in der Handschrift der Ausführung Verschiedenheiten auf, was auch durch die weit auseinander liegenden Wohnorte der Besteller ohne weiteres einleuchtend war. Wie soll man solchen Erscheinungen gegenüber mit weitschweifigen Analysen des Stils etwas Sicheres erreichen! Unlängst konnte man von einer "Sankt Gallener Schule" lesen. Nun steht fest, daß die reformierten S. Gallener Bürger ihre Bestellungen in Zürich, die katholischen in Wyl ausführen ließen. Damit stimmt auch überein, daß in allen Archivalien nicht das mindeste von einem S. Gallener Glasmaler zu finden ist. Der auf einer Scheibe in Schloß Maihingen genannte Franz Fehr ist lediglich Glaser und Stifter, nicht aber Anfertiger der betreffenden Scheibe. Wir begnügen uns daher mit einem kurzen Abriß der Schweizer Kabinettsglasmalerei und verweisen für die Details auf P. Ganz, Handzeichnungen Schweizer Meister, H. Lehmann, Katalog der Sammlung Sudely; die Berner Glasmalerei ${ }^{1}$ ), Fischer, Alte Glasgemälde im Schloß Hohenschwangau.

1) Die Glasmalerei in Bern am Ende des I5. und Anfang des 16. Jahrhunderts. Anz. für Schweiz. Altertumskunde, I9I2. ff. 
Die Sitte der Fensterschenkung entwickelte sich seit der zweiten Hälfte des I5. Jahrhunderts und zwar noch nicht mit der Kraft eines im Volke ruhenden Bewußtseins, als vielmehr mit der Seltenheit der Laune der Bemittelten. Darum war der nationale Charakter in diesen Anfängen noch keineswegs in festausgebildete Formen gefaßt. Die am Oberrhein speziell in Basel ausgebildeten Kräfte wirken auch nach den Hauptstätten der eidgenössischen Lande. Man vergleiche z. B. den Scheibenriß eines Züricher Meisters aus dem I 5. Jahrhundert, den Ganz auf Tafel 32 bekannt macht, oder die verschiedenen Visierungen des Ambrosius Holbein. Die entscheidenden Momente sind das Auftreten des jungen Dürer 1492 in Basel und des jüngeren Holbein Reise nach dem Süden. Diese beiden Ereignisse brachten der Schweizer Glasmalerei die nötigsten Vorbedingungen, um der nun in Blüte befindlichen Sitte gerecht werden zu können: eine im Realismus begründete Bewegungsfreiheit_in der Zeichnung und eine diesem angepaßte architektonische Umrahmnng. Des jüngeren Holbeins Risse sind Fundgruben für Renaissancearchitekturen, die beim Meister durch ihre Originalität und ihren Formenreichtum außerordentlich frisch und kräftig wirken, bei den Schülern und Epigonen aber sehr bald von Formen zu Formeln werden und ins Barocke übergehen. "Vergleiche die Gruppe Hans Bock; Hans Jakob Plepp, sowie die sich durch handwerkliches Virtuosentum, aber manchmal hausbackene Trockenheit charakterisierende Gruppe der Han, Ringler in Basel, Ägeri, Bluntschli und Ban in Zürich. Am rassigsten blieb die Berner Glasmalerei, die mit Niclaus Manuel Deutsch, Hans Funk vertreten war. Zürich stieg schon mit der Murerwerkstatt zu seiner früheren Höhe herab, von der es allmählich über die Nüscheler bis zu den rein handwerksmäßigen Arbeiten und letzten Ausläufern, der Weber, Wolf und H. C. Meyer sank. Die Scheiben der katholischen Kantone zeichnen sich durch größere Buntheit der Schwemmfarben aus. Durch die Beiziehung von Heiligen und Legenden bekommen diese Scheiben mehr Abwechslung. Nebst Zürich ist die Glasmalerei Berns am weitesten und charakteristischen entwickelt. Bern hat sich in der Kabinettsglasmalerei am engsten an die Traditionen der Monumentglasmalerei angelehnt. Darum waren kräftige, sattere, der Zahl nach beschränkte Farben beliebt, im Gegensatz zu der 
bunten, manchmal unruhigen Schwemmfarbenkarte Luzerns. Außer Rotlot, Jean Cousin, Schwemmblau und den verschiedenen Nuancen des Silbergelbs, das häufig als leuchtendes Braungelb für den Hintergrund Verwendung findet, hat Bern nur ein paarmal das prachtvolle Emailgrün, das wir auf den Scheiben des Chr. Brandenberger, der Maurer in Reutlingen so besonders schön finden.

Während des ganzen I8. Jahrhunderts bleibt die Berner Glasmalerei im Vollbesitz der glasmalerischen Mittel, eines erlesenen Geschmackes und Verständnisses, während beispielsweise Zürich mit den Epigonen Weber, Wolf, Meyer seit Beginn des I 8. Jahrhunderts einen völligen Niederbruch der Glasmalerei erlebte. Um I680 arbeitet der Glasmaler Güder mit glanzvollem roten Hüttenglas, stellt als Kontrast ein leuchtendes Blau dagegen, ganz nach dem alten glasmalerischen Grundprinzip und zeichnet sich durch die vortreffliche Verwendung des Rotlots und insbesondere des Silbergelbs aus. $\mathrm{Zu}$ derselben Zeit entstanden in Zug die Arbeiten der Müller, des Adam zum Bach, deren Scheiben lediglich mit Schwemmfarben ausgeführt, einer bunten Musterkarte von Farbflecken gleichen. Wenn nun auch um die Wende des i7. und im Anfang des i 8. Jahrhunderts in gewissen Werkstätten der Sinn für die Farbwirkung zugleich mit den Farbmitteln selbst verloren ging, so auf der Scheibe des Abr. Tillier I700, die außer Schwarzlot und Silbergelb nurmehr ein stumpfes Graublau kennt, auf einer Scheibe der „ehrendten Landschaft Interlaken I7 I4", auf der ein sattes Rotlot und ein schönes Jean Cousin und ein in verschiedenen Tönen erglänzendes Silbergelb verwendet sind, erstrahlt eine prachtvolle Scheibe, entworfen von J. R. Huber, im schönsten Stil der Kabinettsglasmalerei. Die Scheibe aber stammt aus dem Jahre I704. Außer über einen satten roten Überfang, ein ebenso leuchtendes Rotviolett, verfügt der Meister über prächtiges Schwemmblau, und über das so seltene Emailgrün. Auch an den kleinsten Stellen ist das Grün nicht in der bequemen Weise eines Silbergelbs auf Blau, sondern in der komplizierteren Art des Emailgrüns hergestellt. Eine ähnlich schöne Scheibe findet sich in der historisch-antiquarischen Sammlung zu Schaffhausen. Aus dem Jahre I7I9 stammen eine Reihe von Scheiben, die sich im 
Vollbesitz aller Schwemmfarben befinden. Mit dem dritten Jahrzehnt konzentriert sich die Technik auf die Anwendung des Schwarz- und Rotlots, sowie des Silbergelbs. Das letztere verschwindet im zweiten Drittel. Das vierte und fünfte Jahrzehnt kennt nur mehr das Schwarz- und Rotlot. Unter dem Einfluß der damals besonders blühenden Trinkglasschleiferei verließ man die unfruchtbare Epigonenarbeit und versuchte sein Wappen samt einer mehr oder weniger geistreichen Inschrift statt auf Glas zu malen, in dasselbe schleifen zu lassen. Der Stadtkaminfeger Emmanuel Schrötter von Bern scheint unter den ersten gewesen zu sein, die ihr Wappen in lichtes Glas setzen ließen. Seine Scheibe stammt aus dem Jahre I75I. Das Berner Museum besitzt eine große Zahl solcher Weißscheiben, deren jüngste aus dem Jahre I816 stammt. Zwischenhinein fällt die merkwürdige Scheibe des M. Messerlin aus dem Jahre I 783 . Sie kennt noch alle Schwemmfarben. Thr Schmelz aber und durchsichtiger Glanz ist verloren; ihr Auftrag gleicht in seinem rußigen Ton eher einer Kohlenzeichnung als einem Glasgemälde. Aber es ist charakteristisch für den starken Sinn des Schweizer Volkes für die Glasmalerei, daß es auch in den Zeiten technischen und stilistischen Niederganges nicht von der liebgewohnten Sitte lassen wollte.

\section{Die Kunstverglasung.}

Nach unseren im ersten Kapitel gemachten Andeutungen ist die Kunstverglasung nicht etwa ein Ableger der Glasmalerei. Sie steht vielmehr am Anfang der Entwicklung des buntfarbigen Fensterschmucks. Die noch erhaltenen ältesten Denkmale der Glasmalerei, insbesondere auch der Reliquienschrein aus dem 9. Jahrhundert, der auf einem französischen Friedhof gefunden wurde, beweisen diesen Satz mit unumstößlicher Sicherheit ${ }^{1}$ ). Ursprünglich waren die mit steinernen Rippen ausgestatteten Fenster mit farbigem Glas gefüllt. Diese Rippen wurden schon während des frühesten Mittelalters ornamental behandelt und zwar nach Motiven, die aus dem Orient stammen. An den Fenstern des

1) Abgebildet bei Bégule, les vitraux dans la région Lyonnaise, S. 3. 


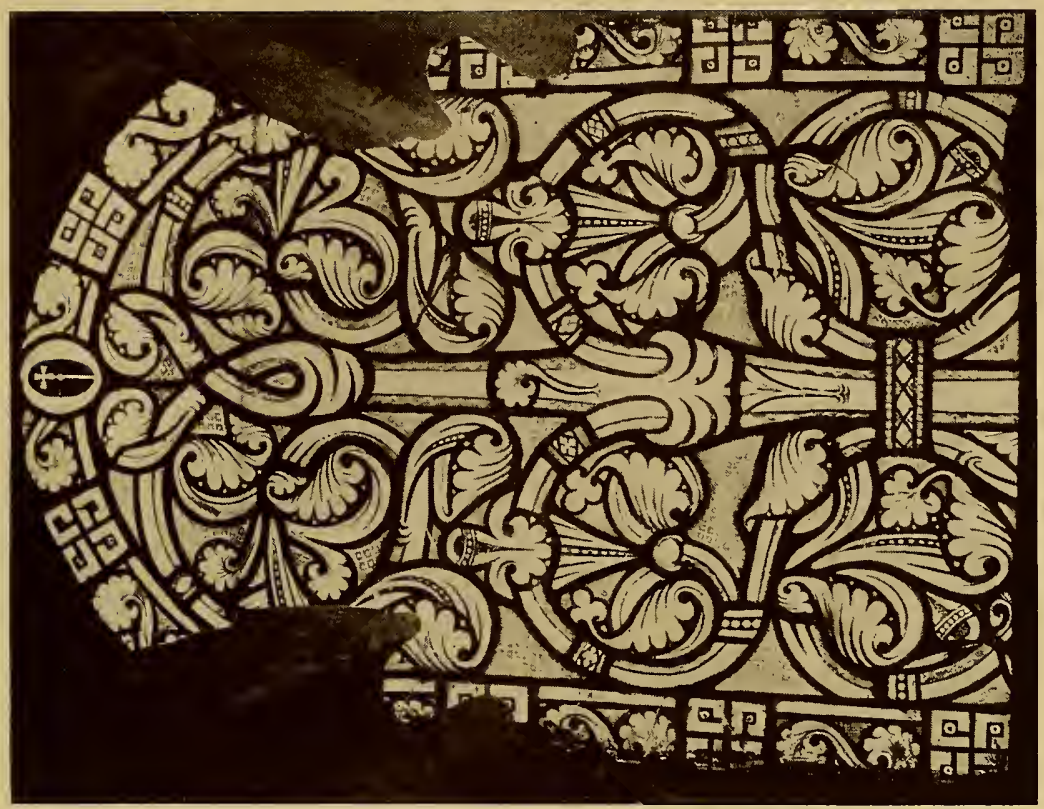

O

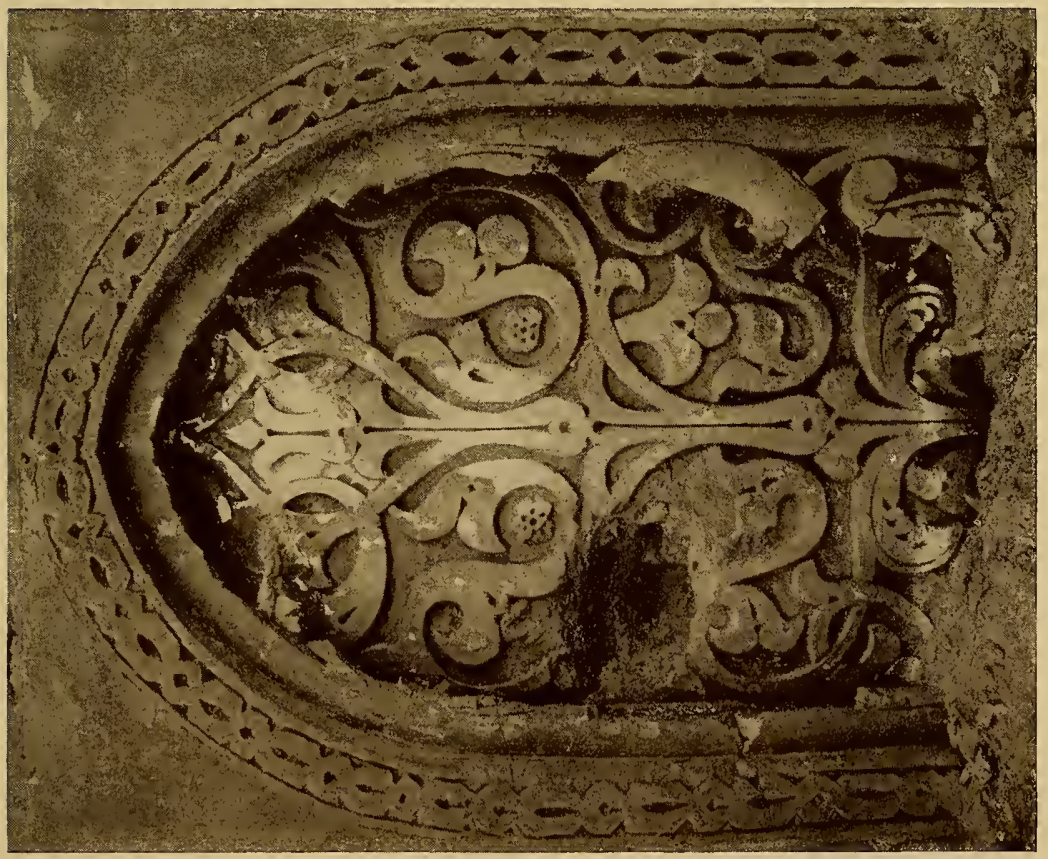

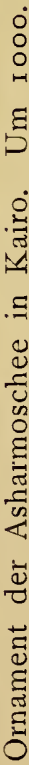



Domes zu Augsburg haben wir, im Vergleich mit den sassanidisch-persischen Messinggefässen, Stoffen und Gläsern, erstmals den Nachweis liefern können, daß der ornamentale Reichtum der romanischen Glasmalerei aus dem Orient kommt. Nun ist vor Jahresfrist auf den Ruinenstätten Kairos ein außerordentlich interessanter Fund gemacht worden, der unsere Feststellung wesentlich stützt und sie insbesondere für die Kunstverglasung belegt. J. Flury hat in seinem Buch: Die Ornamente der Hakimund Asharmoschee in Kairo, das reiche Material alter islamischer Kunst publiziert. Unter den die Ornamente leitenden Motiven, findet sich dekorative Ausgestaltung der zu ornamentalen Zwecken außerordentlich geeigneten arabischen Schriftzeichen. Diese Ornamente haben durchweg etwas Gespreiztes und ermangeln der Monumentalität und Frische. Daneben findet sich aber ein unversiegbarer Quell prächtiger Motive, deren Heimat ohne weiteres als der oben genannte sassanidisch-persische Kunstkreis angesprochen werden kann. Es sind die längst uns geläufigen Ganzund Halbpalmetten, Dreipässe, Ranken, ineinander geschlungene doppeltprofilige Bandornamente, wie wir sie in dem Ornamentschatz der Langobarden, der Gothen und Mauren in Spanien, ebenfalls als aus dem Ornament mitgebrachte Traditionen kennen. Unter jenen von Flury bekannt gegebenen Ornamentmustern befindet sich eines, das mit einem Fenster im Kloster Heiligenkreuz im Wiener Wald geradezu überraschende Ähnlichkeit aufweist (siehe die Taf. IOI-IO3.) Das Bleinetz der Kunstverglasung läßt sich direkt aus dem Steingerippe des Moscheemotivs ableiten. Ursprünglich haben primitive und doch unendlich reizvolle Motive dem Steinfenster seine charakteristische Note gegeben. Oft sind es nur Kreise oder kleine geometrische Figuren, die aus dem Steinkörper ausgespart waren. Man hat in der Wiederholung dieser Figuren das Symbol der Unendlichkeit und Ewigkeit erblicken wollen, das ebenfalls im Orient oft in diesem Sinne gebraucht wurde. Wie dem auch sei, jedenfalls ist der Hinweis auf den Orient für uns sehr wichtig. Noch heute kann man übrigens derlei, sicher auf alte Traditionen zurückgehende, Fensterverschlüsse mit den reizendsten Motiven in einzelnen Tälern Steiermarks an Scheunen beobachten. Aus den massigen Steingerippen wurden immer leichtere Gebilde, 
zum Teil auch aus Holz, bis sie schließlich zur Karolingerzeit im Bleinetz ihr letztes Stadium der Entwicklung fanden. Aus der Periode vor der Bleiverwendung ist nichts auf uns gekommen. Dagegen können aber die Ornamentmuster der Hakim- und Asharmoschee als Beispiele der Frühzeit gelten. Als die figürliche Glasmalerei in Übung gekommen war, versäumten die

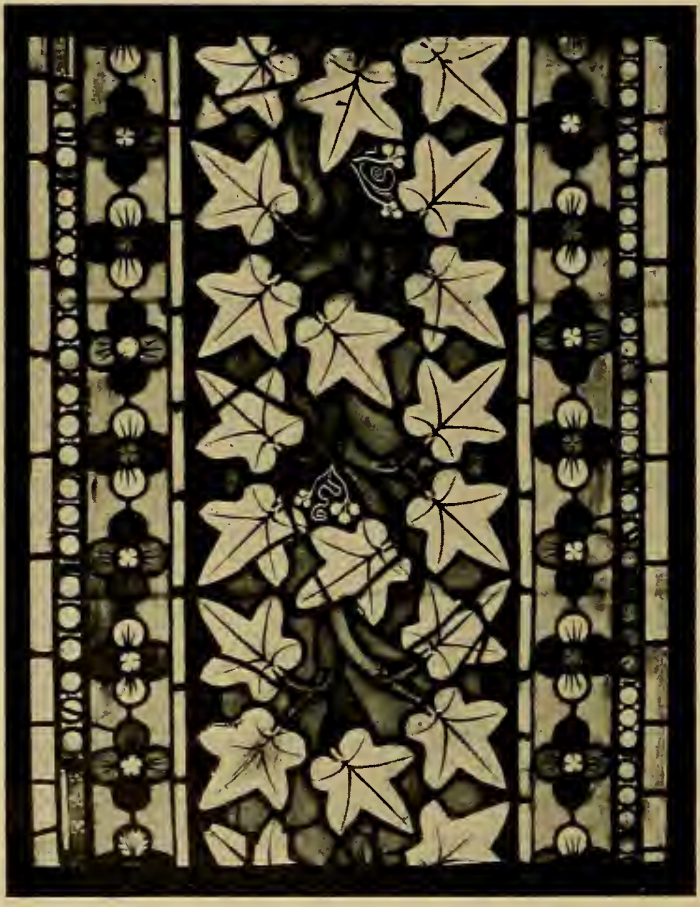

Abb. 42. Teppichmuster. Dom zu Regensburg. I4. Jahrhundert.

Künstler nicht, alte Ornamente, wie sie die Kunstverglasung geschaffen hatte, in die Umrahmungen aufzunehmen. Es scheint, als ob der ornamentaleFormenreichtum hauptsächlich über Regensburg nach dem Westen gewandert wäre. Denn auf den Fenstern der bayrisch - alamannischen Volksstämme hat sich der ornamentale, teppichartige Einschlag selbst in Figurenfenstern am längsten erhalten. Auch die Ausgestaltung der alten und die Erfindung neuer Motive blühte gerade in diesen Gebieten am schönsten. (Abb. 42.) Anstelle der exotischen Palmette traten die Blätter und $\mathrm{Zweige} \mathrm{heimischer} \mathrm{Pflanzen} \mathrm{und}$ Bäume, die mit feinster Naturbeobachtung wiedergegeben wurden. Das Verbot figürlichen, überhaupt buntfarbigen Fensterschmucks, das von dem Zisterzienserkapitel im Jahre II 34 erlassen wurde, brachte die Kunstverglasung en grisaille zu neuer Entwicklung. Im allgemeinen blieb Belgien das Land, in dem die Grisaillekunst lange Zeit und vereinzelt bis zur Gegenwart geübt wurde. An- 


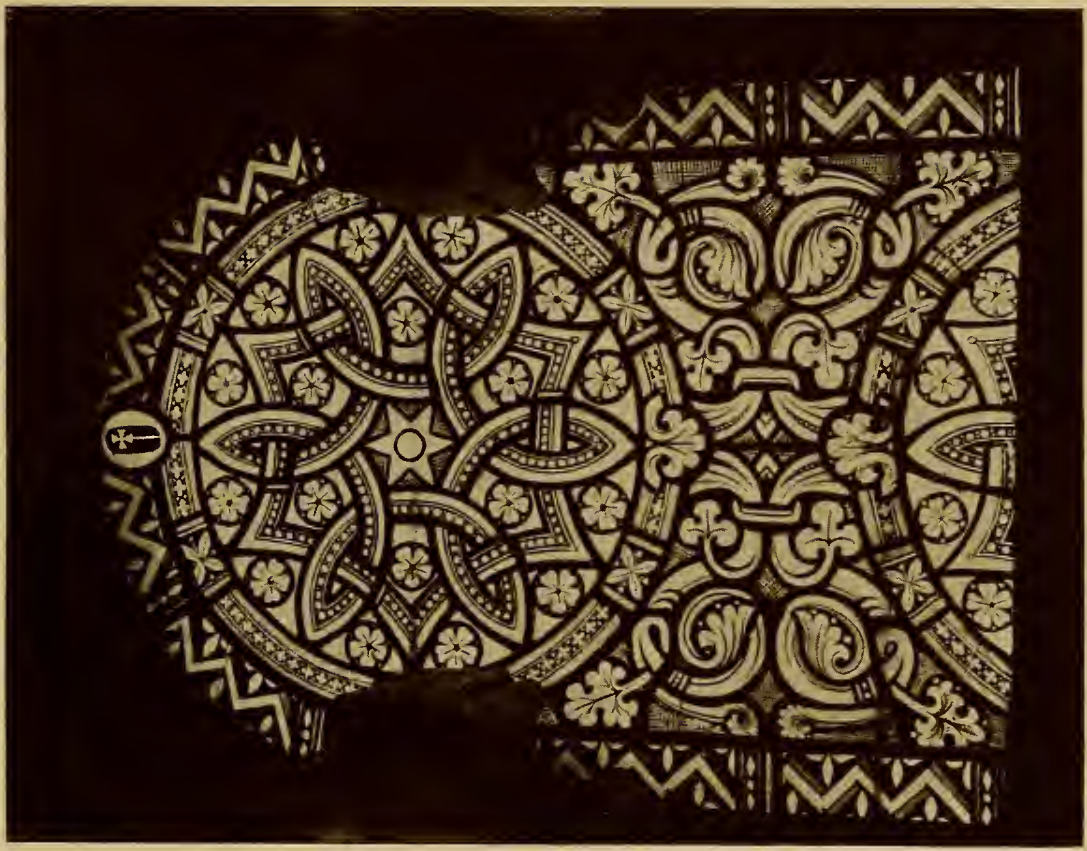

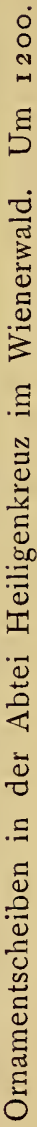

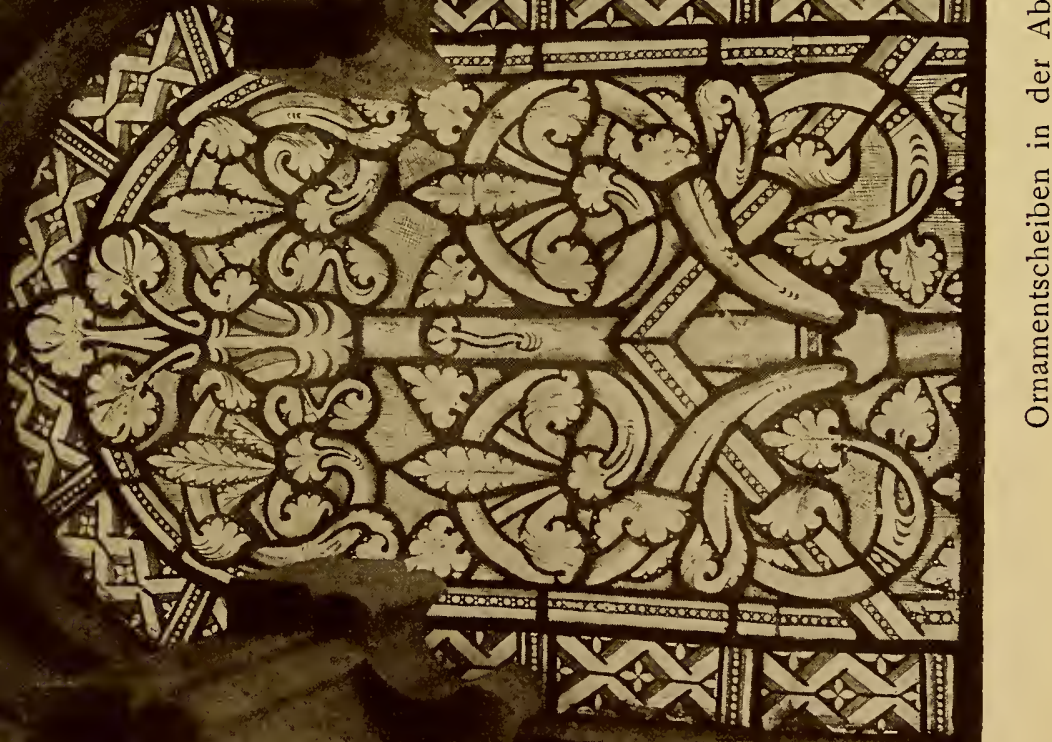

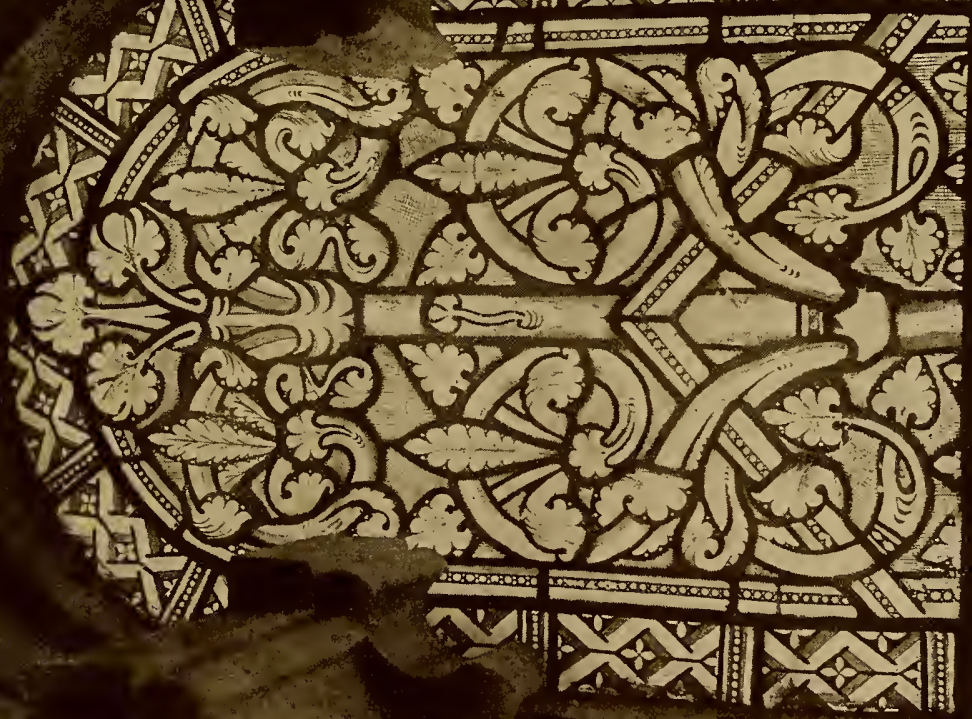

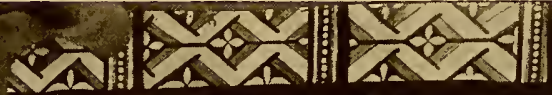





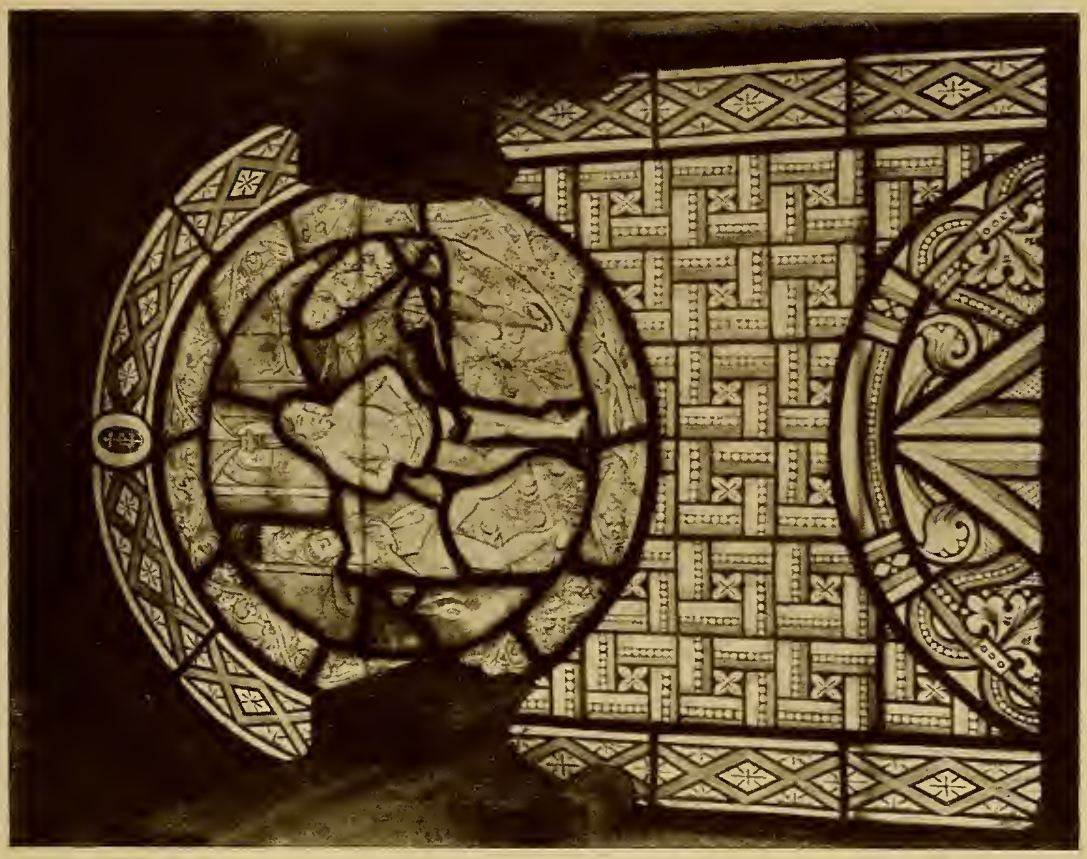

|

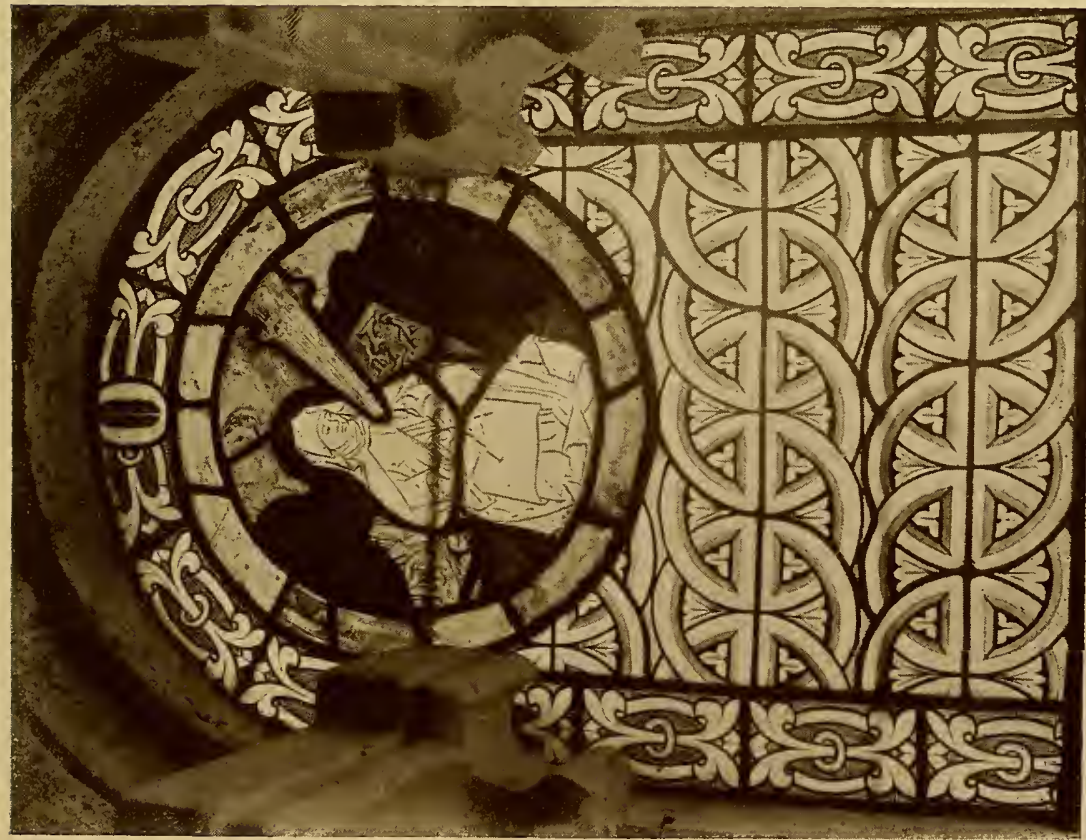

ב 

dere Gebiete wandten sich dem buntfarbigen Ornamentfenster zu. Seit Beginn des.15. Jahrhunderts bürgert sich in den Fürstensitzen der burgundisch-französischen Dynasten die Sitte ein, religiöse und profane Räume mit Rautenmuster $z u$ verglasen. Die Sitte wanderte den Rhein aufwärts, unterlag aber zumeist der alamannischen Butzenverglasung.

Jahrhundertelang blieb die Butzenverglasung die einzige lebendige, allerdings schwache Erinnerung an die Kunstverglasung. Erst seit etwa 20 Jahren begann man wieder die Häuser, insbesondere Treppenhäuser, Fluren, Dielen mit buntfarbiger Kunstverglasung zu schmücken. Die Glasmalerei überließ diese Aufgabe in bedenklicher Kurzsichtigkeit den einfachen Glasern, die um so geschmackloseres Zeug einsetzten, je allgemeiner damals der Mangel an feinem künstlerischem oder gar kunstgewerblichem Empfinden war. Die Folgen dieser sogenannten Kunstverglasungen zeigten sich in einer immer größeren Unlust an Glasmalerei, da man gleichzeitig mit der Verachtung der Entartungen auch den künstlerischen Schöpfungen auf dem Gebiete der Glasmalerei Mißtrauen und Vorurteil entgegenbrachte. Erst in allerletzter Zeit hat die Kunstverglasung unter Führung bedeutender Ornamentisten wieder einen Anlauf genommen und nicht bloß nach alter Gewohnheit Blumen und Ornamente, sondern sogar Tiere und Menschen in ausschließlich ornamentaler Auffassung als Kunstverglasung ausgeführt. Man darf somit hoffen, daß die große Bedeutung der Kunstverglasung für die vornehmsten, wie auch besonders für weniger gepflegte Räume immer mehr erfaßt wird und zwar ebenso von Bestellern, wie von ausführenden Künstlern ${ }^{1}$ ).

\section{Die Hinterglasmalerei. ${ }^{2}$}

Die Hinter- oder Unterglasmalerei steht eigentlich nur in sehr losem Zusammenhange mit der Glasmalerei. Denn die Technik der Hinterglasmalerei läuft dem Wesen der Aufglas-

1) Siehe Fischer, Die Entwicklung der Kunstverglasung, Zeitschrift für alte und neue Glasmalerei i 9 I3, S. $37 \mathrm{ff}$., $50 \mathrm{ff}$.

2) Wessels, Ernst, Hinterglasmalerei, Esslingen 19r3; enthält die Anleitung zur praktischen Betätigung der Hinterglasmalerei. 
malerei direkt zuwider. Es wird nichts gebrannt und nichts gebleit. Man konturiert auf die Hinterseite des Glases, läßt die Konturen trocknen und trägt hernach die nötigen Lokaltöne und Lasuren mittels einfacher Ölfarben auf. Die ältesten Bilder hinterlegte man mit Quecksilber, so daß sie als Spiegelbilder wirkten. Man konnte auch die Konturen gummieren, füllte sie mit Blattgold aus und schwärzte die Hintergründe mit Ruß. Auf diese Weise entstanden Hinterglasmalereien, die beim flüchtigen Blick wie Kabinettscheiben mit Schwarzlot und Silbergelb aussahen. In neuerer Zeit hinterlegt man mit dünngewalztem Zinn (Stanniol). Der Stanniolbogen wird auf der blanken Seite mit stark verdünntem Malerleim befeuchtet und auf die Malerei gelegt. Dieses Verfahren stammt aus Frankreich. Die Farben werden lediglich der Luft zur Eintrocknung überlassen. Allerdings wird auch empfohlen, die Scheibe in einer Bratröhre auf $60^{\circ}$ Celsius zu erhitzen, weil dadurch die Farben fester zu sitzen kämen. Diese Praxis hat jedoch nichts mit dem Einbrennen des Schwarzlots und sonstigen Farben der Aufglasmalerei zu tun. Diese werden vielmehr infolge einer chemischen Verbindung des leicht flüssig gemachten Glases fest mit der Oberfläche verschmolzen.

Als ältestes Glasbild erscheint das im Stift Göttweig befindliche Brustbild eines älteren Mannes mit üppigem Nasenauswuchs. Es trägt die Inschrift: Herr Gerhard Janssen, Kunstberühmter Bürger, glaßmahler wie auch wohlerfahrener Meister der Ätzkunst wurde gebohren zu Utrecht Anno I636 den 2I. July gestorben zu Wien Anno I725 den 3. Juny. Seines Alters 88 Jahr Io Monat 8 tag. Bezeichnet und gemahlt von A. D. Metzgern von Speyer, gleichfalls in diesen Kunsten sich exelierenden Liebhabern, der Zeit anwesend zu Maria hilff bey Wien Anno I725 den 9. July. Siehe die Abbildung dieser Scheibe in der "Österreichischen Kunsttopographie“ I, S. 366. Ein ähnliches Glasbild befindet sich in der Sammlung des Grafen Wilczek (abgebildet im Monatsblatt des Wiener Altertums-Vereins I 896, S. I 7). Jüngst tauchte im Münchener Privatbesitz ein großes Hinterglasgemälde auf, das auf Finke Bom zurückgehen soll. Die eigentliche Stätte der Hinterglasmalerei ist das bayerische Gebirgsdorf; einst soll die Kunst aus Italien gekommen sein. Hans Kysser berichtet 
darüber in einem Artikel: "Über eine sterbende Volkskunst" (Berliner Tageblatt 6. 9. I 2.). „Aus einer alten Kunstgewerbs- und Handwerksgeschichte Augsburgs erfährt man, daß sie auch in Augsburg geübt worden ist, wie es auch im Württembergischen solche Maler heute noch geben soll. Man sagt, daß Lenbachs Vater, als er von Tirol nach Schrobenhausen kam, sich im Winter mit dem Malen solcher Glasbilder beschäftigt haben soll. Als eine Art Hausindustrie aber wurde sie seit der Mitte des vorigen Jahrhunderts in Murnau und dem benachbarten Fischerdörfchen Seehausen am Staffelsee betrieben. Auf ihren Kraxen trugen Händler die Bilder durch die bayerischen Dörfer, und schon für dreißig Kreuzer konnte man ein Originalgemälde erwerben.

Heute muß man diese Bilder suchen, ihre kundigsten Meister sind tot und die eigenen Landsleute haben sie vergessen. Möchte man über Art und Herkunft dieser Glasmalereien Näheres erfahren, so muß man mit den letzten Malern über den Tisch weg, muß die alten Kirchenbücher nachschlagen und Grabsteine fragen.

Obschon dieser Volkskunst eine schöne Anonymität anhaftet, sie war doch die Arbeit von Menschenhänden mit ihren Fehlern und Geheimnissen. Die Meister der ältesten und schönsten Bilder, der Spiegelbilder, werden wohl immer unbekannt bleiben, und man wird auch nicht erfahren, wer die schwarzen Madonnen gemalt oder die Christus- und Gottvaterköpfe, deren dunkler bis zur freien Oberlippe spitz hinaufgezogener Vollbart dem Gesicht einen so tiefen, schweren Ernst verleiht. Aber nennen wir hier wenigstens einmal die Namen derer, über die uns noch Urkunden zugänglich sind. Da schufen in Seehausen die Malerfamilien der Kirchmeir, Gege und Noder. Eine Tochter oder die Witwe des Michel Kirchmeir heiratete 1785 den Paulus Gege, der selbst ein ausgezeichneter Glasmaler war, und im Hause Gege erbte sich diese Kunstübung über den Sohn Aloys (I795- I 864), den Enkel Sebastian (1822-I889), bis zum Urenkel, dem heute noch lebenden Joseph Gege (geboren 1866) fort. Man nannte auch die Maler nach dem Namen ihres Hauses, und so findet man in den Malerfamilien der Noder den Matthias Noder „zum Unterweiß“ (I773-I869), den Ignaz. Noder „zum Lurger“ (I783-I852), den Sebastian Noder „zum Malerschneider“ (1786-I845). In Murnau aber malten etwa Ignaz Schmid (I802-I 833), Matthias Gast „zum 
Schragl“ (I773-I82I), Johann Gastl „zum Welsch“ (geboren I 790, gestorben ?), seine Tochter Karoline, Dominikus Gastl „zum Nok“ ( I 763-I 844), Xaver Kistler „zum Schloßmaler“ (I 836- I 883), Jacob Geiger (I810-I882), Johann Chrysostomus Geiger (I766 bis I 845) und dessen Sohn Florian.

Wäre diese Kunst nur Handwerk oder Spielerei, sie müßte, in solcher Fülle dargeboten, den unbefangenen Blick mindestens mehr ermüden als erfreuen. Sie wirkt aber überraschend, einfach und groß. Unter vielen gleichgültigen Christusköpfen begegnen manche, die durch eine beinahe schablonenhafte Konvention der Zeichnung hindurch wirkliche Züge des Schmerzes, mit einer harten Falte, einer versteinerten Starrheit des Auges, Gequältheit, Bitternis, Zerknirschung offenbaren. Sie rufen ihre toten Meister von den Toten und lassen durch die Masken der heiligen Männer ihre persönlichen Weltgefühle auf uns strömen. Dann bleibt der kalte Quecksilbergrund kein Spiegel; er wird zur kühlen, eisig schimmernden Unendlichkeit. Wie oft findet man ein Christuskind auf einem Bette liegend. Dornen umkränzen das Bett, und eine Krone liegt greifnah den Händen; aber das ganz besondere milchbläuliche Weiß des Bettes, die aufdringliche Schwärze der Dornen darauf, die anbetende Melodie, nach der sie sich zum Kranze um das schimmernd gebettete Kindlein fügen, der Ernst des wütend zusammengewürgten Dornenstranges vor dem kleinen Wesen, dazu der unbewegt einförmige Hintergrund fangen an zu reden. Eine Komposition kann man übernehmen, aber sie noch einmal in Farbe und Form komponieren, bis sie wieder Leben und Gegenwart wird, das kann niemand übererben. Man erstaunt so bei den verschiedensten Motiven, wie eindeutig sicher die Farben durch das Bild zusammenklingen, bald durch die ganze Skala alle Formen erwärmend, bald sie verdüsternd und belastend. Mitunter ist das Bewußtsein des Könnens so stark geworden, daß aus dem Erstrahlen der Farben immer neue Fabeln sich enthüllen. Es gibt in der Krötzschen Sammlung zum Beispiel eine Magdalena in Tönen von so sanfter Stärke und so gewollter Bestimmtheit der Wechselwirkung, daß sie von einem modernen französischen Maler sein könnte. Andere erinnern an älteste Holzschnitte und Miniaturen. Und hat man seinen Blick erst einmal den einzelnen Malern be- 


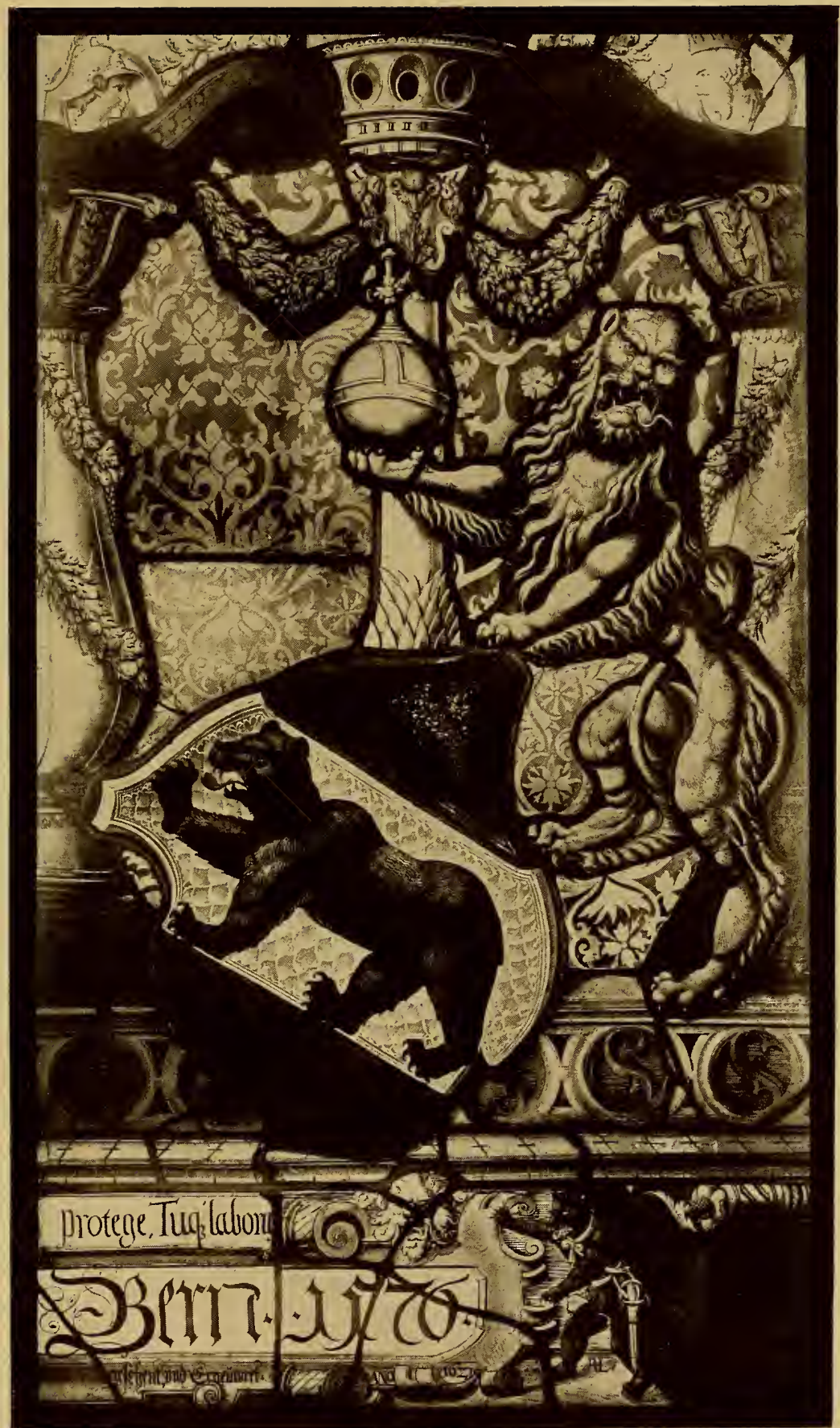

Berner Standesscheibe aus dem Jahre 1576 , erneuert im Jahre I $62 \mathrm{I}$ von dem Glasmaler Hans Rudolf Lando. Historisches Museum in Bern. 

sonders hingegeben, so erkennt man sie leicht wieder: den an den wunderbaren blauen Schatten, jenen an der feinen Zeichnung der Hände und des Gesichtes, andere an der zackigen Starrheit der Linien.

Dem billigen Farbendruck hat diese Kunst weichen müssen. Man kaufte sich die neuen "schöneren" gedruckten Bilder und warf die alten handgemalten auf den Kehricht. Die Maler aber quälten sich ab, die Glätte und die Motive der Farbendrucke nachzuahmen; so entstanden peinliche Werke, und niemand mochte den Preis der mühevollen unfruchtbaren Arbeit bezahlen. Steigt man heute von Murnau nach Seehausen in das Haus „Zum Kramerl" herab, wo der letzte Glasmaler aus der Familie der Grege wohnt, so stellt sich ein kleiner, kräftiger, schwarzbärtiger Mann vor, der freundlich-bitter seine Auskunft gibt. Man merkt ihm an, daß es im wehe tut, ein Gewerbe, von Urgroßvaters Zeit geübt, gänzlich aussterben zu sehen. Daß die schöne Kunst der alten Glasmalerei in ihm selbst gestorben ist, weiß er nicht. Seine Bilder scheinen peinlichst ausgeführte Kopien von schlechten Farbendrucken. Sein Fleiß hat keinen Preis, sein Können nicht die Kunst. In Murnau aber malt als einziger noch der junge Heinrich Rambold: im Sommer streicht er Zäune und Häuser an, im Winter lebt er seiner Glasmalerei. Alle seine Farben lachen, und er weiß, worauf es ankommt: ein reines Rot und Blau und herzhafte Striche. Das findet er bei den ältesten Meistern, und auf sie greift er am liebsten zurück. Bei seinen Heiligen, selbst wenn sie wie der heilige Dionys den Kopf in der Hand halten, geht einem das Herz in Fröhlichkeit auf. In ihm lebt noch eine helle Ahnung des Wesentlichen und des Volkstümlichen. Aber ein einzelner kann das Sterben einer Volkskunst nicht aufhalten. 


\section{III.}

\section{Die Wiederbelebung der monumentalen Glasmalerei im 19. Jahrhundert.}

Man ist allgemein der Überzeugung, daß mit der zweiten Hälfte des I6. Jahrhunderts die Glasmalerei, soweit der monumentale Stil in Betracht .käme, auf lange Zeit in einen völligen, ungestörten Schlaf versunken sei, aus dem sie erst der Nürnberger Porzellanmaler Sigismund Frank wieder erweckt habe. Im Laufe des letzten Jahres sind jedoch drei Glasgemälde bekannt geworden, die beweisen, daß sich eine leise Tradition durch alle Jahrhunderte erhalten haben muß. Zuerst tauchte eine Scheibe mit Herz Jesu aus dem Kloster Maursmünster in der Pfalz auf, die durchweg mit farbigen Hüttengläsern behandelt war. Laut Umschrift stammt sie von "Johann Adolf Danegger. Civ. et scab. Argent. I 767 " (Abb. 43). Eine andere, Figurenscheibe, entdeckte Hans Kunze ${ }^{1}$ ) im Straßburger Münster und der Schreiber dieser Zeilen stieß in einem württembergischen $S c h l o ß$ auf eine große in farbigem Hüttenglas ausgeführte Wappenscheibe mit der klein eingeritzten Inschrift AD. Danegger. Argent. In der zweiten Hälfte des I8. Jahrhunderts existierte also eine Glasmalerfamilie Danegger in Straßburg, die noch im Vollbesitz der technischen Ausdrucksmittel der monumentalen Glasmaler war. Knorr sagt von dem einen, A. D. Danegger: er war Kupferstecher und hat nach Strobl auch in Glas gemalt, "ohne jedoch ein hohen Gipfel der Vollkommenheit zu erreichen". Ein von ihm und einem C. Seyfried auf Glas gemaltes Porträt befand sich ehedem auf der Bibliothek zu Straßburg ${ }^{2}$. - Die letztgenannte Scheibe

1) Straßburger Münsterblätter 1913. S. I 22.

2) Becker-Thieme Künstlerlexikon s. v. Danegger. 
ist trotz der begreiflichen Befangenheit in der Zeichnung sehr gewandt ausgeführt. Auch des Johann Adolf Danegger Glasgemälde zeigen eine Reihe von Vorzügen. Jedenfalls ist durch die Glasgemälde der beiden Danegger der Nachweis erbracht, daß die Kunst der Glasmalerei ebenso wenig völlig auch nur kurze Zeit ausgestorben ist, wie das Rezept für Herstellung farbiger Gläser. Darum muß auch das ästhetische Vorurteil, als habe Barock und Rokoko selbst empfunden, daß Glasmalerei nicht für sie passe, weil absolut gar nichts in diesen Stilperioden geschaffen worden sei, bedeutend korrigiert werden.

Die Tätigkeit des Nürnberger Porzellanmalers Sigismund Frank verliert durch diese Tatsachen indes nichts an ihrer Bedeutung, da Frank von den Glasmalereien der Danegger sicher nichts gewußt hat. In einer Gelegenheitsschrift haben wir die Tätigkeit Franks näher untersucht(VierzigJahre

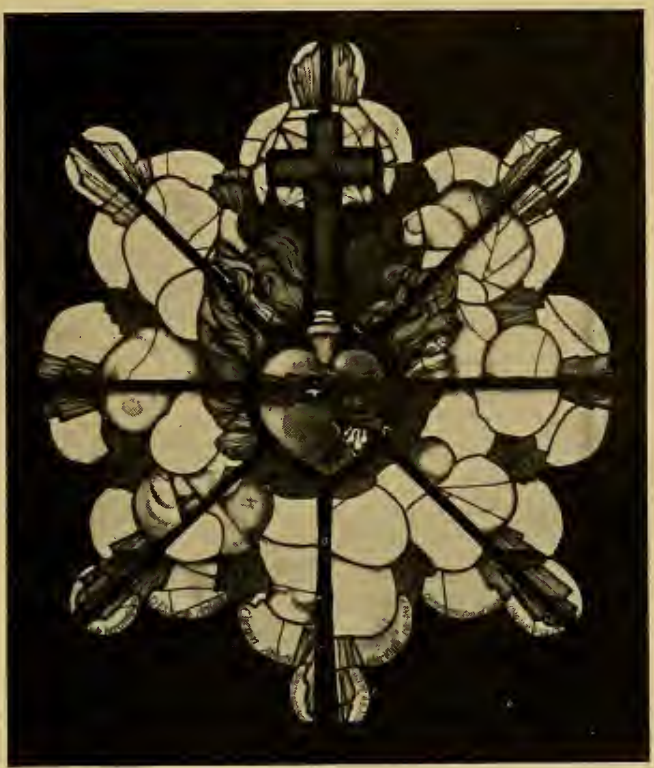

A bb. 43. Glasgemälde in Maursmünster J. D. Danegger aus Straßburg 1767.

Glasmalkunst, S. 27). Als Resultat ergab sich folgendes Bild: Bereits gegen Ende des I 8. Jahrhunderts hatte Sigmund Frank (geb. I 770 , gest. I 847) Versuche unternommen, die Glasmaltechnik wieder herzustellen; ihnen widmete Frank eine Zähigkeit und Festigkeit, die über die vielen Mißerfolge hinweg doch schließlich zu einem gewissen Ziel führten. Zu Beginn des 19. Jahrhunderts gelang es ihm, jene Farben wieder zu schaffen, die sich auf Glas einbrennen lassen. Franks erste Arbeiten waren Wappen, Porträts und Landschaften. Seine fortgesetzten Versuche verschafften ihm erst beim Fürsten Wallerstein, dann bei König Max I. eine feste 
Stellung; dieser setzte ihm 800 Gulden Jahresgehalt aus und ließ $\mathrm{ihm}$ unter Einverleibung in die kgl. Porzellanmanufaktur einen Brennofen bauen. Franks Verfahren war folgendes: „Er nahm einen Kupferstich oder eine Zeichnung und zog die Umrisse auf der weißen Glastafel nach, setzte dann mit Schmelzfarben auf der Rückseite des Glases die Lokaltöne auf und schattierte auf der Vorderseite die einzelnen Partien. Es waren also diese Bilder einfach kolorierte Kupferstiche auf Glas. Das tadelte auch das amtliche Gutachten vom IO. März I820: ,Die Behandlung der Farben ist nicht eine malerische, sondern mehr die Illuminierung eines Kupferstichs. Außerdem fehlt das Rubinrot der Alten und ein kräftiges Grün noch ganz،." Franks größter Irrtum war der, daß er vom weißen statt vom farbigen Hüttenglas ausging bzw. stets an jenem haftete. Von seinen Kabinettsmalereien besitzt beispielsweise das Bayerische Nationalmuseum sieben Stücke; auch das Kgl. Kunstgewerbemuseum Berlin verwahrt einige Arbeiten. Diese Scheiben sind zum Teil aus farbigem Hüttenglas geschnitten und mit Buntfarben, wie z. B. dem herrlichen Frankschen Rosarot, behandelt. Im Jahre 1858 hatte der große Philosoph Schelling als Präsident der Akademie der Wissenschaften Anlaß genommen, einen offenen im Journal des débats 20. I 2. I 838 abgedruckten Brief an Saint Marc Girardin in Paris zu richten, in dem er dem Adressaten auf dessen Befragen offiziellen Bescheid über die Entwicklung der neubelebten Glasmalerei gibt. Darin heißt es von S. Frank: „Er war zu wenig Künstler, als daß von ihm der gewünschte Aufschwung der Glasmalerei hätte ausgehen können." In diesem gewiß richtigen Satz kommt die Anschauung jener an Öl- und Freskogemälden überreichen Zeit zum Ausdruck, die im Glasgemälde zuerst den Karton suchte und erst hernach die Technik, wenn überhaupt, so nebenbei betrachtete. Nachdem sich Frank mehr auf farbige Hüttengläser (hergestellt in Benediktbeuren) konzentriert hatte, war er seinen Zeitgenossen in der spezifischen Auffassung der Glasmalerei sicher vorbildlich. Und als die Glasmalerei mit der Bestellung der Fenster für den Dom zu Regensburg und Köln durch König Ludwig I. von Bayern den ersten größeren Auftrag bekam, da zeigte sich, daß die von Frank gemalten Fenster technisch weit vollendeter waren, als die nach den Kartons von Schraudolph. 
Tafel 105

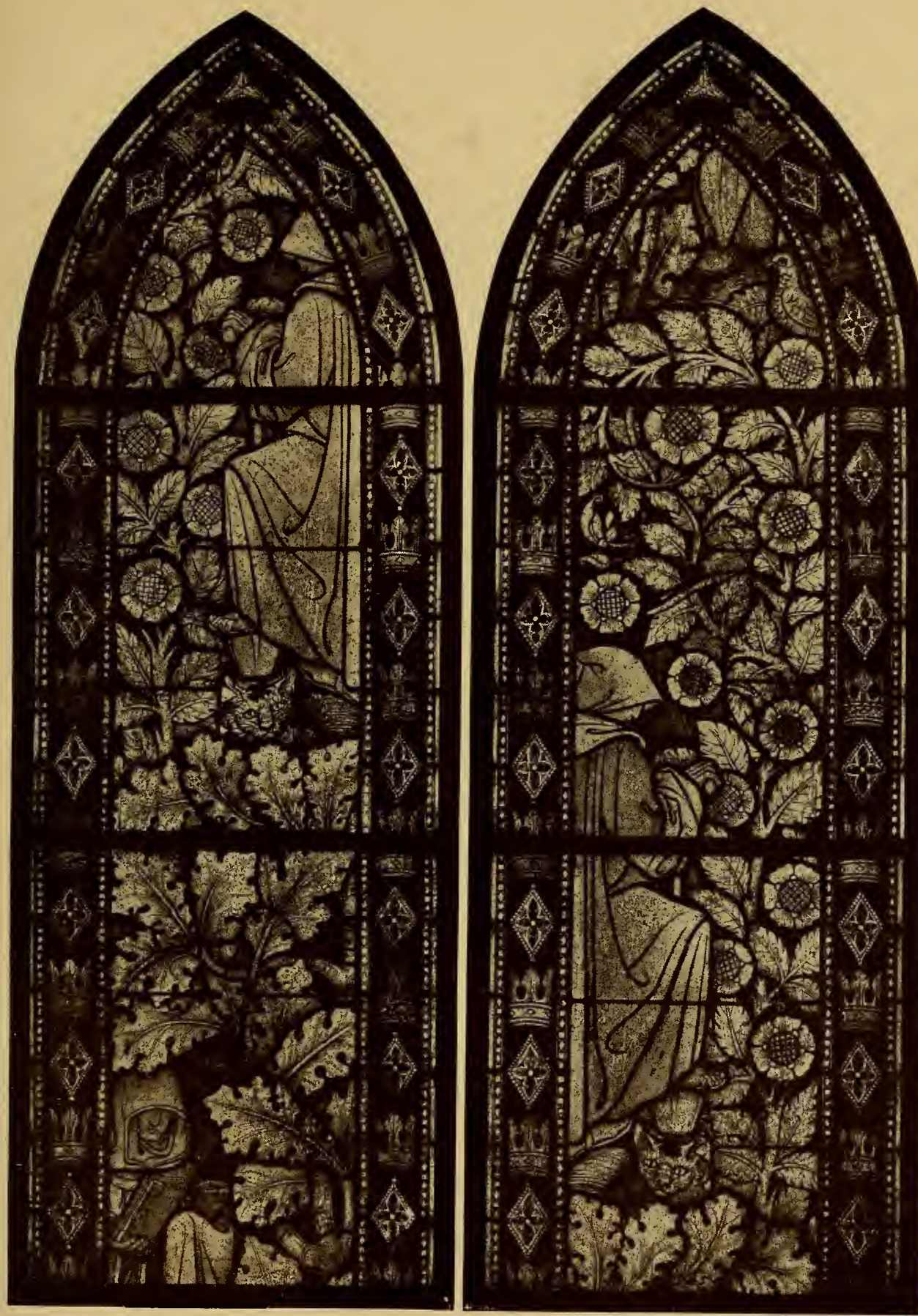

Detail eines Teppichfensters für den Dom zu Altenberg. Entworfen und ausgeführt von Prof. Alex. Linnemann, Frankfurt, I892. 

Im Jahre I 827 errichtete Ludwig I. die Kgl. Glasmalerei, seit I 837 mit Ainmüller als' technischem und Heinrich $\mathrm{Heß}$ als künstlerischem Leiter. Die bedeutendste Arbeit dieses' Instituts sind die neun Fenster für die Mariahilfkirche in der Münchener Vorstadt Au, die I 832-i 846 nach Kartons der beiden Corneliusschüler Christian Ruben (I $805-$ I 875 ) und Wilh. Röckl (I 804 bis I 843 ) und besonders des Heßschülers Jos. Ant. Fischer (I 8 I I bis I 859) ausgeführt wurden (Abb. 44). Der bekannte Kenner der Glasmaler M. A. Gessert rühmt von ihnen: „Die Vorzüge beziehen sich nicht allein auf die Farbe und Farbenwirkung, welche sinnlich und geistig gesteigert und einem Punkte nahegebracht ist, von dem es sich kaum vorstellen läßt, daß irgend noch darüber könne hinausgegangen werden, sondern betreffen ebensowohl und weit noch mehr die Komposition, die Durchdringung des Gegenstandes und zumal das tiefere Eingehen und sich

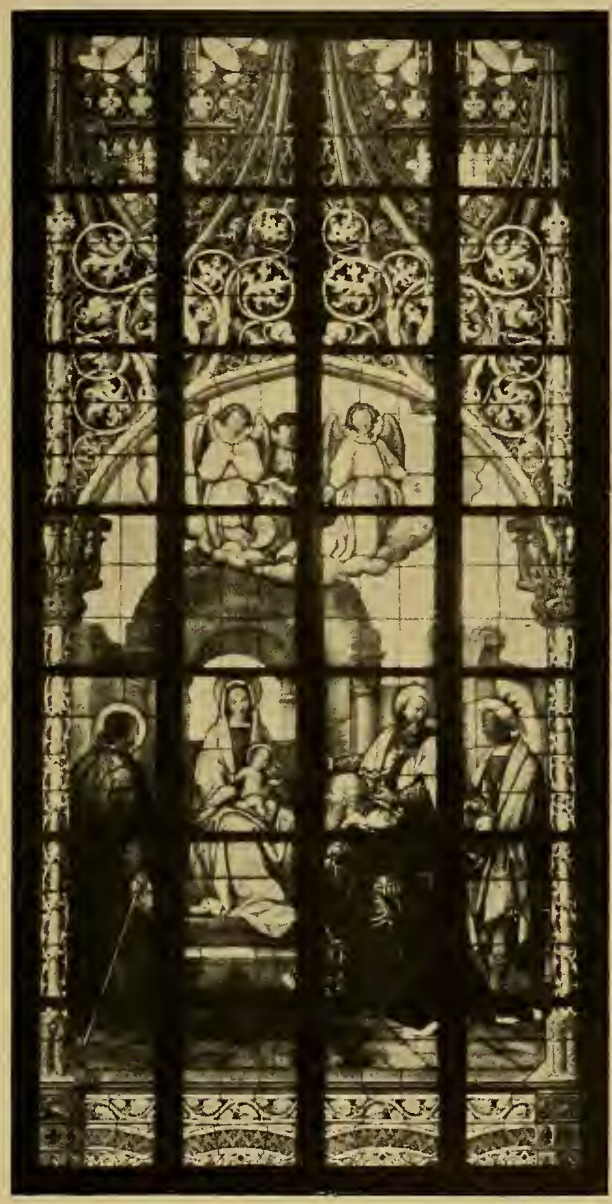

Abb. 44. Glasgemälde in der Mariahilfkirche zu Münster. Karton von Josef Anton Fischer. 1838 . Einleben in jenen symbolischen kirchlich höchsten Stil, durch welchen es der Glasmalerei verliehen ist, vermöge einer wunderbaren, kïhnen und innigen Verbindung des Architektonischen, Bildlichen und Ornamentalen in eine Region sich $z u$ erheben, wohin die Malerei 
sonst auf keine Weise zu gelangen vermag“. Freilich befriedigen die Fenster unsere moderne Auffassung von dem Wesen und Reiz der Glasmalerei nicht. Die Fenster haben in ihrer Kompositionstechnik eine allzustarke Anleihe bei der Ölmalerei genommen. Die Konturen sind schwach, alles ist zu sehr auf die Perspektive eingestellt. $\mathrm{Zu}$ wenig und $\mathrm{zu}$ schwache Bleie bilden ein dürftiges Gerüste. Noch bedenklicher steht es mit den Gläsern. Die Auer Fenster sind zum größten Teil aus dem heute sog. französischen Glas hergestellt. Die Masse dieses Glases ist vollständig rein, die Oberfläche spiegelglatt, die Durchsicht kristallhell. Bei auffallendem Sonnenlicht bricht der ganze Farbenakkord zusammen, der an sich schon mangelhaft klingt. So steht beispielsweise neben dem blendenden Schwefelgelb des ungeheuer weitläufigen architektonischen Ornaments eine relativ nicht minder große eintönige Fläche von Hellgrau, in der eingezeichnete Köpfe wegen ihres ähnlichen Graus ebenfalls fließen. Es ist klar, daß bei strahlender Sonne die Lichtfülle nahezu unbehindert durchströmt und den Beschauer blendet. Umgekehrt verliert ein opaker Akkord (blau-rot-grün) bei Wolkenhimmel jede Leuchtkraft oft derart, daß die Zeichnung die genügende Deutlichkeit einbüßt. Wären die großen Flächen der Hintergründe, der Gewänder auch nur ein paarmal gebrochen, so würden die sehr gut komponierten Fenster eine mächtige und bereits echt glasmalerische Wirkung hervorrufen. Am besten sind jene Fenster gelungen, die sich von einem Naturhintergrund abheben; auf ihnen kommt die perspektivische Lichtwirkung am fernen Horizont zu selten erreichtem Ausdruck. Die Reaktion gegen dieses sog. französische Glas blieb nicht lange aus; sie bereitete sich in England vor. England hat während der ersten Hälfte des 19. Jahrhunderts seinen Bedarf an gemalten Glasfenstern aus Deutschland, speziell aus München bezogen. Bekannt sind die unter Ainmüllers Leitung in der kgl. Glasmalereianstalt gefertigten Fenster für die Kathedrale $\mathrm{zu}$ ^Glasgow, für die Paulskirche in London, die Universitätskirche in Cambridge, für den Vatikan in Rom. Im Jahre I85 I war die Glasmalereianstalt dem bisherigen Leiter Ainmüller auf seine Privatrechnung übertragen worden, während der Staat die Baukosten deckte. Ainmüller führte sie in dem bereits dargelegten Sinne 


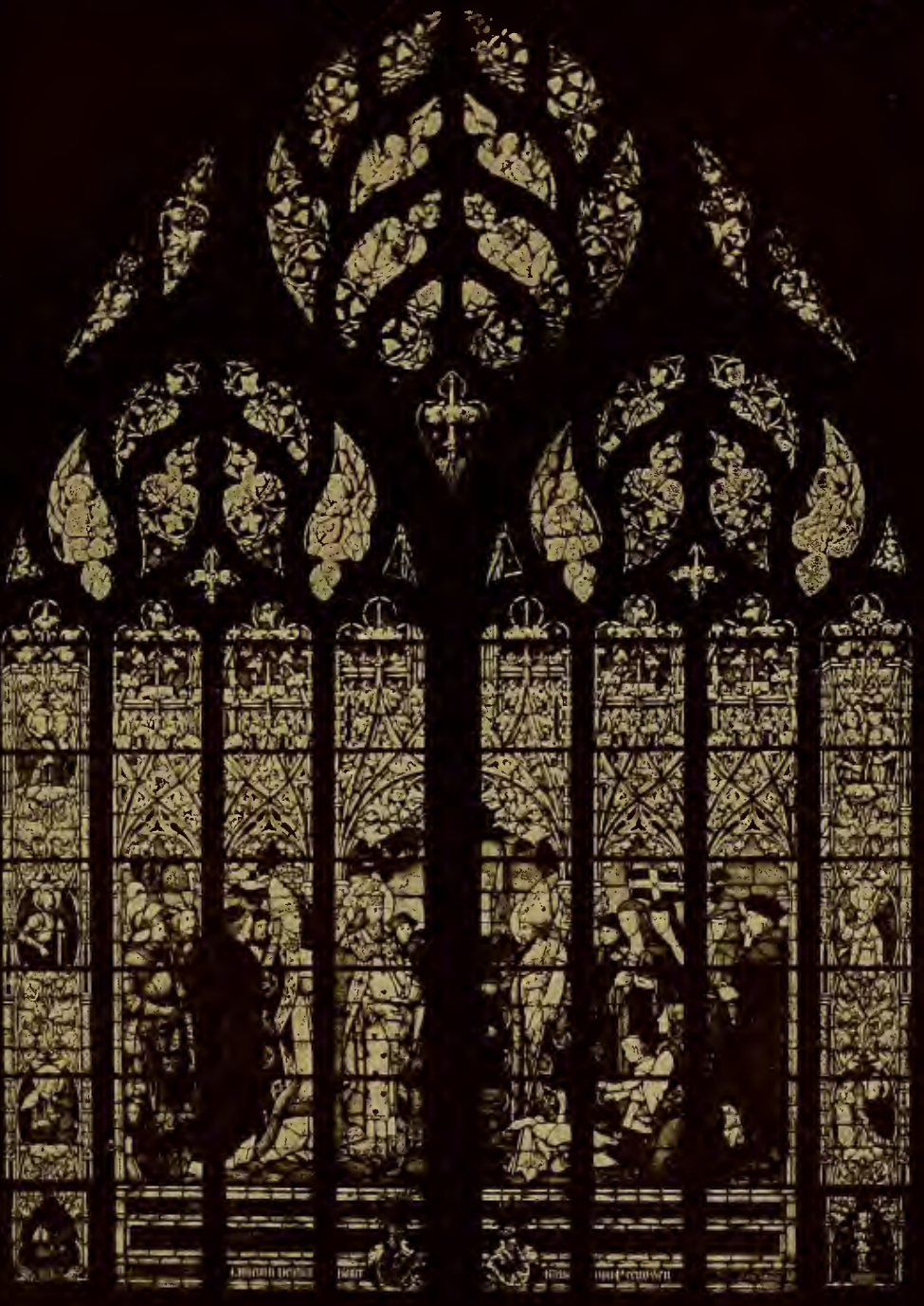

Glasgemälde, als Stiftung des Deutschen Kaisers, entworfen und ausgeführt von Prof. C. de Bouché, München. 

und Stile bis $\mathrm{zu}$ seinem am I2. Dezember 1870 erfolgten Tode weiter.

Neben München hat sich die Werkstatt des Ludwig Mittermaier in Lauingen ( I 827- - 864) hervorgetan. In Dresden versuchten sich Mohn und Wilhelm Vörtel; in Meißen, wo dieverwandte Technik der Porzellanmalerei von selbst zu Versuchen reizte, beschäftigte sich Scheinert mit Glasmalereien. In Köln machte ein humorvoller Marktschreier R. Birrenbach sich anheischig, gegen pränummerierte zehn Karolinen pro Person das verlorene Geheimnis „das er wiedergefunden, gemeinnützig zu machen und nicht mit ins Grab zu nehmen". In Berlin ergaben sich Scheidt und Frick einer primitiven Glasmalerei und erregten wenigstens das Interesse, so daß sich das Terrain für eine besondere Pflegestätte der Glasmalerei ebnete. Kurz nach den Erfolgen der Münchener Anstalt wurde in Berlin
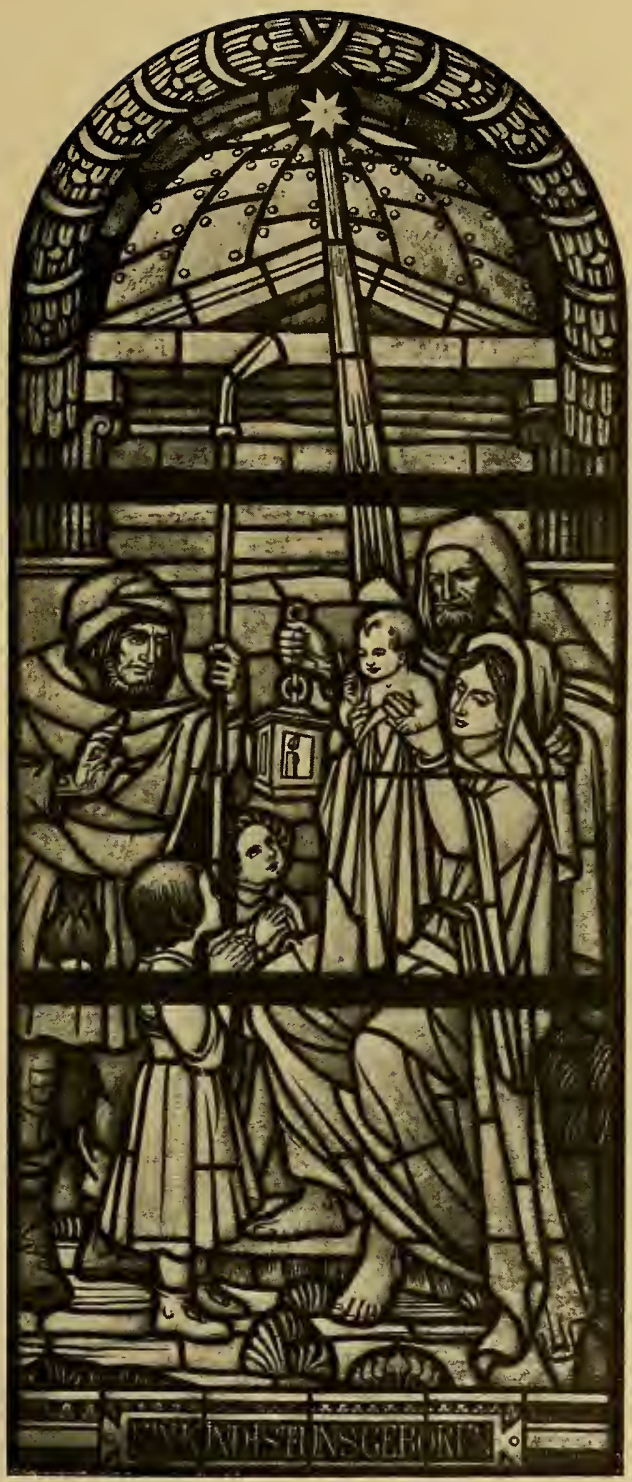

Abb. 45. Glasgemälde in der Kirche zu Lennewitz. Entworfen und ausgeführt von R. Linnemann, Frankfurt. im Jahre I 843 durch königliche Munificenz eine Anstalt ins Leben gerufen, die I 883 reorganisiert, I 887 verstaatlicht und 1905 , wie früher 
das von König Ludwig geschaffene bayrische Schwesterinstitut, in Ansehung der zu hoher Blüte gediehenen Privatindustrie auf allerhöchsten Beschluß wieder aufgelöst wurde. Friedrich Wilhelm IV war bekanntlich ein die Romantik liebender König; der geheimnisvolle Farbenzauber, die Glasmalereien der alten Dome reizten ihn, und so gründete er, dem Vorgange des kunstbegeisterten Bayernkönigs folgend, in seiner Hauptstadt zur Wiedererweckung dieser schönen Kunst ein gleiches Institut, dessen Kosten er aus seiner Privatschatulle bestritt: Das Königliche Institut für Glasmalerei zu Berlin. Die Leitung dieser Anstalt wurde dem General Vogel von Falckenstein übertragen, dessen Feldherrntalent sich mit entsprechenden künstlerischen Anlagen glücklich vereinte. Unter dieser Führung wurden außer privaten Schöpfungen zahlreiche Kirchenfenster für die Dome in Cöln, Aachen, Breslau, Stralsund und an vielen anderen Orten in der wie man glaubte wieder neu gewonnenen Technik ausgeführt. Das letzte Monumentalwerk dieser Anstalt und auch wohl die bedeutenste Leistung war das Fenster in der Karthause zu Nürnberg. Nach dem Tode des Generals wurde die Verwaltung des Instituts von dessen Sohn als Erbe übernommen, und von Kaiser Wilhelm I. bestätigt, führte dieser als damaliger Oberst das Regiment der Kunstanstalt noch einige Jahre, bis von staatlicher Seite eine der Schatullverwaltung der Kosten wegen auch wohl erwünschte Art von Vergewaltigung stattfand, das Institut in die Verwaltung des Staates überging und reorganisiert wurde. $\mathrm{Zu}$ diesem Behufe wurde ein tüchtiger Glasmaler aus der Zettler'schen Anstalt in München zum künstlerischen Leiter berufen. Die Anstalt selbst wurde dem Ressort der Handels- und Gewerbeverwaltung zugeteilt. Im Staatshaushaltsetat war nun aber das Institut von der Gnade der Abgeordneten abhängig und bildete durch das jährlich ausgeübte Bewilligungsrecht seiner Betriebsmittel ein geeignetes Streitobjekt, wodurch die Existenzfrage nicht wesentlich gefördert wurde. Ohne Zweifel wurde jedoch auf die Entwicklung der Kunst insofern ein entscheidender Einfluß ausgeübt, als durch die Verarbeitung des inzwischen auch von deutschen Glashütten produzierten Antikglases der richtige Weg zur Entfaltung angebahnt und durch vielfache öffentliche Ausstellungen solcher aus farbigem Hüttenglas hergestellten Werke die Ge- 


schmacksrichtung wesentlich beeinflußt wurde. Leider vermochte der leitende Künstler, der ein gelernter Porzellanmaler war, sich von dieser in der Jugend und der späteren Praxis ausgeübten Technik nicht ganz loszusagen und blieb zeitlebens in einer bildmäßigen, zum Naturalismus hinneigenden Darstellungsweise befangen, sodaß bei aller Korrektheit der angewandten Technik und technischer Geschicklichkeit das Institut nicht aus der Zeitströmung heraus zu einem wirklichen Höhenflug eigenen künstlerischen Schaffens gehoben wurde. Dagegen war ihm in der Wiederherstellung alter Fenster eine Aufgabe gestellt, der er in befriedigender Weise gerecht wurde. Iier stand dem künstlerischen Leiter in der Person des I89I zum Direktionsassistenten ernannten Maler Engel eine Kraft zur Seite, die mit historischem Sinn sich in die alten Darstellungen $\mathrm{zu}$ vertiefen verstand und die intuitive Veranlagung besaß, die notwendigen Ergänzungen mit Verständnis und Geschick in ihrem logischen Zusammenhange $z u$ erkennen, sodaß eine Wiedergeburt des verloren gegangenen erfolgen und das Alte in seinerEin-

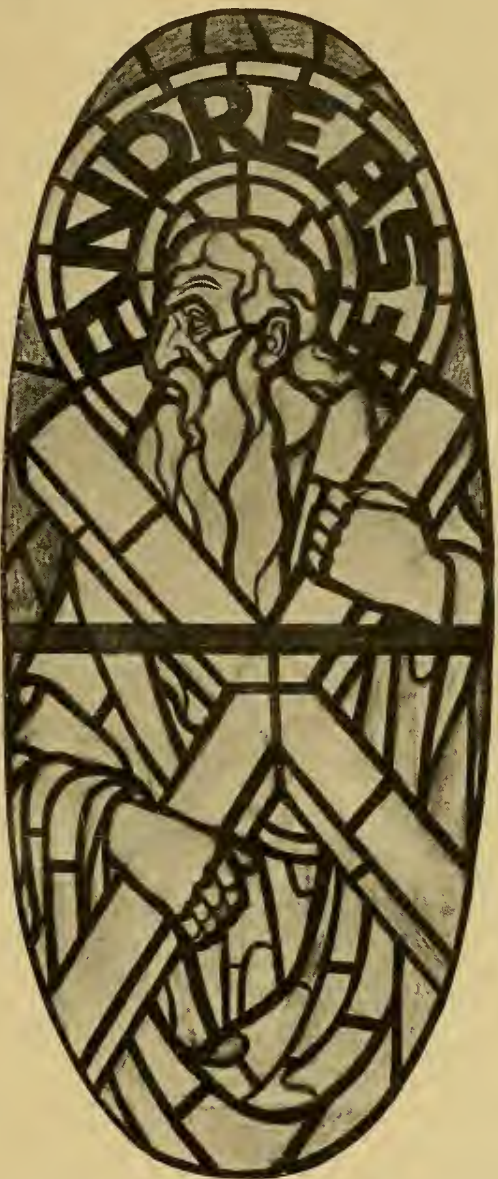

Abb. 46. Glasgemälde, entworfen und ausgeführt von der Glasmalerei Binsfeld, Trier. heit wieder erstehen konnte. Seine erste Arbeit war die Sichtung des vorhandenen alten Glasmalereibestandes des Domes von Stendal, und mit der Verarbeitung und Unterbringung der letzten vorhandenen Reste, die er nach dem Ableben des Direktors Bernhard selbständig zu Ende führte, schloß auch merkwürdigerweise seine Tätigkeit zugleich mit der des 
Instituts. Im Auftrage des Kultusministers führte Engel die Wiederherstellung der figürlichen Chorfenster der Elisabethkirche in Marburg, die von Dr. Arthur Haseloff in einer großen Monographie herausgegeben wurden, aus. Haseloff rühmt dieser Arbeit nach (a. a. O. S. 7) „die alten und die erneuerten Teile stimmen so völlig zu einander, daß es heute selbst für den Fachmann, sei er Gelehrter, sei er Künstler, schwer sein dürfte, mit Bestimmtheit die alten Stücke von den Ergänzungen zu scheiden“. An sämtlichen anderen Wiederherstellungsarbeiten alter Glasmalereien ist aber Engel in einer besonderen Weise auch noch dadurch beteiligt, daß er ein photographisches Archiv seiner eigenen Aufnahmen dieser alten Glasmalereien anlegte, wodurch es nun wenigstens ermöglicht ist, dieses Material der Kunstforschung und dem Kunststudium überhaupt zugänglich zu machen.

Die nicht unerheblichen Schwierigkeiten der Zusammengehörigkeit der Reste wurden von Engel, der zu diesem Behuf in Ermangelung anderer Unterstützung in jener Zeit selbst umfassende Studien auf dem Gebiete der christlichen Ikonographie und Hagiologie machen mußte, in jeder Beziehung glücklich gelöst. Es wurde ihm daher auch seitens der Regierung nahe gelegt, die von ihm gesammelten Aufnahmen durch zweckgemäße Veröffentlichung einem größeren Publikum zugängig zu machen. Nach Einsichtnahme einiger uns eingesandter Stücke wäre dies auch im hohen Maße wünschenswert, und wir hoffen, daß durch bereitwillige Mitarbeiter und Herausgeber sich dieser Plan bald verwirklichen lassen wird.

Außer den Glasmalereien des Doms in Stendal liegen an Material vor: Die Chorfenster aus der Stiftskirche zu Ramelsloh bei Lüneburg, dem Dom zu Wilsnack, der Johanneskirche zu Werden, dem Dom zu Havelberg, der Kirche zu Kentz in Vorpommern, dem Dom zu Halberstadt, sechs Fenster aus dem hohen Chor des Erfurter Doms, Fenster aus der Kirche des Klosters Neuerdorf bei Gardelegen und aus der Kirche zu Uslar. Von der Elisabethkirche zu Marburg besitzt Engel außer seinen photographischen Aufnahmen auch noch eine Anzahl farbiger Wiedergaben von Fenstern in natürlicher Größe, u. a. auch des Medaillonfensters mit der Legende der hl. Elisabeth, von dem in 


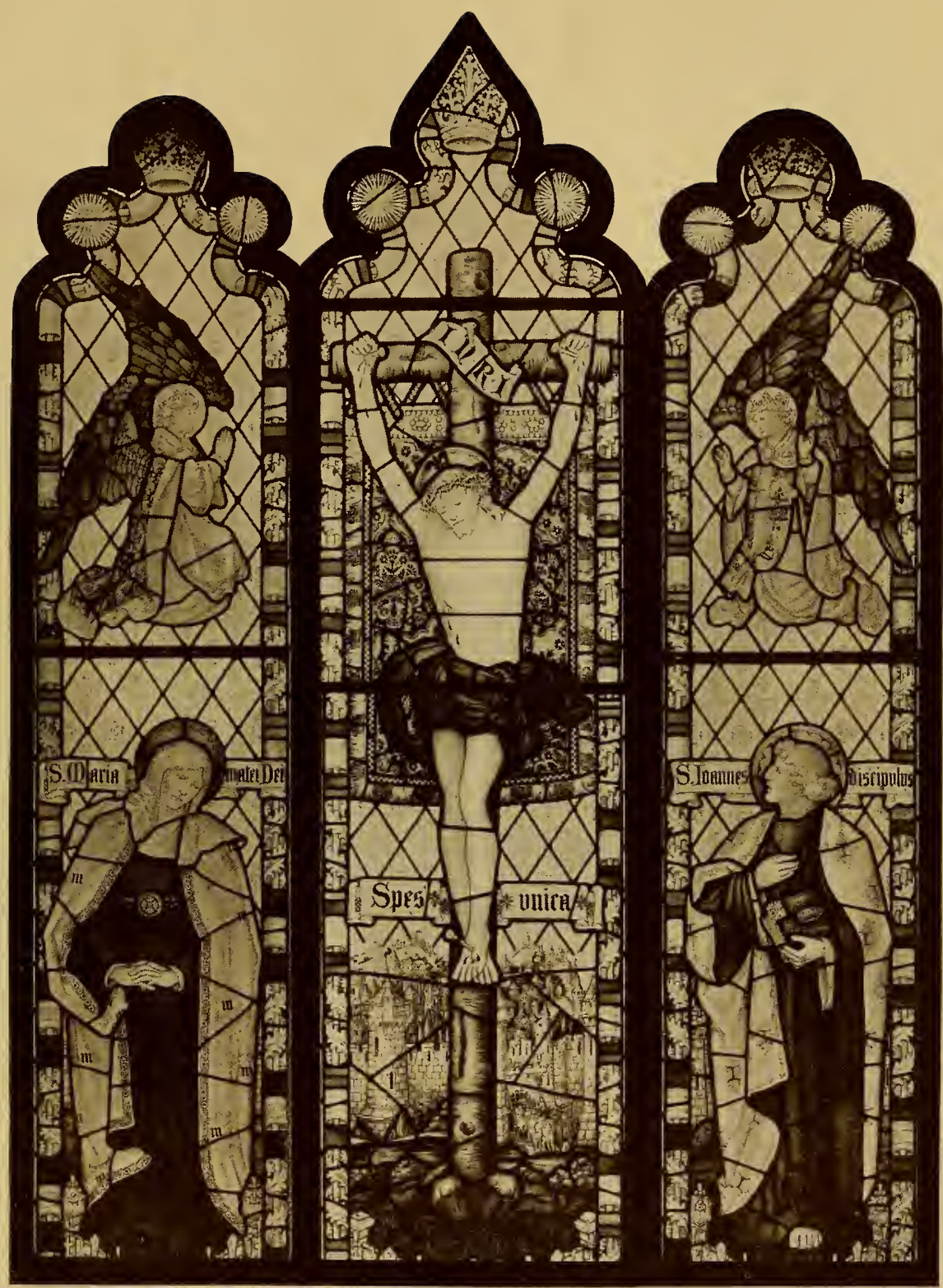

Detail aus einem Glasgemälde von C. E. Kempe, London. 

der Haseloff'schen Monographie nur eine minder glückliche farbige Darstellung gebracht ist.

Seit Gründung des neuen Deutschen Reichs hat die Glasmalerei in zwar langsamen aber stetigem Kurs eine Aufwärtsbewegung genommen. Die Münchener Werkstätten waren insofern führend, als sie unter großen Kosten mit der herrschenden Technik und Stilistik, die sich am besten in den Fenstern der Mariahilfkirche in München-Au charakterisiert, brachen und die gesunden

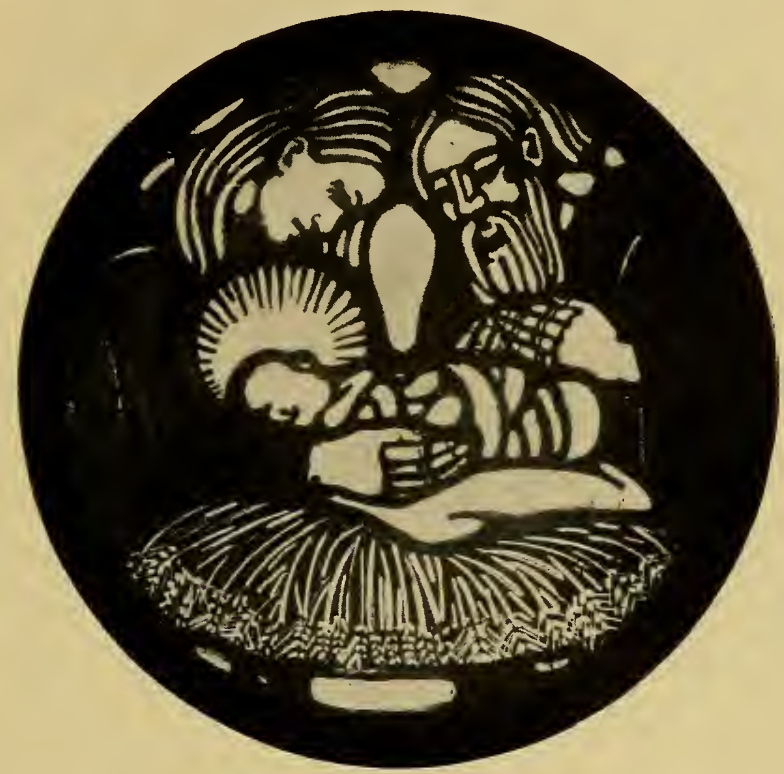

Abb. 47. Monolithscheibe in Schwarzlot und Silbergelb, entworfen und ausgeführt von Glasmaler K. Gläsche, Stuttgart.

Prinzipien der Alten wieder in die Praxis einführten. Das bezog sich vor allem auf das Glas. Mit rücksichtsloser Energie wurde das sogen. französische Glas verrufen und als allein berechtigtes Material das Antikglas zugelassen, soweit es sich um künstlerische Arbeiten handelte. Der flächige Charakter der Glasmalerei kam wieder zu Ehren und die technischen Grundprinzipien handhabte man bald mit größter Virtuosität. Der Karton konnte im Anfang freilich nicht sofort von aller Beeinflussung durch die Tafelmalerei frei sein. Der herrschende Geschmack an italienisierenden, 
gefühldurchtränkten Formen lag der Zeit noch so in den Adern, daß es schwer war, sich ohne jede Mittelstufe mit einem Gewaltstreich von ihm frei zu machen. Daß ein Tafelmaler wie Heinrich - Hess, künstlerischer Leiter der kgl. Glasmalereianstalt in München, war, erklärt am besten die langen und langsamen Befreiungskämpfe in der Glasmalerei. Aus ihnen erklärt sich aber auch der sogen. Münchener Stil, der verächtlich als Sentimentalität gebrandmarkt wird ${ }^{1}$ ). Wenngleich auch wir uns zu dem Grundsatz bekennen, daß die Glasmalerei am meisten gibt, je weniger sie an Detail hat, daß das Prinzip des bloßen Konturierens und Wischens, wenn auch nicht alleinseligmachend, so doch die Sprache höchster Kraft ist, so muß man doch so viel historischen Sinn haben, um den sogen. Münchener Stil der achtziger und neunziger Jahre zu begreifen und wenigstens zu wissen, daß zu der gleichen Zeit, als im Norden überhaupt noch tiefe Nacht herrschte, München schon seinen eigenen Stil hatte.

1) Vgl. das "Süßliche" in der Glasmalerei, Zeitschrift für alte und neue Glasmalerei I9r3, S. I33. 


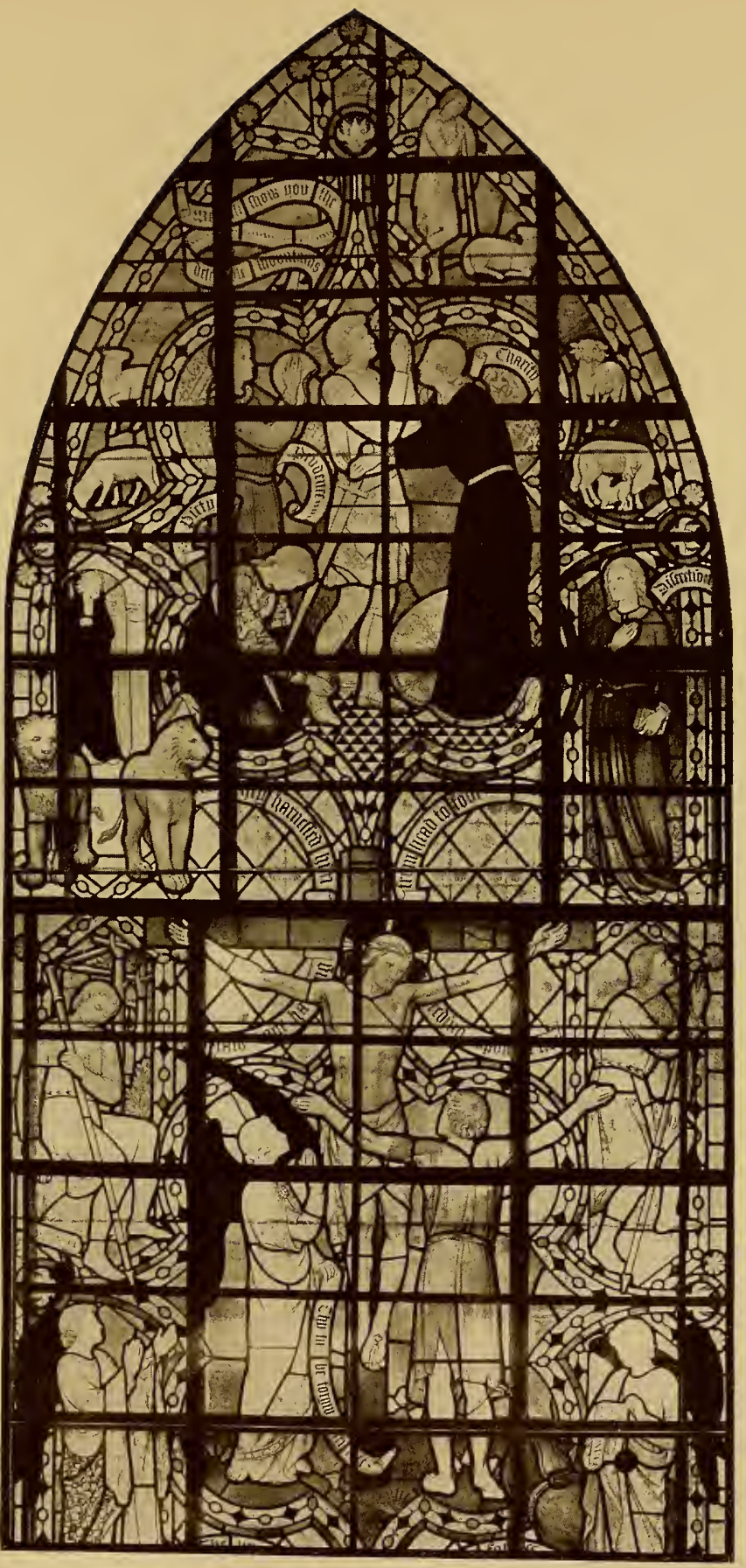

Glasgemälde in der Westminsterabtei von J. N. Comper, London. 



\section{IV. \\ Die Technik.}

\section{A) Das Material.}

Licht und Glas! Wer diese beiden Elemente richtig zu handhaben und ineinander zu stimmen weiß, der hat das Geheimnis der Glasmalerei erfaßt. Wie oft haben die Alten große Ungeschicklichkeiten, ja Fehler in der Zeichnung begangen, wie oft haben sie flüchtig und schlecht gemalt, aber das alles verschwindet gegen ihre Fähigkeit, Licht und Glas wie den Glanz von Edelsteinen leuchten zu lassen. In keiner anderen Kunst greifen Entwicklung des Stils und Entwicklung der Technik so ineinander, wie in der Glasmalerei, und wenn der an sich wertlose Vergleich zwischen beiden angestellt werden sollte, so muß man von einer direkten Vorherrschaft des Materials sprechen. Darum haben die Alten dem Material stets die größte Sorgfalt entgegengebracht.

Die Legende läßt die Phönizier im Erfinderruhm wie für verschiedene andere wichtige Dinge, so auch für das Glas einherschreiten: „In Phönizien, am Fuße des Carmelgebirges, wo der Fluß Belus bei Tolomaida ins Meer fällt, strandete ein Fahrzeug, an dessen Bord sich Sodahändler befanden. Um eine Mahlzeit zu bereiten, legten sie in Ermangelung von Steinen Sodastücke unter ihre Töpfe. Diese fingen nun durch die Hitze des Feuers zu glühen an und vermengten sich mit dem reinen Flußsande zu einer durchsichtigen Masse, welche fortfloß - dem Glase!" Der leichtgläubige Plinius und seine leichtgläubigen Leser hatten offenbar keine Ahnung, daß zur Bereitung des Glases eine etwas größere Hitze notwendig ist, als jene, die hinreicht, sich ein Stück Fleisch zu rösten. Aber abgesehen von dieser sachlichen Unrichtigkeit, hat die Legende des Plinius auch im allgemeinen jegliche Wahr- 
scheinlichkeit gegen sich. Denn alle angeblich von Semiten gemachten Erfindungen haben sich als das geistige Eigentum anderer Völkerstämme erwiesen. Den Semiten bleibt das einzige Verdienst, die Erfindungen anderer Rassen gewinnbringend ausgenützt und daher auf dem Handelsweg verbreitet zu haben. Auch der schönen Legende des Plinius von glaserfindenden Phö-

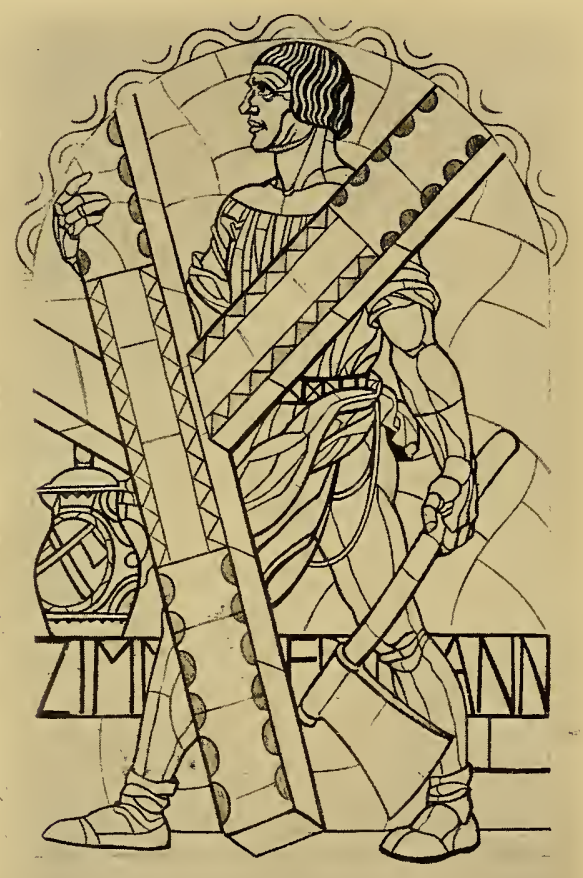

Abb. 48. Entwurf zu einer Kunstverglasung von Prof. Julius Diez, München. niziern ist durch die Ausgrabungen ein Ende bereitet worden. An den geheiligten Ufern des sagenumsäumten Nils fanden sich die ältesten Spuren des Glases. Allerdings hat man das Alter dieser Funde häufig überschätzt, indem man annahrn, daß bereits im vierten vorchristlichen Jahrtausend im Reich der Pharaonen Glas bereitet worden sei. So erklärte jüngst Professor Rathgen, der Chemiker der Kgl. Museen in Berlin, in einem Vortrag, daß eine schwarze Perle, jetzt im Museum zu Oxford, aus einem Grabe stamme, das der ersten ägyptischen Königsdynastie angehöre (um 3600 vor Chr.) Auch deutete man ein Relief, auf dem der Vorgang des Metallötens dargestellt war, fälschlicher Weise als glasblasende ägyptische Sklaven. Nach den Forschungen des berühmten englischen Ägyptologen W.M.Flinders Petrie hat als ältestes gegossenes Glasstück zu gelten ein Glasauge mit dem Namen Amenhoteps I., za. I 55 o vor Christus; daran reiht sich das Fragment eines inkrustierten Glasgefäßes aus der Zeit Tahutmes III. In dieser Periode gebrauchte man schwarze Perlen mit einem weißen Fleck auf zwei Seiten. Außerdem besitzt man 


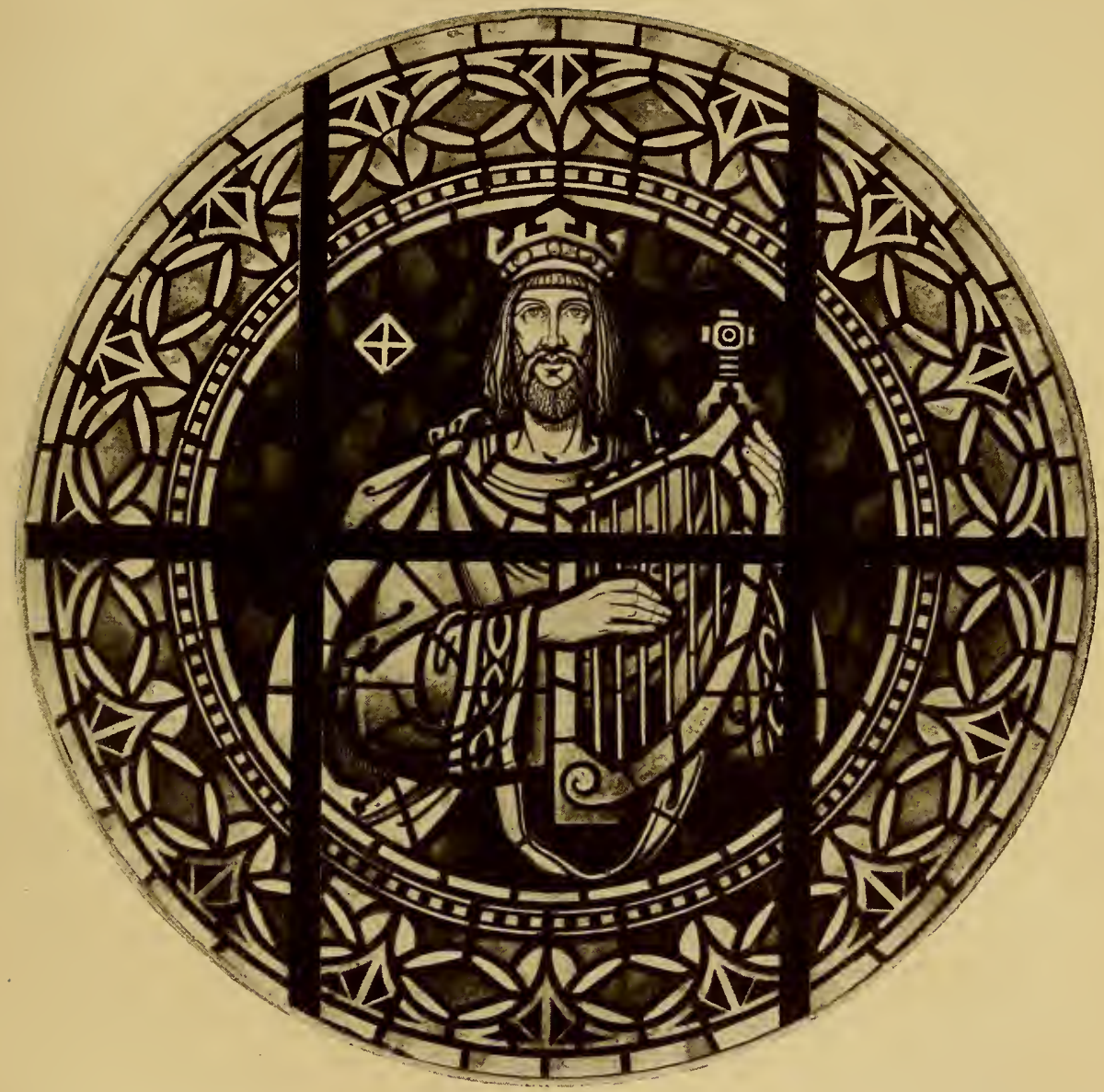

Glasgemälde, entworfen und ausgeführt von der Glasmalerei H. Oidtmann, Linnich. 

schwarze und weiße Schalen, die derselben Periode angehören. Die Zahl der Farben wächst rapid und unter der Regierung der Pharaonen Amerihoteps III. und IV. (bis zum Jahre I4IO) lassen sich nachweisen ein Violett, ein Preußischblau, ein Hellblau, ein Grün, ein Gelb, ein Orange und ein (allerdings selten angewandtes) Rot. Dazu kam weißes und schwarzes Glas. Da der Quarzsand an den Ufern des Nils chemisch rein vorhanden ist, konnten die Ägypter bereits im 16. vorchristlichen Jahrhundert farbloses Glas herstellen. Außerdem war ihnen die entfärbende Kraft des Braunsteins nicht unbekarint.

Bis zur römischen Zeit verwendeten die Ägypter das Glas lediglich zu Gefäßen und Schmuckgegenständen. Da ihr Glas nicht geblasen, sondern lediglich in handwarmem Zustand geformt war, hatten sie auch keinen besonderen Anreiz zu dekorativer Verwendung des Glases. Erstmals läßt sich die Glaspfeife in der Zeit um Christi Geburt in syrischen Werkstätten nachweisen, in denen die Glasfabrikation $\mathrm{zu}$ solch technischer Höhe emporstieg, daß mit deren Erzeugnissen auf dem Markt zu Rom geradezu unerhörte Preise erzielt wurden, die weit über den Preis von echtem Kristall hinausgingen. Von Ägypten verbreitete sich die Kunst des Glasmachens über Indien, Persien, Griechenland aus. Auf seinen Entdeckungsreisen im Innern Afrikas traf Leo Frobenius auf Glasbereitung bei dem Stamm der Massagas. Nach seinen Forschungen handelt es sich um eine uralte, heilig gehaltene Tradition, nicht um Material- oder Rezeptimport aus Europa. Er sah, wie in Bilda, der Hauptstadt dieser Massagas, Glas bereitet und gläserne Gegenstände geformt wurden und macht dies in dem zweiten Band seines Werkes „Und Afrika sprach" I9I2 bekannt mit dem Bemerken; "Ich erachte es für einen wesentlichen Erfolg, daß ich dies hier angeben kann: auch noch heute stellen die Massagas schwarzes und gelbes Glas selbst her. Die Sache beruht also nicht auf einem Materialimport, sondern auf einer fundamentalen Kenntnis der Glasbereitung. Damit schaltet also die recht oberflächliche, aber herkömmliche Behauptung aus, die Glasindustrie sei auf europäischen Materialimport begründet.“

$\mathrm{Zu}$ der Zeit, als das kaiserliche Rom das Herz für die gesamte Kulturwelt geworden war, suchte die Stadt alle Künste 
und Industriezweige an sich zu ziehen. Im Jahre 14 nach Christus legten ägyptische Arbeiter an der Porta Cassena die älteste römische Glashütte an und binnen kurzem hatte die römische Glasindustrie der alexandrinischen und syrischen den Rang abgelaufen. Insbesondere die Färbung des Glases entwickelte sich neben der technischen Vervollkommnung in der Bereitung von Glasgefäßen. In vornehmen Wohnhäusern wurde das Glas an der Wand als opus musivum, das heißt geschmückt mit Goldplättchen und vielfarbigen Glassteinen verwendet, welches Wort dann für die Verwendung in Kirchenfenstern vorbildlich wurde und in dem heute in der Bedeutung etwas veränderten Ausdrucke Glasmosaik und musivische Glasmalerei fortlebt.

Während des Mittelalters sind Glashütten, die sich mit der Herstellung von Tafelglas beschäftigten, in der Nähe von Glasmalerschulen angelegt worden. So wissen wir zum Beispiel, daß das Kloster Tegernsee im Anfang mit großen Schwierigkeiten zu kämpfen hatte, die nötige Menge Glases anzufertigen, da es zu vielen anderen dringenden Arbeiten das Glas selbst machte, beziehungsweise machen mußte. Nach Lehmann war in Hauterive eine Glashütte, von der Erzeugnisse für die Zeit II63-II8I nachgewiesen sind. Da man zur Glasbereitung von verschiedenen Naturprodukten abhängig war, so von der Menge des Brennmaterials und von dem Quarzsand, so lag die Entwicklung von der Fabrikation des Eigenbedarfs zu Überproduktion und Handel sehr nahe. Auch bildeten sich an einzelnen Orten sehr früh Spezialitäten aus. So war das Rot von Rouen besonders beliebt. Im übrigen erinnern noch zahlreiche Orte mit dem Namen Glashütte an die einstige Tätigkeit daselbst. Seit der zweiten Hälfte des Mittelalters war fast überall der Zusammenhang zwischen Glasmalerstube und Glashütte gelöst. An die Stelle der Bedarfsproduktion trat ein oft weithin ausgedehnter Handel, mit dem sich Marktgesetze und Zunftverordnungen zu beschäftigen hatten. IVie aus der ziemlich klar gelegten Geschichte der Glasshütte in der Klus bei Solothurn hervorgeht, mußten die Glasbläser daselbst zu den stärksten Mitteln des wirtschaftlichen Kampfes greifen, um sich halten zu können. Dies ist zwar nur für das Ende des I 5. Jahrhunderts bezeugt. Aber bei der stabilen Technik und bei der örtlich allzeit beschränkten Herstellungsmöglichkeit dürfen 


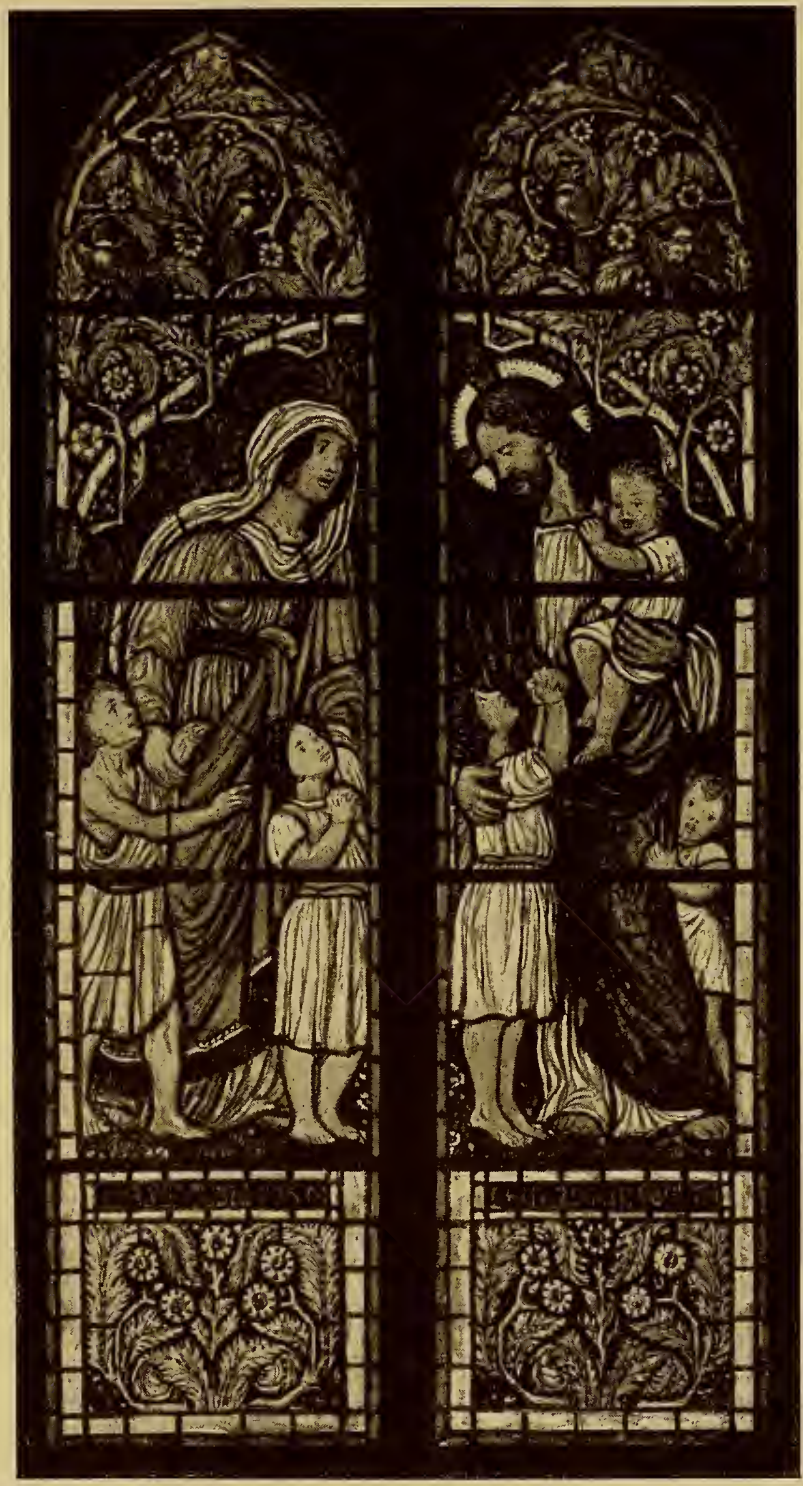

Glasgemälde, entworfen von Becker-Tempelburg, ausgeführt von der Glasmalerei G. Heinersdorff, Berlin. 

wir ähnliche Zustände auch für frühere und spätere Zeiten voraussetzen.

Aus der Tatsache, daß sehr früh Spezialitäten einer Glashütte auftauchten und das Hausieren mit Glastafeln weit verbreitet war, ergibt sich, daß die Verwendung ein und derselben Glassorte an verschiedenen Fenstern nur in sehr bedingter Weise Kriterium der Zusammengehörigkeit von noch vorhandenen Scheiben sein kann. Denn es lag in dem Geschmack des einzelnen Glasmalers, wie er sich zu den von Ort zu Ort verhausierten Glassorten stellte. Dabei muß zugegeben werden, daß die Vorliebe für gewisse Gläser verschiedene Glasmalerkonkurrenten am Platze verleiten konnte, bei demselben Händler zu kaufen, um dadurch konkurrenzfähig zu bleiben. Das wissen wir z. B. von den Zuger Glasmalern Adam zum Bach und M. Müller, die sich in allem kopierten, um ja dem anderen keinen Vorsprung bei der Kundschaft zu lassen. So hebt sich die Ulmer Schule des beginnenden 15. Jahrhunderts durch ein charakteristisches Ziegelrot, um die Mitte durch ein stumpfes Gelb und Grün scharf von den benachbarten Zentren ab. Wohl steht in der zweiten Hälfte des Jahrhunderts Hans Wild als greifbares Haupt der Schule da; allein außer ihm lebten zu gleicher Zeit noch ein halb Dutzend bekannter und vielleicht ein weiteres Dutzend unbekannter Glasmaler in Ulm, die natürlich dem herrschenden Geschmack untertan sein mußten. Darum ist es erklärlich, daß auf den Glasgemälden in Ulm und solchen, die ihrer Provenienz nach ebenfalls auf U1m weisen, jene Farben regelmäßig wiederkehren.

Über die Rohstoffe und deren Verarbeitung verordnet Rugerus folgendes Rezept: „Schneide viel Buchenholz zusammen und laß es trocknen. Hernach verbrenne es an einem reinen Ort und sammle die Asche sorgfältig. Gib aber ja darauf acht, daß du keine Erde oder Steine darunter bringst. Von dieser Asche nimmst du zwei Teile und dazu einen Teil von Sand, wie du ihn an Gewässern findest. Der Sand muß sorgfältig von Erde und Steinen gereinigt sein. Menge die beiden Bestandteile tüchtig untereinander. Hernach bring sie mit einem eisernen Löffel in den kleineren Teil des Ofens auf den oberen Herd, damit sie anziehen. Sobald das Gemenge warm wird, rühre es sofort um, damit es nicht flüssig werde und zusammengehe. So mach es 
einen Tag und eine Nacht. Hernach schöpfe die Masse in irdene Gefäße und laß sie eine Nacht hindurch sehr stark kochen, damit das aus Asche und Sand hervorgegangene Glas recht gut geschmolzen werde." Die Gefäße, die aus weißem Ton geformt waren, müssen nach des Rugerus Vorschrift unten eng, und oben breit sein und an der Mündung einen kleinen nach innen gebogenen Rand haben. Der in diesen Töpfen geschmolzene Glasfluß wird nunmehr geblasen, und zwar mittels der auch heute noch gebrauchten Glaspfeife. Etwas phantastischer ist das Rezept des Heraklius. Wer ist dieser Heraklius? Ebenfalls ein Mönch, ebenfalls ein Techniker. Der Name Heraklius klebt als Autorenschild an einem Konvolut von Schriften und Rezepten, die weder aus der gleichen Zeit, aus dem gleichen Land stammen, sondern erst durch einen sehr spät lebenden Kompilator gesammelt und mit einer einheitlichen Etikette versehen wurden. Die ersten zwei Bücher in Handwerkerpoesie scheinen im zehnten Jahrhundert verfaßt zu sein und enthalten Anweisungen für Glasuren, Miniaturen und Edelsteintechnik. Das dritte Buch aber, das für unser Thema allein in Betracht kommt, ist erst nach der Schedula des Rugerus verfaßt und galt als ziemlich belanglos, da man die Quellen, aus denen der Kompilator schöpfte, für sehr spät hielt. Dazu kommt, daß die in diesem Buch enthaltenen Rezepte den geheimnisvollen fast abergläubischen Einschlag ins Christentum eingedrungener Gebräuche der nordischen Sagenwelt lieben. Da aber die Zitate aus den verschiedensten antiken und karolingischen Schriften entnommen sind, müßten erst sämtliche Kapitel auf ihre primären Quellen untersucht werden, ehe ein abschließendes Urteil über den Gesamtwert der Kompilation möglich ist. Für den Kulturhistoriker würde dabei sehr interessantes Material gefunden werden, weniger jedoch für unsere Zwecke, da die Technik der Glasmalerei in des Rugerus Buch eine ebenso frühe wie präzise Fassung erhalten hat. Über die Glasbereitung gibt Heraklius folgendes Rezept: „Glas entsteht aus Asche, näherhin aus Farnkraut- und Feinasche (Buchenasche) von kleinen Bäumen, die im Wald wachsen. Das Farnkraut wird vor dem Feste des hl. Johannes des Täufers gepflückt, sehr gut getrocknet und hernach zu Asche verbrannt. Ähnlich verfährt man mit dem Buchenholz. Beides wird gemischt und zwar kommen auf zwei Teile Farnkrautasche 


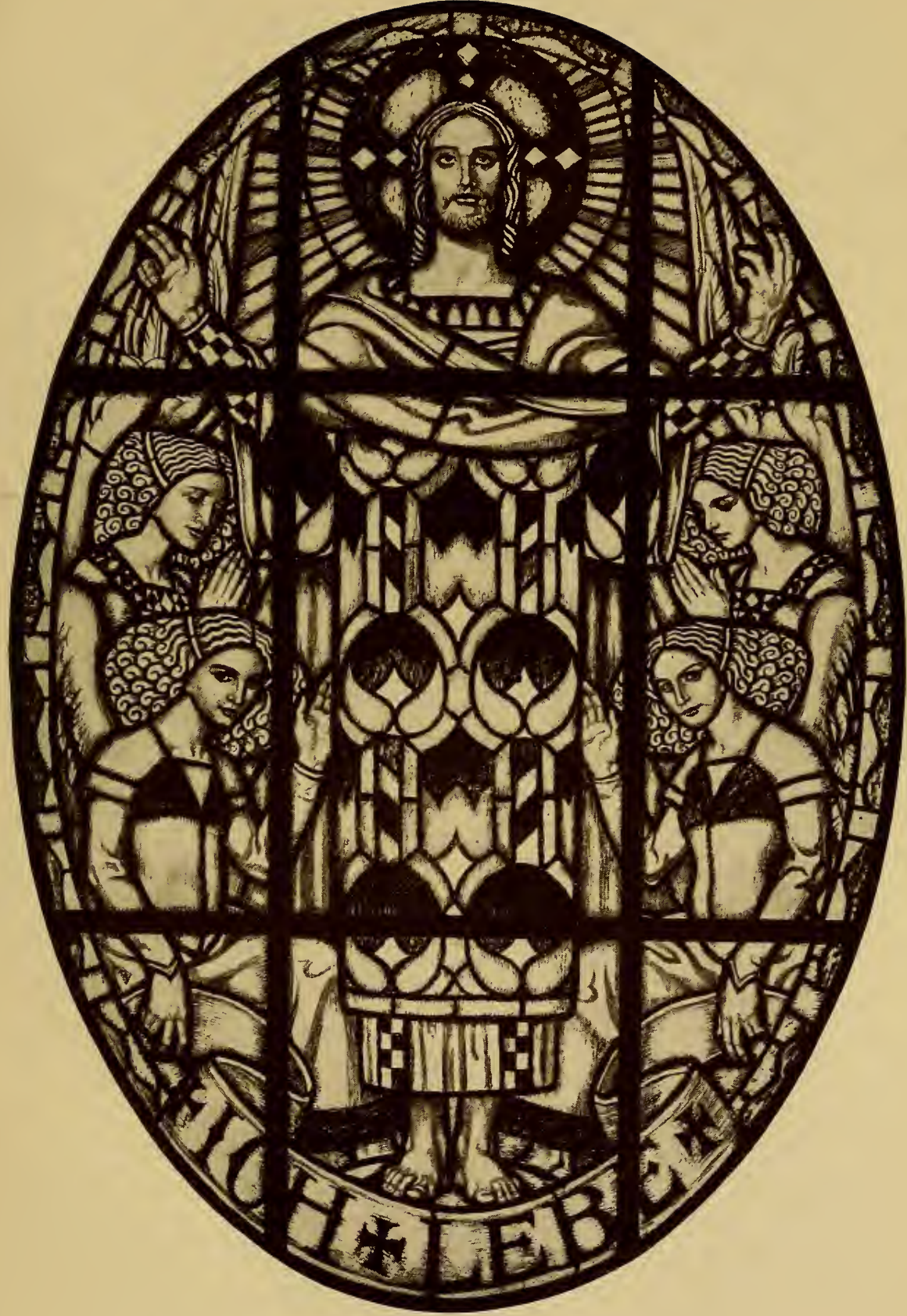

Glasgemälde, entworfen und ausgeführt von der Hofglasmalerei F. X. Zettler, München. 

ein Teil Buchenholzasche." An dieses Rezept schließt Heraklius wie Rugerus Vorschriften über den Bau des Ofens, der ein etwas abweichendes System darstellt, vergißt aber den anderen Bestandteil zum Glasfluß, den Sand. Des Heraklius Rezept ist also nicht eine bloße Kopie der Anweisung des Rugerus, sondern Tradition einer anderen Hütte bzw. eines anderen Klosters. Ilg weist auf die altnordische Sitte hin, auf Grund deren allenthalben am Tage der Enthauptung des Täufers Johannes Farnkraut gesammelt wurde. Trotz der gemeinsamen Technik, trotz der ähnlichen Konstruktion der Werköfen stellen beide Quellen verschiedene Hüttenpraktiken dar. Auch heute noch wird aus Buchenasche und Kieselerde Glas bereitet, wenngleich sich die moderne Industrie alle Fortschritte der exakten Chemie gegen die Hüttenempirie der Alten dienstbar gemacht hat.

Nicht so beredt wie über Öfen und Fritte sind die beiden Quellen über die Färbung des Glases. Rugerus kennt die Farbenskala saffrangelb (croceum), purpurrot (purpureum), grün (viride), blau (saphireum) und das sogen. Galien; bei Heraklius fehlt das Blau. Über die Herstellung des Gelb sagen die Quellen:

\section{Rugerus}

Wenn du siehst, daß irgend ein Gefäß eine Färbung ähnlich dem Saffran annehme, so lasse es bis zur dritten Stunde schmelzen und du leichten Saffran bekommst, so arbeite du davon, soviel du willst, auf die obige Weise (des Blasens) aus. Wenn du es noch drei Stundenlängen kochen lassen willst, so bekommst du rötliches Saffrangelb.
Heraklius

Saffrangelbes Glas entsteht folgendermaßen: Nimm rohe Asche, wirf sie in den Mörser und schmelze sie; gib ein wenig Sand darunter und ziemlich wenig, wenn ich nicht irre, von Kupferfeile, rühre es und es entsteht ein saffrangelbes Glas, das wir Cerasin nennen.

Das Rezept für purpurfarbenes Glas lautet:

Rugerus

Wenn du bemerken solltest, daß irgend ein Gefäß (mit Glasfluß) ins Rötliche spielt, dies dem Fleische ähnlich ist, so nimm dieses Glas für Hautfarbe und

\section{Heraklius}

Purpurnes und fleischfarbenes Glas wird aus Buchenasche bereitet und so wie die weiße Asche gekocht, in einen Topf gefaßt und so lange im Siede- 
schöpfe so viel du willst. Das übrige la $\beta$ zwei weitere Stunden kochen und du bekommst leichtes Purpurrot, bei noch drei Stunden Kochen erhältst du einen gesättigten roten Purpur. zustand erhalten bis es sich rot färbt. Während des Kochens soll es oft gerührt werden, gerade wie anderes Glas; und wenn du siehst, daß der Glasfluß sich rot färbt, so nimm beliebig viel davon und verfahre weiter, bis es sich in Membrun (Fleischfarbe) färbt.

Gelb und Rot sind die einzigen Farben, die Rugerus bespricht. Wohl war in der Urschrift des Buches auch Grün, Blau und das sogen. Galien angeführt; allein diese Kapitel sind verloren. Nur die Überschriften haben sich erhalten, während keine der bekannten Handschriften Reste von jenen Kapiteln aufweist. Unter diesen Umständen hat man bei Heraklius Rats geholt und in dessen Rezepten für die Auszüge aus des Rugerus Anweisungen Ersatz erhofft. Mit schlagender Kürze sagt Heraklius: „Willst du, daß das Glas rot wird, solange der Fluß nicht völlig ausgeschmolzen ist, so verfahre folgendermaßen: Nimm Kupferfeile und brenne sie zu Pulver, wirf dieses in die Häfen und es entsteht ein rotes Glas, das wir Galienum nennen. “ Die Erzeugung roten Glases durch Kupferfeile ist ein Verfahren, das bis zur Gegenwart gebraucht wird. In der Natur kommt dieses Mittel als Rotkupfererz vor, die moderne Glasindustrie verwendet es in der Form des chemisch reinen Kupferoxyduls. Dadurch entsteht das herrliche Rubinrot des Glases (Kupferrubin).

Man hat sich viel Kopfzerbrechen darüber gemacht, was der Grund für das Fehlen gerade der wichtigsten Kapitel in des Rugerus Schedula sein könnte. Die einen nehmen an, sie seien als Rezepte ausgeliehen, andere glauben, sie seien durch einen Mönch herausgerissen worden. An sich ist schon auffällig, daß Rugerus die Entstehung des saffrangelben und purpurnen Glases nur dem Zufall und der kürzeren oder längeren Dauer des Schmelzungsproßesses farbenlosen Glases überläßt. Sollte nicht schon bei diesen Kapiteln das Farbmittel herausgestrichen worden sein? Man weiß, wie geheim man in alter und neuerer Zeit die Rezepte für Glasfärbung hielt. Wahrscheinlich wurden die fehlenden Kapitel gleich von Anfang an herausgerissen, als ein Kloster um 


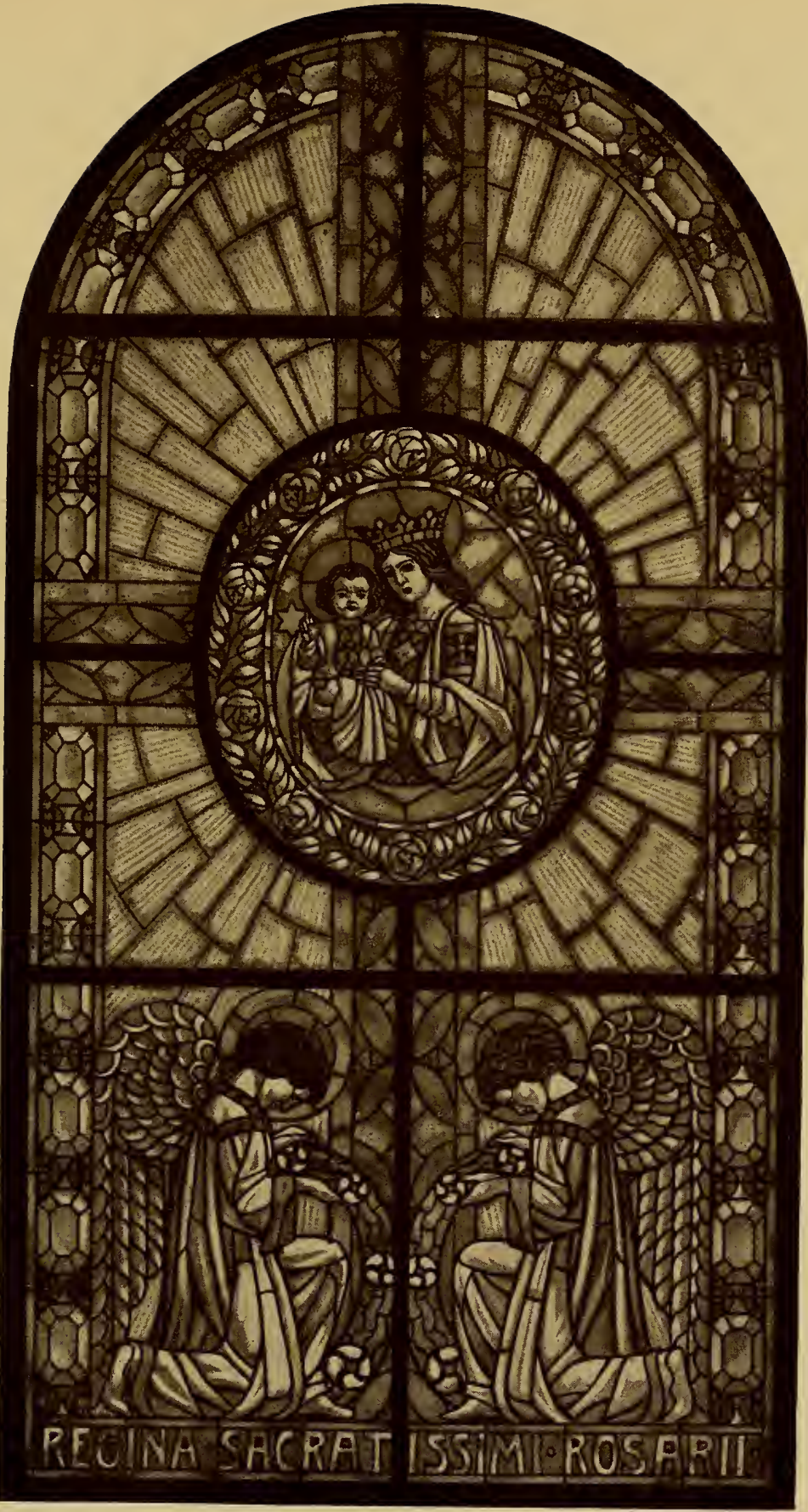

Kunstverglasung in Schwarzlot und Silbergelb, entworfen und ausgeführt von der Hofglasmalerei Ostermann und Hartwein, München. 

Überlassung des Buches gebeten hatte. Nach dem heutigen Verfahren entstehen folgende Farben:

$$
\begin{aligned}
\text { Gelb durch }\left\{\begin{array}{l}
\text { Eisenoxyd } \\
\text { Schwefel } \\
\text { Ceroxyd } \\
\text { Uranoxyd } \\
\text { Silber }
\end{array}\right. \\
\text { Rot durch }\left\{\begin{array}{l}
\text { Kupferoxydul } \\
\text { Gold } \\
\text { Selen }
\end{array}\right. \\
\text { Blau durch }\left\{\begin{array}{l}
\text { Kupferoxyd (Kupferhammerschlag) } \\
\text { Kobalt }
\end{array}\right. \\
\text { Grün durch }\left\{\begin{array}{l}
\text { Eisenoxydul } \\
\text { Kupferoxyd } \\
\text { Chromoxyd } \\
\text { Uranoxyd }
\end{array}\right.
\end{aligned}
$$

Violett durch $\left\{\begin{array}{l}\text { Manganoxyd } \\ \text { Manganoxyd mit wenig Kobalt }\end{array}\right.$

Man ersieht aus dieser Zusammenstellung, daß die Verbindungen des Eisens und Kupfers den Hauptbestandteil der Färbemittel bilden und daß die Mengen des Farbmittels und die Höhen der Temperatur die einzelnen Farbtöne scheiden und schieden, genau wie auch Rugerus angibt. Das bestätigt in uns die Annahme, daß aus den Kapiteln über die saffrangelben und purpurnen Gläser der das Färbmittel angebende Satz, samt den weiteren Kapiteln entfernt worden ist und zwar aus Angst vor Verbreitung eines im eigensten Interesse der Geheimhaltung bedürftigen Rezeptes. Gallienum nennt Heraklius das rote Glas; auch Rugerus hat in einer der Überschriften diesen Namen. Man erklärt ihn allgemein als Bezeichnung der Herkunft dieses Glases von Gallien, also von Frankreich. Man kann diese Erklärung doch nur als Verlegenheitsdeutung auffassen, denn die Namen von Farben haben die verschiedensten Gründe; so führt Heraklius unter den Namen Cerasin ein gelbes Glas an; Ilg leitet dieses Wort von cera Wachs ab. Man muß beachten, daß die klassischen Namen Gallia und Galli sehr früh den Namen Francia 
und Franci der mittelalterlichen Latinität Platz gemacht haben. So sagt Rugerus selbst: Franci in hoc opere peritissimi.

Die Beschaffenheit des alten Glases können wir noch an vielen Fenstern studieren. Meist sehr dick und massig, weist es auf der Oberfläche zahlreiche kleine Bläschen und Schlieren auf. Ähnlich war auch das Glas der alten Römer beschaffen. Nur jene Zeit, die für das Wesen der Monumentalglasmalerei kein Verständnis hatte, konnte an diesem Glas Anstoß nehmen. Die Unregelmäßigkeiten erzeugen zahlreiche Lichtbrechungen und dadurch ein munteres Oszillieren des Lichtes, einen eigenen Reiz für das Auge, wie eine außerodentliche Unterstützung des künstlerischen Eindrucks. Darum war das Glas, das heute den Namen Antikglas führt, auch während des Mittelalters die einzige Glassorte, deren sich die Glasmalerei bediente. Sie wurde durch die Kabinettsglasmalerei im I6., I7. und I8. Jahrhundert mehr und mehr verdrängt. Das rote Glas hielt sich am längsten. Vereinzelt blieb das Antikglas noch bis tief ins I8. Jahrhundert herein in Übung. So befindet sich beispielsweise in dem Kloster Maursmünster in der Pfalz wie wir schon gesehen haben, ein Glasgemälde des Straßburger Meisters Danegger, das im Jahre I763 angefertigt und durchweg mit farbigen Hüttenglas ausgeführt worden ist. Als man zu Beginn des 19. Jahrhunderts an verschiedenen Orten den Versuch machte, die Glasmalerei zu neuem Leben zu erwecken, da verursachte die Herstellung der Gläser besondere Schwierigkeiten, so große Schwierigkeiten, daß man bei der Kabinettsmalerei statt bei der Monumentalglasmalerei anzufangen für gut befunden hat.

Die Rezepte der Alten beruhen auf Empirie. Sowoh1 die Gewichte der färbenden und Flußmittel, als auch deren Darstellung, entbehren der chemischen Reinheit und Exaktheit. Es scheint aber, daß dieser Mangel den alten Gläsern nichts geschadet hat. Mit all ihrer Wissenschaft ist es den modernen Glashütten noch nicht gelungen, jenes herrliche Rubinrot der Alten wieder herzustellen ${ }^{1}$. Daß außer dem Antikglas jede andere Sorte nur in sehr bedingter Weise für die hehre Glasmalerei zugelassen werden darf, ist bei der strahlenden Überlegenheit

1) Das beste Rot erzeugen heute die Zwieseler Glashütten. 


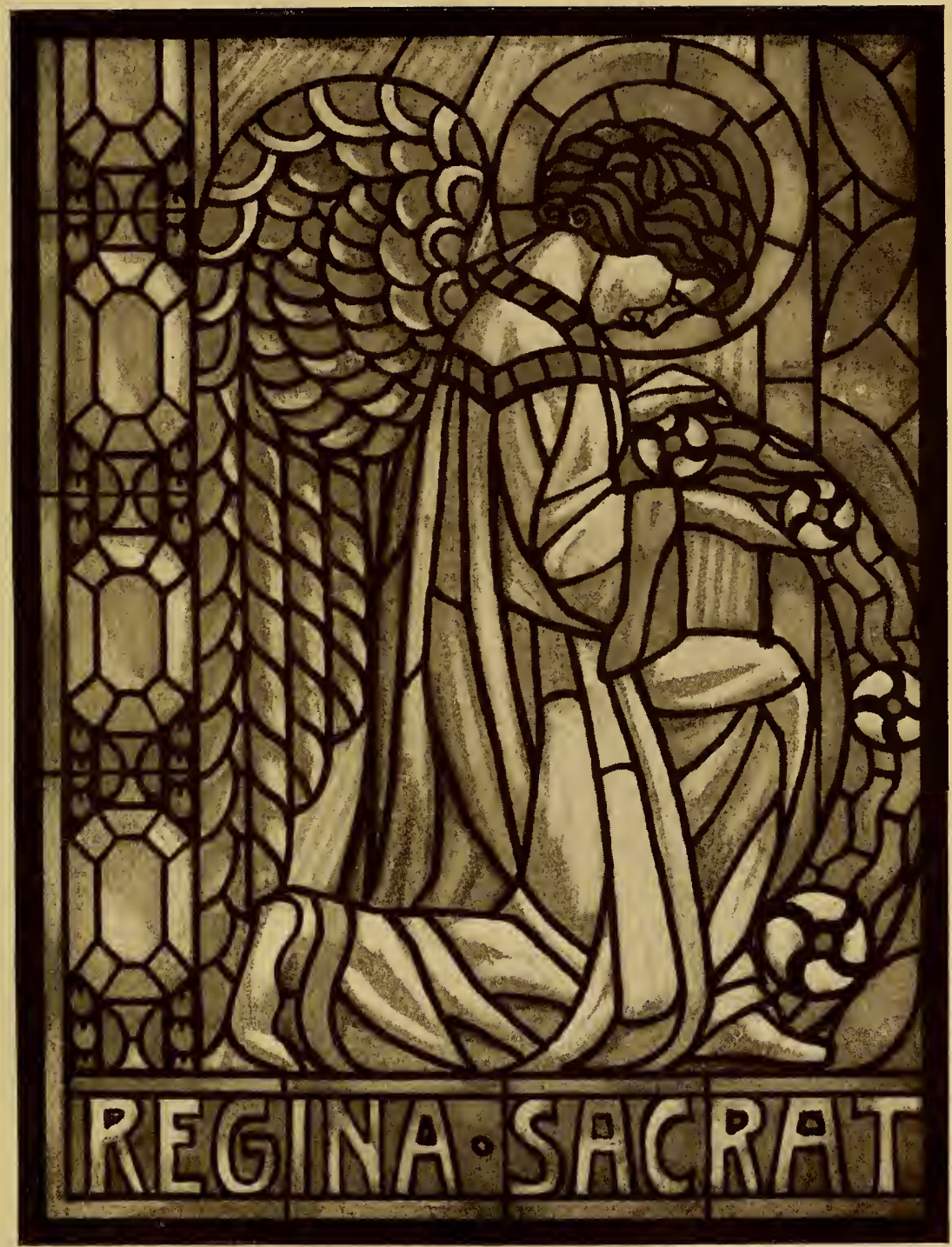

Detail aus der Abbildung Tafel I I 2. 

des Antikglases eigentlich selbstverständlich, ebenso selbstverständlich wie die Konstatierung, daß das sogen. französische Glas mit seiner spiegelglatten Fläche und vollends das nicht einmal geblasene und nur mit hochtrabendem Namen ausgestattete Kathedralglas keine Berechtigung haben. Andererseits hat man in letzter Zeit die verschiedenartigsten Gläser zur Erreichung bestimmter Wirkungen herangezogen. Bekannt ist die eine Zeitlang hochmoderne Verwendung des Tiffanyglases, was nun allerdings jetzt wieder ganz außer Übung ist. Auf der Internationalen Baufachausstellung zu Leipzig waren verschiedene Fenster teils figürlichen Inhalts, teils ornamentalen Charakters zu sehen, deren Entwürfe von Professor Seliger-Leipzig; stammten. Sie gelten dem Versuch des sogenannten Reliefglases, dem an sich gar keine künstlerische Eigenschaft innewohnt und sich mit seiner starren Gleichheit des Musters sonst nur für Industriezwecke verwenden läßt, zu künstlerischen Zwecken heranzuziehen, um so mehr als das Relief der Pressung des Glases die Lichtzufuhr nicht mindert, sondern reizvoll zerstreut und dadurch die besonders bei Profanbauten strengen Lichtforderungen befriedigt. Durch die verschiedenen Strahlenbrechungen, die bei Wechseln des Standpunktes und des Sonnenlichts entstehen, ergeben sich zahlreiche Wirkungen. Dieses Glas verträgt auch volle Sonne; in diesem Zustand glitzern die Scheiben mild wie gefrorene Scheiben, die mit Diamanten besetzt sind. Zur Bemalung eignen sich diese Gläser natürlich nicht, so daß sie fast nur für Kunstverglasung in Betracht kommen können. Eine andere, neuerdings sehr gebräuchliche Glassorte, ist endlich das von Puhl \& Wagner erfundene Gold- und Silbermosaikglas. Bei diesem Glas ist zwischen zwei Schichten eine zarte Schicht Gold oder Silber eingeschmolzen, die bei durchfallendem Licht unsichtbar bleibt, bei auffallendem Licht aber leuchtet, so daß Fenster, die aus solchem Glas hergestellt sind, sowohl bei auffallendem, als durchfallendem Licht eine Farbwirkung äußern. Besonders für Ornamente geeignet, sind diese Glassorten auch zu größeren Werken ornamentalen Stils herangezogen worden.

So sehr wir den Fortschritt und das Streben nach neuen Effekten anerkennen, so müssen wir doch konstatieren, daß der höchste künstlerische Gehalt in der Glasmalerei nur von dem 
Antikglas ausgedrückt werden und daß es sich bei weitgehender Verwendung anderer Glassorten lediglich um schlichte Zweckmäßigkeitsfenster oder Kunstverglasungen handeln kann.

\section{B) Die Malfarben.}

Das Schwarzlot. „Nimm dünn geschlagenes Kupfer, brenne es in einer kleinen Schale völlig zu Pulver, nimm kleine Teile von grünem Glas und griechischem Saphir; reibe jedes einzeln $z$ wischen zwei Porphyrsteinen. Diese drei Dinge werden gemischt, je ein Drittel Pulver, Grün und Saphir. Zerreibe das Ganze auf eben diesem Stein mit Wein oder Urin so sorgfältig wie möglich. Das Gemengsel schütte in ein Eisen- oder Bleigefäß." So verordnet Rugerus über die Bereitung des Schwarzlots. Heraklius dagegen gibt das Rezept: „Nimm ein Grossinum ( $3-5 \mathrm{~g}$ ) Saphir und ein Drittel Grossinum Eisenhammerschlag, dazu füge Bleiglas, sogenanntes Judenglas, vermische alles tüchtig auf Marmor." Es sind also zwei verschiedene Traditionen, die während des Mittelalters nebeneinander hergehen. Die französischen Gläser weisen meistens und schon sehr früh, im I2. und I3. Jahrhundert, d. h. in der Entstehungszeit des III. Herakliusbuches, Eisenschwarzlot auf. Heraklius vertritt also, wie öfter, die französische Tradition, und Ilg erklärt den Verfasser des III. Buches nicht mit Unrecht für einen Franzosen. Deutschland und Italien folgten mehr der Tradition des Rugerus, so Cennini, Antonio da Pisa. Letzterer sagt: „nimm von jenen kleinen Paternosterkügelchen aus gelbem Glas, $d$. h. von jenen feinen venezianischen, die dem gelben Bernstein ähnlich sind, und zerstoße sie gut. Wenn sie fein pulverisiert und gemahlen sind, nimm ein Tiegelchen mit Kupferhammerschlag, der ganz rein und echt sein muß und zwei Tiegelchen von dem eben genannten Glaspulver, menge es und mahle es auf einem Porphyr sehr sorgfältig zusammen. Und wenn du keine Paternosterkügelchen bekommen solltest, nimm gelben Schmelz (smalto) und dazu etwas Kobalt." Der Glasfluß kann also gelb oder grün sein, beides wird beim Brand des bemalten Fensters schwarz. Der Name Schwarzlot läßt sich erstmals bei Kunckel im I8. Jahrhundert nachweisen. Wie Kunckel zu diesem rätselhaften Namen gekommen ist, harrt 


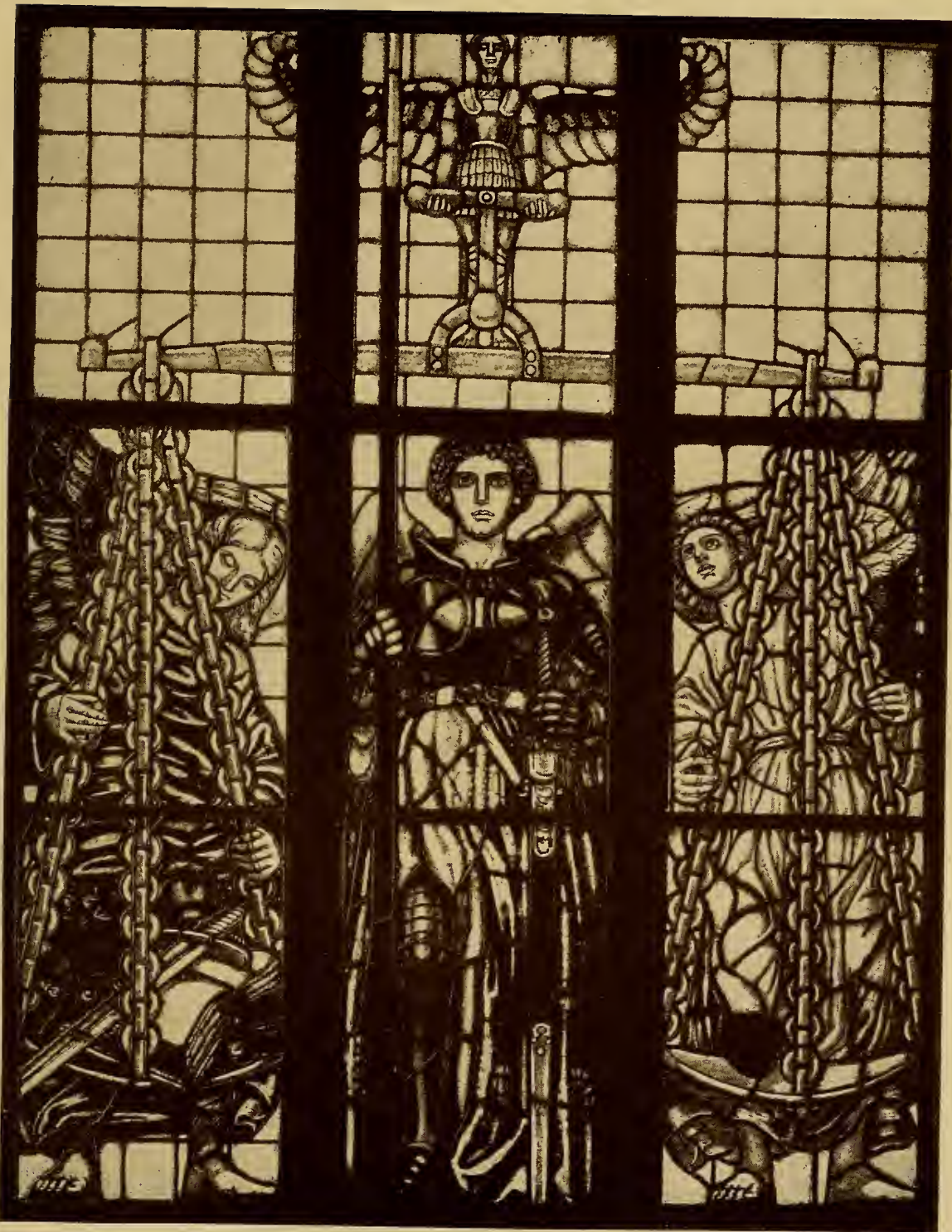

Glasgemälde von Professor Josef Huber-Feldkirch, Düsseldorf. 

noch der Erklärung. Im Mittelalter und auch in der neueren Zeit hieß das Schwarzlot schlechthin die Farbe, mit der man auf Glas malt.

Das Silbergelb. Im Gegensatz zu Schwarzlot, das eine eigene Malfarbe ist, stellt das Silbergelb lediglich eine Lasur dar. Die Sage hat sich wie bei allen Erfindungen, auch um die Entdeckung des Silbergelbs gerankt. Der im Jahre I407 zu Ulm geborene Kaufmannssohn Jakob Griesinger, der zu Bologna in den Dominikanerorden eingetreten war, soll für ein Opfer seines blinden Gehorsams gegen die geistlichen Oberen mit jener Entdeckung belohnt worden sein. Während nämlich Jakobus ein zum Brennen bereites Glas in den Ofen brachte, sei ein silberner Knopf darauf gefallen. Im gleichen Augenblick vom Prior abgerufen, habe er bei der Rückkunft den Knopf durch das Feuer verzehrt, auf dem Glase oben einen gelben Fleck gefunden. Diese Entdeckung verursachte die Erhebung des Jakobus Alamanus zum Patron der Glasmaler. Lehmann entdeckte indes das Silbergelb bereits auf einem Fenster, das noch dem letzten Jahrzehnt des I3. Jahrhunderts angehört. Das älteste Rezept enthält die Schrift des Antonio da Pisa: „Wenn du gelb machen willst, gib viel von gemahlenem Silber und wenn du es kräftig an Farbe machen willst, so füge ein wenig Ocker bei, wie dies die Maler gebrauchen." Genauer ist folgendes von Stahl als "mittelalterlich" bezeichnetes Rezept, das heute noch zur Ausführung gelangt: Drei Teile dünngeschlagenes Silber werden in Streifen geschnitten. Sodann pulverisiert man einen Teil rohes Antimon und einen Teil Schwefel, mischt dieselben und bedeckt mit der Mischung den Boden eines Schmelztiegels, bringt eine Schicht Silber auf, bedeckt diese wieder mit dem Gemenge und so fort, bis alles eingefüllt ist. Die oberste Schicht muß Schwefelantimon sein. Man setzt nun den Tiegel ins Feuer und wartet bis der Schwefel brennt, ein Zeichen, daß die Masse in Fluß ist. Nun gießt man den Inhalt des Tiegels in Wasser, trocknet ihn, vermischt ihn mit drei Teilen dunkelgebranntem Ocker und verreibt alles recht fein.

Mit diesen beiden Farben kamen die Glasmaler während des ganzen Mittelalters aus. Erst mit dem Auftreten der Kabinettsmanier regte sich das Bedürfnis nach neuen Ausdrucksmitteln. 
Man erfand während des 16. Jahrhunderts eine Reihe von Farben, die auf Glas aufgetragen wurden und beim Brand durchsichtig blieben. Sie sind unter dem Namen Schwemmfarben bekannt, da sie, um zu wirken, nicht ängstlich aufgelegt werden durften, sondern kräftig aufgeschwemmt wurden. Am schönsten gelangen die blauen Flüsse, am wenigsten die roten, weswegen rotes Hütenglas am längsten im Gebrauch blieb. Die moderne Glasmalerei arbeitet, wenn immer möglich mit farbigem Hüttenglas. Zudem beziehen die modernen Glasmalereien etwa notwendige Malfarben fertig von den Fabriken. Darum können wir die Aufzählung aller Farbenrezepte übergehen und verweisen den Interessenten auf die Kataloge der verschiedenen Glasfarbenfabriken.

\section{C) Die Bearbeitung des Materials.}

Man hört oft, es sei außerordenlich schwer, die Technik der Glasmalerei gewandt und sicher zu beherrschen. Das mag für jene Zeiten zugetroffen haben, in denen man die Glasmalerei für nichts anderes ansah, als für die Übertragung eines Ölbildes auf Glas. Darum haben auch alle Kenner der glasmalerischen Entwicklung das Verdienst des Sigismund Frank so hoch eingeschätzt, da er unter außerodentlichen Schwierigkeiten die begrabenen Geheimnisse der Technik wiedergefunden habe. Frank begann mit dem Schwierigsten, der Kabinettsmanier, anstatt mit der monumentalen Glasmalerei. Er und seine Zeitgenossen lebten sich dadurch von vornherein in die Idee hinein, die Glasmalerei sei so schwer, wie den Alchymisten die Goldbereitung, verwechselten das Kunstwerk mit dem Kunststück. Wenn man die auf Frank folgenden Arbeiten größeren Charakters z. B. in Hohenschwangau oder aber gar die sogenannten monumentalen Glasgemälde z. B. in der Mariahilfkirche der Au betrachtet, so staunt man über die außerordentlich peinliche und ins Detail gehende Arbeit, die einer besseren Sache würdig gewesen wäre. Die Glasmalerei war auf falschem Wege und hätte ins Verderben rennen müssen, wenn nicht wieder einmal die Technik sich stärker gezeigt hätte, als der Mensch und im letzten Drittel des vergangenen Jahrhunderts mit Macht auf die Manier der Alten zurïckgedrängt hätte. Gerade das Einfachste ist das Größte und 


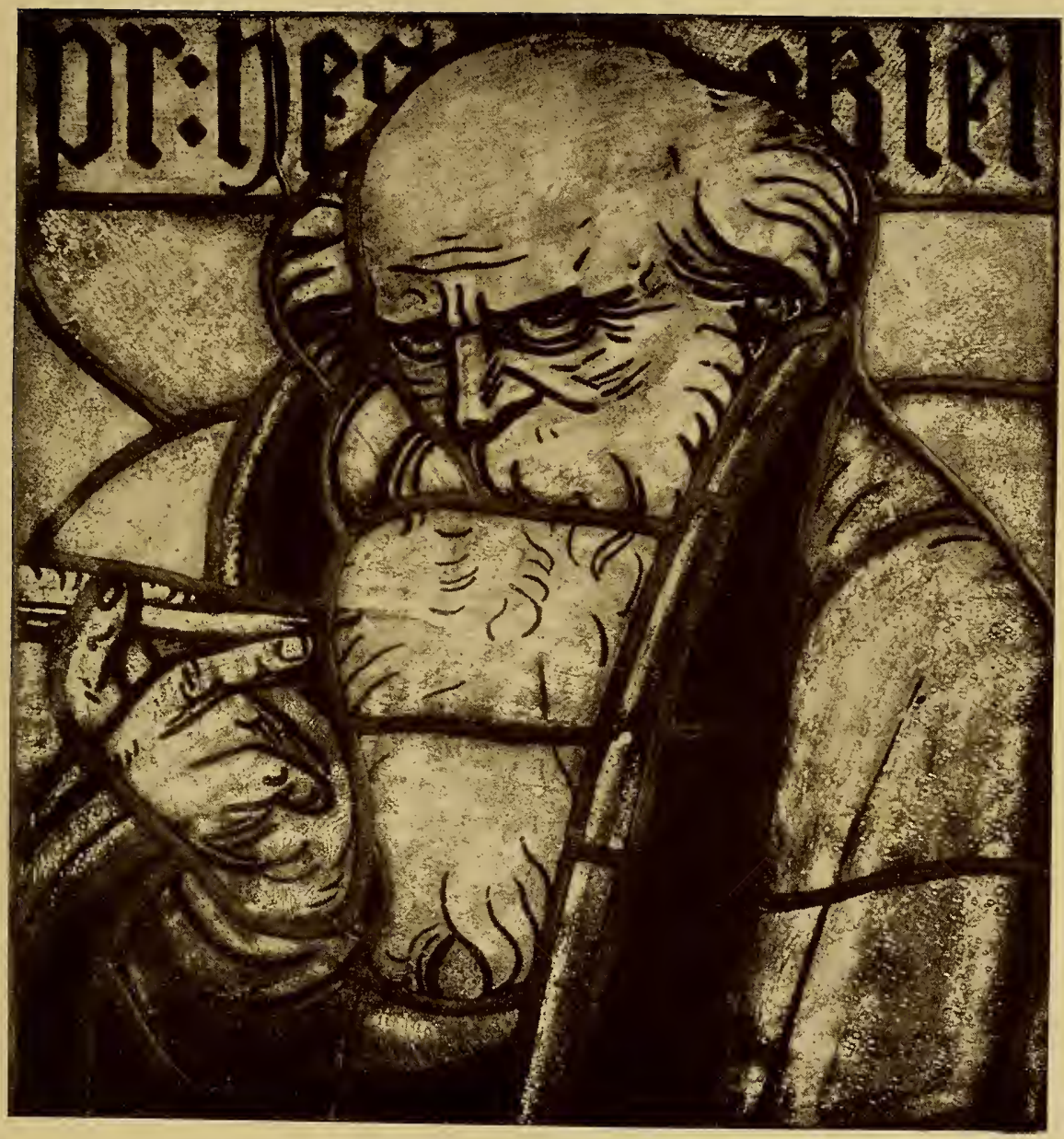

Detail aus einem Glasgemälde von Professor Josef Huber-Feldkirch, Düsseldorf. 



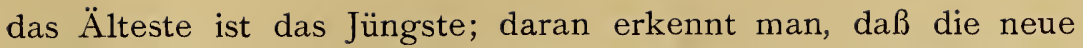
Glasmalerei auf dem rechten Wege ist, wenn sie die Prinzipien der Alten als oberste Richtschnur gelten läßt. Licht und Farben sind diese beiden Prinzipien, die von den Alten, von den größten Meistern bis zu den handwerksmäßig arbeitenden Glasmalern, niemals außer Acht gelassen wurden. Hören wir zunächst die alten Schriftsteller, was sie über die Technik zu sagen haben: „Wenn du Glasfenster machen willst, so nimm eine ebene Holztafel von der Breite und Länge, daß du jedes einzelne Fenster darauf arbeiten kannst. Nimm Kreide und schabe von ihr mit dem Messer über die ganze Tafel hin. Darauf sprenge Wasser und verreibe alles mit einem Tuch. Reiss die Gemälde darauf zunächst mit Blei oder Zinn, hernach mit roter oder schwarzer Farbe; mach aber ja alle Linien recht sorgfältig, weil du hernach, wenn du das Glas bemalst, nach dem Riss auf der Tafel Licht und Schatten vereinigen mußt. Indem du hierauf die verschiedenen Gewänder verteilst, notiere dir die Farbe eines jeden Teils an seinem Ort und was du sonst bemalen willst, davon notiere dir ebenfalls die Farbe mit einem Buchstaben. Mach in einem Bleigefäß eine Mischung von Wasser und Kreide und bereite dir zwei bis drei Pinsel aus Haaren vom Schwanze des Marders oder Grisiums, oder des Eichhörnchens oder der Katze oder aber aus einer Eselsmähne. Nimm ein beliebiges Stück Glas, das größer ist als die zu schaffende Fensterfläche, leg es auf die Tafel und zeichne darauf die Konturen, die du durchschimmern siehst, jedoch nur die äußeren, nach. Wenn das Glas $z u$ dicht wäre, daß du die Konturen nicht durchsehen würdest, so zeichne erst auf ein weißes Glas und dann lege das dunklere gegen das Licht darauf und zeichne die Kontur, wie du sie siehst. Auf dieselbe Weise wirst du alle Gattungen des Glases für Gesichter, Gewänder, Füsse, Ränder kurz alle Stellen, wo du Farben anbringen willst, bezeichnen." Rugerus spricht also von dem noch heute üblichen System der Pause, allerdings einem umständlicheren Verfahren, indem die Werkzeichnug erst auf Holz und dann auf geweißtes Glas übergetragen werden muß, während heute nach dem Karton lediglich eine Schnittpause gemacht wird, ähnlich wie bei dem Zuschneiden von Kleidungsstücken. Auf den Pausen will Rugerus nur die „äußeren“ d. h. jene Konturen 
angegeben wissen, die sich mit den Randlinen der zu verarbeitenden Farbengläser decken. Da Rugerus, überhaupt die mittelalterliche Technik nur das Schwartlot als Malfarbe kannten, können die Ausdrücke "gemalt" natürlich nur im übertragenem Sinn gedeutet werden als Anwendung verschiedenfarbigen Hüttenglases. Heraklius berichtet über diesen Teil der Technik nichts. Des Anonymus Angaben ruhen völlig auf der Vorschrift des Rugerus. Daß Antonio da Pisa nichts davon berichtet, läßt die Vermutung entstehen, zu seiner Zeit habe man sich nicht mehr mit der umständlichen genau darzulegenden Weise der Werkzeichnung, sondern mit dem einfacheren System der Pause beschäftigt. Denn daß Antonio auf eine so komplizierte und schwere Sache wie die Werkzeichnug war, einfach vergessen habe sollte, ist nicht anzunehmen, da er sonst alles mit größter Genauigkeit erzählt. Sicher ist, daß wenige Jahrzehnte später Cennino Cennini das heutige System der Pause genau kennt. Er sagt: „Der Maler solle sich soviele Blätter Papier zusammenkleben als er nach dem Maaßverhältnissen des Fensters braucht, darauf das Bild zuerst mit Kohle, dann mit Tinte zeichnen und dann wie ein Tafelgemälde vollends schattieren. Die Zeichnung soll der Glasmaler auf einem ebenen oder großen Tisch ausbreiten, um darnach die Farbengläser stückweise zurechtzuschneiden."

Diese Norm mußte im Mittelalter streng eingehalten werden, sei es nun in der Form der umständlichen Werkzeichnung, sei es in der bequemeren der Papierpause. Denn das Mittelalter fertigte nur solche Fenster an, die für einen bestimmten Raum bestellt waren, also feststehende Maaße hatten. Heute werden indess verschiedene Glasgemälde nurmehr für die Bleikontur gepaust, im übrigen wird völlig frei verfahren. Die Arbeit der Werkzeichnung oder Schnittpause ist eine mehr handwerksmässige, setzt aber immerhin eine gewisse Geschicklichkeit voraus. Damit sich die Zeichnung bei der Verbleiung nicht verschiebt, indem der Bleikern das unmittebare Aneinandertreten der Glasteile hindert, schneidet der Glaser bei Anfertigung der Schablonen, mit einem Doppelmesser, dessen Schneiden paralell gehen und in einen dem Bleikern entsprechenden Abstand sind, der Bleikontur folgend, gleichzeitig ein schmales Papierstreifchen eben für den Bleikern aus. 


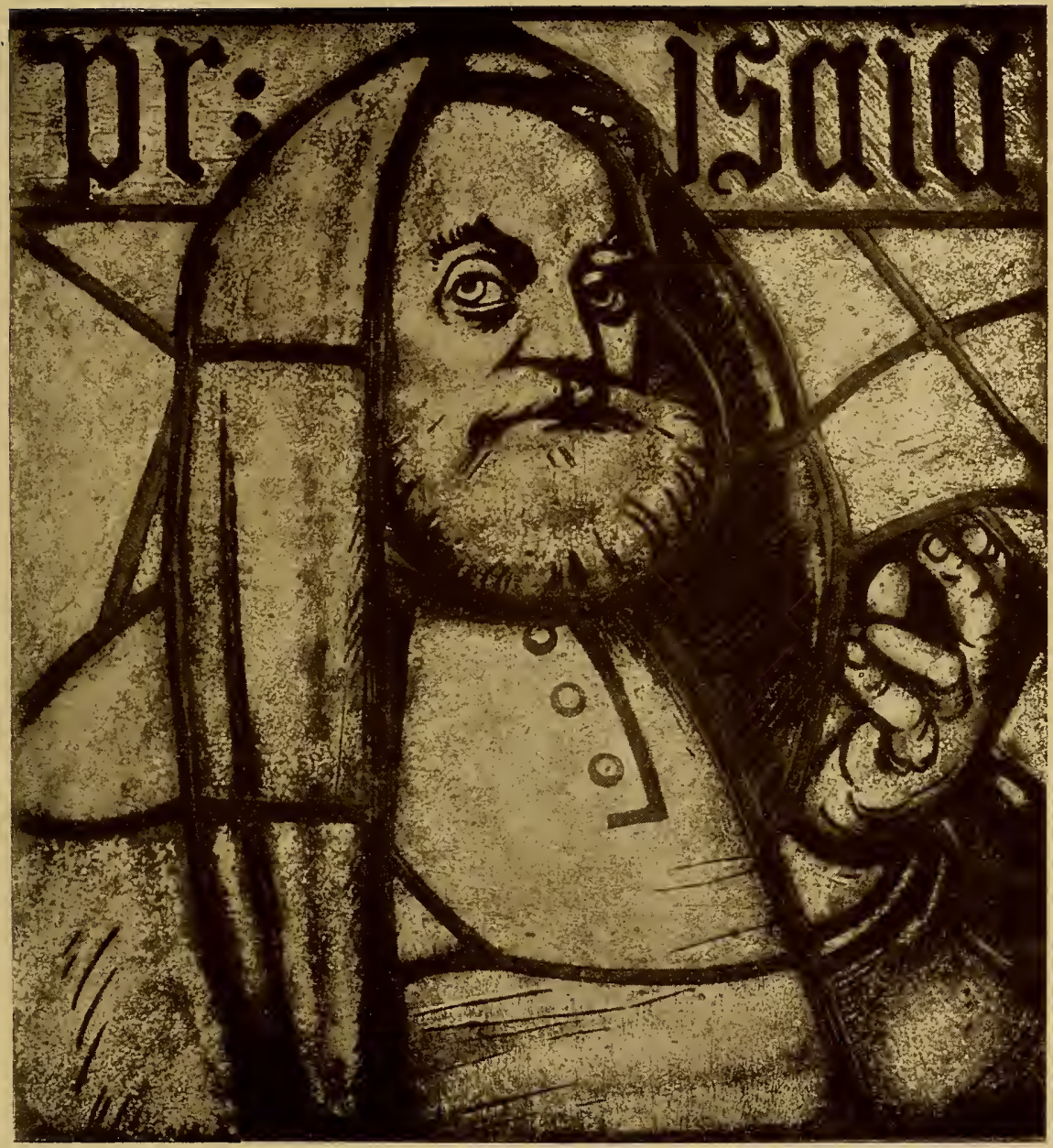

Detail aus einem Glasgemälde von Professor Josef Huber-Feldkirch, Düsseldorf. 

Soweit kann also keinerlei Schwierigkeit bestehen. Die Technik der alten ist geblieben, weil sie die zweckmäßige, die richtige ist. Die nun folgende eigentliche Bemalung hat während der vergangenen Zeiten die verschiedensten Wandlungen durchgemacht und hängt zum größten Teil von der Auffassung ab, die eine Zeit von dem Wesen der Glasmalerei hat. Rugerus beschränkt sich auf eine kleine Anzahl von Vorschriften: „Bemale mit der Farbe (dem Schwarzlot) das Glas mit aller Vorsicht nach den Linien, die auf der Tafel stehen. Wenn du auf dem Glase Buchstaben machen willst, so bedecke die betreffenden Stellen ganz mit dieser Farbe, indem du mit dem Pinselstiel hineinschreibst. Schatten und Lichter an Gewändern kannst du, wenn du sorgfältig verfahren willst, genau so machen wie in der gewöhnlichen Farbenmalerei, nämlich wenn du mit der oben erwähnten Farbe (dem Schwarzlot) die Konturen auf den Gewändern aufgetragen hast, so vertreibe das Schwarzlot mit einem Pinsel, so daß das Glas an der Stelle durchsichtig wird, wo in der gewöhnlichen Malerei Lichter angebracht werden. Der Auftrag sei an einer Stelle dicht, an der anderen leichter, an einer dritten noch feiner mit so viel Sorgfalt abwechselnd nuanciert, daß es den Anschein hat, als seien drei Farben aufgetragen. Dieses Verfahren sollst $d u$ auch bei den Augenbrauen, den Augen, der Nase, dem Kinn, jugendlichen Gesichtern, Füßen, Händen und den übrigen Nacktpartien einhalten, und das Glasgemälde möge das Aussehen einer aus verschiedenen Farbtönen zusammengesetzten Malerei bekommen. Außerdem habe das Glasgemälde irgend ein Ornament, nämlich auf den Gewändern, den Stühlen, den Hintergründen, auf Grün, Weiß, Blau und Hellpurpur. Wenn die ersten Schatten auf derartigen Kleidern trocken sind, so überziehe all den Rest des Glases mit einem leichten Ton, der die Mitte zwischen dem zweiten und dritten der oben genannten Töne hält. Wenn er trocken ist, so spare mit dem Pinselstil neben den ersten Schatten beiderseits feine Linien aus, so daß zwischen diesen Linien und den ersten Schatten nur ganz leichte Töne sichtbar bleiben. Im übrigen mach Kreise und Ranken und darin Blumen und Blätter auf dieselbe Art, wie sie in gemalten Buchstaben gemacht werden. Die Felder, die in gemalten Buchstaben mit Farben überzogen werden, sollst 
du auf dem Glas mit sehr feinem Rankenwerk bemalen. In die genannten Kreise kannst du auch kleine Tiere, Vögelchen oder Würmchen und nackte Gestalten einfügen. Auf ähnliche Weise kannst du Figuren vom glänzendsten Weiß abheben lassen und sie mit Blau, Grün, Purpur und Rosa bekleiden. Umgekehrt mach auf grünen und blauen, in der geschilderten Art bemalten und unbemalt roten Hintergründen Kleider aus hellstem Weiß. Denn es gibt nichts Prächtigeres als derartige Gewänder. Mit den drei Farbtönen kannst du auf Säumen Gerank und Blätter, Blumen und Knoten auf die beschriebene Weise malen. Endlich kannst du diese Töne auf Gesichtern, Händen und Nacktteilen allgemein statt der im vorigen Buch genannten Farbe Posch gebrauchen (eine Farbe, die zur Buchillustration und zu Freskomalerei verwendet wird)." Rugerus meint natürlich nur, daß der geschilderte Schwarzlotton dort angewendet werden soll, wo in anderen Techniken las sogenannte Posch steht. Diese Farbe könnte auf Glas selbstverständlich nicht gebraucht werden. „Saffrangelbes Glas verwende für Gewänder, nicht nur für Kronen und solche Teile, bei denen in der Malerei Gold verlangt wäre $\left.{ }^{1}\right)$. "

1) Dic Angaben des Rugerus werden von Geiges nicht in allcm sehr gewertet, was wohl damit zusammenliängt, daß er die Übersctzung des Rugerus von IIg benützt hat. Trotz großcr Vorzüge wcist die Übersetzung Ilgs zahlreiche Unverständlichkeiten auf, da ihm die Technik der Glasmalerei nicht genügend bekannt war. Geiges sagt: „Vollständig unklar ist namentlich im ersten Satz des XX. Kapitels die Stelle: Wenn $\mathrm{du}$..... die Linien gemacht hast, so breite sie mit dem Pinsel aus ... und nicht minder dic allerdings eines sachlichen Wertes entbehrende Schlufbemerkung: und sei diese Malerei in dem Reichtum der wechselnden Töne begründet. In Verbindung mit den übrigen Textstellen vermag ich das Ausbreiten mit dem Pinsel nur in dem Sinne zu verstehen, daß die nach der Visierung zunächst nur andeutungsweise aufgetragencn Linien in Durchsicht auf ihre volle Breite gebracht wurden, denn nur bei dem Arbeiten in der Durchsicht war es möglich, dem Ton die beabsichtigte Tiefe zu geben. $\mathrm{Ob}$ diese Auslegung die richtige ist, das ließe sich jedoch nur durch eine genauere Untersuchung der wenigen in Betracht kommenden Originale des II. und I2. Jahrhunderts ermitteln, wozu sich mir bis jetzt keine ausreichende Gelcgenheit bot." (S. 177.) Was zunächst die erste Stelle betrifft, so lautet das Original: Cum feceris tractus in vestimentis ex colore praedicto, sparge eum cum pincello ... Wenn du die Konturen auf den Gewändern mittels der genannten Farbe, dem Schwarzlot gemacht hast, so vertreibe sie mit dem Pinsel. Das "sie" bezicht sich also nicht auf die Konturen, wie Geiges nach dem Wortlaut der Übersetzung annehmen konnte, sondern auf das Schwarzlot. Wir übersetzen besser: so vertreibe von ihm (dem Schwarzlot). Der Sinn ist also ganz klar. Zuerst sollen die Konturen gemacht werden, hernach auf den 


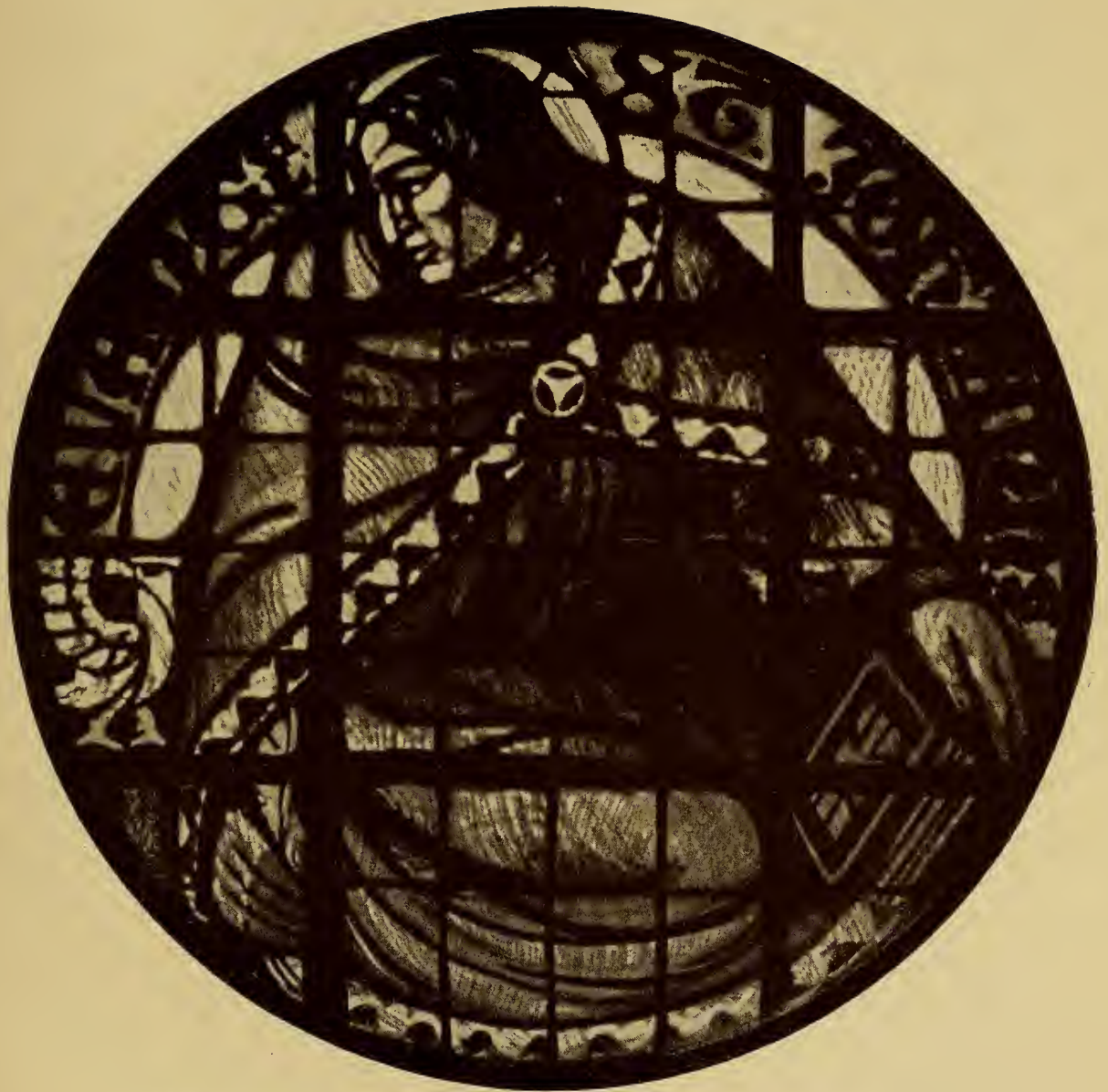

Glasgemälde, entworfen und ausgeführt von Wilh. Pütz, Köln. 

Außer diesen Vorschriften kennt Rugerus nichts, was er seinen Schülern als Ausdrucksmittel für Glasmalerei zu bieten hätte. Nur von einer kleinen Spielerei spricht er noch: wie man Edelsteine auf gemaltes Glas setzen könne. „Wenn du bei den Figuren auf Kreuzen, auf Büchern oder auf dem Schmuck der Gewänder auf das gemalte Glas ohne Verbleiung Edelsteine von einer anderen Farbe z. B. Hyazinth oder Smaragd aufsetzen willst, so verfahre auf folgende Weise: Wenn du an den entsprechenden Stellen, im Heiligenschein Gottes, sowie das Buch oder die Zierraten auf Gewandsäumen gemacht hast, die in der Malerei aus Gold oder einer goldähnlichen Farbe gemacht würden, so mach dies bei Fenstern aus lauterem Saffrangelb. Wenn du alles auf Goldschmiedsart gemacht hast, so wähle die Stellen, an denen du Steine aufsetzen willst, nimm kleine hellblaue Glasstücke, bilde daraus Hyazinthe nach der Größe der für sie bestimmten Stellen. Für Smaragde nimm in entsprechender Weise grünes Glas und ordne es so an, daß zwischen zwei Hyazinthe immer ein Smaragd zu stehen kommt. Wenn sie an ịhren Plätzen verbunden und mittels eines provisorischen Bindemittels festgemacht sind, so ziehe mit dem Pinsel einen dichten Schwarzlotkreis, damit nichts zwischen den beiden Gläsern ineinanderfließt. So brenne sie mit den übrigen Stücken im Ofen und sie werden hernach haften, daß sie nie mehr wegfallen." Es ist mir von dieser Technik nie ein Stück alten Materials in die Hände gekommen. Denn die einfachere Art ist die Einbleiung solcher Zieraten in die Fläche. Der Vorgang beruht darauf, daß in der Glut des Brandes das provisorische Bindemittel verflüchtigt und die beiden Gläser aneinander schmelzen.

Ich habe diese wichtigen Kapitel in ihrem Wortlaut beigegeben und erneut übersetzt, da außer der manchmal etwas unklaren Übersetzung von Ilg keine Bearbeitung existiert, die weiten Kreisen die Benützung dieser goldenen Sätze ermöglicht.

Gläsern Schwarzlot vertrieben werden, aus dem dann die Lichter herausgearbeitet werden. Der letzte Satz aber lautet: Sitque species picturae composita colorum varietate. Es entstehe der Schein eines Gemäldes, der durch die verschiedenen Farben hervorgebracht ist. Das heißt das Glasgemälde soll durch den verschieden stark aufgetragenen Ton des Schwarzlots das Aussehen eines aus verschiedenen Farben zusammengesetzten Gemäldes bekommen. 
Rugerus, der vortreffliche Kenner aller damals geübten kunstgewerblichen Techniken, gibt ein so allgemein gültiges Programm für die monumentale Glasmalerei, daß man nur zuzugreifen hätte, um die größten Wirkungen auch heute noch zu erzielen. Denn des Rugerus Anweisungen beruhen auf einem gründlichen Verständnis des wahren Wesens der Glasmalerei. Wo sind bei ihm jene Düfteleien und minutiösen Ausarbeitungen von plastischen Einzelheiten, die noch heute so manches Glasgemälde entstellen? Wo sind jene Weichheiten und Weichlichkeiten in den zahlreichen Nuancen kräftiger Grundfarben, wo jene kleinlichen Mittel, wie sie beispielsweise bei sogen. Porträten zur schönsten Blüte gelangen? Breit und kräftig stehen seine Vorschriften, wie die Kontur auf den Augsburger Fenstern. Unübertroffen rufen sie zur Nachahmung, als wären sie erst gestern geschrieben. Die Technik, die Rugerus lehrt, drückt sich so ungewollt und so modern jedem echten Künstler in die Hand, daß er neue Ideen am besten eben mit diesen alten Ausdrucksmitteln zur Auswirkung bringt. Antonio, der schon das Silbergelb kennt, legt ein besonderešs Gewicht auf die Zusammenstimmung der farbigen Hüttengläser. Nach ihm sollen die Hintergründe von Figuren immer azurblau sein. „Wenn du eine Figur gelb oder weiß kleidest, mach die Umschläge der Kleider rot, grau, grün oder blau, vorausgesetzt daß das Blau nicht schon daneben als Hintergrund steht. Du mußt außerdem im Besitz von grünem Glas zum Abstücken sein und davon in deine Arbeiten setzen, das wird dir Anerkennung bereiten. Auch vergiß nie, in deine Arbeiten mindestens ein Drittel weißes Glas zu setzen, weil das Weiß deine Arbeiten heiter und leuchtend macht. Nehmen wir den Fall, man braucht ein Fenster, zu dem man hundert Teile Glas bedarf, so nimm vollauf 3 Teile in weißem Glas und arbeite in den angegebenen Verhältnissen. Merke übrigens, daß der hl. Petrus immer mit gelbem Mantel und blauem Unterkleid gemalt sein will und die Umschläge rot oder grau. Im übrigen geh in die Kirchen und sieh dir an, was von Malern gemacht ist und ahme es nach, und wenn du nicht gut verstündest die Farben zu verteilen, schau dich in Kirchen um, wo Arbeiten von mir sind, dem mastro Antonio da Pisa, Meister in solcher Kunst und verteile nach dieser Art und du wirst nicht fehlen." Für 


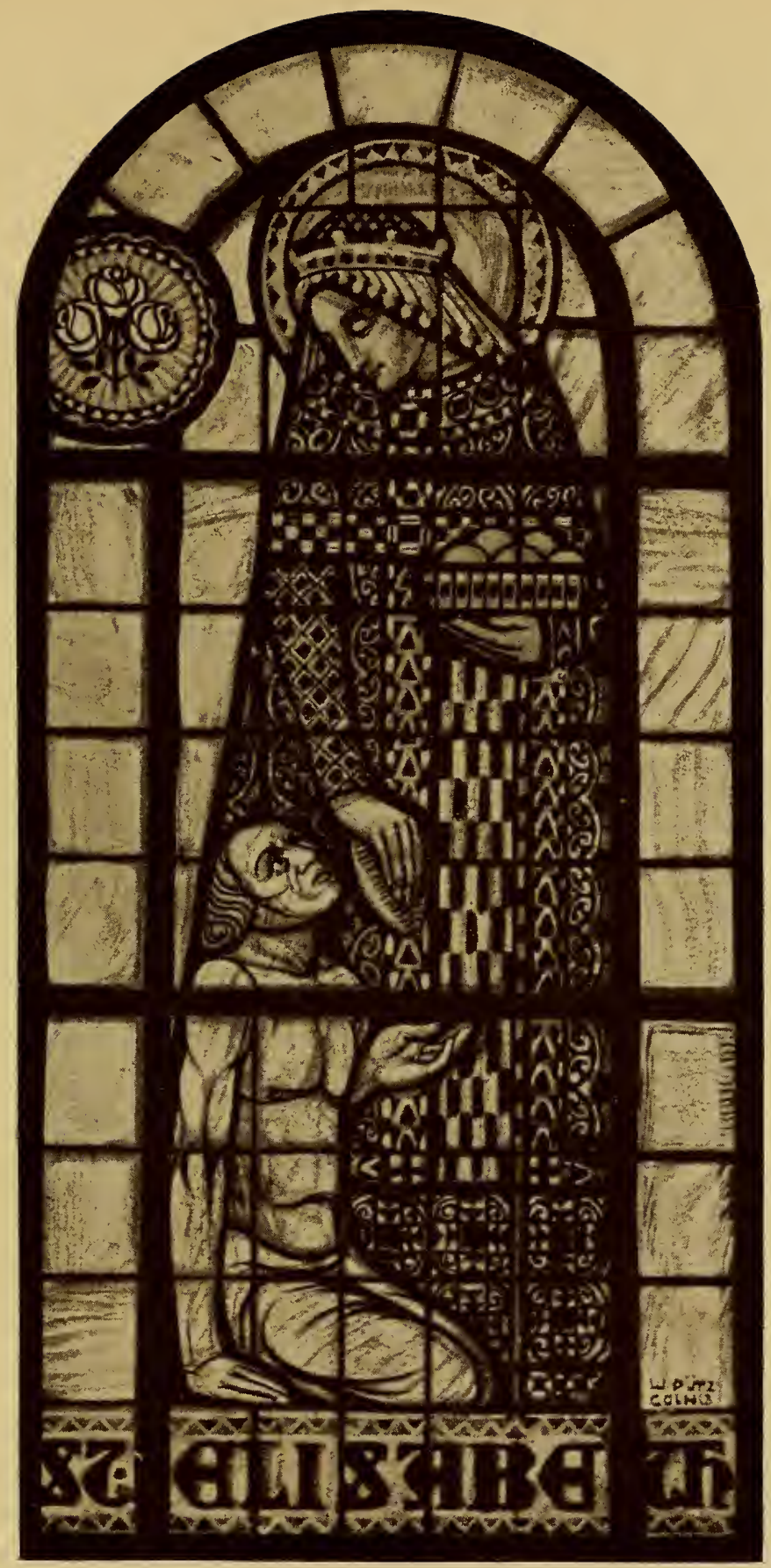

Glasgemälde, entworfen und ausgeführt von Wilh. Pütz, Köln. 

einzelne Glasmalereien empfiehlt er noch folgendes: „Wenn du einen Tabernakel (einen Baldachin) machen willst, so mach Basis und Kapitelle aus gelbem Glas, die Säulen aus weißem, rotem oder fleischfarbigem Glas und die Sockel aus weißem Glas in Nachahmung des Marmors. Für Holzwerk wende immer gelbes Glas von dem hellsten, das du haben kannst; um Backstein darzustellen, nimm rotes Glas von hellerer Nuance. Bei der Darstellung von großen Figuren achte darauf, daß du zu grünem Kleid einen roten oder lackfarbigen Mantel und einen weißen Mantelumschlag machst. Wenn du aber auf einem Gruppenbild von den Figuren die eine in Grau, die andere in Rot oder Lackfarbe kleidest, so setze zwischen diese beiden Farben hinein stets eine weiß oder gelb gekleidete Figur; dadurch werden sich die Figuren hervorheben. Wenn der Mantel oder das Kleid azurblau sein sollte, mach den Hintergrund rot." So sehr also Antonio den blauen Hintergrund bevorzugt, so läßt er den roten doch auch gelten.

Die Modellierung, die Rugerus erlaubt, ist also äußerst bescheiden. Sie soll sich nach seinen Angaben nur auf das allernotwendigste beschränken. Wichtiger als alles erscheint die Wahl und Zusammenstellung des farbigen Hüttenglases. Sie ist nicht leicht, sagt uns Antonio, und erfordert großen Farbensinn und gründliches Studium bewährter Meister. Aber elementare Regeln, die auf ästhetischen Prinzipien beruhen, können diese beiden Schriftsteller doch bieten. Sie stimmen darin überein, daß die Farben möglichst kontrastreich nebeneinander zu stehen kommen. Nur keine ineinander übergehende Töne. Am sichersten klingt der Zweiklang blau-rot, indem der eine Ton den Hintergrund, der andere die Hauptfarbe der Darstellung vertritt. Dabei wird heute leider zu leicht übersehen, daß blau die Farbe ist, die alles andere überstrahlt, also einen besonders starken Überzug oder eine kräftige Damaszierung verlangt. Am gelungensten ist nach der Meinung dẹr Alten jenes Fenster, bei dem der Glasmaler mit wenigen Farben auskommt und die teppichartige flächige Wirkung durch eine ausgezeichnete Verteilung der Farben und durch deren geschmackvolle Zusammenstimmung erreicht. Wir halten es nicht für einen Fortschritt, da $\dot{\beta}$ die moderne Glasmalerei sich ihres reichen Materialschatzes 
rühmt, überhaupt rühmen kann. Denn die zahlreichen Nuancen, die heute in farbigem Hüttenglas zur Verfügung stehen, verleiten unbedingt zu gebrochenen Tönen, zu Spielereien, zu stets gefahrvollen Annäherungen an die Ölmalerei. Die monumentale Glasmalerei muß stets auf Fernwirkung eingestellt werden, diese aber verlangt satte, kräftige und darum kontrastreiche Farben. Damit hängt zusammen, daß Rugerus und Antonio von jeder Wirklichkeit abstrahieren. Was kạnn es den Glasmaler kümmern, ob die Garderoben, die er seinen Figuren genehmigt, mit den Triumphen der augenblicklichen Mode übereinstimmen, was kann ihn der Ingrimm des Botanikers kümmern, wenn dieser zürnt, daß alle seine Lehren am Glasmaler ergebnislos vorübergegangen sind, und er zu seinem größten Verdruß sogar rote oder gelbe Bäume sehen muß? Tut ein roter Fleck in der Fläche not, so mag der darzustellende Heilige sich roter Stiefel nicht schämen. Wenn es daher einmal einem modernen Künstler gelingen sollte, einen modisch gekleideten Stifter so zu stilisieren, daß er in ein Glasgemälde Aufnahme finden kann, so möge er sich angelegen sein lassen, auch die Farben des Gewandes zu stilisieren. Auf der Ausstellung des Berliner Künstlerbundes sah ich vor einigen Jahren Scheiben, die betitelt waren: rote Putten, blaue Putten. Ganz im Einklang mit den oben angegebenen Grundsätzen der Alten war es also den Künstlern, die jene Glasgemälde entworfen haben, lediglich um ein Farbenexempel zu tun, das freilich die beabsichtigte Wirkung deswegen nicht ganz erreichte, weil die gewählten Farben Selbstzweck waren und nicht in innerer Beziehung zu dem Gesamtarrangement der Scheiben standen.

Man liest weder bei Rugerus, noch bei Antonio, nach welchen Vorlagen sie die Werkzeichnung auf dem Brett entwerfen ließen, insbesondere fehlt jede Angabe über den Anhaltspunkt, den der Glasmaler zur Bestimmung der Farben hatte. Die mit dem Bleinetz zusammenfallenden Konturen, wie jene, die das Schwarzlot auszuführen hat, sind sorgfältig angegeben, auch kargt Rugerus nicht mit Licht und Schatten, aber welchen Orientierungen soll denn der Glasmaler bei der Auswahl der Farben folgen? Man hat gemeint, Rugerus habe dabei die allgemeinen Vorlagen im Auge gehabt, die dem Fresko- und Handschriftenmaler ebenso gedient hätten, wie dem Glasmaler. Das könnte nur für die 


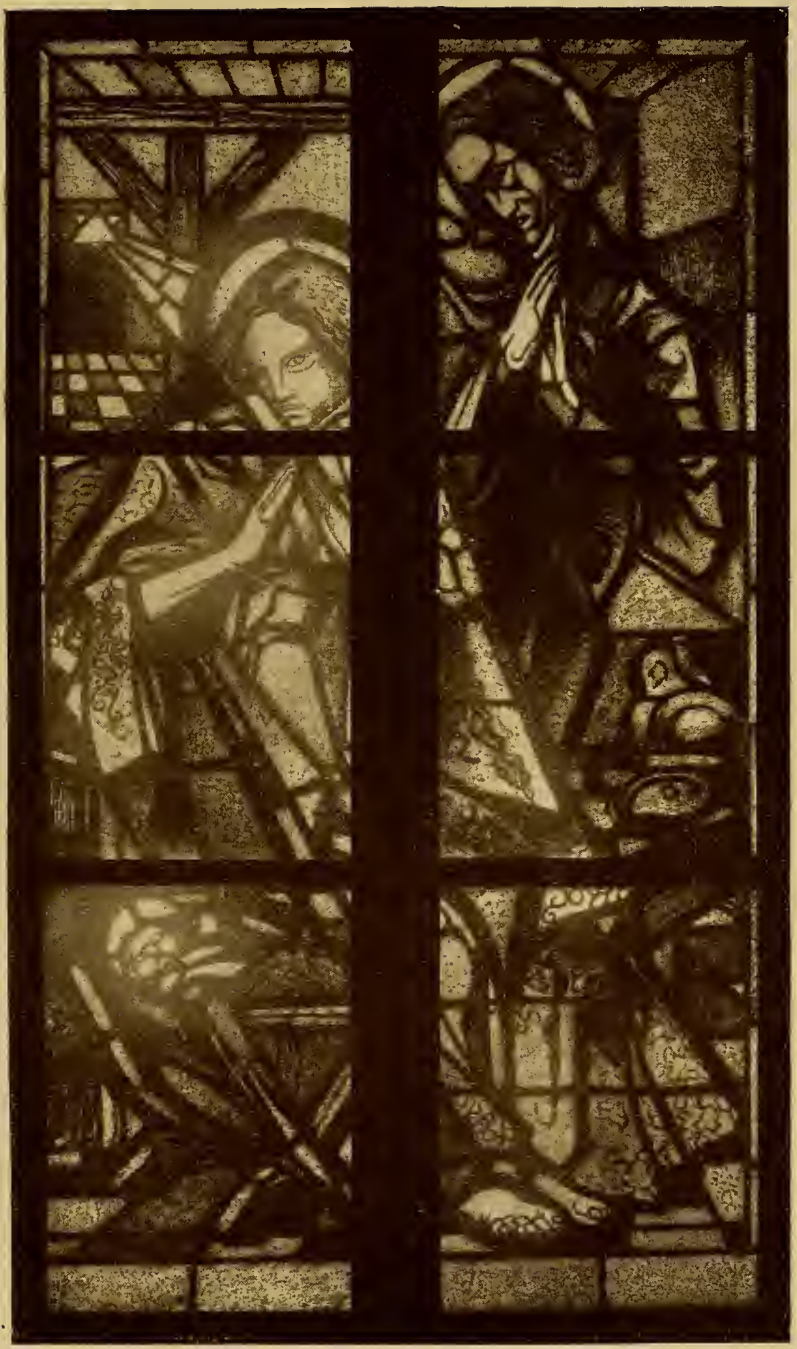

Glasgemälde nach einem Entwurf von Thorn-Prikker, ausgeführt von der Glasmalerei G. Heinersdorff, Berlin. 

Zeichnung, nicht aber für die Farben gelten, da der Kolorismus des Glasmalers ganz anderen Gesetzen untertan ist. Mir scheint. daß der im Geiste des Rugerus arbeitende Glasmaler überhaupt keinen farbigen Karton gebraucht hat. Waren die Umrisse durch Schwarzzeichnung gegeben, so notierte sich der Glasmaler erst die Farben, wobei ihm sein ererbter und in festen Traditionen weitergegebener Farbensinn alles Notwendige sagte. Je einfacher der dargestellte Gegenstand ist, desto größer die Möglichkeit, mit wenigen Farben große Wirkungen zu erzielen. Wem es nicht gegeben ist, aus einem Gefühl für glasmalerischen Kolorismus Entwürfe zu skizzieren, der tut besser, eine Schwarzweißzeichnung anzufertigen und hiernach die Farben mit Abstraktur von der Wirklichkeit einzutragen. Das Antikglas hat mit seinen Schlieren und Bläschen, mit seinen von selbst sich ergebenden Nuancen auf einer Tafel soviel Abwechslung, daß es unnötig ist, nach den zahlreichen Übergangstönen etc. zu rufen. Gerade die Technik mit den ungezählten Nuancen verteuert uns heute die Glasmalerei. Der Glasmaler ist gezwungen, sich ein großes Lager zu halten, von dem er gewisse Töne vielleicht lange Zeit gar nicht braucht, hat großen Verschnitt usw. Beides sind Spesen, die der Kunst gar nichts nützen und von denen höchstens der Glashändler gewinnt. Je kleiner die Palette, desto reiner und größer werden die Wirkungen einer Glasmalerei. Da der Glasmaler in diesem Falle sich mit wenigen, aber besonders kräftigen und gegensatzreichen Gläsern versehen muß, bekommen alle seine Arbeiten einen monumentalen, vielleicht gar herbeñ Charakter; hunderte von süßen Tönen werden verschwinden. Zunächst mag sich der Glasmaler freilich beengt fühlen, da er viele auf dem Karton vorgezeichnete Details nicht ausführen kann. Die Beschränkung auf die ästhetisch allein zulässige kleine Palette würde also vor allem auch eine Reform der Zeichnung zur Folge haben, die sich endgültig und ohne Vorbehalt aus den verlockenden Umarmungen der Tafelmalerei befreien müßte. Die kleinste Konzession an die Ölmalerei sollte den Freund der Glasmalerei veranlassen, die ganze Zeichnung schon wegen dieser kleinen Liebelei zu verurteilen. Dabei klagen die Glasmaler über die modernen Künstler, die die ganze Kartonzeichnung an sich gerissen hätten und zu Tyrannen gegenüber 
den ausführenden Glasmalern, wie der Glasmalerei als solcher geworden seien. Umgekehrt klagen die Kartonzeichner über die Glasmaler, daß diese nicht imstande seien, ihre Absichten zu verstehen und auf Glas zu übersetzen. Wir sind daher auch durch diese Erfahrung zur Überzeugung gelangt, daß die Verbindung von Kartonzeichner und Glasmaler in einer Person doch das Ideal bildet. Dabei gestehen wir gerne zu, daß manchmal sich Männer mit dürftigen Kenntnissen und noch dürftigerem Geschmack, aber ungleich kräftiger Begabung für das Geschäftliche als fachkundig empfehlen, eine Zeit lang Vertrauen genießen, solange über den wahren Charakter der Glasmalerei Nebel verbreitet sind, und währenddessen aber gewissermaßen eine Glasmalerfabrik etabliert haben. In einer solchen herrscht Arbeitsteilung. Der eine macht nur Architekturen, der andere nur Köpfe, wie in großen Konfektionshäusern der eine nur Hosenschnallen, der andere nur Knöpfe. Solche Glasmalerunternehmer richten unter den künstlerischen Bestrebungen der Glasmalerei das größte Unheil an.

Ebenso schädlich ist der noch immer nicht ausgestorbene oder eigentlich jetzt erst recht wieder lebendige Versuch, die Glasmalerei aus ihrer Stellung als Kunstgewerbe in die Höhen der absoluten Kunst $\mathrm{zu}$ forzieren. Man betrachte dagegen, wie in allen mittelalterlichen und insbesondere Schweizer Glasgemälden stets ein Hauptgewicht auf das echt Handwerkliche, Kunstgewerbliche in der Glasmalerei gelegt wurde. Die einzelnen Meister schämten sich nicht, denselben Riß, den ein Konkurrent schon einmal ausgeführt hatte, wiederum von neuem zu bearbeiten. Auch sie schufen also manchmal nach fremden Zeichnungen; allein der sichere Takt für das Glasmalerische bewahrte sie vor Auswüchsen, die leider im 19. Jahrhundert nicht gerade selten waren. Heute soll jedes Glasgemälde im Rang eines absoluten Kunstwerks gehen, bei dem der Karton die Hauptsache ist. Das muß die Glasmaler zwingen, wenn sie Aufträge bekommen und konkurrenzfähig bleiben wollen, sich, wenn auch widerwillig, den Wünschen der Kartonzeichner zu unterordnen und Farbennuancen zu halten, die ein direktes Unglück für die Glasmalerei bilden und den Geschmack des Publikums immer mehr verderben. Darum Vereinfachung der Palette! Das ist die erste Reform, 

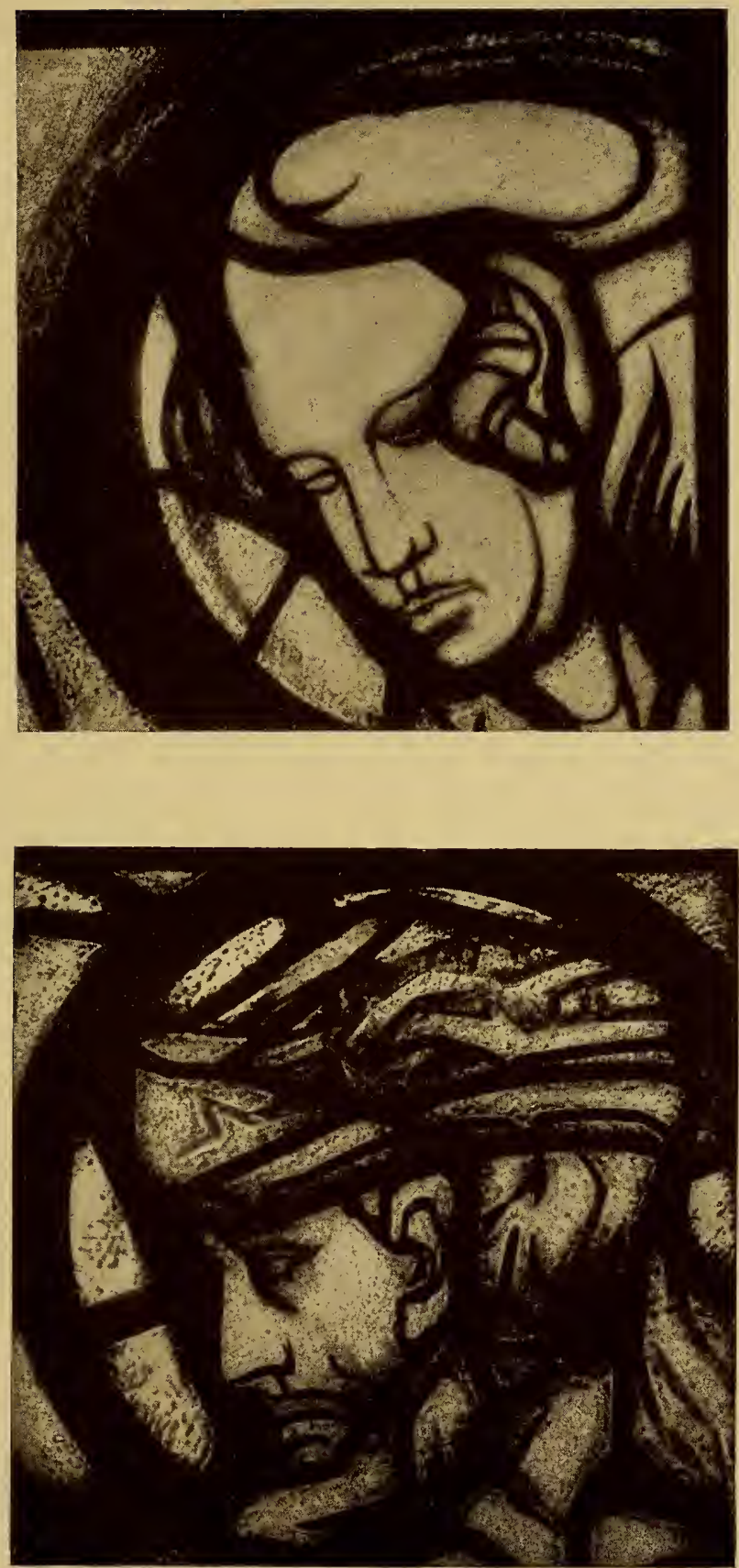

Details aus einem Glasgemälde, entworfen von ThornPrikker, ausgeführt von der Glasmalerei G. Heinersdorff, Berlin. 

die auf die Entwicklung der Technik, wie auf den Kartonzeichner Wunder wirkt.

Nach erfolgter Auswahl der farbigen Hüttengläser schreitet der Glasmaler zur eigentlichen Bemalung, wobei ihm ein inspirierender Blick in seinen Rugerus auch heute noch zu statten käme. In der Regel werden zunächst die hauptsächlichsten Konturen mit Schwarzlot aufgetragen. Zu diesem Zweck muß diese Farbe eigens bereitet werden. Man macht das in Pulverform erhältliche Schwarzlot mit Wasser an und zerreibt es auf einer Platte. Die Hauptsache, die bereits Rugerus betont, ist die sorgfältige Zerreibung, damit nicht kleine Körnchen und Klümpchen sich bei der Bemalung abheben. Meistens gibt man Öl oder Sirup als Bindemittel bei, das dann beim Brand vernichtet wird. Diese Bindemittel erschweren jedoch die flotte Arbeit. Ö1 wird schnell zäh und Sirup behindert das Überziehen. Darum ist die einfache Wassermischung das beste und freieste Verfahren. Viel wichtiger erscheint, daß der Glasmaler auf absolute Reinlichkeit dem zu bemalenden Glas gegenüber hält, denn jeder Fleck durch Berührung hemmt die beabsichtigte Wirkung des Schwarzlots.

Man hat sich viel darüber den Kopf zerbrochen, welche Bindemittel die Alten angewandt hätten, um das Schwarzlot fest auf die Glasstücke anzuheften. Rugerus nennt nur Wein und Harn als Zusatz beim Reiben des Gemenges. Diese beiden Flüssigkeiten haben den Vorzug, daß das Pulver sehr fein darin zu lösen ist. Im Gegensatz zu einer Reihe von Autoren glaubt Geiges, daß Theophilus aus irgend einem Grund die Angabe des Bindemittels unterlassen habe. Denn jene beiden Flüssigkeiten hätten keinerlei bindende Kraft, ihre Anwendung sei vielmehr, namentlich was den Harn betrifft, noch auf einem gewissen abergläubisch-mystischen Erdreich gewachsen. - Wir geben Geiges in diesem letzteren Punkte Recht; auch legen wir an sich keinen Wert auf die Tatsache, daß Rugerus über das Bindemittel nichts erwähnt. Denn man muß mit den beiden Möglichkeiten rechnen, daß der Mönch absichtlich oder unabsichtlich das eine und andere übergangen hat. Da aber auch Antonio da Pisa kein Bindemittel angibt, will es uns scheinen, daß die Alten gar keines verwendet haben. Denn dasselbe war nicht notwendig, da man leicht auch 
ohne Bindemittel arbeiten kann, wie wir eben sagten, und bei komplizierten Stellen ein schönes und leichtes Mittel, nämlich den Brand zur Verfügung hat. Nach des Rugerus Anweisung wurde erst die Kontur aufgetragen und getrocknet. Er sagt im 2 I. Kapitel: „Wenn die ersten Schatten trocken sind, so bedecke, was vom Glase übrig bleibt, mit einem leichten Ton ..." Vielleicht wurde nach der Konturierung zum erstenmal gebrannt, hernach die Modellierung mit den drei Tönen ausgeführt und dann abermals gebrannt. Genaue Studien an den Augsburger Fenstern haben ergeben, daß das Schwarzlot sowohl als Kontur, wie auch als (dünn aufgetragener) Ton der Modellierung außerordentlich gut und frisch noch heute auf dem Glase sitzt. Darum gewinnt der Gedanke an Wahrscheinlichkeit, daß die ältesten Glasmalereien, die dem Stand der Rugerustechnik entsprechen, wiederholt gebrannt sind. Aber auch ohne diese Annahme ist es keineswegs notwendig, bei Rugerus die Kenntnis und Verwendung eines Bindemittels für die Malfarbe (das Schwarzlot) vorauszusetzen. Erst die Nürnberger Handschrift empfiehlt „Gummywasser zum Anmachen des Schwarzlots".

Der Auftrag des Schwarzlots soll breit und kräftig sein, muß aber trotz aller Stilisierung in innerer Beziehung zum Objekt stehen. Am reinsten und wirksamsten kommt die Zeichnung der Schwarzlotkontur in der romanischen Zeit zum Ausdruck.

Nicht immer wird in der Technik mit dem Auftrag der Schwarzlotkontur begonnen. Manchmal ist vielmehr der sogenannte Überzug das erste, das der Glasmaler an den zurechtgeschnittenen Glasstücken vornimmt. Die ganze Glasfläche wird dabei mit Schwarzlot überzogen und getrocknet. Aus dieser Schicht wischt der Glasmaler die verschieden starken Lichter heraus. Die Behandlung des Überzugs verlangt eine besonders entwickelte Meisterschaft und ist dementsprechend bei den verschiedenen Glasmalern verschieden. Vor allem muß sich der Glasmaler eine genaue Kenntnis von den Lichtverhältnissen verschaffen, in die das zukünftige Glasgemälde kommen soll. Denn der Überzug ist ja nichts anderes als ein Spiel mit dem Licht, als ein Mittel, eine das Auge erfreuende Abwechslung innerhalb den Grenzen hell und dunkel. Mancher Überzug war im Atelier des Glasmalers vortrefflich in der Wirkung. Im Bau eingesetzt 


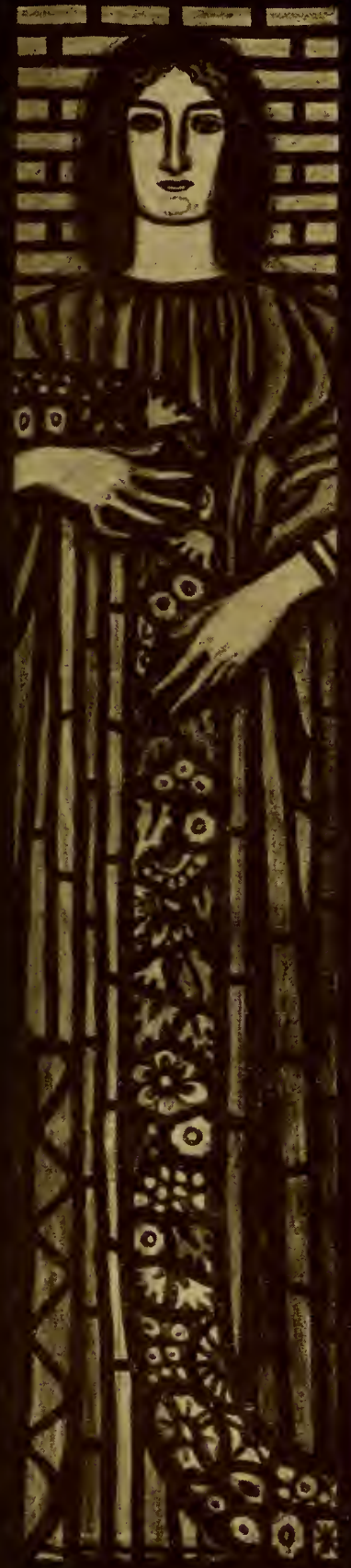

Glasgemälde von Professor Josef Goller, Dresden.
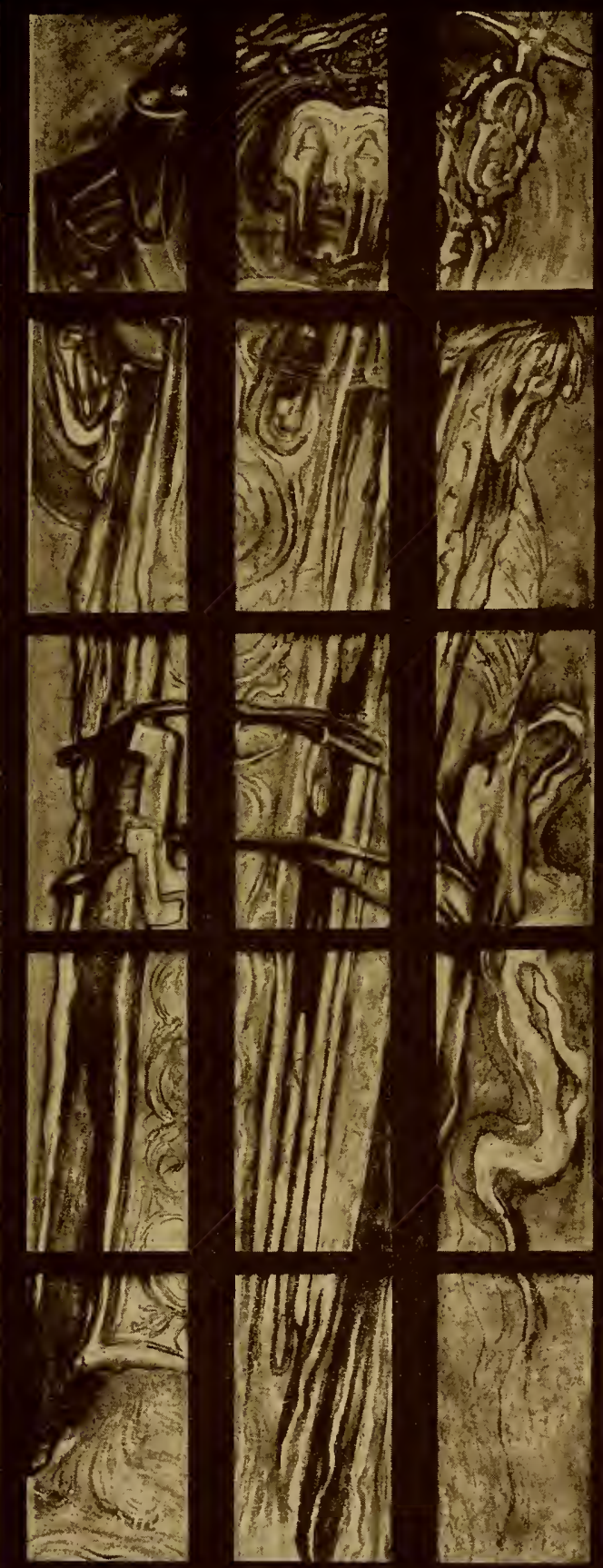

Karton zu einem Glasgemälde von Stanislaus Wyspianski, Krakau. 

fiel diese ab, und warum? Weil der Glasmaler übersehen hatte, daß der Überzug an Dichtigkeit verliert und heller wird einmal durch den Brand, namentlich wenn ein wiederholtes Brennen vorgenommen wird, sodann durch das erweiterte Licht im Bau und endlich durch das Bleinetz, das den Überzug heller erscheinen läßt. Auf diese drei Gesichtspunkte muß daher besonders Rücksicht genommen und das Schwarzlot darf nicht gar zu zaghaft aufgetragen werden. Gewisse Kunstgelehrte und Praktiker nehmen prinzipiell gegen jeden Überzug Stellung, da er eine beabsichtigte Täuschung darstelle, insofern er an dem Körper des Glases Wirkungen hervorrufe, die nur durch die Zeit geschaffen würden. Der Überzug sei also eine Art künstlicher Patina und daher unter allen Umständen verwerflich. Eine genaue Untersuchung der Augsburger Domfenster hat ergeben, daß die ausführenden Glasmaler die Malfarbe lediglich zur Angabe von zeichnerischen Umrissen und Schatten verwendeten und daß sie jene Glasflächen, die keinerlei Zeichnungswerte repräsentierten, vollständig blank ließen. Die Alten hatten somit ihre Freude an dem neu Aussehenden; wenn wir heute die Farbgläser ohne den Patinaüberzug, mit dem die Zeit Grelles abgetönt, Kontrastreiches ausgeglichen hat, herstellen wollen, so werden wir erstaunt sein, wie anders das Aussehen heute glühend verehrter alter Glasgemälde einstens war. Die Alten richteten die Farben und insbesondere die durch das Fenster durchgelassenen Lichtwerte nach der erstrebten Beleuchtung des Raumes ein. Frisch eingesetzt war also das durchdringende Licht für die kirchlichen Bedürfnisse hinreichend. Mit der Zeit aber dunkelten die Fenster nach, überzogen sich mit edler Patina und unedlem Schmutz; und wir begreifen bis zu einem gewissen Grad, wenn die Domherrn in den Perioden der Aufklärung und des I9. Jahrhunderts gegen die verdunkelnden Glasgemälde wüteten, nachdem in jenen Zeiten kein künstlerisches Verständnis oder gar Interesse den Sündern Verzeihung für ihre „dunkle Seele" vermittelte. Heute will man im allgemeinen nicht warten, bis die Zeit ihr Patinierungswerk verrichtet. Was sollen erst Enkel und Urenkel genießen, nachdem die Väter die Kosten des Genusses getragen haben! Auch wollten manche Glasmalereianstalten in früheren Zeiten überzeugend dartun, daß die Stim- 
mung ihrer Arbeiten durchaus nicht hinter dem mystischen Eindruck der Alten zurückbleibe. Aus dem Zusammenwirken dieser Momente entstand in den neunziger Jahren des vorigen Jahrhunderts eine Richtung, die die schönsten Farbwerte in einer Weise abdunkelte, daß von deren naivem Glanz kaum mehr eine Spur blieb. Die gesunde Technik hat sich auch von diesen Verirrungen wieder erholt und heute versucht man, die frischen Farbwerte der Alten mit dem unvergleichlichen Reiz der echten Patinierung mittels eines leichten Überzugs zusammenzustimmen. Als oberstes Prinzip ist dabei zu berücksichtigen, daß der Überzug nie zu stark sein darf, da das Glasgemälde mit der Zeit von selbst nachdunkelt. Lieber $\mathrm{zu}$ wenig als $\mathrm{zu}$ viel Überzug. Im übrigen kommt es ganz darauf an, wie der Überzug aufgetragen und behandelt wird. Für die Handhabung gerade dieses Ausdrucksmittels ist eine besondere Fähigkeit notwendig ${ }^{1}$ ). Es bietet dem Glasmaler unzählige Nuancen, um bestimmte Zwecke zu erreichen. Er kann vom Überzug Schlieren auswischen, um die natürlichen Schlieren des Glases zu unterstützen, sie geradlinig, wellenförmig oder wie immer hineinziehen, oder auch tupfenförmig den Hobel der Glasoberfläche unterstützen. Dabei bedarf er keiner zahlreichen und weitläufigen Instrumente. Außer dem Kontur-, dem Vertreiber-, Verwaschpinsel kann er für gewisse Effekte mit großem Erfolge ein paar abgenutzte Dekorationspinsel benützen, die weit besser sind als die künstlich zurechtgemachten. Damaste, Schriften, Blumen und sonstige Ornamente werden mit einem Pinselstiel oder mit einer Nadel ausradiert. So schreibt bereits Rugerus dieses Verfahren für Schriften vor. Es war während des Mittelalters so verbreitet, daß es als Bild für dichterische Vergleiche diente. Beispielsweise führt Hartmann von der Aue in seinem Erek (ca. I.195) einen solchen Vergleich durch. Als die Heldin dieses Stückes ihren halbtoten Geliebten erblickt, wird sie von Jammer und Verzweiflung ergriffen. Es ist also gerade so, wie wenn ein lauteres Glas mit düsterem Schwarz überzogen wird. Aber der Geliebte erholt sich von den Wunden; da

1) Vgl. Das Schwarzlot als Kontur und Überzug in der Glasmalerei, Zeitschrift für alte und neue Glasmalerei I 9 I4, S. $35 \mathrm{ff}$. 

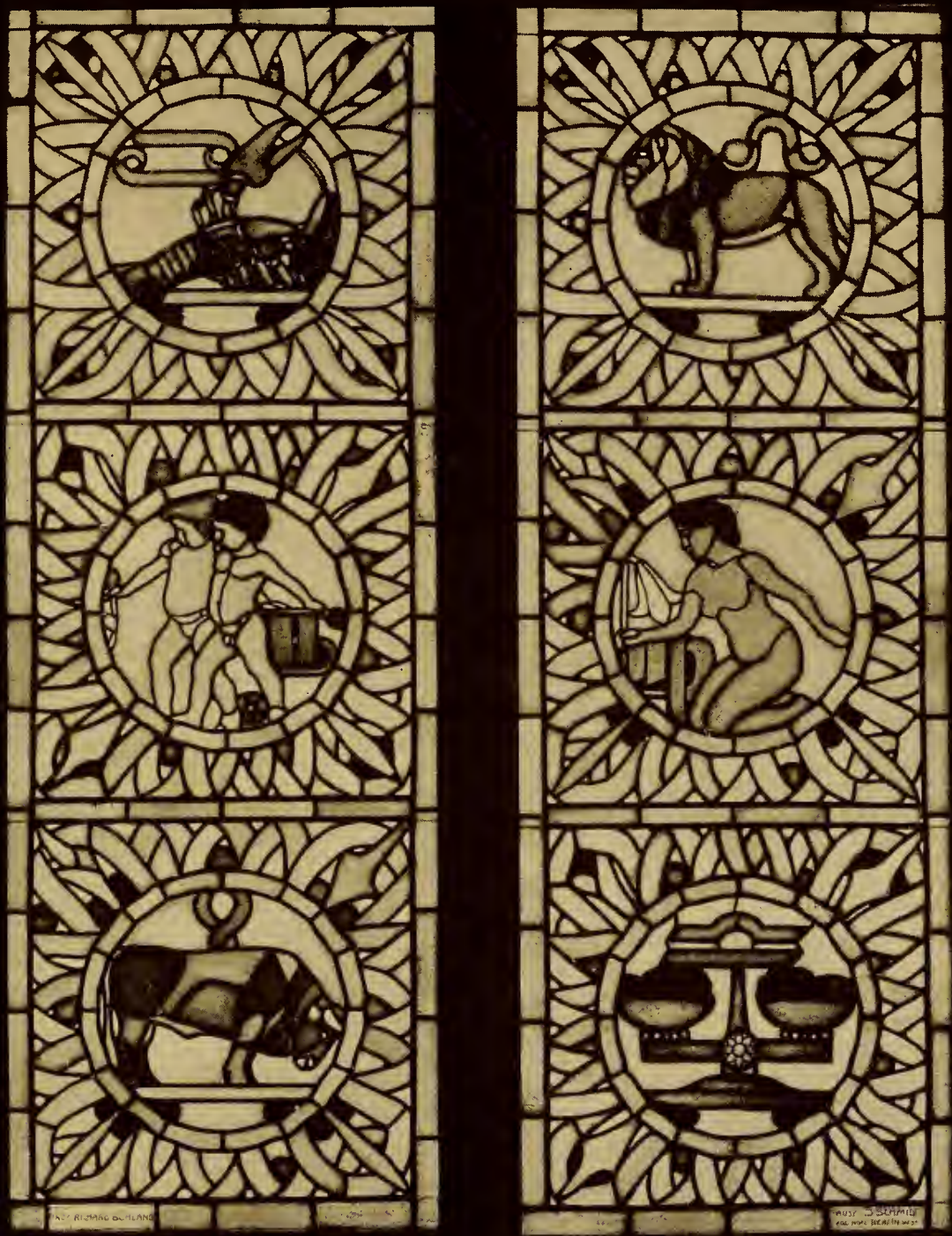

Kunstverglasung: Die 6 Sommermonate; für die Berliner Kunstausstellung I 9 I 3. Entworfen von Professor Rich. Böhland, ausgeführt von der Glasmalerei J. Schmidt, Berlin. 

verkerte sich dem wibe

ir herzen trüebe

als ein glas darz wol schüebe,

daz von schwarzer varwe

bestrichen wäre begarwe

sô diu farwe abe kaeme

sô wurde ez genaeme

und licht daz ê vinster war.

sus war ir herze ein luter glas,

der erren sorgen beschaben

unde wol ze lichte erhaben

mit unvalscher vünne

sam sie nie leit gewünne.

(Es verwandelte sich dem Weibe ihr trauriges Herz, wie Glas, das zuvor mit schwarzer Farbe ganz bestrichen war, und es nun einer so abschabt, daß die Farbe abgeht, so daß lieblich und licht ist, was zuvor finster war, so war ihr Herz ein lauter Glas, der früheren Sorgen entschabt und wohl ins Lichte gehoben mit echter Wonne, als wenn sie nie Leid erfahren hätte.)

Trotz dieser allgemeinen Sitte, Schriften aus dem Schwarzlotauftrag heraus zu radieren, sind die Fälle nicht selten, in denen die Schrift wie eine andere Kontur auf das Glas aufgetragen wurde und also schwarz erscheint. Dieses letztere Verfahren eignet sich sehr für die gotische Majuskel, während die Antiquaschrift am wirkungsvollsten ausradiert wird. Alle bis jetzt beschriebenen Bemalungen werden auf der Vorderseite (der dem Beschauer zugekehrten Seite) angebracht. Auf der Rückseite pflegt man nur leichte Töne zur Unterstützung der Zeichnung auf der Vorderseite anzubringen. Immer aber muß das Silbergelb auf der Rückseite aufgetragen werden.

Im Gegensatz zum Schwarzlot, das als Mal- und Lasurfarbe gebraucht wird, ist das Silbergelb eine reine Lasurfarbe. Wie schon erwähnt, begegnet es uns erstmals auf einem Fenster in der Schweiz und zwar näherhin auf einem Glasgemälde in der Kirche zu Blumenstein im Kanton Bern. Dargestellt ist der hl. Christophorus. In naiver Weise hat der Glasmaler das Wasser, durch das der Heilige schreitet, an dessen Füßen durch schwimmende Fischlein angedeutet. Die Fischlein aber sind in Silber- 
gelb ausgeführt. Diese eigenartige Anwendung des Silbergelbes läßt darauf schließen, daß es mindestens schon ein bis zwei Jahrzehnte im Gebrauch war, bis man es so keck für Figürliches gebrauchte. Seine hauptsächlichste Stelle hatte es an Nimben und Heiligenscheinen, an Mandorlen und Gewandsäumen. Die großen Effekte, die man mit dem Silbergelb vom Hellgelb bis zum tiefsten Goldrot erzielen konnte, reizte die Glasmaler des I6. Jahrhunderts, sogenannte Monolithscheiben mit Schwarzlot und Silbergelb auszuführen. Dieses System war namentlich in Süddeutschland, im Anschluß an die Blütezeit der graphischen Künste beliebt. Prachtvoll ist die Wirkung des Silbergelbes, wenn es sich gegen blau oder grün abhebt. Die Anwendung des Silbergelbes in der Gegenwart hat sich gegen die früheren Perioden nicht wesentlich verschoben. Höchstens versucht man es viel weitläufiger zum Tonen eines farblosen Glases heranzuziehen. Bereits den Alten war bekannt, daß man durch Hinterlegung mit Silbergelb den Farbcharakter des Hüttenglases verändern kann, daß zum Beispiel mit Silbergelb hinterlegtes Blau grün erscheint. Auch zu diesem Zweck wird das Silbergelb heute noch viel verwendet. 


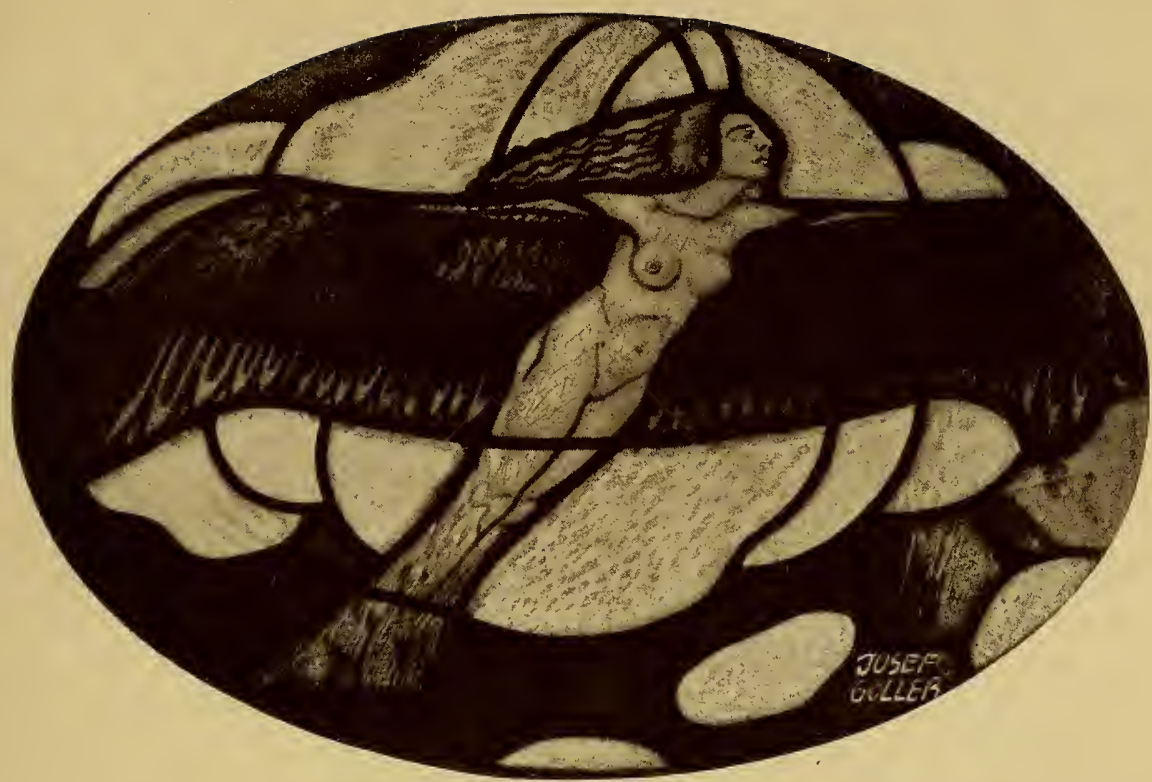

Glasgemälde von Professor Josef Goller, Dresden.
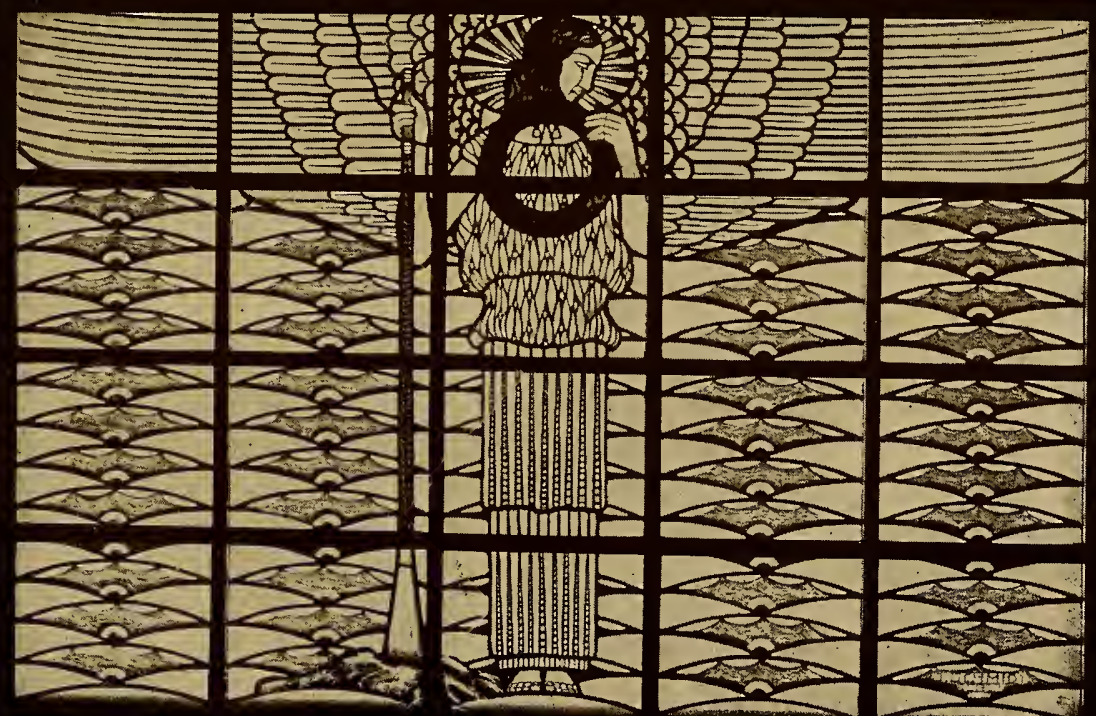

Kunstverglasung für das Krematorium zu Breslau. Entwurf von Wenzel Oswald, Wien, ausgeführt von J. Schmidt, Berlin. 



\section{V. \\ Die auf Glasgemälden dargestellten Gegenstände.}

Entsprechend dem Zweck, dem die Glasmalerei in alter und neuer Zeit dient, hat sich die Darstellung des Gegenständlichen verhältnismäßig wenig entwickelt. Wie in dem Kapitel „Der Schönheitsgedanke in der Glasmalerei" näher ausgeführt ist, hatte die Glasmalerei in alter Zeit ein dreifaches Amt, ein praktisches, Abschluß gegen Wind und Wetter, ein ästhetisches, Vollendung der Architektur, und ein didaktisches, Beispiel für die Gläubigen zu sein. Die aus diesen drei Punkten resultierende Gemeinsame charakterisiert Form und Inhalt der Glasmalerei. In den ersten Zeiten des buntfarbigen Fensterschmucks überwog naturgemäß das Ornament, wie wir bei der Entwicklung der Kunstverglasung beobachtet haben. Pflanzenranken und geometrische Motive waren das Thema, mit dem sich die Kunstverglasung beschäftigte, und als sie langsam auf das Figürliche zusteuerte, war die Einzelfigur das Zunächstliegende, weil am leichtesten ausführbar. Man kann beobachten, daß die alamannisch-bayrische Schule mit Vorliebe an der Einzelfigur festhält, was aus dem zeichnerischmonumentalen Stil dieser Schule ohne weiteres erklärt wird. Als die Welle, die die Glasmalerei vom Osten nach Westen trug, im 13. Jahrhundert über den Rhein zurückbrandete, brachte sie ein festes System der Darstellungen mit ${ }^{1}$ ), das zwar allenthalben Bewunderer, aber nur wenig Nachfolger fand. Frankreich war der dogmatischen Theologie mit ihren scharfen Sätzen mehr zugänglich; es liebte das dramatisch ausgestaltete System.

1) Mâle Émile, L'art réligieux du XIII. siècle en France, Paris igro. 
der auf romanischem Boden hervorgesproßten Scholastik. Was die ersten christlichen Schriftsteller mehr noch in lehrhafter und moralisierender Absicht in ihre Bücher aufgenommen hatten, 'wurde im Laufe des I2. Jahrhunderts zu einem festen Kanon geschlossen, der ebenso für den Prediger, wie für den Künstler zwingend war. Die theologische Schule und spätere Universität Paris bildete für das christliche Abendland das Beispiel, dem man nachzueifern hatte. Der gelehrte Abt von Royaumont, Vinzenz von Beauvais, hatte in seinem Speculum majus (ca. I250) alles zusammengefaßt, was die Theologie in Paris lehrte. Sein Buch wurde die Vorlage für die gesamte Ikonographie; es umfaßte vier Abteilungen, das speculum naturale, historiale, doctrinale, dem ein späterer Schriftsteller das speculum morale hinzufügte. Für das speculum naturale hat Vinzenz als Hauptquelle den Honorius von Autun benützt, der in seinem speculum ecclesiae eine eigenartige Symbolik und Ikonographie bietet. Nach diesem Speculum ecclesiae war außer dem Portal der Kathedrale von Laon, ein Fenster in der Kathedrale zu Lyon ausgeführt mit folgendem System:

Christus in der Mandorla

Maria und die Apostel nach der Himmelfahrt

Der Kladrius Himmelfahrt Christi Junge Adler fliegen zum Licht

Jonas ans Land Auferstehung Christi Die Löwin mit ihren gespien

Isaaks Opfer

Christus am Kreuz

Jungen

Der brennende Dorn-

Geburt Christi

Eherne Schlange

busch

Isaias mit Schrift-

Verkündigung der

Gideons Vließ

tafel

Geburt Christi

Das Fenster stammt aus dem Beginn des I3. Jahrhunderts. Diese sehr alte Typologie der französischen Glasgemälde charakterisiert sich durch eine auffallende Bevorzugung der Beispiele und Gleichnisse aus der Natur, näherhin aus dem Tierreich. Auch bei jenen Szenen, die aus dem Alten Testament hergeholt sind, macht sich diese Hinneigung zu den Wundern der Natur: Eherne Schlange, Gideons Vließ, brennender Dornbusch, der 


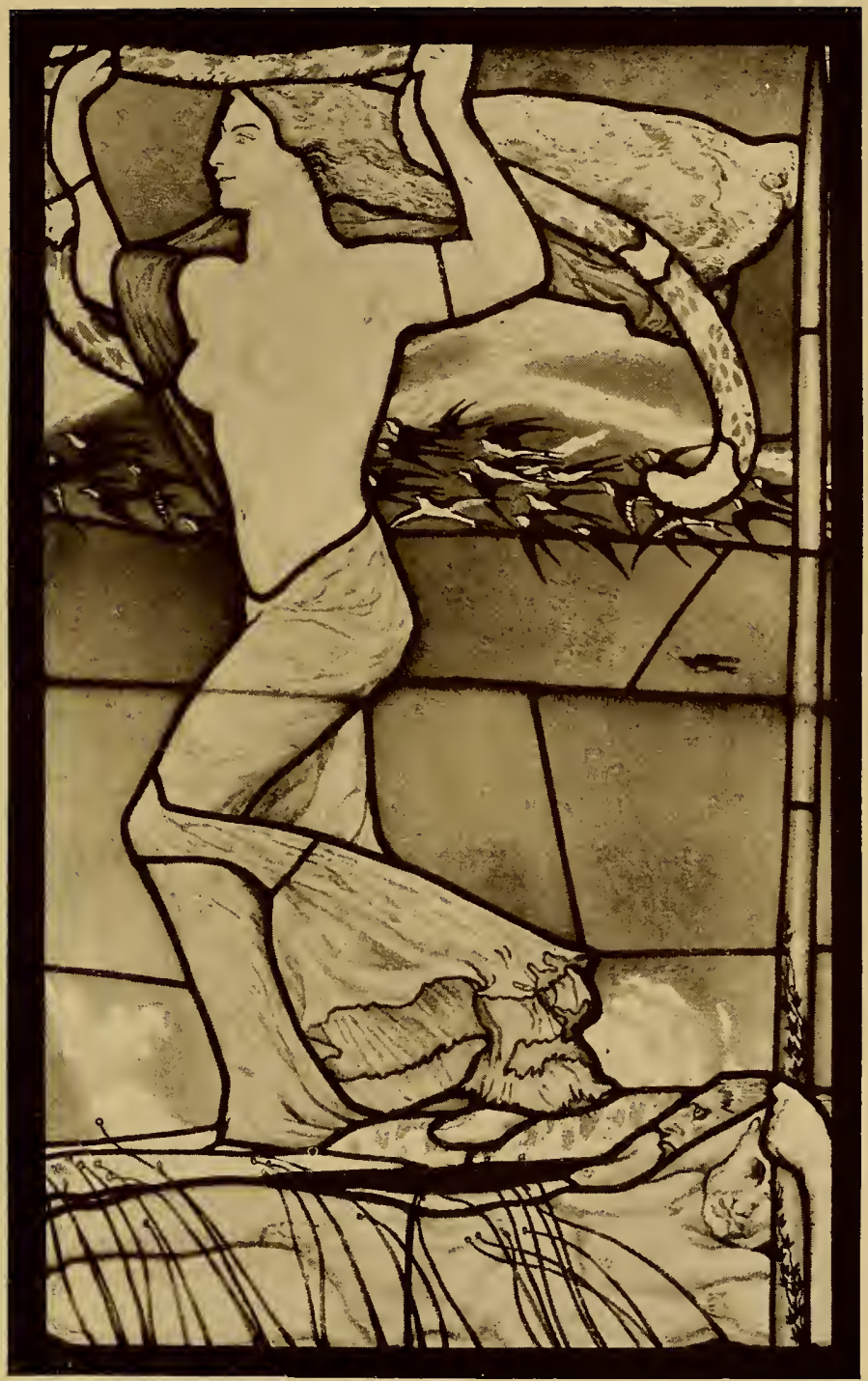

Freya. Glasgemälde, entworfen von Horst-Schulze, ausgeführt von der Glasmalerei Richter \& Römer, Leipzig. 

Fisch des Jonas, bemerkbar. Honorius hat sein Wissen aus dem Physiologus geschöpft. Dieses seltsame Buch war bekanntlich während der ersten Zeit der romanischen Periode sehr beliebt, diente besonders als Quelle für Skulpturen an Portalen und in Giebeln, an Friesen und Kapitellen. Während aber seine Erzählungen von den Bildhauern ohne Zutat aus den Evangelien dargestellt wurden, hat ihn Honorius in ein festes System, in vorbildliche Beziehung zu wichtigen Lehren des Christentums gebracht. Der Kladrius, oder wie er im Physiologus heißt, Charadius, ist ein Vogel, der weiß, ob ein Kranker stirbt oder ob er genesen wird. Muß der Patient sterben, so dreht der Vogel seinen Kopf weg, wird er aber genesen, so heftet der Charadius seine Blicke fest auf den Kranken und saugt die Krankheit ein. Hernach fliegt er zur Sonne und atmet sie wieder aus. Vom Adler aber berichtet. der Physiologus: Wenn der Adler seine Jungen das Fliegen lehrt, so hält er sich im Anfang über sie, damit sie niicht allzusehr von der Sonne geblendet werden. Die Löwin bringt nach den Darlegungen des Physiologus ihre Jungen totgeboren zur Welt. Nach drei Tagen aber werden sie durch das Brüllen des Löwen zum Leben erweckt. Die anmutigste aller Sagen ist jene vom Einhorn. Das Einhorn ist ein sehr wildes Tier und um sich seiner zu bemächtigen, muß man seine Zuflucht $\mathrm{zu}$ einer Jungfrau nehmen. Wenn das Tier eine Jungfrau sieht, eilt es in deren Schoß und läßt sich fangen.

Trotz der großen Autorität des Honorius von Autun, trotz der Beliebtheit des Physiologus hat sich doch das Lyoner System nicht durchsetzen können. Vereinzelt finden sich noch Anklänge, wie die Löwenszene auf einem Fenster zu Le Mans und zu Bourges; allein der Norden rückt ziemlich energisch vom Physiologus ab und wendet sich der aus dem Alten und Neuen Testament gebildeten Typologie zu. Im übrigen aber schafft der französische Kunstkreis durch den engeren Abschluß an des Vinzenz' Speculum völlig neue Sujets, die in sehr modifizierter Form einige Dezennien später nach dem Westen wandern. Ganz neu ist der Darstellungskreis, der sich auf das 2. Buch des Speculums baut, des speculum scientiae, Spiegel des Wissens. Unter Wissen ist nicht allein das abstrakte Wissen zu verstehen, sondern in erster Linie das praktische Wissen, die Arbeit. Die 
Arbeit ist ein göttliches Gesetz. Darum finden wir, wie z. B. in Chartres die Darstellung der Handwerke einen so breiten Raum einnimmt. Die verschiedenen Berufe sind in Fensterstiftungen vertreten, aber nicht mit einer einfachen Stiftungsinschrift, sondern mit der Darstellung eines genauen Vorgangs der einzelnen Handwerkszweige. Der Handwerker ist in sein Berufsgewand gekleidet und mit seinen Arbeitsgeräten ausgerüstet. Ja noch mehr, auf einem Glasgemälde in der Kirche Notre-Dame au Sémur ist die detaillierte Darstellung der Tuchfabrikation zu sehen, nicht etwa als Stifterscheibe, sondern eigens für sich. Denn das Fenster enthält sonst nichts. In dieser Zerlegung der Arbeit ist auch begründet, daß wir so viele Kalenderdarstellungen finden, obwohl der Tierkreis dem Heidentume entnommen ist. Solche Monatsbilder finden wir zum Beispiel in der Rosette der Kathedrale zu Lausanne, in dem Museum zu Freiburg. Für das Wissen im engeren Sinne des Wortes hat Vinzenz auf das Buch des afrikanischen Schulmeisters Martianus Capella zurückgegriffen. Das Buch, Nuptiae Mercurii et Philologiae betitelt, bringt unter dem anmutigen Bilde eines philosophischen Hochzeitsgesprächs den gesamten Stoff des allerdings manchmal trockenen Wissens der ausgehenden Antike. An sich ohne größeren literarischen Wert, ist, das Buch für die Kunst- und Kulturgeschichte des Mittelalters von einschneidender Bedeutung geworden, denn es hat Typen geschaffen, dadurch daß Capella jeden einzelnen Teil des Wissens durch eine von $\mathrm{ihm}$ geschaffene Figur vortragen läßt. Es sind jene Figuren, die uns allen unter der Zusammenfassung der sieben freien Künste des Quadriviums und des Triviums bekannt sind, die Grammatik, die Dialektik, die Rhetorik, die Geometrie, die Arithmetik, die Astronomie und die Musik. In der Tat finden wir auf französischen Glasmalereien, z. B. in der Rosette zu Auxerre die Darstellung dieser sieben freien Künste, und zwar sind es weibliche Idealfiguren, die mit einem charakteristischen, allerdings nicht mehr durchweg mit Capella übereinstimmenden Attribute, versehen sind, So trägt die Grammatik eine Rute, die Dialektik hat eine Schlange, die Rhetorik charakterisiert sich durch Rednergebärde, die Arithmetik steht mit ausgestreckten Händen oder auch mit Rechenkugeln da, z. B. auf einem Glasgemälde zu Laon, die Astronomie hält 


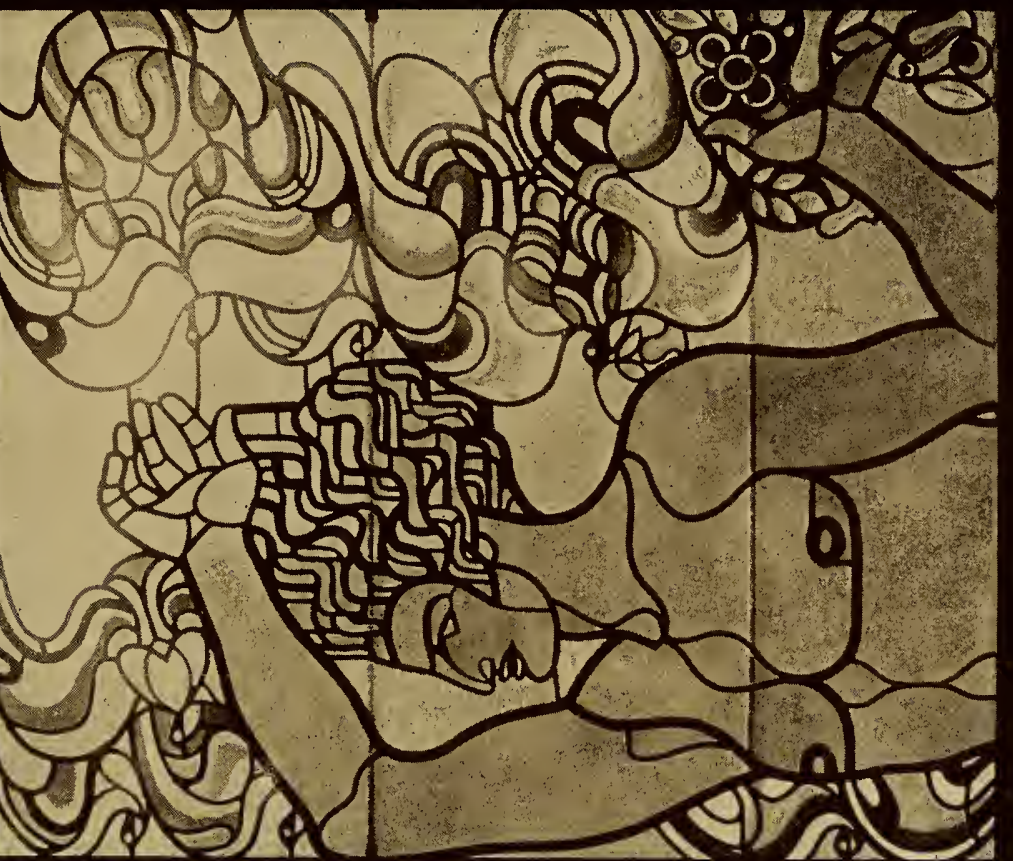

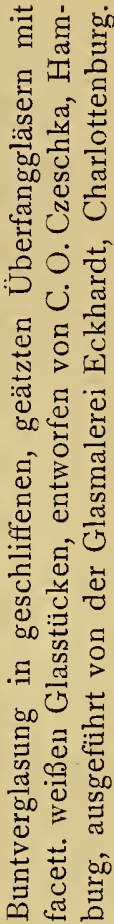
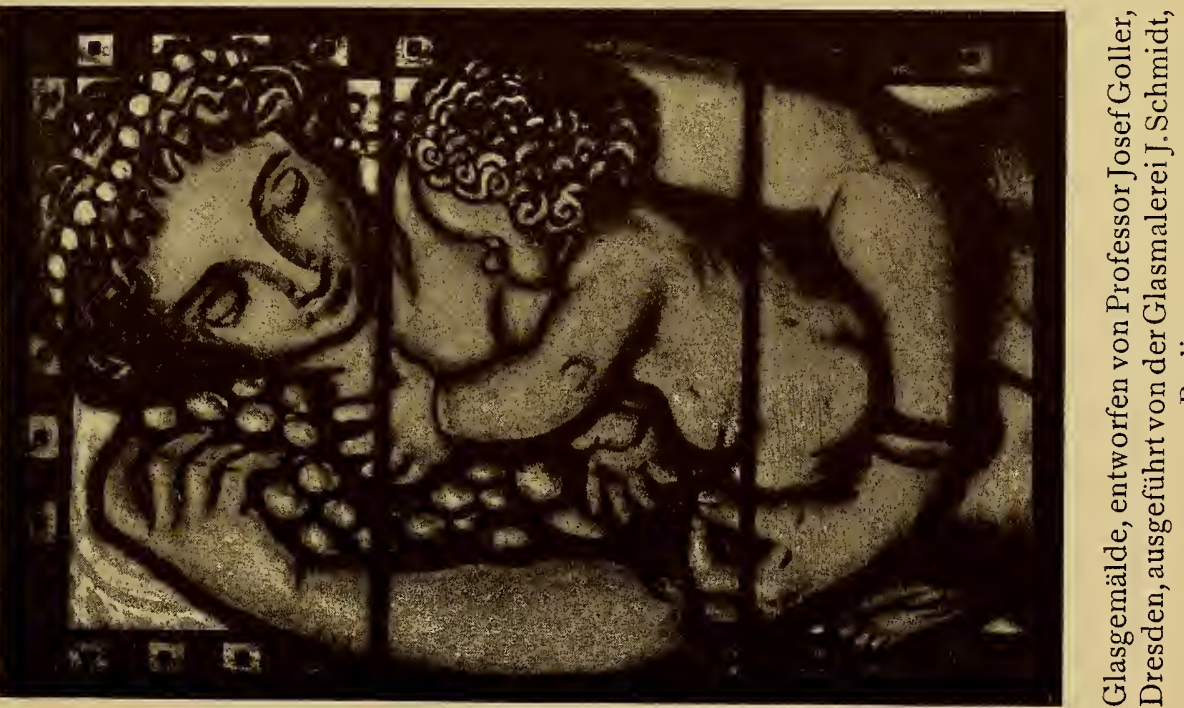

das bekannte Beobachtungsinstrument, während die Musik die Harfe schlägt, später aber mit einem Hammer an aufgehängten Glocken verschiedenen Tons pocht, wie wir auf einem Glasgemälde zu Laon bemerken können. Im weiteren Mittelalter kommt dazu noch die Medizin. Während Capella sich auf weibliche Figuren beschränkt, hat Vinzenz aus den großen Männern des klassischen Altertums je einen Vertreter hinzugefügt. Obwohl uns nur mehr bildhauerische Zeugen dieses Systems, z. B. an dem Chorgestüh1 des U1mer Münsters erhalten sind, so muß es doch einstens verschiedenen Glasgemälden zum Vorwurf gedient haben. Wenigstens sind aus dem englischen Kloster Sankt Alban Erinnerungen an derlei Fenster auf uns gekommen. Wir wissen nicht sicher, aus welcher Zeit die Glasgemälde von Sankt Alban stammen, vermutlich aber gehören sie dem I4. Jahrhundert an. Sie sind nur mehr aus den Inschriften unter jenen Fensterflügeln bekannt, die einst die oft unverständlichen Szenen zu erläutern bestimmt waren. Man sieht, nebenbei bemerkt, auch in diesem Punkt wieder, wie groß die Abhängigkeit der englischen Glasmalerei von der französischen ist. Die Inschriften müssen wir uns unmittelbar unter die einzelnen Figuren gesetzt denken. Im ersten Fenster war zu lesen:

I. Doctor eram minimus, docui magis ipse (....)

Pastor et egregius rexi magis imo regendus, Mitram deposui, libro studioque vacavi.

Ruffus eam sumpsi loca libris hae cque paravi.

In diesem Fenster war also Abt Ruffus dargestellt. Daran schlossen sich

I. Die sieben freien Künste:

I. Grammatik:Donatus, Didymus von Alexandrien, Priscianus, Hugucio.

2. Rhetorik: Cicero, Sallustius, und Poetik: Musäus, Orpheus.

3. Dialektik: Aristoteles, Phorphyrius, Plato, Pythagoras.

4. Arithmetik: Chrysippus, Nikomachus aus Gerasa.

5. Musik: Guido von Arrezzo.

6. Geometrie: Euklid, Archimedes.

7. Astronomie: Ptolemäus, Albumasar. 
II. Theologie:

I. Jüdische:

a) des Alten Bundes: Moses, Aaron.

b) Talmudisten: Rabbi Moses, Rabbi Salomon.

2. Christliche: Petrus, Paulus, Athanasius, - - ?

III. Jurisprudenz:

a) Bürgerliches und canonisches Recht: Justinian, Gratianus, Accursius, Hugutius.

b) Klösterliche Legislatur: Benedict, Augustinus, Bernardus Cassinensis, Nicolaus Trevet.

IV. Medizin: Hippokrates, Galenus, Guilelmus, Brunus.

V. Landwirtschaft: Palladius, Vergil, Petrus, Bartholomäus.

Diese trockene, nur aus der weltfremden, abstrakten Gelehrsamkeit der Scholastik erklärbare Darstellung hat im Lande des tiefen Gemüts, in dem Lande der Mystik, keine Gegenliebe gefunden; uns ist wenigstens auf deutschem Boden nichts bekannt, was an den eben geschilderten Gedankenkreis anknüpfen würde. Aber auch in der Darstellung des Alten und Neuen Testaments scheidet sich die romanische von der germanischen Auffassung. Die französische Typik ist weit mehr von der abstrakten Dogmatik beeinflußt, als die deutsche. Die französischen Glasgemälde erregen Bewunderung und Überraschung, die deutschen ermahnen in schlichter Größe zu christlichem Lebenswandel. Dabei soll nicht verschwiegen werden, daß beide Gesichtspunkte auf sämtlichen erhaltenen Glasgemälden zu beobachten sind, daß sie sogar manchmal ineinander fließen. Gleichwohl kann man konstatieren, daß auf den französischen Glasgemälden die dramatisch-realistische, in Deutschland die zeichnerisch schlichte Note vorherrscht. Als Beispiel der eigenartigen Kombinationen möge ein Fenster der Kathedrale in Bourges dienen. Es enthält in fünf großen Rundmedaillons die Parabel vom barmherzigen Samariter. Die Zwischenräume an den Rändern sind mit Halbkreisen ausgefüllt, die Szenen aus dem Alten und Neuen Testament aufweisen. Diese Zusammenstellung ergibt folgendes höchst seltsames Bild: 


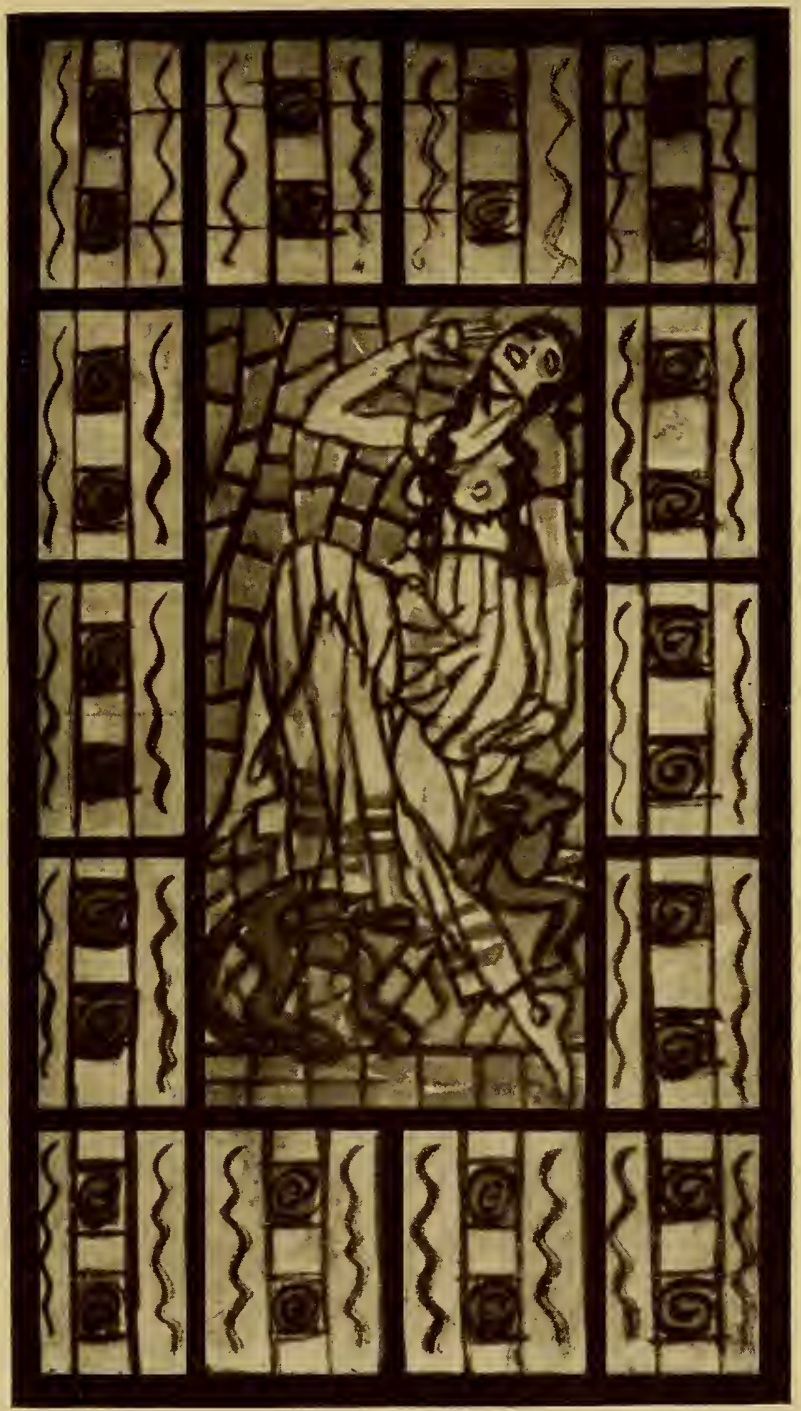

Glasgemälde für den Zirkus Sarasani; entworfen von Ludwig Kainer, Berlin, ausgeführt von der Glasmalerei Eckhardt, Charlottenburg. 

Der Mann von Jericho

zieht schwer beladen aus.

Gott schafft Sonne und Mond.

Gott erschafft die Eva.

Die Räuber überfallen den Wanderer.

Gott zeigt den Menschen die

Bäume des Paradieses.

Gott hält den Menschen die

Sünde vor. Er trägt zwei Gesetzestafeln.
Gott erschafft die Engel.

Gott erschafft den Adam.

Der Sündenfall.

Gott führt dem Adam die

Tiere des Gartens zu.

Die Räuber ziehen dem

Verwundeten den Rock aus.

Vertreibung aus dem Paradies.

Der brennende Dornbusch.

Priester und Levit vor dem Verwundeten.

Die Jüdinnen bringen Ringe zum Guß des goldenen Kalbes.

Christi Geißelung.

Der Samariter bringt den Verwundeten zu einem Gastwirt.
Ein Engel schließt den Paradiesgarten.

Moses schlägt Wasser aus dem Felsen.

Die Juden vor dem goldenen Kalb.

Christus am Kreuz.

Auch in den Darstellungen der marianischen und Heiligenfenster liebt die französische Lebhaftigkeit aufgeregte Szenen. Insbesondere werden die Martyrien der Heiligen mit erschöpfender Ausführlichkeit wiedergegeben, so z. B. das Martyrium des h1. Gervasius und Protasius in Le Mañs, die Stephanus-, Jakobus-, Thomas-, Johanneslegenden in Bourges, Chartres und Lyon. Während des I 3. Jahrhunderts wurden diese Legenden neu bearbeitet von dem Dominikaner und Erzbischof von Genua, Jacobus de Voragine ( $t$ I 298) in seinem weithin berühmt gewordenen Buche Legenda aurea, Die deutsche Glasmalerei hat sich dem Realismus der französischen Martyrerfenster nicht geneigt erwiesen. Wir finden nur wenige Fenster, auf denen sich ein Martyrium in einzelnen Szenen abspielt, z. B. das Katharinenfenster in Schlettstadt, Münnerstadt, Regensburg, das Martyrerfenster in Niederhaslach oder die Erzählung von Johannes dem Täufer auf verschiedenen deutschen und Schweizer Fenstern.

In den ersten Jahrhunderten ihres Entstehens hat die deutsche Glasmalerei die Einzelfigur der Szene vorgezogen. $\mathrm{Ab}$ und $\mathrm{zu}$ mag wohl ein Legendenfenster im Anschluß an die Miniatur gemacht worden sein, wie z. B. im S. Ulrich zu Augsburg. Im allgemeinen aber herrschte die Einzelfigur, was zu den ästhe- 
tischen Anschauungen der deutschen Frühzeit über die Glasmalerei vorzüglich paßte. Hauptsächlich sind es die Propheten des Alten Testaments samt dem König David, Evangelisten, Lokalheilige, Madonna mit Kind, oder Christus am Kreuz, unter dem Johannes und Maria stehen. Wo die französische Kunstinvasion sich geltend machte, bemerkt man auch Heilige, deren Kult nur in Frankreich volkstümlich war, z. B. in EBlingen die hl. Rusticus, Marcel, Leodegar, Eleutherius und Thomas Becket. Unter dem Einfluß der französischen Glasmalerei begann man im I4. Jahrhundert auch am Rhein eine einzige Szene auf ein ganzes Fenster zu verteilen, z. B. die Anbetung der drei Könige oder die Kreuzesszene (Köln, Freiburg).

Die deutschen Legendenfenster kommen erst seit dem I4. Jahrhundert in Verbreitung; sie wandeln aber andere Bahnen. Sofort mit ihrem ersten Auftreten sind sie von einem gebundenen System beeinflußt, das ebenso absolut herrscht, wie das Speculum des Vinzenz von Beauvais, und das in verschiedenen, zeitlich einander sehr nahe stehenden Büchern fixiert worden ist. Diese Bücher heißen Speculum humanae salvationis, Spiegel des menschlichen Heils, biblia pauperum, Armenbibel, biblia picturata, Bilderbibel, concordantia caritatis, Übereinstimmung der Liebe. Trotz der großen Literatur, die über diese wichtigen Bücher, die Vorlagen der gotischen Künstler besteht, ist noch wenig geklärt, namentlich nicht das Verhältnis, in dem diese Bücher zu einander stehen. Für das älteste hält man insgemein die Biblia pauperum, Armenbibel. Woher der Name Biblia pauperum stammt, weiß man nicht genau. Er findet sich erstmals auf einer Handschrift in Wolfenbüttel von einem späteren Benützer angefügt. Der Titel kam also zu einer Zeit auf, in der der Inhalt der Biblia bereits in Fenster- und andere Darstellungen gedrungen war. Die Wolfenbütteler Handschrift kannte bereits Lessing und er war der Meinung, der Name Biblia pauperum sei auf das Verschulden des Bibliothekars Lauterbach zurückzuführen, der sich durch eine auf der Handschrift befindliche spätere Bemerkung irreführen ließ. Der Inhalt der Armenbibeln gibt auch keinen näheren Aufschluß über die Entstehung des Namens. Aufgebaut auf dem erstmals von dem Verfasser des Matthäusevangeliums systematisch durchgeführten Satz: Novum 


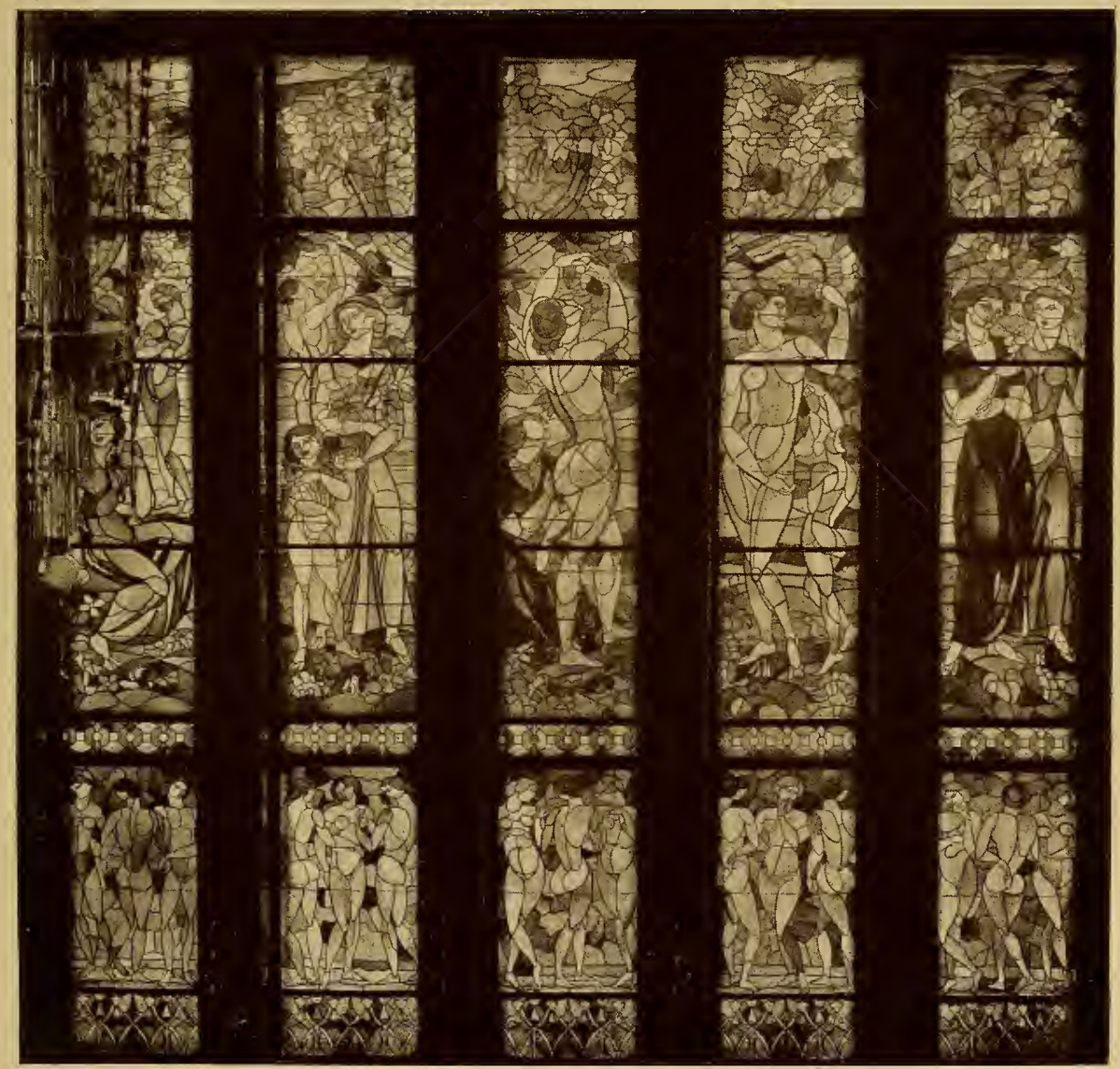

Glasgemälde nach einem Entwurf von J. Méhoffer, Krakau, ausgeführt von der Glasmalerei Zelenski, Krakau. 

testamentum in vetere patet, vetus testamentum in novo patet, enthält die Biblia pauperum die wichtigsten Ereignisse aus dem Leben und der Lehre Jesu. Jeder Szene sind zwei Begebenheiten aus dem Alten Testament als Vorbilder beigegeben. Dazu kommen Prophetensprüche, die Erklärungen spenden. Das Speculum humanae salvationis kennt zu jeder Szene des Neuen Testaments noch einen weiteren Typus aus dem Alten Testament, während die concordantia caritatis den ganzen Apparat typologischen Wissens spielen läßt. Das Speculum ist in der ersten Hälfte des I4. Jahrhunderts entstanden, und in einer großen Anzahl von illustrierten Handschriften erhalten. Man nimmt an, daß der Dominikaner Ludolff, Prediger in Straßburg, sein Verfasser sei. Die Dominikaner wurden jedenfalls sehr frühe die Führer des oberrheinischen Mystizismus, der mit Johannes Tauler (I 290-I36I) einen gewissen Höhepunkt erreichte. Aus der Blüte der oberrheinischen Mystik ist der Geist des Heilsspiegels am besten zu erklären. Vor allem weist die starke Betonung der Marienlegende auf den Dominikanerorden, da dessen Stifter eine besondere Neigung zur Marienverehrung seinem Orden als Erbe hinterlassen hatte. Sodann macht sich in der Zusammenstellung der Vorbilder der den Mystikern eigene Zug geltend, auch die Profangeschichte $z u$ vergeistigen. Während die lebhafte Phantasie der Franzosen sich an den Phantasmen des Physiologus berauschte, hat das deutsche Gemüt sein Augenmerk auf ernstere Dinge, auf den göttlichen Plan der Weltgeschichte gelenkt. Darum finden wir im Heilsspiegel die Einbeziehung der alten Geschichte in den Vorbildsgedanken. Judentum und Heidentum weisen, wenn auch im Grade verschieden, gleichmäßig auf den Erlöser und dessen Reich hin. Wir geben zunächst das System des Speculum humanae salvationis ${ }^{1}$ ):

I. Sturz Luzifers.

Erschaffung Evas.

Vertreibung aus dem Paradies.
Gott führt dem Adam die Eva zu.

2. Sündanfall.

Adam und Eva auf der Erde.
Versuchung Evas.

Arche Noahs.

1) Die in Kleindruck angegebenen Motive bilden die Vorbilder zu dem dargestellten (im Großdruck angegebenen) Hauptthema. 
3. Verkündigung der Geburt Mariae.

Traum des Astyages, der sieht, wie vor seiner Tochter Cyrus sproßt.

Die Wurzel Jesses.
Der verschlossene Garten des Hohenliedes

(Kap. 4)
Balaams Esel

(4. Mos. 22)

\section{Mariae Geburt.}

Die verschlossene Pforte (Ezech. 44).

Der Tempel Salomons (1. Kön.).

\section{Mariae Darstellung im Tempel.}

Der Fisch der Sonne, der von Fischern gefangen, Apollo geweiht wird.

Tobias Vermählung.

Moses vor dem brennenden Dornbusch.

\section{Traum von Pharaos Mundschenken.}

Die Magier sehen den Stern in ihrer Heimat.

Die Bundeslade.

\section{Die Ägypter machen ein Bild:} Maria mit Kind.

Das eherne Becken im Vorhof zu Jerusalem.

\section{Das Opfer Jephthas}

(Richter I I).
Die Perserkönigin schaut von einem überhöhten Garten voll Heimweh nach ihrem Vaterland.

\section{Mariae Vermählung.}

Der Turm Baris von einem Makkabaer erbaut.

\section{Der Turm Davids, an dem 1000 Schilde hängen (Hohelied 4).}

7. Mariae Verkündigung.

Gedeons Vließ.

Rebekka tränkt Eliezer.

8. Geburt Christi.

Arons Stab.

9. Die hl. 3 Könige.

Die tapferen Mannen Davids bringen ihm Wasser (1. Kön. 23).

Io. Darstellung im Tempel.

Der siebenarmige Leuchter.

Oktavianus Augustus bei der Sibylle.

Der Thron Salomons, davor die Königin von Saba.

Darstellung Samuels im Tempel.

I I. Flucht nach Ägypten.

Moses als Kind vor

Pharao, nimmt eine heiße Kohle in den Mund.

Das Traumbild des Nabuchodonosor.

I2. Taufe Jesu.

Heilung Naamaus des Syrers.
Die Arche wird durch

das trockene Jordanbett getragen.

I 3. Christus vom Teufel versucht.

Danicl tötet den Drachen.

\section{David tötet Goliath.}

David tötet Bärcn und Löwen.

I4. Maria Magdalena zu Füßen Jesu.

König Manasses in Der verlorene Sohn.

David und Nathan.

(II. Chron. 33). 


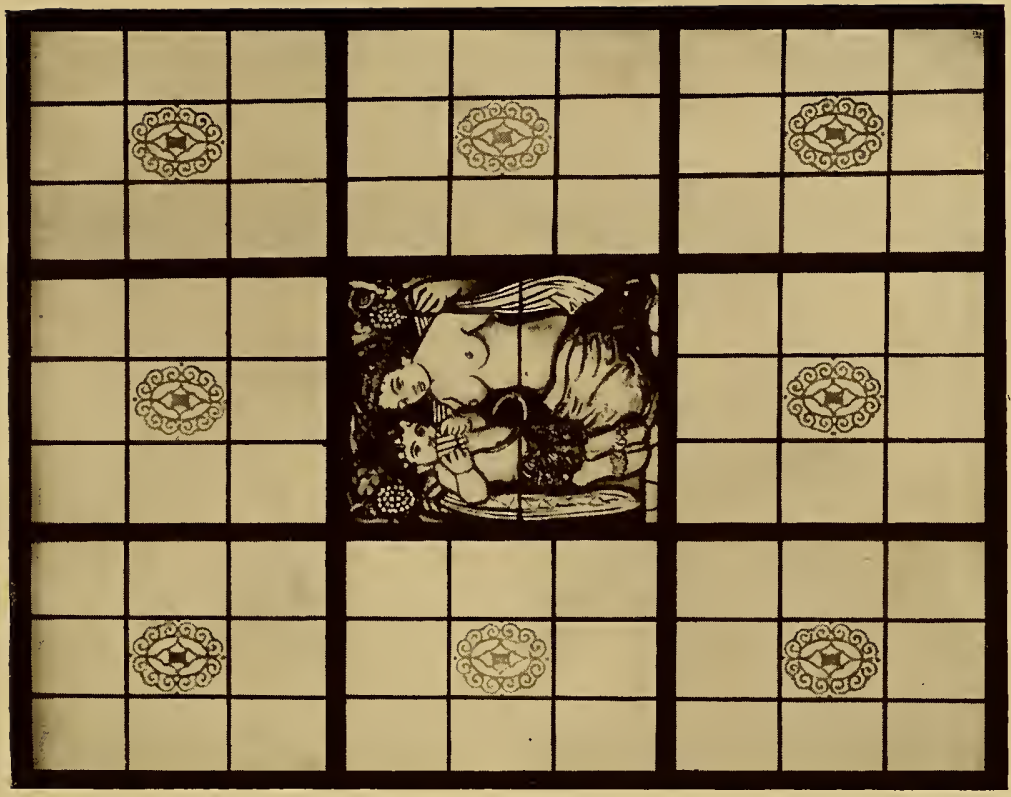

告
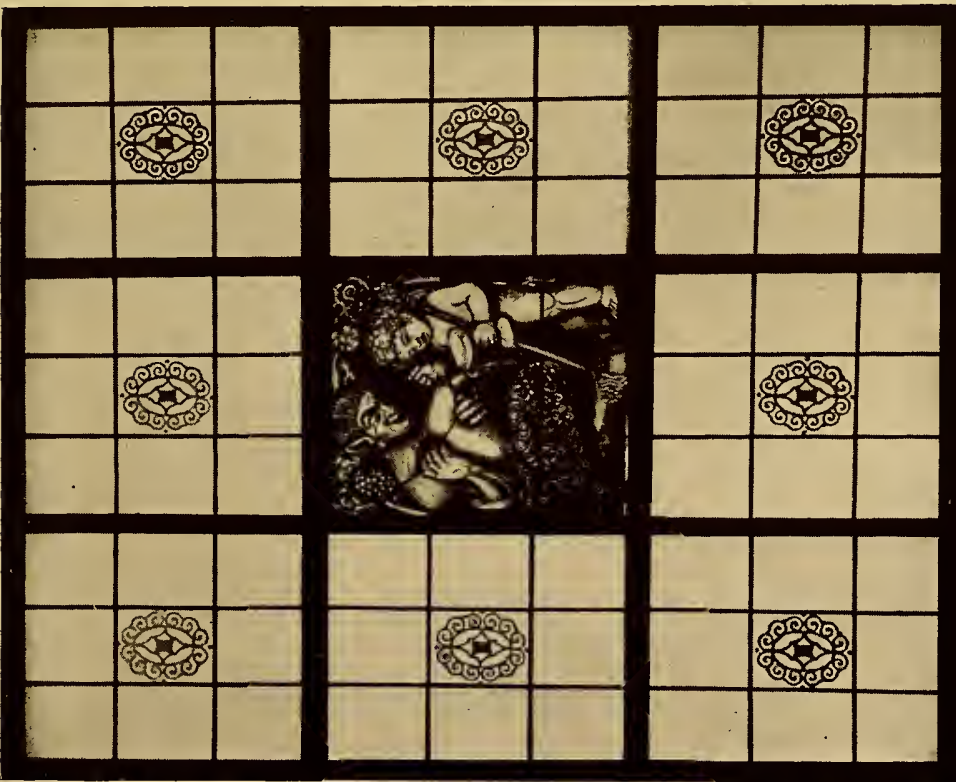

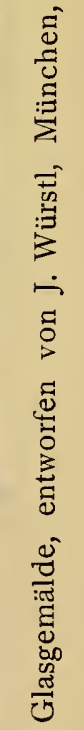



Jeremias auf den

Trümmern Jerusalems.

Der Mannaregen.
I5. Jesus Einzug in Jerusalem.

David mit dem Haupt

Goliaths wird feierlich empfangen.
Heliodor für seine Tempelschändung gezüchtigt.

I6. Das Abendmahl.

I7. Die Soldaten stürzen vor Jesus im Garten Gethsemane nieder.

Samson tötet rooo

Männer mit einem

Eselskinnbacken.

Joab tötet meuchlings den Amasa.

Hur wird verspottet.

Achior auf Befehl des Holofernes an einem Baum gegeißelt (Judith 6).

Die Konkubine Davids gibt dem König eine Ohrfeige (2. Kön. 3).

Isaak trägt das Holz.

Jubal und Tubalkain schmieden Nägel.
Schamgar tötet 600 Feinde

(Richter 3).

David tötet 800 Feinde.

\section{I8. Der Judaskuß.}

Saul wirft die Lanze nach David.

Kains Brudermord.

19. Christus wird verspottet.

Cham verspottet Noah. Samson wird geblendet.

20. Geißelung.

Lamech wird von seinen Weibern geschlagen.

Job vom Satan und seiner Frau geschlagen.

\section{I. Dornenkrönung.}

Simei verspottet

David (2. Kön. I6).

König Amon entehrt Davids Gesandte

(2. Kön. Io).

22. Christus trägt das Kreuz.

Die Winzer töten den Sohn des Herrn. (Matth. 2 I.)

Die Kundschafter mit der Traube.

\section{Kreuzigung.}

Jesaias wird zersägt.

Der König von Moab opfert seinen Sohn.

(2. Kön. 3.)

24. Christus zwischen den Schächern.

Traum Nabuchodonosors.

Das Opfer des Kodrus.

25. Tod Jesu.

Michol verspottet David. (II. Kön. 6.)

26. Kreuzabnahme.

Jakob erhält Josefs Rock. Adam und Eva beweinen Abel.

\section{Grablegung.}

David hinter der Leiche Josef wird in die Zysterne Abners.
Eleazar tötet einen über ihn schreitenden Elefanten. (I. Makk. 6.)

Evilmerodach tötet und zerstückelt seinen Vater.

Noemis Totenklage.

Jonas vom Fisch verschlungen. 
28. Christus in der Vorhölle.

Die drei Jünglinge im Feuer- Daniel in der. Löwengrube. Ein Strauß befreit sein in ofen.

einem. Glas eingeschlossenes Junges.

29. Christus tötet den Teufel.

Benajas tötet einen Löwen. Samson tötet ein en Löwen. Aioth tötet den König Eglon.

30. Maria zertritt den Teufel.

Judith tötet den Holofernes. Jabel tötet den Sisera. Tomyris tötet den König (Richter 4.) Cyrus.

3I. Christus befreit die in der Vorhölle Gefangenen.

Moses führt die Israeliten Abraham von Jahve aus dem Loth zieht mit den aus Ägypten.

Feuer der Chaldaer befreit.

(Gen. I 2.)

Seinigen aus Sodoma.

32. Auferstehung.

Samson trägt die Tore von Jonas ans Land gespieen. Der Stein, den die Bauleute Gaza.

33. Himmelfahrt.

Jakobsleiter.

Das wiedergefundene Schaf. verwarfen.

Des Elias Himmelfahrt.

\section{Sendung des hl. Geistes.}

Der babylonische Turm. Moses empfängt die Gesetzes- Das ÖI in den Krügen tafeln.

der Witwe von Sarepta.

\section{Maria betrachtet das Leiden Christi.}

Anna Tobias Gemahlin, trauert Die verlorene Drachme. Ptholiel weist trauernd die über dessen Abwesenheit. Hand von Michol ab.

(I. Kön. I 8.)

\section{Mariae Krönung im Himmel.}

David tanzt vor der Arche. Das Weib im Sonnengewand. Salomon setzt seine Mutter (Apocalypsis 1 2.) auf den Thron.

37. Maria die Mittlerin zwischen Christus und den Menschen.

Abigail versöhnt David.

(I. Kön. 25.)
Thekuites versöhnt David.

(II. Kön. I4.)

Die weise Frau von Abela versöhnt David, indem sie den Kopf des Aufrührers Seba vor die Stadt wirft.

\section{Schutzmantelbild.}

Tarbis, dieäthiopische Königs- Abimelech durch den David durch Sauls Tochter tochter, schaut auf den anstür- Steinwurf eines Weibes Michol befreit. (I. Kön. XIX.) menden Moses. getötet.

39. Christus zeigt dem Vater seine Wundmale.

Antipater zeigt dem Julius Maria zeigt dem Sohn ihre Esther bittet den Assuerus Caesar seine Wunden.

Briste. für das Volk.

40. Das Weltgericht.

Die klugen und törichten Jungfrauen.
Die Parabel von den Pfunden.
Die schreibende Hand vor Belsazar in Babylon. 
4I. Die Hölle.

David peinigt seine Feinde. Gedeon straft seine Feinde. Pharao im Roten Meer ver(II. Kön. I 2.)

(Richt. 8.)

senkt.

42. Die Freuden des Himmels.

Die Königin von Saba be- Das Gastmahl des Königs Das Gastmahl der Söhne sucht Salomon. Assuerus.

Jobs.

Nach diesem Speculum sind z. B. die noch erhaltenen Glasmalereien der S. Stephanskirche zu Mülhausen entworfen, wobei freilich im äußeren Rahmen das System der Biblia pauperum, das System der Dreiteilung eingehalten wurde, während das Speculum mit seinen drei Vorbildern zu jeder neutestamentlichen Szene Vierteilung kennt. Es ist bezeichnend, daß gerade wieder eine elsäßische Stadt sich an das Speculum angelehnt hat. Wie verhält sich nun aber die Armenbibel zu dem Heilsspiegel? Bisher nahm man allgemein an, daß der Heilsspiegel wie die Concordantia caritatis Weiterbildungen der Armenbibel seien, was man damit begründete, daß der Heilsspiegel drei Vorbilder an Stelle der Zweizahl in der Armenbibel habe. Zeitlich läßt sich garnichts für oder wider obige Meinung anführen, da die ältesten Handschriften beider Werke ziemlich gleichzeitig nebeneinander hergehen. An sich scheint ja bei der Vermehrung der Typen im Heilsspiegel der Gedanke einer Weiterentwicklung berechtigt, da das Einfachere als das Anfängliche gilt. Allein mir will scheinen, als liege in diesem Falle eine Ausnahme vor und als sei der Heilsspiegel das Ursprüngliche. Bei seiner Entstehung innerhalb des Dominikanerordens bekam er ein, weniger praktische Gesichtspunkte betonendes, als unabhängig religiöses Aussehen. Aus diesem üppig blühenden Blumenbeete entnahm eine einfachere Richtung unter den Klerikern, soviel $\mathrm{zu}$ bestimmten Zwecken nötig, wählte die für Buchschmuck, Wand- und Glasmalerei geeignetere Dreiteilung. Diese einfachere Richtung nannte sich pauperes, die Armen. Luttor weist in seiner Studie: „Biblia pauperum“ daraufhin, „daß die Mönche des Benediktinerordens sich ausdrücklich arm genannt hätten: ,Arme Christi, arm mit ihm, dem Armen', und daß die bisher bekannten ältesten Exemplare der Armenbibel (auch die verwandten Glasgemälde) aus den Benediktinerklöstern stammen. Außerdem ist $\mathrm{zu}$ beachten, daß die Autoren mystischer Bücher ihren Namen aus 
Demut verborgen haben." Die Pauperes wären also die armen (demütigen) Mönche und Prediger aus dem Benediktinerorden. Diese Anschauung Luttors wird durch einen Vers bestätigt, der sich auf einer Handschrift des Heilsspiegels findet, die im Stift Kremsmünster aufbewahrt wird und folgendermaßen lautet:

Praedictum proemium de contentis huius libri compilavi

Et propter pauperes praedicatores apponere curavi;

Quod si forte nequiverint totum librum comparare, si sciunt historias, possunt ex ipso proemio praedicare.

„Das obige Vorwort habe ich aus dem Inhalt dieses Buches ausgezogen und wegen der armen Prediger anfügen lassen. Wenn sie das ganze Buch nicht erwerben können, so sind sie imstande, aus eben diesem Vorwort zu predigen, vorausgesetzt, daß sie die Geschichten wissen." Dieses Vorwort ist nun nichts anderes als die Armenbibel, also eine Kompilation, ein Auszug aus dem totus liber, aus dem Gesamtbuch, dem speculum humanae salvationis. In dem Zusammenhang dieses Vorworts hat es nun allerdings den Anschein, als sei pauper in seiner eigentlichen Bedeutung arm, unbemittelt, aufzufassen. Wie dem auch sei, wir können als feststehend erachten, daß die Armenbibel dem praktischen Zweck der Predigt zu dienen hatte, während der Heilsspiegel mehr ein Buch für den internen Gebrauch in Klöstern und Schulen darstellte. Wir können an diesem Ort unsere Anschauung, daß die Armenbibel aus dem Heilsspiegel entstanden und nicht umgekehrt der Heilsspiegel eine Erweiterung der Armenbibel sei, nicht im einzelnen dartun, mußten aber wenigstens soviel davon erwähnen, da die Armenbibel äußerst fruchtbar auf die Ikonographie der Glasmalerei eingewirkt hat. In ihrem Zweck, ein Buch der Predigt zu sein, traf die Armenbibel mit der lehrhaften Tendenz der mittelalterlichen Glasmalerei zusammen. Nicht in allen Kirchen konnte man den ganzen Zyklus der Armenbibel festhalten; wo immer es aber ging, wählte man größere oder kleinere Ausschnitte. Wenn das Wort des Predigers auf der Kanzel verhallt war, so konnte sich das Volk durch einen Blick auf die Glasgemälde den Inhalt derselben im Herzen fortwirken lassen. Am vollkommensten war der Zyklus, der einst das Kloster Hirsau im württembergischen Schwarzwald zierte. Abt Parsimonius hat ihn in einem noch erhaltenen, mit 
vielen Miniaturen versehenen Kodex beschrieben. Zwar wird für die Entstehung der Biblia von verschiedener Seite jene Typologie als Vorstufe erklärt, auf der sich neben der neutestamentlichen Szene nur eine alttestamentliche finde. Uns ist außer einer Altartafel in Klosterneuburg nur ein Glasfenster bekannt, das ein volles System aufweist, nämlich das mittlere Chorfenster zu Weißenburg i. E. Dieses Glasgemälde entstammt dem Ende des I3. Jahrhunderts, ist also wiederum ein Beweis, wie sehr sich gerade das Elsaß in der Entwicklung der Typologie hervorgetan hat. Das Fenster enthält folgende Szenen:

Christus im Himmel thronend. Maria mit Kind.

Christi Himmelfahrt.

Auferstehung.

Christus in der Vorhölle.

Christus am Kreuz.

Christus an der Geißelsäule.

Abendmah1.

Des Elias Himmelfahrt.

Jonas wird vom Fisch ans Land gespieen.

Auszug aus Ägypten.

Isaaks Opfer.

Amon verletzt den Gesandten Davids.

Christus und die Ehebrecherin(?). Taufe.

Darstellung im Tempel.

Geburt Christi.

Abraham und Melchisedech.

Salomons Urteil.

Durchzug der Ägypter durch das Rote Meer.

Aarons Stab.

Enochs Entrückung (?).

Man kann an der Deutung der Szene Christus und die Ehebrecherin Anstoß nehmen, das unbestreitbare Vorbild Salomons Urteil weist auf ein Gegenbild hin, in dem Christus den Juden ebenfalls ein überraschendes Urteil abgibt. Dabei kann man an das Urteil über die Ehebrecherin denken, das zwar stets das Urteil Daniels im Susannaprozeß als Gegenbild hat. Ebenso einleuchtend ist auch die Deutung: Christus und die Zinsmünze, wozu Haltung der linken Hand und Geste des links von Christus stehenden Juden stimmen würde. Wie dem auch sei, weder die eine noch die andere Szene kommt in der Armenbibel vor und die Ausarbeitung der einzelnen Szenen geht im Gegensatz zu allen bekannten Miniaturen ganz eigene Wege. Wir können daher dieses System als selbständige Äußerung (natürlich innerhalb der allgemein geltenden Ikonographie) betrachten. Wir 
geben im folgenden ein aus den verschiedensten uns bekannt gewordenen Handschriften der Armenbibeln zusammengesetztes Gesamtbild aller vorkommenden Typen.

\section{Mariä Geburt.}

Jesses Stammbaum. Bileams Weissagung.

2. Mariä Vermählung.

Tobiths Vermählung. Isaaks Vermählung.

3. Verkündigung der Geburt Jesu.

Eva und die Schlange. Gideons Vlieb.

(Verheißung Isaaks).

Jethro besucht Moses.

4. Mariä Heimsuchung.

Der brennende Dornbusch. (Geburt Obeds aus Ruth).

Der Levit besucht seinen Schwiegervater.

5. Christi Geburt.

Aarons Stab.

Die Geburt Johannes des Täufers.

6. Beschneidung Christi.

Beschneidung Abrahams.

Beschneidung Isaaks.

7. Die hl. drei Könige.

Abner vor David.

Die Königin von Saba.

8. Darstellung im Tempel.

Aufopferung der jüdischen Erstgeburt. Samuels Aufopferung.

9. Flucht nach Ägypten.

Jakobs Flucht vor Esau.

Davids Flucht durch Vermittlung Michols.

Io. Aufenthalt in Ägypten und Zerstörung der Götterbilder. Zerstörung des goldenen Kalbes.

Dagons Sturz.

I I. Der Kindermord des Herodes.

Saul tötet die Priester.

Athalia tötet die königlichen Kinder.

I 2. Rückkehr aus Ägypten.

Rückkehr Davids nach Sauls Tod.

Jakobs Heimkehr.

I3. Taufe Christi.

Durchgang durch das Rote Meer.

Die Kundschafter mit der Traube.

I4. Versuchung Christi.

Esau verkauft die Erstgeburt.

Sündenfall.

I5. Auferweckung des Lazarus.

Elias erweckt den Sohn der Witwe. Elisa erweckt einen Toten.

I6. Verklärung auf Tabor.

Abraham und die drei Engel.

Die drei Jünglinge im Feuerofen.

I7. Christus und Magdalena.

David und Nathan.

Maria, die Schwester Mosis, von dem Aussatz gereinigt. 
Jesajas Klage.

I8. Jesus weint über Jerusalem.

Jeremias Klage.

19. Einzug Jesu in Jerusalem.

Davids Siegeszug nach Goliaths Tötung. Die Prophetenschüler empfangen den Elias.

20. Jesus vertreibt die Händler aus dem Tempel.

Esdras baut den Tempel.

Judas der Makkabäer reinigt den Tempel.

2 I. Judas verhandelt mit den Hohenpriestern.

Josefs Brüder beratschlagen.

Absalon wiegelt das Volk gegen David auf.

22. Judas empfängt die 30 Silberlinge.

Josef an die Ismaeliten verkauft. Josef an Potiphar verkauft.

Abimelech verkauft um 70 Silberlinge seine Brüder und tötet sie.

23. Das Abendmahl.

Melchisedeks Opfer.

Der Mannaregen.

\section{Fußwaschung.}

Des Moses Fürsprache für das Volk. Der demütige Job.

25. Jesus am Ölberg.

Jorams Gesandter am Tore zertreten.

Michaeas vor Achab.

Susanna betet um Rettung.

Ezechias betet für das Volk.

26. Verrat des Judas.

Die törichten Jungfrauen.

Lucifers Fall.

27. Gefangennehmung Jesu.

Abner von Joab getötet.

Tryphon sucht Jonathan zu fangen.

28. Christus vor dem Hohenpriester.

Jezabel tötet die Propheten.

Daniel von den Vornehmen verklagt.

\section{Verspottung Christi.}

Cham verspottet den trunkenen Noah,

(Onias wird verleumdet.)

Die Kinder verspotten den kahlköpfigen Elisa.

Hanon beschimpft die Boten Davids.

30. Ecce homo.

Das Volk verklagt den Judas Makkabäus Jonathan beim König verklagt. bei Demetrius.

\section{I. Geißelung Christi.}

Lamech von sënen Frauen verachtet.

(Abels Ermordung.)

Job vom Satan geschlagen.

(Die Marter der makkabäischen Brüder.)

\section{Dornenkrönung.}

Dic Buhlerin reißt dem König die Krone Simei verhöhnt David.

ab.

Samson, geschoren und geblendet.
Davids Verleumdung bei Achis

I. Kön. 29, 5 .

33. Pilatus wäscht die Hände.

Jezabels Anschlag auf des Elias Leben. Die Babylonier verklagen David.

Phassus schlägt den Jeremias. 
Jezabel läßt den Naboth töten.

34. Pilatus' Urteilsspruch.

Isaak trägt das Holz.

\section{Kreuztragung.}

36. Christus redet $\mathrm{zu}$ den weinenden Frauen.

Abschied Davids von Jonathan.

Das Volk trauert üher Judiths Tod.

Jephtas Tochter.

37. Christus der Kleider beraubt.

Oza berührt die Bundeslade und stirbt. David entblößt sich vor der Bundeslade. Josef seines Rockes entkleidet.

38. Kreuzigung.

Lamech und Tubalkain schmieden Nägel. Jesaja wird zersägt.

Arche Noahs.

Jakobs Leiter.

39. Christus mit der Lanze durchbohrt.

Evas Erschaffung.

Moses schlägt Wasser aus dem Felsen.

40. Abnahme vom Kreuze.

Josua läßt den König Hai vom Kreuz Davids Befehl, Sauls Söhne vom Kreuz abnehmen. abzunehmen.

4I. Christus auf Mariae Schoß.

Adam und Eva beweinen Abel.

Noemi weint über ihre Söhne.

Klage des Volkes über Josias Tod.

Klage der Juden auf Judas den Makkabäer.

42. Grablegung.

Josef in die Zisterne geworfen. Jonas vom Fisch verschlungen.

David und Goliath.

43. Christus in der Vorhölle.

44. Auferstehung.

Samson trägt die Tore Gazas weg. Jonas ans Land gespieen.

45. Die Frauen am Grabe.

Ruben sucht Josef.

Die Braut sucht den Bräutigam.

46. Christus erscheint der Magdalena.

Daniel aus der Löwengrube befreit.

Die Braut findet den Bräutigam.

47. Gang nach Emaus.

Jakob empfängt von Isaak unerkannt des- Der Engel begleitet den Tobith. sen Segen.

48. Jesus erscheint den Aposteln.

Der Engel spricht zu Gedeon.

Jakob ringt mit dem Engel.

49. Christi Himmelfahrt.

Enoch wird entrückt.

Des Elias Himmelfahrt.

50. Sendung des hl. Geistes.

Moses empfängt die Gesetzestafeln. Das Opfer des Elias.

51. Mariae Tod.

David und die Bundeslade.

Abigail wird vor David berufen. 

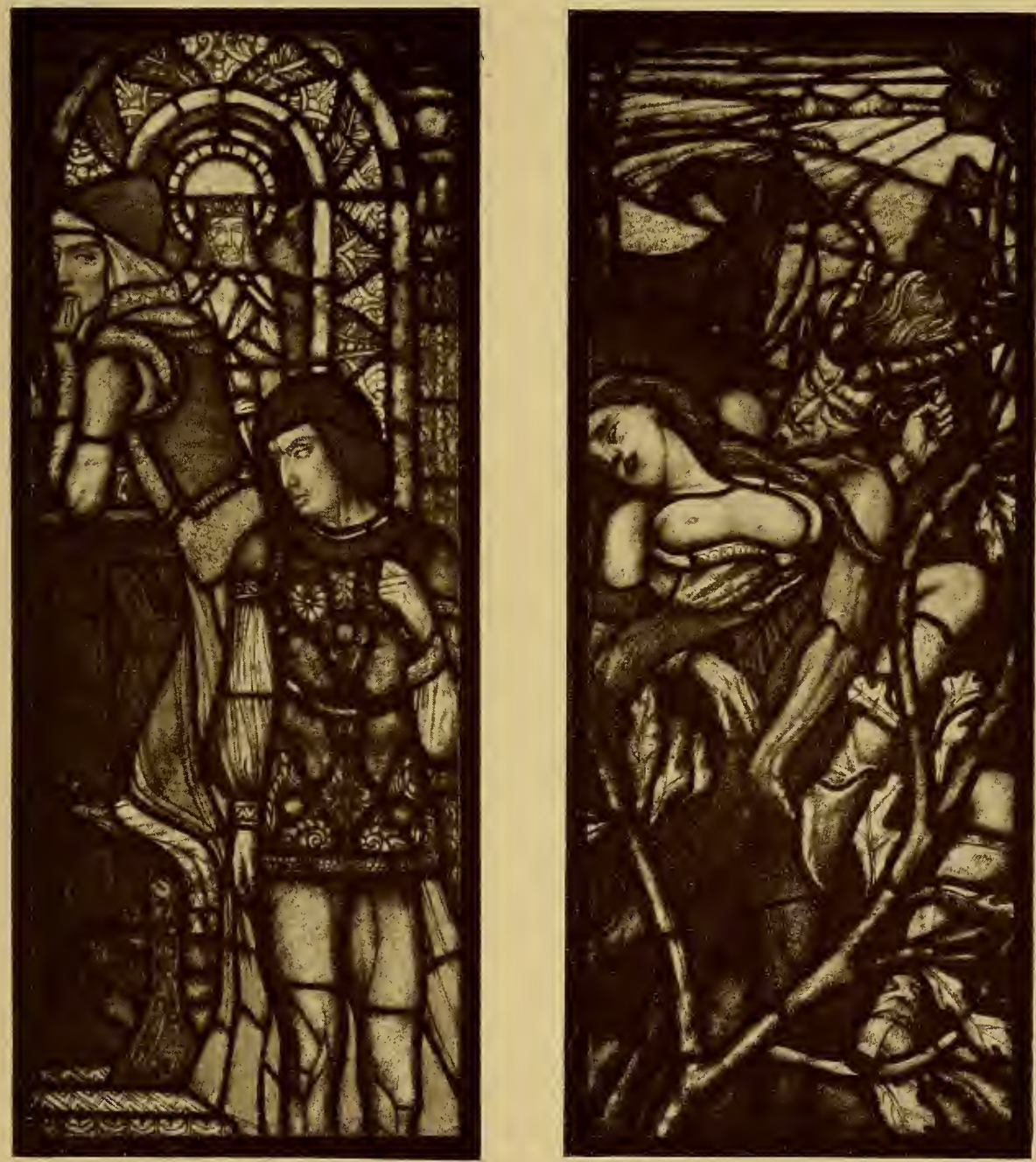

Glasgemälde für das Kulturhaus in Marosvasarhely. Entworfen von Sandor Nagy, ausgefuhrt von der Glasmalerei M. Roth, Budapest. 

52. Krönung Mariae.

Salomon krönt seine Mutter.

Salomons Urteil.

Die Rotte Korahs.

Gastmahl der Kinder Jobs.
Assuerus und Esther.

53. Weltgericht.

Asahel wird getötet.

54. Die Hölle.

Brand Sodoms.

55. Der Himmel.

Jakobsleiter.

56. Die Belohnung der Auserwählten.

Die Tochter Zions findet ihren Bräutigam. Der Engel zu Johannes sprechend.

Heilsspiegel und Armenbibel sind die hauptsächlichsten Quellen, aus denen die deutschen Glasmaler des I4. Jahrhunderts ihre Stoffe geschöpft haben. Freilich konnte man nicht in allen Kirchen das ganze System durchführen, sondern mußte sich ab und zu mit Teilen begnügen. In England bildete sich ein eigenes System aus, das uns durch einen günstigen Zufall wenigstens der Beschreibung nach erhalten ist. Bei der großen Abhängigkeit der englischen Glasmalerei von Frankreich, besonders von der Gegend um Rouen, kann allerdings nicht von einer Eigenart im strengen Sinne des Wortes, sondern nur von einer nationalen Weiterbildung fremder Elemente gesprochen werden. Wir nannten oben alte Glasgemälde in dem englischen Kloster S. Alban, die erklärende Unterschriften trugen. Diese Inschriften sind uns bekannt und wir können uns wenigstens auf diese Weise ein Bild von dem eigenartigen Glasgemäldeschmuck machen, den einst der Kreuzgang von S. Albăn besessën hat. Wie er aus den Unterschriften rekonstruiert werden kann, so soll er im folgenden wiedergegeben werden:

Geburt Isaaks

Einsturz der Mauern Jerichos

Moses schlägt Wasser aus dem Felsen

Elisäus versüßt den bitteren Quell durch eingeworfene Holzstücke

Der heilende Quell zu Nicopolis
Geburt Christi

Einsturz des Friedenstempels bei der Geburt Christi

$?$
Jesus verwandelt Wasser
in Wein

?
Geburt Samuels

Einsturz der Götzenbilder in Ägypten

Elias erbittet von der Witwe einen Krug Wasser

Moses gibt dem Volk Wasser in der Wüste

Der wundertätige 'Teich Siloah 
Plötzlicher Tod Ozas, der dieBundeslade unehrerbietig berührte

Moses teilt das Rote Meer

Moses durchschreitet mit dem Volke das Meer

Die keusche Susanna

Heilung des Tobias durch Schwalbenmist

Jakob bercitet dem sterbenden Isaak ein Essen

Elias erweckt den Sohn der Witwe

Der Donnergott Javhe erschreckt die feindlichen Välker

Stillstand der Sonne während Josuas Kampf

List der Gibioniten Buch Josua Kap. 9

Rat des Königs Ozochias 2. Chron. 20
Die blutflüssige Frau berührt den Saum des Kleides Christi

Christus gebietet dem Meer und den Winden

Christus und Petrus auf dem Meere wandelnd

Christus und die Ehebrecherin

Heilung des Blinden durch Christi Speichel

Verklärung auf Tabor

Christus erweckt den Sohn der Witwe

Die Krieger fallen im

Garten Gethsemane nieder, als sie Jesum fangen wollen

Sonnenfinsternis bcim Tode Jesu

Christus verstellt sich auf dem Weg nach Emaus, als wolle er weitergehen

Christus und Abgar
Die Hand des Königs Jeroboam vertrocknet plötzlich, als er sie gegen einen

Propheten ausstreckt

Elias teilt den Jordan

Pharao von den Meereswogen ergriffen

Salomons Urteil

Der barmherzige Samaritan heilt durch reines Öl

Joseph gibt seinem Vater Jakob in Agypten ein Mahl

Totenerweckung durch Elisäus

Gott schreckt die Ägypter durch die zehn Plagen

Dum rex fert signum se traxit salque retrorsum

List des Achis

Heilung des Königs Ezechias

Diesem in der mittelalterlichen Typologie wohl einzig dastehenden Bild liegt die nicht überall bekannte Erzählung des Eusebius zu Grunde, daß Christus von dem syrischen Fürsten Abgar von Edessa einen verehrungsvollen Brief erhalten habe, den er auch in höflicher Form beantwortet hätte. Eusebius führt den Briefwechsel im Wortlaut an. Obwohl dessen Erfindung klar auf der Hand liegt, fand diese Korrespondenz bis ins 19. Jahrhundert ernsthafte Verteidiger.

Das Manna

Saul will im Wahnsinn den harfenspielenden David ermorden

Samson wird geblendet

Lamech wird von seinen Fraven geschlagen

Die Geretteten tragen an sich den Buchstaben Thau
Das Abendmahl

Der Verrat des Judas

Christus wird verspottet

Christus wird gegeißelt

Christus trägt sein Kreuz
Das Opfer des Melchisedech

Basia perque doli fert Amasa vulnera fratri. (Joab tötet meuchlings den Amasa?)

Hur wird verspottet

David wird von Simei verspottet

Isaak trägt das $\mathrm{Holz}$ 
Jeremias wird gesteinigt

Absalon bleibt am Baum hängen

Jakob beweint den totgeglaubten Joseph

Joseph wird in die Zisterne geworfen

Daniel in der Löwengrube

Gott erscheint dem Moses im brennenden Dornbusch

Entrückung des Henoch

Gesetzgebung auf Sinai

Das Urteil Pharaos über seinen Hof bäcker und Hofschenken
Christus am Kreuz

Christus mit der Lanze durchbohrt

Maria beklagt den toten Jesu

Grablegung Jesu

Christus in der Vorhölle

Christus erscheint der Maria

Himmelfahrt Jesu

Herabkunft des Heiligen Geistes

Das jüngste Gericht
Jesaias wird zersägt

Eleasar im Heere des Judas Makkabäus durchbohrt von unten einen Elefanten des syrischen Heeres

Abel wird von seinen Eltern beklagt

Jonas vom Fisch verschlungen

Die drei Jünglinge im Feuerofen

Die drei Engel bei Abraham Himmelfahrt des Elias

Verteilung der feurigen Zungen

Heeresmusterung des Nabuchodonosor

Mit dem Heilsspiegel und der Armenbibel sind nun freilich nicht alle Quellen der Ikonographie erschöpft. Man findet vielmehr noch an manchen Orten Glasmalereien, die in keines der beiden Systeme zu passen scheinen. Eine große Zahl von Glasgemälden ist auf den ikonographischen Gesichtspunkt hin noch gar nicht untersucht, so daß es sich lohnen würde, wenn die Forschungen an diesem Punkt einsetzen würde, da dadurch manches Rätsel klar würde. Außerdem sind die meisten Fenster anläßlich der verschiedenen Restaurationen beim Wiedereinsetzen der einzelnen Flügel in Unordnung gekommen, so daß man bei Konservierungsarbeiten über die ursprüngliche Zusammengehörigkeit im Zweifel ist; schließlich wäre es für unsere modernen Künstler ein dankbares Feld, wenn sie den großen Ideenschatz, der in den mystischen Ikonographien zum Ausdruck kommt, in neue Formen leiten wollten. Wir haben uns daher der Mühe unterzogen, eine Reihe alter Handschriften zu durchforschen und alle uns bekannt gewordenen Typologien zu einem Ganzen zu vereinen, das wir im folgenden wiedergeben, soweit Abweichungen und Ergänzungen zu den im vorausgehenden angeführten Systemen in Betracht kommen. Um das weitere Studium zu erleichtern, haben wir die alttestamentlichen Bücher angegeben, aus denen die Ikonographie geschöpft hat. 
Verkündigung der Geburt Christi.

Verkündigung der Geburt Isaaks. I. Mos. I 8.

Verkündigung der Geburt Samsons. Richt. I3.

Gideons Vließ. Richt. 6.

Die verschlossene Pforte. Ezech. 44.

Der elfenbeinerne Turm. I. Kön. Io.

Das Manna in goldenen Gefäßen. II. Mos. I6.

Esther küßt das Scepter des Königs. Esth. 8.

Das Rhinozeros schläft im Schlosse der Jungfrau (Naturgesch.).

Mariä Heimsuchung.

Moses und Aron küssen sich auf dem Berg. II. Mos. 4.

Zwei Cherubim küssen sich. II. Mos. 37 .

Geburt Christi.

Jakob bekleidet seinen Sohn mit einem bunten Rock. I. Mos. 37 .

Assuerus gibt Esther einen mit seinem Siegelring gezeichneten Brief. Esth. 8.

Der Stein, der sich ohne Menschenhände vom Berge loslöst. Dan. 2.

Die Erscheinung des Engels bei den Hirten.

Raphael grüßt den Tobias. Tob. 5 .

Ein Engel kündigt dem Daniel die Geburt Christi. Dan. 9. Anbetung der drei Könige.

Die Boten des Königs von Babylon bringen dem Ezechias

Brief und Geschenke. II. Kor. 20.

Der Kindermord.

Pharao läßt die jüdischen Knaben ersäufen. II. Mos. I.

Antiochus läßt zwei Frauen mit ihren Säuglingen über die

Stadtmauer stürzen. II. Makk. 6.

Der zwölfjährige Jesus im Tempel.

Der Knabe Samuel zeigt dem Hely sein Traumgesicht an.

I. Sam. 3 .

Daniel unter den Weisen Babels. Dan. 2.

Josef weissagt dem Pharao. I. Mos. 4I.

Die Taufe Jesu.

Moses wird in das Wasser ausgesetzt. II. Mos. 2.

Moses weiht den Aaron. II. Mos. 29. 
Elisa gießt Wasser über die Hände des Elias. II. Kön. 3 . Ezechiel sieht Wasser von dem Tempel herausfließen. Ezech. 47.

Das 40 tägige Fasten.

Fasten des Moses, II. Mos. 24., des Elias, I. Kön. I9., des Daniel, Dan. I 3 .

Die Versuchung Christi.

Schlangenszene im Paradies. I. Mos. 3.

Esau verkauft sein Erstgeburtsrecht. I. Mos. 29.

Der dürstende David gießt das dargebotene Wasser zu Boden. II. Sam. 33 .

Ezechias zeigt den Boten des Königs von Babylon seine Schätze. II. Kön. 20.

Laban streitet mit Jakob auf dem Berg. I. Mos. 3 I. Elisa verachtet die Reichtümer des Naaman. II. Kön. 5 . Die drei Jünglinge verweigern die Anbetung der Statue.

Dan. 3 .

Die Verklärung auf Tabor.

Das strahlende Angesicht des Moses. II. Mos. 34. Jesaja erblickt Gott in seiner Herrlichkeit. Jes. 6.

Die Berufung der Apostel.

Gott schafft die Vögel über den Wassern. I. Mos. I.

Moses fordert den Elias auf, mit ihm ins verheißene Land zu ziehen. IV. Mos. IO.

Elias beruft den Elisa vom Pflug weg. I. Kön. I9.

Heilung der Aussätzigen.

Mirjam, die Schwester des Moses wird vom Aussatz gereinigt. IV. Mos. I 2.

Heilung des Naaman. II. Kön. 5 .

Jesus am Jakobsbrunnen.

Rebekka gibt dem Eilieser zu trinken. I. Mos. 24.

Jakob am Brunnen mit Rahel. I. Mos. 24.

Heilung des Sohnes des Hauptmanns von Kapernaum.

David bittet für seinen Sohn. II. Kön. I 2.

Jeroboam schickt seine Frau zum Propheten. I. Kön. I4. Ezechias wird von Jesaja geheilt. II. Kön. 20.

Abimelech wird geheilt. I. Mos. 20. 
Stillung des Seesturms.

Die Sonne steht still vor Josua. Jos. Io.

Auf das Wort Samuels erschallen Stimmen vom Himmel. I. Sam. I 2.

Elias schließt den Himmel auf. I. Kön. I7.

Die Heilung des Besessenen.

Das Rote Meer. II. Mos. I4. Die Rotte Korahs. IV. Mos. I6.

David vertreibt den bösen Geist von Saul. I. Sam. 8. II. Sam. Io.

Die Heilung des Gichtbrüchigen.

Steh auf deine Füße. Ezech. 2.

Nabuchodonosor wird wieder 'zu der Königsherrlichkeit erhoben. Dan. 4.

Gabriel richtet den gefallenen Daniel auf. Dan. 8.

Gastmahl bei Levi.

Jakob ißt mit Laban auf einem Stein. I. Mos. 3 I.

Die Raben bringen dem Elias Speise. I. Kön. I7.

Habakuk bringt dem Daniel Nahrung. Dan. I4.

Heilung der trockenen Hand.

Heilung der trockenen Hand Jeroboams. I. Kön. I 3.

Moses bestreicht den Aron mit Blut. III. Mos. 8.

Heilung des Tauben.

Eliezer gibt der Rebekka goldene Ohrringe. I. Mos. 24. Heilung des Stummen.

Die Lippen des Daniel werden gereinigt. Dan. Io.

Des Jesaja Lippen werden von einem Cherubim mit einer glühenden Kohle gereinigt. Jes. 6.

Die Speisung der Fünftausend.

Elias lebt von dem Ö1 und Mehl der Witwe. I. Kön. 17.

David ißt die Schaubrote. I. Sam. 2 I.

Christus auf den Wassern wandelnd.

Elias und Elisa gehen trockenen Fußes durch den Jordan.

II. Kön. 2.

Heilung des Blinden.

Tobias wird durch Fischgalle von seiner Blindheit geheilt. Tob. Io.

Jonathan kostet vom Honig und seine Augen werden erleuchtet. I. Sam. I 4 . 
Auf das Gebet des Elias öffnen sich die Augen des Knaben.

II. Kön. 6.

Einzug in Jerusalem.

David am Grabe Abners. II. Sam. 32.

Nehemias Einzug in die Stadt. Neh. 2.

Jephtas Ernennung zum Oberhaupt von Gilead. Richt. I I. Jeremias auf Trümmern Jerusalems. Klagel. I.

Die Hochrufe auf Salomon. I. Kön. I.

Triumphzug des Mardochaeus. Esth. 6.

Joseph auf dem Wagen Pharaos. I. Mos. 4I.

Tempelreinigung.

Heliodors Vertreibung aus dem Tempel. II. Makk. 3.

David treibt die Blinden und Lahmen aus der Burg Zion.

II. Sam. 5 .

Vertreibung Adams aus dem Paradies. I. Mos. 3.

Athalias Vertreibung aus dem Tempel. II. Kön. I1.

Gott schließt die Tür an der Arche. I. Mos. 7.

Die Türhüter bewachen die Tempelpforte. II. Kön. I I.

Abendmahl.

David tanzt vor der Arche. II. Sam. 6.

Gastmahl des Assuerus. Esth. I.

Gastmahl des Job. Job. 29.

Fußwaschung.

Abraham wäscht den drei Engeln die Füße. I. Mos. I 8, ebenso Lot I. Mos. 19.

Laban reicht Wasser zur Waschung der Kamelsfüße.

İ. Mos. 24.

Ölberg.

Elias auf dem Berge Karmel. I. Kön. I 8.

David auf dem Ölberg. II. Sam. I 5.

Schlafende Jünger.

Abner wird von David geweckt und wegen seines Schlafens gescholten. I. Sam. I6.

Elias wird von einem Engel geweckt. I. Kön. I6.

Jonas wird geweckt. Jon. $\mathrm{r}$. 
Judaskuß.

Ein auf einen Baum sich stützender Elefant fällt ins Netz der Jäger, nachdem der Ast heimlich abgeschnitten ist (Naturgeschichte).

Fall der Soldaten vor Christus.

Sturz Lucifers. Jes. I 4.

Die törichten Jungfrauen werden zurückgewiesen. Matth. 25. Elias tötet die Feldherren des Ozochias durch Feuer. II. Kön. I.

Gefangennahme.

Josef von seinen Brüdern ergriffen. I. Mos. 37 .

Samson wird ergriffen. Richt. I6.

Die Bundeslade wird gefangen genommen. I. Sam. 4.

Abraham bindet den Isaak. I. Mos. 22.

Christus vor dem Hohenpriester.

Potiphar verklagt den Josef. I. Mos. 39.

Micha wird von Sedechias auf die Wange geschlagen. I. Kön. 22.

Selbstmord des Judas.

Tod des Absalon. II. Sam. I 7.

Selbstmord des Achitophel. II. Sam. I 8.

Dornenkrönung.

Sacharjah läßt eine Krone anfertigen. Zach. 6.

Alchimus gibt dem König Ptolemaeus eine Krone. II. Makk. I 4.

Kreuzigung.

Isaaks Opfer. I. Mos. 22.

Das Passahlamm. II. Mos. I 2.

Opfer der roten Kuh. IV. Mos. I9.

Eherne Schlange. IV. Mos. 2 I.

Samson stirbt unter den Trümmern des Hauses. Richt. I6.

Eleasar opfert sich. II. Makk. 6.

Gebet Jesu für seine Verfolger.

Samuel betet für Saul. I. Sam. I 5 .

Aron betet für das Volk. IV. Mos. I6.

Christus empfiehlt seine Mutter dem Johannes.

David empfiehlt seine Eltern dem König von Moab. I.Sam.22. Tobias empfiehlt seinen Sohn der Mutter. Tob. 4 . 


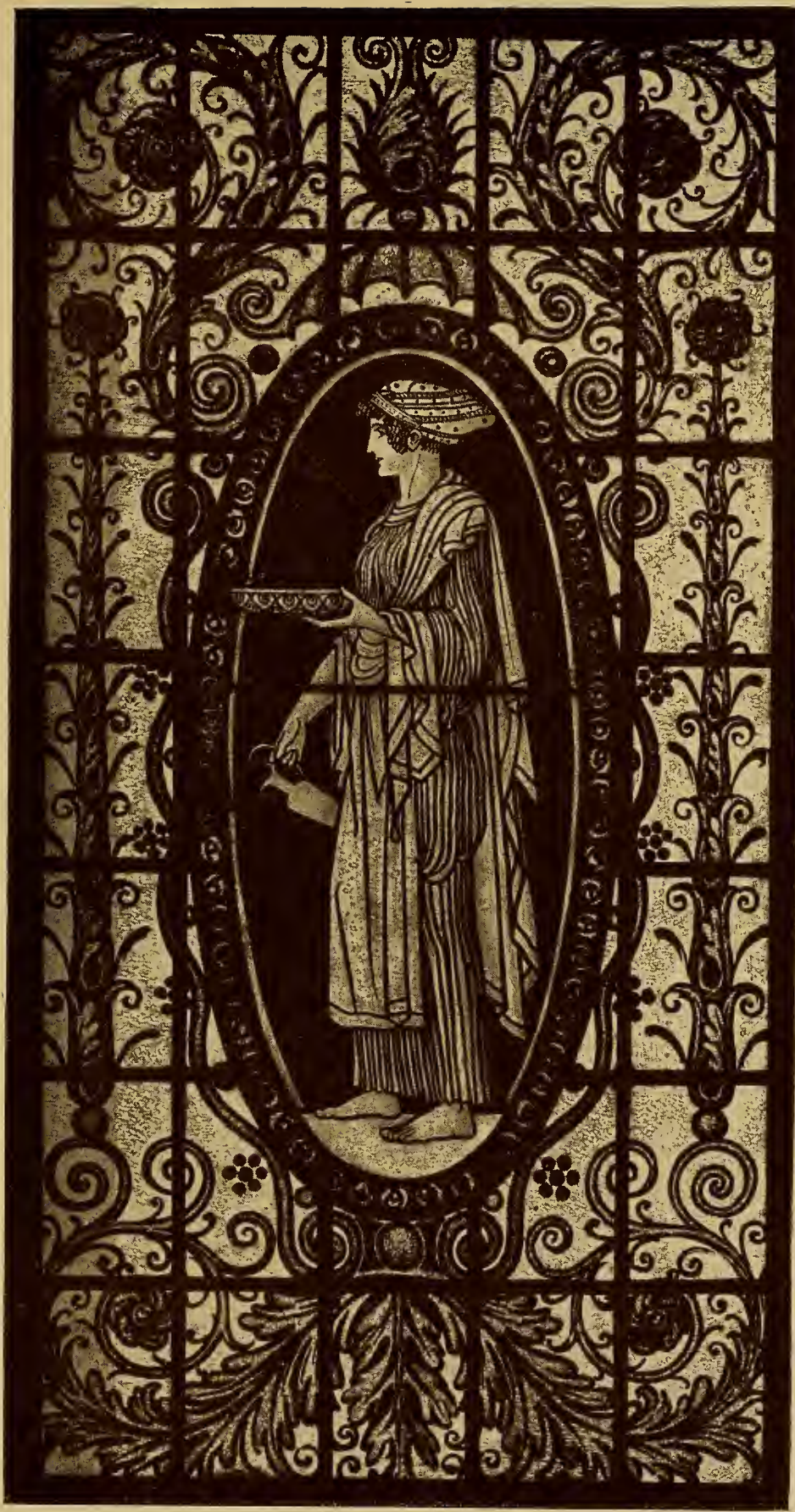

Detail aus den Trausaalfenstern des Spandauer Rathauses. Entworfen und ausgeführt von R. Linnemann, Frankfurt. 

Auferstehung.

Der lebende Sperling fliegt ins freie Feld. III. Mos. I4.

Daniel steigt aus der Löwengrube. Dan. 6.

Das Beil, das auf dem Jordan schwimmt. II. Kön. 6 .

Jephta besiegt seine Feinde. Richt. I I.

Christus erscheint der Maria von Magdala.

Moses verbietet den Berg Sinai zu berühren. II. Mos. I9.

Die Sunnaniterin wirft sich auf dem Berg Karmel zu Füßen des Elisa. II. Kön. 4.

Christus erscheint den Jüngern.

Josef gibt sich zu erkennen. I. Mos. 45.

Rückkehr des verlorenen Sohnes. Luk. 25.

Christus und Thomas.

Abraham läßt den Knecht die Hand auf seine Leber legen.

I. Mos. 24.

Josef legt die Hand auf die Leber seines Vaters zum Schwur. I. Mos. 47 .

Isaak betastet die Hände Jakobs. I. Mos. 27.

Jakob ringt mit dem Engel. I. Mos. 32.

Gideon und der Engel. Richt. 6.

Himmelfahrt.

Moses geht auf den Berg Nebo um zu sterben. V. Mos. 34.

Der Sündenbock geht in die Wüste. III. Mos. I6.

Moses findet den Stab Arons. IV. Mos. I7.

Pharao setzt den Josef auf den königlichen Wagen. I. Mos. 4I. Sendung des Geistes.

Die Friedenstaube kommt an die Arche. I. Mos. 8. Weltgericht.

Die Chaldäer werden von Flammen ergriffen. Dan. 3.

Josef gibt seinen Brüdern je ein Festkleid, dem Benjamin aber fünf. I. Mos. 5 .

Der apokalyptische Reiter. Offbg. Joh. I9.

Der Menschensohn mit der Sichel. Offbg. Joh. I4.

Adam gibt den Tieren Namen. I. Mos. 2.

Josef entscheidet die Träume im Gefängnis. I. Mos. 40.

Moses verurteilt die Kalbanbeter. II. Mos. 32.

Himmel.

Simon zieht mit den Seinigen in die Burg ein. I. Makk. I 3. 
Der Inhalt des dritten Buches des Speculum von Vincenz, des Speculum morale, hat gleich starke Einwirkung auf die Glasmaler ausgeübt, wie die übrigen und auch in Deutschland intensive Nachahmung gefunden. Bis das Grundthema der Kampf des Guten gegen das Böse, in die darstellende Kunst überging, hatte es von Prudentius über Honorius bereits eine Entwicklung durchgemacht. In der Frühzeit war der Kampf selbst dargestellt, an dessen Statt im I2. Jahrhundert die Auffassung des Sieges trat. Die Tugenden sind nicht mehr als streitende, lebhaft bewegte Figuren wiedergegeben, sondern sie stehen in monumentaler Haltung als Sieger in dem eben beendeten Kampfe. Namen und Zahl der Tugenden wurde selbstverständlich von den Theologen festgesetzt. Zwölf Tugenden sind es, denen ebensoviel Laster entgegengesetzt wurden. So sind sie in die Fenster der Westfassade von Notre Dame in Paris, in den Kathedralen zu Paris und Lyon aufgenommen. Die Tugenden tragen charakteristische Attribute. Die Laster dagegen sind handelnd dargestellt. $\mathrm{Zu}$ den wichtigsten Paaren gehören zunächst die drei göttlichen Tugenden und die vier Kardinaltugenden:

Glaube - trägt im Schild einen Götzendienst - Ein Mann betet von einem Kreuz überragten einen Affen an. Kelch.

Hoffnung - im Schild ein Kreuz. Verzweiflung - Selbstmord. Liebe - im Schild ein Lamm. Geiz - wühlt in Schätzen, Keuschheit - mit Phönix.

Klugheit - mit Schlange.

Demut - mit Taube.

Unkeuschheit - Kourtisane mit Spiegel.

Narrheit - ein Mann mit einer Keule, führt ein Stück Käse zum Mund (Volkssitte).

Hochmut - Ritter stürzt mit seinem Pferd in einen Graben.

Stärke - gewappnete Frau mit Feigheit - Ergreifen des Hasen-

Löwen im Schild. paniers.

Geduld - Stier auf dem Schild. Zorn - ein Laie ersticht einen Kleriker.

Sanftmut - mit Lamm auf dem Schild.

Hartherzigkeit - eine Frau gibt einem Diener, der ihr etwas reicht, einen Fußtritt. 
Eintracht - mit Ö1zweig auf Zwietracht - häusliche Szene. dem Schild.

Gehorsam - knieendes Kamel Rebellion - ein Mann erhebt die auf dem Schild.

Beharrlichkeit - Krone auf dem Schild.

Hand gegen einen Bischof. Unbeständigkeit - Entweichender Mönch.

$\mathrm{Zu}$ den ältesten Darstellungen der Tugenden und Laster in Deutschland gehören die Fenster im Westchor des Domes zu Naumburg, die um das Jahr I 240 entstanden sind. Wiederum haben wir es mit zwölf Paaren zu tun, allein nur neun Paare sind mit den französischen Vorbildern identisch, die übrigen weisen eine andere Vorlage auf. Außerdem kommt auf den Naumburger Fenstern noch eine andere Eigentümlichkeit zur Wiedergabe. Die Tugenden sind auf je einen Apostel als deren besonderes Beispiel verteilt, und als abschreckende Exempel für die Laster müssen gewisse Gestalten aus der alten Heidenwelt herhalten. Die Beziehung der einzelnen Apostel und Heiden auf die entsprechenden Tugenden bzw. Laster ist keineswegs von zwingender Logik, jedenfalls aber geht die Anordnung auf eine, uns allerdings unbekannte Vorlage zurück. Es ergibt sich folgendes System:

\begin{tabular}{|c|c|c|}
\hline Mittleres & Fenster & Link \\
\hline Petrus & Fides & Persevera \\
\hline Simon Magus & Infidelitas & Inconsta \\
\hline Jacobus maior & Mansuetudo & Sapienti \\
\hline Herodes & Insolentia & Insipient \\
\hline Johannes & Caritas & Pax \\
\hline Domitian & Avaritia & Discordia \\
\hline Andreas & Fortitudo & Justitia \\
\hline \multirow[t]{10}{*}{ Aegcus } & Timor & Injuria \\
\hline & Rechtes & Fenster \\
\hline & Philippus & misericordia \\
\hline & ? & intoleranti \\
\hline & Bartholomäus & benignitas \\
\hline & Astrages & invidia \\
\hline & Matthaeus & patientia \\
\hline & Hirtacus & ira \\
\hline & Thomas & spes \\
\hline & Mesdeus & desperatio \\
\hline
\end{tabular}


Auch im Elsaß begegnen uns verschiedene Tugendfenster in Mülhausen (um I 330) ${ }^{\mathbf{1}}$ ) und in Niederhaslach (um I400). In beiden Fällen weicht die Grundanlage von den französischen System ab und lehnt sich an die ursprüngliche Idee eines wirklichen Kampfes. Die überlegenen Tugenden durchbohren mit einer langen Lanze die bereits an den Boden geworfenen Laster. Ohne Attribute sind die Tugenden dargestellt; darum sagt eine beigegebene Inschrift, worum es sich bei jeder einzelnen Szene handelt. Auch in der Auswahl der Tugenden weisen namentlich die Niederhaslacher Fenster Abweichungen von dem französischen wie Naumburger System auf.

In enger Verwandtschaft zu den Tugenden und Lastern steht die Darstellung der Werke der Barmherzigkeit, wie sie insbesondere als Vorwurf der Fenster in der Elisabethkirche zu Marburg und der Stephanskirche zu Mülhausen gedient hat. Auch die Glasgemälde mit den klugen und törichten Jungfrauen gehört in diese Kategorie, z. B. auf den Fenstern in Marburg in S. Walpurgis bei Leoben und in S. Dionys zu Eßlingen. Den Inbegriff des gesamten neutestamentlichen Geistes gegenüber dem alten Testament bildet die uralte Gegenüberstellung der ecclesia und der Synagoge. Ursprünglich waren die Personifikationen dieser beiden Ideen als weibliche Figuren unter das Kreuz gestellt. Rechts stand die mit Krone geschmückte ecclesia, das aus der Seitenwunde ausströmende Blut in einen Kelch auffangend, links aber stand die Synagoge mit zerbrochenem Scepter in der Hand. Die Krone entfällt dem Haupt und eine Binde bedeckt die Augen. So ist die Szene auf einem Glasgemälde in der Kathedrale zu Bourges, in einem Fenster zu S. Kunibert in Köln dargestellt. Öfters findet sich die Gegenüberstellung auch ohne Kreuzigungsgruppe, z. B. in Le Mans, in Mülhausen, im Dom zu Halberstadt.

Mit diesem Formenschatz ist die Glasmalerei bis zu ihrem Niedergang überall ausgekommen. $\mathrm{Ab}$ und $\mathrm{zu}$ finden sich einige Weiterbildungen oder kleinere Neuerungen, wie z. B. die Darstellung der Io Gebote (Niederhaslach, Köln), der sieben Sakramente (Augsburg), des Meßopfers und spät auch des Rosenkranzes

1) Davon abhängig die Fenster in Hall und Thüngenthal. 
und der Kreuzwegstationen. Mit der Glaubensspaltung hat sich auch eine Konfessionalisierung der Glasgemälde geltend gemacht, insofern $\mathrm{da}$ und dort Reformatoren in Kirchenfenstern dargestellt wurden, so z. B. Gustav Adolph. Da aber die protestantische Konfession auf gemalte Darstellungen religiöser Personen keinen Wert legte, kommt die Glasmalerei in protestantischen Kirchen nicht mehr in Betracht. Selbstverständlich ist die Wahl des Stoffes Sache der Besteller und Stifter, und in letzter Instanz der kirchlichen Behörden gewesen, und so verhält sich die Sache auch heute. Kein Künstler wird sich weigern, die von dem Auftraggeber gewünschte religiöse Szene in dessen Sinn auszuführen; es wäre aber andererseits sehr zu wünschen, wenn die kirchlichen Kreise den Glasmaler immer mehr von Aufgaben entbinden würden, die nun einmal mit dem wahren Wesen der Glasmalerei absolut nicht in Einklang zu bringen sind, z. B. die Darstellung der Madonna von Lourdes, überhaupt süßlicher Szenen. Der Ideenschatz unserer alten Theologen und Prediger ist, wie wir gezeigt haben, so reich und fruchtbar, daß er noch unendlich viele Benützer zur Arbeit einladet. Sumptus nec consumitur!

Die ersten Darstellungen weltlicher Stoffe auf Glasgemälden, die nicht in Kirchen sich befinden, treffen wir in Frankreich, wenn wir von den heraldischen Figuren auf oberrheinischen Glasmalereien absehen. $\mathrm{Zu}$ den ältesten gehört ein Glasgemälde auf Schloß Sassangy (Saône-et-Loire). Es ist ein berühmtes Stück, da man es als die Darstellung einer Familienszene aus der adeligen Gesellschaft ansah: Herr Eduard von Beaujeu verführte beim Schachspiel die Tochter eines Herrn de la Bessée. Diese Tat vollzog sich um I400, während das betreffende Glasgemälde ca. 40 Jahre später entstanden ist. Nach den Ausführungen Bégules lag also kein Grund vor, in so später Zeit auf diese Tat zurückzukommen, so daß es sich bei dem fraglichen Glasgemälde lediglich um ein Genrebild, eine Schachbrettszene handelt. Mit dem Aufblühen des Kupferstichs und des Holzschnitts drang der ganze weltliche Gehalt der Kunst des ausgehenden Mittelalters und der Renaissance in die Glasmalerei ein. Damit traf die von Italien und den Niederlanden ausgehende Bewegung zusammen, das weltliche Gebäude ebenfalls künstlerisch ausgestalten. In der Butzenverglasung hatte man ein bequemes Feld für Ein- 
setzen von einzelnen Scheiben. Die Reichhaltigkeit der von den Glasmalern übernommenen Stoffe kann in diesem Zusammenhang auch nicht einmal andeutungsweise wiedergegeben werden. Die Stiche der großen und kleinen Graphiker sind teils in Kopien auf einzelnen Scheiben in der Kabinettsmanier gemalt worden, teils haben sie als Oberlichtsszenen die in ungeheurer Anzahl hergestellten Wappenscheiben geziert. Dabei sind Szenen aus der Vaterlandsgeschichte (vgl. dabei besonders die Schweizer Scheiben) aus dem täglichen Leben, aus der Mythologie herangezogen worden. Die moderne Glasmalerei greift ihre Stoffe mit Vorliebe aus dem täglichen Leben. Sie paßt dieselben dem Raume an, den das Glasgemälde schmücken soll. So finden wir in Kinderzimmern die Darstellung der beliebtesten Volksmärchen, in Boudoirs und größeren Zimmern stimmungsvolle Genres aus der Natur, besonders auch dem Tierleben. Beruf und Sport, Handel und Industrie, alle öffentlichen Interessen und Ämter hat die Glasmalerei in den Dienst ihrer Darstellung gezogen und auch von diesem Gesichtspunkt den Nachweis erbracht, daß sie durch und durch eine im besten Sinn des Wortes moderne Kunst ist. 
VI.

\section{Die gesellschaftliche und materielle Lage des Glasmalers.}

Wie alle anderen kunstgewerblichen Berufe ist auch das Handwerk des Glasmalers aus der Tätigkeit der operaii, der Hörigen in königlichen Pfalzen und Villen hervorgewachsen. Zu einer Pfalz oder einem königlichen Meierhof gehörten außer den Feldarbeitern die verschiedenen Handwerker, wie Sattler, Schuster, Schmied, aber auch Waffen- und Edelschmied, kurz alle, die zur Ausstattung einer königlichen Wohnung wie zur Verfeinerung des täglichen Lebens beitragen konnten. Sie waren jenen, die die den einfachsten Tagesbedürfnissen dienten, völlig gleich erachtet. Nach dem Muster des Königshofes richteten sich die Klöster ein, jedoch mit dem besonderen Vorteil, daß sie ganz unentbehrliche Kräfte in den geistlichen Verband aufnahmen, um sie desto fester an das Kloster zu ketten. Wenn nun fast alle Namen von Glasmalern der Frühzeit auf den Zusammenhang mit den Klöstern weisen, so begreift sich dies aus der Tatsache, daß die Kirchen in erster Linie die Tätigkeit der Glasmaler in Anspruch nahmen. Eigentlich ist der Ausdruck Glasmaler in diesem Zusammenhang sehr verfänglich. Die älteste Bezeichnung lautet vitrearii oder vitriarii, Glaser. Zweifellos haben bereits in den fränkischen und später karolingischen Pfalzen solche vitriarii Glaser ihr Handwerk ausgeübt. So nennt eine Urkunde Karls des Kahlen im Jahre 863 den vitrearius Baldricus und vitrearius Ragerulfus mit Frau und Kindern. Diese vitrearii wurden gleich den Goldschmieden und anderen, wie wir es heute nennen, Handwerkern und Kunsthandwerkern als artifices bezeichnet. Wenigstens heißt es von dem Abt Benedikt von Wiremouth 
um 700 , daß er sich aus Frankreich vitri factores, videlicet artifices Britannis eatenus incognitos habe kommen lassen. Die Glaser waren also in der Karolingerzeit Hörige der Klöster. Solange es sich um die einfache Verglasung oder höchstens Kunstverglasung handelte, lag kein Grund vor, ein besonderes Augenmerk auf die vitrearii $\mathrm{zu}$ haben. Erst als die figürliche Glasmalerei in Übung kam und man es dabei mit technischen, diskret zu hehandelnden Kunststücken zu tun hatte, empfahl es sich, die Mönche selbst für die Ausübung der Glasmalerei zu interessieren. Von Ludwig dem Frommen wird gerühmt, seine Freigebigkeit gegen die Alleruntersten sei so groß gewesen, daß er dem vitrearius Stracholfus, dem Hörigen des hl. Gallus (des Klosters S. Gallen), alle seine Kleider habe schenken lassen. Stracholfus hat den König während des Aufenthalts in S. Gallen bedient. Der vitrearius Stracholfus gehörte also zu den untersten Klassen ${ }^{1}$ ). Kaum war aber die Glasmalerei in die verschiedenen Klöster eingedrungen, da änderte sich sofort die Lage der vitrearii. An die Stelle der Hörigen traten Kleriker, Kloster- oder Weltgeistliche. Aus den Akten des Klosters Le Mans teilt der Abt Lottin mit: Wilhelm der Glaser, Kanonikus, habe sein eigens Haus, das er sich durch die Arbeit seiner Hände hatte erbauen können, verkaufen lassen, und im Martyrologium dieses Klosters wurde sein Andenken bis zum Jahre I790, dem Jahre der Säkularisation des Stiftes, mit den Worten weiter geführt: Eodem die obiit Guillelmus vitriarius, istius ecclesiae canonicus (ca. I IOO). Dieser Glaser Wilhelm war also Kanoniker und unterschied sich sehr wesentlich von dem Stande der Hörigen. $\left.{ }^{2}\right)$ Von dem Bischof Gottfried von Auxerre (1052-I076) wird berichtet, er habe mit dankbarer Zustimmung seines Kapitels verschiedene Männer zu Ehrenkanonikern gemacht, nämlich einen berühmten Goldschmied, einen geschickten Maler und einen ausgezeichneten Glaser. ${ }^{3}$ ) Wir

1) Pertz Mon. Germ. II, S. 763: Hludovici liberalitas usque ad infimos adeo pervenit, adeo ut Stracholfo vitrearo, servo S. Galli, totam vestituram suam tunc sibi servienti praeceperat dari.

7) Hucher, Calques des vitraux peints de la cathedrale de Bourges I864.

$\left.{ }^{3}\right)$ Dieser Bischof „vir providus et benignus excogitans ecclesiae suae quascumque poterat temporales et aeternas utilitates elegit etiam, cum laude et cum gratiarum capituli sui actione, quosdam, quos gratis canonicos ad praefinitam oboedientiam con- 


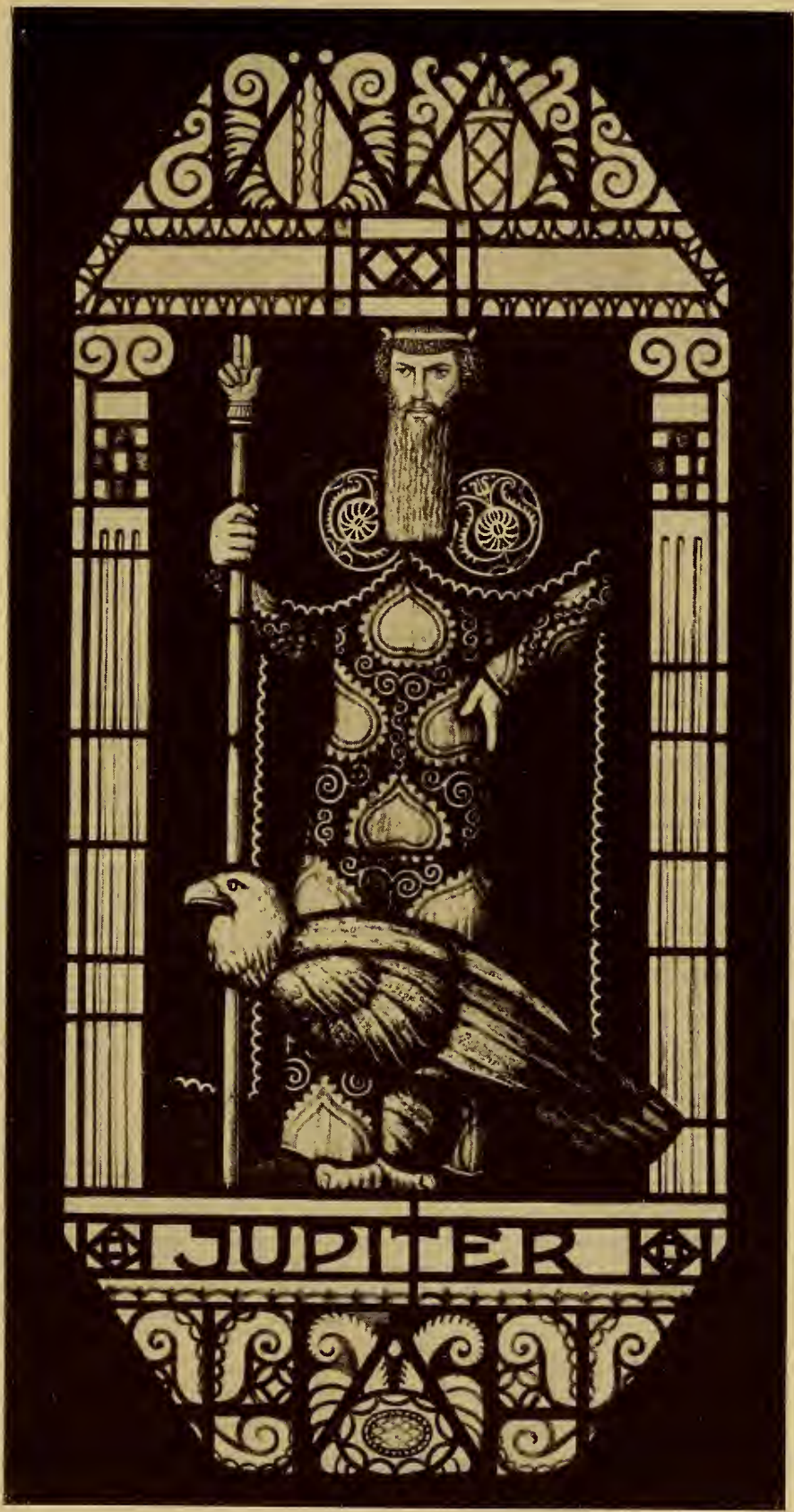

Glasgemälde, unter Verwendung antiker Motive entworfen und ausgeführt von der Hofglasmalerei F. X. Zettler, München. 

können im Zusammenhang damit die pueri, von denen im Briefe des Abtes Gozbert von Tegernsee die Rede, als Scholaren, junge Kleriker, ansprechen. Am Hofe des Bischofs Godehard von Hildesheim lebte ein junger Künstler aus vornehmen Geschlecht, der außer mit seinen Berufsgenossen sehr gerne mit "jenen verkehrte, die Fenster machten ". ${ }^{1}$ ) Das I I. und I 2. Jahrhundert kennt also in erster Linie angesehene Kleriker als Schöpfer von Glasmalereien. Von dieser Tatsache fällt ein glänzendes Licht auf die Hochschätzung, deren sich die Glasmalerei allenthalben erfreute. Der Name vitrearius ist geblieben, aber seine Bedeutung hat sich gehoben. Die Glasmaler werden meistens zusammen mit den Malern genannt. Sie wohnten auch in vielen Klöstern mit diesen in einem Trakt; so ist dies z. B. für das Kloster Salem am Bodensee bezeugt. In Köln erscheint um die Mitte des I2. Jahrhunders der Name fenestrator, während der Abt Suger von S. Denis die Glasmaler einfach magistri nennt. Beiläufig bemerkt, ist nach den Worten Sugers die Glasmalerei eine so bedeutende Sache, daß deren tüchtigste Meister weithin Ruf genießen: „Wir haben die Glasfenster durch viele Meister aus verschiedenen Nationen malen lassen." Die Betätigung der Glasmalerei durch Weltgeistliche und Mönche dauerte durch das ganze Mitteltalter, wenn auch mit verschiedenen Einschränkungen und mit abnehmender Tendenz. Namentlich in Italien widmeten sich Mönche der Glasmalerei. So glaubt u. a. Giusto*) annehmen zu können, daß die ältesten Glasmalereien der Basilika zu Assisi von Franziskanermönchen im I 3. Jahrhundert ausgeführt worden seien. Diese hatten zur Mitarbeit Laien, aus denen dann zahlreiche Glasmalerfamilien, namentlich in Venedig und Murano, hervorgingen. Die Stiftung des hl. Franziskus kannte außer der ersten und hauptsächlichsten Klasse noch einen sogenannten dritten Orden, dem unter gewissen leichten Bedingungen Laien beiden Geschlechts beitreten konnten. Es ist wiederholt bezeugt,

stituit, aurifabrum mirabilem, pictorem doctum, vitrearium sagacem alios necnon, qui singuli prout cuique erat facultas, in officiis deservirent. (Labbe Nor. Bibliot. MSS. I, 453.

1) Leibnitz, Script. vet. rer. Brunsvic. I, 500: interdum et pictoribus et eis qui fenestras componebant, se admiscuit, inter quos etiam utiliter operosus exstitit.

2) Giusto le vetrate di S. Francesco d'Assisi I 912, S. $28 \mathrm{ff}$. 
daß diesem dritten Orden Glasmaler als „Brüder“ angehörten. Die Tradition vererbte sich in Assisi außerordentlich lange. Noch im Jahre I 8 I 2 wird ein Mönch erwähnt, der an den Glasmalereien $\mathrm{zu}$ bessern hatte. Außer den Franziskanern widmeten sich auch die Karmelitermönche der Glasmalerei. So erfahren wir, daß im Jahre I387 Giovanni Bettì, monaco carmelitano, ein Fenster für die Taufkapelle des Domes zu Pistoja ausführte. Während also in Deutschland die Benediktiner sich um die Glasmalerei verdient machten, waren es in Italien die Minoriten, die dieser Kunst eine besondere Pflege entgegenbrachten. Weltgeistliche, denen eine kleine Pfründe beschieden war, suchten nicht selten ihre mageren Einkünfte durch Beschäftigung mit der Glasmalerei zu erhöhen. So erfahren wir, daß der berühmte Glasmaler Bartolomeo di Tommaso Fiorentino (erste Mälfte des I 5. Jahrhunderts), der Meister verschiedener Fenster, z. B. zu Pistoja für S. Stefano d'Empoli, Gutleutpriester in Valdarno inferiore, dann Pfarrer von S. Croce sul Arno war. Laut einer Urkunde vom 2 I. März I 425 bekommt "Meister Thoman, der Glaser, pfarrer zu Hollabrunn, ein Judenhaus als Lohn für, verglasen der Newn kapellen in vnserer Burg zu Wien'“" Der Pfarrer Thoman, mit dem Familiennamen Pawngarten, hatte ein Haus in Wien, wahrscheinlich als Werkstätte, und arbeitete mit Gesellen. Nicht überall hat man sich die Arbeit der Glasmaler geistlichen Standes gefallen lassen, sondern sie da und dort als Konkurrenz gegen die Tätigkeit der Laien bekämpft. So ist in einer Glasmalerordnung der Stadt Freiburg i. Br. vom Jahre I 484 bestimmt: „Priester mögen wol in selbs (d. h. für sich selbst, für eigenen Gebrauch) glaswerck machen, doch niemen anderen." Diese Bestimmung wurde im Jahre I5I3 verschärft. Auf die Klage der Glaser verordnete der Rat: „wenn hinfür die glaser, so sie seßhaft sint und zünftig, alweg in erfarung haben, und wo sy erfunden, das die geischlichen umb lon ouch usserhalb irer closter und heusser glasent, so solend sy die selben einem ersamen rat anbringen, so wils ein rat nach sinen vermogen abstellen. "1) Auch die Bestimmung des Züricher Rates im Jahre I 5 I6 hatte eine scharfe Spitze gegen die geistliche Konkurrenz: „weder geistlich noch weltlich mach

1) Geiges a. a. O. S. $68 \mathrm{ff}$. 
kein gebrennt schyben noch ruten werch er habe es dann gelernt... welicher priester oder geistlicher (Mönch) wölle glasen, derselb solle kein knecht anstellen. " ${ }^{1}$ )

Diese zielbewußten Kämpfe treten verhältnismäßig spàt auf. Das hängt damit zusammen, daß sich die Glasmaler erst spät nach Zunftart organisieren konnten, weil ihr Gewerbe stets unter einer gewissen Beschränkung auf zahlkräftige Kreise litt. Die Glasmaler haben sich nie große Vermögen zu erwerben verstanden. Darum neigten sie von Anfang zu dem Streben, sich irgend einen Nebenberuf zu sichern, wenn sie sich nicht der Existenzsicherung wegen von vornherein an gewisse Personen verdingten. So hat sich obengenannter Fulko in den Dienst des Konventes von S. Albin zu Anvers gestellt: „Eines Tags kam ein Mann, namens Fulko, ausgerüstet mit der Kunst des Malens, in das Kapitel zu S. Albin und schloß folgenden Vertrag. Er muß das ganze Kloster ausmalen und die gläsernen Fenster machen. Er wurde Bruder und außerdem als freier Mann des Abtes erklärt. Mönche und Abt gaben ihm einen Weinberg als Lohn und ein Haus unter der Bestimmung, daß er es während seiner Lebzeiten benutzen und daß es nach seinem Tode an das Kloster zurückfallen solle, es sei denn, daß er einen Sohn habe, der die Kunst seines Vaters handhaben und so dem hl. Albinus dienen könne." Das Lehen, das Fulko bekam, war also gewissermaßen ein Berufslehen, das an dem Beruf des Malers und Glasers hing. Man sieht, wie langsam der Betrieb der Glasmalerei vonstatten ging. Die Notiz über diesen Fulko ist auch das älteste Beispiel für die Verbindung von Malerei und Glasmalerei in einer Person. Der Meister Nicklas in Augsburg wird ebenfalls Maler genannt (I 373), ${ }^{2}$ ) ferner der Glasmaler "Michael pictor de civitate Zwett1" († I387). In Breslau hat "Magister Conrad der Maler globit den Monchen czum Brige I 2 Tafeln Glaswerchs." In den Hüttenbüchern des Ulmer Münsters stehen folgende bemerkenswerte Einträge: „I 4I 7 maister Jakoben dem mauler geben 20 Gulden von $\mathrm{dz}$ fenster wegen. Item 4 Pfund dem Mauler Lukas (Moser?) von gleser ze machen in $\mathrm{dz}$ hus. "3) I4I9 malt

1) Meyer, Die schweizerische Sitte der Fenster- und Wappenstiftungen, S. 334.

9) Bruno Bucher, Geschichte der technischen Künste I, S. 74 .

3) Repertorium für Kunstwissenschaft I9IO, S. 4I6. 
"maister Simon der maler" ein Fenster für S. Michael zu Wien; ebenso I45I "Caspar der Maler". I 480 pessert "maister Hanns Red der Maler" die Gläser im Rathaus zu Wien. ${ }^{1}$ ) Gegen Ende des I 5. und während des I6. Jahrhunderts mehren sich die Fälle, in denen die Glasmalerei Nebenberuf des Malers ist. Das hängt, wie wir an anderem Ort gezeigt haben, zum großen Teil mit der Entwicklung der rein kunstgewerblichen zur künstlerischen Glasmalerei zusammen.

Außer glaser, maister tragen die mittelalterlichen Glasmaler den Namen „schiltaere“; so z. B. in den Dichtungen Wolframs von Eschenbach. $\left.{ }^{2}\right)$ Schiltäre sind vom Maler geistlicher Stoffe verschiedene Künstler, die Glas- und Wappenschilder bemalten. Vergleiche zum Beispiel die Neuordnung "von der schilter, geistlicher Maler, glaser etc. “ zu Wien im Jahre i4 Io. In dieser Neuordnung werden zum erstenmal die verschiedenen kunstgewerblichen Gebiete auseinander gehalten. Es heißt daselbst: „Von der schilter, geistlicher maler, von glasern, von goldslahern (Goldschmiede) und auch von denen, die nur slechts (schlichtes, einfaches) glaswerch kunnen und nicht geprants...." Im I3. und I4. Jahrhundert also faßte man diejenigen, die weltliche Stoffe auf Glas malten, unter die schiltere zusammen, während die Meister großer kirchlicher Aufgaben den Namen glaser führten.

$\mathrm{Zu}$ einer Standesorganisation konnten die Glasmaler nur sehr langsam gelangen, da an einem, wenn auch größeren Ort, die Aufgaben nicht so reichlich waren, um eine Mehrheit von Glasmalermeistern sicher zu ernähren. Mit dem Aufblühen der Zünfte lag es auch im Interesse der Glasmaler, einer bestimmten Zunft angegliedert zu sein. Von selbst empfahl sich dabei die Zunft der Schilter, in der die Maler saßen, und die schon wegen des Zusammenhangs der Glaser mit den Schiltern am ehesten in Betracht kam. Dieser Verzunftungsprozeß muß sich im Laufe des I4. Jahrhunderts vollzogen haben. Das I4. Jahrhundert war

1) Feil a. a. O. S. 25 I.

2)

Der tjoste venster was gesniten

mit der Glawine wit

alsus malet der strit:

wer gultes den Schiltären

ob ihr farwe alsus wären? 
die nie mehr in dieser Ausdehnung wiedergekehrte Blütezeit des Handwerks. Die mächtig sich entfaltenden Städte hatten alles Interesse an einem möglichst kräftigen Handwerkerstand. Sie begünstigten die Bildung von handwerklichen Großbetrieben, die sich während des I 5. Jahrhunderts zu Unternehmerfirmen ausdehnten. Darum unterstützten die Städte alle zünftig organisierten Handwerker gegen wandernde Meister, gegen jede Art unlauteren Wettbewerbs und machten bei ihrem Kampf nicht einmal bei den in einer Vorzugsstellung befindlichen Geistlichen Halt. Wir haben daher verschiedene scharfe Bestimmungen der Stadträte, die den Glasmalern das Fortkommen erleichtern sollten. Die älteste uns bekannte Ordnung ist die Glaser- und Glasmalerordnung von I4lo der Stadt Wien: „Von der schilter, geistliche maler, von glasern, goldslahern wegen uns auch von die nur slechts glaswerch kunnen und nicht geprants usw." Darin wird bestimmt: Der Glasmaler solle zur Erprobung seiner Meisterschaft „machen ain stuckh ainer kaufellen lankch und glaswerch mit pilden, das sol darjn geprant sein und das mit sein selbs hant, das sol er tun in vir wochen". Alle jene, die "slechts glaswerch arbaittend vnd geprants werch nicht kennen", sollen beweisen, daß sie „des slechten Glaswerch Maister" sein konnten. In „der newordnung der maler, schilter, glaser“ usw. vom 20. Juli I 446 wird beigefügt: Der um die Meisterschaft sich bewerbende soll „entwerffen und malen ein pild von Glaswerch ain Kaufellen lanckh, das sol darein geprant sein "1). Offenbar wurde die erste Ordnung von einigen Prüflingen dadurch umgangen, daß sie sich die Visierung durch jemand anderen anfertigen ließen, womit der Wiener Rat gar nicht einverstanden war und daher ausdrücklich verfügte, wer Meister werden wolle, müsse beides verstehen, das "entwerffen und malen“. Wir können das Milieu, aus dem diese Verordnungen erwachsen sind, leicht und sicher ergänzen. Nur wer die Meisterschaft auf rechtem Weg erworben hat, darf das Gewerbe ausüben. Zur Meisterschaft führt der Befähigungsnachweis für "entwerfen und malen". Trotz solcher scharfen Bestimmungen sind die Glasmaler erst spät bestimmten Zünften angeschlossen worden. In Zürich war die Zahl der Glasmaler

1) Feil a. a. O. S. 25 I. 
im Jahre I 47 I noch so klein, daß sie vom Zunftzwang ausgenommen waren ${ }^{1}$ ). Zur Zeit der höchsten Blüte der Glasmalerei in der Schweiz traten die Glasmaler mit Vorliebe in die Zunft ein, der die Maler angehörten. Auch in München traten die Glasmaler bis ins I7. Jahrhundert in die Zunft der Maler. Je mehr seit dem I6. Jahrhundert die Bedeutung der Zünfte gegen die Stellung der Fürsten in den Hintergrund trat, desto mehr empfahl sich für die bedeutenderen Glasmaler, in den Dienst der Fürsten zu treten. Bereits im Jahre I 5 I 6 bekommt der Augsburger Meister Hans Knoder "der Hofmaller" von Kaiser Maximilian I. glasmalerische Aufträge. Besonders lehrreich ist in dieser Beziehung die Verhandlung König Ferdinands I. mit seinem „Hofglaser“ Urban Telchinger und Paul Dax, dem Hofmaler wegen eines Auftrags für die Burg zu Innsbruck ${ }^{2}$ ). Am Hofe Wilhelms V. von Bayern wirkte seit I 574 der „fürstliche Hofglaßer Hans Höbenstreyt", später der "fürstliche Hofglaßer Georgus Höbenstreyt". Als zu Beginn des vorigen Jahrhunderts die Glasmalerei zu neuem Leben erweckt wurde, da zog der bayrische König Maximilian I. den Mann, der sich um jene Neubelebung besonders verdient gemacht, Sigismund Frank, an seinen Hof. Bis um das Jahr I 870 blieb die Glasmalereianstalt eine königliche Sache. Ähnlich war es auch an anderen fürstlichen Residenzen. In neuerer Zeit fand die Glasmalerei ihre Pflege in größeren oder kleineren Instituten. Nicht immer war der Leiter einer solchen Anstalt künstlerisch oder technisch vorgebildet. Gleichwohl muß konstatiert werden, daß die Gegenwart der Glasmalerei eben auf jenem wagemutigen Unternehmertum der achtziger Jahre beruht. Ihm haben wir zweierlei zu danken. Es hat, ohne auf die Ungunst der Verhältnisse zu achten, die Liebe zur Glasmalerei in weitere Kreise getragen, und, was uns fast noch wichtiger erscheint, in eben den Künstlerkreisen das Verständnis für die Eigenart der Glasmalerei wachgerufen. Das letztere will sehr viel heißen. Denn wer weiß, mit welchem Starrsinn die ungesunde Bevormundung des Kartons durch die Tafelmalerei gerade in führenden Künstlerkreisen festgehalten

3) Lehmann a. a. O. S. $22 \mathrm{I}$. Über die Zünfte in anderen Städten siehe W. WackernageI, Geschichte der Glasmalerei S. 66.

2) Siehe Fischer, Die Beziehungen der Augsburger Glasmaler und Rißzeichner zum Hause Kaiser Maximilians I. Zeitschrift für alte und neue Glasmalerei I, S. 96, I08ff. 
wurde, der muß es jenen Leitern von Glasmalereianstalten danken, daß sie mit Zähigkeit und von besserer Einsicht geleitet ihre Glasmaler auf die Gerüste vor die Werke der Alten gestellt haben, damit sie von dort die rechte Stilistik und Technik mitbrächten; und sie haben sie mitgebracht. Die Unternehmer jener Zeiten sind die Väter der modernen Glasmalerei. Nun lehnen sich, wie es ja immer ist, die jüngeren gegen die älteren. Mit großer Schnelligkeit hat sich das Verhältnis umgedreht. Während bisher die Anstalten, die mit Aufträgen bedacht wurden, sich je nach deren Eigenart die Künstler herausgesucht haben, ergeht in der Gegenwart der Ruf vom Bauherrn bezw. Bauleiter häufig direkt an einen bestimmten Künstler, daß er Kartons entwerfe und dort ausführen lasse, wo es nach seiner Meinung am besten geschieht. Der Inhaber einer Glasmalerei tritt gegen den entwerfenden und bisweilen auch ausführenden Künstler zurück. Dadurch sinkt die Bedeutung des Inhabers immer mehr und zwar um so gründlicher, je weniger derselbe ein aktives Verhältnis zur Glasmalerei hat, vielmehr kaufmännisch arbeitender Leiter des Materialwesens und Malpersonals ist. Auf derartige Verhältnisse drängt der gegenwärtige Stand der Entwicklung. Begreiflicherweise setzen sich jene Glasmalereianstalten, deren Inhaber und Leiter selbst Künstler sind, einem solchen Prozeß gegenüber zur Wehr und verteidigen jenen Zustand als Ideal, indem der entwerfende Künstler sein eigener Glasmaler ist. Wir geben ohne weiteres zu, daß auch wir nach wie vor die Verbindung von Künstler und Techniker in einer Person für das von Ort und Zeit unabhängige Ideal in der Glasmalerei halten. Allein wir bringen auch jenen Anstalten Verständnis entgegen, die mit keinem anderen Anspruch auftreten, als getreue Vermittler der Intentionen eines Künstlers zu sein $^{1}$ ). Wir wenden uns nur gegen solche Glasmalereiinstitute, die auch noch heute im reinen Unternehmertum stecken geblieben sind, die die Glasmalerei einer Fabrikware gleich erachten, bei der das Prinzip der Arbeitsteilung Gewinne abwerfen muß, um die gerade für solche Anstalten hohe Spesen zu decken. Binnen kurzem werden sich

1) Vergleich dazu den Meinungsaustausch Heinersdorff-Linnemann in der Zeitschrift für alte und neue Glasmalerei I, S. I26, I3 8 . 
größere oder kleinere Künstlergruppen eine eigene Glasmalerei halten, zunächst noch auf den Namen und die Rechnung eines selbständigen Besitzers, hernach aber auf eigene Regie. Der Kunstfreund kann bei diesem Entwicklungsprozeß nur den einen Wunsch haben, daß derselbe zum Heil und zur Blüte der Glasmalerei gereicht.

Wir haben oben bemerkt, daß es den allerwenigsten Glasmalern und zwar aller Zeiten gelungen ist, sich aus ihrer Tätigkeit Reichtümer zu erwerben. Die Materialkosten sind zu groß. Dazu kommt der große Verschnitt, die oft nötige Wiederholung des Brandes und dergleichen mehr. Solange die Glasmaler dem Kloster inkorporiert waren, mußte selbstverständlich nur das Material bezahlt werden, während der um Gottes Lohn arbeitende Mönch vom Kloster lediglich seinen Lebensunterhalt bekam. Schon sehr früh ereignete sich, daß Glasmaler, die nicht in direktem Klosterverband standen, mit einer Pauschalsumme oder einem Lehen für eine längere Zeit abgefunden wurden. So erhielt der Glasmaler Fulko einen Weinberg als Lehen, sowie ein Haus, damit er zeitlebens dem Kloster seine Dienste leiste. Waren die Glasmaler Geistliche, so gab man ihnen Pfründen und Ehrenkanonikate. Dagegen scheint sich der Glasmaler Wilhelm (um I IOO) in Le Mans bereit sein eigenes Haus durch Glasmalerei erarbeitet zu haben. $\mathrm{Zu}$ einer eigentlichen Tarifentwicklung konnte es erst kommen, als sich selbständige Laien mit der Betätigung der Glasmalerei befaßten. Wir haben nun eine ungeheuere $\mathrm{Zahl}$ von Preisnotizen aus allen Jahrhunderten; allein da wir die Werke, die um die genannte Summe hergestellt wurden, regelmäßig nicht kennen, so ist nur sehr selten eine bestimmte Rechnung zu ermitteln. Bezahlt wurde Jahrundertlang nur die rein handwerkliche Arbeit und das Material, nicht aber die künstlerische Idee. Darum finden wir verhältnismäßig wenig Preisdifferenzen bei Konkurrenzen. Man kann auf einem Quadratmeter oft 500 bis 600 Stückchen Glas zählen. Vergegenwärtigen wir uns noch einmal die Technik: Die einzelnen Stücke wurden nicht wie heute mit dem Diamant geschnitten, sondern mit dem Eisen abgestoßen und geriffelt. Die Bleie wurden gegossen und mit dem Hobel sorgfältig bearbeitet. Nur der Zeitaufwand, viel größer als heute, der Hände Arbeit wurde bezahlt, was damit 
Tafel 133

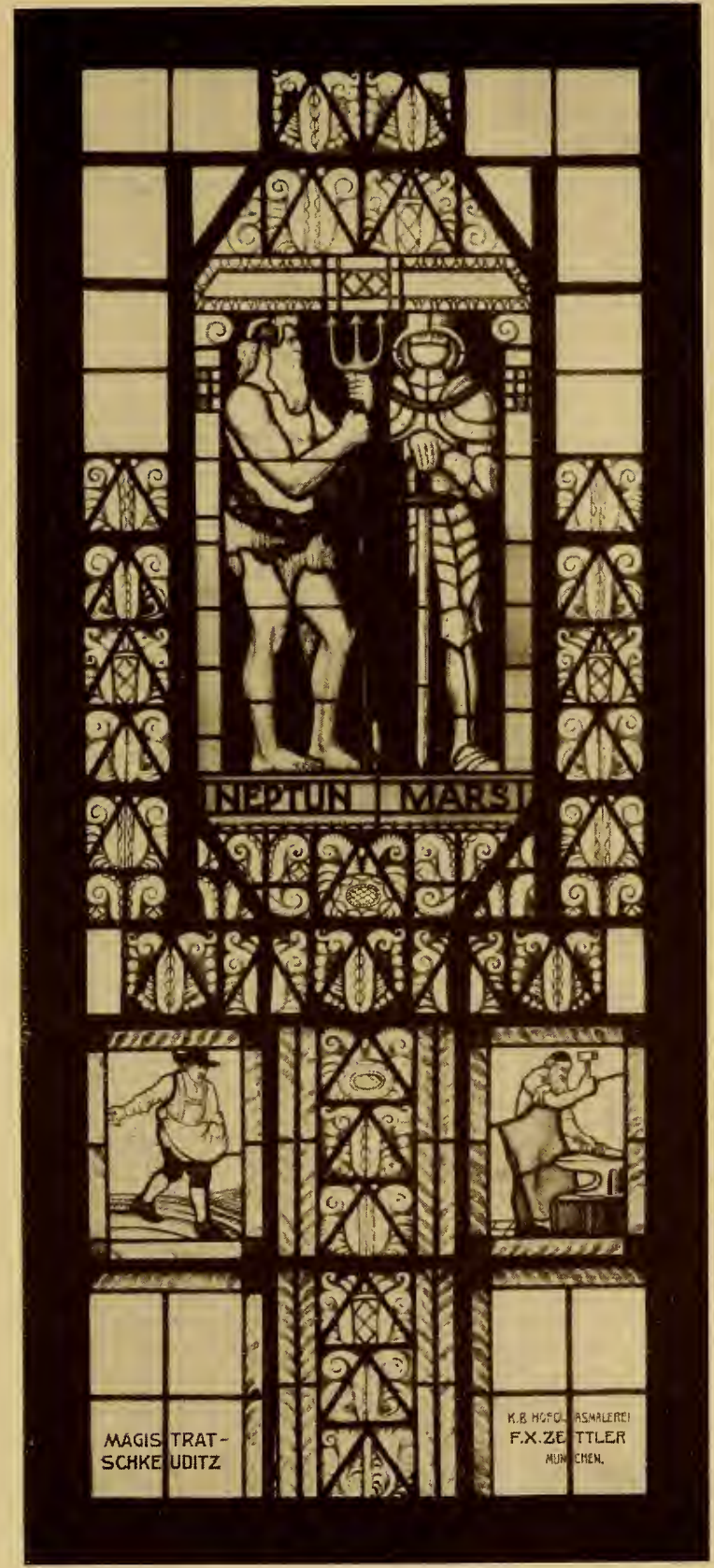

Glasgemälde, unter Verwendung antiker Motive entworfen und ausgeführt von der Hofglasmalerei F. X. Zettler, München. 

übereinstimmt, daß die Glasmaler nichts anderes waren, als Handwerker. Ein charakteristisches Beispiel dafür, wie die künstlerische Seite an der Glasmalerei eingeschätzt wurde, bildet der Streit zwischen Paul Dax und dem Hofglaser Urban Telchinger im Jahre I 538 wegen der Glaser- und Glasmalerarbeiten für die köngliche Burg zu Innsbruck. Der Arbeits- und Materialwert wurde von den Baumeistern auf 430 Gulden geschätzt. Im Lauf der Verhandlungen wurde Dax beauftragt, in Originalgröße die Visierungen herzustellen. Da sich die Wappen wiederholten, fertigte er "vier gemalte pletter auf zwo langen Zetln“ an. Für diese Arbeit bekam er „5 Gulden zu seiner ergötzlichkeit“ das heißt za. I 5 Mark Trinkgeld und dies auch nur, weil der Gesamtauftrag von 430 Gulden geteilt wurde. Als relativ arme Leute hatten die Glasmaler sehr häufig Schulden. Soweit sie in höfischen Dienst waren, bezahlte der Fürst die Schulden, wofür Glasgmälde als Gegenleistung geboten wurden. So erhielt der Hofmaler Hanns Knoder von Augsburg, der die Scheiben von Leermoos anfertigte, "I 5 rheinisch guldin zur bezalung seiner Schulden sowie ein Hofwinterclait." In ähnlicher Weise hatte einst (1 425) der Pfarrer von Holabrunn und Glasmaler Thomen Pawngartner, um seine Schuld von 8 Gulden an das Stift S. Florian, ein "tauel gemacht, was derselb gemacht wert ist.“ "Caspar der Maler und Margreth sein haussvrau haben ihr haus versatzt dem kirchenmaister vnser frawn kapellen auf der stetten zu Wienn, das Caspar der maler alle gleser in derselben Capellen Es sey Im kor oder in der kirchen on abslag der versetzten zwai und dreyßig ph. Jerlichen machen vnd pessern sol nach Iren notdurften Ausgenomen ob-icht von weters wegen oder von prunst ob ob icht phosten indergingen, das sol von der kirchen gut widergemacht werden." Es handelt sich also um eine Art Sicherheitshypothek, die bei der Kirchenpflege auf die Summe von 32 Pfund eingetragen, und deren Verzinsung in Form von Reparaturarbeit geleistet wurde. Da die Aufträge nicht immer reichlich flossen, nahmen die Glasmaler zu verschiedenen Machinationen ihre Zuflucht. So fertigten sie auf Geradewohl Scheiben an, schenkten sie an Korporationen oder begüterte Privatpersonen, auf deren Noblesse pochend und in der Hoffnung, daß ein Gegengeschenk baldmöglichst erfolge. Meistens begriffen die Be- 
schenkten sehr schnell und sie zahlten den normalen Preis als Schenkung: So bekam eines Tages die Kammer zu Innsbruck ein "geschmelzt glas" geschenkt; schon tags darauf wurde in den Kammerrechnungen gebucht: „Dem Maler . . . für ein geschmelzt glas das er den Herren der Kammer geschenkt, 6 Gulden zu seiner Verehrung." Man sollte meinen, daß die Blüte der Schweizer Kabinettsglasmalerei den Meistern reichere Einnahmen gebracht hätte. Indes ist gerade das Gegenteil der Fall. Selbst die angesehensten und am meisten beschäftigten Meister taten sich stets nach einem Gemeindeamt um, da sie sich von den Einnahmen aus ihrem Beruf nicht nähren konnten. Starb ein Glasmaler, bevor er ein solches Amt erlangt hatte, so mußte die Gemeinde Witwe und Kinder unterstützen, z. B. den Berner Glasmaler Samson Stark.

Aus den Fällen, in denen wir Rechnung und Glasgemälde identifizieren können, wollen wir drei charkteristische Fälle anführen. Um das Jahr I 372 wurden einem Glasmaler Jakobus für Figurenfenster Io Mark bezahlt. Nach P. Stephan Beissel war um I 372 die rheinische Stiftsmark gleich za. 8 Mark heutiger Währung, so daß für die ganze Arbeit ungefähr 80 Mark bezahlt wurden für eine Arbeit, die heute beläufig mindestens auf 3000 Mark zu stehen käme ${ }^{1}$ ). Im Jahre I52 I wurde in Lübeck ein Glasgemälde mit der Krönung Mariae eingesetzt. Einstens war es in der Sängerkapelle, während es sich jetzt über dem Westportal befindet. Nach den noch vorhandenen Rechnungen kostete das Fenster

1) Für diese und die folgenden Rechnungen möge eine kurze Skizzierung des Münzsystems angefügt werden. Das Wort Mark bedeutete in alter Zeit ein bestimmtes Gewicht, das je nach dem Ort, an dem es gebraucht war, verschiedene Schwere hatte. Am beliebtesten war die kölnische Mark mit ungefähr 233 Gramm. Aus dieser kölnischen Mark Feinsilber wurden mit einem Münzfuß von za. 930 Feinheit 240 Pfennige oder ein Pfund Pfennige ausgebracht, so daß also in der Numismatik das Wort Pfund nicht ein Gewicht, sondern eine Zahl nämlich 240 bedeutet. Solange man aus einer Mark Gewicht 240 Pfennige ausprägte, stimmte die Gewichtsmark mit der Zählmark gleich einem Pfund überein. Allein aus begreiflichen Gründen verschlechterte sich stets das Geld, so daß um das Jahr I 300 bereits über 700 Pfennige, also drei Zählmarken à 240 Pfennige aus einer Gewichtsmark geprägt wurden. Im I6. Jahrhundert (I 559) wurde der Guldentaler (Gulden) als Einheit festgestellt mit 60 Kreuzern à 4 Pfennig, sodaß also der Gulden 240 Pfennige hatte und einem Zählpfund gleich kam. Ein Pfund des 16. Jahrhunderts ist also soviel wie ein Gulden. 
I 50 Mark und außerdem wurden für das Einsetzen nochmals 32 Mark bezahlt, also im ganzen belief sich die Rechnung auf I82 Mark gleich nicht ganz 500 Mark heutiger Währung. In Hohenschwangau befinden sich zwei Scheiben, die ich auf Grund stilistischer und archivalischer Gesichtspunkte dem Münchener Glasmaler Paulus Loth zuweisen konnte. Für diese beiden Scheiben bekam Loth 20 Gulden. Sie haben zusammen einen Flächeninhalt von ungefähr einem halben Quadratmeter.

Um bei diesen sehr mäßigen Preisen ein auskömmliches Verdienst $\mathrm{zu}$ haben, mußten die Glasmaler alle Mittel anwenden, um einen Auftrag zu bekommen. Daß es dabei nicht ohne scharfen Konkurrenzkampf abging, ist selbstverständlich. Vor allem wehrten die Glasmaler alle nicht zunftgemäße Konkurrenz und zwar fast überall mit Erfolg ab. Durchziehende Glasmaler mußten Bürgerrecht und Zunftgerechtigkeit erwerben, ehe sie in der betreffenden Stadt das Glasmalerhandwerk ausüben durften. Man hoffte sie durch die hohen Gebühren und sonstige kleine Boshaftigkeiten weiterzuekeln. Nur wenn an einem Ort das Glasmalergewerbe sehr darniederlag, glaubte der Rat fremden Meistern die Ansiedelung erleichtern zu müssen, so z. B. der Rat von Nürnberg dem Glasmaler Reuter im Jahre ı607. Unter den gleichberechtigten Zunftgenossen begann oft eine wilde Jagd nach Aufträgen. Man kopierte sich gegenseitig bis auf die unbedeutendsten Kleinigkeiten, imitierte jede Neuheit, um unter allen Umständen konkurrenzfähig zu bleiben. Das wissen wir z. B. von den Zuger Glasmalern Müller und Adam zum Bach. Risse wurden kopiert, verhandelt und verarbeitet. Die traurigsten Auswüchse der Konkurrenz läßt uns eine Glasmalerordnung der Stadt Zürich aus dem Jahre I 569 blicken. Züricher einheimische Glasmaler hatten sich beschwerdeführend an den Rat gewandt wegen unlauteren Bewerbs aus den Reihen von Kollegen, die aufs Gerüst stiegen, um die Baumeister „für sich zu gewinnen“, wegen der Konkurrenz auswärtiger Glasmaler und insbesondere wegen der allzu großen Ausdehnung des Lehrlingswesens.

Der Rat von Zürich gab auf die Beschwerden folgenden Bescheid:

„Wann nun wir genannte meister glasmaler und glaser inn irem muntlichen fürbringen sambt ihren schriftlichen vor uns 
ingelegten Suplicationen der lenge unnd notturpft nach gehördt, unnd die gestaltsame jetziger zyt unnd läuffen eigentlichen betrachtent und erwägen, was inen inn die Hand zu geben syge, haben wir uns uf ob ingelybten ir der meister glasmalern und glasern uns für getragne artickel gesetzt unnd geordnet:

Erstlichen, das kein meister glasmaler oder glaserhandtwerchs dem anderen, wie dann bisher geschechen, um arbeit vorlouffen, nach den andren mit gelt zu den büwen ald sunst ze lychen hinderenn. Ouch weder zimberlüth noch steinmetzen von den glaseren geschenk nemmen, einen umb arbeit mer dann den anndern ze förderen, sunder einem jeden, der buwen hat, oder buwen wil, synen frygen willen lassen, ein glasmaler oder glaser synnes gfallens zu nemen. Und sy die meister ouch ein anndern der billigkeit nach betrachten, mit der erlütherung, wo einer oder mer hin für wider diss ansehen einem oder dem andern gelt uf einen buw, damit ime zu glasen werde, lychen, das der so das gelt empfacht nit schuldig syn sölle, ime das uf das angesetzt zil wider zu gebenn. Sonder er ime das gelt auf versicherung an einer gült stan lassen, und die losung an des empfachers willen stann. Zudem wo sy erfarenn, das einer also gelt geben hatte, oder dem andern gfarlich vorglouffen were, ald zimberlüth oder steinmetzen hiewider gehandlet, sömlichs unns fürzubringen, dieselben wir nach der gebür straffen.

Fürs annder möginnd die unnseren, es sygen allhie burger ald landlüth, ouch bürger uf der landschaft wol stören und glasen, wie inen das zukompt, doch das sy gute werschaft machen, aber sonnst kein hindersäss in unser statt für sich sölbs anndern glasen, es gescheche dann einem meister des handwerchs dienstwyse. Wann aber frömbde ussländische personen uf unser landschaft glasent und stören wollten, das ein jeder undervogt wo inen das vonn den meisteren dis handwerchs klagt wirt, dieselben frömbden hinwegwysen, damit unsere burger und die heimbschen mit frembden destminder beschwert werden.

Fürs drit, der leerknabenn halb, lassen wir zu, dass jeder meister allein ein leerknaben haben, ein glasmaler denselben drü jar und ein glaser den so im verdinget wirt, zwei jar lang leeren solle und keinen anndern anzenemen gwalt (habin solle), der ander habe dann anderthalb jar lang gelernet. Und das aber 
kein leerknab dem handtwerch nüt ze geben schuldig syn, und wer sölliches übersehe, würden wir die ungehorsamen strafen.

Und als jetz ein zyt har mit den Eerenwapen und fenstern so wir verschänken dem alten bruch zuwider auch etwas vortheils gebrucht sin möchte, ist zu fürkomung desselben von uns angesehen. So wir hinnfür also wapen und fenster verschänken, sölle unser oberister knecht, wer der je zu zyten sin wirt, acht haben dasselb under den glasmaleren und glaseren umbgan zlassen. Dergstalt welicher maalen und glasen kan, und gute subere werschaft macht, denselben wapen und fenster machen ze lassen. Welcher aber nit maalen kann und die Kere an im ist, demsölben das fennster zu machen zustellen, um etwan ein anderem vlyssigem maaler das wapen machen lassen. Oder aber ab dem Rathus eines daryn ordnen. Und also uffs glychist ustheilen, damit etwan die armen ouch einen pfenning gewünnen, doch das maaler und glaser flyssige und gute werschaft machend. Ouch das ein jeder unser Buwmeister gmeiner unser Statt büwen glaserwerch nach billigkeyt und gstalt der sachen ze machen ustheilen, wie dann ein jeder hierinn die bescheidenheyt ze haben wol wüssen wirt.

Und wellicher under inen, den meisteren glasmaleren und glaseren diser artigklen einen oder mer übersehe und uns geleidet würde, den wollent wir zu gmeiner unnser statt handen gebürlich strafen. Doch mit dem vorbehalt söllichs alles je zu zyten nach gstalt der sachen und louffen widerumb zu endern, $\mathrm{zu}$ mindern unnd $\mathrm{zu}$ meeren als unns bedünkt die notturft das erfordern werde. Und das alles zu waarem urkundt so haben wir unser statt Zürich secret insigel uf ir der meister glasmaler und glaser handwerchs begeren offenlich gehennkt an diesen Brief, der geben ist Samstags den 5ten hornung nach der gepurt christi gezalt fünfzehn hundert sechzig und nün jar."1) „Leider“ haben die Alten die herrliche Einrichtung des Submissionswesens nicht gekannt, sonst wäre der Ring aller Konkurrenzblüten von heute geschlossen.

In den modernen Betrieb der Glasmalerei hat das Submissionswesen schweres Unkraut gesät. An sich ist die Glas-

1) Meyer a. a. O. Seite $335 \mathrm{ff}$. 
malerei als Kunstgewerbe überhaupt kein Gegenstand für Submissionen. Sie wäre es, wenn auch heute bloß die handwerkliche Arbeitsleistung und das Rohmaterial bezahlt würde. Und selbst in diesen Punkten ist eine so große Spannung möglich, daß Schwankungen $z$ wischen dem ein- und sechsfachen vorkommen. Mit der fortschreitenden Kartellierung der Glashütten wird das Material in der Kalkulation und daher in dem Angebot allerdings immer weniger einen nennenswerten Faktor bilden, aber selbstverständlich vorausgesetzt, daß sämtliche Konkurrenten nur erstklassiges Glas verwenden. Mehr Verschiebungen können die Spesen bringen, die bei den verschiedenen Anstalten sehr von einander abweichen. Von ausschlaggebender Bedeutung müßte eigentlich allein die künstlerische Qualität eines Fensters sein. Jeder Bauherr oder Bauleiter, überhaupt jeder Besteller sollte wissen, daß die Honorare für eine wirkliche gute Sache so hoch sind, daß man um wenig Geld nichts Wertvolles mehr bekommen kann. Mir sind Submissionsspannungen zwischen 2000 und I600o Mark bekannt geworden und dabei hat jene Anstalt, die um 2000 Mark sich anheischig machte, eine sehr gute Skizze eingereicht. Das ist für viele Auftraggeber verfänglich, da sie über gute und zugleich billige Skizzen gegenüber von guten und teuren Skizzen zu entscheiden haben. Auf den Moment, in dem Entwürfe zu Glasgemälden eingeliefert werden können, harren die Glasmalereianstalten meist in großer Zahl. Bei einem mäßigen Auftrag wurden einmal über 60 Angebote gezählt. Die eingesandten Skizzen sind fast durchweg gut, so daß der Preis den Ausschlag gibt, da niemand einsieht, warum ein gleich guter Entwurf nicht dem zur Ausführung übertragen werden soll, der ihn um ein billigeres liefern will. Denn daß in der Ausführung ein gewaltiger Unterschied herrscht, ist eine Erfahrung, die bei den allerwenigsten Auftraggebern vorausgesetzt werden kann. Das weiß auch der alles unterbietende Unternehmer und auf diese Unkenntnis seiner Kunden baut er seine Absicht auf. Ist ihm das Fenster zugeschlagen, so führt er es innerhalb der von dem geringen Preis gezogenen Leistungsgrenze auf, liefert ab, setzt ein, bekommt sein Geld und geht. Nicht selten werden die geringen Angebote mit hochklingenden Phrasen garniert: Es sei dem Glasmaler mehr um die Ehre zu tun, für einen 
bestimmten Bau eín Glasgemälde ausführen zu dürfen, und er trage nur die Selbstkosten. Es darf rühmend anerkannt werden, daß der Widerstand gegen derartige Submissionsblüten aus den Kreisen der ernst und ehrlich denkenden Glasmaler organisiert wird. Auf seinen Hauptversammlungen hat sich der Verband deutscher Glasmalereien wiederholt mit der Frage beschäftigt, wie man der Hydra des Submissionswesen am schnellsten und gründlichsten Herr wird. Übereinstimmend mit anderen kunstgewerblichen Korporationen, die unter demselben Übel zu leiden haben, erkennt der Verband deutscher Glasmalereien die einzigen Mittel zur Abhilfe in der unausgesetzten Aufklärung des Publikums und in der Aufstellung von Sachverständigen. Aus diesem Grund, der Aufklärung des Publikums, haben auch wir an diesem Ort eingehend $z u$ der Frage Stellung genommen, indem wir gleichzeitig berücksichtigten, daß ohne die grundsätzliche Lösung des Problems die stetige Fortentwicklung des Kunstgewerbes ständig bedroht ist. Darum hat sich bereits das preußische Abgeordnetenhaus und dann auch der Hansabund eingehend mit Besserungsvorschlägen beschäftigt, die auf dem im Sommer I9I 2 abgehaltenen Delegiertentag des Verbandes deutscher Kunstgewerbevereine von Professor Dr. Haupt-Hannover einer eingehenden Würdigung unterzogen wurden. Seine Vorschläge faßte er in die von dem Delegiertentag einstimmig angenommene Resolution zusammen: „der Delegiertentag begrüßt die von Regierungen, Behörden und Vereinigungen unternommen Schritte, die Übelstände zu beseitigen, die dem öffentlichen Verdingungswesen bis jetzt anhaften. Der Delegiertentag sieht darin eine gebieterische Notwendigkeit, daß dies Ziel baldmöglichst erreicht werde, in der Überzeugung, daß das zukünftige Gedeihen des Handwerks und damit des Kunstgewerbes in erheblichem Maße von dieser Regelung abhängen wird. Als wichtigste Punkte betrachtet der Delegiertentag, daß kunstgewerbliche Arbeiten nur der beschränkten Submission oder auch der freihändigen Vergebung unterliegen, daß in der Ausschreibung, Übertragung und Abnahme von Arbeiten, die das Kunstgewerbe herstellt, Sachverständige wirksam sind, daß der Zuschlag keineswegs ausschließlich an den Mindestbietenden, sondern nur an solche erfolgt, die die Gewähr für eine preiswerte und gediegene Arbeit leisten, daß die Regelung des öffent- 
lichen Verdingungswesens durch Reichsgesetz und, falls dies nicht möglich ist, durch Landesgesetze veranlaßt wird. Bei beschränkten Ausschreibungen sind die Selbstkostenpreise für Modelle, Skizzen usw. nach besonderen Taxen von Sachverständigen von den Ausschreibern zu bezahlen. Die Überwachungsämter sollen die richtige Handhabung des Verdingungswesens beaufsichtigen." Bis zur gesetzlichen Regelung des Submissionsverfahrens möge sich der Auftraggeber an folgende praktische Winke halten: Die eingelieferte Skizze darf nicht allein, ja nicht einmal in erster Linie entscheiden. Darum beschränke man die Zahl der zugelassenen Skizzen, ich meine, der etwa bestellten Skizzen. Letztere müssen übrigens laut der Eisenacher Ordnung, die von den Gerichten schon wiederholt für Entscheidungen als bindend angesehen wurde, nach einer bestimmiten Taxe bezahlt werden. Die Eigenart eines Auftrags verengt von vornherein den Kreis der in Betracht kommenden Glasmaler. Es gibt zwar Institute, die schlechthin alles machen; gleichwohl lehrt die Beobachtung, daß sich auch unter den Glasmalern gewisse Spezialitäten ausgebildet haben. Eine genaue Norm, nach der man den Preis für Glasmalereien tarifmäßig festlegen könnte, ist freilich nicht möglich, immerhin aber kann man unter den heutigen. Verhältnissen ein gewisses Preisminimum definieren, unter dem eine künstlerisch und technisch solide Arbeit einfach unmöglich ist. Dieses Minimum beträgt für den Quadratmeter einfach figürlicher Glasmalerei I 50 Mark, wobei die Versendung und Einsetzung nicht gerechnet sind. Wer schon einmal der schönen Sitte buntfarbigen Fensterschmucks Eintritt in sein Haus verschafft, der lasse ihr wenigstens die Möglichkeit, in ihrem echten strahlenden Feierkleid zu erscheinen. Wenn kein Bauleiter mehr die Hand zu einem Fenster bietet, das unter dem genannten Preisminimum hergestellt werden soll, wird Pfuscherarbeit sehr schnell verschwinden. Für die meisten Auftraggeber ist es sehr schwer, zu kontrollieren, ob ein Fenster jene techniche Vollkommenheit besitzt, die man von jeder Arbeit verlangen müßte. Darum übergehe man unter allen Umständen unterbietende Firmen und wähle solche Glasmaler, von denen man die Garantie hat, daß sie solide Arbeit liefern. Die moderne Konkurrenz hat den Erfahrungssatz geprägt: Weitaus die meisten Geschäftsleute geben mit ihren 


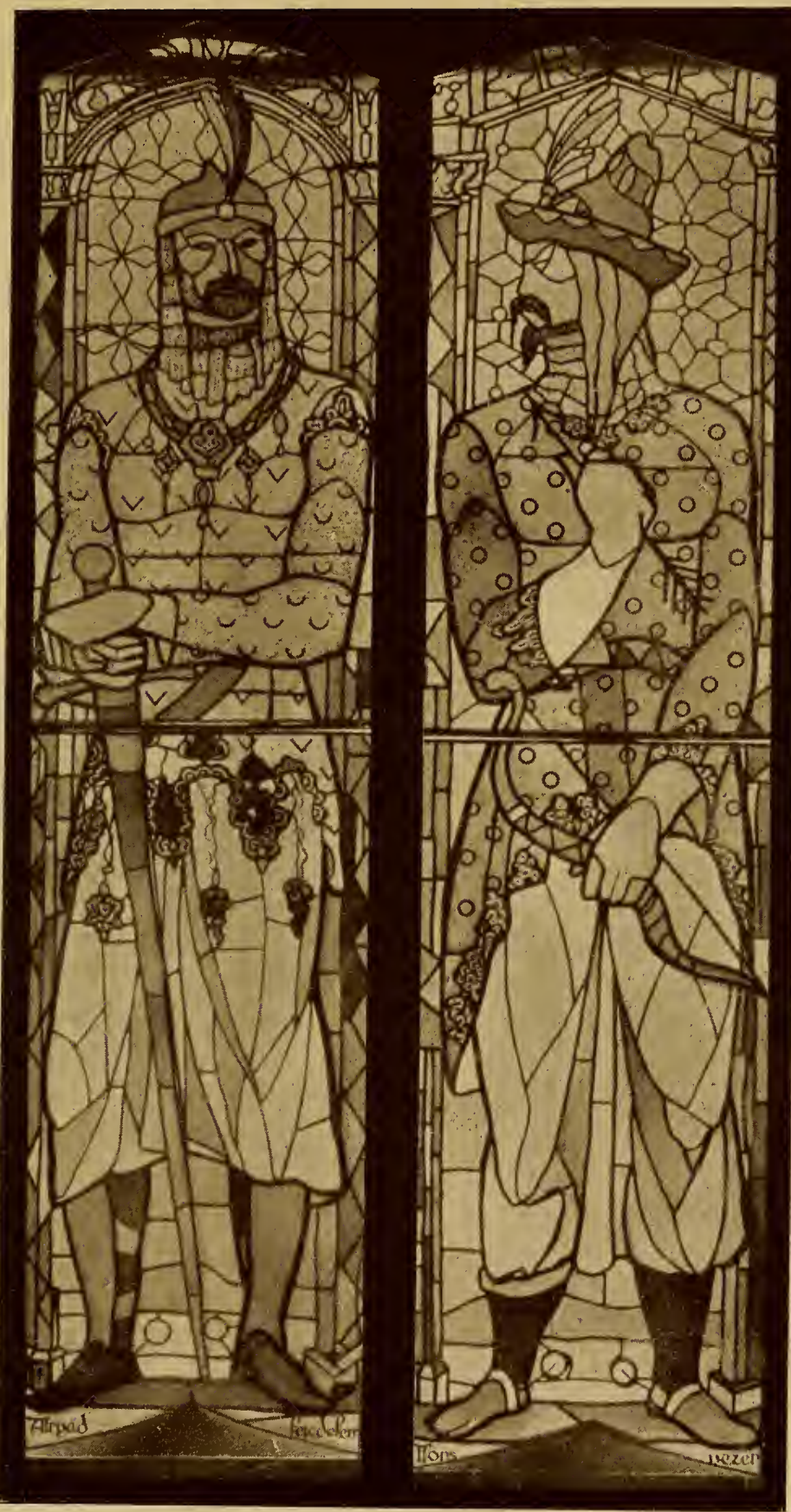

Glasgemälde, entworfen von Karl Kernstock, ausgeführt von Gedeon Walther in Budapest. 

Kostenanschlägen die unterste Grenze, unter die sie nicht mehr herunter können, wenn sie einerseits gute Qualitäten liefern und anderseits den bescheidensten Verdienst haben wollen. Genau so verhält es sich mit der Glasmalerei, bei der, wie immer wieder betont werden soll, doch künstlerische Gesichtspunkte den Ausschlag geben müssen. Wer auf dem Gebiete der Technik nicht Bescheid weiß, ziehe einen Sachverständigen bei, der nicht selbst ausübender Glasmaler ist, damit er sicher gehen kann, ein von nichts beeinflußtes Urteil zu bekommen. Zum Beweis für die Wichtigkeit des Preisminimums möchte ich nochmals unseren alten Bekannten und Fachmann reden lassen, den Maestro Antonio da Pisa. Er weiß „über die Art sich bezahlen zu lassen“ folgendes zu berichten: „Ich will dich über die Art der Bezahlung von Glasfenstern unterrichten und zwar in dreierlei Form. Wenn du ein Figurenfenster ausführen willst, so beherzige dies: Berechne was das Glas kostet, die Bemalung, die Bleie, Eisen und alle Spesen, die dazu gehören. Soviel Geld bring für deine Person in Anrechnung, als die Gesamtausgaben betragen. Übernimm nie, wenn du auskommen willst (si te vuoi salvare), für weniger als 4 Gulden die florentinische Elle, wenn es sich um ein großes Figurenfenster handelt. Für Einzelfiguren ist das allerwenigste $3 \frac{1}{2}$ Gulden, Gruppen aber werden mit 5 Gulden berechnet, (zum allermindesten $4^{1} / 2$ Gulden). Wenn du billiger arbeiten wolltest, so würdest du nichts verdienen. Zwei Gulden pro Elle müssen berechnet werden, wenn der Auftraggeber alle Ausgaben trägt für Blei, Eisen und Netz (das netzartig geschnittene Glạs, also kurz) das Glas und die Gerüste zur Ausführung der Arbeit.“ Der Quadratmeter figürlicher Glasmalerei kostet darnach I60-200 Mark. Antonio mahnt schon zur Vereinfachung der Spesen: „In dem Ort, wo du arbeitest, arbeite stark und bleibe an jenem Ort als Arbeiter und reise nicht, wenn du verdienen willst, sonst würdest du nichts erübrigen, und wenn dir doch eine große Arbeit von Nutzen unter die Hände käme, außerhalb des Ortes, an dem du dich niedergelassen hast, so gehe und mache sie und dann kehre zurück an deinen Wohnort und schnell. Wenn man Ehre von der Kunst haben will und die Kunst gut ausüben, muß man ansässig bleiben. Und mache dich nicht über die Kunst der Gasmalerei lustig, 
welche dich gut ernährt, guten Profit bringt und Nutzen und Ehre."

Wenn so bereits Antonio für eine Mindestbezahlung eintritt, so gilt dies um so mehr für unsere Zeit, die Zeit des einseitigsten Submissionswesens. Antonio setzt für reinen Werklohn pro Elle $=0,25$ Quadratmeter 2 Gulden fest, sodaß sich Material und Arbeit in gleichem Wertverhältnis bewegen. Dieses Verhältnis kann heute nicht mehr aufrecht erhalten werden, auch ist für den Mindestpreis von 160 bis 200 Mark nur eine zwar gute und solide, aber keineswegs außergewöhnliche Arbeit zu erwarten. Wo besondere künstlerische Qualitäten verlangt werden, muß das in der Regel nicht kleine Honorar für den Karton eigens bezahlt werden.

Die Geldquellen, aus denen man die Kosten für ein Fenster bestritt, waren im Mittelalter verschiedener Art, soweit die äußere Form in Betracht kommt. Denn, vom äußeren entkleidet, war es schließlich nur eine Quelle, nämlich die Mildtätigkeit der Gläubigen. Diese floß entweder direkt als Stiftung für ein bestimmtes Fenster, oder aber der Glasmaler wurde aus dem Säckel der Kirchenfabrik bezahlt. An Fensterstiftungen beteiligte sich Hoch und Nieder, Einzelpersonen und Korporationen. In Chartres stifteten Metzger, Bäcker, Sattler, Zimmerleute, ja sogar die Geldwechsler und Münzknechte, je ein Fenster, aus der Ulmer Münstergeschichte kennen wir das Marner- und Kramerfenster. Es verdient hervorgehoben zu werden, daß die Fenster nicht wie heute nach Vollendung des Baus, sondern schon während desselben gestiftet und ausgeführt wurden. Sehr häufig wendete man im Mittelalter Geldstrafen der Anfertigung von Glasfenstern zu. So wurde beispielsweise die Baronin de Heese im Jahre I 436 von der Stadt Brüssel verurteilt, Ioo ryders d'or für ein Glasgemälde zu bezahlen. Eine solche Buße wäre auch heute von großem Vorteil für die Glasmalerei, da die Stiftungen und staatlichen Geldmittel äußerst spärlich fließen. Doch scheint die Zeit nicht mehr ferne zu sein, daß, für öffentliche Bauten wenigstens, die Glasmalerei als integrierender Bestandteil des Bauprogramms angesehen wird. Wenn das erreicht ist, werden die Kosten der Glasmalerei, wie die für ein anderes Bau- und Ausstattungsglied, von vornherein in den Baufond hinein kalkuliert, wie einstens bei den großen Bauten des Mittelalters. 


\section{VII. \\ Das Glasgemälde als Sammelobjekt. Echt und falsch.}

Viel später als sich das Augenmerk kunstliebender Fürsten auf den Erwerb guter Tafelgemälde oder auf Werke der Goldschmiedekunst gerichtet hat, begann man mit dem planmäßigen Sammeln von Glasmalereien. Es war auch nicht so leicht, die nötigen Fensteröffnungen $\mathrm{zu}$ finden, die einer auch nur einigermaßen bedeutenden Sammlung Raum boten. Mehr wie bei allen andern Gebieten der Kunst gab in der Sammlung von Glasmalereien das praktische Bedürfnis den Ausschlag. Man wollte in der guten alten Zeit, die zu wenig fruchtbar war, um Neues zu schaffen, gleichwohl nicht auf die Stimmung verzichten, die buntfarbiger Fensterschmuck dem Raume gab. So erwarb man, und wahrlich um billiges Geld, was gemeinhin als wertlose Ware, ja als Spielzeug für Kinder, umher lag. Es ist darum nicht merkwürdig, daß die Anfänge des Sammelns von Glasmalereien mit jener Zeit zusammen fällt, in der die schöpferische Tätigkeit auf dem Gebiete des Glasmalens aufhörte. $\mathrm{Zu}$ den frühesten systematischen Sammlern gehört Fürst Leopold Friedrich von Anhalt-Dessau, der in den Jahren I 780-90 mit Hilfe Lavaters eine große Sammlung anlegte, die heute das Gotische Haus zu Wörlitz ziert. Außer vielen Schweizer Scheiben, unter denen die Serie vom verlorenen Sohne aus der Murerwerkstatt in Zürich zum Schönsten gehört, besitzt das gotische Haus bedeutende süddeutsche Arbeiten aus der spätgotischen Zeit. Einen ähnlichen kompilatorischen Charakter trägt die Sammlung des Fürsten zu Oettingen-Wallerstein in Maihingen. In 14 Spitzbogenfenstern finden sich allerhand Scheiben teilweise in verstümmeltem Zustande, der durch den 
Unverstand des die Einglasung besorgenden Handwerkers manchmal geradezu barbarisch wirkt. Zwei Fenster enthalten je zwei Rundscheiben im Frührenaissancecharakter, die nach einer, allerdings unverbürgten Tradition aus Regensburg stammen. Unter den deutschen Kabinettsscheiben ragen eine prachtvolle Volckamerscheibe, eine Scheibe des Bischofs Christof von Eichstätt (I 536), eine Oettingen-Wappenscheibe im Charakter des Nürnberger Frühbarocks und zahlreiche Rundscheiben aus der Spenglerwerkstatt in Konstanz hervor. Von den Schweizerscheiben stammen zwei aus der Murerwerkstatt, zwei weisen auf Niklaus Bluntschli, zwei stammen von Melchior Schmitter aus Wyl, vier aus dem Kreise der Nüscheler. Außerdem ist ein bisher unbekannter Meister vertreten, nämlich der Glasmaler Marx Grimm aus Schaffhausen mit einer Scheibe aus dem Jahre I599. Dieser Werkstatt ist auch, nebenbei bemerkt, die Scheibe des Conrad Baldenhofen 1603 zuzuweisen, die sich im Bayrischen Nationalmuseum befindet (vgl. Schinnerer, Katalog No. 226) ${ }^{1}$ ).

In der Sammlung zu Hohenschwangau²), die König Maximilian II., als bayrischer Kronprinz unter Mithilfe des Rektors Beyschlag von Augsburg im Anfang des i9. Jahrhunderts angelegt hat, überwiegen ebenfalls die Schweizer Scheiben. Unter ihnen heben wir die prachtvollen Scheiben aus der Parabel vom verlorenen Sohn (Murerwerkstatt), eine große Serie von Arbeiten des Hans Jegly aus Zürich hervor, ferner besonders schöne Glasgemälde aus der Werkstatt der Nüscheler, dem Atelier des Daniel Lindtmeyer aus Schaffhausen. Die deutschen Arbeiten sind zwar an der Zahl bedeutend geringer, aber desto wichtiger für die Geschichte der Glasmalerei. Durch archivalische Forschung ließen sich zwei Scheiben des Hofglasers Paul Loth, dem Vater des bekannten Malers Ulrich Loth feststellen, die im Jahre I6I4 als herzogliche Stiftung für das Kloster Einsiedeln entstanden sind. Kronprinz Maximilian hat die Sammlung aus der reinen Zuneigung zu dem Schönheitsgehalt der Glasmalerei und deren dekorativen Kraft angelegt. Darum ließ er nichts restaurieren

1) Fischer, Zwei Scheiben der Schaffhausener Glasmalerfamilie Grimm. Zeitschr. t. alte und neue Glasmalerei I9I3, S. I2 If.

2) Fischer-Zettler, Alte Glasgemälde im Schloß Hohenschwangau. I9I2. 
oder auffrisieren, sondern in ihrer unbefleckten Schönheit und Wirkung in die einzelnen Fensterflügel einsetzen. Im Schloß verteilt bilden sie dessen schönsten Schmuck, an den die Farben der Maler um König Ludwig I. nicht heranreichen.

In dem gräflichen Schloß zu Erbach ist seit einem Jahrhundert eine Sammlung untergebracht, die zwar kein geschlossenes Gesamtbild irgend eines Gebietes der Glasmalerei gibt wie die Sammlungen zu Friedrichshafen und Heiligenberg, durch die Qualität der einzelnen Scheiben aber zu den bedeutendsten Sammlungen gehört. Eine Serie spätgotischer Rundscheiben, die der Schule des Hans Wild zugeschrieben wird, eine Gruppe von frühgotischen Glasgemälden, die aus Wimpfen stammend, jene Stufe der monumentalen Glasmalerei darstellend, die das System der französischen Glasmalerei um I300 wahrscheinlich durch. Vermittlung der Bettelorden nach Deutschland verpflanzt, eine Anzahl deutscher und schweizerischer Kabinettsscheiben, meist in sehr gutem Zustand, bilden den Grundstock der Sammlung. Von ihr wird, wie von der Sammlung auf Schloß Heiligenberg in Bälde eine Monographie erscheinen. ${ }^{1}$ )

Diese Sammlungen werden als Fideikommißgüter für längere Zeit beieinander bleiben. Da sie sämtlich unter gewissen Bedingungen dem Studium zugänglich sind, geben sie nicht nur ein wertvolles Material für das kunstwissenschaftliche Studium, sondern vor allem für das Verständnis der Farbenmystik und des wahren Wesens der Glasmalerei. In den meisten Sammlungen sind Restaurationen in größerem Stil nicht vorgenommen worden und darum bieten sie auch für das Studium von echt und falsch die gediegensten Beispiele.

Das auf dem Markt vorhandene Material echter Glasmalereien ist gering. Zwei Drittel davon dürfte in den Händen privater Sammler vorübergehend aufgespeichert sein. Am größten war der Besitz des Lord Sudeley, der vor zwei Jahren in München zur Versteigerung kam. Zuvor hatte der beste Kenner der

1) Wir haben bei Aufzählung der Sammlungen von den Sammlungen des Staates und einzelner Städte abgesehen, da die größeren bereits in Bearbeitungen und Katalogen bekannt sind. Auch von jenen haben wir Abstand genommen, die bereits versteigert wurden (z. der Sammlung des Fürsten Wolfegg-Zeil, versteigert 1913 in Müuchen, der Sammlung Oppenheim usw.). 
Schweizerscheibe Hans Lehmann die Sammlung in einem für die künftige Erforschung der Schweizer Kabinettsscheibe grundlegenden Katalog dem Studium zugänglich gemacht. Im übrigen mag die Zahl der bedeutenderen Privatsammlungen sich auf ein Dutzend belaufen, von denen zwei in der Kölner Gegend, zwei in Salzburg, eine in Wien demnächst eine wissenschaftliche Bearbeitung erfahren sollen. Die staatlichen und städtischen Sammlungen biëten nur in ihrem Gesamtbild halbwegs geschlossene Reihen irgend einer Periode der Glasmalëreien; wenn auch der Grundstock einer jeden Sammlung aus der näheren und entfernteren Umgebung stammt, so befinden sich daneben zahlreiche, vereinzelte Fremdlinge aus allen Himmelsrichtungen. An sich wäre ja das Ideale, wenn die museale Sammeltätigkeit auf die Vervollständigung des Gebietes beschränkt bliebe, das man billiger Weise nach den Tendenzen des Museums erwarten darf. Im Interesse geschlossener Reihen müßte man sogar einem Austausch der entsprechenden Stücke - unter den einzelnen Museen - das Wort reden, was freilich durch andere Gesichtspunkte unmöglich gemacht wird. Immerhin läßt sich durch die allmählich sich ausbreitende Praxis wissenschaftlicher Kataloge eine große Vollständigkeit in der Nutzbarmachung des noch vorhandenen Materials erreichen. Eine Reihe wertvoller Kataloge sind in den letzten Jahren erschienen, so über die Sammlung des Germanischen Museums zu Nürnberg, der Vaterländischen Altertümer zu Stuttgart, des Bayrischen Nationalmuseums zu München, des königlichen Kunstgewerbemuseums in Berlin, der Schweizerscheiben des Louvremuseums in Paris. Über die literarische Bedeutung dieser Arbeiten findet sich das Nähere in dem Kapitel: Die Glasmalerei als Gegenstand der wissenschaftlichen Forschung.

In der Gegenwart ist das Sammeln alter Glasmalereien wohl das Zeichen erlesenen Geschmacks und großen Verständnisses. Allein die Seltenheit guter alter Scheiben erschwert das einfache Sammeln. Denn die auch auf dem Gebiet der Glasmalerei in unerhörtem Schwung befindliche Fälschung ist nur durch lange Übung mit Sicherheit von echten Stücken zu unterscheiden. Darum geht das hauptsächliche Bestreben des Sammlers dahin, die Glasgemälde nicht mehr um ihrer selbst willen zu erwerben, 
als vielmehr in der Absicht, ihre mit den Mitteln vergangener Zeiten ausgestatteten Räume durch ein paar schöne, alte Scheiben stimmungsvoll $\mathrm{zu}$ machen und $\mathrm{zu}$ vervollkommnen. Es wird ja der Tag kommen, an dem erste Qualität von Scheiben zu einigermaßen erschwinglichen Preisen nicht mehr zu haben ist und es sich darum frägt, ob man nicht viel eher erste Qualität moderner Scheiben erwerben soll. -

Die außerordentlich hohen Preise, die für gute Glasgemälde bezahlt werden, halten schon seit mehreren Jahrzehnten gewisse Fälschergruppen in Arbeit, die um so rentabler ist, als der tatsächliche Bestand an gutem altem Material sehr knapp ist. Dazu kommt, daß gerade bei Glasgemälden die Unterscheidung zwischen echt und falsch große Schwierigkeiten bereitet. Denn es gibt nicht gerade wenig Glasmaler, die "Kopieen“ alter Glasgemälde verblüffend gut herstellen können. Da die meisten Glasgemälde im Laufe der Jahrhunderte ein- oder mehreremal neu verbleit wurden, bietet also das Bleinetz von vornherein keinen Anhaltspunkt. Nur in den seltensten Fällen werden Anachronismen der Technik das Geheimnis des Fälschers entlarven, z. B. die Verwendung des Silbergelbs auf romanischen Glasgemälden, Ätzungen (statt Ausschliffe), andere Glassorten als Antikglas, Diamantschnitt, obwohl ich sämtliche Fehler sogar auf Scheiben renommierter Sammlungen beobachtet habe. Dagegen bildet dünnes, ebenes Hüttenglas stets Anlaß zu ernsten Bedenken. Das Glas der Alten war dick, massig, uneben, starkschlierig; trotz aller Fortschritte der Modernen, kann das Glas der Alten mit seiner naiven Empirie nicht erreicht werden, obwohl oder vielmehr weil die moderne Technik mit den Rezepten der exakten Chemie an die Bereitung des Glases geht. Das ist nun kein Tadel der modernen Glashütten. Je weniger im Gegenteil die Glashütten das alte Glas zu kopieren trachten, desto größere Dienste leisten sie der modernen Glasmalerei und desto mehr verderben sie der Fälschung das Handwerk. Man wende dagegen nicht ein, die möglichst getreue Kopie alten Glases sei zur Restaurierung alter Glasgemälde erforderlich. Auch derjenige, der für das System der Restaurationen das weiteste Herz hat, verzichtet gern auf jede erstrebte sklavische Übereinstimmung mit den Zufälligkeiten des Materials, des Brandes, der 
Handschrift, jene Übereinstimmung, die dem alten Teil des Kunstwerkes gegenüber immer etwas Unmoralisches an sich hat. Die Beschaffenheit des Glases bildet also ein nicht zu unterschätzendes Kriterium für das Alter eines Glasgemäldes. Nur muß man beachten, daß gerissene Fälscher das Glas durch mehrmaliges Brennen „verbessern“, daß sie echtes altes Glas verwenden. Es ist sogar schon vorgekommen, daß von einer schwarzgelben Scheibe minderer Qualität die Kontur der Vorderseite weggeätzt und das Silber der Rückseite gelassen wurde. Die Ränder der geätzten Stellen waren so stark mit Schwarzlot bestrichen, daß es nicht leicht war, die Fälschung zu bemerken. In den seltensten Fällen ist an einer als alt im Handel befindlichen Scheibe alles neu. Fast stets finden sich alte Teile darin, auf die dann mit der Bemerkung hingewiesen wird, die Scheibe sei natürlich ergänzt und restauriert, aber man könne nicht alle neuen Stücke genau angeben. Eine solche Scheibe ist gar nie des Erwerbens wert, da in der Regel auch an den echten Teilen herumgearbeitet ist und meistens ein Nachbrand stattgefunden hat. Bei Kabinettsscheiben bilden die Schwemmfarben einen sehr wichtitigen Betrachtungspunkt. Man übe das Auge an echten Scheiben, insbesondere auf das eigentümliche kristallklare Blau, dessen Nachahmung bei Kabinettsscheiben in der Regel zum Verräter wird.

Bei Führung des Schwarzlots, bei der Art der Radierung haben sich in den alten Werkstätten Traditionen ausgebildet, die auch der gewiegteste Fälscher nicht nachahmen kann. Die Kenntnis dieser Eigenschaften kann aber nur durch das Studium an Originalen erworben werden. Selbst die beste Kopie ist im Detail stets befangen, unsicher; ein einigermaßen geübtes Auge sieht in der Kopie stets das echte Spiegelbild. Die größte Vorsicht ist bei Scheiben geboten, die sogenannten Überzug haben.

Auch die Provenienz bildet kein absolut sicheres Kriterium. Denn es ist wiederholt vorgekommen, daß anstelle der echten alten Scheiben, die zum Ausbessern weggegeben wurden, Kopien zurückkamen, die der Besitzer von den Originalen gar nicht zu unterscheiden vermochte, sich dazu auch keine Mühe gab, da er keine Zweifel hegte. Wenn nun von ernsthaften Glasmalereien in dieser Hinsicht nichts $z u$ befürchten ist, so hat doch die 
3 VAVAVAV VAVAV V V V VAVAL

$>\quad 0.40 .960$ (c)

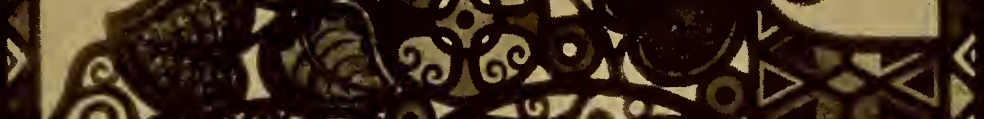

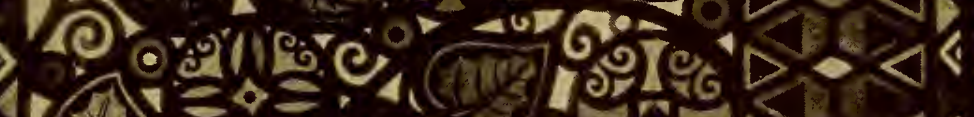

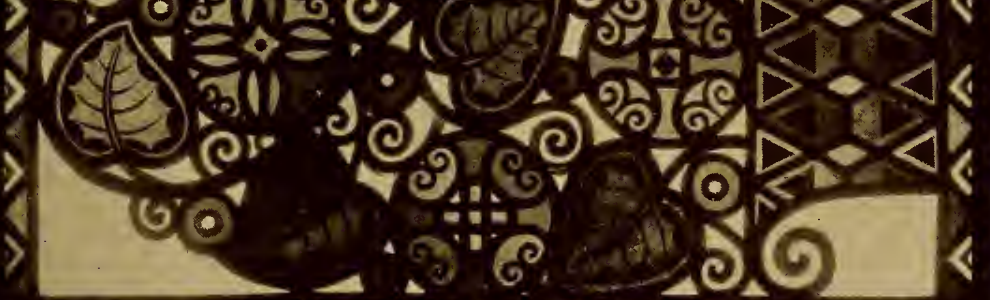

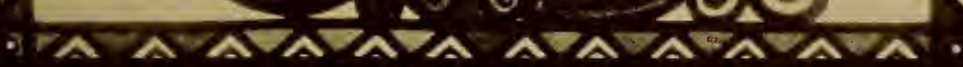
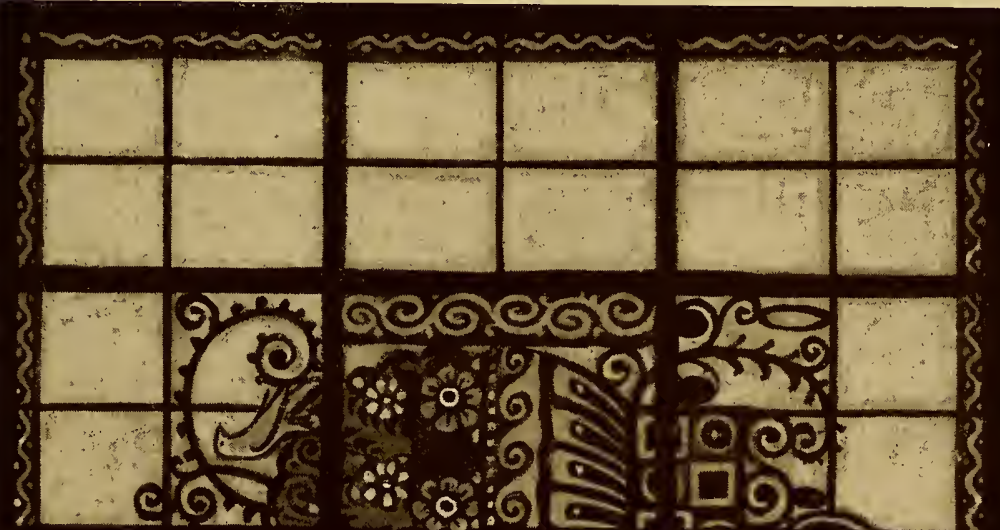

ब०, 0,0

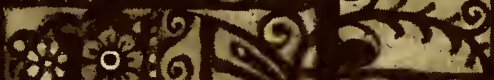

$50: 0$ [10

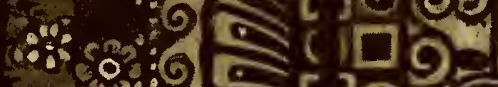
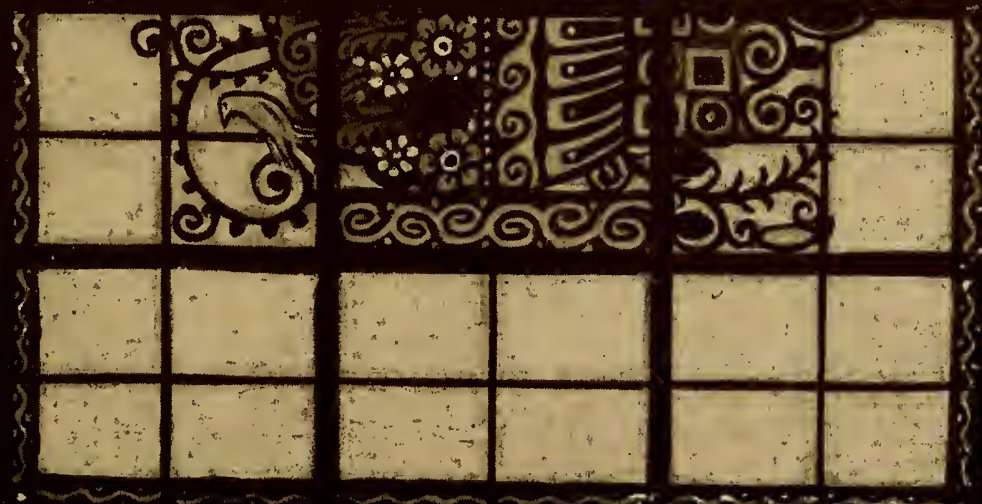

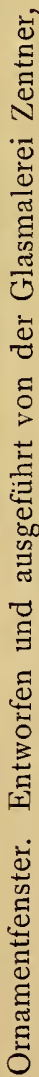



Vergangenheit verschiedene traurige Fälle gezeitigt. So waren vor einigen Jahren die Scheiben aus einem Schloß, in dem sie sich nach den Inventaren seit uralter Zeit befanden, zum Angebot gelangt. Eine nähere Prüfung ergab ihre Unechtheit und es grelang auch festzustellen, daß die Originale nach verschiedenen Irrwegen nun in einem Museum ihre letzte Ruhestätte gefunden haben. Lichtscheue Fälscher machen dabei manchmal die sonderbarsten Mätzchen. So waren mir einst Scheiben zur Begutachtung zugesandt, an denen alle Damasthintergründe entfernt waren. An deren Stelle stand teils ordinäres Fensterglas, teils aber Gläser, auf die ein Damast gebrannt, hernach wieder weg geätzt war. Gingen Zeichnungen über den Damast, so waren diese in Kaltmalerei mit absichtlicher Schlechtigkeit nachgeführt. Es sollte also der Anschein erweckt werden, als sei die Scheibe einem schlechten Restaurator in die Hände gefallen und die Ersetzung der farbigen Damasthintergründe durch Blankverglasung sollte außerdem noch auf die Meinung bringen, der Besitzer habe sich lichte Blicke ins Freie verschaffen wollen. Natürlich war die Scheibe im obigen Sinne gefälscht, daß ein paar alte Stücke, aus anderen Scheiben, wie Inseln in dem weiten Meer der Neuheiten saßen. Noch mehr wie bei anderen Altertümern gilt: Man kaufe nur dann, wenn die äußeren Bedingungen des Verkäufers eine Fälschung für ausgeschlossen erscheinen lassen. Der sicherste Prüfstein der Echtheit liegt in den Fingerspitzen. Die Gläser bekommen durch die Zeit etwas Eigenartiges, das trotz aller Kniffe nicht $z u$ kopieren ist, auch nicht durch wiederholten Brand. 


\section{VIII.}

\section{Die Erhaltung und Wiederinstandsetzung alter Glasgemälde.}

Die sprichwörtliche Vergänglichkeit von Glück und Glas hat nicht jenen Grad von Vorsicht veranlaßt, den man hätte erwarten müssen, um die auch in vergangenen Zeiten hochgeschätzten Glasgemälde vor Zerstörung zu schützen. Steinwurf, Sturm, Hagelschlag sind die gefährlichsten äußeren Feinde, die schon oft traurige Verheerungen unter den ehrwürdigen Arbeiten unserer alten Meister angerichtet haben. Man hat zwar schon in den frühesten Zeiten sich mit breiten Sturmbändern gegen des Wetters Unbill zu schützen versucht, allein noch heute gibt es Kirchen, die über ihre Kostbarkeiten nicht einmal ein sicherungbietendes Schutzgitter gebreitet haben. Windeisen, Schutzgitter, tadellose Verbleiung reichen im allgemeinen hin, um allen äußeren Feinden erfolgreich Trotz zu bieten. Darum haben jene, deren Beruf es ist, über anvertraute Glasgemälde zu wachen, die strenge Pflicht, Windeisen und Schutzgitter von Zeit zu Zeit auf ihre Solidität zu prüfen, da diese gerne rosten oder sonst sich lockern können. Auch das Bleinetz müßte erneuert werden, sobald die Scheibe nicht mehr den festen Zusammenhalt hat, den ihm eine gute Verbleiung gibt. Kunstgeschichtliche Bedenken können nicht maßgebend sein, da das Bleinetz als rein technisches Hilfsmittel nur solange Recht auf Konservierung hat, als es seinen Zweck zu halten und festzufügen, erfüllt.

Außer von Wind und Steinwurf drohen den Glasgemälden noch ernstere Gefahren, die auf Farbe und Zeichnung zielen. Nicht alles alte Glas hat der zersetzenden Verwitterung stand 
zu halten vermocht. Wir reden nicht von jenem Belag, der als Patina den Glasgemälden die stille und geheimnisvolle Stimmung gibt; es handelt sich vielmehr um jene Gläser, deren Oberfläche langsam verwittert. Auch das Schwarzlot steht nicht mit absoluter Haltbarkeit da. Wir sehen von jenen Fällen aber, die auf schlechten Brand und sonstige Sorglosigkeit der alten Glasmaler zurückzuführen sind. Auch das Mittelalter mußte eben die Mischung von solider und oberflächlicher Arbeit erleben. Während auf den einen Fenstern das Schwarzlot noch fest auf dem Grund steht, kann es auf anderen Fenstern von dem unschuldigen Besen eines Fegers in seiner Existenz bedroht werden. Infolge der Einwirkung säurehaltiger Luft, insbesondere solcher, die mit schwefliger Säure gemischt ist, entsteht durch die Zersetzung ein dicker weißer Belag, der die Durchsichtigkeit des Glases aufhebt. Orte, die starke Industrie aufweisen, sind solcher Zerstörung besonders gefährlich. Am meisten haben die Fenster der S. Sebaldkirche in Nürnberg gelitten, offenbar durch die reichlich in die Luft gewanderte schweflige Säure, die sich beim Schwefeln des Hopfens entwickelt. Darum hat man sich eifrig mit der Frage beschäftigt, ob diesem Zerstörungsprozeß Einhalt getan und ob vielleicht das Vernichtete erneuert werden kann. Bei besonders hart mitgenommenen Stücken war die Durchsicht völlig aufgehoben, ohne eine Spur farbiger Wirkung. Der verwitterte Belag war lose auf dem Untergrund, hatte ein poröses, blasiges Aussehen und konnte leicht abfallen. Auf der Innenseite waren die Konturen nicht nur größtenteils verschwunden, sondern auch die wenigen Reste durch den Zerstörungsprozeß losgelöst und ebenfalls stark verwittert. Man stellte nun in der Hofglasmalerei F. X. Zettler zu München umfassende Regenerierungsversuche an, die sich hauptsạ̈chlich auf die Möglichkeit des Wiederanschmelzens der los gewordenen Bemalung bezogen. Es wurde daher der Gedanke einer Überglasung zu verwirklichen gesucht. Da sich das Glas zu einem neuerlichen Brand geeignet erwies, wurde an die Herstellung eines geeigneten Glasflusses geschritten. Die Proben führten zu einem guten Resultat, nachdem es auch gelungen war, das Ausscheiden des restigen Schwefelsäurekalkes aus dem verwitterten Glase beim Brand zu erzielen. Das Glas erhielt durch dieses Verfahren wieder seine frische Farbe und 
Bemalung, sofern es unter der Farbe nicht auch zerstört war. Selbst die Patina kam wieder zu ihrer alten Befestigung an Glasspiegel. Dieses Verfahren ist von den Fachleuten auf seine chemisch-physikalische Gediegenheit geprüft und als sehr geeignet für Konservierung des Glases befunden worden. Auch derjenige, dem alles an der tadellosen Instandhaltung der künstlerischen Form liegt, kann gegen diese Konservierungsmethode keinen Einwand erheben, da sie alles unverändert läßt, nichts hinwegnimmt und nichts hinzutut.

Über die Frage der Wiederinstandsetzung beschädigter Glasgemälde herrscht in den in Betracht kommenden Kreisen erhebliche Meinungsverschiedenheit. Man kann einerseits von der Tatsache ausgehen, daß die Glasgemälde, wie alle anderen kirchlichen Gegenstände, einem religiösen Ziele, ebenso wie der ästhetischen und praktischen Aufgabe, dienen. Die Absicht der Stifter sei dahin gegangen, daß die einzelne Stiftung „ewig“ an seinem bestimmten Platze bleibe und im Falle einer Beschädigung gebessert werde. Es liege daher nicht im Sinne jener frommen Wohltäter, das zu Schaden gekommene.Fenster einfach in ein Museum wandern und sie dann modernen Kopien Platz machen zu lassen. Die Fenster würden doch ihren beabsichtigten Zweck nur dann erfüllen, wenn Löcher und sonstige Schäden vö1lig restauriert werden. Darum sei gegen eine sachverständige Wiederinstandsetzung nicht nur nichts einzuwenden. Man müsse sie vielmehr direkt verlangen; es bleibe nur die Frage offen, wie man für spätere Geschlechter die Restauration kenntlich machen wolle. Zur Stütze dieses Prinzips kann man auf die zahlreichen Ausbesserungen hinweisen, die im Lauf der Jahrhunderte an noch vorhandenen alten Glasgemälden vorgenommen wurden. Dies geschah nicht nur an Kirchenfenstern, die unter allen Umständen unversehrt sein müssen, sondern auch Kabinettsscheiben wurden ausgebessert, obwohl das Bedürfnis nicht so dringend, wie bei der kirchlichen Glasmalerei, war. Verschiedene Glasmaler haben ihre bessernde Tätigkeit ausdrücklich vermerkt. Im Historischen Museum zu Bern befinden sich zwei Scheiben, die in dieser Beziehung sehr lehrreich sind. Auf einer von ihnen, einer Berner Standesscheibe des Jahres I 576 steht zu lesen „erneuwert ANO I62I HRL“ (Taf. IO4); auf der anderen, einer Scheibe 
der Stadt Biel, aus dem Jahre I 576 sind gleich zwei derartige Vermerke: „Das Wapen ward ernüwrett gar (ganz) Im I62 I. jar", auf einem späteren Flickstück: „Diß stuek ward erneuwert I665 per HHL“. Die Alten trugen also keine Bedenken zu bessern, wo es nötig war. Allerdings beziehen sich derartige Restaurationen nur auf kleinere Teile und auf solche Schäden, die durch Unfälle entstanden waren. Was die Zeit abnutzte, wurde nie aufgefrischt oder nachgegangen. Wenn man die Restaurationen betrachtet, die mehr als die Hälfte des vorhandenen Fragments neu geschaffen haben, wenn man vollends die sogenannten "Wiederinstandsetzungen" aus den Jahren i 840 bis I 890 mustert, so wird man wohl begreifen können, daß sich eine starke prinzipiell gegen jede Restaurierung sich wendende Richtung entwickelt hat. Sie will an deren Stelle andere Methoden angewandt wissen. Bei großen Schäden soll das Fragment in die schützenden Hallen eines Museums wandern, wo auch Fragmente ihre ästhetische und kunstgeschichtliche Bedeutung behalten. Eine gelungene Kopie, wenn die Gemeinde sich unter keinen Umständen von dem Gewohnten trennen wolle, besser aber eine im Stil der Gegenwart hergestellte Neuschöpfung möge den Platz des Fragments einnehmen. Bei kleineren Schäden möge man die Lücken mit dem entsprechenden Farbton aus Antikglas verschließen, das aber keinerlei Zeichnung bekommen dürfe. Nur ganz unbedeutende Mackel könne man dem Glasmaler zur Wiederinstandsetzung anvertrauen, was dieser aber in unauffälliger Weise auf den Scheiben anzumerken habe. Diese strenge Richtung ist zweifellos das Ideal, dem der Kunsthistoriker unter allen Umständen seine Zustimmung geben muß. Freilich stößt es, wie alle Ideale, auf die vielen Hemmnisse der Wirklichkeit. Vor allem wird für die Kopie oder Neuschöpfung nicht immer die nötige Summe bereitstehen und die Stimmen derer werden nicht leiser, die neben dem kunstgeschichtlichen Standpunkt auch noch den religiösen und die Pietät auf die Stifter gewahrt wissen wollen. In solchen Fällen wird es wohl am Ende stets zu Kompromissen kommen, die dadurch nicht unbedenklicher werden, daß sie der Staat, wenn ihm der Unterhalt einer Kirche obliegt, gewissermaßen sanktioniert, indem er einfach nach den jeweils herrschenden Grundanschauungen der Konservatorien den Auf- 
trag zur Restauration erteilt. Wenn wir uns in den unmittelbaren Eindruck versenken, den eine solche "restaurationsbedürftige“ Kirche, wie etwa die Frauenkirche zu München macht, so werden wir zunächst gar nicht merken, daß die Fenster restaurationsbedürftig sind. Die Darstellungen sind so klein und so stark mit Patina überzogen, daß wir längere Zeit brauchen, um zu sichten und $\mathrm{zu}$ entdecken, was eigentlich dargestellt ist. Allein der Wohllaut der Farbe, die Symphonie der herrlichsten Akkorde läßt das für Farbenästhetik empfindliche Gemüt gar nicht aus und ehe man sich ans logische Zergliedern macht, hat man den schönsten Genuß im Beschauen, im Versenken in die tiefe Mystik der Farben, in das geheimnisvolle Dämmern des Raums. Gerade das logisch am klarsten Gegliederte, dem Betrachter ohne Mühe sein Thema verratende Fenster, das dem Hans Wild zugeschrieben wird, macht weitaus den schwächsten Eindruck. Was soll nun an den Fenstern dieser Kirche geschehen? Daß Zusammengehörendes wieder vereint wird, dagegen gibt es wohl keine Erinnerung. Sollen etwa entstehende größere Lücken mit neuen Szenen und Scheiben ausgefüllt werden? Wir müssen davon abraten. Setze man zusammen, was sich ohne ästhetische und inhaltliche Bedenken an einander reihen läßt. Kleine Lücken fülle man mit dem zugehörigen Farbton, der mit einem leichten Überzug versehen, die Wirkung nicht stören wird. Was den äußeren Belag betrifft, so hat man mit der sogenannten Reinigung die allerschlechtesten Erfahrungen gemacht. Nicht selten weisen gereinigte Stellen Mängel an der Zeichnung auf, die dann nachgebessert werden, was doch sicher nicht dem Ideal einer zielbewußten Denkmalspflege entspricht.

Wo eine Glasscheibe nicht unbedingt zum Abschluß eines Fensterraums $\mathrm{zu}$ dienen hat, vielmehr gegen Fensterglas hängt oder gehängt werden kann, verbietet sich eine weitergehende Restaurationsarbeit von selbst. Denn für sie kann gar kein praktischer oder religiöser Gesichtspunkt geltend gemacht werden. Bei einer größeren Wiederinstandsetzung sind neue Kompositionen größerer oder kleinerer Gebiete notwendig, bei jeder Ergänzung eines Torso muß die kombinierende Phantasie ins Mittel treten und bei der Ausführung ist der Glasmaler genötigt, fremde Handschriften zu kopieren. Das sind lauter 
Momente, bei denen auch der fähigste und geübteste Glasmaler großen Gefahren ausgesetzt ist. Man hat Thorwaldsen den nachgeborenen Griechen genannt, und es gab wohl keinen Würdigeren, dem man die Ergänzung der Äginetentorsi anvertrauen konnte. Und doch sind die Stimmen nicht verstummt, die an Thorwaldsens Ergänzungen unter Vorlegung sehr gewichtigen Materials energischen Anstoß nehmen. Dabei wird Thorwaldsens Können natürlich nicht geschmälert, so wenig in dieser Debatte verkannt und vergessen sein soll, daß von den vielen Restaurationen, die bisher an alten Glasgemälden vorgenommen worden sind, der größere Teil ein sehr beträchtliches Maß von der Kunst „sich in der Zeiten Geist zu versetzen" aufweist. Allein trotzdem kann der Tag kommen, an dem man über die heute als sehr gelungen anerkannten Restaurationen anders urteilt, da vielleicht ein verstaubter Riß, eine verschollene Visierung aus dem langen Schlaf eines Archivs hervorgezogen wird und so ganz anders über das ursprüngliche Aussehen eines ergänzten Glasgemäldes lehrt. Darum ist das Sicherste, daraufhin zuarbeiten, daß alle Glasgemälde überhaupt nicht in größerem Maß restaurationsbedürftig werden.

Wir wissen wohl, daß sich die Mehrzahl der Menschen an jedem Torso stößt, an ihm nur das sieht, was nicht da ist und darum Ergänzungen an Glasgemälden verwerfen wird, die ohne Kontur und Bemalung, lediglich den Farbton wiedergeben. Für die kunstverständigen Vorsteher der Kirchengemeinde ergibt sich so ein arges Dilemma, das sie nicht selten gegen ihren Willen, aber nach dem Wunsch der Mehrheit in dem Sinne einer durchgreifenden Restauration zu lösen sich für verpflichtet halten. Um dieser nicht ungefährlichen Praxis erfolgreich entgegenzutreten, bedarf es allseitiger A ufklärungsarbeit. Mit einigen guten Willen ließe sich folgende Praxis allmählich einbürgern: Bei kleinen Schäden begnüge man sich mit Ersetzung des Farbtons oder wo nur geringe Konturen, über deren Verlauf ein Zweifel nicht bestehen kann, zu ergänzen wäre, mögen sie von einem kundigen Glasmaler ausgebessert werden. Solange der Schöpfer des Glasgemäldes auf seiner Arbeit noch vollständig allein herrscht und der Nachgeborene keinerlei geistiges Eigentum von sich hinzugibt, kann gegen eine Ausbesserung der Zeichnung nichts eingewendet werden; sobald aber z. B. ganze Köpfe fehlen, geht 
es ohne Eigenarbeit der Restauratoren nicht mehr ab. Wir hielten in diesem Falle für das Idealere, wenn die Lücken mit dem Lokalton ausgebessert würden. Bei größeren Defekten, die eine geordnete Betrachtung unmöglich machen oder wenigstens sehr erschweren, empfiehlt sich eine völlige Ersetzung durch moderne Arbeiten. Die alten Teile können entweder in einem Fenster gegen weitere Zerstörung geschützt, oder aber in einem Museum Unterkunft finden. In allen Fällen gelte als oberstes Prinzip: Das Eigene des alten Meisters bleibe unter allen Umständen unangetastet! 


\section{Die Glasmalerei als Gegenstand der kunstwissenschaftlichen Forschung.}

Wem es Pflicht oder persönliche Neigung zur Aufgabe gemacht hat, alles was in den letzten Zeiten über Glasmalerei geschrieben und geredet wurde $\mathrm{zu}$ verfolgen, der wird beobachtet haben, daß fast allgemein mit einer bewegten Klage über die mangelhafte Pflege der Glasmalerei als Forschungsgebiet eingeleitet werde. Dem ist aber nicht so. Es gab eine Zeit, in der Werke von ungeheurer Kostspieligkeit über Glasmalerei verfaßt und ausgestattet wurden. Die erste Periode der Literatur über Glasmalerei brachte eine große Anzahl französicher Werke hervor, die in den Jahren I840-I870 entstanden sind. Unter ihnen steht an der Spitze die monumentale Arbeit von Martin et Cahier, Les vitraux peints de Saint-Etienne de Bourges. Recherche detachée d' une monographie de cette cathédrale. Paris I 84I-I 844. Auf 72 kolorierten Steindrucktafèln wird in diesen Riesenwerk eine sehr gelehrte Abhandlung über die frühromanischen Glasmalereien Frankreichs geboten, die nun zwar in mehr deskriptiver Weise das hagiologische der Fenster beschreibt, aber schon recht bemerkenswerte Anläufe zu kritischer Forschung über den Kunstkreis und die Künstler der romanischen Zeit macht. Um dieses große Werk gruppieren sich zahlreiche kleinere Sonnen und Sterne, auf denen man zerstreut eine größere oder geringere Fülle Materials findet, je nach dem Standpunkt, von dem aus die Glasmalerei betrachtet wird. Aus den zahlreichen Tafeln, die den einzelnen Werken beigegeben sind, läßt sich wohl die Komposition und Farbzusammenstellung ersehen, der Stil und die Technik aber bleiben nicht nur völlig unbekannt, sondern man 
bekommt, da alles auf Zeichnungen beruht, manchmal etwas ganz anders. Darum hat die umfangreiche Literatur nicht den nachhaltigen Einfluß auf die Verbreitung der Kenntnis und weiteren Forschung der Glasmalerei ausgeübt, den man eigentlich hätte erwarten sollen.

Die zweite Periode der glasmalerischen Schriftstellerei setzte vor ungefähr I5-20 Jahren ein. Man kann sie kurz die Publikationsperiode nennen. Die Fortschritte auf dem Gebiet der Photographie, des Lichtdrucks und der übrigen Illustrationsmöglichkeiten veranlaßte einen neuen Gang in die überreichen Gefilde glasmalerischer Schönheiten. Konnte man die Farben auch nur in den seltensten Fällen wiedergeben, so gelang es andererseits, die Zeichnung und die Technik im Bilde völlig getreu festzuhalten. Der begleitende Text begnügte sich vorerst, die Farben usw. zu schildern, machte aber vor der kunstwissenschaftlichen Forschung bewußt oder unbewußt Halt. Auch haben nur wenige Gelehrte und Ästheten versucht, der dem Raumbild dienenden Stellung der Glasmalerei gerecht $\mathrm{zu}$ werden. Viollet le duc scheint der einzige gewesen zu sein, der die Glasmalerei über ihre Besonderheit als kunstgewerbliche Erscheinung hinaus im Zusammenhang mit dem Bau betrachtet hat. Dieser zweiten Periode ist in dem jüngst verstorbenen rheinischen Schriftsteller über Glasmalerei, H. Oidtmann ihr fruchtbarster Vertreter erstanden.

Mit ganz unzureichenden Hilfs- und Vergleichsmitteln hat der Verfasser des Glasgemäldekatalogs des Germanischen Museums zu Nürnberg die deskriptive Methode in das Gebiet der kritischen Forschung vorgeschoben. ${ }^{1}$ ) Bewundernswert bleibt diese Leistung, auch wenn sie in einem Katalog niedergelegt ist, der nur denen etwas sagt, die bereits eine tiefere Kenntnis der Glasmalerei besitzen. Der Verfasser gruppiert das reiche Material nach bestimmten Gruppen und Meistern, wobei sehr häufig Resultate festgestellt werden, die man auch mit besseren Hilfsmitteln wohl ergänzen, aber nicht wesentlich erweitern kann. Nun loderte allmählich an verschiedenen Orten das Feuer der

\footnotetext{
1) Der Verfasser ist der jüngst verstorbene Direktor des Bayrischen Nationalmuseums in München, Dr. Hans Stegmann.
} 
kritischen Methode auf. Man suchte einzelne Glasgemälde mit bestimmten Meistern und Schulen in Verbindung zu setzen, reihte die Glasmalerei in das Gebiet der allgemeinen Entwicklung der Kunst. Dabei ergaben sich schon sehr bald überraschende Resultate. In Einzeluntersuchungen stellten Geiges die Beziehung Baldungs zur Glasmalerei fest, Schinnerer und Hofmann klärten die Nürnberger Glasmalerei um I500, Dirr entdeckte Holbeins Tätigkeit zu Gunsten der Glasmalerei; man fand Jörg Breu, Jost Amman auf Glasmalereien wieder, Pöllmann erkannte die Bedeutung Jerg Zieglers für die Glasmalerei und jüngst traf der Schreiber dieser Zeilen auch Matthias Grünewald unter denen, die für die Gestaltung des Kartons von Einfluß waren. In großartiger Weise wurde von H. Lehmann das Gebiet der Schweizer Glasmalerei behandelt, das zum erstenmal die archivalische und stilkritische Methode mit einander verband. Swarzenski hatte auf die Untersuchung der Beziehungen aufmerksam gemacht, die zwischen der Miniatur und der Glasmalerei bestehen, was später Girodie für das 15. Jahrhundert unternahm. Frankl erforschte das Atelier des Glasmalers Hans Wild und ordnete das Material, das aus dem I 5. Jahrhundert in Bayern und Schwaben noch erhalten ist, nach bestimmten Gruppen. Die Bearbeitung von Glasgemäldekatalogen erweiterte sich allmählich zu kunstkritischen Abhandlungen, so Schinnerers Katalog der Glasgemälde im Bayrischen Nationalmuseum, während die ähnliche Aufgabe, die Leo Balet für die Glasgemälde der Vaterländischen Altertümer in Stuttgart unternahm, der Durcharbeitung und Einordnung in die allgemeine Entwicklung der Glasmalerei entbehrt. Zuletzt hat H. Schmitz, unterstützt von den reichen Mitteln der Orlopstiftung alle bisherigen Vorarbeiten zusammengefaßt und in seinem Katalog der Berliner Glasgemäldesammlung zu einer Geschichte der deutschen Glasmalerei erweitert, stets unter dem von seinem Leher O. v. Falke vertretenen Gesichtspunkt der entwicklungsgeschichtlichen Erfassung der Zusammenhänge der Glasmalerei mit den übrigen Künsten. Der Berliner Katalog ist somit das umfassendste Werk, das unter Verzicht auf die deskriptive Methode in stilkritischer Analyse das vorhandene Material sichtet und lediglich vom kunstgeschichtlichen Standpunkt aus behandelt. 
Im Ausland hat die wissenschaftliche Behandlung der Glasmalerei ebenfalls einen Aufschwung erlebt. Im vorigen Jahr ist aus der kundigen und für die Schönheit der Glasmalerei begeisterten Feder des englischen Glasmalers Maurice Drake ein Buch übèr the History of the English Glass-painting erschienen, das an vornehmer Ausstattung und Reichhaltigkeit des Materials alles hinter sich läßt, was über diese Materie in England je geschrieben worden ist. Aus Drakes Abhandlung ergibt sich die Bestätigung dessen, was auch wir im Verlauf unserer Untersuchung wiederholt konstantiert haben, daß nämlich die englische Glasmalerei ihre Anregungen immer wieder von Frankreich bekommen und nur unbedeutend und vorübergehend auf einige Gebiete des Festlands Einfluß genommen hat.

Die kunstwissenschaftliche, stilkritische Erforschung der Glasmalerei ist somit im schönsten Fluß. Zu einer zusammenfassenden Arbeit in großem Umfang ist jedoch noch ein weiter Schritt. Viele Glasgemälde, die anläßlich einer Restaurierung photographiert wurden, stehen nun, vielleicht auf viele Jahrzehnte, wieder an ihrem Ort, an dem sie nur schwer aufzunehmen sind. Die Vorbedingung für eine großzügige Erforschung und Publikation der Glasmalerei, zunächst deutschen Glasmalerei, dürfte nach unserem Ermessen in der Anlage einer Photographiezentrale bestehen. Dem Schreiber Zeilen standen zur Abfassung seines Handbuches mehr wie tausend Photographien alter Glasgemälde zum Vergleich, und doch bildet diese an und für sich vielleicht große Zahl einen verschwindenden Bruchteil von dem bereits photographierten und unphotographierten Material. Es wäre leicht möglich, eine solche Zentrale zu schaffen, da sich eine große Reihe von Photographien in den Händen von Privaten finden, deren Zusammenarbeit nur Sache einer energischen Persönlichkeit ist. Neben dieser Sammeltätigkeit müßte die $\mathrm{Zu}$ sammentragung aller Archivalien, die in großer Zahl veröffentlicht sind, hergehen. Nirgends ist die rein stilkritische Methode größeren Gefahren ausgesetzt als gerade in der Glasmalerei. So sehr die Publikation einzelner Sammlungen Lob und Anerkennung verdient, so wenig können wir in der Veröffentlichung lokaler Arbeiten eine durchweg erfreuliche Erscheinung erblicken, da der allseitige Vergleich mit dem vorhandenen Material gar 
nicht möglich ist und so das Wichtigste, die Darstellung des Stilzusammenhangs mit der übrigen Glasmalerei und Kunst überhaupt mangelhaft bleiben muß. Alle Mittel sollten daher zentralisiert werden, um ein einheitliches System der Forschung im angegebenen Sinn zu befolgen.

Wir haben die wichtigste Literatur über die Glasmalerei zusammengetragen, um die Detailforschung möglichst zu fördern und $\mathrm{zu}$ erleichtern.

A mé, E., Recherches sur les anciens vitraux incolorés du département de l'Yonne. Paris 1854 .

A msler-Ruthardt, Entwürfe zu Glasfenstern. In Originalzeichnungen alter Glasmaler des 16. u. 17. Jahrhunderts. Berlin 1895.

André, A., De la verrerie et des vitraux peints dans l'ancienne province de Bretagne. Reims, J. Plihon, 1878.

Andreae, Gedanken, Studien und Erfahrungen auf dem Gebiete der Glasmalerei. Vortrag. Leipzig, Naumann, I 888.

Arendt, Ch., Analyse d'un manuscript de 1565 traitant de la technique de la peinture sur verre. Publ. de la féderat. arch. et hist. de Belgique. XVIII. congrès Mons 1904.

Balet, Leo, Schwäbische Glasmalerei. Stuttgart I9I2.

Ballantine, J., A tratise on painted glass, showing its applicability to every style of architecture. 8 plates $(6$ col.). London 1845 . Deutsch von H. Gauss. Weimar I 855 .

Baeschlin, J. H., Schaffhauser Glasmaler des I6. und I7. Jahrhunderts. Schaffhausen. $17 \mathrm{~S}$. I Kupfer.

Barbier de Montault, X., L'arbre de Jesse et la vie du Christ, vitraux du XIIIe siècle à la Cathédrale d'Angers. Angers, Germain et Grossin, 1887. 23 p.

Batissier, L., Traité de la peinture sur verre (en Histoire de l'art monumental). Paris 1845 .

Baveux, Les vitraux de l'église de Brienne-le-château. Compte-rendu au 69. congrès archéol. de France à Troyes.

Bèaupré, Les gentilhommes verriers ou recherches sur l'industric et les privilèges des verriers dans l'anciennc Lorraine. Ed. 2. Nancy 1847 .

Bégin, E. A., Histoire de la Cathédrale de Metz. 2 Vol. Metz I843.

Bégule, L., Monographie de la Cathédrale de Lyon. Lyon r 880.

- Vitraux du muyen-âge et de la rénaissance dans la région lyonnaise. I9II.

Berlepsch, H. E. von, Die Entwicklung der Glasmalerei in der Schwciz. (Zeitschrift des Kunstgewerbevereins.) München 1886.

- Die Glasgemälde im Kreuzgange des ehemaligen Klosters Wettingen. (Kunstgewerbeblatt, 6.) München I 886.

Bertrand, L., Peinture sur verre. Notice sur les travaux de M. Vincent Larcher, Troyes 1845 . 
Bethune, Quelques notes sur l'art de la vitrerie selon la tradition médiévale. Bulletin des comm. Royales d'art et d'archéol. XX.

Birglin, M. E., Les vitraux de M. Maréchal à la chapelle du Sacré-coeur de la cathédrale de Metz. (Extrait des Memoires de la Société des lettres, sciences et arts de Bar le Duc. T. VII.)

Blanquardt, Notice sur les vitraux de Gisors. Ière partie. Les peintres-verriers. (Extrait de Mémoires de la Société historique du Vexin.)

Boeheim, W., Alte Glasgemälde in Wiener Neustadt. (Mitteilungen der k. k. Zentralkommission.)

Bosschere, Les vitraux de Notre Dame d'Anvers. Art flam. et holl. I905.

Bruck, Rob., Elsäßische Glasmalerei. Straßburg I9oI.

- Der Traktat des Antonio da Pisa über die Glasmalerei; verdeutscht. Rep. f. Kunstwissenschaft, Band 25.

Bruyn, Hyac., Notices sur les anciennes et les nouvelles verrières de l'église de Notre-Dame à Bruxelles. I 866.

Bubeck, W., Die Entwicklung der Glasmalerei. (Schweizer Gewerbeblatt.)

Burkhardt, A., Dic Glasgemälde aus der Kirche zu Läufelfingen.

Camesina, A., Die ältesten Glasgemälde des Chorherrnstifts Klosterneuburg und die Bildnisse der Babenberger in der Cistercienser-Abtei Heiligenkreuz.

— Glasgemälde aus dem I2. Jahrhundert im Kreuzgange des Cistercienserstiftes Heiligenkreuz im Wienerwalde.

Caneto, Monographie de la Cathédrale d'Auch.

Carter, O. B., A series of ancient painted glass of Winchester Cathedral XVI century. London I 845 .

Catalog der Douglas'schen Sammlung. Köln I897.

Catalog von Glasgemälden, versteigert bei Hugo Helbing, München I9I2 und I9I3.

Catalog der Sammlung Sudeley rgi2.

Catalog der Sammlung Usteri I 894 .

Catalog der von Zwierleinschen Sammlungen von gebrannten Glasfenstern usw. Mit Io Lichtdrucktafeln. Köln I887.

Caussemaker, J. de, Les anciens vitraux de Flêtre. (Revue de l'art crétien.)

Cecchetti, B., Sulla storia dell'arte vetraria Muranese. Venezia I865.

Champigneulle, C., Le vitrail, conférence faite au palais de l'industrie. Paris, Imprimerie de Bornoil, I 885.

Champollion-Figeac, Peinture sur verre. (Lacroix et Seré. Moyen-âge et renaissance.)

Charles, B., Un atelier de peintres-verriers à Montoire au XVIe siècle. (Extrait du Bulletin de la Société archéologique du Vendômois.) Vendôme, Imprimerie Lemerrier et fils, I879.

Charles, M. H., Les anciennes fenêtres de Cortaillod avec planches d'après Alb. Vouga. (Musée Neuchâtelois, Sept.)

Charles, R., Le vitrail de la compassion de la vierge à l'église de la Ferté-Bernand. (Sarthe).

Chaulnes, de, Notice sur les vitraux de l'église de Notre-Dame de Sablé.

Creutz, M., Johann Thorn-Prikker. Dek. Kunst, I9I3, S. 2 I9. 
Crist ofani, L'iconographie des vitraux du XIll. siècle d'Assisi. Revue de l'art chrétien. 1912.

Dassel, O., Glasmalereien der Familie Dassel, Familiengesch. Blätter II, S. I2. Descamps et Lemaitre d'Anstaing, Les vitraux de la Cathédrale de Tournay. Avec I4 planches dessinées par Capronnier. Bruxelles 1848 .

Des Granges, Ch., Le vitrail d'appartement. Paris 1864 .

Detzel, Alte Glasmalerci am Bodensee und seiner Umgebung. Lindau I89r.

Didot, A., Recueil des oeuvres choisis de Jean Cousin, reproduits en facsimile. 4 pl. Paris I 873 .

Didron, E., Histoire de la peinture sur verre en Europe. (Annales archéologiques.)

Didron et Thibaud, Manufacture des vitraux. Paris s. a.

Drake, M. A., History of English Glass-painting. I9 2.

Dupasquier, L., Monographie de Notre-Dame de Brou. Avec 30 planches dont I 2 en chromo.

Eggert, F., Die I9 Glasgemälde: Darstellungen aus dem Leben Maria in der Maria Hilfkirche in der Münchener Vorstadt Au. 19 Tafeln Lichtdruck. München I845.

- Abbildungen der Glasgemälde in der Salvatorkirche zu Kildown in der Grafschaft Kent. Mit I 5 Tafeln.

Egli, Altromanische Glasmalerei in der Pfarrkirche zu Tabern. Trier Archiv VII.

Elis, C., Handbuch für Mosaik- und Glasmalerei. I 89 I.

Engel, Jul., Die Chorfenster der Elisabethkirche zu Marburg. Antiquitätenrundschau II, Nr. 8.

- Adolf Menzel als Glasmaler. Kunst u. Künstler, 1906, S. 277.

Ertborn, M. van, Recherches sur peinture en verre. Gand 1839.

Ettermann, M., Glasmaler und Glasmalerei im Dienste des Stiftes Bero-Münster. (Archiv für schweizerische Altertumskunde.)

Fastidio, L'arte del vetro. Napoli nobilissima XV. 1906.

Fischer, Josef L., Vierzig Jahre Glasmalkunst. I9II.

Fischer-Zettler, Die Glasgemäldesammlung in Schloß Hohenschwangau. I9I2.

Florival, A. de, et M. Midoux, Le vitraux de la Cathédrale de Laon. ${ }^{3} 6$ p. I6 planches. Paris, Didron, I882.

Fowler, W., Coloured engravings of Roman mosaic pavements etc., also of the stained glasswindows of the cathedrals of York, Lincoln etc. 2 Vol. Fol. With 82 coloured plates. $1796-$ I 829.

Frankl, P., Die Glasmalerei des I5. Jahrhunderts in Bayern und Schwaben. I9I2.

- Der Ulmer Glasmaler Hans Wild. Jahrb. der preußischen Kunstsammlungen, I9I 2 , S. $3 \mathrm{I}$.

Freystadl, A., Über Glasmalerei. (Archiv für christliche Kunst.)

Freytag, F., Vermischte Aufsätze, I903, II, S. 254.

Fromberg, E. O., Handbuch der Glasmalerei oder gründliche Anleitung, die Glaspigmente und Flußmittel darzustellen. Quedlinburg 1844 .

Gailhaboud, J., L'Architecture du Ve au XVIe siècle et les arts qui en dépendent. Paris, Gide et Baudry, I $850-59$.

Galabert, L'église et les vitraux des Caylus. Montauban, Imprimerie Forestier, I 88 I. 
Geiges, F., Der Fensterschmuck des Freiburger Münsters. I - 3. Freiburg, I90 I ff.

- Das S. Annenfenster im jetzigen S. Alexanderchörlein des Freiburger Münsters. Sep.-Abdr. aus den Freib. Münsterblättern, I 908.

Gerin, J., Les vitraux de. la chapelle de l'hospice de Beauvais. Imprimerie Père, I 879. Gessert, M. A., Geschichte der Glasmalerei in Deutschland und den Niederlanden, Frankreich, England, der Schweiz, Italien und Spanien. Stuttgart I839.

- Die. Kunst, auf Glas zu malen und die hiezu nötigen Pigmente und Flußmittel zu bereiten. Nebst einer Anweisung zur Konstruktion des Ofens und Leitung des Schmelzbrandes. Stuttgart 1842.

- Rudimentary treatise on the art of Glass Staining. To which is added an appendix on the art of enamelling.

Geuer, H. J. S., Grisaillemuster und Mosaiken. Sammlung von Mustern für monumentale Glasmalerei. Nebst Auszug aus der Geschichte der Glasmalerkunst. Utrecht, J. R. van Rossum, I 882 .

Gilbert, J., Fragments towards a history of stained glass and the sister arts of the middle ages. With woodcuts and two chromos. London 1840.

Giusto, E., Le vetrate di S. Francesco in Assisi. I9II.

Godard, E., Traité pratique de peinture et dorure sur verre. 7 I p. Paris, Gauthier Villard, I 885 .

Grotefend, Die Zunft der Glaser und Glasmaler zu Frankfurt a. M. Mitteilungen des Vereins für Geschichte und Altertumskunde zu Frankfurt. I88I.

Guerber, V., Essai sur le vitraux de la cathédrale de Straßbourg. Straßbourg, Le Roux, 1848.

Guiffrey, J., La famille de Jean Cousin, peintre et verrier du XVIe siècle. 22 p. Nogent-le-Rotrou, Imprimerie Daupeley-Gouverneur. I 882.

Guillaume, P., Maître Jaques Jouin, peintre verrier à Embrun, I67I. Revue de l'art francais. Juin I 889.

Hafner, A., Meisterwerke Schweizer. Glasmalerei, herausgegeben vom historischantiquarischen Verein Winterthur. 60 Tafeln in Licht- und Farbendruck. Berlin, Claesen, 1888 .

Hancock, The Amateur Pottery and Glass painter. London, Chapman \& Hall, I879. Hasel off, Die Glasgemälde der Elisabethkirche zu Marburg. Max Spielmeyer, Berlin. Haupt, Über dänische mittelalterliche Glasmalereien. Kunstchronik XVIII.

Heinersdorff, G. (und K. Scheffler), Die Glasmalerei. Berlin I9I3.

Herberger, Th., Die ältesten Glasgemälde im Dome zu Augsburg. 6 Tafeln (5 koloriert). Augsburg 1860.

Heuss, Th., Der Künstlerbund für Glasmalerei. Dek. Kunst, 19II, S. I 29 :

Heyne, M., Zur Geschichte der deutschen Glasmalerei (Anzeiger für Kunde der deutschen Vorzeit. Nürnberg I88I.

Hofmann, Fr. H., Das Markgrafenfenster in S. Sebald zu Nürnberg. Hohenzollernjahrbuch IX, 06, S. 67 .

Hucher, E., de l'etude des anciens vitraux peints. Paris 1855.

- Les vitraux peints de la cathédrale du Mans, vitraux des XII, XIII, et XIV es siècles. Avec 100 planches coloriées. Le Mans 1864. 
Hucher, E., La restauration du vitrail de Beillé (Sarthe) aux armes de MontmorencyBois-Dauphin. 6 p. avec fig. Tours, Imprimerie Bousserez, $188_{3}$.

- La restauration de vitraux de l'eglise de Sôbrele Château Nord. I 5 p. avec dessins. Extrait du bulletin monumental. Tours, Imprimerie Bousserez, r 883 .

- Vitraux peints de la Cathédrale du Mans, ouvrage renfermant les reductions des plus belles verrières et la description complète de tous les vitraux. Fol. 20 planches.

Jaennike, Fr., Handbuch der Glasmalerei. Stuttgart 1890.

Janitsch, J., Die älteren Glasgemälde des Straßburger Münsters. (Repertorium für Kunstwissenschaft, III, p. I88o/81.

Jenny, S., Glasgemälde aus Vorarlberg. Mitteilungen der k. k. Zentralkommission I 888.

Jessel, L., Glasmalerei und Kunstverglasung. 6o Tafeln. Berlin, Claesen \& Co., 1884 .

Joyce, J. G., The Fairford Windows. A Monography with 42 plates mostly coloured. Fol. London 1872. Arundel Society.

Klein, J., Kirchliche Kunst. Cartons für Glasmosaik und Tafelmalerei. Einteilung und erläuternder Text von E. Lind. Folge I. Io Tafeln in Lichtdruck. Fol. Wien 1880.

Kolb, H., Glasmalereien des Mittelalters und der Renaissance. Original-Aufnahmen. Stuttgart, Wittwer, $1884 \mathrm{ff}$.

Kunze, H., Bestand und Anordnung der Glasgemälde des Straßburger Münsters um die Mitte des 19. Jahrhunderts und in der Gegenwart. Straßburger Münsterblätter, I9I3. S. 105.

Lafond, Jean, Arnoult de la pointe, peintre et verrier de Nimègue et les artistes etrangers à Rouen aux XV et XVI siècles I9I2.

- Un vitrail d'Engrand le prince etc. Paris 1909.

Lamort, Notice sur les vitraux peints de l'église du Locon. 2 pl. St. Omer 1846.

Langlois, E. H., Essai historique et descriptif sur la peinture sur verre, ancienne et moderne, et sur les vitraux les plus remarquables. I 832 .

Lasteyrie, F. de, Histoire de la peinture sur verre d'après ses monuments en France. Paris $1838 / 53$.

- Histoirc de la peinture sur verre d'après ses monuments du Pas de Calais ct du Nord. 36 p. Amiens, Imprimerie Yvert, 188I.

Lavergne, N., Les vitraux de Claudius Lavergne placés dans l'église de Saint-Cyr au Mont-d'or (diocèse de Lyon). 39 p. Paris, Imprimerie Mersch, I 888.

- Les vitraux de Claudius Lavergne placés dans la cathédrale de Beauvais (Chapelle de Saiute-Anne et de Saint Joseph). I9 p. Beauvais, Imprimerie Père, I 886.

Le Vailland de la Fieffe, O., Les verreries de la Normandie, les gentils hommes et les artistes verriers normands. Rouen 1873.

Le Vieil, P., L'art de la peinture sur verre et de la vitrerie. Paris 1774 . Dcutsche Übersetzung von Harrepeter. Nürnberg I 779/80. 3 Teile.

Lehmann, Hans, Zur Geschichte der Glasmalerei in der Schweiz, Mitteilungen der Antiquarischen Gesellschaft in Zürich. 1903-I9I2.

- Katalog der Sammlung Sudeley, München I9I I.

Fischer, Handbuch der Glasmalerei. 
Lehmann, Hans, Die Glasmalerei in Bern am Ende des 15. und Anfang des

I6. Jahrhunderts, Anzeiger für schweiz. Altertumskunde I9I2-I9I4.

- Die zerstörten Glasgemälde in der Kirche von Hindelbank. Bern I9I3.

Lehnert, H., Anleitung zur Cabinetglasmalerei. 2. Auflage. Berlin, Claesen, I887.

Lenoir, A., Histoire de la peinture sur verre et description des vitraux anciens et modernes, pour servir à l'histoire d'art relativement à la France, ornée de 54 gravures (fable de Cupidon et Psyché d'après Raphael). Paris I803. Musée des Monuments français. Paris 1803.

Lévy, E. et Capronnier, Histoire de la peinture sur verre en Europe et particulièrement en Belgique. Bruxelles I 855 .

Liebenau, Th. von, Hausbuch des Glasmalers F. Fallenter. (Anzeiger für schweizerische Altertumskunde.) I 882 .

- Vom Aufkommen der Glasgemälde in Privathäusern. (Anzeiger für schweizerische Altertumskunde.) I 882 .

- Zur Entstehungsgeschichte der Glasgemälde im Kreuzgange zu Muri. (Anzeiger für schweizerische Altertumskunde.) I882.

- Die Glasgemälde der Benediktiner-Abtei Muri. Aarau I892.

Löw, A., Entwicklungsgeschichte der Glasmalerei. Wiener Bauhütte I.

Lucot, Les verrières de la cathédrale de Châlons en général et plus paticulièrement les verrières des collatéraux. $16 \mathrm{p}$. Châlons-sur-Marne, Imprimerie Thoullin, I 884 .

- Les verrières de la chapelle du petit séminaire de Saint-Memmien-les Châlons. I 2 p. Châlons, Martin, I $88_{3}$.

- Les vitraux de l'église Saint-Etienne. 3 I p. Châlons-sur-Marne, M. Martin frères, I 887 .

Luebke, W., Die Glasgemälde im Kreuzgange zu Kloster Wettingen. Mit 3 Abbildungen. Zürich $\mathrm{I} 86_{3}$.

- Die Glasgemälde im Chor des Klosters Königsfelden. Mit 41 Tafeln. Zürich I867. M., Zur Geschichte der Glasmalerei. Kunstgewerbeblatt. N. F. XVII, I906. S. 163. Magne, L., L'oeuvre des peintres verriers français: verrières des monuments élévés par les Montmorency. Avec I 22 illustrations et Atlas de 8 planches in fol. Paris, Firmin Didot, 1885 .

- Le vitraux de Montmorency. Revue des arts décoratifs. I887.

- Le vitrail. Gazette des Beaux Arts, 1885.

- L'art et les vitraux moderne. L'art decoratif XIX, 1906.

Mancini, Guglielmo de Marcillat. Florenz I9I2.

Mandach, Schweizerische Glasgemälde im Ausland. Anz. f. schweiz. Altertumskunde. N. F. IX.

Marchand, J., Les verrières du choeur de l'église métropolitaine de Tours, avec I 8 planches coloriées. Fol. Tours I 849 .

Martin, Ch., Essai critique et descriptif sur les nouveaux vitraux de l'église NotrcDame de Bourg. 53 p. Bourg, Martin Bottier, 1876.

Martin et Cahier, Les vitraux peints de Saint-Etienne de Bourges. Recherches detachées d'une monographie de cette cathédrale. 72 planches. Fol. Paris I $84 \mathrm{I}-\mathrm{I} 844$. 
Mayer von Mayerfels, K., Die Glasmalereien im ehemaligen Kloster Hofen, jetzigem Sommerresidenzschlosse des Königs von Württemberg. (Schriften des Vereins für die Geschichte des Bodensees.) I 882 .

Maxe-Werly, L., Les vitraux de Saint-Nicaise de Reims. (Extrait de Bulletin du comité des travaux historiques No. 2.) 8 p. et planche. Paris, Imprimerie nationale, I 884.

Meguen, Clamens et Borderau. Quelques lignes sur la peinture sur verre. Vitraux du XVe siècle de l'église de Joné. (Maine et Loire.) I 2 p. Angers, Imprimerie Lachère et Dolbeau, I881.

Meiss, Das Tagebuch des Glasmalers Christof Brandenberg von Zug. Geschichtsfreund XXXV, S. 187 .

Mêloizes, A. de, Les vitraux de la cathédrale de Bourges postérieurs au XIIe siècle. (Bulletin archéologique 3.) 1887.

Mély, F., Etude iconographique sur les vitraux du XIIIe siècle de la cathédrale de Chartres (Revue de l'art chrétien), I 888.

Menard, Le vitrail de Troyes. L'art et l'autel I903 u. I904.

Merson, Ol., Les vitraux. Paris 1895.

Meyer-Zeller, H., Der Glasmaler Monogrammist A. H. II. Hälfte des I6. Jahr-

hunderts. (Anzeiger für schweizerische Altertumskunde, I 879.)

Meyer, H., Die schweizerische Sitte der Fenster und Wappenschenkung vom 15. bis

I7. Jahrhundert. Nebst Verzeichnis der Züricher Glasmaler von 1540 an und Nachweis noch vorhandener Arbeiten derselben. Eine kulturgeschichtliche Studic. 384 S. Frauenfeld, Huber, $188_{3}$.

Merz, W., Führer durch die Klosterkirche zu Königsfelden, I9r3.

Miller, F., Glass-painting. A Course of instruction in the various methods of painting glass and the principles of design. I $24 \mathrm{p}$. with 72 illustrations. London, Wyman, I885. Miller, A. H., Stained glass, (art Journal N. Ser. 4.) r881.

Muller, E., Le vitrail de Saint Pantaléon à la cathédrale de Noyon. Revue de l'art chrétien. I $88 \mathrm{I}$.

Müller, Die Katharinenkirche zu Oppenheim, ein Denkmal deutscher Kirchenbaukunst aus dem I3. Jahrhundert, geometrisch und perspektivisch dargestellt, mit erläuterndem Text. Fol. Darmstadt I 824.

Müller, M., Die Fabrikation der für die Glasmalerei, Emailmalerei und Porzellanmalerei geeigneten Farben. Weimar, Voigt, I880.

Mülinen, Glasgemälde des Standes Bern. Berner Kunstdenkmäler llI.

Nodet, V., Un vitrail de l'eglise de Brou. Gazette des Beaux arts XXXV.

Notice explicative des vitraux de Saint-Winoc posés en I87 dans l'église paroissiale de Bergues. 97 p. Bergues, M. Hilst.

Notice sur les vitraux de l'église de la Madeleine de Verneuil. Io p. Evreux, Imprimerie Odieuvre, 1882 .

Nott, The stained glass-windows of great Malvern Priory Church. Journal of the British Archaeological Association, I882.

O'Kelly Notice sur la peinture sur verre en Belgique au I9. siècle 1859.

Oidtmann, H., Die Glasmalerei, ihre Technik und Geschichte. Köln I893.

- Die Glasmalerei als kirchliche Kunst. (Archiv für kirchl. Kunst.) I882.

- Über alte und neue Glasmalerei im Bauwesen. (Deutsche Bauzeitung.) I882. 
Oidtmann, H., Die Glasmalerei in ihrer Anwendung auf den Profanbau.

- Die Glasmalerei im alten Frankenland.

- Der Fensterschmuck der zerstörten Magdalenenkirche zu Straßburg. Zeitschrift f. chr, Kunst. XVIII, S. 335 .

- Über die Instandsetzung alter Glasgemälde. Zeitschr. f. chr. Kunst. XIX, I 906.

- Geschichte der Schweizer Glasmalerei. 1905.

- Rheinische Glasmalereien. I. (Der zweite Band erscheint im Laufe des Jahres I9I4, bearbeitet vom Sohn des Verfassers.)

- Alte Glasmalereien aus der Pfarrkirche zu Monreal bei Moyen. Zeitschr. f. chr. Kunst. I9I3. S. 6.

Osterrath, Etudes de la peinture sur verre. Bull. des métiers d'art I904.

Ottin, L., Le vitrail. Paris 1896.

Pattison, M., The glass painting of Jean Cousin at Sens. (Academy 607.) I883. Powell, H. S., The Picture Windows. Bresl. Majar. VlII, Igo6. S. 35 .

Probst, B., Notice sur les anciens vitraux de l'église de Saint-Julien sur ceux de Notre-Dame de Brou (Aix) Pl. Lons-le-Saulnier, Declume fréres, I $88_{3}$.

Rahn, J. R., Über die Anfänge der Glasmalerei (Augsburger allgemeine Zeitung) I879.

- Die Glasgemälde in der Rosette der Kathedrale von Lausanne. Ein Bild der

Welt aus dem I3. Jahrhundert. Mitteilungen der antiquarischen Gesellschaft in Zürich, XX. I. 2. 9 Tafeln. Zürich, Orell Füssli \& Co., I879.

- La rose de la cathèdrale de Lausanne, I879.

- Die Glasgemälde Christoph Maurers im germanischen Museum zu Nürnberg. (Anzeiger für schweizerische Altertumskunde, V.) $188_{3}$.

- Die Glasgemälde im gotischen Hause zu Wörlitz. 50 S. Leipzig, Seemann, I885.

- Glasgemälde in Muri-Gries bei Bozen. Anzeiger für schweizerische Altertumskunde, 2. 1888.

Reboulleau, Magnier et A. Romain, Nouveau Manuel de la peinture sur verre. Paris, Roret, 1885 .

Rondot, N., Les peintres-verriers de Troyes du XIVe et XVe siècle. (Revue de l'art français, 8.) I 887.

Rosen, C. von, Der Fensterschmuck der Wallfahrtskirche zu Kentz in Neuvorpommern. Stralsund I 865 .

- Die Glasgemälde der St. Marienkirche zu Stralsund.

Saumier, Le vitrail dans l'Amerique du Sud. L'art et décoration. XXIII.

Schaefer, Über die Glasmalerei. (Zeitschrift des Vereins für Ausbildung der Gewerbe in München.) 1867 .

Schaefer, C., Die Glasmalerei des Mittelalters und der Renaissance im Abriß dargestellt. 47 S. 2I Holzschnitte. Berlin $\mathbf{3} 88 \mathrm{I}$.

Schaefer, C. und A. Rosstaeuscher, Ornamentale Glasmalerei des Mittelalters und der Renaissance nach Original-Aufnahmen in Farbendruck. Fol. Berlin, Wassmuth, I 885 .

Scharf, G., Artistic notes on the windows of Kings college chapel, Cambridge. (Archaeological Journal. p. 356.) 1855.

Scharold, Glasmaler, Die in Würzburg gewirkt. (Diamant.) I 884 .

Schauenbourg, La peinture sur verre. Strassbourg 1865. 
Schimmel, C., Die Cisterzienser-Abtei Altenberg bei Cöln. I 5 lith. Bl. Roy.-Fol. Mit historischen Erläuterungen. Münster, Theissing, 1832.

Schinnerer, Joh., kirchliche Glasmalerei zur Zeit der Spätgotik und Frührenaissance in Nürnberg. I 908.

- Katalog der Glasgemälde des Bayr. Nationalmuseums. I 908.

Schmitz, F., Der Dom zu Coeln, seine Konstruktion und Ausstattung. Imp.-Fol. I IO S. mit I 26 lith. Taf. teilweise in Farbendruck. Cöln, Schwann, I867/76.

Schmitz, H., Die deutsche kirchliche Glasmalerei der neuesten Zeit. Die Kirche. I9I2 S. $221 ; 1913$ S. 26.

- Die Glasgemälde des Kgl. Kunstgewerbemuseums in Berlin. I9I3. 2 Bände.

Schnütgen, Kölnisches Glasgemälde des I4. Jahrhunderts. (Zeitschrift für christliche Kunst. I 888.)

Sepp, J. N., Ursprung der Glasmalerei. $\quad$ I 878.

Stahl, C. J., Glaserkunst, Glasmalerei und moderne Kunstverglasung. I 9 I 2.

Stallius, A., Quelques reflexions sur l'art de la peinture sur verre. Anvers I908.

Statz, V., Glasfenster im gotischen Stile. Entwürfe für Kunstglaser und Architekten.

Fol. I 5 lith. Taf. Berlin, Claesen, I885.

Statz: V. und G. Ungewitter, Gothisches Musterbuch. Mit Einleitung von

A. Reichensperger. Fol. Leipzig, Weigel, I856/6I.

Strele, C., Handbuch der Glasmalerei. 4. Auf. Weimar I883.

Styger, Glasmaler und Glasgemälde im Lande Schwyz, I465-I680. Mitteilungen

des historischen Vereins des Cantons Schwyz. I 886.

Sudre, P., La Chapelle de S. Ferdinand. Paris 1846 .

Texier, Origine de la peinture sur verre. Paris $185^{\circ}$.

- Histoire de la peinture sur verre en Limousin. Paris I847.

Theophilus Presbyter, Diversarum artium schedula. Quellenschriften für Kunstgeschichte, Band VII. Wien I875.

Trost, Die GlasgemäIde in der k. rumänischen Sommerresidenz zu Sinaia. (Mitteilungen des nordböhmischen Gewerbemuseums zu Reichenberg. I 888 .

Tschischka, F., Der St. Stephansdom in Wien und seine alten Denkmale der Kunst.

8 Bde. 45 Taf. Wien, Doll, 1832.

Ulke, R., Katechismus der Porzellan- und Glasmalerei. Leipzig I 894.

Unger, F. W., Glasmalerei. (Ersch und Gruber: Encyclopädie. Bd. LXIX.) I 859.

V an Constenoble, F., Les anciens vitraux de Flêtre. 4 p. Lille, Imprimerie Danel.

Van de Velde, M., Les vitraux incolorés des anciens monuments de Belgique. Anvers 1865.

Verhaegen, N., L'art de la peinture sur verre au moyen-âge. Revue de l'art chrétien. Nouv. Série 1V, I887.

Vermeuil, Vitraux etrangers. L'art et décoration 1908.

Veuclin, E., Quelques mots sur les vitraux anciens de l'église paroissiale d'Orbec (Calvados). 8 p. Orbec, Legrand, I 878.

Vigné, Peinture sur verre. Paris I 840.

Viollet le Duc, Vitrail (Dictionaire raisonné de l'architecture français. Vol. IV.) Paris, Morel, I 868. 
Vischer-Merian, K., Die Glasgemälde in Meiringen und deren Stifter H. Immer von Gilgenberg. (Beiträge zur vaterländischen Geschichte.) Basel I 887.

Voegelin, S., Die Glasgemälde aus der Stiftsprobstei, der Chorherrenstube und aus dem Pfarrhause zum Großmünster. (Neujabrsblatt, herausgegeben von der Stadtbibliothek in Zürich.) Zürich I882.

Wackernagel, W., Die deutsche Glasmalerei. Leipzig 1855 .

Warnecke, F., Musterblätter für Künstler und Kunstgewerbetreibende, besonders für

Glasmaler. 5 Lieferungen à 30 Blatt. Berlin, H. S. Hermann, I886-88.

Waring, J. B., Examples of stained glass. London 1858 .

Warrington, W., The history of stained glass. London 1848 .

Wartmann, W., Les vitraux Suisses au Musée du Louvre. I908.

Weale, J., Quarterly papers on architecture. 4 vols, 245 plates. London 1844 .

- Divers works of early masters in christian decoration, with examples of ancient painted and stained glass. 75 plates. Fol. London 1846 .

Weber, A., Glasmalereien im Zuger Lande. Zug, Anderwert, I889.

Weissenbach, H. v., Die Stilgesetze der Glasmalerei. Nürnberg 1877 .

Westheim, P., Glasmalerei oder Mosaikverglasung. Deutsche Kunst und Dekoration, I9JO, S. 297.

Westlake, N. H. J., History of design in Painted glass from the earliest time until

the XIth century. With many woodcuts. Vol. I. London, Parker, $188 \mathrm{I}$.

- Stained glass. (Art Journal, March.) I 882.

Wienecke, Hertha, Konstanzer Malereien des I4. Jahrhunderts. Halle I9I2.

Wetzel, C. J., Neuestes und vollständiges Handbuch der Glasmaler. Heilbronn I 853 .

Will, Schweizerische Glasgemälde in Lichtenthal. (Anzeiger für schweizerische Altertumskunde, I 887 .)

Willement, Th., A concise account of the principale works in stained glass that have been executed by Th. Willement I 8 I2-I 840 . With I coloured plate. 75 p. London 1840 .

Winston, C., A inquiry into the difference of style observable in ancient glass-paintings especially in England. 2 Parts. Oxford $1847-67$.

- Memoires illustrative of the art of glass-painting. London 1865 .

Abbildungen der Glasgemälde in der Pfarrkirche der Vorstadt Au. 25 Taf. Fol. München 1850 .

Glasmalerei als Fensterschmuck unserer Wohnräume. (Mitteilungen des mährischen Gewerbemuseums, 1887.)

Die Königlich bayerische Hofglasmalerei von F. X. Zettler und ihre Werke. 3 I S. München I887. Druck der Wild'schen Buchdruckerei.

De la pratica di comporre finestre a vetri colorati, trattatello del secolo $\mathrm{XV}$, edito per la prima volta. 32 p. Siena, L. Lazzari, I 886.

Die alten Glasmalereien der Kirche d. h. Laurentius zu St. Leonhard im Lavantthale.

(Mitteilungen der k. k. Zentralkommission, I 888.)

Die moderne Glasmalerei in der Scbweiz. Allgemeine Zeitung S. 327. 1888. 
Neue Herstellung von Glasmosaikfenstern. Schweizer. Gewerbeblatt. 1889 .

Märkische Wappenscheiben. Korrespondenzblatt zum deutschen Maler-Journal, I887. Vitraux d'art pour églises et appartements. Modèles Nos. I-6. Nancy, Impr. H. Christophe, I888.

Le vitrail de Maredsous. Revue de l'art chrétien XLVII, S. $47 \mathrm{I}$.

Vorbildliche Glasmalereien aus dem späten Mittelalter und der Renaissancezeit. Herausgegeben von der Kgl. Akademic des Bauwesens in Berlin. Nach den Aufnahmen der Glasmalerei Linnemann. 4 Lieferungen. Fenster aus dem Kölner Dom, der Kirche S. Gudule-Brüssel, der Stiftskirche zu Kyllbury, dem Rathaus zu Emden, der Sebalduskirche zu Nürnberg und der Kirche S. Jacques zu Lüttich. Berlin, E. Wasmuth, I9II-I9I5. In diesem Jahre erscheint das Volkamerfenster in S. Lorenz zu Nürnberg.

Zeitschrift für alte und neue Glasmalerei, zugleich Organ des Verbandes deutscher Glasmalereien; erscheint seit I9I 2. 


\section{Register.}

Die Ortsnamen bedeuten, daß an den genannten Orten Glasgemälde sich befinden, die an der betreffenden Stelle des Buches besprochen sind.

$$
\mathrm{Gl} .=\text { Glaser. } \mathrm{Gm} .=\text { Glasmaler. }
$$

A.

Achatz, Gm. I 54 .

Acker, Gm. II2, I Igf.

Adelmann (Vierpaßscheibe) I6I.

Ägeri, Gm. I 80 .

Ainmüller, Gm. I 93 .

Alpirsbacher Rundscheibe, jetzt in der

Sammlung zu Stuttgart 56.

Altenberg 8o.

Altötting, Tillykapelle I I 4 .

Ambierlé 123.

Angers 64.

Anhalt, Leop. Friedr. von, Sammler 2, 283.

Anonymus über Glasmalerei 2 I 6 .

Antikglas $204 \mathrm{ff}$.

Antonio da Pisa $220 \mathrm{ff}$., 28 I ff.

Anvers 125.

Arnold von Cronberg I 27.

Arnold der Glaser I 5 I.

Arnold von Nimwegen 127.

Asharmoschee 183 .

Assisi 83.

Ässlinger, Contz, Gm. I $42 \mathrm{f}$.

Augsburg, Domfenster I 2, 45 ff., I 19.

Augsburg, Dompfarrei 153.

Augsburg, S. Ulrich 49 ff., 57.

B.

Baldricus vitrarius 263 .

Baldung, I37ff., I6I, I66.

Ban, Gm. I 80 .

Baumburg I 54 .
Bartolomeo di Tommaso, Gm. 266.

Bayr. Nationalmuseum:

Andreasscheibe 72 .

Zyklus aus Seligenthal 73 .

Zyklus aus Regensburg $93 \mathrm{ff}$.

Medaillonscheibe 98 .

Wertingerscheiben $\mathbf{I} \mathbf{5}$.

Breuscheiben 164 .

Beauvais 122, I25, 232.

Beham 165, 168.

Benediktiner, Pflege der Glasmalerei 41 .

Benkert, H., Gm. I 70.

Berlin, Kunstgewerbemuseum:

Kreuzigungsgruppe $64 \mathrm{ff}$.

Wertingerscheiben $\mathbf{I}_{\mathbf{5}} \mathbf{2}$.

Bern, Münster, Dreikönigsfenster 98 .

Bern, Passionsfenster im Münster I I 9 f., I 5 I.

Bertha, Äbtissin in Zürich 5, 40.

Berulles I 24.

Betti, Giov., Gm. 266.

Biblia pauperum $238 \mathrm{ff}$., $243 \mathrm{ff}$.

Biel I 6.

Bindemittel 225 .

Birrenbach 195 .

Bluntschli, Gm. I80, 284.

Blutenburg I 50.

Bock, H., Gm. I 80 .

Bourges $236 \mathrm{f}$., 260 .

Bouts, Dierick I 15 .

Branca von Savoyen, Gebetbuch 93, 102.

Brandenberg, Gm. I 7 I, I8I.

Braun, Hans, Gm. 152, I62, 164 . 
Brechtl, Joh., Gm. I69.

Breu, Jörg 152, $162 \mathrm{ff}$.

Broederlam 104.

Bronner, Gg., Gl. I 57.

Brou 125.

Bruyn, Bartholomäus I 70 .

Bülach, Glasgemälde daselbst $\mathbf{r}$.

Burkmaier, H. I 52, I 62.

Byzantinischer Kunstkreis, Verhältnis zur Glasmalerei 6o, 67 .

c.

Cambridge 194.

Candid, P. 168.

Cappenberg $64 \mathrm{ff}$.

Caspar der Maler, Gm. 268, 273.

Cennini 216.

Châlons sur Marne, Kathedrale I 3, 63, I 22, I 29.

Chailly I 23 .

Champ (Isère), Glasgemälde 26.

Chartres I 7, 58 ff., 8o, 237.

Cimabue 83 .

Cleen (Vierpaßscheibe) I6I.

Concordantia caritatis 243 .

Cöln, allgemeines 78 .

Cöln, Dom 79, Königsreihe 79.

Cöln, Dom, kleine Glasgemälde I92.

Cöln, Stephanskapelle im Dom 82.

Cöln, S. Kunibert 68, 70, 260.

Crabeth, W. I6o.

D.

Daig I I $2 f$.

Danegger, Gm. Igof.

Dax, P., Gm. 270, 273.

Deckinger I I 2, I I $9 f$.

Deutsch, N. M., Gm. I8o.

Devon 127.

Dirnhofer, M., Gl. I 5 I.

Douglas'sche Scheiben 178.

Dürer I 25 f., I $33 \mathrm{ff}$.

E.

Eberhard, Glasmaler 69.

Egmoutiers I 23.

Emailfarben $2 \mathrm{I} 3 \mathrm{f}$.
Engel, Julius 197.

Erbach 158, 284.

Erdödy 156.

Erfurt, Dom I 14 .

Eriskirch 106.

Esconnes 122.

Ess, H., Gm. I69.

Eblingen $77,81,97,107,238,260$.

Evangeliar aus Hardehausen 65 .

Evangeliar des Heriman 65.

Evrenx 122.

Exeter $\mathbf{2 7}$.

\section{F.}

Faber, Gm. I 70 .

Farbenzusammenstellung $220 \mathrm{ff}$.

Fischer, Jos. A. 193.

Flums, Glasgemälde, jetzt im Schweiz.

Landesmuseum 55 .

Frank I 90 ff., 270.

Frankfurt, Historisches Museum, Scheibe mit Christus an der Geißelsäule 70.

Franziskaner, ihr Verhältnis zur Glasmalerei 265 .

Franz glaser, Gm. 142.

Frater Theutonicus 83 .

Franenfeld $77,80$.

Freiburg i. B. 77, 104, 139.

Freie Künste 234.

Freising 95 f., I 42 .

Freyhart, Math., Gm. II 3 .

Fulko, Gm. 267.

Funk, H., Gm. I8o.

G.

Garmisch 99.

Genf, Nationalmuseum 99.

Gerlach, Maler 66.

Giotto IO4ff.

Glasbereitung im Altertum $201 \mathrm{ff}$.

$$
\begin{aligned}
& \text { im Mittelalter } 204 \mathrm{ff} \text {. } \\
& \text { ", in der Neuzeit } 209 .
\end{aligned}
$$

Glaser Hanns, G). I 52 .

Glaser Ulrich I I 2.

Glasgow 194.

Glasmalereianstalt, Kgl.

zu Berlin $195 \mathrm{ff}$. 
Glasmalereianstalt, Kgl.

zu München I93 ff.

Glasmalerordnungen $266,269,275$.

Glasverschleiße 157.

Goethe über Glasmalerei I.

Goldschmiedekunst, Verhältnis zur Glasmalerei 9, 59, 108.

Goltzius 159.

Gondorf I 29.

Gozbert, Abt von Tegernsee $42 \mathrm{ff}$.

Gralsburg, Glasgemälde 4 .

Grimm, M., Gm. 284.

Grünewald, M. 299, Taf. 65/66.

Guillelmus vitrearius 264 .

\section{H.}

Hakimmoschee 183 .

Hall 8I.

Hamer, V., Gm. 142.

Hänle, Hans, Gm. I 79.

Hans v. Kulmbach 135 .

Hans von Ropstein I38, I 66.

Hans von Ulm, Gm. I I6, I I 9 f., I 45 .

Hans von Wesel 127.

Hausbuchmeister I60, I62, I 78 .

Hebenstreit, Gm. I42, I67, 270 .

Heiligenberg 77,8 I, I I3, 285.

Heiligenkreuz 69 .

Heiligkreuzthaler Scheiben (jetzt in Stuttgart) II 3 .

Heine über Glasmalerei I.

Helmhack, A., Gm. I 70 .

Heraklius 206 u. a, vielen Orten.

Herbst, Gm. I 70.

Herkommer, H., Gm. I42.

Hermann von Münster 8o.

Hernperger, L., Gl. I 52.

Hess, H. 193.

Heurtault, M., Gm. I 26.

Hirsvogel 135, I69.

Hohenschwangau 284.

Holbein, H. d. Ä. I 53 .

Holbein, H. d. J. I 80 .

I.

Isenmann, Kaspar I I 5, I 44 .

Italien $82 \mathrm{f}$.
Jacobus, Gm. 274.

Jacobus, Alamanus.

Jacobus, vitrifex, Köln 8o.

Jacob der mauler (Ulm) 103, 267.

Jegly, Gm. 258.

Jenkofen $15 \mathrm{I}$.

Jorg van Delft I3I.

Joris van Pourse I3I.

Jork 63 .

\section{K.}

Kaiserlautrer, H., Gm. I42, 145.

Kappel 77.

Kassa I 55.

Karlsruhe, Großh. Museum 77.

Karlstatter, J., Gm. I42.

Karthaus Prüll I 50, I 70.

Kathedralglas 2 I I.

Keyll, Gm. I 70.

Kistenfeger, Jac., Gm. 142, 149.

Klein, H., Gm, 142.

Knoder, Hans, Gm. I64, 273.

Koburg I34.

Koniz 77.

Konstanz, Dominikanerkloster 78, 8 r.

Krakau I 55 .

Kreutzperger, P. u. W. I52.

Krinaberger, M., Gm. I 69.

\section{L.}

Lactantius 38 .

Lambrecht, Pfaffe 4.

Landsberg a. L. 150, 167.

Landshut $15 \mathrm{I}$.

Leermoos 164 .

Legenda aurea 237.

Lebez 155.

Le Mans, Kathedrale $13,63,237,249$ 264.

León 83.

Limburg a. d. L. 82 .

Limoges 122.

Lindtmeyer, Dan., Gm. I 73.

Livres d'heures, Verhältnis zur Glasmalerei $24,78,102$. 
Lohne 67.

London I94.

Loth, Paul, Gm. I67, 284.

Ludwig der Bayer, Gebetbuch 94.

Ludwig der Heilige, Psalter 19, $76 \mathrm{f}$.

Lukas von Leyden I27, I 55.

Lübeck 274 .

Lüneburg, Rathaus 105.

Lyon 123, 232, 237.

\section{M.}

Magister, Conrad, Gm. 267.

Maler von Dingolfing 154 .

Marburg 7 I.

Marienburg 95.

Märkl, H., Gm. I42.

Markterlbach Io8.

Martin glaser, Gm. I $42 \mathrm{f}$.

Marx Glaser I 5 I.

Mathaeus v. Burghausen, GI. I 5 I.

Mauler Lukas (Ulm) I03, 267.

Maurer, Gm. I7 I, I8I.

Mayingen 283 .

Mayinger, Conntz, Gl. I I 3 .

Medaillonmeister 9I, 95.

Meister des hl. Bartholomäus I 30 .

Meister Nicklas, Gm. 267.

Meister Hanns Red der Maler, Gm. 268.

Meister von S. Severin 130.

Meister E. S. I I 5, I 28 , I 6o, I 78.

Meister Thoman der Glaser 266.

Meister Simon der Maler, Gm. 268.

Metz, Dom 8o.

Metz, S. Segolena $64 \mathrm{f}$.

Meyer, Gm. I 8 I f.

Michael pictor, Gm. 267 .

Mikó, Gm. I 55 .

Miniatur, Verhältnis zur Glasmalerei I3, $53,85 \mathrm{ff} ., 237$.

Mittenmaier I95.

Mohn 195.

Moosburg 152.

Mosaik, Verhältnis zur Glasmalerei 8 .

Moser Lukas IO2.

Mühlhausen i. Th. 82 .

Mülhausen i. E. 8 I, 90, 97, 260.
Mülhofer, M., Gl. I I 3 .

Müller, Gm. I8I.

Müller, L., GI. I I 3 .

Multscher ro3.

München, Frauenkirche, Mariologisches

Fenster 99.

München, Frauenkirche $95 \mathrm{ff}$., 98, I 4 I ff.

München, Frauenkirche, Scharfzandtfenster

I I9, I 2 I.

München, Mariahilf kirche I94.

München, Michaelskirche I67.

München, Salvatorkirche I $43 \mathrm{ff}$.

Münnerstadt I I4.

Murer, Gm. I 70, 284 .

\section{N.}

Narbonne, Altardecke 93.

Naumburg $67,69,259 \mathrm{f}$.

Neuburg I64.

Neuweiler, Timotheusfenster jetzt im Clunymuseum 55.

Niclaus, Gm. I 6 .

Niederhaslach 80, 92, 237, 260.

Noll, Gm. I 6 .

Nuptiae Mercurii des Martianus Capella 234.

Nürnberg, Germanisches Museum, Prophetenscheibe 129.

Nürnberg, S. Lorenz, Volkamerfenster I I 9, I 32, 284 .

Nürnberg, S. Sebald 29 I.

Nürnberg, Markgrafenfenster I 36.

Nüscheler, Gm. 284 .

\section{o.}

Oberndorffer, B., Gl. I 52.

Olein, H., Gm. 142.

Ostendorffer, B., Gm. I42.

Öttingen-Wallerstein 283 .

Otto, Fenestrator in Köln 57.

\section{$\mathbf{P}$.}

Paul v. Limburg 108, 123.

Paris Ste Chapelle 85 .

Peich, H. I67.

Pentelinck I 30.

Peterslahr 64 .

Physiologus 233. 
Pisano Giov. 99.

Pistoja 93.

Plepp, Jak., Gm. I8o.

Poitiers 64.

Polen 95, I 55.

Pollack, Jon, $146 \mathrm{ff}$.

Pöndl 167.

Pont-Audemer 126.

Porträt 66, I 28.

Preise für Glasgemälde 272.

Prag (Karlstein) 93f, I Io, I I 3 f.

Prielmair, W., Gm. 167 .

Primitive, französische, ihr Verhältnis zur Glasmalerei 85 .

Primitive, italienische 85 .

Pronner (Bronner), Gm. I42.

Prudentius 2.

\section{R.}

Radiertechnik 217, 228 f.

Ragerulfus vitrearius 263 .

Raphael, S. als Vorlage 126.

Raynold 8o.

Ravensburg, Pfarrkirche 107.

Regensburg, Dom 69, 192.

Regensburg, Katharinenfenster I I4.

Regensburg, Schreibstube 60.

Reichenau (Mittelzell) 30, I 13.

Reliefglas 2 II.

Reutter, H., Gm. 169, 275.

Ringler, Gm. I8o.

Röckl 193.

Rosenweiler 96.

Rosray 124.

Rothenburg II I, II4.

Rouen I26, 134 .

Ruben 193.

Rugerus $204 \mathrm{ff}$.

S.

Sankt Alban 235, 249.

Saint Denis $62 \mathrm{ff}, 69$.

Saint-Ouen 126.

St. Julien-du-Sault I 24, 129.

St. Parre-les-Vaudes 124.
Salzburg, Miniaturen, Verhältnis zur Glasmalerei $59 \mathrm{ff}$.

Salzburg, Museum 164.

Salzburg, Schule 112, 119.

Sassanidisch-persischer Kunstkreis, sein VerhäItnis zur Glasmalerei. Die Frühzeit 54 .

Schaffer, J., Gm. 142.

Schaffhausen 18 I.

Schaper, J., Gm. I 70.

Schäuffeleinschule I I3.

Scheinert 195 .

Schlettstadt I06f, I I 5 f, 237.

Schmid, H., Gm. I47.

Schmitter, M., Gm. 284.

Schnitzer, B., Gl. II3.

Schneider, A., Gm. I68.

Schongauer $160,162,178$.

Schöpl, J., Gm. I42.

Schraudolph 192.

Schwarzlot 2 I $2 \mathrm{f}$.

Schweindl, K., Gm. 142.

Seligenthal 73 .

Sengenrieder, Gm. I42f.

Sery-les-Mézières, Reliquienschrein 39.

Siber, Hanns, Gm. I 5 I.

Silbergelb 2 I 3 .

Sippenmeister I 30 .

Spanien 83.

Speculum humanae salvationis $239 \mathrm{ff}$.

Spengler, Gm. 284.

Springinklee, H. I68, I70.

Staufberg II6.

Stendal I IO.

Stöckl, J., Gm. I42.

Stracholfus vitrearius 57,264 .

Straßburg, Königsreihe im Münster 74 ff, 81 .

Straßburg, Laurentiuskapelle 97.

Straßburg, Magdalenenkirche I 19.

Straßburg, S. Wilhelm 90, I I 6.

Straßburg, Salomofenster im Münster I 7 .

Hochschiffenster in Münster $73 \mathrm{ff}$.

Straubing $\operatorname{Iog} \mathrm{f}$, I $5 \mathrm{I}$.

Strauß, Jac., Gl. I5I.

StrawB, H., Gm. I47.

Submissionswesen $277 \mathrm{ff}$.

Sugerus, Abt von St. Denis 63 . 
T.

Taucher, H., Gm. I 69.

Tegernsee, Glasmaler daselbst $42 \mathrm{ff}$., 56, 72 .

Telchinger, U., Gm. 270, 273.

Thann 95, 98, 102, I 05, I I I, I I 6.

Theoderich Maler 94.

Thophilus siehe Rugerus.

Thoma, Hans, Gm. I 52, I64, 273.

Thomas von Modena 94, I I I, I I 4 .

Tieffenthal, Hans I05, I07, I I 5.

Tiffanyglas $2 \mathrm{I}$.

Tizian, als Vorlage 125.

Tölz 154.

Troyes 124.

Tübingen, Stiftskirche I I 9.

Tugenden und Laster 258.

U.

Überzug 226.

Ulm, Münster 95f., I 99 , I Iof., I I 4, I I 9.

Ulm, Bessererfenster I03, I 45.

Ungarn 155 .

Unverdorben, G., Gm. I 70.

Urach II 8 .

Urspring I I 3 .

Uta-Evangeliar $50 \mathrm{ff}$.

V.

Vendôme 64 .

Vicenza Tympanonfries 96, I I I, I I4.

Vierpaßscheiben I6off.

Vennd, Balt., Gl. I I 3 .

Vörtel I95.

W.

Walburg I I 5 .

Wald, G., Gm. I69.
Walter, Friedr., Glasmaler I 12.

Wattenhofer, L., Gm. II 3 .

Weber, Gm. I 8 I f.

Weiler, Hanns, Gl. I 52.

Weißenburg 81, 82, 245.

Weltliche Sujets $26 \mathrm{I}$ f.

Werden 40.

Werder, Urs I 16.

Werkzeichnung 2 I5.

Wertinger, Hans I 52 .

Westhofen 8o.

Wiedmann, G., Gm. I69.

Wieland, M., Gl. I5 I.

Wien, Hofmuseum, Dürerfälschung I 34 .

Wiener Neustadt I3I.

Wild, Hans, Gm. I I $7 \mathrm{ff}$, I 28, I 43, 285.

Winbart, H. u. V., Gm. I $42 \mathrm{f}$.

Witz I02, I05, I I 5 .

Woensam, Anton I3O.

Wolf, Gm. I8I f.

Wolfram von Eschenbach 4 .

Wolgemut I32, 162.

Wörle, Gm. I67.

Wörlitz, Gotisches Haus 2, 283.

Wurmser, Nicolaus 94.

X.

Xanten, Viktorskirche 80,82 .

Z.

Zabern I I 5, II 7 .

Ziegler, Jerg I I2, I I3, I66.

Zisterzienserkapitel $1 \mathrm{I} 34$ 4, 22, 57, I85.

Zumbach, Gm. I 8 I.

Zunft und Glasmalerei $269 \mathrm{f}$.

Zürich, Glasgemälde des Kleinmünsters $5,40$. 
Unter den photographischen Vorlagen sind dem Verfasser zur Verfügung gestellt worden von

Hofglasmalerei Zettler, München, die Vorlagen für 'Tafel I-4, I6-I8, 30, 33, 4I, $42,64,72-79,82$. Abb. 27, 28.

Verlag Richn \& Tietze, München, für Tafel 6, 25-29, 80, 88. Abb. 8, 29.

Glasmalerei Linnemann, Frankfurt, für Tafel 12, 34-36, 40, 44-46, 56-58, 65, 83-85. Abb. 6, 7, 10, 32, 33 .

Schweizerisches Landesmuseum (Direktor H. Lehmann) für Tafel I $8-20,93,96,99$, I04. Abb. 40, 4I.

Dr. Julius Engel, Magdeburg, für Tafel 36, 39.

Glasmaler Statsberger, München, für Tafel 37-38, I02-103.

Hofglasmalerei de Bouché, München, für Tafel 53, 54.

Dr. Lossnitzer, Dresden, für Tafël $62 / 63$.

Hofglasmalereibesitzer Oscar Zettler für Tafel 68-70, 92, 94-95, 98.

Dr. Haupolder, Salzburg, für Tafel 89. Abb. 37 .

Delphinverlag, München, für Abb. 2.

Bayr. Nationalmuseum, München (Prof. Halm), für Abb. 23-25.

Hofphotograph Höfle, Augsburg, für Abb. 3o.

Hofphotograph Kratt, Karlsruhe, Tafel I4. Abb. 39. 


\section{Hiersemanns Handbücher:}

Band I. W. J. Anderson und R. Ph. Spiers, Die Architektur von Griechenland and Rom. Eine Skizze ihrer historischen Entwickelung. Autorisierte Übersetzung aus dem Englischen von Konrad Burger. Groß-Oktav. 375 Seiten, 185 Abbildungen. Leipzig 1905. In elegantem Leinenband.

M. $18 .-$

Band II. Ernst Kiesling, Wesen und Technik der Malerei. Ein Handbuch für Künstler und Kunstfreunde. Oktav. I6 65 Seiten. ro Textabbildungen. I 7 Tafeln. Leipzig 1908 .

Geheftet M. 3.60, gebunden M. 4.80

Band III. A. Kisa, Das Glas im Altertume. Unter Mitwirkung von Dr. Ernst Bassermann-Jordan. Mit einem Beitrag über Funde antiker Gläser in Skandinavien von Dr. Oskar Almgren, Stockholm. Oktav. XXII, 980 Seiten, mit 395 Textabbildungen und 12 Tafeln, davon 6 farbig, und 7 Formentafeln mit ca. 440 Fig. Leipzig 1908. Geheftet M. 42.-, in 3 eleganten Leinenbänden M. 45.-

Band IV. Rudolf Neugebauter und Julitus Orendi, Handbuch der orientalischen Teppichkunde. Mit einer Einführung von Richard Graul. Oktav. XII, 246 Seiten Text, 153 Abbildungen, 16 farbige Tafeln, I 2 Motivblätter, I Karte. Leipzig I 909.

In elegantem Leinenband M. 20.-

Band V. P. L. Bouviers Handbuch der Ölmalereí für Künstler und Kunstfreunde. Nebst einem Anhang über Konservierung, Regeneration und Restauration alter Gemälde von Adolf Ehrhardt. 8. Auflage. Mit einer Einleitung versehen und revidiert von Ernst Berger. Oktav. XX, 444 Seiten, 3I Abb. Leipzig 1910. Gebunden M. ro.-

Band VI. Ad. Ehrhardt, Die Kunst der Malerei. Eine Anleitung zur Ausbildung für die Kunst nebst einem Anhang zur Nachhilfe bei dem Studium der Perspektive, Anatomie und Proportionen. Oktav. XXV, 302 S. Mit 53 Tafeln und Text-Illustrationen in Holzschnitt. 3. Aufl. Revidiert von Ernst Berger. Leipzig I910. Geb M. 8.-

Band VII. Oscar Doering, Dertschlands mittelalterliche Kunstdenkmäler als Geschichtsquelle. Groß-Oktav. XV, 4I4 Seiten Text mit I 9 Abbildungen. Leipzig r9 10.

Geb. M. I 2.- 
Speculum humanae salvationis. Kritische Ausgabe, Übersetzung von Jean Mielot (1448). Die Quellen des Speculums und seine Bedeutung in der Ikonographie, besonders in der elsässischen Kunst des XIV. Jahrhunderts. Mit der Wiedergabe in Lichtdruck auf 140 Tafeln der Schlettstadter Handschrift, ferner sämtlicher alten Mülhauser Glasmalereien, sowie einiger Scheiben aus Colmar, Weißenburg usw. von J. Lutz und P. Perdrizet. 2 Bände. Gr.-4. XX, 35 r S. Text u. I 40 Tafeln. Leipzig 1907-09.

M. I $40 .-$

Essenwein, Dr. August Ritter von, Die farbige Ausstattung des zehneckigen Schiffes der Pfarrkirche zum Heíligen Gereon in Köln durch Wand- und Glasmalereien.

21 Seiten Text und 36 Tafeln, meist Photolithographien, in Farben- und Schwarzdruck darunter zur Hälfte Wiedergaben der Fenster. Großfolioformat $\left(80 \times 6_{4} \mathrm{~cm}\right)$. Frankfurt a. M. (Leipzig) I 89 г. In Mappe.

M. I 60.-

Zeller, Adolf, Die Stiftskirche St. Peter zu Wimpfen im Tal. Baugeschichte und Bauaufnahme. Grundsätze ihrer Wiederherstellung. Mit einem Anhang: Die Glasmalereien der Stiftskirche zu Wimpfen von Prof. Geiges, Freiburg.

Textband von IX, 50 Seiten und Atlas von 32 Tafeln in Photolithographie und Lichtdruck, enthaltend 228 Abbildungen, darunter solche der erhaltenen und restaurierten Glasgemälde. Folio. Leipzig 1903. In Mappe. M. 48.-

\section{Pic, Dr. J. L., Le Hradischt de Stradonitz en Bohême.}

Ouvrage traduit du tchèque par Joseph Déchelette. Gr.-4. 68 pages texte avec $5^{8}$ planches hors texte, dont 4 en couleurs et I 5 figures dans le texte. Leipzig 1906 . Relié en toile. M. 48.-

Enthaltend farbige und schwarze Wiedergaben der Funde antiker Glasarbeiten.

Pazaurek, Dr. Gustav E., Díe Gläsersammiung des nordböhmischen Gewerbemuseums in Reichenberg.

Im Auftrage des Kuratoriums herausgegeben. Mit 37 Lichdruckund 3 Farbentafeln und 18 Textabbildungen. 1902. In eleganter Mappe.

M. $48 .-$

$\overline{\text { Buchdruckerei Emil Herrmann senior, Leipzig. }}$ 
SMITHSONIAN INSTITUTION LIBRARIES 